Report on Carcinogens

MONOGRAPH ON

HaloACETIC ACIDS Found AS

Water Disinfection By-PROdUCtS

ROC MONOGRAPH 12

MARCH 2018 


\title{
Report on Carcinogens Monograph on Haloacetic Acids Found as Water Disinfection By-Products
}

\author{
RoC Monograph 12
}

March 2018

\author{
National Toxicology Program \\ Public Health Service \\ U.S. Department of Health and Human Services
}

ISSN: 2331-267X

Research Triangle Park, North Carolina, USA 


\section{Foreword}

The National Toxicology Program (NTP), established in 1978, is an interagency program within the Public Health Service of the U.S. Department of Health and Human Services. Its activities are executed through a partnership of the National Institute for Occupational Safety and Health (part of the Centers for Disease Control and Prevention), the Food and Drug Administration (primarily at the National Center for Toxicological Research), and the National Institute of Environmental Health Sciences (part of the National Institutes of Health), where the program is administratively located. NTP offers a unique venue for the testing, research, and analysis of agents of concern to identify toxic and biological effects, provide information that strengthens the science base, and inform decisions by health regulatory and research agencies to safeguard public health. NTP also works to develop and apply new and improved methods and approaches that advance toxicology and better assess health effects from environmental exposures.

The Report on Carcinogens Monograph series began in 2012. Report on Carcinogens Monographs present the cancer hazard evaluations of environmental agents, substances, mixtures, or exposure circumstances (collectively referred to as "substances") under review for the Report on Carcinogens. The Report on Carcinogens is a congressionally mandated, sciencebased, public health document that provides a cumulative list of substances that pose a cancer hazard for people in the United States. Substances are reviewed for the Report on Carcinogens to (1) be a new listing, (2) reclassify the current listing status, or (3) be removed.

NTP evaluates cancer hazards by following a multistep process and using established criteria to review and integrate the scientific evidence from published human, experimental animal, and mechanistic studies. General instructions for the systematic review and evidence integration methods used in these evaluations are provided in the Handbook for the Preparation of Report on Carcinogens Monographs. The handbook's instructions are applied to a specific evaluation via a written protocol. The evaluation's approach as outlined in the protocol is guided by the nature, extent, and complexity of the published scientific information and tailored to address the key scientific issues and questions for determining whether the substance is a potential cancer hazard and should be listed in the Report on Carcinogens. Draft monographs undergo external peer review before they are finalized and published.

The Report on Carcinogens Monographs are available free of charge on the NTP website and cataloged in PubMed, a free resource developed and maintained by the National Library of Medicine (part of the National Institutes of Health). Data for these evaluations are included in the Health Assessment and Workspace Collaborative. Information about the Report on Carcinogens is also available on the NTP website.

For questions about the monographs, please email NTP or call 984-287-3211. 


\section{Table of Contents}

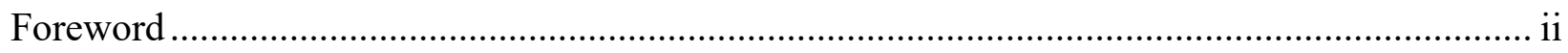

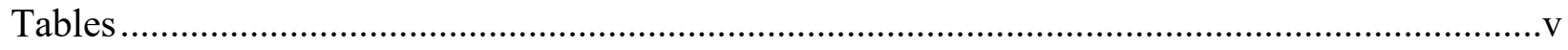

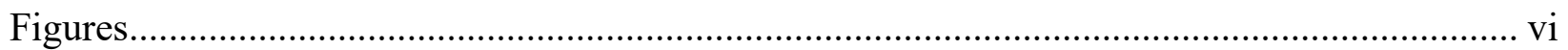

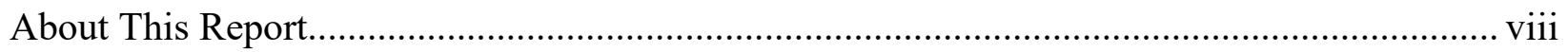

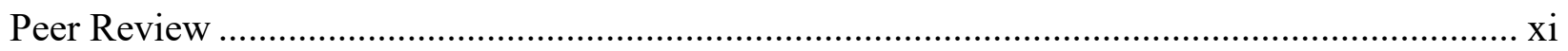

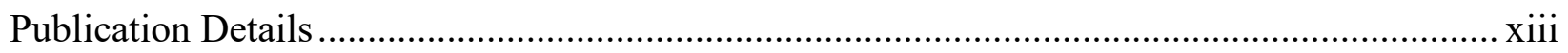

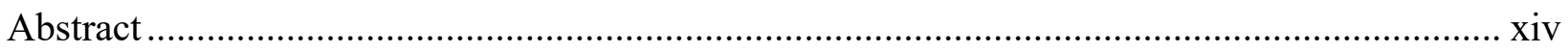

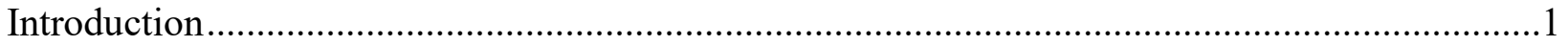

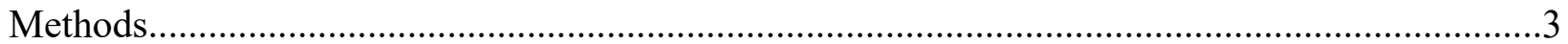

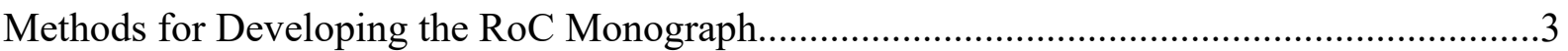

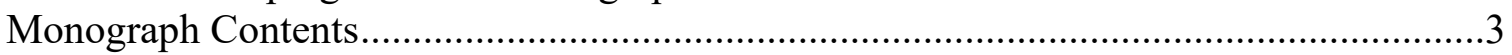

Key Scientific Questions for Each Type of Evidence Stream ............................................. 4

Methods for Preparing the Monograph ............................................................................

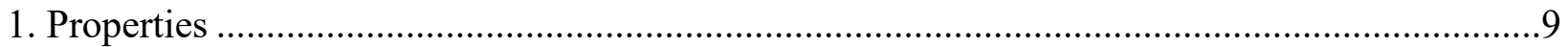

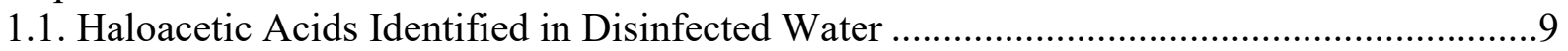

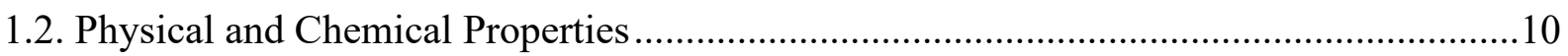

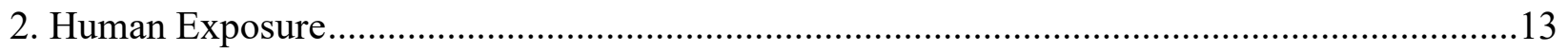

2.1. Water Treatment and Formation of Disinfection By-products .........................................13

2.2. Factors That Affect Formation of Disinfection By-products .............................................14

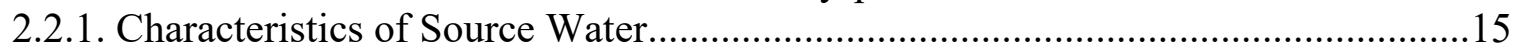

2.2.2. Characteristics of Disinfection Methods....................................................................17

2.2.3. Effects of Time, Temperature, $\mathrm{pH}$, and Other Factors on Formation of

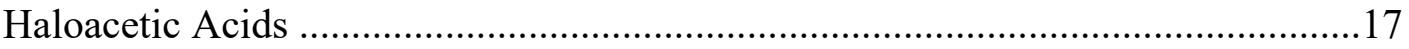

2.2.4. Chemistry of Formation of Haloacetic Acids during Water Disinfection with Chlorine-containing Disinfectants ..................................................................18

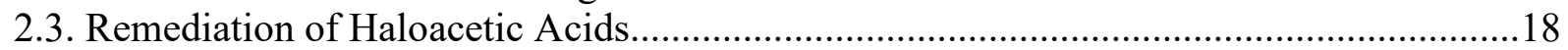

2.4. Formation in Swimming Pools and Spas and Other Domestic Uses ................................22

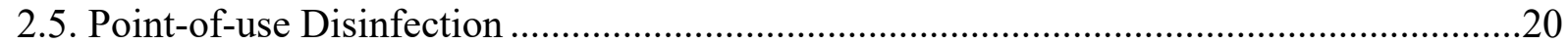

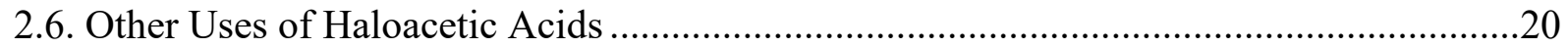

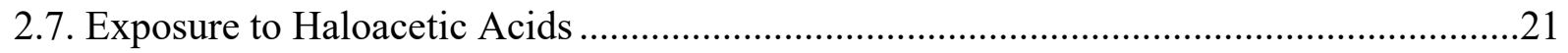

2.7.1. Occurrence of Haloacetic Acids in Treated Water ...................................................21

2.7.2. Correlation of Haloacetic Acids and Trihalomethanes in Treated Water................24

2.7.3. Potential Exposure from Beverages Prepared with Treated Water .........................25

2.7.4. Potential Exposure from Foods.............................................................................25

2.7.5. Potential Exposure from Other Sources...............................................................26

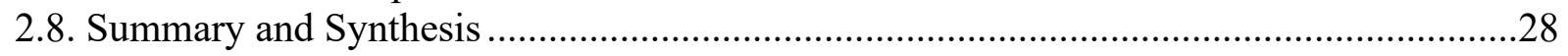

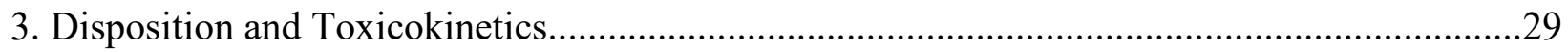

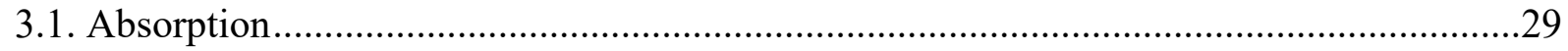

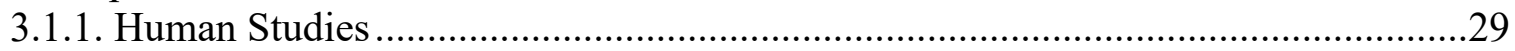




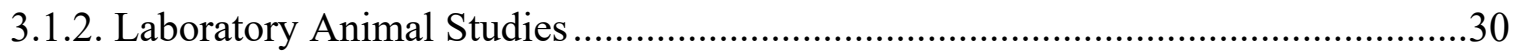

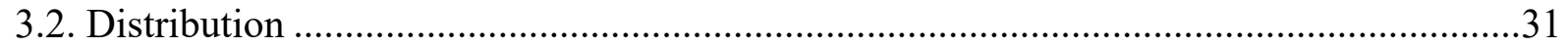

3.2.1. Blood Concentration-time Profiles .........................................................................

3.2.2. Blood:plasma Ratios and Protein Binding ............................................................. 31

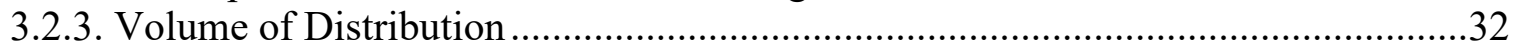

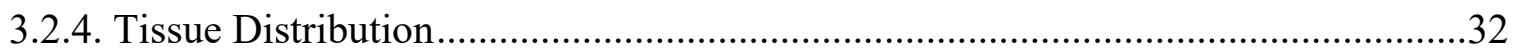

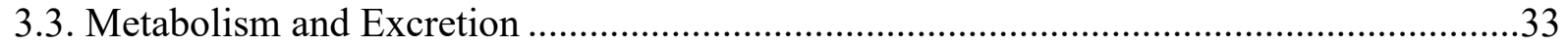

3.3.1. Trihaloacetic Acid Metabolism and Excretion ..........................................................34

3.3.2. Dihalo- and Monohaloacetic Acid Metabolism and Excretion................................35

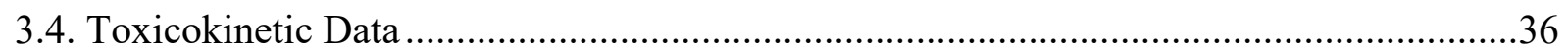

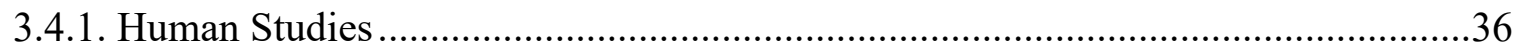

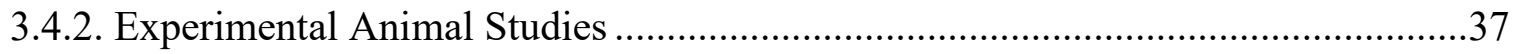

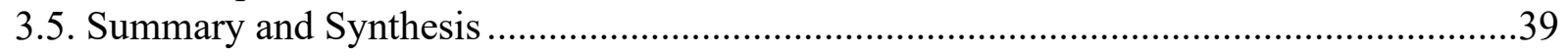

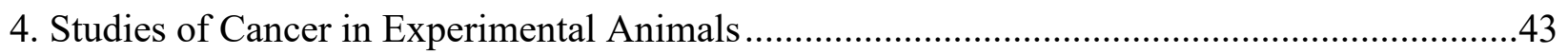

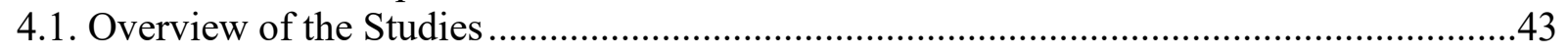

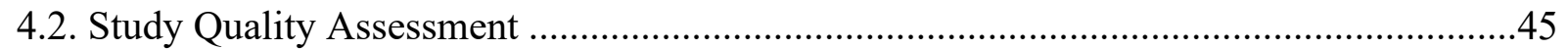

4.3. Neoplastic Findings from Carcinogenesis Studies............................................................51

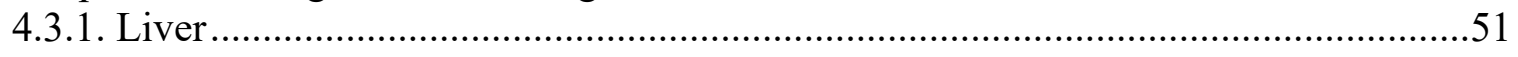

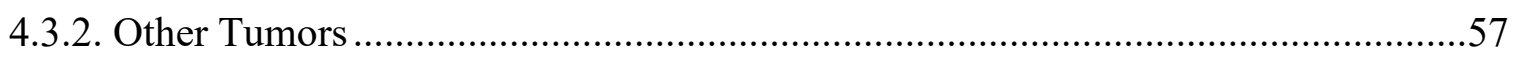

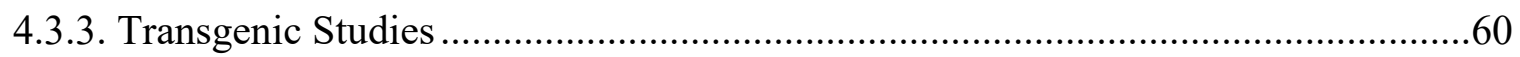

4.3.4. Initiation-promotion Studies ………………………......................................61

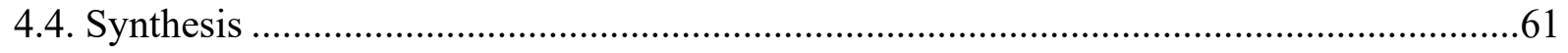

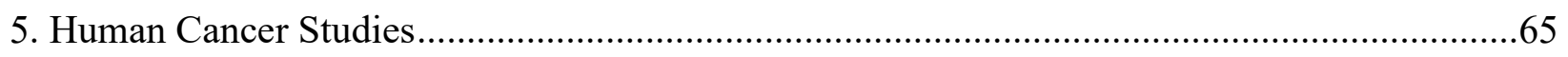

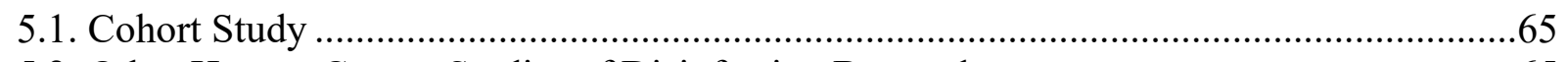

5.2. Other Human Cancer Studies of Disinfection By-products ................................................65

5.3. Preliminary Level of Evidence Conclusion .....................................................................66

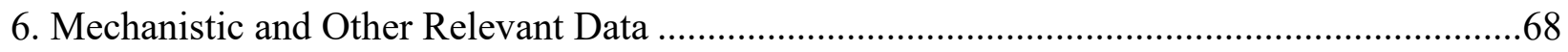

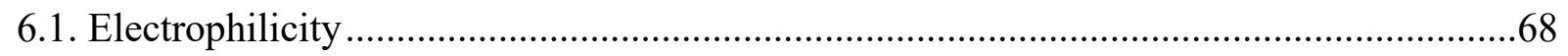

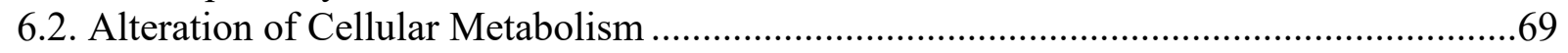

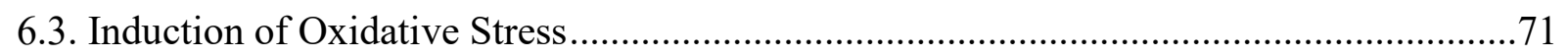

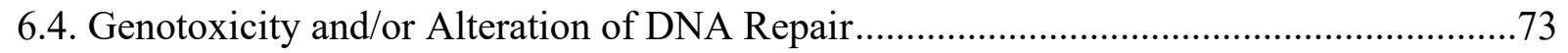

6.4.1. Mutagenic and Genotoxic Effects......................................................................73

6.4.2. Mutagenic and Genotoxic Potency ……………..................................................79

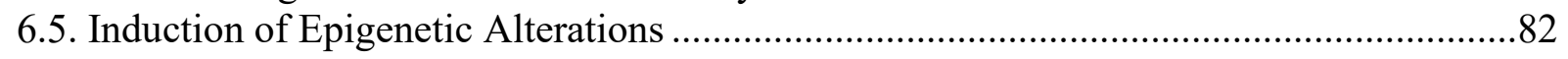

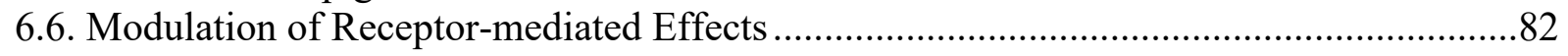

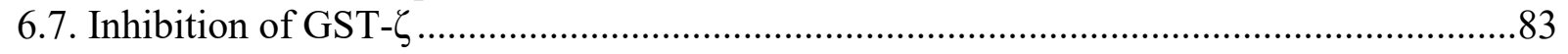

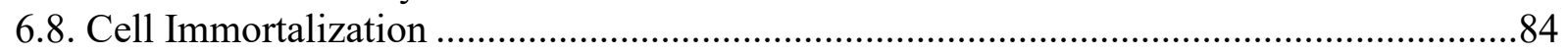

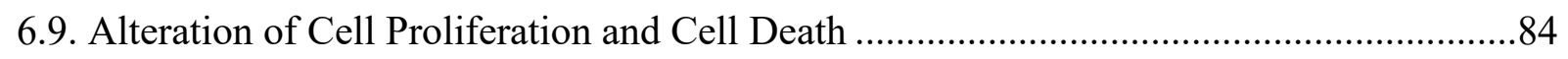

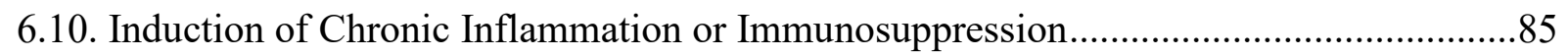

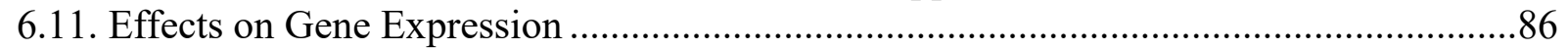

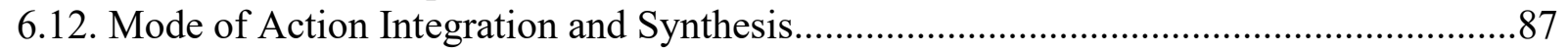

7. Evaluation of Haloacetic Acids as a Class or Subclass(es) ………………………...................92

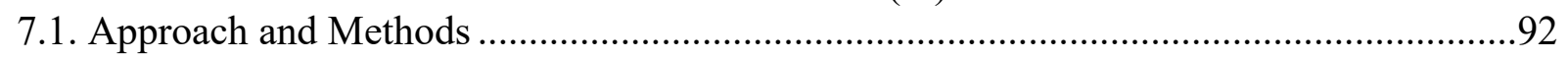

7.1.1. Approach for Evaluating Haloacetic Acids as a Class.............................................93

7.1.2. Approach for Evaluating Subclasses of Haloacetic Acids.......................................96 
7.1.3. Approach for Evaluating Haloacetic Acids for a Potential Analogue

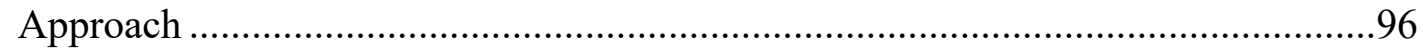

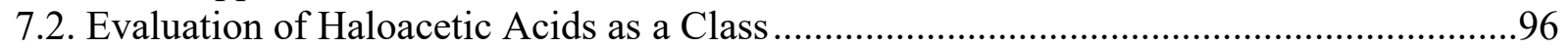

7.3. Potential Haloacetic Acid Subclasses ..............................................................................97

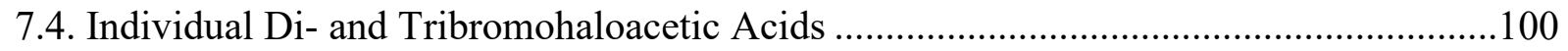

7.4.1. Metabolism and Toxicokinetics ........................................................................100

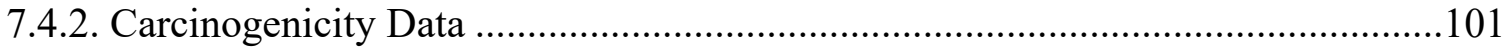

7.4.3. Supporting Mechanistic Data........................................................................102

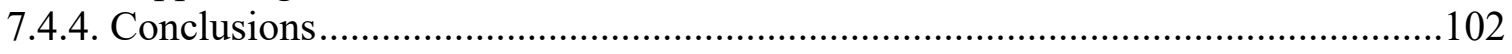

8. Overall Cancer Evaluation and Preliminary Listing Recommendation...................................104

8.1. Evidence of Carcinogenicity from Studies in Experimental Animals .............................104

8.2. Summary of Mechanistic Data and Read-across Approach............................................105

8.3. Preliminary Listing Recommendation ...........................................................................105

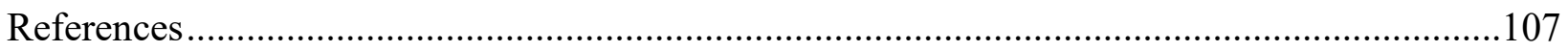

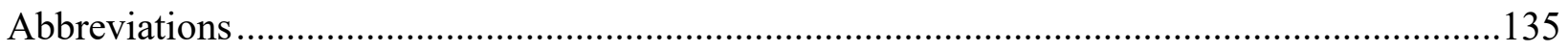

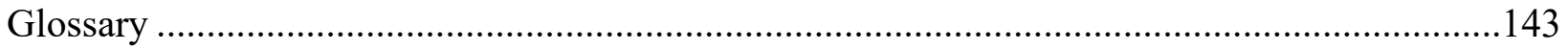

Appendix A. Literature Search Strategy ………………………...................................... A-1

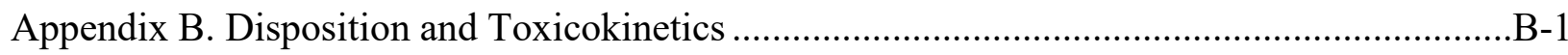

Appendix C. Animal Studies …………………………..................................................

Appendix D. Oxidative Stress and Genotoxic Potency Data for Haloacetic Acids.................... D-1

\section{Tables}

Table 1-1. Structures of 13 Haloacetic Acids Present in Disinfected Water .................................10

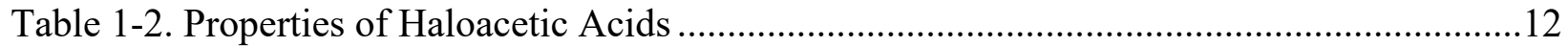

Table 2-1. Effects of Sources of Bromide and Iodide in Source Water on Haloacetic Acid

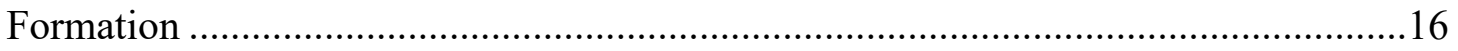

Table 2-2. Comparison of Water Disinfection Methods..........................................................17

Table 2-3. Methods for Remediation of Haloacetic Acids ..............................................................19

Table 2-4. Concentration Ranges for Mono-, Di-, and Trihaloacetic Acids in Tap Water, Finished Drinking Water, and Other Similar Sources................................................22

Table 3-1. ADME Information for Haloacetic Acids in General and for Trihaloacetic and Dihaloacetic Acids as a Class..................................................................................4

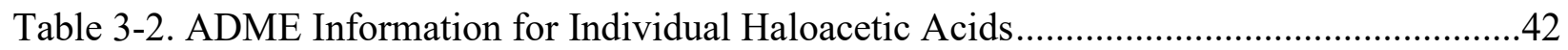

Table 4-1. Overview of Cancer Studies in Experimental Animals...............................................4

Table 4-2. Quality Evaluations of Cancer Studies in Experimental Animals..................................46

Table 4-3. Hepatocellular Neoplasms in Mice Exposed to Bromine-Containing

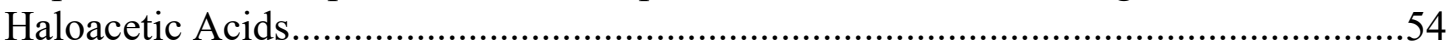

Table 4-4. Results from Cancer Studies in Experimental Animals ...............................................63

Table 5-1. Haloacetic Acid Exposure and Kidney Cancer .........................................................66

Table 6-1. Electrophilic Properties of Haloacetic Acids ..............................................................69

Table 6-2. Summary of the Mutagenic and Genotoxic Effects of Haloacetic Acids.......................77

Table 6-3. Transcriptome Pathways in Human Cells Induced by Monohaloacetic Acids .............86 
Table 6-4. Possible Modes of Carcinogenic Action for Haloacetic Acids and the 10 Characteristics of Carcinogens.....

Table 7-1. Comparison of Relative Potency Estimates for Mechanistic Endpoints and Chemical Properties of Haloacetic Acids ...................................................................94

Table 7-2. Evaluation of Subclasses of Haloacetic Acids .............................................................98

Table 7-3. Tumor Profiles in Source Chemicals and Predicted Tumor Profiles in Target Chemicals.

Table 8-1. Evidence of Cancer in Experimental Animals 105

\section{Figures}

Figure 1. Organization of Information in the RoC Monograph for Haloacetic Acids......................5

Figure 2-1. Conventional Water Treatment Flow Diagram............................................................14

Figure 2-2. Major Factors Affecting the Formation of Halogenated Disinfection Byproducts.

Figure 2-3. National HAA5 Occurrence Data for 1997 through 2014 .........................................23

Figure 2-4. HAA5 Occurrence Data for 2006 through 2011 from EPA Safe Drinking Water Act National Compliance Monitoring for the Third Six-year Review .............23

Figure 2-5. Correlation Data for Haloacetic Acids and Trihalomethanes in Treated Water .........25

Figure 3-1. Oral Bioavailability and Peak Blood Concentration of Di- and Trihaloacetic Acids in Rats... .30

Figure 3-2. Mean Absorption Time and Time to Peak Blood Concentration of Di- and Trihaloacetic Acids in Rats .30

Figure 3-3. Oral Bioavailability of Dichloroacetic Acid in Naïve and GST- $\zeta$-depleted Rats .....

Figure 3-4. General Metabolic Pathways for Tri- and Dihaloacetic Acids ..................................33

Figure 3-5. Comparison of Renal and Nonrenal Clearance of an Equimolar I.V. Dose $(500 \mu \mathrm{mol} / \mathrm{kg})$ of Haloacetic Acids in Male Rats

Figure 3-6. Clearance of Dichloroacetic Acid in Naïve and GST- $\zeta$-depleted Male Rats

Figure 3-7. Clearance of Dihaloacetic Acids (A) and Trihaloacetic Acids (B)

Administered as Mixtures of Di- and Trihaloacetic Acids at Equimolar I.V.

Doses $(25 \mu \mathrm{mol} / \mathrm{kg})$ to Male Rats.

Figure 3-8. Stereospecific Clearance of an I.V. Dose $(520 \mu \mathrm{mol} / \mathrm{kg})$ of $(-),(+)-$

Bromochloroacetic Acids Administered to Naïve and GST- $\zeta$-depleted Male

Rats

Figure 4-1. Hepatocellular Carcinoma in Female and Male Mice Exposed to Di- and

Trihaloacetic Acids .55

Figure 4-2. Hepatoblastoma in Male Mice Exposed to Di- and Trihaloacetic Acids

Figure 4-3. Malignant Mesothelioma Incidence in Male Rats Exposed to

Bromochloroacetic Acid, Dibromoacetic Acid, or Bromodichloroacetic Acid

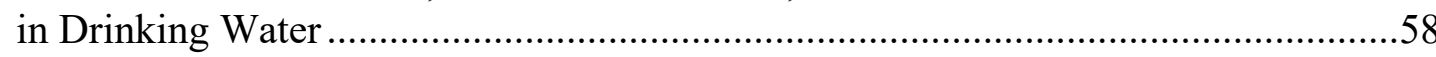

Figure 6-1. Inhibition of GAPDH and PDK by Haloacetic Acids and Effects on Glucose

Metabolism

Figure 6-2. Relative Potency of Haloacetic Acids to Induce Oxidative Stress in Human Cancer Cell Lines; (A) Monohaloacetic Acids, (B) Di- and Trihaloacetic Acids. 
Figure 6-3. Relative Potency of Haloacetic Acids to Induce Oxidative Damage in Mouse Liver In Vivo

Figure 6-4. Relative Genotoxicity Potency Estimates of Haloacetic Acids in the SOS-umuC Assay

Figure 6-5. Relative Genotoxicity Potency Estimates of Haloacetic Acids in Bacteria and Mammalian Cells.

Figure 6-6. Interactions of Potential Modes of Action and Key Events Associated with Haloacetic Acid-induced Carcinogenicity

This report has been reformatted to meet new NTP publishing requirements; its content has not changed. 


\section{About This Report}

National Toxicology Program ${ }^{1}$

${ }^{1}$ Division of the National Toxicology Program, National Institute of Environmental Health

Sciences, Research Triangle Park, North Carolina, USA

\section{Collaborators}

Gloria D. Jahnke, Stanley T. Atwood, Ruth M. Lunn, Sanford C. Garner, Andrew Ewens, Alton Peters

Division of the National Toxicology Program, National Institute of Environmental Health Sciences, Research Triangle Park, North Carolina, USA

Responsible for oversight and coordination of activities including conception, design, and planning of the cancer hazard evaluation

Gloria D. Jahnke, D.V.M., DABT, Project Co-lead

Contributed to design, conduct, technical review, and writing of cancer hazard evaluation, and the interpretation and integration of studies in the evaluation

Ruth M. Lunn, Dr.P.H.

ILS, Inc., Research Triangle Park, North Carolina, USA

Responsible for oversight and coordination of activities including conception, design, and planning of the cancer hazard evaluation

Stanley T. Atwood, M.S., Project Co-lead

Contributed to design, conduct, technical review, and writing of the cancer hazard evaluation, and interpretation and integration of studies in the evaluation

Andrew Ewens, Ph.D.

Sanford C. Garner, Ph.D.

Alton Peters, M.S.

\section{Contributors}

\section{RoC Information Group}

Provided scientific input on specific issues related to the approach for carrying out the cancer hazard assessment

Scott Auerbach, Ph.D.; Division of the National Toxicology Program (DNTP), National Institute of Environmental Health Sciences (NIEHS)

Michael DeVito, Ph.D., DNTP, NIEHS

Stephen Ferguson, Ph.D., DNTP, NIEHS

Scott Masten, Ph.D., DABT, DNTP, NIEHS

Ron Melnick, Ph.D., Ron Melnick Consulting, LLC, North Logan, Utah, USA

Arun Pandiri, Ph.D., DACVP, DABT, DNTP, NIEHS

Grace Patlewicz, Ph.D., U.S. Environmental Protection Agency (U.S. EPA), Research Triangle

Park, North Carolina, USA 
Michael J. Plewa, Ph.D., University of Illinois, Champaign-Urbana, Illinois, USA Susan Richardson, Ph.D., University of South Carolina, Columbia, South Carolina, USA Jane Ellen Simmons, Ph.D., U.S. EPA, Research Triangle Park, North Carolina, USA

\section{RoC Internal Review Group}

Provided critical scientific review of the draft monograph prior to external peer review and public release

Scott Auerbach, Ph.D., DNTP, NIEHS

Windy Boyd, Ph.D., Office of the Director, NIEHS

Michael DeVito, Ph.D., DNTP, NIEHS

Michelle Hooth, Ph.D., DABT, DNTP, NIEHS

Scott Masten, Ph.D., DABT, DNTP, NIEHS

Suril Mehta, M.P.H., DNTP, NIEHS

Arun Pandiri, Ph.D., B.V.Sc. \& A.H., M.S., Ph.D., DACVP, DABT, DNTP, NIEHS

Kristen Ryan, Ph.D., DNTP, NIEHS

Suramya Waidyanatha, Ph.D., DNTP, NIEHS

Nigel Walker, Ph.D., DNTP, NIEHS

Vickie Walker, B.S., DNTP, NIEHS

Amy Wang, Ph.D., DNTP, NIEHS

\section{External Reviewers}

Reviewed sections of the draft monograph prior to external peer review and public release Ron Melnick, Ph.D., Ron Melnick Consulting, LLC, North Logan, Utah, USA

Grace Patlewicz, Ph.D., U.S. EPA, Research Triangle Park, North Carolina, USA

Michael J. Plewa, Ph.D., University of Illinois, Champaign-Urbana, Illinois, USA

Susan Richardson, Ph.D., University of South Carolina, Columbia, South Carolina, USA

Jane Ellen Simmons, M.S.P.H., Ph.D., DABT, ATS, U.S. EPA, Research Triangle Park, North Carolina, USA

\section{Division of the National Toxicology Program, National Institute of Environmental Health} Sciences, Research Triangle Park, North Carolina, USA

Provided web-based database development

Andy Shapiro, M.S. (now at U.S. EPA)

Provided oversight of peer review of the draft monograph

Mary S. Wolfe, Ph.D.

\section{ILS, Inc., Research Triangle Park, North Carolina, USA}

Drafted human cancer section of the monograph

Whitney Arroyave, Ph.D.

Provided support for literature identification during monograph preparation Jessica A. Geter, M.S.L.S.

Provided administrative assistance during monograph preparation

Ella J. Darden, B.S.

Tracy L. Saunders, B.S. 


\section{ICF International, Inc., Durham, North Carolina, USA}

Conducted quality assurance of subsections of the monograph

Anna Engstrom, Ph.D.

Provided editorial support for the monograph

Susan Dakin, Ph.D.

Coordinated peer review of the draft monograph

Louise Assem, Ph.D.

Susan Blaine, B.A.

Canden Byrd, B.S.

Anna Stamatogiannakis, B.S. 


\section{Peer Review}

Peer review of the draft RoC Monograph on Haloacetic Acids Found as Drinking Water Disinfection By-products was conducted by an ad hoc expert panel at a public meeting held July 24, 2017, in the Rodbell Auditorium at the National Institute of Environmental Health Sciences, David P. Rall Building, Research Triangle Park, NC (see http://ntp.niehs.nih.gov/go/38854 for meeting materials, public comments, and peer review report (panel recommendations) from meeting). The selection of panel members and conduct of the peer review were performed in accordance with the Federal Advisory Committee Act and federal policies and regulations. The panel members served as independent scientists, not as representatives of any institution, company, or governmental agency.

The charge to the Peer-review Panel was as follows:

1) Comment on whether the draft RoC Monograph on Haloacetic Acids Found as Water Disinfection By-products is technically correct, clearly stated, and objectively presented.

2) Provide opinion on whether there is currently or was in the past significant human exposure to haloacetic acids found as disinfection by-products.

The panel was asked to vote on the following questions:

1) Whether the scientific evidence supports NTP's conclusions on the level of evidence for carcinogenicity from cancer studies in animals for six individual haloacetic acids found as water disinfection by-products.

2) Whether the scientific evidence supports NTP's preliminary policy decision on the listing status of six individual haloacetic acids found as water disinfection byproducts.

The monograph was revised based on NTP's review of the panel's peer-review comments. The Peer-review Panel Report, which captures the panel recommendations for listing status of haloacetic acids found as water disinfection by-products in the $\mathrm{RoC}$ and their scientific comments, are available on the Peer-Review Meeting web page for haloacetic acids (http://ntp.niehs.nih.gov/go/38854).

At a public meeting on December 7, 2017, NTP provided the NTP Board of Scientific Counselors with information about the peer review and finalized the RoC monograph for Haloacetic Acids Found as Water Disinfection By-products after the meeting.

The final monograph does not include the draft profiles for the six haloacetic acids recommended for listing as reasonably anticipated to be a human carcinogen. As per the $\mathrm{RoC}$ process, NTP submits the draft substance profiles for newly reviewed substances with their recommended listing status to the NTP Executive Committee for consultation and then to the Secretary of Health and Human Services for review and approval. Upon their approval by the Secretary, the substance profiles for newly reviewed substances are added to the next edition of the $\mathrm{RoC}$ and the $\mathrm{RoC}$ is prepared in electronic format, transmitted to Congress, and published on the NTP website. 


\title{
Peer Reviewers
}

\author{
Weihsueh Chiu, Ph.D. (Chair) \\ Professor \\ Department of Veterinary Integrative Biosciences \\ College of Veterinary Medicine and Biomedical Biosciences \\ Texas A\&M University \\ College Station, Texas, USA
}

Julia H. Carter, Ph.D.

President and Chairman

Wood Hudson Cancer Research Laboratory

Newport, Kentucky, USA

Lawrence H. Lash, Ph.D.

Professor and Associate Chair

Wayne State University School of Medicine

Detroit, Michigan, USA

\section{Shahid Parvez, Ph.D.}

Assistant Professor

Environmental Health Science

Richard M. Fairbanks School of Public Health

Indiana University-Purdue University Indianapolis

Indianapolis, Indiana, USA

\section{Mathias Attene-Ramos, Ph.D.}

Associate Professor

Department of Environmental and Occupational Health

George Washington University

Washington, District of Columbia, USA

\section{Stephen M. Roberts, Ph.D.}

Director and Professor

Center for Environmental and Human Toxicology

University of Florida

Gainesville, Florida, USA

\section{Consolato Sergi, M.D., Ph.D., FRCPC}

Professor

Medicine and Dentistry

Laboratory Medicine and Pathology

University of Alberta

Edmonton, Alberta, Canada

Susan C. Tilton, Ph.D.

Assistant Professor

Environmental and Molecular Toxicology

Oregon State University

Corvallis, Oregon, USA 


\section{Publication Details}

Publisher: National Toxicology Program

Publishing Location: Research Triangle Park, NC

ISSN: 2331-267X

DOI: https://doi.org/10.22427/ROC-MGRAPH-12

Report Series: RoC Monograph Series

Report Series Number: 12

Official citation: National Toxicology Program (NTP). 2018. Report on Carcinogens monograph on haloacetic acids found as water disinfection by-products. Research Triangle Park, NC:

National Toxicology Program. RoC Monograph 12.

\section{Acknowledgments}

This work was supported by the Intramural Research Program (ES103316 and ES103317) at the National Institute of Environmental Health Sciences, National Institutes of Health and performed for the National Toxicology Program, Public Health Service, U.S. Department of Health and Human Services under contract GS00Q14OADU417 (Order No. HHSN273201600015U). 


\section{Abstract}

Introduction: Water disinfection is among the most important and beneficial public health advances of the 20th century. A consequence of water disinfection processes is the formation of a large number of unintended compounds from chemicals and organic material in the water, which are of potential public health concern. Haloacetic acids (HAAs) constitute approximately $50 \%$ of total measured halogenated disinfection by-products and are formed when chlorine-based disinfectants react with chemicals and organic material naturally present in the source water.

The National Toxicology Program (NTP) conducted a cancer hazard assessment of 13 HAAschlorine, bromine, and iodine containing mono-, di-, or trihaloacetic acids identified in disinfected drinking water - for potential listing in the Report on Carcinogens (RoC). NTP has forwarded its RoC listing recommendations to the Secretary of Health and Human Services.

Methods: This monograph used systematic review to identify the available, relevant scientific information and assess quality from human, experimental animal, and mechanistic studies for individual HAAs and used read-across principles to determine if the 13 HAAs could be evaluated as a chemical class or subclass(es). Mechanistic data based on the 10 key characteristics of carcinogens, along with disposition and toxicokinetic data, were reviewed and organized. Relative trends in chemical and mechanistic potencies were identified and compared with observed animal cancer endpoints. RoC listing criteria were applied to the scientific information to recommend RoC listing status.

Discussion: Because only one epidemiology study was identified, the epidemiological data were considered inadequate to evaluate the relationship between exposure to any of the 13 HAAs and cancer in humans . Six of the HAAs were tested in experimental animals. Four HAAs (dichloroacetic acid, dibromoacetic acid, bromochloroacetic acid, and bromodichloroacetic acid) met RoC criteria for sufficient evidence of cancer. All four HAAs caused liver tumors in rodents, three also caused malignant mesotheliomas, and two also caused mammary gland cancer. Monochloroacetic acid and trichloroacetic acid did not meet the criteria for sufficient animal cancer evidence. No experimental animal cancer data were available for the remaining seven HAAs.

The primary key characteristics of carcinogens for the HAAs were electrophilicity, genetic toxicity, and oxidative stress and a read-across approach was used to define potential subclasses of carcinogens. Tri-HAAs are metabolized by $\mathrm{P} 450$ reductive dehalogenation, forming dihaloacetic acids via dihaloacetic acid radical intermediates, with bromine substitution on triHAAs generating a stronger leaving group than chlorine substitution. The data did not support grouping HAAs as a class or subclasses; however, read-across principles were used to evaluate two individual brominated tri-HAAs with sufficient metabolism and supporting mechanistic data. No experimental animal cancer data were available for either tribromoacetic acid or chlorodibromoacetic acid; however, they had similar properties to bromodichloroacetic acid, which had sufficient animal cancer evidence. In addition, tribromoacetic acid metabolized to dibromoacetic acid and chlorodibromoacetic acid metabolized to chlorobromoacetic acid, each of which caused cancer in experimental animals.

Conclusions: NTP recommended that dichloroacetic acid, dibromoacetic acid, bromochloroacetic acid, and bromodichloroacetic acid be listed in the $\mathrm{RoC}$ as reasonably anticipated to be human carcinogens based on sufficient evidence from studies in experimental 
animals and supporting mechanistic data. NTP recommended that chlorodibromoacetic acid and tribromoacetic acid be listed in the $\mathrm{RoC}$ as reasonably anticipated to be human carcinogens based on convincing relevant information that indicate these agents act through mechanisms likely to cause cancer in humans. 


\section{Introduction}

Water disinfection is among the most important and beneficial public health advances of the 20th century and has substantially reduced the United States incidences of cholera, typhoid, and amoebic dysentery caused by waterborne pathogens (Richardson et al. 2007). According to the U.S. Environmental Protection Agency (EPA), over 48,000 U.S. public water systems provide disinfected water to more than 250 million people, while $10 \%$ to $15 \%$ of the U.S. population uses private groundwater wells that are typically not disinfected (USEPA 2005; 2015a; 2015b). In addition, swimming pools and spas use on-site chlorination or bromination of water for disinfection. A consequence of the water disinfection process is the formation of a large number of unintended compounds from chemicals and organic material in the water; these unintended chemicals are of potential public health concern (IPCS 2000). Reports have put the number at over 500 chemicals, and identification of more by-products is ongoing. Haloacetic acids (HAAs) and trihalomethanes (THMs) are the largest groups of water disinfection by-products by weight and make up about $50 \%$ to $75 \%$ of total halogenated disinfection by-products measured and about $25 \%$ to $50 \%$ of total organic halides measured (Krasner et al. 2016a; Krasner et al. 2006). Two of four EPA-regulated trihalomethanes, chloroform and bromodichloromethane, are listed in the RoC as reasonably anticipated to be a human carcinogen. Over 30 different forms of haloacetic acids are chemically possible, including iodinated and fluorinated forms. Some of these halogen-substituted acetic acids have been identified in drinking water and five are regulated by USEPA (2010).

The Office of the Report on Carcinogens (ORoC) has evaluated mono-, di-, and trihaloacetic acids identified in drinking water for possible listing in the RoC. The haloacetic acids evaluated consist of nine chlorine and bromine-containing mono-, di-, or trihaloacetic acids either regulated by EPA or being considered for regulation and four iodine-containing acetic acids for a total of 13 haloacetic acids (see Properties section for a list of the HAAs evaluated). As part of the evaluation, ORoC assessed whether some or all of these chemicals can be considered members of a class of carcinogens or if they should be considered separately. It is known that the type and proportion of haloacetic acids formed differ with different disinfection processes and water sources. In addition, some haloacetic acids in drinking water that are not monitored or regulated may have health consequences. It is important to review the haloacetic acid chemical group for carcinogenicity and identify chemicals that may be cancer hazards as this information can help to inform public health decisions on water regulations and on water disinfection processes.

As per the process for preparation of the Report on Carcinogens (RoC), the Office of the RoC released a draft concept document for "Haloacetic Acids (HAAs) Found as Water Disinfection By-products," which outlined the rationale and proposed the approach for their review, for public comment. ORoC also presented the draft to the NTP Board of Scientific Counselors (BSC) at the April 11, 2016 meeting, which provided opportunity for written and oral public comments. Subsequent to the meeting, the concept was finalized and HAAs were approved by the NTP Director as a candidate substance for review. The concept document is available on the RoC website (https://ntp.niehs.nih.gov/go/790113).

At an Information Group Meeting on HAAs at NIEHS on September 9, 2016, input from scientific experts on water disinfection by-products and cancer mechanisms was requested early in the review process. The approach to evaluation of individual HAAs and data needs were 
discussed for evaluation of physicochemical, mechanistic, and cancer endpoints. A "read-across" approach (see Section 7 for discussion of this approach), based on available data for the HAAs (classified by the number of halogen substitutions [e.g., mono-, di-, or tri-] or type of halogen substitution [e.g., chlorine, bromine, and iodine]), to determine if haloacetic acids could be evaluated as a chemical class, or subclass(es), was considered. Technical advisors for the review of HAAs Found as Water Disinfection By-products are identified on the "About This Report" page of this monograph.

Public comments on scientific issues were requested at several times prior to the development of the $\mathrm{RoC}$ monograph, including the request for information on the nomination, and the request for comment on the draft concept document, which outlined the rationale and approach for conducting the scientific review. In addition, NTP posted its protocol for preparing the draft RoC monograph on Haloacetic Acids Found as Water Disinfection By-products for public input on the ORoC website at https://ntp.niehs.nih.gov/go/790113 prior to the release of the draft monograph. 


\section{Methods}

\section{Methods for Developing the RoC Monograph}

This RoC monograph on HAAs Found as Water Disinfection By-products evaluates the available, relevant scientific information and assesses its quality, for each individual HAA or for potential evaluation of the HAAs as a chemical class or subclass, applies the RoC listing criteria to the scientific information, and recommends an RoC listing status (see Figure 1). The draft monograph submitted for peer review also included draft profiles containing NTP's preliminary listing recommendation, a summary of the scientific evidence considered key to reaching that recommendation, and data on properties, use, production, exposure, and federal regulations and guidelines to reduce exposure to haloacetic acids in the public water supply and from other potential exposures. As noted above in the Peer Review section, the draft profiles are not part of the final monograph.

\section{Monograph Contents}

The process of applying the RoC listing criteria to the body of evidence includes an assessment of the level of evidence from cancer studies in humans and experimental animals on haloacetic acids. In addition, an assessment is made on the available mechanistic and other relevant data (such as disposition and toxicokinetics), and the final listing recommendations are based on an integration of all the relevant information. A key question is whether the scientific information supports listing haloacetic acids as a class, as subclasses, or as individual haloacetic acids. Readacross principles were used in this assessment based on discussions with information groups. In addition, listing in the RoC requires that a significant number of people residing in the United States are exposed to haloacetic acids and the monograph provides information on the relevant exposure information. This information is captured in different sections of the monograph as outlined below.

- Properties (Section 1)

- Human Exposure (Section 2)

- Disposition and Toxicokinetics (Section 3)

- Studies of Cancer in Experimental Animals (Section 4)

- Human Cancer Studies (Section 5)

- Mechanistic and Other Relevant Data (Section 6)

- Evaluation of HAAs as a Class or Subclass (Section 7)

- Overall Cancer Evaluation and Preliminary Listing Recommendation (Section 8)

The latter sections (Sections 7 and 8 ) of the monograph are informed by the information and assessments of the data reported in the earlier sections, especially Sections 1, 3, 4, and 6 (see Figure 1). The information must come from publicly available sources. The appendices in the RoC monograph contain important supplementary information, including the literature search strategy, disposition data tables, tables with results of animal studies and/or study quality tables for cancer studies in experimental animals, and results from the mechanism studies (e.g., genotoxicity studies). 


\section{Key Scientific Questions for Each Type of Evidence Stream}

The monograph provides information relevant to the following questions for each type of evidence stream or section topic. Only one human cancer study on exposure specific to haloacetic acids was identified. The study was summarized and reviewed; however, the data were inadequate to conduct a formal assessment.

\section{Questions Related to the Evaluation of Properties and Human Exposure Information}

- What are the physicochemical properties of HAAs and how do they differ with number and type of halogen substitutions?

- Are a significant number of people residing in the United States exposed to haloacetic acids found in disinfected drinking water?

- In what ways can the population be exposed to HAAs?

- What are the levels of HAAs in drinking water and what federal regulations and guidelines limit exposures?

- How is exposure controlled; what remediation methods are used or proposed? 
Type of evidence: Individual HAAs (Section 1 to 6 )

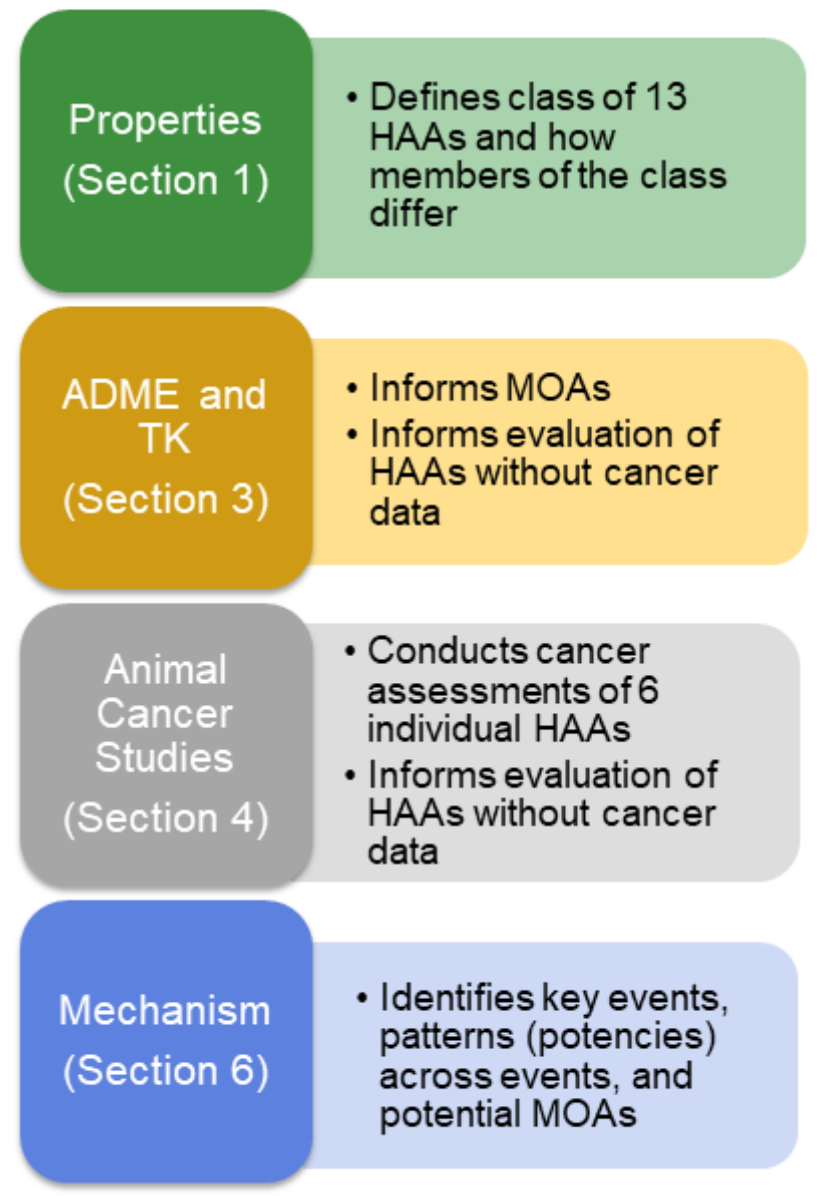

\section{Evidence integration: \\ Class/subclass \\ assessments (Section 7)}

\begin{tabular}{|l|l|l|l|}
\hline Endpoint & $\begin{array}{l}3 \text { mono } \\
\text { HAAs }\end{array}$ & $\begin{array}{l}6 \text { di } \\
\text { HAAs }\end{array}$ & $\begin{array}{l}4 \text { tri } \\
\text { HAAs }\end{array}$ \\
\hline $\begin{array}{l}\text { Properties } \\
\text { (reactivity) }\end{array}$ & Electrophilicity, pKa \\
\hline TK & Comparative data \\
\hline $\begin{array}{l}\text { Key } \\
\text { Events }\end{array}$ & Potencies \\
\hline $\begin{array}{l}\text { Animal } \\
\text { Cancer } \\
\text { Data }\end{array}$ & $\begin{array}{l}\text { Predicted } \text { TD }_{50} S \text { and BMDs } \\
\text { for carcinogenicity }\end{array}$ \\
\hline
\end{tabular}

Read-across-like approaches

- 13 HAAs as a class?

- Subclasses of HAAs (\# and type of

halogen substitution)?

Individual HAAs without cancer

data?
Overall cancer hazard

evaluation

(Section 8)

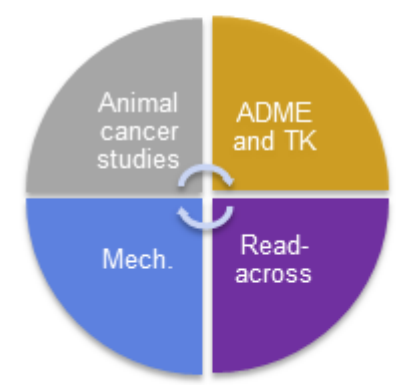

RoC

Listing

Criteria

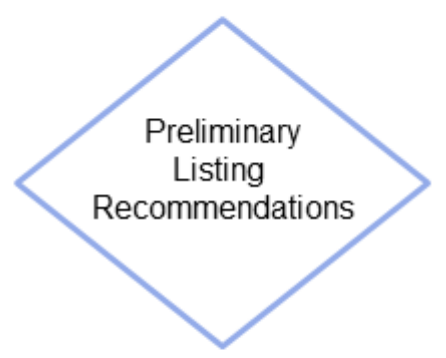

Figure 1. Organization of Information in the RoC Monograph for Haloacetic Acids

$\mathrm{BMD}=$ benchmark dose, which is a dose or concentration that produces a predetermined change in response rate of an adverse effect compared to background; HAAs = haloacetic acids; MOAs = modes of action; RoC $=$ Report on Carcinogens; $\mathrm{TK}=$ toxicokinetics; $\mathrm{TD}_{50 \mathrm{~s}}=$ chronic dose rate that would induce tumors in half the animals tested. 


\section{Questions Related to the Evaluation of Disposition and Toxicokinetics}

- How are HAAs absorbed, distributed, metabolized, and excreted (ADME)?

- What are the primary metabolites? What is their relative distribution in blood and/or urine? What parent compounds or metabolites may have a role in carcinogenesis?

- What are the differences/similarities between humans and experimental animals for ADME?

- Can existing data on ADME or toxicokinetics inform the potential outcomes for HAAs with insufficient data? For example, can information on chlorinated and brominated HAAs be used to predict outcomes for iodinated species?

\section{Questions Related to the Evaluation of Cancer Studies in Experimental Animals}

- What is the level of evidence (sufficient or not sufficient) of carcinogenicity of HAAs from animal studies?

- What are the methodological strengths and limitations of the studies?

- What are the tissue sites and are there any trends in tissue sites with number or type of halogen substitutions?

\section{Questions Related to the Evaluation of Mechanistic Data and Other Relevant Data}

- What are the genotoxic effects due to exposure to HAAs? Does genotoxicity vary by individual HAA or by number or type of halogen substitutions? Do findings from in vitro studies correlate with those from in vivo studies?

- What are the cytotoxic or toxic effects of individual HAA exposure? Does cytotoxicity or toxicity vary by HAA, such as, by type or number of halogen substitutions?

- What are the major mechanistic modes of action for the carcinogenicity of HAAs?

- What are the common key steps or potential molecular initiating events of toxicity or carcinogenicity across different HAAs?

- What factors influence biological or carcinogenic effects?

\section{Questions Related to Evaluation of HAAs as a Class}

- Is there evidence that supports grouping HAAs as a class or as a subclass in the assessment?

\section{Methods for Preparing the Monograph}

The methods for preparing the RoC monograph on HAAs are described in the "Haloacetic acids:

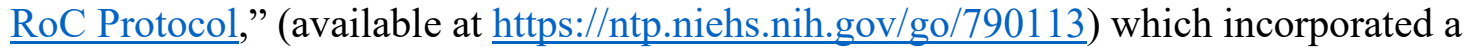
systematic review approach for identification and selection of the literature (see Appendix A), using_inclusion/exclusion criteria, extraction of data and evaluation of study quality using specific guidelines, and assessment of the level of evidence for carcinogenicity using established criteria. Links are provided within the document to the appendices, and specific tables or sections can be selected from the table of contents. 
General procedures: (See the RoC Protocol for a detailed description of methods).

Selection of the literature: The preparation of this RoC monograph on HAAs began with development of a literature search strategy to obtain information relevant to the topics listed above for Sections 1 through 7 using search terms outlined in the Protocol. The 6,630 ${ }^{1}$ citations identified from these searches were uploaded to web-based systematic review software for evaluation by two separate reviewers using inclusion/exclusion criteria, and $336^{2}$ references were selected for final inclusion in the monograph using these criteria. Literature searches were updated to May 2017 and additional references recommended by the peer reviewers were added to the final bibliography.

Data extraction and quality assurance procedures: Information for the relevant cancer and mechanistic sections was systematically extracted in tabular format and/or summarized in the text from studies selected for inclusion in the monograph. All sections of the monograph underwent scientific review and quality assurance (QA, i.e., assuring that all the relevant data and factual information extracted from the publications have been reported accurately) by a separate reviewer. Any discrepancies between the writer and the reviewer were resolved by mutual discussion in reference to the original data source.

Evaluation of cancer studies in experimental animals: Evaluation of the potential for biases as well as other elements were assessed based on a series of a priori considerations (questions and guidelines for answering the questions), which are available in the protocol (available at https://ntp.niehs.nih.gov/go/790113). Two reviewers evaluated the quality of each study. Any disagreements between the two reviewers were resolved by mutual discussion or consultation with a third reviewer in reference to the original data source. The approach for synthesizing the evidence across studies and reaching a level of evidence conclusion is outlined in the protocol. Level of evidence conclusions were made by applying the RoC criteria (see above) to the body of evidence. Because one of the objectives of the monograph was to determine whether haloacetic acids could be evaluated as a class or subclasses, level of evidence conclusions for carcinogenicity (sufficient, not sufficient) were made after the evaluation of the mechanistic data and reported in the overall evaluation.

Evaluation of mechanistic and other relevant data and approaches for evaluating HAAs as a class or subclasses: As mentioned in the protocol, the mechanistic data were organized by characteristics of carcinogens (such as genotoxicity, oxidative stress, altered energy metabolism, and epigenetic alterations) to help inform the relevant modes of action, identify key events or molecular initiation events or adverse pathways. Mechanistic data and toxicokinetic data are discussed across the haloacetic acids to determine if there are any patterns between effects and the number and type of halogen substitutions. This information (e.g., key events and differences in potency for key events and toxicokinetics across haloacetic acids) as well as information on physical properties, and animal carcinogenicity data were used in a read-across-like analysis to

\footnotetext{
${ }^{1}$ ERRATUM: Errors were identified in the Report on Carcinogens Monograph on Haloacetic Acids Found as Water Disinfection By-products. The number of citations was incorrect in the original text. These errors have been corrected; 11,600 was changed to 6,630 and italicized.

${ }^{2}$ ERRATUM: Errors were identified in the Report on Carcinogens Monograph on Haloacetic Acids Found as Water Disinfection By-products. The number of references selected for final inclusion was incorrect in the original text. These errors have been corrected; 328 was changed to 336 and italicized.
} 
determine whether haloacetic acids could be evaluated as a class or subclass (see Figure 1). Details on these methods are reported in Section 7 of this monograph.

Overall evaluation and preliminary listing recommendation: The evidence from the cancer studies in experimental animals was integrated with the assessment of the mechanistic and other relevant data, as well as the conclusions of the assessments of HAAs as a class or subclass (see Figure 1). The RoC listing criteria were then applied to the body of knowledge to reach listing recommendation(s) regarding HAA exposures.

\section{RoC Listing Criteria}

\section{Known to Be Human Carcinogen}

There is sufficient evidence of carcinogenicity from studies in humans*, which indicates a causal relationship between exposure to the agent, substance, or mixture, and human cancer.

\section{Reasonably Anticipated to Be Human Carcinogen}

There is limited evidence of carcinogenicity from studies in humans*, which indicates that causal interpretation is credible, but that alternative explanations, such as chance, bias, or confounding factors, could not adequately be excluded, OR

there is sufficient evidence of carcinogenicity from studies in experimental animals, which indicates there is an increased incidence of malignant and/or a combination of malignant and benign tumors (1) in multiple species or at multiple tissue sites, or (2) by multiple routes of exposure, or (3) to an unusual degree with regard to incidence, site, or type of tumor, or age at onset, OR

there is less than sufficient evidence of carcinogenicity in humans or laboratory animals; however, the agent, substance, or mixture belongs to a well-defined, structurally related class of substances whose members are listed in a previous Report on Carcinogens as either known to be a human carcinogen or reasonably anticipated to be a human carcinogen, or there is convincing relevant information that the agent acts through mechanisms indicating it would likely cause cancer in humans.

Conclusions regarding carcinogenicity in humans or experimental animals are based on scientific judgment, with consideration given to all relevant information. Relevant information includes, but is not limited to, dose response, route of exposure, chemical structure, metabolism, pharmacokinetics, sensitive sub-populations, genetic effects, or other data relating to mechanism of action or factors that may be unique to a given substance. For example, there may be substances for which there is evidence of carcinogenicity in laboratory animals, but there are compelling data indicating that the agent acts through mechanisms which do not operate in humans and would therefore not reasonably be anticipated to cause cancer in humans.

*This evidence can include traditional cancer epidemiology studies, data from clinical studies, and/or data derived from the study of tissues or cells from humans exposed to the substance in question that can be useful for evaluating whether a relevant cancer mechanism is operating in people. 


\section{Properties}

Water disinfection is among the most important and beneficial public health advances of the 20th century in the United States and worldwide (Calderon 2000). Disinfection of water has substantially reduced the incidence of cholera, typhoid, and amoebic dysentery caused by waterborne pathogens and has contributed to decreases in infectious diseases and increases in life expectancy (Richardson et al. 2007). The use of chlorine-based disinfection methods for public water supplies began in the early 1900s in the United States (USEPA 2000). Beginning in the 1970s, the formation of disinfection by-products (DBPs) in water due to the reaction between organic precursors in the source water and disinfection agents, primarily chlorine-based, was recognized as a concern (CDC 2016). Since that first discovery, more than 500 unique DBP molecules have been identified, including many different halogen-containing molecules such as haloacids. The two major classes of DBPs by weight are trihalomethanes and haloacetic acids.

\subsection{Haloacetic Acids Identified in Disinfected Water}

Haloacetic acids all share a common structure with acetic acid as the parent compound, thus these molecules consist of two carbons, including a carboxylic acid and an alpha carbon. A total of 34 different mono- (4 molecules), di- (10 molecules), and trihaloacetic acids (20 molecules) can be formed by replacement of one or more of the 3 hydrogens on the alpha carbon with members of the halogens class, which include fluorine, chlorine, bromine, and iodine. No fluorine-containing haloacetic acids have been identified as water disinfection by-products, likely because the energy required to form these molecules is higher than the oxidation potential of the disinfectants in current use (chlorine, chloramine, ozone, and chlorine dioxide) (Richardson 2016, personal communication to NTP on September 7, 2016). Thirteen haloacetic acids containing chlorine, bromine, or iodine or a combination of these halogens have been identified in disinfected water and these are discussed in this document (Table 1-1).

In 1998, EPA first regulated the sum of five haloacetic acids (HAA5) in drinking water (chloroacetic acid, bromoacetic acid, dichloroacetic acid, dibromoacetic acid, and trichloroacetic acid) (Federal Register 1998). In 2016, EPA required monitoring for four additional haloacetic acids (bromochloroacetic acid, bromodichloroacetic acid, chlorodibromoacetic acid, and tribromoacetic acid) in the Fourth Unregulated Contaminant Monitoring Rule (UCMR4) (Federal Register 2016) to encompass a group of haloacetic acids collectively referred to as HAA9.

Four HAAs containing one or more iodine atoms have been detected in treated water, but they are not currently regulated in the United States. Iodoacetic acid and bromoiodoacetic acid were identified in drinking water for the first time by Weinberg et al. (2002). In other laboratory studies of water treatment and uses of treated water, Smith et al. (2010b) showed that diiodoacetic acid was formed in water treated by point-of-use disinfection with iodine tincture, and Becalski et al. (2006) showed that chloroiodoacetic acid was formed from boiling chlorinated tap water with iodized table salt. The 13 HAAs identified in treated water (see Table 1-1) will be discussed in this monograph. 
Table 1-1. Structures of 13 Haloacetic Acids Present in Disinfected Water

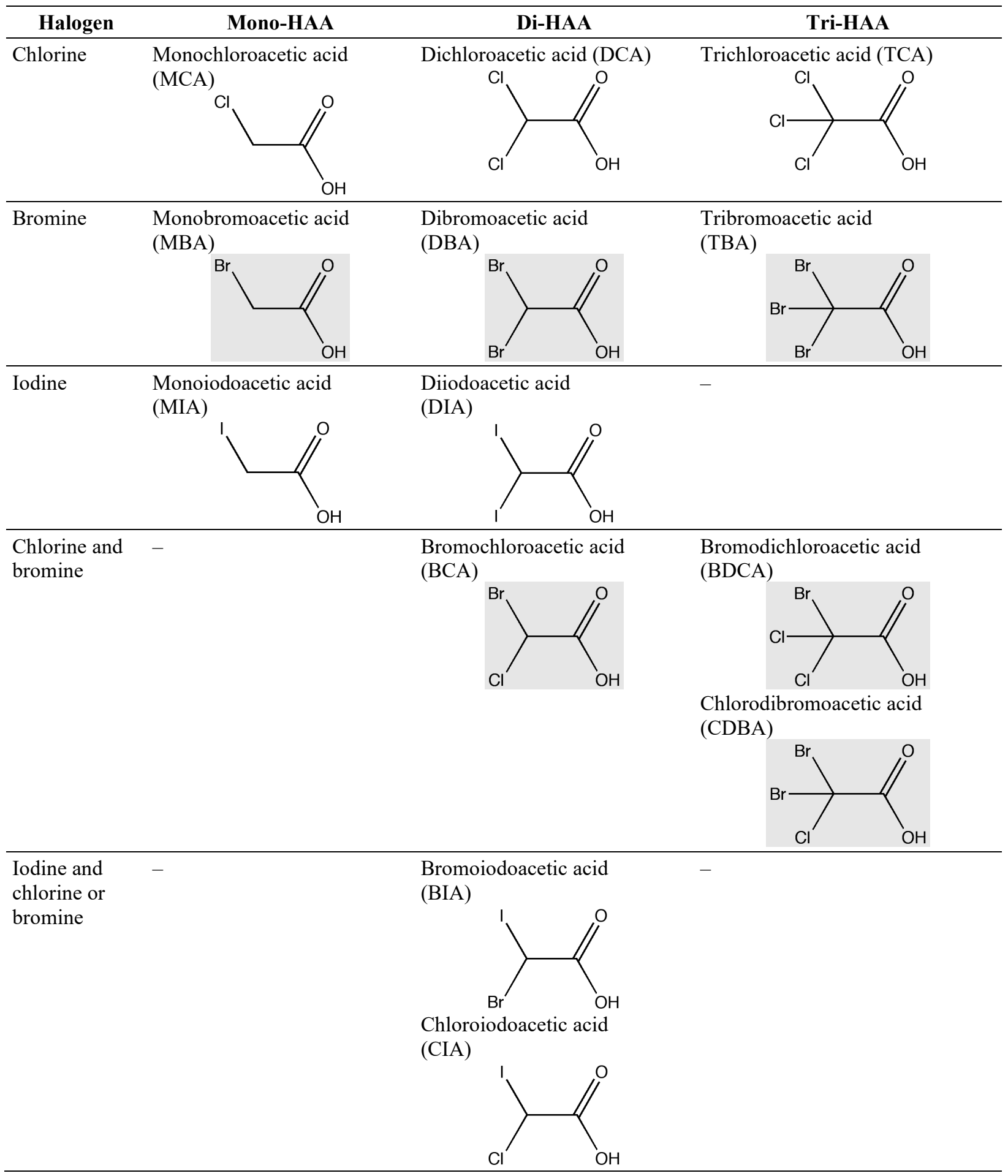

\subsection{Physical and Chemical Properties}

The halogens - fluorine, chlorine, bromine, and iodine - are reactive elements that form a family or group of elements in the periodic table; however, fluorine-containing haloacetic acids are not 
considered further in this monograph as noted in Section 1.1. The presence of halogen atoms affects the reactivity of a haloacetic acid, particularly the reactivity of the alpha carbon to which the halogens are attached and the ionizability of the carboxylic acid. Physical-chemical properties of the halogens that affect the reactivity of the haloacetic acids include electronegativity, polarizability, the physical size of these atoms, and related properties such as the strength of the bond between the halogen and a carbon atom and the potential of a halogen to act as a leaving group.

Electronegativity is defined as the tendency of an atom or functional group to attract electrons from other atoms in a molecule. The electronegativity of the halogens decreases with increasing atomic number moving down the periodic table from chlorine to bromine to iodine. The presence of one or more halogen atoms in a haloacetic acid will affect (1) the strength of the negative charge resulting from ionization of the carboxylic acid, (2) the magnitude of the negative log of the acid dissociation constant ( $\mathrm{p} K_{\mathrm{a}}$ ) of the carboxylic acid, and (3) the reactivity of the alpha carbon in a substitution reaction. Thus, the physical-chemical characteristics of each haloacetic acid depends on the type and number of halogen atoms in the molecule.

The toxic potency of the monohaloacetic acids correlates highly with their electrophilic reactivity or alkylating potential and the quality of the halogen as a leaving group (Pals et al. 2011; Plewa et al. 2004a). The atomic size of the three halogens from smallest to largest is $\mathrm{Cl}<\mathrm{Br}<\mathrm{I}$, and the length of the carbon-hydrogen bond increases in the same order while the bond dissociation energy decreases (Plewa et al. 2004a). The quality of each halogen as a leaving group also increases from chlorine to bromine to iodine and is related to the polarizability of the halogen atom (i.e., the ability of the electrons in the atom to distort or shift due to external influences) and delocalization of the electron cloud (i.e., the spatial distribution of electrons shared among the atoms in a molecule). Both polarizability and delocalization are highest for iodine among the halogens.

An important substitution reaction mechanism in organic chemistry consists of the breaking of one bond and the simultaneous formation of another between reacting molecules. This mechanism is described as "substitution, nucleophilic, with 2 molecules in the rate-determining step" and is commonly abbreviated as $\mathrm{S}_{\mathrm{N}} 2$. The $\mathrm{S}_{\mathrm{N}} 2$ reactivity of the monohaloacetic acids increases from chloride to bromide to iodide (Plewa et al. 2004a).

Three physical-chemical properties likely to be related to the toxicity of the HAAs because they describe the ability of the molecules to enter cells and their potential reactivity with other molecules within a cell are the octanol-water partition coefficient $\left(\log K_{\mathrm{ow}}\right)$, the $\mathrm{pK}$, and the energy of the lowest unoccupied molecular orbital for the deprotonated form of the HAAs that exists in solution at physiological $\mathrm{pH}$ (ELUMo) (Table 1-2). At physiological $\mathrm{pH}$, all of the haloacetic acids will exist in their ionized form, but the $\mathrm{p} K_{\mathrm{a}}$ also indicates the strength of the acid form which increases as $\mathrm{p} K_{\mathrm{a}}$ decreases. The relationship between these physical-chemical properties and the toxicity and potential mechanisms of carcinogenicity of haloacetic acids as a class is discussed further in Section 7.2. QSAR models using these physical-chemical properties have shown significant correlations with endpoints such as the cytotoxicity and genotoxicity of HAAs when two parameters, usually $E_{\text {LUMO }}$ and $\mathrm{p} K_{\mathrm{a}}$, are used in combination but not when either parameter was used by itself (Pals et al. 2011; Plewa et al. 2010; Plewa et al. 2004b; Richard and Hunter 1996; Schultz et al. 2006; Stalter et al. 2016a). 
Table 1-2. Properties of Haloacetic Acids

\begin{tabular}{|c|c|c|c|c|c|c|c|c|c|}
\hline Haloacetic Acid & CAS No. & Formula & $\begin{array}{c}\text { Molecular } \\
\text { Weight }\end{array}$ & $\begin{array}{c}\text { Solubility } \\
\text { in Water } \\
(\mathrm{g} / \mathbf{1 0 0} \\
\text { mL })^{\mathrm{a}}\end{array}$ & $\begin{array}{c}\text { Vapor } \\
\text { Pressure } \\
(\mathbf{m m} \mathbf{H g})^{\mathrm{a}, \mathrm{b}}\end{array}$ & $\begin{array}{c}\text { Dipole } \\
\text { moment } \\
\text { (Debye } \\
\text { Units) }^{c}\end{array}$ & $\begin{array}{l}\text { Octanol-water } \\
\text { Partition } \\
\text { Coefficient } \\
\left(\log K_{\text {ow }}\right)^{d}\end{array}$ & $\begin{array}{c}\text { Dissociation } \\
\text { Constant } \\
\left(p K_{a}\right)^{d}\end{array}$ & $\begin{array}{c}\text { Energy of Lowest } \\
\text { Unoccupied } \\
\text { Molecular Orbital, } \\
{\text { ELUMo }(\mathrm{eV})^{\mathrm{d}}}^{\mathrm{d}}\end{array}$ \\
\hline Chloroacetic acid & $79-11-8$ & $\mathrm{C}_{2} \mathrm{H}_{3} \mathrm{ClO}_{2}$ & 94.5 & 85.8 & 0.065 & 2.716 & 0.22 & 2.97 & 9.43 \\
\hline Bromoacetic acid & $79-08-3$ & $\mathrm{C}_{2} \mathrm{H}_{3} \mathrm{BrO}_{2}$ & 138.9 & 9.4 & 0.119 & 2.722 & 0.41 & 2.96 & 8.68 \\
\hline Iodoacetic acid & $64-69-7$ & $\mathrm{C}_{2} \mathrm{H}_{3} \mathrm{IO}_{2}$ & 185.9 & - & 0.03 & 1.794 & 0.85 & 2.95 & 7.18 \\
\hline Dichloroacetic acid & $79-43-6$ & $\mathrm{C}_{2} \mathrm{H}_{2} \mathrm{Cl}_{2} \mathrm{O}_{2}$ & 128.9 & $\begin{array}{c}100 \\
\left(\text { at } 20^{\circ} \mathrm{C}\right)\end{array}$ & 0.179 & 1.284 & 0.92 & 1.41 & 8.44 \\
\hline Dibromoacetic acid & $631-64-1$ & $\mathrm{C}_{2} \mathrm{H}_{2} \mathrm{Br}_{2} \mathrm{O}_{2}$ & 217.8 & 211 & 0.023 & 1.048 & 0.7 & 1.39 & 7.51 \\
\hline Diiodoacetic acid & $598-89-0$ & $\mathrm{C}_{2} \mathrm{H}_{2} \mathrm{I}_{2} \mathrm{O}_{2}$ & 311.8 & - & - & 2.163 & $1.3^{\mathrm{e}}$ & - & - \\
\hline Bromochloroacetic acid & $5589-96-8$ & $\mathrm{C}_{2} \mathrm{H}_{2} \mathrm{BrClO}_{2}$ & 173.4 & 25 & 0.14 & - & 0.61 & 1.4 & 7.78 \\
\hline Chloroiodoacetic acid & $53715-09-6$ & $\mathrm{C}_{2} \mathrm{H}_{2} \mathrm{ClIO}_{2}$ & 220.4 & - & - & - & 1.2 & 1.47 & 6.40 \\
\hline Bromoiodoacetic acid & $71815-43-5$ & $\mathrm{C}_{2} \mathrm{H}_{2} \mathrm{BrIO}_{2}$ & 264.8 & - & - & - & 1.4 & 1.67 & 6.46 \\
\hline Trichloroacetic acid & $76-03-9$ & $\mathrm{C}_{2} \mathrm{HCl}_{3} \mathrm{O}_{2}$ & 163.4 & 4.4 & 0.06 & 1.564 & 1.33 & 0.66 & 7.13 \\
\hline Tribromoacetic acid & $75-96-7$ & $\mathrm{C}_{2} \mathrm{HBr}_{3} \mathrm{O}_{2}$ & 296.7 & 20 & 0.00028 & 1.552 & 1.71 & 0.03 & 6.12 \\
\hline Bromodichloroacetic acid & $71133-14-7$ & $\mathrm{C}_{2} \mathrm{HBrCl}_{2} \mathrm{O}_{2}$ & 207.8 & 0.49 & 0.036 & - & 1.53 & 0.05 & 6.65 \\
\hline Chlorodibromoacetic acid & $5278-95-5$ & $\mathrm{C}_{2} \mathrm{HBr}_{2} \mathrm{ClO}_{2}$ & 252.3 & 0.24 & 0.0052 & - & 1.62 & 0.04 & 6.42 \\
\hline
\end{tabular}

${ }^{a}$ Reported at $25^{\circ} \mathrm{C}\left(298.15^{\circ} \mathrm{K}\right)$ unless noted otherwise.

bPubChem (2017), except chloroacetic acid, bromoacetic acid, and dichloroacetic acid from ChemIDplus (2017).

cPérez-Garrido et al. (2008).

dStalter et al. (2016a) unless noted otherwise; deprotonated form.

ePubChem (2016a). 


\section{Human Exposure}

A significant number of people living in the United States are exposed to haloacetic acids formed as water disinfection by-products because of the widespread use of chlorine-containing disinfectants for water treatment. As noted in the previous section, water disinfection in the United States and worldwide has provided major public health benefits through decreases in infectious diseases and increases in life expectancy that result from providing safe, clean drinking water.

According to EPA, over 48,000 U.S. public water systems provide disinfected water to more than 250 million people, while $10 \%$ to $15 \%$ of the U.S. population uses private groundwater wells that are typically not disinfected (USEPA 2005; 2015a; 2015b). Thus, the majority of the U.S. population is exposed to mono-, di-, and trihaloacetic acids found as water disinfection byproducts. Ingestion of chlorinated drinking water is the most common exposure route for haloacetic acids (HAAs) for the general public, but inhalation and dermal exposure also can occur. The chemical and physical properties of HAAs (i.e., low volatility and high polarity) limit inhalation and dermal exposures and ingestion accounted for about $94 \%$ of total exposure for swimmers in chlorinated swimming pools (Cardador and Gallego 2011; Kim and Weisel 1998) (see Section 3.1.1). Other potential sources of exposure to HAAs for the general public include consumption of beverages prepared with treated water either in the home or commercially, consumption of food prepared with treated water, accidental ingestion of swimming pool or spa water by heavy swimmers or spa users, and in some limited circumstances from point-of-use disinfection. Information on potential occupational exposure to HAAs is limited, but exposure to swimming pool attendants at indoor and outdoor pools has been documented.

\subsection{Water Treatment and Formation of Disinfection By-products}

The presence of HAAs in the United States is well established, but knowledge of the chemical and physical processes that lead to their formation is important to help control their levels as required by law. Source water, either groundwater or surface water, contains organic carbon that reacts with chlorine-based disinfectants. Elevated levels in source water of bromide and iodide from anthropogenic and natural sources will likely shift production of HAAs during water disinfection toward more brominated and iodinated species. Minimizing the content of HAAs in finished water provided to consumers is an important goal, and the best current strategy for remediation of HAAs is prevention or reduction of their production. This generally involves reducing the potential precursors present as organic carbon in the source water, but manipulation of conditions for disinfection, such as choice of disinfectant, dose, contact time with water, temperature, and $\mathrm{pH}$ can also be effective means to reduce formation. Research into the chemical reactions and intermediate molecules formed also contributes to greater understanding of the process of formation and how to control it.

Water disinfection is regulated by EPA through Surface Water Treatment Rules (SWTRs) that established maximum contaminant level goals (MCLGs) for viruses, bacteria, such as Legionella, and other organisms such as the protozoa species Giardia lamblia and Cryptosporidium. The purpose of water treatment is to remove contaminants and disease-causing agents from drinking water (CDC 2015). The most common steps in conventional water treatment are (1) coagulation and flocculation, (2) sedimentation, (3) filtration, (4) disinfection, 
and (5) storage (see Figure 2-1) (CDC 2015; USEPA 2016a). In disinfection, application of oxidants (chlorine, chloramine, chlorine dioxide, or ozone) or ultraviolet (UV) light kills diseasecausing microorganisms or renders them inactive. Reverse osmosis is another non-chemical water purification method, but its primary use is at the household level rather than by community water treatment facilities other than at desalination plants.

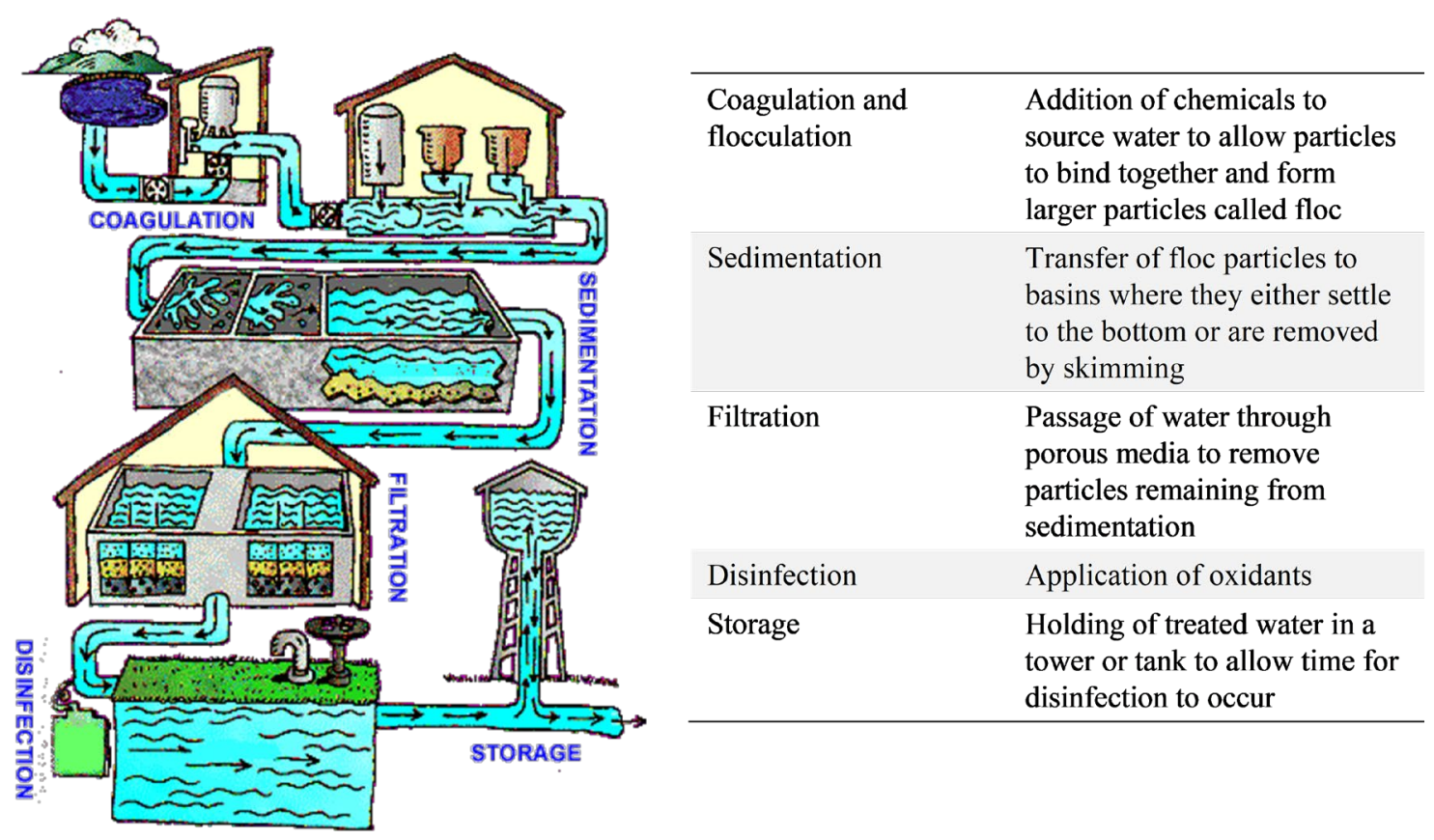

Figure 2-1. Conventional Water Treatment Flow Diagram

Sources: CDC (2015); USEPA (2016a).

\subsection{Factors That Affect Formation of Disinfection By-products}

The factors (see Figure 2-2) that determine the type and amount of disinfection by-products formed during water treatment include (1) the presence of organic matter and inorganic matter in the source water, which is subject to daily as well as seasonal variation in concentration, (2) the disinfecting chemicals used, and (3) the length of time the organic matter is exposed to the disinfecting chemicals, the temperature at which the disinfection process takes place, and the $\mathrm{pH}$ of the water during the disinfection process. The organic molecules in source water are often extremely large, complex molecules and intermediate molecules will form as a result of exposure to disinfecting chemicals; further reaction with those chemicals during the disinfection process and storage will result in formation of halogenated by-products, including haloacetic acids. 


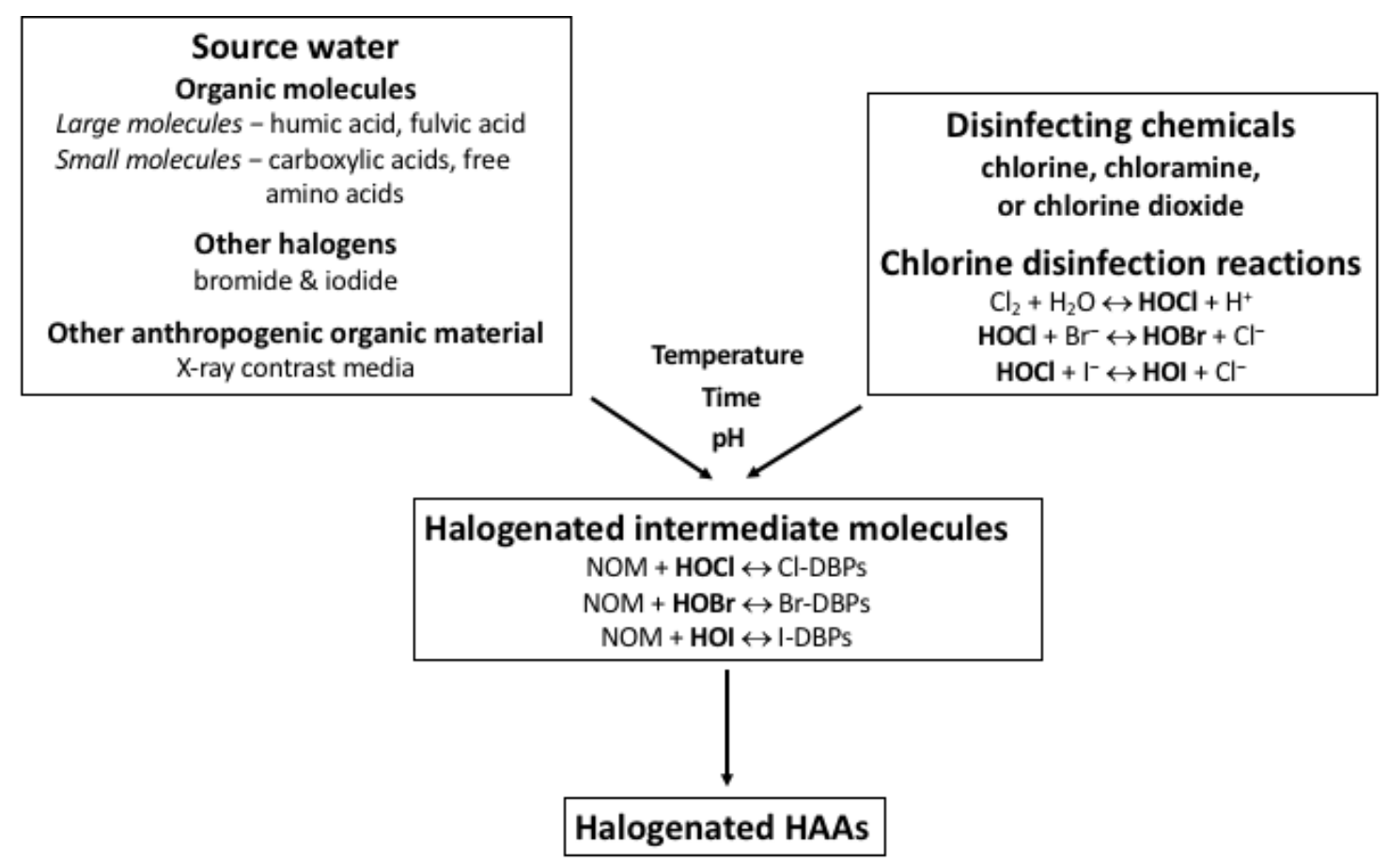

Figure 2-2. Major Factors Affecting the Formation of Halogenated Disinfection By-products

Organic molecules in source water plus naturally occurring or anthropogenic bromide and iodide react with various chlorinecontaining disinfecting chemicals to form halogenated intermediate molecules and ultimately the halogenated HAAs.

$\mathrm{HOBr}=$ hypobromous acid; $\mathrm{HOCl}=$ hypochlorous acid; $\mathrm{HOI}=$ hypoiodous acid; $\mathrm{NOM}=$ natural organic matter.

\subsubsection{Characteristics of Source Water}

The major characteristic of the source water that determines the formation of disinfection byproducts is the type and quantity of potentially reactive natural organic matter (NOM) and the inorganic halogen precursors, bromide and iodide. The organic matter found in either surface or groundwater consists of a mixture of organic compounds derived from sources such as terrestrial plants, microbially derived from algae and bacteria, or from anthropogenic sources. The latter class includes pesticides, pharmaceuticals, personal care products, and newer materials such as carbon nanotubes (Nelson 2015). The molecules of NOM in source water that react with chloride, bromide, and sometimes iodide to form HAAs range from very complex, e.g., humic and fulvic acids, to simple amino acids and dicarbonyl acids (Reckhow et al. 2001; Reckhow and Singer 1985; Zhai and Zhang 2011).

Anthropogenic and natural sources of bromide and iodide (see Table 2-1) can increase concentrations of these halide ions in source waters (e.g., due to incomplete removal or nonremoval in wastewater treatment plants) and create brominated and iodinated HAAs and other disinfection by-products such as trihalomethanes and bromate (McTigue et al. 2014). Elevated levels of bromide and iodide in source water will likely shift production of HAAs during water disinfection toward brominated and iodinated species. 
Table 2-1. Effects of Sources of Bromide and Iodide in Source Water on Haloacetic Acid Formation

\begin{tabular}{|c|c|c|c|}
\hline Source & $\begin{array}{c}\text { Effect on Bromide or } \\
\text { Iodide Ion Concentration }\end{array}$ & $\begin{array}{l}\text { Effect on Disinfection By- } \\
\text { product Formation }\end{array}$ & Reference \\
\hline $\begin{array}{l}\text { Coal-fired electric } \\
\text { power plants }\end{array}$ & $\begin{array}{l}\text { Increased bromide ion } \\
\text { concentration power plant } \\
\text { wastewater discharges }\end{array}$ & $\begin{array}{l}\text { Increased brominated HAA } \\
\text { species }^{\mathrm{a}}\end{array}$ & McTigue et al. (2014) \\
\hline \multirow[t]{2}{*}{$\begin{array}{l}\text { Oil and gas } \\
\text { production }\end{array}$} & $\begin{array}{l}\text { Bromide ion concentration } \\
\text { increased from }<0.02 \mathrm{mg} / \mathrm{L} \\
{[<20 \mu \mathrm{g} / \mathrm{L}] \text { upstream of oil }} \\
\text { and gas } \mathrm{CWT} \text { to } 75 \mathrm{mg} / \mathrm{L} \\
{[75,000 \mu \mathrm{g} / \mathrm{L}] \text { downstream }} \\
\text { of } \mathrm{CWT}\end{array}$ & $\begin{array}{l}\text { Downstream concentration of } \\
\text { DBCNM }^{\mathrm{c}} \text { ranging from } \\
5.7 \mu \mathrm{g} / \mathrm{L}-8.7 \mu \mathrm{g} / \mathrm{L}\end{array}$ & Hladik et al. $(2014)^{\mathrm{d}}$ \\
\hline & $\begin{array}{l}\text { Increased bromide ion } \\
\text { concentration in publicly } \\
\text { owned treatment works } \\
\text { and CWT discharges }\end{array}$ & $\begin{array}{l}\text { Increased brominated } \\
\text { disinfection by-product } \\
\text { formation }^{\mathrm{a}}\end{array}$ & $\begin{array}{l}\text { Hammer and VanBriesen } \\
(2012)\end{array}$ \\
\hline Seawater intrusion & $\begin{array}{l}\text { Bromide concentration } \\
\text { increased from } 38 \mu \mathrm{g} / \mathrm{L} \text { to } \\
974 \mu \mathrm{g} / \mathrm{L} \text { as seawater } \\
\text { content increased from } 0 \% \\
\text { to } 2 \%\end{array}$ & $\begin{array}{l}\text { HAA } 9 \text { concentration increased } \\
\text { from } 39 \mu \mathrm{g} / \mathrm{L} \text { to } 75 \mu \mathrm{g} / \mathrm{L} \text { and } \\
\text { disinfection by-product } \\
\text { formation shifted from chlorine- } \\
\text { containing to bromine-containing } \\
\text { species }\end{array}$ & Ged and Boyer (2014) ${ }^{\mathrm{e}}$ \\
\hline \multirow[t]{2}{*}{$\begin{array}{l}\text { Seawater } \\
\text { desalination }\end{array}$} & $\begin{array}{l}\text { Saudi Arabia, Red Sea } \\
\text { coast: Bromide } \\
\text { concentration in } \\
\text { seawater }=60 \mathrm{mg} / \mathrm{L} \\
{[60,000 \mu \mathrm{g} / \mathrm{L}] \text {; iodide }} \\
\text { concentration }=0.05 \mathrm{mg} / \mathrm{L} \\
{[50 \mu \mathrm{g} / \mathrm{L}]}\end{array}$ & $\begin{array}{l}\text { Reported HAA9 concentration } \\
\text { range in chlorinated } \\
\text { seawater }=5.35 \mu \mathrm{g} / \mathrm{L}-6.86 \mu \mathrm{g} / \mathrm{L}\end{array}$ & Kim et al. (2015) \\
\hline & $\begin{array}{l}\text { United States, Tampa Bay: } \\
\text { Bromide concentration } \\
\text { range in } \\
\text { seawater }=49 \mathrm{mg} / \mathrm{L}- \\
56 \mathrm{mg} / \mathrm{L}[49,000 \mu \mathrm{g} / \mathrm{L}- \\
56,000 \mu \mathrm{g} / \mathrm{L}]\end{array}$ & $\begin{array}{l}\text { Reported HAA5 concentration } \\
\text { range in chlorinated } \\
\text { seawater }=69 \mu \mathrm{g} / \mathrm{L}-175 \mu \mathrm{g} / \mathrm{L}\end{array}$ & \\
\hline $\begin{array}{l}\text { Iodinated X-ray } \\
\text { contrast media }\end{array}$ & $\begin{array}{l}\text { Various iodinated X-ray } \\
\text { contrast media (iopamidol, } \\
\text { iohexol, and iopromide) } \\
\text { dissolved in raw river } \\
\text { water at concentrations } \\
\text { ranging from } 3,880 \mu \mathrm{g} / \mathrm{L}- \\
4,100 \mu \mathrm{g} / \mathrm{L}^{\mathrm{f}}\end{array}$ & $\begin{array}{l}\text { Iodoacetic acid concentrations } \\
\text { ranged from } 0.5 \mathrm{nM} \text { to } 9.6 \mathrm{nM} \\
{[0.09 \mu \mathrm{g} / \mathrm{L}-1.8 \mu \mathrm{g} / \mathrm{L}]}\end{array}$ & Duirk et al. $(2011)^{\mathrm{e}}$ \\
\hline \multicolumn{4}{|c|}{$\begin{array}{l}\text { a No quantitative data on increases in brominated HAA data } \\
\text { b } \mathrm{CWT}=\text { commercial wastewater treatment plant. } \\
\text { c } \mathrm{DBCNM}=\text { dibromochloronitromethane. } \\
\text { d No data on finished water haloacetic acids were reported. } \\
\text { e Laboratory chlorination study. } \\
{ }^{\mathrm{f}} \text { Concentration reported as } 5 \mu \mathrm{M} \text { for all contrast media. }\end{array}$} \\
\hline
\end{tabular}




\subsubsection{Characteristics of Disinfection Methods}

The choice of disinfection methods is generally based on their effectiveness, including their continued presence as a secondary disinfectant in the water distribution system, their overall cost, and their ease of use by water treatment facilities, but chlorine-containing chemical disinfection is by far the most widely used approach in the United States. The major disinfection methods, i.e., chlorine as either a gas $\left(\mathrm{Cl}_{2}\right)$, liquid $(\mathrm{NaOCl})$, or solid $\left(\mathrm{Ca}(\mathrm{OCl})_{2}\right)$ form; chloramine; chlorine dioxide; ozone; and ultraviolet (UV) irradiation are generally effective as a primary disinfectant. A comparison of the major factors differentiating these disinfection methods is provided in Table 2-2.

Table 2-2. Comparison of Water Disinfection Methods

\begin{tabular}{|c|c|c|c|c|c|}
\hline Disinfectant & $\begin{array}{c}\text { Efficacy as } \\
\text { Primary } \\
\text { Disinfectant }\end{array}$ & $\begin{array}{l}\text { Residual } \\
\text { Disinfection in } \\
\text { Distribution } \\
\text { System }\end{array}$ & $\begin{array}{l}\text { Total HAAs } \\
\text { Formation }\end{array}$ & $\begin{array}{c}\text { Other } \\
\text { DBPs } \\
\text { Formed }\end{array}$ & Ease of Use; Cost \\
\hline $\begin{array}{l}\text { Chlorine }\left(\mathrm{Cl}_{2},\right. \\
\left.\mathrm{HOCl}, \mathrm{OCl}^{-}\right)\end{array}$ & $\begin{array}{l}\text { High to } \\
\text { intermediate }\end{array}$ & Yes & High & $\begin{array}{l}\text { THMs, } \\
\text { HANs }^{\mathrm{a}}\end{array}$ & $\begin{array}{l}\text { Easiest method to use for } \\
\mathrm{HOCl} / \mathrm{OCl}^{-} \text {; least expensive }\end{array}$ \\
\hline $\begin{array}{l}\text { Chloramine } \\
\left(\mathrm{NH}_{2} \mathrm{Cl}\right)\end{array}$ & Intermediate & $\begin{array}{l}\text { Yes (more } \\
\text { effective that } \\
\text { chlorine alone) }\end{array}$ & $\begin{array}{l}\text { Intermediate } \\
(\sim 1 / 3 \text { level } \\
\text { formed with } \\
\text { chlorine })^{b}\end{array}$ & $\mathrm{HANs}^{\mathrm{a}}$ & $\begin{array}{l}\text { Requires additional } \\
\text { equipment to add ammonia; } \\
\text { slightly more expensive than } \\
\text { chlorine alone }\end{array}$ \\
\hline $\begin{array}{l}\text { Chlorine } \\
\text { dioxide }\left(\mathrm{ClO}_{2}\right)\end{array}$ & $\begin{array}{l}\text { High to } \\
\text { intermediate }\end{array}$ & No & $\begin{array}{l}\text { Intermediate } \\
\text { (less than } 1 / 2 \\
\text { level formed } \\
\text { with chlorine) }{ }^{b}\end{array}$ & $\begin{array}{l}\text { Chlorite \& } \\
\text { chlorate } \\
\left(\mathrm{ClO}_{2}\right. \\
\text { breakdown } \\
\text { products })\end{array}$ & $\begin{array}{l}\text { Requires more technical skill } \\
\& \text { requires secondary } \\
\text { disinfection; more expense } \\
\text { for equipment and chemicals }\end{array}$ \\
\hline Ozone $\left(\mathrm{O}_{3}\right)$ & High & No & $\begin{array}{l}\text { Low (generally } \\
\text { only in presence } \\
\text { of } \mathrm{Br}^{-} \text {) }\end{array}$ & Bromate & $\begin{array}{l}\text { Requires more technical skill } \\
\& \text { requires secondary } \\
\text { disinfection; more expense } \\
\text { for equipment and chemicals }\end{array}$ \\
\hline UV irradiation & High & No & No & No & $\begin{array}{l}\text { Requires more technical skill } \\
\text { and training \& requires } \\
\text { secondary disinfection; more } \\
\text { expense for equipment and } \\
\text { chemicals }\end{array}$ \\
\hline
\end{tabular}

$\mathrm{HAN}=$ haloacetonitrile; $\mathrm{TOC}=$ total organic carbon .

aPCS (2000).

bZhang et al. (2000).

\subsubsection{Effects of Time, Temperature, $\mathrm{pH}$, and Other Factors on Formation of Haloacetic Acids}

The initial reaction of chlorine with NOM results in rapid formation of HAAs during the first 4 to 8 hours with approximately $90 \%$ of the final concentrations of trichloroacetic acid and dichloroacetic acid formed during the first 24 hours after chlorine is added to water. Formation of dibromoacetic acid may not level off until 18 to 20 hours after chlorination begins. In general, the formation rates for HAAs increase with increasing temperature. Effects of $\mathrm{pH}$ on HAA formation can vary, depending on which chlorine species (i.e., hypochlorous acid or hypochlorite 
ion) predominates. For example, the more active form of chlorine, hypochlorous acid, is present at higher concentrations below $\mathrm{pH} 7.5$ than above. Thus, increasing $\mathrm{pH}$ has been associated with decreasing concentrations of HAAs (IPCS 2000). The water disinfection process can be described by the product (CT) of chlorine concentration (C) times contact time (T) (SDWF 2009). Chlorine must be added until competing pathways with reducing compounds in the source water and the combination of chlorine with other molecules are saturated with chlorine and a free chlorine residual is present at what is referred to as the breakpoint for chlorination. Beyond the breakpoint, the remaining free chlorine will disinfect the water and provide a residual for secondary disinfection during storage and distribution.

\subsubsection{Chemistry of Formation of Haloacetic Acids during Water Disinfection with Chlorine-containing Disinfectants}

Proof of the concept that interaction of chlorine-containing disinfectants with natural organic substances in source water can result in formation of HAAs has been achieved by laboratory experiments demonstrating formation of halogenated intermediate molecules that give rise to HAAs from samples of humic acid. Reaction pathways of the reactive forms of chloride with organic matter include oxidation, addition, and electrophilic substitution reactions (Deborde and von Gunten 2008), and most reactions between chlorine and humic acids within NOM result in oxidation of humic acids rather than chlorine substitution (Dickenson et al. 2008).

Research on formation of HAAs and other disinfection by-products supports the formation of a number of potential intermediate molecules from precursors in natural organic matter in source water (Reckhow et al. 2001; Reckhow and Singer 1985; Zhai and Zhang 2011). These smaller intermediate molecules, mostly organic acids (but also substituted phenolic compounds), can give rise to HAAs (Bond et al. 2012; Dickenson et al. 2008).

\subsection{Remediation of Haloacetic Acids}

Remediation of haloacetic acid disinfection by-products can be divided into three general approaches: (1) removal of precursors (i.e., NOM) prior to disinfection, (2) modification of disinfection practices (e.g., altering disinfectant dose, type, or application point in the water treatment process), and (3) removal of disinfection by-products after formation. Table 2-3 summarizes potential methods for remediation of HAAs before, during, and after the water treatment process.

USEPA (2006) reported that $9.6 \%$ of plants of all sizes in the United States treating surface water used granular activated carbon (GAC) while only $0.9 \%$ of the plants treating ground water used GAC. GAC has been shown to remove $38.5 \%$ to $91.2 \%$ of bromide ion from water in bench-scale and pilot-scale experiments (Zhang et al. 2015b), thus reducing potential formation of brominated HAAs. Biologically active carbon (BAC), i.e., GAC with a natural bacteria population on its surface, was able to remove up to $100 \%$ of HAAs by biodegradation while ozonation removed only $10 \%$ to $20 \%$ (Ratasuk et al. 2008). BAC was much more effective than sterilized GAC, which would remove HAAs only by adsorption.

The use of home water filters, either pitchers with filters, faucet filters, or whole-house systems, have become more common. A report on home water treatment by USEPA (2005) indicated that more than 4 in 10 homes have some form of home water treatment unit. A study of the 
effectiveness of point-of-use water filters (Stalter et al. 2016b) concluded that removal of halogenated disinfection by-products by activated carbon-based tap water filters could provide a public health benefit.

Table 2-3. Methods for Remediation of Haloacetic Acids

\begin{tabular}{|c|c|c|}
\hline Remediation Process & Method Description & Effectiveness/Comments \\
\hline \multicolumn{3}{|c|}{ Removal of precursors prior to disinfection } \\
\hline Coagulation & $\begin{array}{l}\text { Addition of metallic salts, e.g., alum, which } \\
\text { neutralize negative charges on particles, so } \\
\text { they agglomerate and precipitate to remove } \\
\text { precursors }\end{array}$ & $\begin{array}{l}15 \%-78 \% \text { removal of precursors by } \\
\text { alum coagulation; (typically } 15 \%-20 \% \text { ) }\end{array}$ \\
\hline Ion exchange & $\begin{array}{l}\text { Exchange of ions between aqueous solution } \\
\text { and solid phase, e.g., resin, to remove } \\
\text { precursors }\end{array}$ & $\begin{array}{l}52 \%-72 \% \text { removal of precursors } \\
52 \%-80 \% \text { removal in combination } \\
\text { with alum coagulation }\end{array}$ \\
\hline Membrane filtration & $\begin{array}{l}\text { Size exclusion, electrostatic repulsion, and } \\
\text { differences in solute diffusion rates across } \\
\text { membranes to remove precursors }\end{array}$ & $\begin{array}{l}67 \%-99 \% \text { removal by nanofiltration, } \\
\text { which is most effective for removal of } \\
\text { hydrophilic, low-molecular weight } \\
\text { precursors }\end{array}$ \\
\hline $\begin{array}{l}\text { Activated carbon } \\
\text { filtration }\end{array}$ & $\begin{array}{l}\text { Reversible physical adsorption by nonspecific } \\
\text { forces with preferential removal of } \\
\text { hydrophobic NOM }\end{array}$ & $\begin{array}{l}60 \%-91 \% \text { removal of precursors by } \\
\text { granular activated carbon (GAC) }\end{array}$ \\
\hline $\begin{array}{l}\text { Biotreatment } \\
\text { (biologically activated } \\
\text { carbon) }\end{array}$ & $\begin{array}{l}\text { Enzyme-controlled microbial degradation and } \\
\text { adsorption involving growth of a biofilm on } \\
\text { sand or activated carbon filter media }\end{array}$ & $\begin{array}{l}\text { Up to } 62 \% \text { removal by bioactive sand; } \\
\text { TCA precursors more biodegradable } \\
\text { than DCA precursors }\end{array}$ \\
\hline $\begin{array}{l}\text { Advanced oxidation } \\
\text { processes (AOPs) }\end{array}$ & $\begin{array}{l}\text { In situ generation of highly reactive hydroxyl } \\
\text { radicals to degrade precursors through fast, } \\
\text { non-selective reactions with organic } \\
\text { compounds. May include ozone plus UV, } \\
\text { ozone plus hydrogen peroxide, or UV plus } \\
\text { hydrogen peroxide }\end{array}$ & $\begin{array}{l}\mathrm{Up} \text { to } 83 \% \text { removal by } \mathrm{O}_{3} / \mathrm{UV} \\
\mathrm{Up} \text { to } 85 \% \text { removal by } \mathrm{O}_{3} / \mathrm{H}_{2} \mathrm{O}_{2} \text { with } \\
\text { biologically activated carbon }\end{array}$ \\
\hline Ozone & $\begin{array}{l}\text { Oxidation, bond cleavage, and hydroxyl radical } \\
\text { reactions preferentially with aromatic } \\
\text { compounds, alkenes, and amines }\end{array}$ & $\begin{array}{l}\text { Relatively ineffective at low ozone } \\
\text { concentrations } \\
\text { At higher concentrations may increase } \\
\text { HAA levels }\end{array}$ \\
\hline $\begin{array}{l}\text { Modified disinfection } \\
\text { practices }\end{array}$ & $\begin{array}{l}\text { Eliminating pre-oxidation or changing the pre- } \\
\text { oxidation chemical, e.g., using potassium } \\
\text { permanganate, hydrogen peroxide, or ozone as } \\
\text { a pre-oxidant rather than pre-chlorination } \\
\text { Alternative disinfectants, such as chloramines, } \\
\text { chlorine dioxide, ozone, or UV irradiation }\end{array}$ & $\begin{array}{l}\text { No data found on percent effectiveness } \\
\text { Alternative methods, particularly } \\
\text { ozone and UV, do not leave a } \\
\text { disinfectant residual in the distribution } \\
\text { system }\end{array}$ \\
\hline $\begin{array}{l}\text { Removal of HAAs after } \\
\text { formation }\end{array}$ & $\begin{array}{l}\text { Filtration using biologically active granular } \\
\text { activated charcoal }\end{array}$ & $\begin{array}{l}\text { Up to } 99 \% \text { at early stage of operation } \\
\text { (via physical adsorption) but decreased } \\
\text { over } 3.5 \text {-month time period; removal } \\
\text { again increased up to } 99 \% \text { after } 6 \\
\text { months (via biodegradation) } \\
\text { Removal of precursors is greatest when } \\
\text { temperatures are high and residual } \\
\text { chlorine concentration is low }\end{array}$ \\
\hline
\end{tabular}

Source: Bond et al. (2011); Kim and Kang (2008); Singer et al. (2002).

HAAs $=$ haloacetic acids; $\mathrm{NOM}=$ natural organic matter; $\mathrm{UV}=$ ultraviolet light. 


\subsection{Formation in Swimming Pools and Spas and Other Domestic Uses}

The disinfection of water for swimming pools and spas also results in formation of HAAs but often at higher levels than in disinfected tap water because of the use of a higher chlorine residual and higher temperatures than in typical water distribution systems (Chowdhury et al. 2014; Parinet et al. 2012). Dichloroacetic acid and trichloroacetic acid are the most abundant HAAs detected in swimming pools (Teo et al. 2015). For U.S. swimming pools disinfected with chlorine, dichloroacetic acid concentrations have been reported to range from $52 \mu \mathrm{g} / \mathrm{L}$ to $6,800 \mu \mathrm{g} / \mathrm{L}$, and trichloroacetic acid concentrations from $76 \mu \mathrm{g} / \mathrm{L}$ to $1,900 \mu \mathrm{g} / \mathrm{L}$ (Kanan 2010). Additional human precursors (e.g., sweat, urine, hair, cosmetics) can affect the speciation of disinfection by-products formed in swimming pools (Richardson and Postigo 2015). The levels of HAA9 in seawater swimming pools treated with chlorine bleach as disinfectant ranged from $417 \mu \mathrm{g} / \mathrm{L}$ to $2,233 \mu \mathrm{g} / \mathrm{L}$ for different pools tested (Parinet et al. 2012). However, the levels of individual HAAs were generally highest for brominated HAAs, i.e., bromoacetic acid, bromochloroacetic acid, dibromoacetic acid, bromodichloroacetic acid, and chlorodibromoacetic acid, consistent with the presence of bromide in sea water.

The active ingredient in common household bleach is sodium hypochlorite, which is also used in some systems for water disinfection. Thus, use of bleach containing hypochlorite for household cleaning and laundry can produce haloacetic acids and other disinfection by-products observed in disinfected drinking water (EU 2007).

\subsection{Point-of-use Disinfection}

Most laboratory studies of disinfection by-product formation from point-of-use disinfection report trihalomethane occurrence data; only limited data were identified for HAA formation (Lantagne et al. 2008; Lantagne et al. 2010; Smith et al. 2010b; Werner et al. 2016). Iodoacetic acid levels of $9.7 \mathrm{nM}$ to $22.9 \mathrm{nM}$ [1.8 $\mu \mathrm{g} / \mathrm{L}$ to $4.3 \mu \mathrm{g} / \mathrm{L}]$ have been reported from use of iodine tincture; bromoiodoacetic acid and diiodoacetic acid were also detected but were not quantified because they were below method detection limits (Smith et al. 2010b).

\subsection{Other Uses of Haloacetic Acids}

Several haloacetic acids have had limited uses medically or in research laboratories; the more extensive commercial uses are listed below. Dichloroacetic acid is used as a chemical manufacturing intermediate (e.g., for glyoxylic acid), in polyethylene terephthalate production, as a skin cauterizing agent, as a medicinal disinfectant (e.g., a substitute for formalin), as a treatment for congenital lactic acidosis, and it has been proposed as a targeted cancer therapeutic agent (IARC 2014a). The main use of trichloroacetic acid in the past was as an herbicide; however, all registrations for this use in the United States were voluntarily canceled by 1992 (some existing stock may have been used after that date). Trichloroacetic acid also has other industrial uses (e.g., surface treatment of metals), and is widely used as a laboratory reagent and as a treatment for dermatological diseases. Chloroacetic acid is used in the manufacture of organic chemicals including cellulose ethers (used mainly for drilling muds, detergents, food, and pharmaceuticals), glycine, thioglycolic acid, dyes, synthetic caffeine, and as a postemergence contact herbicide and defoliant (PubChem 2016b). Tribromoacetic acid has been used in organic synthesis (HSDB 2009c). Diiodoacetic acid has been used as a chemical intermediate 
(PubChem 2005). Bromoacetic acid has been used for organic synthesis and abscission of citrus fruit (HSDB 2009). Iodoacetic acid has been used as a food additive and as an intermediate in pharmaceuticals, herbicides, antipyretic, anti-inflammatories, and analgesics (HSDB 2003). Dibromoacetic acid and bromochloroacetic acid were reported to be used only in research (IARC 2013c).

\subsection{Exposure to Haloacetic Acids}

Exposure to HAAs as disinfection by-products affects almost all people living in the United States because the vast majority of water treatment facilities use chlorine-based disinfection methods due to their ease of use and low cost. In addition to ingesting HAAs by drinking plain tap water, humans can also be exposed to HAAs from other beverages prepared with treated water such as tea or coffee or fruit drinks and soft drinks or by ingesting food that came in contact with treated water. Foods, both canned and fresh, are generally washed with or soaked in treated water and are cooked in treated water. Dermal and inhalation exposure from swimming pools and spas where water is disinfected and from occupational exposure also can occur. Occupational exposures to some HAAs can also occur.

Eleven of the 13 HAAs discussed in this monograph have been identified in disinfected water (see Section 2.7.1 and Table 2-4); the remaining two are iodinated molecules formed under experimental conditions. Haloacetic acids (HAAs) and trihalomethanes (THMs) are the largest groups of water disinfection by-products by weight and make up about $50 \%$ to $75 \%$ of total halogenated disinfection by-products measured and about $25 \%$ to $50 \%$ of total organic halides measured (Krasner et al. 2016b; Krasner et al. 2006). Both HAAs and total trihalomethanes (TTHMs) are regulated by EPA, and epidemiological studies have tended to use TTHMs as a surrogate for disinfection by-product exposures. HAAs are generally correlated with TTHMs but the ratio between these disinfection by-products may vary depending on water source and methods of disinfection. Relevant epidemiological studies measuring internal exposure to HAAs are not available, in part because of the lack of a specific marker.

\subsubsection{Occurrence of Haloacetic Acids in Treated Water}

The highest levels of HAAs have been detected for the molecules chloroacetic acid, dichloroacetic acid, trichloroacetic acid, chlorobromoacetic acid, and bromodichloroacetic acid (Table 2-4). The presence of chlorine atoms in these molecules is expected since chlorination is overwhelmingly the most commonly used water disinfection method in the United States and estimates indicate that about $98 \%$ of U.S. water treatment systems use some type of chlorine disinfection process such as chlorine, chlorine dioxide, or chloramine (American Chemistry Council 2016). As described above, a number of sources (Table 2-1) for increased bromide concentrations in source water have been identified.

National occurrence data from the American Water Works Association (AWWA) for HAA5 (the sum of five HAAs - bromoacetic acid, dibromoacetic acid, chloroacetic acid, dichloroacetic acid, and trichloroacetic acid - for 1997 through 2014 and representing 93\% of U.S. systems serving populations greater than 100,000 people (collected to assess impacts of the EPA Stage 2 Disinfectants and Disinfection By-products Rule [DBPR]) indicate that 95th percentile HAA5 concentrations have displayed a generally decreasing trend since 2000 (largely due to plants switching from chlorine to chloramines for disinfection) and have been at or below the EPA 
maximum contaminant level (MCL) of $60 \mu \mathrm{g} / \mathrm{L}$ for HAA5 since 2004 (Seidel et al. 2017). Figure 2-3 presents this information. There is some evidence that smaller facilities have more difficulty in meeting the regulatory limits. Data from EPA collected under the Safe Drinking Water Act (SDWA) national compliance data for the third Six-Year Review (SYR3) for 2006 to 2011 indicated that systems serving fewer than 10,000 people had a 95th percentile HAA5 concentration that remained above the HAA5 $60 \mu \mathrm{g} / \mathrm{L}$ MCL throughout the period studied whereas the $95 \%$ percentile was below the MCL for systems serving more than 100,000 people (see Figure 2-4). In addition, the 10 highest levels reported for HAA5 based on data from the Environmental Working Group (EWG 2016) were facilities serving fewer than 4,000 persons.

Table 2-4. Concentration Ranges for Mono-, Di-, and Trihaloacetic Acids in Tap Water, Finished Drinking Water, and Other Similar Sources

\begin{tabular}{|c|c|c|}
\hline Mono, Di-, or Trihaloacetic Acid & Range $(\mu \mathrm{g} / \mathrm{L})$ & Reference \\
\hline Chloroacetic acid & $3(1-11)^{\mathrm{a}}$ & USEPA $(2016 b)^{b}$ \\
\hline Bromoacetic acid & $1.6(0.59-7.3)^{\mathrm{a}}$ & USEPA $(2016 b)^{b}$ \\
\hline Iodoacetic acid & Up to 1.7 & Richardson et al. (2008) \\
\hline Dichloroacetic acid & $10.4(1.3-32)$ & USEPA (2016b) \\
\hline Dibromoacetic acid & $2.1(0.63-12)$ & USEPA (2016b) \\
\hline Diiodoacetic acid & $-^{\mathrm{d}}$ & - \\
\hline Chlorobromoacetic acid & $\mathrm{BDL}^{\mathrm{c}}-18$ & HSDB (2009a); IARC (2013c) \\
\hline Chloroiodoacetic acid & $-^{\mathrm{d}}$ & - \\
\hline Bromoiodoacetic acid & Up to $1.4^{\mathrm{b}}$ & Richardson et al. (2008) \\
\hline Trichloroacetic acid & $8(1.1-32)$ & USEPA (2016b) \\
\hline Tribromoacetic acid & 0 -approx. $10^{\mathrm{e}}$ & McGuire et al. (2002) \\
\hline Bromodichloroacetic acid & $5.28-12.2$ & $\operatorname{HSDB}(2009 b)$ \\
\hline Chlorodibromoacetic acid & $\mathrm{BDL}^{\mathrm{c}}-5.37$ & $\operatorname{HSDB}(2009 d)$ \\
\hline
\end{tabular}

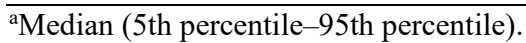

${ }^{b}$ Third Six-Year Review Information Collection Request dataset, https://www.epa.gov/dwsixyearreview/six-year-review-3compliance-monitoring-data-2006-2011.

'Below detection limit; detection limit not specified.

${ }^{\mathrm{d}}$ No data identified.

${ }^{\mathrm{e}}$ One extreme value of $\sim 20 \mu \mathrm{g} / \mathrm{L}$ was reported. 


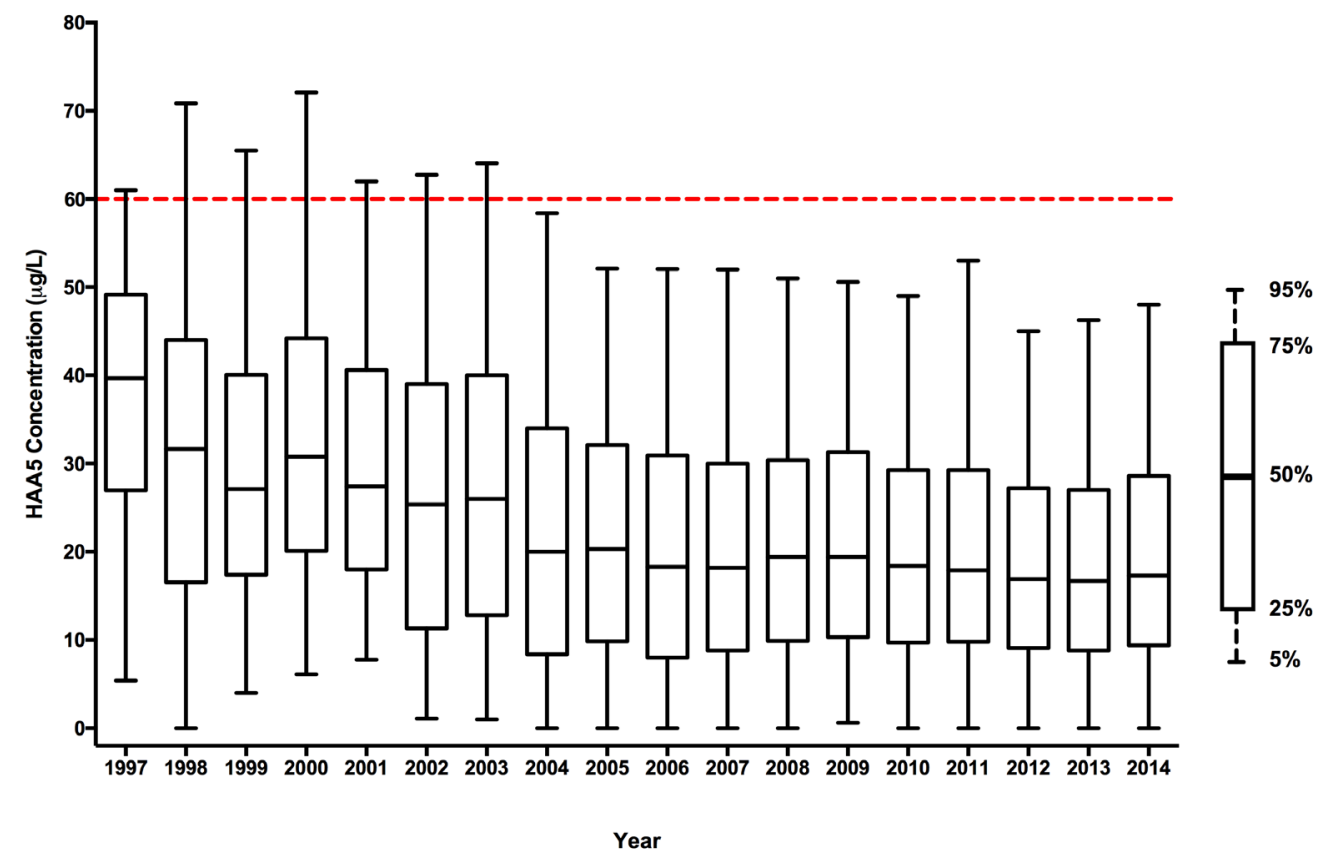

Figure 2-3. National HAA5 Occurrence Data for 1997 through 2014

Source: Adapted from Seidel et al. (2017).

Data are presented for 5th, 25th, 50th, 75th and 95th percentiles for each year from 1997 to 2014 for U.S. water systems supplying more than 100,000 people.

Dashed horizontal line $=$ HAA5 maximum contaminant $(\mathrm{MCL})$ of $60 \mu \mathrm{g} / \mathrm{L}$.

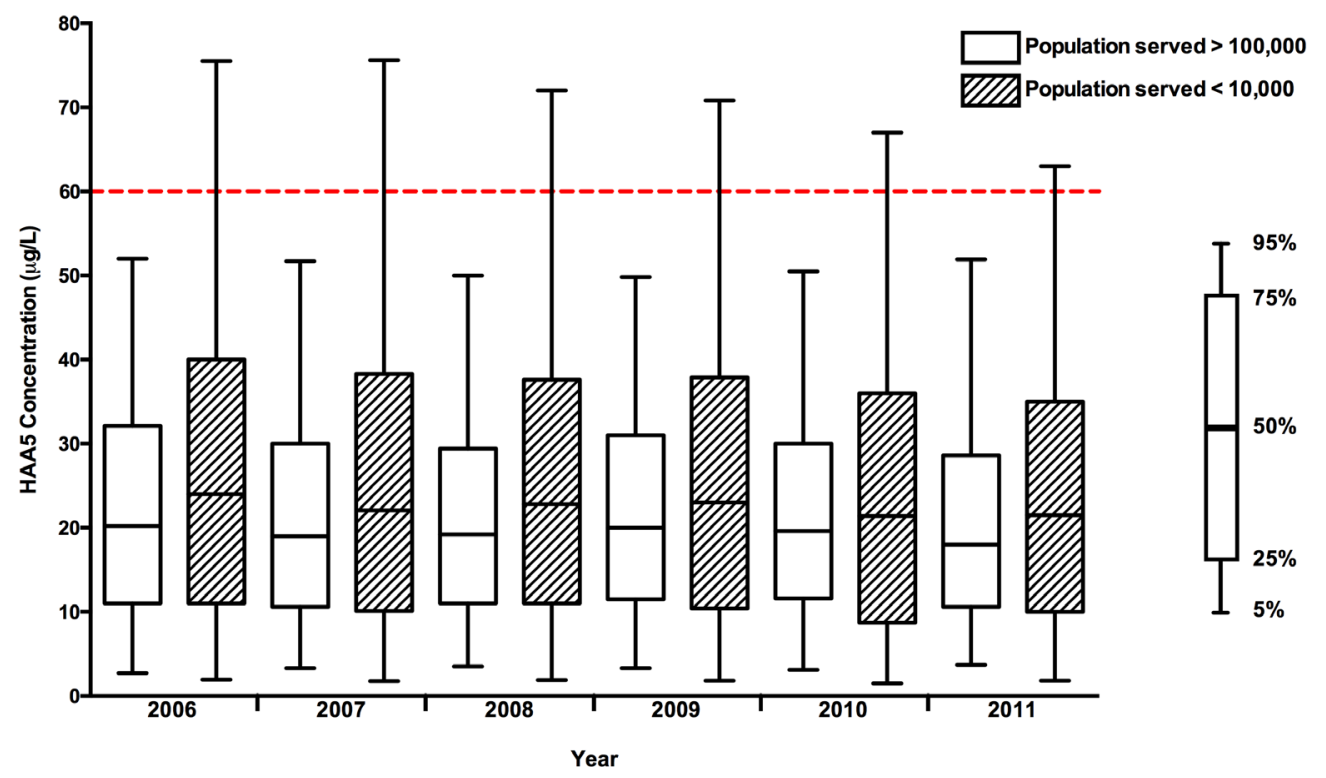

Figure 2-4. HAA5 Occurrence Data for 2006 through 2011 from EPA Safe Drinking Water Act National Compliance Monitoring for the Third Six-year Review

Source: USEPA (2016b).

Data are presented for 5th, 25th, 50th, 75th and 95th percentiles for each year from 1997 to 2014 for U.S. water systems supplier more than 100,000 people.

Dashed horizontal line $=$ HAA5 maximum contaminant $(\mathrm{MCL})$ of $60 \mu \mathrm{g} / \mathrm{L}$. 


\subsubsection{Correlation of Haloacetic Acids and Trihalomethanes in Treated Water}

In the majority of reported studies, total HAAs (THAAs) have been found to correlate with total trihalomethanes (TTHMs); correlation coefficients ranging from $\sim 0.6$ to 0.92 in the majority of studies although a few studies found lower rates, mostly between 0.4 and 0.6 with one outlier of 0.1 (see Figure 2-5). While TTHMs and THAAs or HAA5 have been the primary surrogate measure used in epidemiological studies to estimate exposure to disinfection by-products, concern has been raised for how well these substances can represent the hundreds of disinfection by-products in treated water (Parvez et al. 2011; Plewa and Wagner 2015). No data were identified for correlations between either THMs or HAAs and other disinfection by-products. However, THMs and HAAs are expected to be inversely related to some emerging disinfection by-products (e.g., $N$-nitrosodimethylamine [NDMA] and iodinated disinfection by-products) because chloramination maximizes their formation and vastly reduces the formation of THMs and HAAs.

The ratio of HAAs to THMs is usually around 1:1 but can be higher or lower depending on source water characteristics and disinfection conditions [e.g., Singer et al. (2002) reported that lower chlorination $\mathrm{pH}$ tends to favor HAA9 formation while higher $\mathrm{pH}$ favors THM formation] (Chang et al. 2010a; Krasner et al. 2006; Liang and Singer 2003; Roberts et al. 2002; Roccaro et al. 2014; Singer et al. 2002; Villanueva et al. 2003a; Weinberg et al. 2002). Individual studies with different ratios between HAAs and THMs suggest as much as a 4-fold spread for the ratio [i.e., ranging from 2:1 for THAA to TTHM (Villanueva et al. 2003a) to 1:2 for the same comparison (Roccaro et al. 2014)].

Extensive data are available for levels of TTHM and HAA5 from municipal water-treatment facilities regulated by EPA (see Section 2.7.1), but the relationship between these disinfection by-products and nonregulated disinfection by-products has not been well established.

Disinfection of water involves complex interactions between the disinfecting agents and the organic and inorganic components of the source water, which can include bromide and iodide ions in mildly saline groundwaters from coastal aquifers (Szczuka et al. 2017). For example, Szczuka et al. (2017) measured regulated (trihalomethanes and haloacetic acids) and nonregulated (haloacetonitriles, haloacetamides, and haloacetaldehydes) disinfection by-products formed by chlorination of coastal groundwater samples containing bromide and iodide and found that the haloacetonitriles and the haloacetaldehydes, along with haloacetic acids, were major contributors to the calculated toxicity of the disinfection by-products. Further, Ged and Boyer (2014) measured HAA5 and HAA9 during laboratory chlorination studies of fresh groundwater spiked with up to $2 \%$ seawater, which increased the bromide concentration by more than 25 -fold and the mass concentration of HAA9 almost doubled due to increased formation of brominecontaining HAAs while the HAA5 concentration stayed the same or decreased (4 of the 6 bromine-containing HAAs are not regulated in HAA5) under the conditions tested. Thus, the continued contaminant monitoring by EPA will be important in better defining control of the regulated disinfection by-products and those that are not currently regulated. 


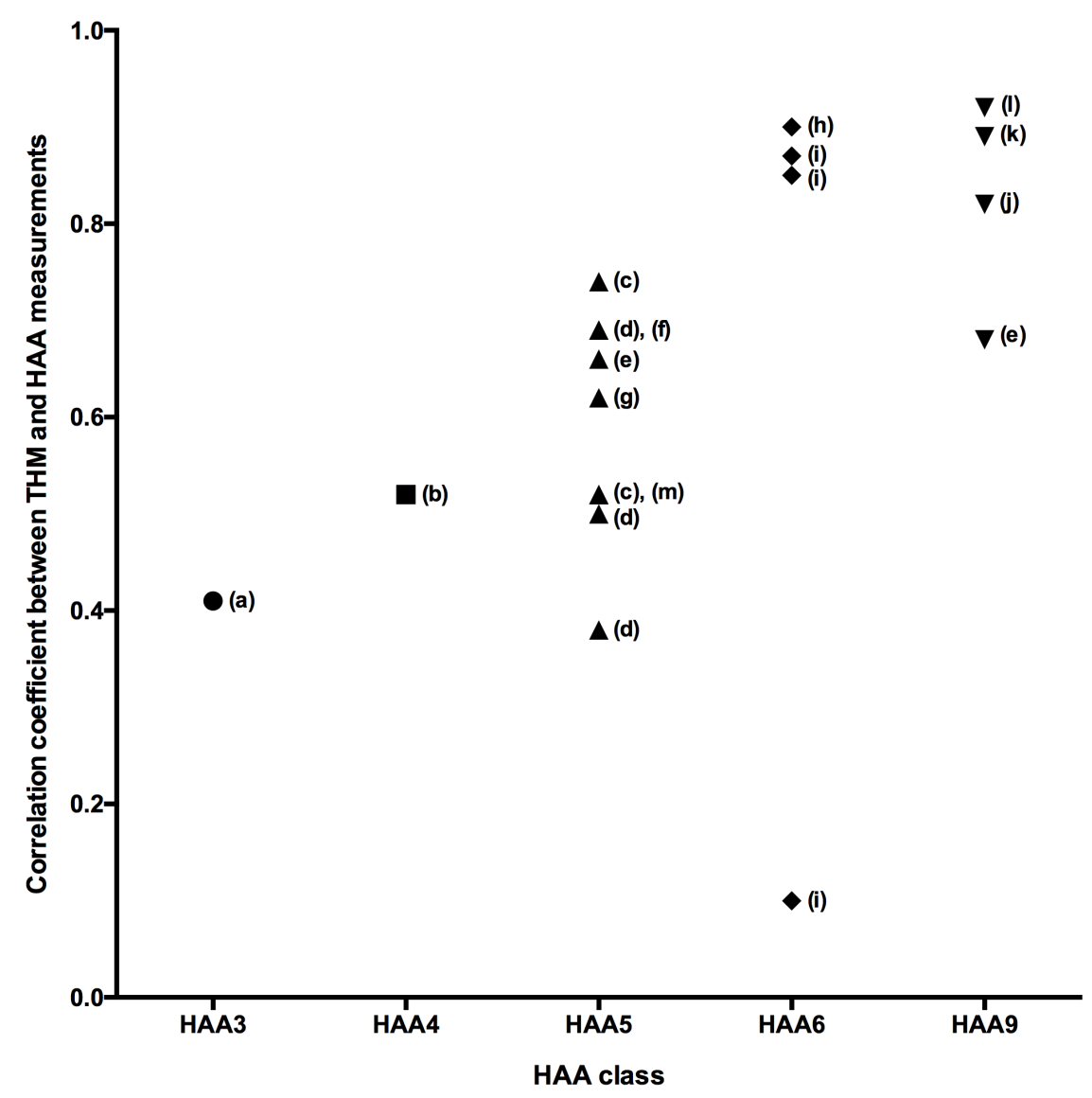

(a) Lee et al. 2001

(b) Nieminski et al. 1993

(c) King et al. 2004

(d) Rodriquez et al. 2007

(e) Chang et al. 2010

(f) Wei et al. 2010

(g) Hinckley et al. 2005b

(h) Nissinen et al. 2002

(i) Malliarou et al. 2005

(j) Villanueva et al. 2003

(k) Roccaro et al. 2014

(l) Ates et al. 2007

(m) Parvez et al. 2011

Figure 2-5. Correlation Data for Haloacetic Acids and Trihalomethanes in Treated Water

Sources: Ates et al. (2007); Chang et al. (2010b); Hinckley et al. (2005); King et al. (2004); Lee et al. (2001); Malliarou et al. (2005); Nieminski et al. (1993); Nissinen et al. (2002); Parvez et al. (2011); Roccaro et al. (2014); Rodriguez et al. (2007); Villanueva et al. (2003b); Wei et al. (2010).

\subsubsection{Potential Exposure from Beverages Prepared with Treated Water}

Beverages that are prepared in the home, such as tea, coffee, or infant formula, or commercially, such as fruit juices and soft drinks, may be prepared with treated water. Several HAAs, primarily dichloroacetic acid, chloroacetic acid, dibromoacetic acid, and bromochloroacetic acid, are quite stable in boiling water with losses of less than $20 \%$ after 60 minutes (Raymer and Michael 2010), so home-prepared tea or coffee would have levels of HAAs similar to those in tap water. Cardador and Gallego (2015) measured levels of 10 HAAs in $2100 \%$ juice products $(0.07 \mu \mathrm{g} / \mathrm{L}$ to $0.08 \mu \mathrm{g} / \mathrm{L}$ ), 37 reconstituted juices (mean $=4.5 ; 0.5 \mu \mathrm{g} / \mathrm{L}$ to $31 \mu \mathrm{g} / \mathrm{L}$ ), 32 nectar juices $($ mean $=6.7 ; 0.2 \mu \mathrm{g} / \mathrm{L}$ to $22 \mu \mathrm{g} / \mathrm{L})$, and 55 soft drinks $($ mean $=12 ; 0.3 \mu \mathrm{g} / \mathrm{L}$ to $73 \mu \mathrm{g} / \mathrm{L})$ sold in Spain. The mean for soft drinks was increased by inclusion of tonic water (mean $=40.2 \mu \mathrm{g} / \mathrm{L})$ and soda water $($ mean $=33.5 \mu \mathrm{g} / \mathrm{L})$ which had higher levels than other drinks sampled.

\subsubsection{Potential Exposure from Foods}

HAAs may be present in natural foods in relatively low amounts, but preparation of food by rinsing before or after cooking or cooking in treated water may add to the levels. Another potential source of HAAs is reaction of iodide in iodized table salt with chlorine in tap water to 
form hypoiodous acid (HOI), which can react with residual organic matter in tap water and organic matter from food to form iodinated disinfection by-products (Becalski et al. 2006; Pan et al. 2016).

Solid and liquid phases of canned vegetables can contain disinfection by-products from contact with treated water and chemicals used in the canning process (e.g., washing, sanitizing, blanching, and filling with sauces or brine solutions) (Cardador and Gallego 2017). HAAs have been found to be predominant in the liquid phase, which is consistent with their ionic and nonvolatile characteristics.

A limited range of six foods — chicken, three vegetables, dried beans, and pasta — were cooked in purified water, which would not be expected to contain disinfection by-products, and analyzed for nine HAAs; all six foods contained dichloroacetic acid (31 ng/g to $100 \mathrm{ng} / \mathrm{g}$ ) and trichloroacetic acid (19 ng/g to $81 \mathrm{ng} / \mathrm{g}$ ) with one to five other HAAs also detected (Raymer and Michael 2010). During controlled laboratory experiments reported by Raymer and Michael, several foods (frozen carrots and green beans, dried pinto beans, chicken, spaghetti, and lettuce) were cooked in haloacetic acid-spiked water, and uptake of the total HAAs available in the cooking water into the food was reported to be as high as $85 \%$ (for uptake of dibromoacetic acid by dried pinto beans) although uptake was generally in the range of $2 \%$ to $25 \%$ for other foods and HAAs. Raymer and Michael also estimated intakes of HAAs from food based on the uptake of HAAs from water containing the MCL of $60 \mu \mathrm{g} / \mathrm{L}$ and reported $3.75 \mu \mathrm{g}$ per serving for cooked green beans and $6 \mu \mathrm{g}$ per serving for cooked pasta.

Foods, both canned and fresh, are generally washed with or soaked in treated water and are cooked in treated water. The median amounts of HAAs expressed in $\mu \mathrm{g}$ per $\mathrm{kg}$ of food range from less than $1 \mu \mathrm{g} / \mathrm{kg}$ for milk to greater than $10 \mu \mathrm{g} / \mathrm{kg}$ for soft drinks, prepared salads, and minimally processed vegetables such as fruits or vegetables washed with chlorine-based chemicals in water (Cardador and Gallego 2017). Canned vegetables, fruit juices, and cheese fall between these levels. Canned vegetables generally contain several-fold higher levels of HAAs in the liquid phase than the solid phase because of their ionic and polar nature.

\subsubsection{Potential Exposure from Other Sources}

\section{Occupational Exposure to Swimming Pool Attendants}

No data were found for other potential occupational exposures to HAAs, but limited information was found for exposure to swimming pool attendants. HAAs are neither volatile nor appreciably skin permeable (Regli et al. 2015; Xu et al. 2002), but studies of haloacetic acid exposure from indoor and outdoor swimming pools indicate that limited inhalation and dermal exposure also can occur (e.g., ingestion $\sim 94 \%$ contribution, inhalation $\sim 5 \%$, and dermal $\sim 1 \%$ ) (Cardador and Gallego 2011). The authors also reported that HAAs (mostly dichloroacetic acid) can get into the atmosphere of indoor swimming pools through aerosols in ambient air and be inhaled.

The HAAs mono-, di-, and trichloroacetic acid have been measured in the urine of swimmers, and di- and trichloroacetic acid have been measured in the urine of swimming pool attendants (Cardador and Gallego 2011; IARC 2014; Kim and Weisel 1998). After 2 hours of exposure, indoor pool attendant urine samples contained $313 \mathrm{ng} / \mathrm{L}[0.313 \mu \mathrm{g} / \mathrm{L}]$ dichloroacetic acid and $120 \mathrm{ng} / \mathrm{L}[0.120 \mu \mathrm{g} / \mathrm{L}]$ trichloroacetic acid (Cardador and Gallego 2011). After 4 hours, indoor attendant urine samples contained $450 \mathrm{ng} / \mathrm{L}[0.45 \mu \mathrm{g} / \mathrm{L}]$ dichloroacetic acid and $139 \mathrm{ng} / \mathrm{L}$ 
$[0.139 \mu \mathrm{g} / \mathrm{L}]$ trichloroacetic acid. Outdoor pool attendant urine samples contained $51 \mathrm{ng} / \mathrm{L}$ $[0.051 \mu \mathrm{g} / \mathrm{L}]$ dichloroacetic acid after 2 hours of exposure and $58 \mathrm{ng} / \mathrm{L}[0.058 \mu \mathrm{g} / \mathrm{L}]$ dichloroacetic acid after 4 hours of exposure. No trichloroacetic acid was detected in the urine of outdoor pool attendants.

\section{Releases to the Environment}

Although some haloacetic acids, such as trichloroacetic acid, dichloroacetic acid, and chloroacetic acid have some uses in industry or medicine, only chloroacetic acid (of the 13 haloacetic acids being reviewed) is on the Toxics Release Inventory (TRI) reporting list for 2015 (the most recent year for which TRI data are available). Total reported on- and off-site release of chloroacetic acid was approximately 5,470 pounds from 19 U.S. facilities in 2015 (TRI 2017). Calculations based on media-specific release data from TRI indicate that releases to air accounted for $94.8 \%$ of total releases, off-site disposal for $4.6 \%$, and land for $0.6 \%$.

\section{Overall Potential for Exposure to HAAs}

Individuals living in the United States are exposed to HAAs primarily from drinking treated tap water or other beverages prepared from treated water with additional exposure likely from foods that are prepared using treated water. Consumption of water from all foods and liquids per day has been estimated by CDC (Rosinger and Herrick 2016) to be $3.46 \mathrm{~L}$ for men over 20 and $2.75 \mathrm{~L}$ for women over 20 . The contribution from plain water, i.e., tap water, is approximately $1 / 3(33.3 \%)$ of the total. The Institute of Medicine estimates that $20 \%$ of total water consumption is derived from foods, and the remaining $46.7 \%$ would derive from beverages such as tea, coffee, soft drinks, and fruit drinks.

No data were identified that provided overall estimates for consumption of HAAs; however, based on the MCL for HAA5, and assuming that all water consumed contained HAAs at that level, total water consumption would result in exposure to approximately $210 \mu \mathrm{g}$ per day for men and $165 \mu \mathrm{g}$ per day for women in the United States. Data for U.S. water facilities serving communities of all sizes in 2011 indicate a median value for HAA5 of $20.1 \mu \mathrm{g} / \mathrm{L}$ with the $5^{\text {th }}$ percentile at $2.0 \mu \mathrm{g} / \mathrm{L}$ and the 95 th percentile at $59.0 \mu \mathrm{g} / \mathrm{L}$. The median exposure would therefore be about $69 \mu \mathrm{g}$ per day ( $5 \%$ to $95 \%=6.9 \mu \mathrm{g}$ to $204 \mu \mathrm{g}$ per day) for men and $55 \mu \mathrm{g}$ per day $(5 \%$ to $95 \%=5.5 \mu \mathrm{g}$ to $162.2 \mu \mathrm{g}$ per day) for women. At the median exposure and above, these levels will likely overestimate actual exposure for most people since the data reported above for beverages such as fruit drinks and soft drinks and for foods prepared with treated water suggest lower concentrations of HAAs compared with the typical water supply. In addition, any effort to determine total consumption of HAAs would need to take into account consumption of bottled water and point-of-use filtration methods in the home (Wright et al. 2006).

Relatively few data on potential exposure to HAAs from other sources such as swimming pools and spas; cooking and food; and point-of-use disinfection have been found, but the following information has been identified:

- HAAs form in swimming pools or spas disinfected with chlorine-based disinfectants and detectable levels of both dichloroacetic acid and trichloroacetic acid have been reported in swimming pool water and in urine samples from swimming pool attendants. 
- Data were identified for HAAs in only a few foods, but each of the HAA9 components was detected in one or more common foods cooked in purified water that would not be expected to contain HAAs.

- Use of HAA-spiked water to cook food or to rinse food after cooking resulted in measurable uptake of HAAs. Estimates of possible intakes from such uptakes indicate several $\mu \mathrm{g}$ per serving could be consumed due to cooking food with treated water.

- Point-of-use disinfection methods based on iodine-containing disinfectants have been shown to result in formation of HAAs, but the use of these methods is limited.

\subsection{Summary and Synthesis}

Disinfection of water has achieved tremendous public health benefits in the United States and worldwide through reduction in exposure of individuals to disease-causing microorganisms. However, a side effect of water treatment is that over 250,000,000 people in the United States are exposed to chlorinated drinking water, indicating that a significant number of people in the United States are exposed to mono-, di-, and trihaloacetic acids found as water disinfection byproducts. Ingestion of chlorinated drinking water is the most common exposure route for HAAs, but inhalation and dermal exposure also can occur. Other potential sources of exposure to HAAs include swimming pools and spas, cooking and food, and point-of-use disinfection. Disinfection by-products are formed from the reaction of chemical disinfectants (e.g., chlorine, chloramines, chlorine dioxide, or ozone) with organic precursors, and inorganic precursors (most often certain halide ions, i.e., bromide $\left[\mathrm{Br}^{-}\right]$or iodide $\left[\mathrm{I}^{-}\right]$). The primary factors affecting the formation of disinfection by-products are (1) source water quality and characteristics, (2) types and concentrations of precursors, and (3) type of disinfection method and dose.

Anthropogenic and natural sources of bromide and iodide can increase concentrations of these halide ions in source waters (e.g., due to incomplete removal or non-removal in wastewater treatment plants) and create brominated and iodinated HAAs and other disinfection by-products such as trihalomethanes and bromate.

Remediation of haloacetic acid disinfection by-products can be divided into three general approaches: (1) removal of precursors prior to disinfection, (2) optimization or modification of disinfection practices (e.g., altering disinfectant type, dose, or application point in the water treatment process), and (3) removal of disinfection by-products after formation. 


\section{Disposition and Toxicokinetics}

Disposition and toxicokinetics refer to how a chemical can enter and leave the body, what happens to it while it is in the body, and the rates of these processes. Disposition includes absorption, distribution, metabolism and excretion (ADME: Sections 3.1 to 3.3) while toxicokinetics (Section 3.4) refers to the mathematical description of the time course of disposition of a chemical in the body. A synthesis of the data is provided in Section 3.5.

Overall, the data indicate that the haloacetic acids are well absorbed following oral exposure, widely distributed, and excreted unchanged or as metabolites in the urine, or exhaled as carbon dioxide $\left(\mathrm{CO}_{2}\right)$. However, there are marked differences in disposition among these compounds that are related to both the number and types of halogen atom substitutions. Disposition studies in humans were available only for dichloro- and trichloroacetic acid while disposition data in experimental animals were available for most of the chlorinated and/or brominated acetic acids as well as some mixtures of these compounds. No disposition studies were identified for the iodinated acetic acids. The mechanistic implications of these data are discussed in Section 6.

\subsection{Absorption}

Haloacetic acids are rapidly and extensively absorbed from the gastrointestinal tract in humans and experimental animals (IARC 2004a; 2004b; 2013a; 2013b; 2014a; 2014b; NTP 1992; 2007a; 2009; 2015; USEPA 2003; 2011a). Dermal absorption also occurs, but it is a minor route of exposure compared with ingestion. Absorption studies in humans and experimental animals are briefly reviewed below.

\subsubsection{Human Studies}

Ingestion is the primary exposure pathway for di- and trihaloacetic acids because their chemical and physical properties (i.e., low volatility and high polarity) limit inhalation and dermal exposures (Cardador and Gallego 2011; Kim and Weisel 1998). Peak plasma concentrations were reached within 15 minutes to 1.5 hours following ingestion (Cardador and Gallego 2011; Curry et al. 1991; Froese et al. 2002; Kim et al. 1999; Rogers 1995; Stacpoole et al. 1998). However, oral bioavailability of dichloroacetic acid in human volunteers (eight men and eight women) was highly variable ( $27 \%$ to $100 \%$ of a single $2 \mathrm{mg} / \mathrm{kg}$ dose) but less than $10 \%$ when administered at $20 \mu \mathrm{g} / \mathrm{kg}$ for 14 days (Schultz and Shangraw 2006).

Cardador and Gallego (2011) reported that ingestion accounted for about $94 \%$ of the total exposure while inhalation (from aerosol droplets) contributed about 5\% and dermal routes about $1 \%$ in swimmers (adults and children) and workers exposed to haloacetic acids in outdoor and indoor swimming pools. However, di- and trihaloacetic acids are detectable in urine 5 to 30 minutes after wading or swimming in chlorinated swimming pools (Cardador and Gallego 2011; Kim and Weisel 1998).

Dermal permeability coefficients calculated for dichloro- and trichloroacetic acid in human subjects were very low $(0.00002$ to $0.008 \mathrm{~cm} / \mathrm{h})(\mathrm{Kim}$ and Weisel 1998). The in vitro permeability coefficients of chloro-, dichloro-, trichloro-, bromo-, bromochloro-, and dibromoacetic acids in aqueous solution across human skin using diffusion chambers were also very low $(0.0011$ to $0.0026 \mathrm{~cm} / \mathrm{h})$ with lag times of 3.7 to 6.5 hours and the authors concluded 
that the dermal dose from bathing in water containing these haloacetic acids would be insignificant compared to the estimated ingestion dose (Xu et al. 2002). Cases of accidental exposure to monochloroacetic acid show that it is readily absorbed through the skin and is corrosive to tissues (Kulling et al. 1992; Kusch et al. 1990).

\subsubsection{Laboratory Animal Studies}

All haloacetic acids administered orally to rats individually or in mixtures were detected in plasma within minutes after oral dosing (Saghir and Schultz 2002; 2005; Schultz et al. 1999). Oral bioavailability, mean absorption time (MAT), peak blood concentration, and time to peak blood concentration $\left(\mathrm{T}_{\max }\right)$ for di- and trihaloacetic acids in rats are shown in Figure 3-1 and Figure 3-2. These data indicate that oral bioavailability was at or near $100 \%$ for trichloro-, bromodichloro-, and chlorodibromoacetic acid but was lower (30\% to 81\%) for dibromo-, bromochloro-, tribromo-, and dichloroacetic acid due to greater first pass metabolism (Schultz et al. 1999). The oral bioavailability of bromodichloroacetic acid in mice ranged from $28 \%$ to $73 \%$ and was lower than reported in rats (Merdink et al. 2001). The bioavailability of chloroacetic acids in rats was $100 \%$ (Saghir and Rozman 2003). Saghir and Schultz (2002) also showed that the oral bioavailability of dichloroacetic acid increased with dose and also increased in glutathione $S$-transferase zeta (GST- $\zeta$ )-depleted rats due to decrease in GST- $\zeta$ mediated metabolism (see Figure 3-3 and Section 3.3). Maximum blood concentrations generally occurred around 1 hour for all di- and trihaloacetic acids, with the exception of dichloroacetic acid (8 hours) (Schultz et al. 1999). Maximum blood concentrations (molar basis) for the trihaloacetic acids were about 1.5 to 6 times greater than the corresponding dihaloacetic acids and reflect the relative bioavailability.

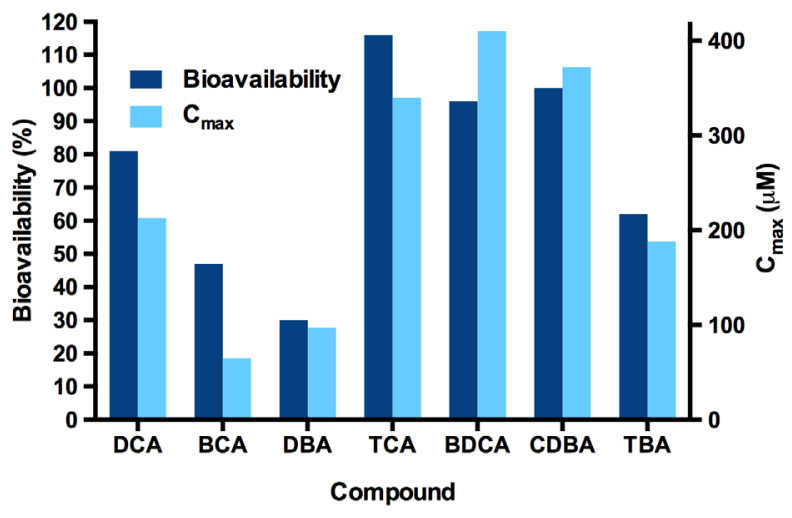

Figure 3-1. Oral Bioavailability and Peak Blood Concentration of Di- and Trihaloacetic Acids in Rats

Source: Schultz et al. (1999).

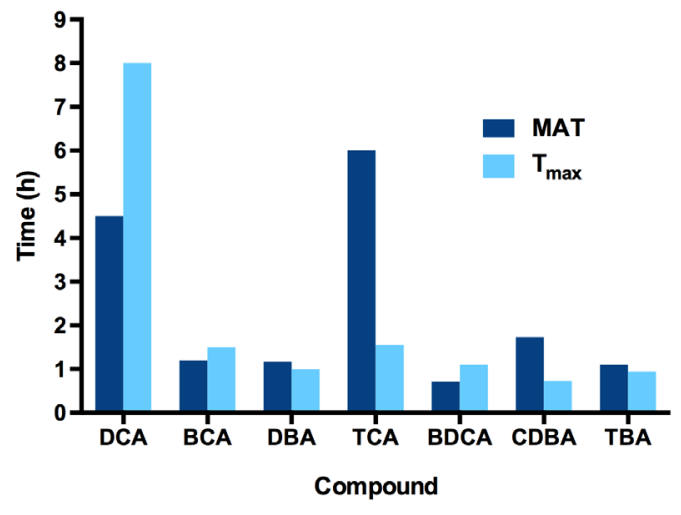

Figure 3-2. Mean Absorption Time and Time to Peak Blood Concentration of Di- and Trihaloacetic Acids in Rats

Source: Schultz et al. (1999). 


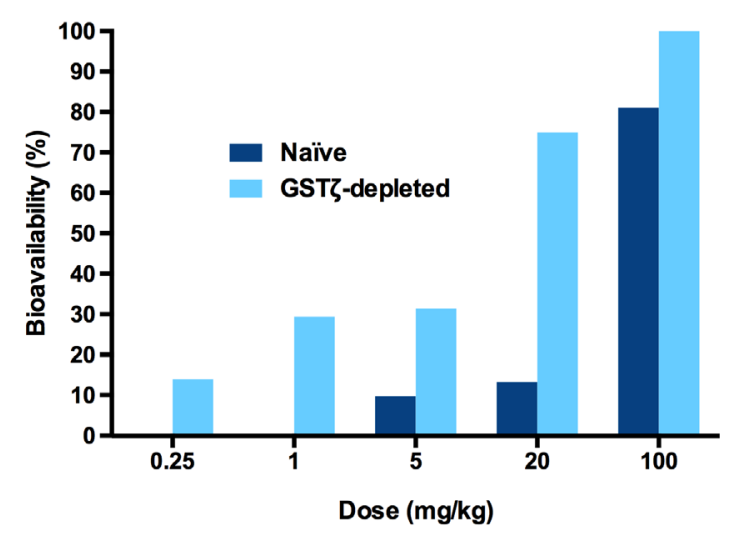

Figure 3-3. Oral Bioavailability of Dichloroacetic Acid in Naïve and GST- $\zeta$-depleted Rats

Source: Saghir and Schultz (2002).

Rats rapidly absorbed (within 15 minutes) over $95 \%$ of the applied dermal dose of monochloroacetic acid from the site of application (Saghir and Rozman 2003). However, much of the absorbed monochloroacetic acid was sequestered in deeper skin layers and served as a "depot" for continued absorption over the course of several hours. No other dermal studies were identified.

\subsection{Distribution}

The degree of reversible plasma protein binding for haloacetic acids is concentration, species, and haloacetic acid dependent. Haloacetic acids show rapid and uniform distribution outside the vascular system to all body tissues with tissue:blood partition coefficients of the unbound fraction generally close to unity. Blood concentration-time profiles, blood:plasma ratios, plasma protein binding, volume of distribution, and tissue distribution data are discussed below.

\subsubsection{Blood Concentration-time Profiles}

Following i.v. (intravenous) dosing in rats, the blood concentrations of di- and trihaloacetic acids (brominated and chlorinated forms) show a short distribution phase followed by a rapid loglinear decline with most concentrations reaching the detection limit within 12 hours (Schultz et al. 1999). Trichloroacetic acid was an exception with detectable blood concentrations after 24 hours. A similar pattern was seen after oral dosing; however, the dihaloacetic acids, particularly dichloroacetic acid, displayed a more complex plasma concentration-time profile characterized by multiple peaks appearing long after the initial absorption phase (Saghir and Schultz 2002; 2005; Schultz et al. 1999). This pattern was not due to enterohepatic recirculation (Schultz et al. 1999). Discontinuous absorption (i.e., region-dependent absorption) from the GI tract was proposed as a possible explanation (Saghir and Schultz 2002). The data suggest that dichloroacetic acid, and possibly other dihaloacetic acids, were absorbed in the upper portion of the GI tract to a higher degree than the trihaloacetic acids (Saghir and Schultz 2002; 2005).

\subsubsection{Blood:plasma Ratios and Protein Binding}

Blood:plasma ratios in rats were close to unity for the dihaloacetic acids and indicate near equal distribution between erythrocytes and plasma (Schultz et al. 1999). Blood:plasma concentration 
ratios for trihaloacetic acids were lower (0.66 to 0.82 ) and indicate preferential distribution to plasma. Monochloroacetic acid did not show significant binding to erythrocytes or hemoglobin but did bind to plasma proteins (Kaphalia et al. 1992).

Dihaloacetic acids exhibited much lower plasma protein binding in rats ( $6 \%$ to $11 \%$ bound) compared to trihaloacetic acids ( $50 \%$ to $80 \%$ bound) (Schultz et al. 1999). In addition, in vitro studies of trichloroacetic acid (doses of $0.01 \mu \mathrm{g} / \mathrm{mL}$ to $1,000 \mu \mathrm{g} / \mathrm{mL}$ ) found that humans have higher plasma binding capacity ( $75 \%$ to $87 \%$ ) compared to rats ( $38 \%$ to $67 \%$ ), dogs ( $54 \%$ to $65 \%$ ), or mice (19\% to 55\%) (Lumpkin et al. 2003; Templin et al. 1995). The higher binding capacity in humans was attributed to more binding sites and slightly higher albumin concentrations (Lumpkin et al. 2003). Higher plasma protein binding increases residence time in the blood and reduces the proportion available for uptake by the tissues. Binding of trichloroacetic acid to plasma proteins is also nonlinear due to partial saturation of plasma binding at high doses in humans, rats, and mice (Lumpkin et al. 2003; Yu et al. 2000).

Both trichloro- and dichloroacetic acid formed adducts to hemoglobin and albumin in rats and mice, but much of the label associated with protein adduction could be accounted for by metabolic incorporation into the amino acid pool and subsequent de novo protein synthesis (Stevens et al. 1992). Mice incorporated a greater portion of the label into proteins than rats, which is consistent with a greater metabolic rate in the mouse. In contrast, Styles et al. (1991) did not find evidence of covalent binding of trichloroacetic acid to DNA or plasma proteins, and very little covalent binding was detected in the liver of mice.

\subsubsection{Volume of Distribution}

Schultz and co-workers tested seven haloacetic acids in rats and did not find any statistically significant difference in steady-state apparent volume of distribution (ranging from $400 \mathrm{~mL} / \mathrm{kg}$ to $881 \mathrm{~mL} / \mathrm{kg}$ ) (Schultz et al. 1999). This range of values is comparable to the total body water volume of rats, suggesting that haloacetic acids evenly distribute outside of the vasculature and are not highly sequestered in peripheral tissues (Schultz et al. 1999). In addition, the similar volume of distribution across haloacetic acids, despite large differences in plasma protein binding, suggests that differences in protein binding are matched in peripheral tissues. Similarly, mice exposed i.v. to $5 \mathrm{~mL} / \mathrm{kg}$ to $100 \mathrm{mg} / \mathrm{kg}$ of bromodichloroacetate had a steady-state volume of distribution of about $380 \mathrm{~mL} / \mathrm{kg}$ to $518 \mathrm{~mL} / \mathrm{kg}$ (also consistent with distribution to total body water) and a blood:plasma ratio of 0.88 (Merdink et al. 2001). However, the volume of distribution for dichloroacetic acid in humans $(190 \mathrm{~mL} / \mathrm{kg}$ to $337 \mathrm{~mL} / \mathrm{kg}$ following $10 \mathrm{mg} / \mathrm{kg}$ or $20 \mathrm{mg} / \mathrm{kg}$ i.v., respectively) was much lower than in rats $(932 \mathrm{~mL} / \mathrm{kg}, 100 \mathrm{mg} / \mathrm{kg}$ dose $)$ and is consistent with greater plasma protein binding in humans (Lukas et al. 1980).

\subsubsection{Tissue Distribution}

Abbas and Fisher (1997) reported tissue:blood partition coefficients ranging from 0.54 (lung) to 1.18 (liver) for trichloroacetic acid in mice. Following oral doses of various mixtures of mono-, di-, and trihaloacetic acids, tissue concentrations were close to plasma concentrations and indicated a rapid equilibrium between plasma and tissues (Saghir and Schultz 2005).

Monochloro- and monoiodoacetic acid distributed rapidly to peripheral tissues, particularly to organs that are rich in sulfhydryl groups, such as the liver and kidney (Hayes et al. 1973; Kaphalia et al. 1992). Distribution patterns were comparable at low $(0.1 \mathrm{mmole} / \mathrm{kg}$ or 
$\sim 9.5 \mathrm{mg} / \mathrm{kg}$ ) and high doses (1 mmole $/ \mathrm{kg}$ or $\sim 95 \mathrm{mg} / \mathrm{kg}$ ) of chloroacetic acid in rats (Kaphalia et al. 1992). Saghir et al. (2001) also reported rapid distribution of chloroacetic acid to tissues but distribution was slower at a toxic dose $(75 \mathrm{mg} / \mathrm{kg})$ compared to a non-toxic dose $(10 \mathrm{mg} / \mathrm{kg}) \mathrm{in}$ male rats. Overall, these data suggest that tissue:blood partition coefficients of haloacetic acids are close to unity and that they distribute uniformly without any significant sequestering in fat or peripheral tissues.

\subsection{Metabolism and Excretion}

Metabolism of haloacetic acids is complex but is qualitatively similar in humans and experimental animals (IARC 2004a; 2004b; 2014a; 2014b; Stacpoole et al. 1998; USEPA 2003; 2011a). A generalized metabolic scheme is shown in Figure 3-4. Although haloacetic acids share common metabolic pathways and metabolites, there are substantial differences in the extent of biotransformation and elimination between compounds and between species. These inter- and intraspecies differences in metabolism and metabolic capacity may explain differences in susceptibility to toxic effects of haloacetic acids. For example, mice have a higher capacity to metabolize dichloroacetic acid compared to rats (Gonzalez-Leon et al. 1999; Larson and Bull 1992).

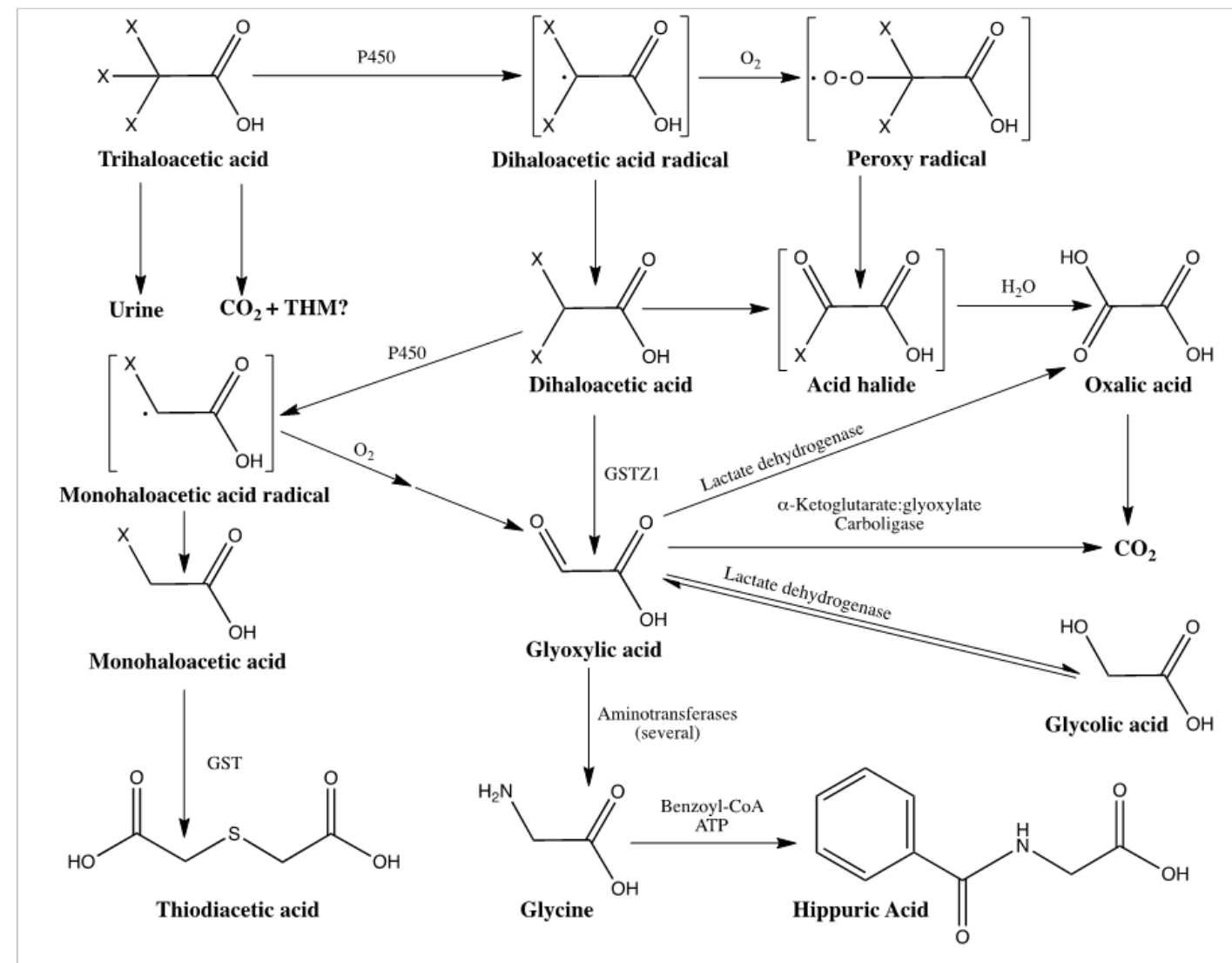

Figure 3-4. General Metabolic Pathways for Tri- and Dihaloacetic Acids

Adapted from: IARC (2013a; 2013b; 2014a; 2014b); Xu et al. (1995).

GSTZ1 = glutathione S-tranferase zeta 1, THM = trihalomethane. 
The haloacetic acids fall into three broad groups based on their metabolism and renal clearance (Saghir and Schultz 2005; Schultz et al. 1999). These groups are broadly described as (1) low metabolism with moderate renal clearance (e.g., trichloroacetic acid), (2) moderate to high metabolism and high renal clearance (e.g., brominated trihaloacetic acids), and (3) high metabolism and low renal clearance (e.g., dihaloacetic acids). Because of the marked differences in the metabolism of various haloacetic acids, the metabolism and excretion of trihaloacetic acids and dihalo- and monohaloacetic acids are reviewed in separate subsections.

\subsubsection{Trihaloacetic Acid Metabolism and Excretion}

Trihaloacetic acids are metabolized primarily by the microsomal fraction, but metabolism also occurs in the cytosolic subcellular fraction (Austin and Bull 1997; Saghir and Schultz 2005). Cytochrome P450 (CYP)-catalyzed reductive de-halogenation of trihaloacetic acids generates a dihaloacetic acid via a free radical intermediate and is then further metabolized by GSTs or can undergo further reductive dehalogenation to form a monohaloacetic acid (discussed in more detail below) (see Figure 3-4) (Merdink et al. 2000; Saghir et al. 2011; Saghir and Schultz 2005; Stacpoole et al. 1998). There is limited evidence for the direct decarboxylation of bromodichloroacetic acid to form $\mathrm{CO}_{2}$ and a trihalomethane (Austin and Bull 1997; Xu et al. 1995). Pharmacokinetic simulations suggest that dichloroacetic acid forms slowly from trichloroacetic acid and is then rapidly metabolized and eliminated, resulting in generally nondetectable levels of dichloroacetic acid in the blood (Merdink et al. 1998).

Trichloroacetic acid is the least metabolized haloacetic acid in humans and experimental animals. Allen and Fisher (1993) estimated that in humans, 93\% of trichloroacetic acid was excreted unchanged in urine while Paykoc and Powell (1945) reported that about $75 \%$ of an i.v. dose ( 1.5 to $3 \mathrm{~g}$ ) administered to six patients was excreted unchanged in the urine after 10 days. Metabolism data in rats and mice show that about $45 \%$ to $84 \%$ of trichloroacetic acid is excreted unchanged in the urine after 24 to 48 hours, and the percent of unchanged trichloroacetic acid in the urine increases with dose (Green and Prout 1985; Larson and Bull 1992; Schultz et al. 1999; $\mathrm{Xu}$ et al. 1995; Yu et al. 2000). Metabolites detected in the urine of rodents exposed orally to trichloroacetic acid include dichloroacetic acid, monochloroacetic acid, glyoxylic acid, glycolic acid, oxalic acid, and some unidentified metabolites and accounted for only $7 \%$ to $13 \%$ of the administered dose (Larson and Bull 1992; Xu et al. 1995). About 4\% to 15\% was metabolized to $\mathrm{CO}_{2}$ and about $1 \%$ to $8 \%$ was excreted in the feces (Green and Prout 1985; Larson and Bull 1992; Xu et al. 1995; Yu et al. 2000).

The metabolism of other trihaloacetic acids (i.e., bromodichloro-, chlorodibromo-, and tribromoacetic acid) was somewhat different from the pattern seen with trichloroacetic acid and indicates that bromine substitution enhances metabolism (Schultz et al. 1999; Xu et al. 1995).

Mice administered 5, 20, or $100 \mathrm{mg} / \mathrm{kg}$ bromodichloroacetic acid eliminated $0 \%$ to $4 \%$ unchanged in the urine, $42 \%$ to $45 \%$ as urinary metabolites (primarily oxalate), $15 \%$ to $30 \%$ as $\mathrm{CO}_{2}$, and $6 \%$ to $10 \%$ in the feces (Merdink et al. 2001; Xu et al. 1995). The large difference in urinary excretion of bromodichloroacetic acid between mice and rats was attributed to a more efficient renal tubular reabsorption mechanism and a greater rate of metabolism in mice compared to rats (Merdink et al. 2001).

In vitro data using rat or human microsomes showed that the rate of metabolism of brominated trihaloacetic acids (i.e., bromodichloro-, chlorodibromo-, and tribromoacetic acid) was directly 
proportional to the number of bromines on the molecule and was further enhanced under reduced oxygen tensions that approximated tissue oxygen levels (Saghir et al. 2011). The brominated trihaloacetic acids were rapidly metabolized by liver microsomes to the dihaloacetic acid product corresponding to loss of a single bromine ion. Reduced oxygen tension ( $2 \%$ oxygen or nitrogen atmosphere) also enhanced the metabolic rate ( $2 \%$ oxygen was selected to be representative of tissue oxygen tension). Reductive dehalogenation of tribromoacetic acid produced dibromoacetic acid in a 1:1 molar ratio with the $\mathrm{Br}^{-}$liberated and there was no evidence of additional metabolism. However, the amount of dibromoacetic acid formed only accounted for about 50\% of the consumption of tribromoacetic acid, particularly at higher substrate concentrations, and suggests the possibility of covalent binding and/or nonmetabolic or degradative loss during chemical analysis.

Metabolism and elimination of haloacetic acids is also affected by exposure to mixtures of haloacetic acids or by pretreatment with dichloroacetic acid or trichloroacetic acid (Austin and Bull 1997; Barton et al. 1999; Gonzalez-Leon et al. 1999; Saghir and Schultz 2005). The primary difference in toxicokinetics of di- and trihaloacetic acids in rats was reduced clearance when administered in mixtures rather than as single compounds (discussed in more detail in Section 3.4) (Saghir and Schultz 2002; 2005; Schultz et al. 1999; Schultz and Sylvester 2001). Urinary recovery of trichloro-, bromodichloro-, chlorodibromo-, and tribromoacetic acid was lower in rats when administered in a mixture and is consistent with increased metabolism at relatively low doses (Saghir and Schultz 2005). However, the data also suggest that metabolism of trihaloacetic acids is possibly increased in mixtures when compared to studies where compounds were administered individually at similar doses.

Pretreatment with trichloroacetic acid inhibited both hepatic cytosolic (up to 70\%) and microsomal (up to 30\%) metabolism of bromodichloroacetic acid in mice but had little effect on dichloroacetic acid metabolism (Austin and Bull 1997). Pretreatment with dichloroacetic acid inhibited cytosolic metabolism of both dichloro- and bromodichloroacetic acid up to $70 \%$ but stimulated microsomal metabolism of bromodichloroacetic acid (1.3-fold); however, there was not a concomitant increase in dichloroacetic acid formation (possibly due to the direct decarboxylation of bromodichloroacetic acid to form $\mathrm{CO}_{2}$ and bromodichloromethane).

\subsubsection{Dihalo- and Monohaloacetic Acid Metabolism and Excretion}

The dihaloacetic acids are extensively metabolized with low amounts of parent compound excreted in the urine (Gonzalez-Leon et al. 1997; James et al. 1998; Larson and Bull 1992; Lin et al. 1993; NTP 2009; Schultz et al. 1999; Xu et al. 1995). In vivo and in vitro studies show that mice have a significantly higher capacity to metabolize dichloroacetic acid than rats (GonzalezLeon et al. 1999; Gonzalez-Leon et al. 1997). When administered as part of a mixture of haloacetic acids, urinary elimination of parent dichloro-, bromochloro-, or dibromoacetic acids were all $<0.1 \%$ (Saghir and Schultz 2005).

Dihaloacetic acids are primarily metabolized in the cytosol to glyoxylate by a glutathionedependent process that is catalyzed by GST- $\zeta$ (IARC 2013a; 2013b). The relative rates of glyoxylate formation among the three chlorinated/brominated dihaloacetates are:

bromochloro- $>$ dichloro- $>$ dibromoacetic acid (Tong et al. 1998). Glyoxylate can be further metabolized to glycolate, oxylate, glycine, and $\mathrm{CO}_{2}$ (Figure 3-4). Reductive dehalogenation of dihaloacetic acids to monohaloacetic acids is a minor pathway. 
Dichloro-, dibromo-, and bromochloroacetic acid are mechanism-based, irreversible inhibitors of GST- $\zeta$ (Anderson et al. 1999; Saghir and Schultz 2002; Schultz and Sylvester 2001). Inhibition of GST- $\zeta$ by dihaloacetic acids reduces the extent of metabolism and increases the plasma halflife, and it has been reported in humans, dogs, and rodents (Anderson et al. 1999; Maisenbacher et al. 2013; Saghir and Schultz 2002; 2005; Tong et al. 1998; Tzeng et al. 2000). However, humans have a lower rate of dichloroacetic acid biotransformation by hepatic cytosol than rats or mice (Tong et al. 1998) and human GST- $\zeta$ is more resistant to inactivation than rodent or dog GST- $\zeta$ (Board and Anders 2011; Maisenbacher et al. 2013). Thus, the use of GST- $\zeta$-depleted rats was shown to be a suitable model for evaluating the kinetics of dichloroacetic acid in humans based on similar in vitro intrinsic metabolic clearance values of low doses in human and rat GST- $\zeta$-depleted liver cytosol (Saghir and Schultz 2002).

In vitro experiments using rat and human hepatic cytosol showed evidence of stereospecific metabolism of bromochloroacetic acid with more rapid elimination of the (-)-bromochloroacetic acid isomer compared to the (+)-bromochloroacetic acid isomer (Schultz and Sylvester 2001). In vivo studies in rats and mice administered a single i.v. dose also showed that the (-) isomer was eliminated about 1.5 to 2.5 times faster than the $(+)$ isomer (NTP 2009). These data suggest that $(+)$-bromochloroacetic acid is a poor substrate for GST- $\zeta$ compared to (-)-bromochloroacetic acid and that another GST isoenzyme may be involved in the metabolism of bromine-substituted dihaloacetic acids.

Several polymorphic variants of GST- $\zeta$ have been identified in humans that differ in their susceptibility to inactivation (Board and Anders 2011; Fang et al. 2006; Li et al. 2012). Human liver samples homozygous or heterozygous for GST- $\zeta 1$ A exhibited a 3-fold higher capacity to dechlorinate dichloroacetic acid than samples carrying other alleles at a given level of expression (Li et al. 2012). GST- $\zeta$ haplotype also influenced dichloroacetic acid kinetics when administered to children with congenital mitochondrial diseases (Shroads et al. 2015). GST- $\zeta$, also known as maleylacetoacetate isomerase (MAAI), is part of the tyrosine catabolism pathway and has been identified as a potential mode of action (see Section 6) (Board and Anders 2011; Schultz et al. 2002; Stacpoole 2011; Stacpoole et al. 2008).

\subsection{Toxicokinetic Data}

The toxicokinetic properties of haloacetic acids in humans and experimental animals are reviewed below. The number and type of halogen substitutions, dose, exposure to mixtures, and age influence the biotransformation and elimination kinetics of haloacetic acids.

\subsubsection{Human Studies}

Most of the toxico- or pharmacokinetic data in humans is for dichloroacetic acid and includes healthy subject volunteers and subjects with various diseases (e.g., lactic acidosis, malaria, liver disease) who were administered dichloroacetic acid as a therapeutic treatment. These studies indicate that the pharmacokinetics of dichloroacetic acid are dose dependent, there are no significant differences between men and women, but there are differences between diseased patients and healthy volunteers (see Appendix B, Table B-1). (Curry et al. 1985; Curry et al. 1991; Henderson et al. 1997; Krishna et al. 1995; Krishna et al. 1994; Krishna et al. 1996; Lukas et al. 1980; Schultz and Shangraw 2006). The distribution phase was generally slower and the plasma $\mathrm{T}^{1} / 2$ was longer in diseased patients. The large interindividual differences in haloacetic 
acid clearance in humans may be due to polymorphisms that alter GST- $\zeta$ activity and expression (Schultz and Shangraw 2006). The urinary excretion half-life of trichloroacetic acid in five healthy volunteers ranged from about 2.1 to 6.3 days and fit a single compartment exponential decay model (Bader et al. 2004). The few human studies that report on the pharmacokinetics of trichloroacetic acid showed a reduced volume of distribution and longer plasma half-life compared to dichloroacetic acid (see Appendix B, Table B-1). Pharmacokinetic modeling of trichloroacetic acid indicates that the volume of distribution is inversely related to body weight, where trihaloacetic acid distributes to about $7 \%$ to $14 \%$ of body weight in humans, compared to $25 \%$ to $51 \%$ for rats and $18 \%$ to $24 \%$ for mice (Allen and Fisher 1993). Systemic clearance of trichloroacetic acid in humans $(0.028 / \mathrm{hr} / \mathrm{kg})$ also is slower than in rodents $(0.045 / \mathrm{hr} / \mathrm{kg}$ to $0.1 / \mathrm{hr} / \mathrm{kg}$ ). The lower volume of distribution and clearance in humans compared to rodents is likely related to greater plasma protein binding in humans.

\subsubsection{Experimental Animal Studies}

Most of the toxicokinetic studies of the haloacetic acids were conducted in male F344 rats (see Appendix B, Table B-2). The data show that the steady-state apparent volume of distribution is similar for di- and trihaloacetic acids while area under the concentration-time curve and clearance show considerable differences (Schultz et al. 1999). Dihaloacetic acids are primarily eliminated by biotransformation (i.e., nonrenal clearance) with very little parent compound excreted in the urine. As mentioned in Section 3.2, the blood concentration-time profiles for the dihaloacetic acids exhibited multiple peaks that resulted in some uncertainty in the start of the log-linear portion of the profiles and complicated calculations of toxicokinetic parameters. In contrast, trihaloacetic acids exhibited simpler blood concentration-time profiles with reduced metabolism and a higher contribution from renal clearance. Bromine substitution enhanced metabolism and increased both renal $\left(\mathrm{Cl}_{\mathrm{r}}\right)$ and nonrenal $\left(\mathrm{Cl}_{\mathrm{nr}}\right)$ clearance, especially for the trihaloacetic acids (Figure 3-5). The combination of a similar distribution volume and increasing clearance with bromine substitution resulted in a progressive decrease in elimination half-lives. The data also show that total dose is an important factor for dihaloacetic acids because clearance is dose-dependent due to saturation and inhibition of the GST- $\zeta$ metabolic pathway (Figure 3-6).

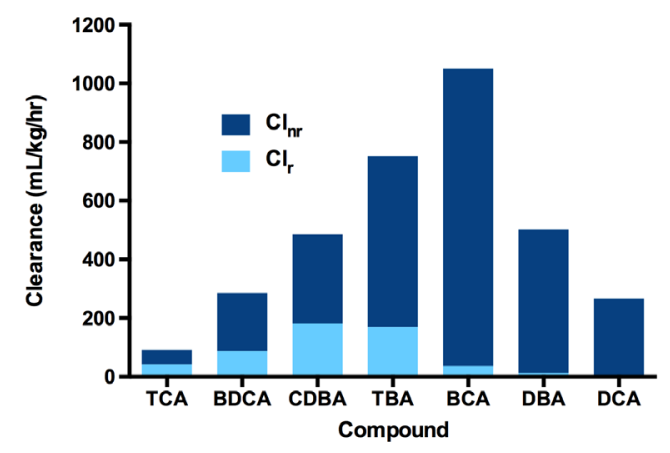

Figure 3-5. Comparison of Renal and Nonrenal Clearance of an Equimolar I.V. Dose $(500 \mu \mathrm{mol} / \mathrm{kg})$ of Haloacetic Acids in Male Rats

Source: Schultz et al. (1999).

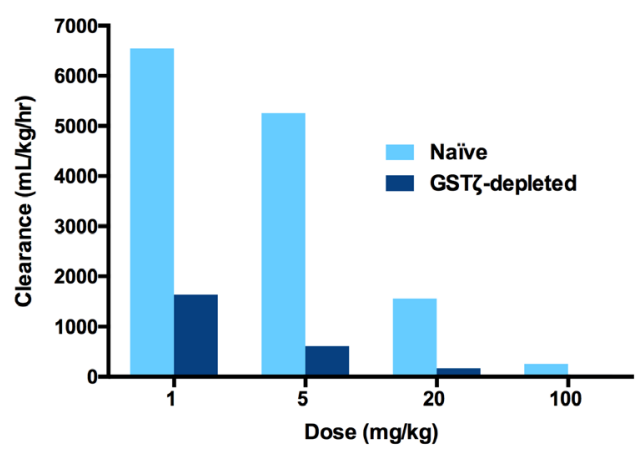

Figure 3-6. Clearance of Dichloroacetic Acid in Naïve and GST- $\zeta$-depleted Male Rats

Source: Gonzalez-Leon et al. (1997); Saghir and Schultz (2002). 
When haloacetic acids were administered to rats as mixtures rather than as single compounds, the primary difference was reduced clearance (with the exception of bromochloro- and dibromoacetic acids), suggesting competitive interactions between di- and trihaloacetic acids (Appendix B, Table B-2) (Saghir and Schultz 2005). The inability to show reduced clearance for bromochloro- or dibromoacetic acid when administered as part of a mixture rather than individually may be explained by dose. The available studies that administered these two haloacetic acids as single compounds used high doses (i.e., $\geq 500 \mu \mathrm{mol} / \mathrm{kg}$ ) where metabolic clearance was likely reduced by metabolic saturation and/or GST- $\zeta$ depletion. The primary effect of GST- $\zeta$-depletion for both mixtures and single compounds was reduced clearance of the dihaloacetic acids (Figure 3-7a). In contrast, GST- $\zeta$ depletion did not affect clearance of trihaloacetic acids (Figure 3-7b). In addition, data for bromochloroacetic acid, a chiral molecule, show stereospecific metabolism with faster elimination of the $(-)$ stereoisomer compared to the (+)-stereoisomer (Figure 3-8). James et al. (1998) showed that the peak plasma concentrations and area under the concentration-time curve were 5- to 6-fold higher in old rats while the elimination half-life was almost 2-fold slower compared to young rats (Appendix B, Table B-2).
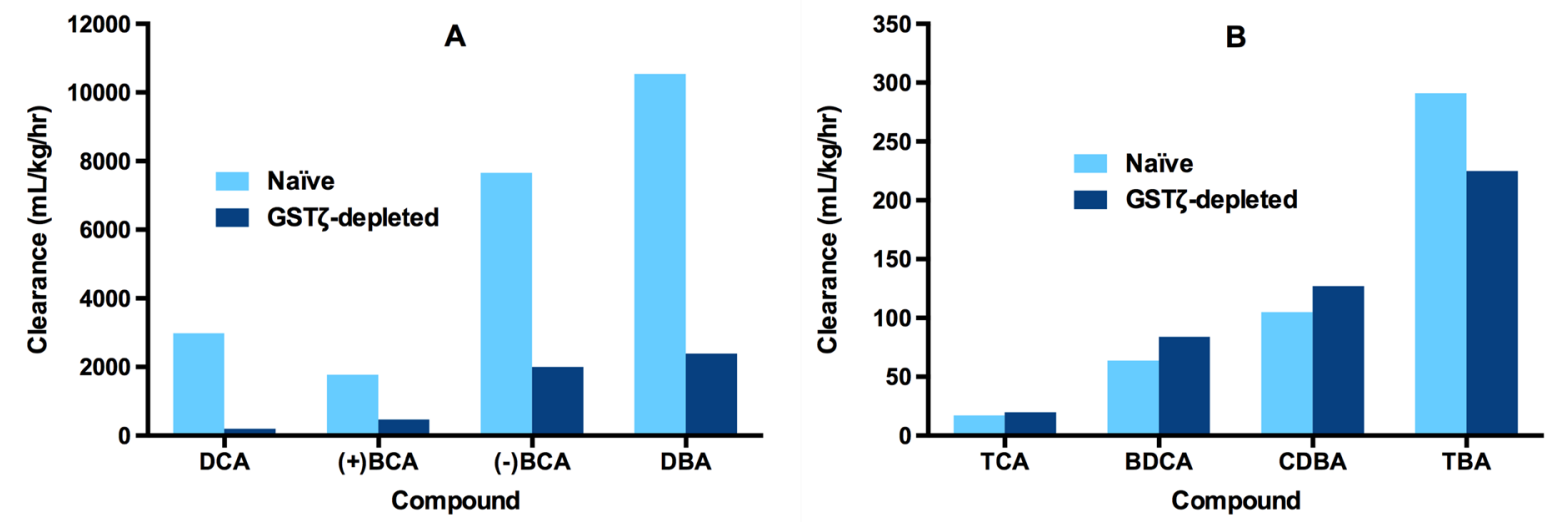

Figure 3-7. Clearance of Dihaloacetic Acids (A) and Trihaloacetic Acids (B) Administered as Mixtures of Di- and Trihaloacetic Acids at Equimolar I.V. Doses (25 $\mu \mathrm{mol} / \mathrm{kg})$ to Male Rats

Source: Saghir and Schultz (2005).

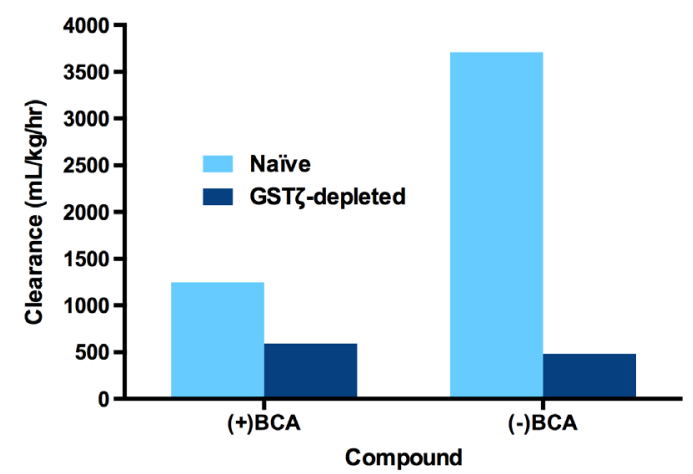

Figure 3-8. Stereospecific Clearance of an I.V. Dose $(520 \mu \mathrm{mol} / \mathrm{kg})$ of $(-),(+)$-Bromochloroacetic Acids Administered to Naïve and GST- $\zeta$-depleted Male Rats

Source: Schultz and Sylvester (2001). 
The clearance values reported for the di- and trihaloacetic acids indicate that there are marked differences in the degree of tubular secretion and reabsorption (Schultz et al. 1999). The adjusted renal clearance values for the trihaloacetic acids approached or exceeded the glomerular filtration rate (GFR) for rats, suggesting tubular secretion is an important factor for the renal clearance of trichloroacetic acids. In contrast, adjusted renal clearance values for the dihaloacetic acids are much lower than the GFR (i.e., similar to the urine flow rate) and indicate that tubular reabsorption is important. Thus, the data support the proposition that urinary excretion of trihaloacetic acids is controlled by tubular secretion while urinary excretion of dihaloacetic acids is controlled by tubular reabsorption in rats.

Toxicokinetic data in mice were limited to a few studies with dichloro- and trichloroacetic acid and one study each with dibromo-, bromochloro-, and bromodichloroacetic acid (Appendix B, Table B-3). Although mice have a higher capacity to metabolize dichloroacetic acid than rats and appear to be less susceptible to GST- $\zeta$ inhibition, the available data in mice are generally consistent with the rat data (i.e., relative rate of clearance of dichloro- > bromodichloro- > trichloroacetic acid) (Gonzalez-Leon et al. 1999; Larson and Bull 1992; Merdink et al. 2001). Elimination kinetics for bromodichloroacetic acid in mice differed from that in rats and is best illustrated by comparing renal clearance (Merdink et al. 2001). Renal clearance adjusted for protein binding in mice suggested a very efficient tubular reabsorption process. In contrast, tubular secretion was the dominant renal process in rats (Merdink et al. 2001; Schultz et al. 1999).

Pretreatment with trichloroacetic acid had no appreciable effect on the toxicokinetics of a challenge dose of either trichloroacetic acid or dichloroacetic acid in mice (Gonzalez-Leon et al. 1999; Schultz et al. 2002). In contrast, pretreatment with dichloroacetic acid caused a significant increase in the blood concentration-time profile and reduced the clearance of dichloroacetic acid (Gonzalez-Leon et al. 1999). However, the impact of dichloroacetic acid pretreatment on clearance in mice was not as great as that observed in rats. As in rats, age was also shown to be an important factor (Schultz et al. 2002). Clearance of dichloroacetic acid in aged control mice was about $25 \%$ of that measured in young control mice. However, compared to age-matched controls, clearance was reduced in young but not aged mice, with a maximum effect observed at 16 hours or less recovery time (see Appendix B, Table B-3).

\subsection{Summary and Synthesis}

Haloacetic acids, especially dihaloacetic and trihaloacetic acids, have many similarities for absorption, distribution, metabolism, and excretion, although differences may exist due to different numbers of halogens on the alpha carbon or the presence of bromine atoms. The findings for absorption, distribution, metabolism, and excretion for haloacetic acids in general and for dihaloacetic and trihaloacetic acids as a class are summarized in Table 3-1 and similar information for seven individual haloacetic acids in Table 3-2. Absorption after oral ingestion is approximately $100 \%$ for trihaloacetic acids in rats, but lower absorption has been reported for bromodichloroacetic acid in mice and for dihaloacetic acids in general in both humans and rats. Once absorbed, haloacetic acids distribute rapidly and uniformly outside the vascular system and tissue:blood partition coefficients are near unity, although binding of trihaloacetic acids to plasma proteins can increase blood concentrations, particularly in humans compared with experimental animals. Blood concentrations decrease rapidly with a log-linear decline within 12 hours of i.v. injection. Metabolism of trihaloacetic acids involves both microsomal and cytosolic 
subcellular fractions although the primary pathway for trihaloacetic acids is through cytochrome P450-catalyzed reductive dehalogenation to generate a dihaloacetic acid via a free radical intermediate. Further metabolism of dihaloacetic acids to glyoxylate and other urinary metabolites (see Figure 3-4) results from a glutathione-dependent process catalyzed by GST- $\zeta$. Elimination for all haloacetic acids is mainly through the urine, although some metabolism to carbon dioxide with elimination from the lungs is possible. Dihaloacetic acids inhibit their own metabolism by inhibiting GST- $\zeta$, thus slowing elimination, but GST- $\zeta$ in humans is more resistant to inactivation than in rats and mice. Haloacetic acids can be broadly described by three patterns of elimination: (1) high metabolism and high renal clearance (bromodichloro-, chlorodibromo-, and tribromoacetic acids), (2) high metabolism and low renal clearance (dihaloacetic acids), and (3) low metabolism with moderate renal clearance (trichloroacetic acid). In general, trichloroacetic acid is an outlier compared with other trihaloacetic acids, with greater binding to plasma proteins, lower volume of distribution, and lower metabolism.

Toxicokinetic studies in experimental animals show no significant differences in the apparent volume of distribution among dihaloacetic and trihaloacetic acids while area under the concentration-time curve and clearance show considerable differences. GST- $\zeta$ depletion did not significantly affect toxicokinetics of trihaloacetic acids, but did significantly reduce clearance and also increased area under the concentration-time curve for dihaloacetic acids. Dihaloacetic acids and trihaloacetic acids likely compete in metabolic processes because the primary effect on haloacetic acid toxicokinetics when administered as mixtures is reduced clearance. 
Table 3-1. ADME Information for Haloacetic Acids in General and for Trihaloacetic and Dihaloacetic Acids as a Class

\begin{tabular}{|c|c|c|c|c|}
\hline HAA & Absorption & Distribution & Metabolism & Excretion \\
\hline All HAAs & $\begin{array}{l}\text { Rapidly absorbed from the } \\
\text { GI tract following } \\
\text { ingestion }\end{array}$ & $\begin{array}{l}\text { Rapid and uniform distribution } \\
\text { to all body tissues } \\
\text { Tissue:blood partition } \sim 1 \\
\text { Apparent volume of } \\
\text { distribution in rats not } \\
\text { significantly different for } 7 \\
\text { HAAs below }\end{array}$ & $\begin{array}{l}\text { Rodents: Ultimate metabolites } \\
\text { glyoxylic acid, glycolic acid, oxalic } \\
\text { acids, glycine, unknown metabolites } \\
\text { Substantial differences in extent of } \\
\text { biotransformation among species but } \\
\text { overall metabolism qualitatively } \\
\text { similar in humans and animals }\end{array}$ & $\begin{array}{l}\text { Substantial differences in } \\
\text { extent of elimination } \\
\text { among species }\end{array}$ \\
\hline $\begin{array}{l}\text { Trihaloacetic acids (Tri- } \\
\text { HAAs) }\end{array}$ & ND & $\begin{array}{l}\text { Overall: Rapid log-linear } \\
\text { decline in blood concentrations } \\
\text { to below LoD within } 12 \mathrm{~h} \\
\text { (except TCA) } \\
\text { Rats: Plasma protein binding } \\
50 \% \text { to } 80 \% \\
\text { Blood:plasma ratio } 0.66-0.82 \\
\text { Maximum blood concentrations } \\
\sim 1.5-6 \text { times greater for tri- } \\
\text { HAAs than di-HAAs }\end{array}$ & $\begin{array}{l}\text { Overall: } \mathrm{P} 450 \text { metabolism in } \\
\text { microsomes to dihaloacetic acid via } \\
\text { dihaloacetic radical } \\
\text { In vitro: Rate of metabolism directly } \\
\text { proportional with number of bromines } \\
\text { Rodents: Moderate to high metabolism } \\
\text { for brominated tri-HAAs }\end{array}$ & $\begin{array}{l}\text { Rodents: High renal } \\
\text { clearance for brominated } \\
\text { tri-HAAs } \\
\text { Rats: Urinary excretion of } \\
\text { tri-HAAs is controlled by } \\
\text { tubular secretion }\end{array}$ \\
\hline $\begin{array}{l}\text { Dihaloacetic acids (Di- } \\
\text { HAAs) }\end{array}$ & ND & $\begin{array}{l}\text { Overall: Rapid log-linear } \\
\text { decline in blood concentrations } \\
\text { to below LoD within } 12 \mathrm{~h} \\
\text { Rats: Plasma protein binding } \\
6 \%-11 \% \\
\text { Blood:plasma ratio } \sim 1\end{array}$ & $\begin{array}{l}\text { Overall: GST- } \zeta \text { metabolism in cytosol } \\
\text { to glyoxylic acid (BCA }>\text { DCA }> \\
\text { DBA); reductive dehalogenation to } \\
\text { monohaloacetic acids is a minor } \\
\text { pathway } \\
\text { Rodents: High metabolism } \\
\text { DCA, BCA, DBA irreversibly inhibit } \\
\text { GST- } \zeta\end{array}$ & $\begin{array}{l}\text { Rodents: Low renal } \\
\text { clearance; low amounts of } \\
\text { parent compounds in urine } \\
\text { Rats: Urinary excretion of } \\
\text { di-HAAs is controlled by } \\
\text { tubular reabsorption }\end{array}$ \\
\hline
\end{tabular}

$\mathrm{BCA}=$ bromochloroacetic acid; DBA $=$ dibromoacetic acid; DCA $=$ Dichloroacetic acid; GST $-\zeta=$ glutathione S-transferase zeta; HAA $=$ haloacetic acid; LoD = limit of detection; $\mathrm{ND}=$ no data; $\mathrm{TCA}=$ trichloroacetic acid. 
Table 3-2. ADME Information for Individual Haloacetic Acids

\begin{tabular}{|c|c|c|c|c|}
\hline Individual HAAs & Absorption & Distribution & Metabolism & Excretion \\
\hline Trichloroacetic (TCA) & Rats: $\sim 100 \%$ & $\begin{array}{l}\text { Humans: Volume of } \\
\text { distribution lower than in } \\
\text { rodents, possibly due to greater } \\
\text { plasma protein binding ( } 75 \%- \\
87 \% \text { ) in humans } \\
\text { Rats: Blood levels still } \\
\text { detectable after } 24 \mathrm{~h} \\
\mathrm{~V}_{\mathrm{d}}=782 \mathrm{~mL} / \mathrm{kg} \\
\text { Mice: } \mathrm{V}_{\mathrm{d}}=571 \mathrm{~mL} / \mathrm{kg}\end{array}$ & $\begin{array}{l}\text { Overall: Least } \\
\text { metabolized HAA in } \\
\text { humans and animals } \\
\text { Rats: Low metabolism }\end{array}$ & $\begin{array}{l}\text { Humans: Urinary clearance } \\
\text { half-life } 2.1-6.3 \text { days; } \\
\text { clearance slower than in } \\
\text { rodents; } 75 \%-93 \% \text { excreted } \\
\text { unchanged } \\
\text { Rats: Moderate renal } \\
\text { clearance }\end{array}$ \\
\hline Bromodichloroacetic (BDCA) & $\begin{array}{l}\text { Rats: } \sim 100 \% \\
\text { Mice: } 28 \%-73 \%\end{array}$ & $\begin{array}{l}\text { Rats: } \mathrm{V}_{\mathrm{d}}=730 \mathrm{~mL} / \mathrm{kg} \\
\text { Mice: } \mathrm{V}_{\mathrm{d}}=518 \mathrm{~mL} / \mathrm{kg}\end{array}$ & $\begin{array}{l}\text { Rodents: Greater rate of } \\
\text { metabolism in mice } \\
\text { compared with rats }\end{array}$ & $\begin{array}{l}\text { Rodents: Urinary excretion } \\
\text { higher in rats than mice, likely } \\
\text { due to more efficient renal } \\
\text { tubular reabsorption in mice }\end{array}$ \\
\hline Chlorodibromoacetic (CDBA) & Rats: $\sim 100 \%$ & Rats: $\mathrm{V}_{\mathrm{d}}=636 \mathrm{~mL} / \mathrm{kg}$ & ND & ND \\
\hline Tribromoacetic (TBA) & ND & Rats: $\mathrm{V}_{\mathrm{d}}=449 \mathrm{~mL} / \mathrm{kg}$ & ND & ND \\
\hline Dichloroacetic (DCA) & $\begin{array}{l}\text { Humans: Variable from } \\
<10 \% \text { to } 100 \% \\
\text { Rats: } 81 \%\end{array}$ & $\begin{array}{l}\text { Rats: Complex concentration- } \\
\text { time profile with multiple peaks } \\
\mathrm{V}_{\mathrm{d}}=618 \mathrm{~mL} / \mathrm{kg} \\
\text { Mice: } \mathrm{V}_{\mathrm{d}}=548,497 \mathrm{~mL} / \mathrm{kg}\end{array}$ & $\begin{array}{l}\text { Humans: Human GST- } \zeta \\
\text { more resistant to } \\
\text { inhibition } \\
\text { Relative rates: Mice }> \\
\text { rats }>\text { humans }\end{array}$ & $\begin{array}{l}\text { Humans: Large } \\
\text { interindividual variations in } \\
\text { clearance may be due to GST- } \\
\zeta \text { polymorphisms }\end{array}$ \\
\hline Bromochloroacetic (BCA) & Rats: $47 \%$ & Rats: $\mathrm{V}_{\mathrm{d}}=881 \mathrm{~mL} / \mathrm{kg}$ & $\begin{array}{l}\text { In vitro: Metabolism } \\
\text { more rapid for }(-) \text {-BCA } \\
\text { compared with }(+)-\text { BCA }\end{array}$ & ND \\
\hline Dibromoacetic (DBA) & Rats: $30 \%$ & Rats: $\mathrm{V}_{\mathrm{d}}=400 \mathrm{~mL} / \mathrm{kg}$ & ND & ND \\
\hline
\end{tabular}

GST $-\zeta=$ glutathione S-transferase zeta; $\mathrm{LoD}=$ limit of detection; $\mathrm{ND}=$ no data. 


\section{Studies of Cancer in Experimental Animals}

This section reviews and assesses the evidence from carcinogenicity studies in experimental animals exposed to any of the 13 haloacetic acids examined in this monograph. Experimental animal carcinogenicity studies were identified using methods described in the protocol (NTP 2017). A total of 24 publications were identified that reported on exposure of experimental animals to a haloacetic acid and met the following inclusion criteria: (1) reported on the presence or absence of neoplastic and related preneoplastic lesions, (2) had a concurrent or historical control group, and (3) either had an observational duration of 12 months or greater for rats and mice or were co-carcinogen exposure studies (initiation-promotion and other co-carcinogen studies). Three papers were excluded because they duplicated the data in other peer-reviewed reports (Carter et al. 2003; Kissling et al. 2009; Melnick et al. 2007). Two additional papers were not peer reviewed and were not included; however, data from one report (Bull 1989) was also reported in a later, peer-reviewed publication, which was considered. The other report by Innes and Ulland (1968) was not considered useful enough to justify peer reviewing it for inclusion.

Section 4.1 provides an overview of the studies, Section 4.2 assesses the quality of the studies, Section 4.3 reports the findings of the studies, organized by the type of neoplasms observed, and Section 4.4 provides a synthesis of the results from all studies.

\subsection{Overview of the Studies}

The 19 remaining publications reported a total of 40 studies; 32 were carcinogenicity studies, three were in transgenic animals (NTP 2007b), and five were initiation-promotion studies (Gwynn and Salaman 1953; Herren-Freund et al. 1987; Pereira et al. 1997). These studies exposed rodents to seven of the 13 haloacetic acids considered in this monograph; six of which were tested in long-term carcinogenicity studies: monochloroacetic acid (DeAngelo et al. 1997; NTP 1992), dichloroacetic acid (Bull et al. 1990; Daniel et al. 1992; DeAngelo et al. 1996; DeAngelo et al. 1991; DeAngelo et al. 1999; Richmond et al. 1995; Wood et al. 2015), dibromoacetic acid (NTP 2007a), bromochloroacetic acid (NTP 2009), trichloroacetic acid (Bull et al. 1990; DeAngelo et al. 1997; DeAngelo et al. 2008; Herren-Freund et al. 1987; Pereira 1996; Von Tungeln et al. 2002), and bromodichloroacetic acid (NTP 2015). In addition, five initiation-promotion studies were identified for monoiodoacetic acid (Gwynn and Salaman 1953), dichloroacetic acid (Herren-Freund et al. 1987; Pereira et al. 1997), and trichloroacetic acid. All haloacetic acids were tested at multiple doses up to at least $1,000 \mathrm{mg} / \mathrm{L}$ for all six tested in long-term studies and up to $5,000 \mathrm{mg} / \mathrm{L}$ for dichloroacetic acid and trichloroacetic acid.

An overview of these studies is provided below (Table 4-1), and tables describing the study conditions and tumor findings are included in Appendix C, Table C-56 through Table C-59. Exposure in almost all of these studies was by an oral route, mostly in drinking water, although two studies were by gavage (NTP 1992), and one study used intraperitoneal exposure (Von Tungeln et al. 2002). Another study exposed a transgenic animal model, Tg.AC hemizygous mice, by dermal application (NTP 2007b). 
Table 4-1. Overview of Cancer Studies in Experimental Animals

\begin{tabular}{|c|c|c|c|}
\hline Species, Strain, (Sex) & Route & Exposure/Study Durations & Reference \\
\hline \multicolumn{4}{|l|}{ Monochloroacetic acid } \\
\hline Rat F344/N (M\&F) & Gavage & $104 \mathrm{wk} / 104 \mathrm{wk}$ & NTP (1992) \\
\hline Mouse $\mathrm{B}_{6} \mathrm{C} 3 \mathrm{~F}_{1}(\mathrm{M} \& \mathrm{~F})$ & Gavage & $104 \mathrm{wk} / 104 \mathrm{wk}$ & NTP (1992) \\
\hline Rat, F344/M, (M) & Drinking water & $104 \mathrm{wk} / 104 \mathrm{wk}$ & DeAngelo et al. (1997) \\
\hline \multicolumn{4}{|l|}{ Monoiodoacetic acid } \\
\hline Mouse albino "S" strain (NR) & Dermal & $27 \mathrm{wk} / 30 \mathrm{wk}$ & Gwynn and Salaman $(1953)^{\mathrm{a}}$ \\
\hline \multicolumn{4}{|c|}{ Dichloroacetic acid } \\
\hline Rat F344 (M) & Drinking water & 100 wk/100 wk \& 103 wk/103 wk & DeAngelo et al. (1996) \\
\hline Rat F344 (M) & Drinking water & $\begin{array}{l}60 \mathrm{wk} / 60 \mathrm{wk} \text { (interim sacrifice) \& } \\
104 \mathrm{wk} / 104 \mathrm{wk}\end{array}$ & Richmond et al. (1995) \\
\hline Mouse B6C3F $(\mathrm{M})$ & Drinking water & $60-75 \mathrm{wk} / 60-75 \mathrm{wk}$ & DeAngelo et al. (1991) \\
\hline Mouse $\mathrm{B}_{6 \mathrm{C}} 3 \mathrm{~F}_{1}(\mathrm{M})$ & Drinking water & $90-100 \mathrm{wk} / 90-100 \mathrm{wk}$ & DeAngelo et al. (1999) \\
\hline Mouse B6C3F $(\mathrm{M})$ & Drinking water & $61 \mathrm{wk} / 61 \mathrm{wk}$ & Herren-Freund et al. (1987) \\
\hline Mouse $\mathrm{B} 6 \mathrm{C} 3 \mathrm{~F}_{1}(\mathrm{M})$ & Drinking water & $61 \mathrm{wk} / 61 \mathrm{wk}$ & Herren-Freund et al. (1987) ${ }^{\mathrm{a}}$ \\
\hline Mouse $\mathrm{B} \mathrm{C} 3 \mathrm{~F}_{1}(\mathrm{M} \& \mathrm{~F})$ & Drinking water & $10 \mathrm{wk} / 94 \mathrm{wk}$ & Wood et al. (2015) \\
\hline Mouse $\mathrm{B}_{6} \mathrm{C} 3 \mathrm{~F}_{1}(\mathrm{~F})$ & Drinking water & $360 \mathrm{~d} / 576 \mathrm{~d} \& 360 \mathrm{~d} / 360 \mathrm{~d}$ & Pereira (1996) \\
\hline Mouse $\mathrm{B}_{6 \mathrm{C} 3 \mathrm{~F}_{1}(\mathrm{~F})}$ & Drinking water & $44 \mathrm{wk} / 50 \mathrm{wk}$ & Pereira et al. $(1997)^{\mathrm{a}}$ \\
\hline Mouse B6C3F $1(M)$ & Drinking water & $52 \mathrm{wk} / 52 \mathrm{wk}$ & Bull et al. (1990) \\
\hline Mouse B6C3F $1(\mathrm{M})$ & Drinking water & $104 \mathrm{wk} / 104 \mathrm{wk}$ & Daniel et al. (1992) \\
\hline Mouse FVB Tg.AC (M\&F) & Drinking water & $26 \mathrm{wk} / 41 \mathrm{wk} \& 26 \mathrm{wk} / 26 \mathrm{wk}$ & $\operatorname{NTP}(2007 b)^{b}$ \\
\hline $\begin{array}{l}\text { Mouse p53 haploinsufficient } \\
(\mathrm{M \& F})\end{array}$ & Drinking water & $26 \mathrm{wk} / 41 \mathrm{wk} \& 26 \mathrm{wk} / 26 \mathrm{wk}$ & $\operatorname{NTP}(2007 b)^{b}$ \\
\hline Mouse FVB Tg.AC (M\&F) & Dermal & $39 \mathrm{wk} / 39 \mathrm{wk} \& 26 \mathrm{wk} / 26 \mathrm{wk}$ & $\operatorname{NTP}(2007 b)^{b}$ \\
\hline \multicolumn{4}{|l|}{ Dibromoacetic acid } \\
\hline Rat F344/N (M\&F) & Drinking water & $106 \mathrm{wk} / 106 \mathrm{wk}$ & NTP (2007a) \\
\hline Mouse $\mathrm{B}_{6} \mathrm{C} 3 \mathrm{~F}_{1}(\mathrm{M} \& \mathrm{~F})$ & Drinking water & $106 \mathrm{wk} / 106 \mathrm{wk}$ & NTP (2007a) \\
\hline \multicolumn{4}{|l|}{ Bromochloroacetic acid } \\
\hline Rat F344/N (M\&F) & Drinking water & $105 \mathrm{wk} / 105 \mathrm{wk}$ & NTP (2009) \\
\hline Mouse B6CC3F $1(\mathrm{M} \& \mathrm{~F})$ & Drinking water & $105 \mathrm{wk} / 105 \mathrm{wk}$ & NTP (2009) \\
\hline \multicolumn{4}{|l|}{ Trichloroacetic acid } \\
\hline Rat F344/N (M) & Drinking water & $104 \mathrm{wk} / 104 \mathrm{wk}$ & DeAngelo et al. (1997) \\
\hline Mouse B6C3F $1(\mathrm{M})$ & Drinking water & $60 \mathrm{wk} / 60 \mathrm{wk} \& 104 \mathrm{wk} / 104 \mathrm{wk}$ & DeAngelo et al. (2008) \\
\hline Mouse B6C3F $1(M)$ & Drinking water & $61 \mathrm{wk} / 61 \mathrm{wk}$ & Herren-Freund et al. (1987) \\
\hline Mouse $\mathrm{B}_{6 \mathrm{C} 3 \mathrm{~F}_{1}(\mathrm{M})}$ & Drinking water & $61 \mathrm{wk} / 61 \mathrm{wk}$ & Herren-Freund et al. $(1987)^{\mathrm{a}}$ \\
\hline Mouse B6C3F $1(F)$ & Drinking water & $576 \mathrm{~d} / 576 \mathrm{~d} \& 360 \mathrm{~d} / 360 \mathrm{~d}$ & Pereira (1996) \\
\hline Mouse B6C3F $1(F)$ & Drinking water & $44 \mathrm{wk} / 50 \mathrm{wk}$ & Pereira et al. $(1997)^{\mathrm{a}}$ \\
\hline Mouse $\mathrm{B} \mathrm{C} 3 \mathrm{~F}_{1}(\mathrm{M})$ & Drinking water & $52 \mathrm{wk} / 52 \mathrm{wk}$ & Bull et al. (1990) \\
\hline Mouse B6C3F 1 (M\&F) & IP inj. & $15 \mathrm{~d} / 20 \mathrm{mo} \& 15 \mathrm{~d} / 12 \mathrm{mo}$ & Von Tungeln et al. (2002) \\
\hline \multicolumn{4}{|l|}{ Bromodichloroacetic acid } \\
\hline Rat F344/NTac (M\&F) & Drinking water & $104-105 \mathrm{wk} / 104-105 \mathrm{wk}$ & NTP (2015) \\
\hline Mouse $\mathrm{B} 6 \mathrm{C} 3 \mathrm{~F}_{1}(\mathrm{M} \& \mathrm{~F})$ & Drinking water & $105 \mathrm{wk} / 105 \mathrm{wk}$ & NTP (2015) \\
\hline
\end{tabular}

anitiation-promotion study.

${ }^{\mathrm{b}}$ Transgenic animal model. 


\subsection{Study Quality Assessment}

Each of these primary studies was systematically evaluated by two independent reviewers for its ability to inform the cancer hazard evaluation using a series of signaling questions related to the following study performance elements: study design, exposure conditions, outcome, confounding, reporting and analysis, and overall utility (see RoC Handbook). A summary of the studies' quality assessments is provided below (Table 4-2), and details of each study assessment and quality criteria on a study-by-study basis are reported in Appendix C.

Most studies conducted by NTP $(1992 ; 2007 a ; 2007 b ; 2009 ; 2015)$ and some of the studies conducted by DeAngelo (1997; 2008) were considered the most informative because they used a sufficient number of experimental animals for a near lifetime exposure duration, tested three dose levels [except for NTP (1992), which used two dose levels] along with an untreated control, and performed full necropsies with histopathology. None of the studies used step-sectioning technique to evaluate an organ. The rat NTP (1992) study had a moderate level of utility because the rats were very sensitive to monochloroacetic acid in the 13-week study and developed noncarcinogenic toxicity, which required the dose level to be reduced in the 2-year study. DeAngelo et al. (1997) and the NTP studies also included historical control data. Data on historical controls is useful for identifying rare tumors.

Many studies were considered somewhat less informative (moderate overall utility) primarily because of sensitivity issues (e.g., elements that limited their ability to detect a true effect, or evaluate dose-response effects) but would not be expected to cause false positives in the studies. The studies with overall rating of ++ either had fewer animals (Daniel et al. 1992; DeAngelo et al. 1996; DeAngelo et al. 1991; DeAngelo et al. 1999; Herren-Freund et al. 1987; Richmond et al. 1995; Von Tungeln et al. 2002; Wood et al. 2015), used only one sex of animal (Daniel et al. 1992; DeAngelo et al. 1996; DeAngelo et al. 1991; DeAngelo et al. 1999; Herren-Freund et al. 1987; Pereira 1996; Richmond et al. 1995), had a shorter exposure duration (Pereira 1996; Von Tungeln et al. 2002; Wood et al. 2015), had to decrease study duration due to hindleg paralysis (Richmond et al. 1995), tested only one dose level (Daniel et al. 1992; DeAngelo et al. 1996; DeAngelo et al. 1991; Herren-Freund et al. 1987), or did not perform full necropsies (Daniel et al. 1992; DeAngelo et al. 1996; DeAngelo et al. 1991; DeAngelo et al. 1999; Herren-Freund et al. 1987; Pereira 1996; Richmond et al. 1995; Wood et al. 2015).

Only a few studies were considered to be of low quality (overall utility of + ) because of not reporting chemical purity (Pereira et al. 1997), testing at only a single dose level (Gwynn and Salaman 1953), use of a small number of animals (Bull et al. 1990; Gwynn and Salaman 1953), or the lack of full necropsies and instead focusing on specific target organs (Bull et al. 1990; Gwynn and Salaman 1953; Pereira et al. 1997) [in one study only a sample of randomly picked gross liver lesions were examined histologically (Bull et al. 1990) and in one study, lesions were classified based on "macroscopic" examination (Gwynn and Salaman 1953)]. 
Table 4-2. Quality Evaluations of Cancer Studies in Experimental Animals

\begin{tabular}{|c|c|c|c|c|c|c|c|c|c|c|c|c|c|}
\hline \multirow{2}{*}{ Study } & \multicolumn{5}{|c|}{ Study Design } & \multicolumn{3}{|c|}{ Exposure Conditions } & \multicolumn{2}{|c|}{ Outcome } & \multirow{2}{*}{\begin{tabular}{|l} 
Confounding \\
Confounding
\end{tabular}} & \multirow{2}{*}{$\begin{array}{c}\begin{array}{c}\text { Reporting } \\
\text { and } \\
\text { Analysis }\end{array} \\
\begin{array}{c}\text { Statistical } \\
\text { Analysis }\end{array}\end{array}$} & \multirow{2}{*}{$\begin{array}{l}\text { Overal } \\
\text { Utility }\end{array}$} \\
\hline & $\begin{array}{l}\text { Randomi- } \\
\text { zation }\end{array}$ & Control & $\begin{array}{l}\text { Animal } \\
\text { Model* }\end{array}$ & $\begin{array}{l}\text { Statistical } \\
\text { Power* }\end{array}$ & Purity & Dosing & $\begin{array}{l}\text { Exposure } \\
\text { Duration* }\end{array}$ & $\begin{array}{l}\text { Dose } \\
\text { Level* }\end{array}$ & $\begin{array}{l}\text { Pathology } \\
\text { Methods }\end{array}$ & $\begin{array}{c}\text { Equal } \\
\text { Treatment }\end{array}$ & & & \\
\hline \multicolumn{14}{|l|}{ Monochloroacetic acid } \\
\hline $\begin{array}{l}\text { NTP (1992), Mouse } \\
\text { M/F }\end{array}$ & +++ & +++ & +++ & +++ & +++ & $++ \pm^{\mathrm{a}}$ & +++ & $++ \pm^{\mathrm{a}}$ & +++ & +++ & $++^{b}$ & +++ & +++ \\
\hline NTP (1992), Rat M/F & +++ & +++ & ++ & +++ & +++ & ++ & +++ & ++ & +++ & +++ & +++ & +++ & ++ \\
\hline $\begin{array}{l}\text { DeAngelo et al. } \\
\text { (1997), Rat M }\end{array}$ & NR & +++ & ++ & +++ & +++ & +++ & +++ & +++ & +++ & +++ & +++ & +++ & +++ \\
\hline \multicolumn{14}{|l|}{ Monoiodoacetic acid } \\
\hline $\begin{array}{l}\text { Gwynn and Salaman } \\
(1953),{ }^{c} \text { Mouse NR }\end{array}$ & NR & +++ & + & + & NR & +++ & ++ & + & + & NR & + & NR & + \\
\hline \multicolumn{14}{|l|}{ Dichloroacetic acid } \\
\hline $\begin{array}{l}\text { DeAngelo et al. } \\
\text { (1996), Rat M (100 } \\
\text { wk), } 2 \text { doses }\end{array}$ & NR & +++ & ++ & ++ & +++ & +++ & +++ & ++ & ++ & ++ & ++ & +++ & ++ \\
\hline $\begin{array}{l}\text { DeAngelo et al. } \\
\text { (1996), Rat M (103 } \\
\text { wk), } 1 \text { dose }\end{array}$ & NR & +++ & ++ & ++ & +++ & +++ & +++ & + & ++ & ++ & ++ & +++ & ++ \\
\hline $\begin{array}{l}\text { Richmond et al. } \\
\text { (1995), Rat M (104 } \\
\text { wk) }\end{array}$ & +++ & +++ & ++ & ++ & NR & +++ & +++ & +++ & ++ & ++ & + & ++ & ++ \\
\hline $\begin{array}{l}\text { DeAngelo et al. } \\
\text { (1991), Mouse M } \\
\text { (60/75 wk) } 3 \text { doses }\end{array}$ & +++ & +++ & ++ & ++ & +++ & +++ & +++ & +++ & ++ & ++ & ++ & +++ & +++ \\
\hline $\begin{array}{l}\text { DeAngelo et al. } \\
\text { (1991), Mouse M } \\
(60 \text { wk), } 1 \text { dose }\end{array}$ & +++ & +++ & ++ & + & +++ & +++ & +++ & + & ++ & +++ & ++ & +++ & ++ \\
\hline
\end{tabular}




\begin{tabular}{|c|c|c|c|c|c|c|c|c|c|c|c|c|c|}
\hline \multirow{2}{*}{ Study } & \multicolumn{5}{|c|}{ Study Design } & \multicolumn{3}{|c|}{ Exposure Conditions } & \multicolumn{2}{|c|}{ Outcome } & \multirow{2}{*}{\begin{tabular}{|l} 
Confounding \\
Confounding
\end{tabular}} & \multirow{2}{*}{$\begin{array}{c}\begin{array}{c}\text { Reporting } \\
\text { and } \\
\text { Analysis }\end{array} \\
\begin{array}{c}\text { Statistical } \\
\text { Analysis }\end{array}\end{array}$} & \multirow{2}{*}{$\begin{array}{c}\text { Overall } \\
\text { Utility }\end{array}$} \\
\hline & $\begin{array}{c}\text { Randomi- } \\
\text { zation }\end{array}$ & Control & $\begin{array}{l}\text { Animal } \\
\text { Model* }\end{array}$ & $\begin{array}{c}\text { Statistical } \\
\text { Power* }\end{array}$ & Purity & Dosing & $\begin{array}{l}\text { Exposure } \\
\text { Duration* }\end{array}$ & $\begin{array}{c}\text { Dose } \\
\text { Level* }\end{array}$ & $\begin{array}{l}\text { Pathology } \\
\text { Methods }\end{array}$ & $\begin{array}{c}\text { Equal } \\
\text { Treatment }\end{array}$ & & & \\
\hline $\begin{array}{l}\text { DeAngelo et al. } \\
\text { (1999), Mouse M, } \\
4 \text { doses }\end{array}$ & +++ & +++ & ++ & ++ & +++ & +++ & +++ & +++ & ++ & ++ & ++ & +++ & ++ \\
\hline $\begin{array}{l}\text { Herren-Freund et } \\
\text { al. (1987), Mouse } \\
\text { M }\end{array}$ & NR & +++ & ++ & ++ & +++ & +++ & +++ & + & ++ & +++ & +++ & +++ & ++ \\
\hline $\begin{array}{l}\text { Herren-Freund et } \\
\text { al. (1987), }{ }^{c} \text { Mouse } \\
\text { M }\end{array}$ & NR & +++ & ++ & ++ & +++ & +++ & +++ & + & ++ & +++ & +++ & +++ & ++ \\
\hline $\begin{array}{l}\text { Wood et al. (2015), } \\
\text { Mouse M }\end{array}$ & NR & +++ & +++ & ++ & ++ & +++ & ++ & +++ & + & +++ & ++ & +++ & ++ \\
\hline $\begin{array}{l}\text { Wood et al. (2015), } \\
\text { Mouse F }\end{array}$ & NR & +++ & +++ & ++ & ++ & +++ & ++ & ++ & + & +++ & ++ & +++ & ++ \\
\hline $\begin{array}{l}\text { Pereira (1996), } \\
\text { Mouse F }(360 \mathrm{~d})\end{array}$ & +++ & +++ & ++ & ++ & NR & +++ & +++ & +++ & ++ & +++ & ++ & +++ & ++ \\
\hline $\begin{array}{l}\text { Pereira (1996), } \\
\text { Mouse F (576 d) }\end{array}$ & +++ & +++ & ++ & ++ & NR & +++ & ++ & +++ & ++ & +++ & ++ & +++ & ++ \\
\hline $\begin{array}{l}\text { Pereira et al. } \\
(1997),{ }^{\text {c }} \text { Mouse F }\end{array}$ & +++ & +++ & ++ & ++ & + & +++ & +++ & +++ & ++ & +++ & ++ & ++ & + \\
\hline $\begin{array}{l}\text { Bull et al. (1990), } \\
\text { Mouse M }\end{array}$ & +++ & +++ & ++ & + & ++ & +++ & +++ & ++ & + & + & + & + & + \\
\hline $\begin{array}{l}\text { Daniel et al. } \\
\text { (1992), Mouse M }\end{array}$ & +++ & +++ & ++ & ++ & +++ & +++ & +++ & + & + & ++ & ++ & +++ & ++ \\
\hline $\begin{array}{l}\text { NTP }(2007 b),{ }^{d} \\
\text { Mouse M/F FVB } \\
\text { Tg.AC dermal ( } 39 \\
\text { wk), } 3 \text { doses }\end{array}$ & +++ & +++ & + & + & +++ & ++ & +++ & +++ & +++ & +++ & +++ & +++ & + \\
\hline
\end{tabular}




\begin{tabular}{|c|c|c|c|c|c|c|c|c|c|c|c|c|c|}
\hline \multirow{2}{*}{ Study } & \multicolumn{5}{|c|}{ Study Design } & \multicolumn{3}{|c|}{ Exposure Conditions } & \multicolumn{2}{|c|}{ Outcome } & \multirow{2}{*}{$\begin{array}{l}\text { Confounding } \\
\text { Confounding }\end{array}$} & \multirow{2}{*}{$\begin{array}{c}\begin{array}{c}\text { Reporting } \\
\text { and } \\
\text { Analysis }\end{array} \\
\begin{array}{c}\text { Statistical } \\
\text { Analysis }\end{array}\end{array}$} & \multirow{2}{*}{$\begin{array}{c}\text { Overall } \\
\text { Utility }\end{array}$} \\
\hline & $\begin{array}{c}\text { Randomi- } \\
\text { zation }\end{array}$ & Control & $\begin{array}{l}\text { Animal } \\
\text { Model* }\end{array}$ & $\begin{array}{c}\text { Statistical } \\
\text { Power* }\end{array}$ & Purity & Dosing & $\begin{array}{l}\text { Exposure } \\
\text { Duration* }\end{array}$ & $\begin{array}{c}\text { Dose } \\
\text { Level* }\end{array}$ & $\begin{array}{l}\text { Pathology } \\
\text { Methods }\end{array}$ & $\begin{array}{c}\text { Equal } \\
\text { Treatment }\end{array}$ & & & \\
\hline $\begin{array}{l}\text { NTP }(2007 b),{ }^{d} \\
\text { Mouse M/F FVB } \\
\text { Tg.AC dermal ( } 26 \\
\text { wk), } 3 \text { doses }\end{array}$ & +++ & +++ & + & ++ & +++ & ++ & ++ & +++ & +++ & +++ & +++ & +++ & + \\
\hline $\begin{array}{l}\text { NTP }(2007 b){ }^{d} \\
\text { Mouse M FVB } \\
\text { Tg.AC (41 wk), } 3 \\
\text { doses }\end{array}$ & +++ & +++ & + & + & +++ & +++ & +++ & +++ & +++ & +++ & +++ & +++ & + \\
\hline $\begin{array}{l}\text { NTP (2007b), }{ }^{d} \\
\text { Mouse F FVB } \\
\text { Tg.AC (41 wk), } 3 \\
\text { doses }\end{array}$ & +++ & +++ & + & + & +++ & ++ & +++ & +++ & +++ & +++ & +++ & +++ & + \\
\hline $\begin{array}{l}\text { NTP }(2007 b),{ }^{d} \\
\text { Mouse M FVB } \\
\text { Tg.AC ( } 26 \text { wk }), 3 \\
\text { doses }\end{array}$ & +++ & +++ & + & ++ & +++ & + & ++ & +++ & +++ & +++ & +++ & +++ & + \\
\hline $\begin{array}{l}\text { NTP }(2007 b),{ }^{d} \\
\text { Mouse F FVB } \\
\text { Tg.AC (26 wk), } 3 \\
\text { doses }\end{array}$ & +++ & +++ & + & ++ & $+++^{a}$ & $+^{e}$ & ++ & +++ & +++ & +++ & +++ & +++ & + \\
\hline $\begin{array}{l}\text { NTP }(2007 b){ }^{d} \\
\text { Mouse M/F p53 } \\
\text { haploinsufficient } \\
\text { (41 wk), } 3 \text { doses }\end{array}$ & +++ & +++ & + & + & +++ & ++ & +++ & +++ & +++ & +++ & +++ & +++ & + \\
\hline $\begin{array}{l}\text { NTP }(2007 b),{ }^{d} \\
\text { Mouse M/F p53 } \\
\text { haploinsufficient } \\
\text { (26 wk), } 3 \text { doses }\end{array}$ & +++ & +++ & + & ++ & +++ & ++ & ++ & +++ & +++ & +++ & +++ & +++ & + \\
\hline
\end{tabular}


RoC Monograph on Haloacetic Acids

\begin{tabular}{|c|c|c|c|c|c|c|c|c|c|c|c|c|c|}
\hline \multirow{2}{*}{ Study } & \multicolumn{5}{|c|}{ Study Design } & \multicolumn{3}{|c|}{ Exposure Conditions } & \multicolumn{2}{|c|}{ Outcome } & \multirow{2}{*}{\begin{tabular}{|l} 
Confounding \\
Confounding
\end{tabular}} & \multirow{2}{*}{$\begin{array}{c}\begin{array}{c}\text { Reporting } \\
\text { and } \\
\text { Analysis }\end{array} \\
\begin{array}{c}\text { Statistical } \\
\text { Analysis }\end{array}\end{array}$} & \multirow{2}{*}{$\begin{array}{c}\text { Overall } \\
\text { Utility }\end{array}$} \\
\hline & $\begin{array}{l}\text { Randomi- } \\
\text { zation }\end{array}$ & Control & $\begin{array}{l}\text { Animal } \\
\text { Model* }\end{array}$ & $\begin{array}{l}\text { Statistical } \\
\text { Power* }\end{array}$ & Purity & Dosing & $\begin{array}{l}\text { Exposure } \\
\text { Duration* }\end{array}$ & $\begin{array}{c}\text { Dose } \\
\text { Level* }\end{array}$ & $\begin{array}{l}\text { Pathology } \\
\text { Methods }\end{array}$ & $\begin{array}{c}\text { Equal } \\
\text { Treatment }\end{array}$ & & & \\
\hline \multicolumn{14}{|l|}{ Dibromoacetic acid } \\
\hline $\begin{array}{l}\text { NTP (2007a) Mouse } \\
\text { M/F }\end{array}$ & +++ & +++ & +++ & +++ & +++ & +++ & +++ & +++ & +++ & +++ & ++ & +++ & +++ \\
\hline $\begin{array}{l}\text { NTP (2007a) Rat } \\
\text { M/F }\end{array}$ & +++ & +++ & +++ & +++ & +++ & $++ \pm^{a}$ & +++ & +++ & +++ & +++ & ++ & +++ & +++ \\
\hline \multicolumn{14}{|l|}{ Bromochloroacetic acid } \\
\hline NTP (2009) Rat M/F & +++ & +++ & +++ & +++ & +++ & +++ & +++ & +++ & +++ & +++ & +++ & +++ & +++ \\
\hline $\begin{array}{l}\text { NTP (2009) Mouse } \\
\text { M/F }\end{array}$ & +++ & +++ & +++ & +++ & +++ & +++ & +++ & +++ & +++ & +++ & +++ & +++ & +++ \\
\hline \multicolumn{14}{|l|}{ Trichloroacetic acid } \\
\hline $\begin{array}{l}\text { DeAngelo et al. } \\
\text { (1997) Rat M }\end{array}$ & NR & +++ & ++ & +++ & +++ & $++ \pm^{a}$ & +++ & +++ & +++ & +++ & +++ & +++ & +++ \\
\hline $\begin{array}{l}\text { DeAngelo et al. } \\
\text { (2008) Mouse M ( } 60 \\
\text { wk) }\end{array}$ & +++ & +++ & +++ & +++ & +++ & +++ & ++ & +++ & +++ & ++ & +++ & +++ & +++ \\
\hline $\begin{array}{l}\text { DeAngelo et al. } \\
\text { (2008) Mouse M } \\
\text { (104 wk), } 1 \text { dose }\end{array}$ & +++ & +++ & +++ & +++ & +++ & +++ & +++ & + & +++ & +++ & +++ & +++ & ++ \\
\hline $\begin{array}{l}\text { DeAngelo et al. } \\
\text { (2008) Mouse M } \\
\text { (104 wk), } 2 \text { doses }\end{array}$ & +++ & +++ & +++ & +++ & +++ & ++ & +++ & ++ & +++ & +++ & +++ & +++ & ++ \\
\hline $\begin{array}{l}\text { Herren-Freund et al. } \\
\text { (1987) Mouse M }\end{array}$ & NR & +++ & ++ & ++ & +++ & $++ \pm^{a}$ & +++ & +++ & $+ \pm^{\mathrm{a}}$ & +++ & +++ & +++ & ++ \\
\hline $\begin{array}{l}\text { Herren-Freund et al. } \\
(1987)^{\mathrm{c}} \text { Mouse M }\end{array}$ & NR & +++ & ++ & ++ & +++ & $++ \pm^{a}$ & +++ & $+t^{b}$ & $+ \pm^{a}$ & +++ & +++ & +++ & ++ \\
\hline $\begin{array}{l}\text { Pereira (1996) Mouse } \\
\text { F (576 d) }\end{array}$ & +++ & +++ & ++ & ++ & NR & +++ & +++ & +++ & ++ & +++ & ++ & +++ & ++ \\
\hline $\begin{array}{l}\text { Pereira (1996) Mouse } \\
\text { F (360 d) }\end{array}$ & +++ & +++ & ++ & ++ & NR & +++ & ++ & +++ & ++ & +++ & ++ & +++ & ++ \\
\hline
\end{tabular}




\begin{tabular}{|c|c|c|c|c|c|c|c|c|c|c|c|c|c|}
\hline \multirow{2}{*}{ Study } & \multicolumn{5}{|c|}{ Study Design } & \multicolumn{3}{|c|}{ Exposure Conditions } & \multicolumn{2}{|c|}{ Outcome } & \multirow{2}{*}{\begin{tabular}{|l} 
Confounding \\
Confounding
\end{tabular}} & \multirow{2}{*}{$\begin{array}{c}\begin{array}{c}\text { Reporting } \\
\text { and } \\
\text { Analysis }\end{array} \\
\begin{array}{c}\text { Statistical } \\
\text { Analysis }\end{array}\end{array}$} & \multirow{2}{*}{$\begin{array}{c}\text { Overall } \\
\text { Utility }\end{array}$} \\
\hline & $\begin{array}{l}\text { Randomi- } \\
\text { zation }\end{array}$ & Control & $\begin{array}{l}\text { Animal } \\
\text { Model* }\end{array}$ & $\begin{array}{l}\text { Statistical } \\
\text { Power* }\end{array}$ & Purity & Dosing & $\begin{array}{l}\text { Exposure } \\
\text { Duration* }\end{array}$ & $\begin{array}{l}\text { Dose } \\
\text { Level* }\end{array}$ & $\begin{array}{l}\text { Pathology } \\
\text { Methods }\end{array}$ & $\begin{array}{c}\text { Equal } \\
\text { Treatment }\end{array}$ & & & \\
\hline $\begin{array}{l}\text { Pereira et al. }(1997)^{\mathrm{c}} \\
\text { Mouse F }\end{array}$ & +++ & +++ & ++ & ++ & NR & +++ & +++ & +++ & ++ & +++ & ++ & ++ & + \\
\hline $\begin{array}{l}\text { Bull et al. (1990) } \\
\text { Mouse M }\end{array}$ & +++ & +++ & ++ & + & ++ & +++ & +++ & ++ & + & + & + & + & + \\
\hline $\begin{array}{l}\text { Von Tungeln et al. } \\
\text { (2002) Mouse M/F } \\
(20 \mathrm{mo})\end{array}$ & + & +++ & ++ & ++ & NR & + & + & ++ & ++ & ++ & ++ & +++ & ++ \\
\hline $\begin{array}{l}\text { Von Tungeln et al. } \\
\text { (2002) Mouse M/F } \\
(12 \mathrm{mo})\end{array}$ & + & +++ & $++ \pm^{a}$ & ++ & NR & + & + & ++ & ++ & ++ & ++ & +++ & ++ \\
\hline \multicolumn{14}{|c|}{ Bromodichloroacetic acid } \\
\hline NTP (2015), Rat M/F & +++ & +++ & +++ & +++ & +++ & +++ & +++ & +++ & +++ & +++ & +++ & +++ & +++ \\
\hline $\begin{array}{l}\text { NTP (2015), Mouse } \\
\text { M/F }\end{array}$ & +++ & +++ & +++ & +++ & +++ & +++ & +++ & +++ & +++ & +++ & +++ & +++ & +++ \\
\hline $\begin{array}{l}\text { *These factors contribu } \\
{ }^{\text {a}} \text { ERRATUM: Errors w } \\
\text { was incorrect in the ori } \\
{ }^{b} \text { ERRATUM: Errors w } \\
\text { was incorrect in the ori } \\
{ }^{\mathrm{c}} \text { Initiation/promotion st } \\
{ }^{\mathrm{d}} \text { Transgenic animal mo }\end{array}$ & $\begin{array}{l}\text { te to the sens } \\
\text { ere identified } \\
\text { ginal table. T } \\
\text { ere identified } \\
\text { ginal table. T } \\
\text { udy. } \\
\text { del. }\end{array}$ & $\begin{array}{l}\text { sitivity of } \mathrm{t} \\
\text { in the Rep } \\
\text { hese error } \\
\text { in the Rep } \\
\text { hese error }\end{array}$ & $\begin{array}{l}\text { the study. } \\
\text { port on } \mathrm{Ca} \\
\text { s have bee } \\
\text { port on } \mathrm{Ca} \\
\text { 's have bee }\end{array}$ & $\begin{array}{l}\text { arcinogens } M \\
\text { en corrected; } \\
\text { arcinogens } M \\
\text { en corrected; }\end{array}$ & $\begin{array}{l}\text { onograpl } \\
\text { one }+ \text { sig } \\
\text { onograpl } \\
\text { one + sig }\end{array}$ & $\begin{array}{l}\text { on Haloa } \\
\text { n was add } \\
\text { on Haloa } \\
\text { n was rem }\end{array}$ & $\begin{array}{l}\text { cetic Acids F } \\
\text { ed and underl } \\
\text { cetic Acids F } \\
\text { oved. }\end{array}$ & $\begin{array}{l}\text { und as } W \\
\text { ned. } \\
\text { und as } W\end{array}$ & $\begin{array}{l}\text { Iater Disinfec } \\
\text { Iater Disinfec }\end{array}$ & $\begin{array}{l}\text { tion By-prod } \\
\text { tion By-prod }\end{array}$ & $\begin{array}{l}\text { ucts. The numbe } \\
\text { ucts. The numbe }\end{array}$ & $\begin{array}{l}\text { of }+ \text { signs in } \\
\text { of }+ \text { signs in }\end{array}$ & hese cells \\
\hline
\end{tabular}


Other studies rated as low utility were not conventional carcinogenicity studies and instead were initiation-promotion studies that did not include groups that exposed animals to the haloacetic acid promoter without the initiator (Gwynn and Salaman 1953; Pereira et al. 1997) or they used p53 haploinsufficient or Tg.AC hemizygous transgenic mice. The p53 haploinsufficient transgenic mice may not be able to detect non-genotoxic carcinogens (Gulezian et al. 2000; Spalding et al. 2000; Tennant and Spalding 1996). Concerns for the Tg.AC hemizygous mice include production of false positive results from vehicle controls (Jacobs and Hatfield 2013), or minor skin abrasions (Fuhrman et al. 2005), and its inability to distinguish between promotion and de novo carcinogenicity (Jacobs and Hatfield 2013; Luijten et al. 2016). The use of the Tg.AC hemizygous mouse is no longer recommended by the FDA (Luijten et al. 2016). Another limitation of these studies was the small number of animals used for each treatment group, further limiting the ability to detect small changes in incidence.

\subsection{Neoplastic Findings from Carcinogenesis Studies}

Results are summarized below for tumors induced by seven mono-, di-, and trihaloacetic acids (monochloroacetic acid, monoiodoacetic acid, dichloroacetic acid, dibromoacetic acid, bromochloroacetic acid, trichloroacetic acid, and bromodichloroacetic acid). Section 4.3.1 discusses liver neoplasms, which are reported by themselves because they developed in mice in all positive studies. The other sections discuss other tumor sites (Section 4.3.2), studies with transgenic animals (Section 4.3.3), and initiation-promotion studies (Section 4.3.4). Table 4-4 in Section 4.4 summarizes results by individual haloacetic acid. The following text summarizes neoplastic findings across tumor sites and across haloacetic acids rather than providing a detailed study-by-study description. Information on the individual cancer studies can be found in tabular form in Appendix C.

\subsubsection{Liver}

Overall, the data from studies that exposed rodents to haloacetic acids provide strong evidence that di- and trihaloacetic acids cause liver neoplasms in rodents (see Table C-56 in Appendix C). Liver neoplasms were significantly induced by all dihaloacetic acids (dichloroacetic acid, dibromoacetic acid, bromochloroacetic acid) and trihaloacetic acids, (trichloroacetic acid, bromodichloroacetic acid) tested by exposure to male and female mice in the drinking water in well-conducted studies for at least 12 months. Significant increases in liver neoplasms for male rats were reported for dichloroacetic acid only.

The routes of exposure were primarily through drinking water with one study using intraperitoneal injection. Either route would be expected to result in initial exposure of the liver by uptake from the gastrointestinal tract circulation via the hepatic portal system. Exposure of the liver to the relatively high concentration of haloacetic acid prior to metabolism and distribution to other tissues could be a factor in the common occurrence of liver neoplasms.

All chronic cancer studies in this section are of moderate study quality except for Bull et al. (1990) which has a lower study quality rating (see Appendix C). Some studies focused on the liver pathology only and did not do a full necropsy on the whole animal; limitations on study quality would not apply to histopathology results for this tissue.

Details on liver findings for the individual HAAs are discussed first, followed by a discussion of the findings across studies. 


\section{Chlorine-only Haloacetic Acids}

No liver tumors were induced by the only monohaloacetic acid tested, monochloroacetic acid, which was administered by gavage to rats and mice (NTP 1992) and in drinking water to rats (DeAngelo et al. 1997).

Dichloroacetic acid was tested for carcinogenicity in more studies than any other haloacetic acid, with 11 publications reporting 13 drinking water studies that varied by species (rat or mouse), sex, dose levels tested (from $50 \mathrm{mg} / \mathrm{L}$ up to $5,000 \mathrm{mg} / \mathrm{L}$ ), and duration of exposure and observation (from 10 weeks to 104 weeks for chronic studies). These studies did not generally provide explanations for the choices of duration, or dose used. In general, most of the studies were in male mice only, a stop-exposure study was reported for male and female mice, two studies were in female mice only, and two studies were in male rats only (see Table 4-1). Overall, increased incidences of liver tumors were reported for both sexes in mice and male rats over a range of doses and duration of exposure indicating a robust tumorigenic response for dichloroacetic acid.

In male mice, dichloroacetic acid induced a significant increase in hepatocellular adenoma and carcinoma at $5,000 \mathrm{mg} / \mathrm{L}$ for 60 weeks in a multiple-dose study for 60 to 75 weeks $(50,500$, $5,000 \mathrm{mg} / \mathrm{L})($ DeAngelo et al. 1991) and at lower doses (starting at 1,000 mg/L) in a multi-dose, two-year study (0, 500, 1,000, 2,000, 3,500 mg/L, see Figure 4-1A) (DeAngelo et al. 1999). Three single high-dose studies of dichloroacetic acid in male mice yielded significant incidence rates for hepatocellular adenoma and carcinoma at $500 \mathrm{mg} / \mathrm{L}$ in a two-year study (Daniel et al. 1992) and 3,500 mg/L (DeAngelo et al. 1991) or 5,000 mg/L (Herren-Freund et al. 1987) in 60week studies. Bull et al. (1990) reported that 50\% (5 of 10) of male mice treated with $2,000 \mathrm{mg} / \mathrm{L}$ of dichloroacetic acid in the drinking water for one year developed hepatocellular carcinoma; however, only mice with gross liver lesions were histologically examined, including only two out of the 35 control mice in this study, which also had other study limitations (see Appendix C). In female mice, dichloroacetic acid caused significant increases in the incidence of hepatocellular adenoma at the mid $(860 \mathrm{mg} / \mathrm{L})$ and high dose $(2,600 \mathrm{mg} / \mathrm{L})$ and carcinoma at the high dose $(2,600 \mathrm{mg} / \mathrm{L})$ in an $\sim 1.5$ year study (Pereira 1996) (see Figure 4-1D); only hepatocellular adenoma was significantly increased at the high dose in a one-year study reported in the same publication.

In a stop-exposure study by Wood et al. (2015), 4-week-old mice were exposed to dichloroacetic acid in the drinking water for 10 weeks and then maintained on deionized water until 98 weeks of age for a total observation period of 94 weeks. In male mice, significant increases in the incidence of hepatocellular adenoma, carcinoma, and adenoma or carcinoma or hepatoblastoma (combined) were induced at the high dose $(3,500 \mathrm{mg} / \mathrm{L})$ with a significant positive trend for all three analyses. Female mice had significantly increased incidences of hepatocellular adenoma or carcinoma or hepatoblastoma combined at $1,000 \mathrm{mg} / \mathrm{L}$ and $2,000 \mathrm{mg} / \mathrm{L}$ with a significant positive trend. Wood et al. (2015) noted that the tumor incidence and number induced by the high dose level in their study were $\geq 85 \%$ of the same findings seen after continuous lifetime exposure, indicating that early life exposure may be as carcinogenic as lifetime exposure.

Dichloroacetic acid significantly increased the incidence of hepatocellular neoplasms in male rats as reported in two studies described in the same publication (DeAngelo et al. 1996) that differed slightly in duration; in the study with a duration of 103 weeks, both the incidence of hepatocellular carcinoma and the combined incidence of hepatocellular adenoma and carcinoma 
were significantly increased at a dose of $2,500 \mathrm{mg} / \mathrm{L}$, and in the second study with a duration of 100 weeks, the combined incidence of hepatocellular adenoma and carcinoma was significantly increased at a dose of $500 \mathrm{mg} / \mathrm{L}$. A non-significant increase in hepatocellular adenoma and carcinoma was observed in male rats exposed to $500 \mathrm{mg} / \mathrm{L}$ (adenoma: $21 \%$ vs. $4 \%$ controls; carcinoma: $10 \%$ vs. $0 \%$ controls) in a 104 -week study and to $2,400 \mathrm{mg} / \mathrm{L}$ (adenoma: $26 \%$ vs. $0 \%$ controls; carcinoma: $4 \%$ vs. $0 \%$ controls) at 60 weeks (Richmond et al. 1995), which provides some support for the findings in the DeAngelo study.

Trichloroacetic acid was also tested in multiple studies (11 studies reported in 7 publications) in male and female mice but with only one study reporting results for male rats. In male mice, significantly increased incidences of hepatocellular adenoma and carcinoma were induced in two drinking water studies, one tested a single dose of $4,500 \mathrm{mg} / \mathrm{L}$ for 2 years and a multi-dose study reported significantly increased incidences after 1 year at $5,000 \mathrm{mg} / \mathrm{L}$ and after 2 years at $500 \mathrm{mg} / \mathrm{L}$ (DeAngelo et al. 2008), and a single-dose study (Herren-Freund et al. 1987) used a dose of $5,000 \mathrm{mg} / \mathrm{L}$ for 61 weeks. Significantly increased incidences of hepatocellular adenoma and carcinoma in male mice was observed at a much lower dose $(500 \mathrm{mg} / \mathrm{L})$ in the only study (multi-dose 50,500 mg/L) that tested for carcinogenicity at doses less than $4,500 \mathrm{mg} / \mathrm{L}$ ) (DeAngelo et al. 2008) (see Figure 4-1A). Bull et al. (1990) reported that a few hepatocellular carcinomas were observed in male mice in the mid dose $(1,000 \mathrm{mg} / \mathrm{L}, 2$ of 5 animals $)$ and highdose trichloroacetic acid groups $(2,000 \mathrm{mg} / \mathrm{L}, 4$ of 11 animals); however, there were only two control mice in this study, which had many study limitations (see Appendix C, Table C-20). In female mice, trichloroacetic acid caused significant increases in the incidence of hepatocellular carcinoma at the mid $(1,100 \mathrm{mg} / \mathrm{L})$ and high dose $(3,300 \mathrm{mg} / \mathrm{L})$ and adenoma at the high dose $(3,300 \mathrm{mg} / \mathrm{L})$ in an $\sim 1.5$ year study (Pereira 1996); the incidence of hepatocellular carcinoma was significantly increased at the high dose in a one-year study reported in the same publication. Trichloroacetic acid did not significantly increase the incidence of hepatocellular neoplasms in a 2-year, multi-dose $(0,50,500,5,000 \mathrm{mg} / \mathrm{L})$ study in male rats (DeAngelo et al. 1997).

Intraperitoneal injection $(2,000 \mathrm{mg} / \mathrm{L}$ over two injections in neonatal male and female mice) of trichloroacetic acid did not induce liver tumors in male or female mice at either the 12-month or 20-month observation period (Von Tungeln et al. 2002).

\section{Bromine-containing Haloacetic Acids: Dibromoacetic Acid, Bromochloroacetic Acid, Bromodichloroacetic Acid}

Exposure to dibromoacetic acid, bromochloroacetic acid, and bromodichloroacetic acid were tested by NTP in male and female mice and male and female rats exposed in the drinking water (NTP 2007a; 2009; 2015). Dibromoacetic acid was given at 50, 500, and $1,000 \mathrm{mg} / \mathrm{L}$ and the bromochloro- and bromodichloroacetic acids were given at 250,500 and $1,000 \mathrm{mg} / \mathrm{L}$. Overall, the studies provide convincing evidence that these chemicals cause malignant tumors in mice: hepatocellular carcinoma in male and female mice and hepatoblastoma in male mice, which were outside the historical control ranges, with positive dose-response trends. Additionally, female mice exposed to bromodichloroacetic acid had a significant increase in hemangiosarcoma in the liver at $1,000 \mathrm{mg} / \mathrm{L}$. A summary of the findings for the different types of hepatocellular neoplasms and combinations is provided in Table 4-3 and the incidences of hepatocellular carcinoma and hepatoblastoma are provided in Figure 4-1 and Figure 4-2. None of the brominecontaining dihaloacetic acids caused a significant increase in the incidence of hepatocellular neoplasms in rats. 
Table 4-3. Hepatocellular Neoplasms in Mice Exposed to Bromine-Containing Haloacetic Acids

\begin{tabular}{|c|c|c|c|c|c|}
\hline HAA (Sex) & $\begin{array}{c}\text { Hepatocellular } \\
\text { Adenoma }\end{array}$ & $\begin{array}{l}\text { Hepatocellular } \\
\text { Carcinoma }\end{array}$ & $\begin{array}{c}\text { Hepatocellular } \\
\text { Adenoma or } \\
\text { Carcinoma } \\
\text { (Combined) }\end{array}$ & Hepatoblastoma & $\begin{array}{l}\text { All Liver } \\
\text { Neoplasms } \\
\text { Combined }\end{array}$ \\
\hline $\begin{array}{l}D B A \\
\text { (males) }\end{array}$ & $\begin{array}{l}\text { Sign. increases at } \\
\text { all doses; positive } \\
\text { trend }\end{array}$ & $\begin{array}{l}\text { Sign. increases at } \\
\text { high dose; positive } \\
\text { trend }\end{array}$ & $\begin{array}{l}\text { Sign. increases at } \\
\text { all doses; positive } \\
\text { trend }\end{array}$ & $\begin{array}{l}\text { Sign. increases at the } \\
\text { mid and high dose; } \\
\text { positive trend }\end{array}$ & $\begin{array}{l}\text { Sign. } \\
\text { increases at } \\
\text { all doses; } \\
\text { positive trend }\end{array}$ \\
\hline $\begin{array}{l}D B A \\
\text { (females) }\end{array}$ & $\begin{array}{l}\text { Sign. increases at } \\
\text { mid and high } \\
\text { doses; positive } \\
\text { trend }\end{array}$ & $\begin{array}{l}\text { Sign. increases at } \\
\text { mid and high } \\
\text { doses; positive } \\
\text { trend }\end{array}$ & $\begin{array}{l}\text { Sign. increases at } \\
\text { mid and high } \\
\text { doses; positive } \\
\text { trend }\end{array}$ & & \\
\hline $\begin{array}{l}B C A \\
\text { (males) }\end{array}$ & $\begin{array}{l}\text { Sign. increases at } \\
\text { low and mid doses; } \\
\text { positive trend }\end{array}$ & $\begin{array}{l}\text { Sign. increases at } \\
\text { mid and high } \\
\text { doses; positive } \\
\text { trend }\end{array}$ & $\begin{array}{l}\text { Sign. increases at } \\
\text { all doses; positive } \\
\text { trend }\end{array}$ & $\begin{array}{l}\text { Sign. increases at all } \\
\text { doses; positive trend }\end{array}$ & $\begin{array}{l}\text { Sign. } \\
\text { increases at } \\
\text { mid and high } \\
\text { doses; } \\
\text { positive trend }\end{array}$ \\
\hline $\begin{array}{l}B C A \\
\text { (females) }\end{array}$ & $\begin{array}{l}\text { Sign. increases at } \\
\text { all doses; positive } \\
\text { trend }\end{array}$ & $\begin{array}{l}\text { Sign. increase at } \\
\text { mid dose; exceeds } \\
\text { historical controls } \\
\text { at all doses }\end{array}$ & $\begin{array}{l}\text { Sign. increases at } \\
\text { all doses; positive } \\
\text { trend }\end{array}$ & & \\
\hline $\begin{array}{l}B D C A \\
\text { (males) }\end{array}$ & & $\begin{array}{l}\text { Sign. increase at all } \\
\text { doses; positive } \\
\text { trend }\end{array}$ & & $\begin{array}{l}\text { Sign. increases at all } \\
\text { doses; positive trend }\end{array}$ & $\begin{array}{l}\text { Sign. } \\
\text { increases at } \\
\text { low and high } \\
\text { dose; positive } \\
\text { trend }\end{array}$ \\
\hline $\begin{array}{l}B D C A \\
\text { (females) }\end{array}$ & $\begin{array}{l}\text { Sign. increase at all } \\
\text { doses; positive } \\
\text { trend }\end{array}$ & $\begin{array}{l}\text { Sign. increases at } \\
\text { mid and high doses } \\
\text { positive trend }\end{array}$ & $\begin{array}{l}\text { Sign. increases at } \\
\text { all doses; positive } \\
\text { trend }\end{array}$ & $\begin{array}{l}\text { Sign. increase at high } \\
\text { dose; positive trend }\end{array}$ & \\
\hline
\end{tabular}



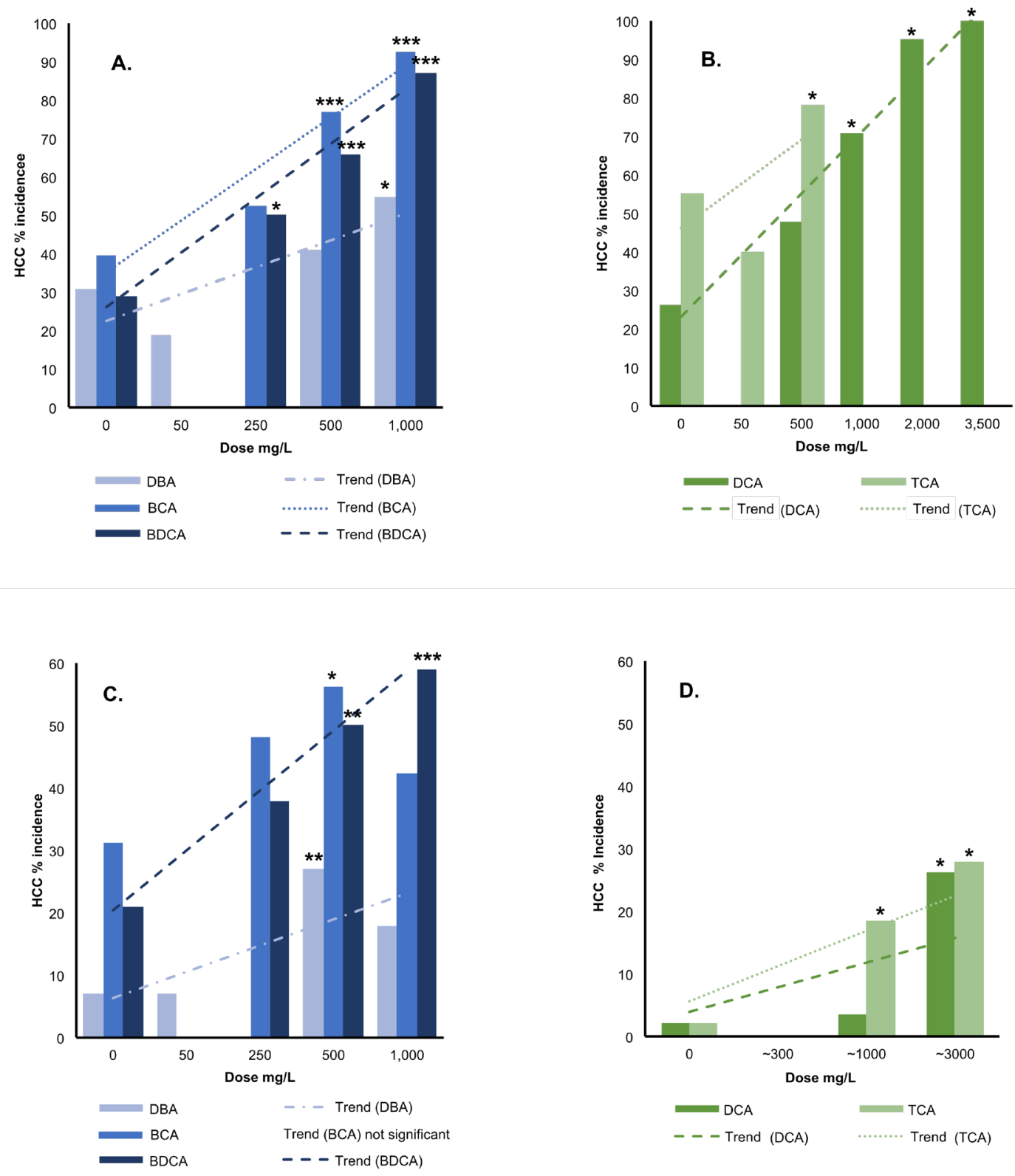

Figure 4-1. Hepatocellular Carcinoma in Female and Male Mice Exposed to Di- and Trihaloacetic Acids

Sources: NTP (2007a; 2009; 2015), for bromine-containing HAA in male (A) and female (C) mice; DeAngelo et al. (1999) for DCA in male mice (B) and DeAngelo et al. (2008) for TCA in male mice (B) and Pereira (1996) for DCA and TCA in female mice (D).

${ }^{*} \mathrm{p}<0.05 ; * * \mathrm{p}<0.01 ; * * * \mathrm{p}<0.001$. Compared with corresponding control group.

$\mathrm{BCA}=$ bromochloroacetic acid, male mice trend $=\mathrm{p}<0.001 ; \mathrm{BDCA}=$ bromodichloroacetic acid, male mice trend $=\mathrm{p}<0.001$, female mice trend $=\mathrm{p}<0.001 ; \mathrm{DBA}=$ dibromoacetic acid, male mice trend $\mathrm{p}<0.001$, female mice trend $=\mathrm{p}=0.019$;

$\mathrm{DCA}=$ dichloroacetic acid, male mice trend $=\mathrm{p}<0.001$, female mice trend $=\mathrm{p}<0.001 ;$ TCA $=$ trichloroacetic acid, male mice trend $=\mathrm{p}<0.01$, female mice trend $\mathrm{p}<0.001$.

Results are shown for bromine-containing HAAs in male mice (Panel A), chlorine-containing HAAs in male mice (Panel B), bromine-containing HAAs in female mice (Panel C), and chlorine-containing HAAs in female mice (Panel D). 
The NTP and DeAngelo studies were 2 years in duration and the Pereira studies were 1.5 years in length. Trend refers to a positive trend and not the shape of the dose-response curve. Trends were not reported by the authors for DCA and TCA, but NTP calculated trends based on the Cochran-Armitage test (indicated by square brackets [ ] around "Trend"). In the NTP studies, BCA and BDCA were not tested at $50 \mathrm{mg} / \mathrm{L}$ and DBA was not tested at $250 \mathrm{mg} / \mathrm{L}$. For the chlorine-only HAAs in males (C), the doses for DCA were 500, 1,000, 2,000, and 3,500 and for TCA they were 50 and $500 \mathrm{mg} / \mathrm{L}$. In females (D), DCA was tested at 260 , 860 , and 2,600 mg/L and TCA was tested at 330,1,100, and 3,300 mg/L (equimolar doses for DCA and TCA).

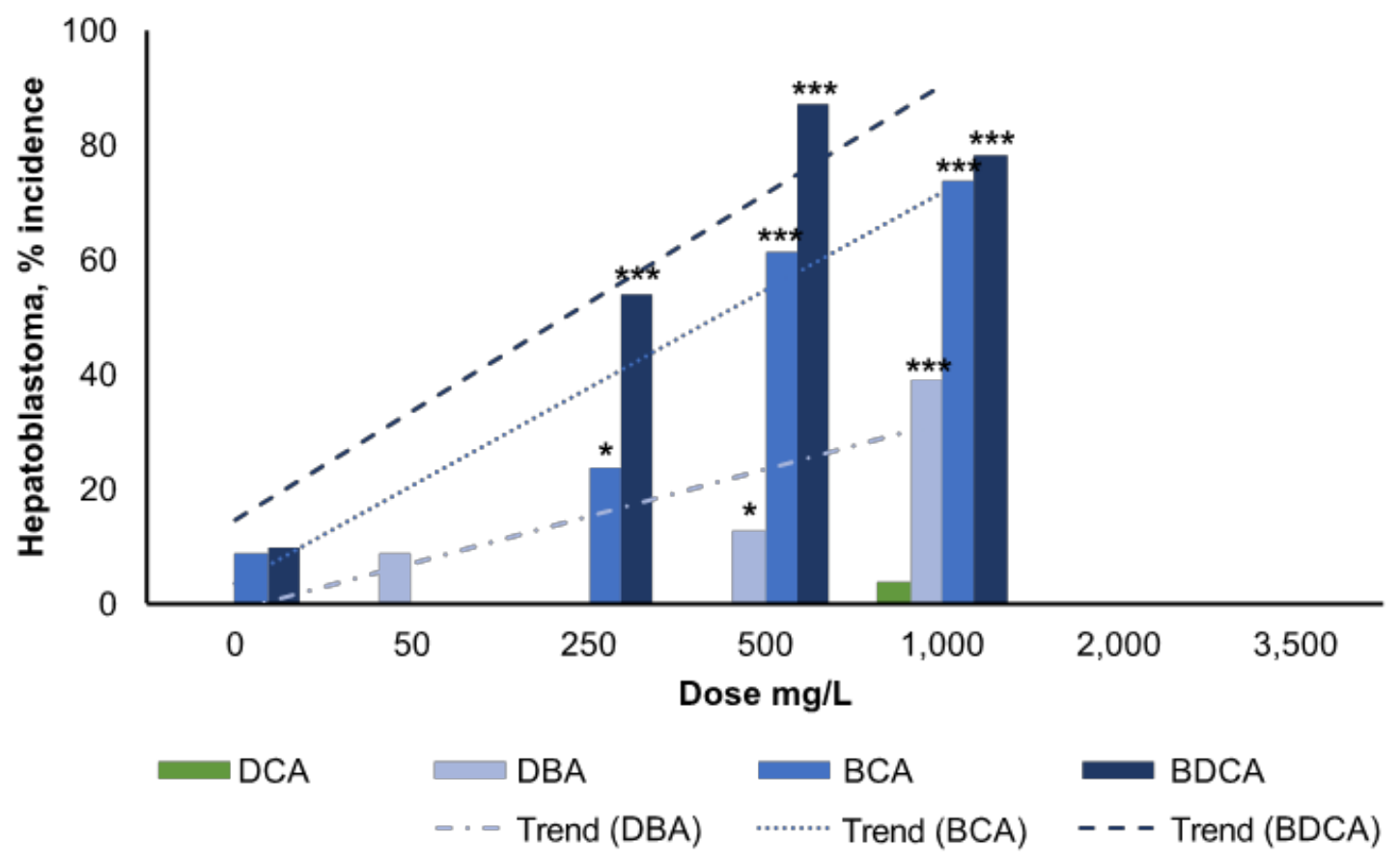

Figure 4-2. Hepatoblastoma in Male Mice Exposed to Di- and Trihaloacetic Acids

Source: NTP (2007a; 2009; 2015) for the bromine-containing HAA and Wood et al. (2015) for DCA (stop exposure study). ${ }^{*} P<0.05 ; * * P<0.01 ; * * * P<0.001$. Compared with corresponding control group.

$\mathrm{BCA}=$ bromochloroacetic acid; $\mathrm{BDCA}=$ bromodichloroacetic acid, trend $P<0.001 ; \mathrm{DBA}=$ dibromoacetic acid, trend $P<0.001 ; \mathrm{DCA}=$ dichloroacetic acid, trend $P<0.001$.

Trend refers to a positive trend and not the shape of the dose-response curve. BCA and BDCA were not tested at $50 \mathrm{mg} / \mathrm{L}$ and DBA was not tested at $250 \mathrm{mg} / \mathrm{L}$. DCA was tested at 1,000, 2,000, and 3,500 mg/L, but no hepatoblastomas were reported for the 2,000 or $3,500 \mathrm{mg} / \mathrm{L}$ doses.

\section{Comparison of Liver Neoplasms Findings Across HAAs}

Figure 4-1 and Figure 4-2 compare the incidences of different types of hepatocellular neoplasms (carcinoma or hepatoblastoma) in male and female mice. (Data from studies with similar designs and/or similar laboratories were chosen for the graphs.) Incidences of combined liver neoplasms were not plotted because of the high background incidence of total liver neoplasms in controls. In general, no clear differences in the strength of the association with liver cancer by type or number of halogens was observed; however, the data are difficult to interpret because of differences in background carcinoma rates (especially between the chlorine-only haloacetic acids and bromine-containing haloacetic acids) and the high incidences of liver neoplasms in treated animals. There is some evidence to suggest that dichloroacetic acid but not the brominecontaining haloacetic acids cause liver neoplasms in rats. In contrast, the bromine-containing haloacetic acids may be linked to hepatoblastoma. Hepatoblastoma is an aggressive malignancy 
originating from embryonic liver cells and is a pediatric liver cancer in humans. Incidences of hepatoblastoma were significantly increased in male mice by the three bromine-containing haloacetic acids tested by NTP and in female mice by bromodichloroacetic acid. The only study to observe hepatoblastoma in mice exposed to a chlorine-only haloacetic acid was the stopexposure study (Wood et al. 2015) which found a single hepatoblastoma at the lowest dose in males and none in females. However, the NTP studies also had the most complete necropsies and pathological evaluations of all of the studies reviewed, which might have contributed to identification of these tumors in mice exposed to bromine-containing haloacetic acids.

\subsubsection{Other Tumors}

The occurrence of tumors at multiple organ sites reinforces the evidence that some halogenated acetic acids have systemic carcinogenic activity in addition to the liver (see Table C-9 and Table C-10 in Appendix C). In addition to liver tumors that developed with chronic exposure to the three brominated haloacetic acids tested by NTP in well-conducted studies, dibromoacetic acid (NTP 2007a), bromochloroacetic acid (NTP 2009), and bromodichloroacetic acid (NTP 2015) increased the incidences of neoplasms at organ sites outside the liver in both rats and mice. No increases in the incidence of neoplasms were observed after exposure to chlorine-only haloacetic acids; however, these tumors were reported only in studies conducted by NTP, which included full necropsies. Since most of the non-NTP studies examined only the liver histologically, the presence of tumors at other sites cannot be definitively ruled out (see Section 4.2, Table 4-2, and Appendix C).

Malignant mesothelioma of the peritoneal cavity lining was the only site to be induced by all three bromine-containing haloacetic acids and thus the findings are discussed across haloacetic acids. The findings for the other neoplasms are organized by the specific haloacetic acid. In the NTP studies, dibromoacetic acid was tested at 0,50 (low), 500 (mid), and 1,000 (high) $\mathrm{mg} / \mathrm{L}$ and bromochloroacetic acid and bromodichloroacetic acid were tested at 0,250 (low), 500 (mid) and 1,000 (high) $\mathrm{mg} / \mathrm{L}$. The study on bromodichloroacetic acid differs from the other two haloacetic acids tested by NTP in that it was conducted in F344/NTac rats whereas the other two haloacetic acids were tested in $\mathrm{F} 344 / \mathrm{N}$ rats. All three of these haloacetic acids were tested in $\mathrm{B}_{6} \mathrm{C} 3 \mathrm{~F}_{1}$ mice. Details on the study designs and findings are provided in Appendix C, Table C-32 to Table C-35, Table C-36 to Table C-39, Table C-52 to Table C-55.

\section{Malignant Mesothelioma}

Dibromoacetic acid (NTP 2007a), bromochloroacetic acid (NTP 2009), or bromodichloroacetic acid (NTP 2015) (Figure 4-3) increased the incidence of malignant mesothelioma in male rats with drinking water exposure. Both dibromoacetic acid and bromodichloroacetic acid caused significant positive dose-response trends. Tumors caused by exposure to bromochloroacetic acid or dibromoacetic acid were found throughout the peritoneum, including the abdominal wall and serosal organ surfaces; tumors caused by exposure to bromodichloroacetic acid were localized to the tunica vaginalis of the testes. The historical control range for these tumors was exceeded for dibromoacetic acid and bromochloroacetic acid (NTP 2009) at all doses and for dibromoacetic acid and bromodichloroacetic acid at the high dose. The strongest response was found for bromodichloroacetic acid, which significantly increased malignant mesothelioma at all doses, reaching $78 \%$ (poly-3 adjusted rate) for male rats exposed to the high dose. 


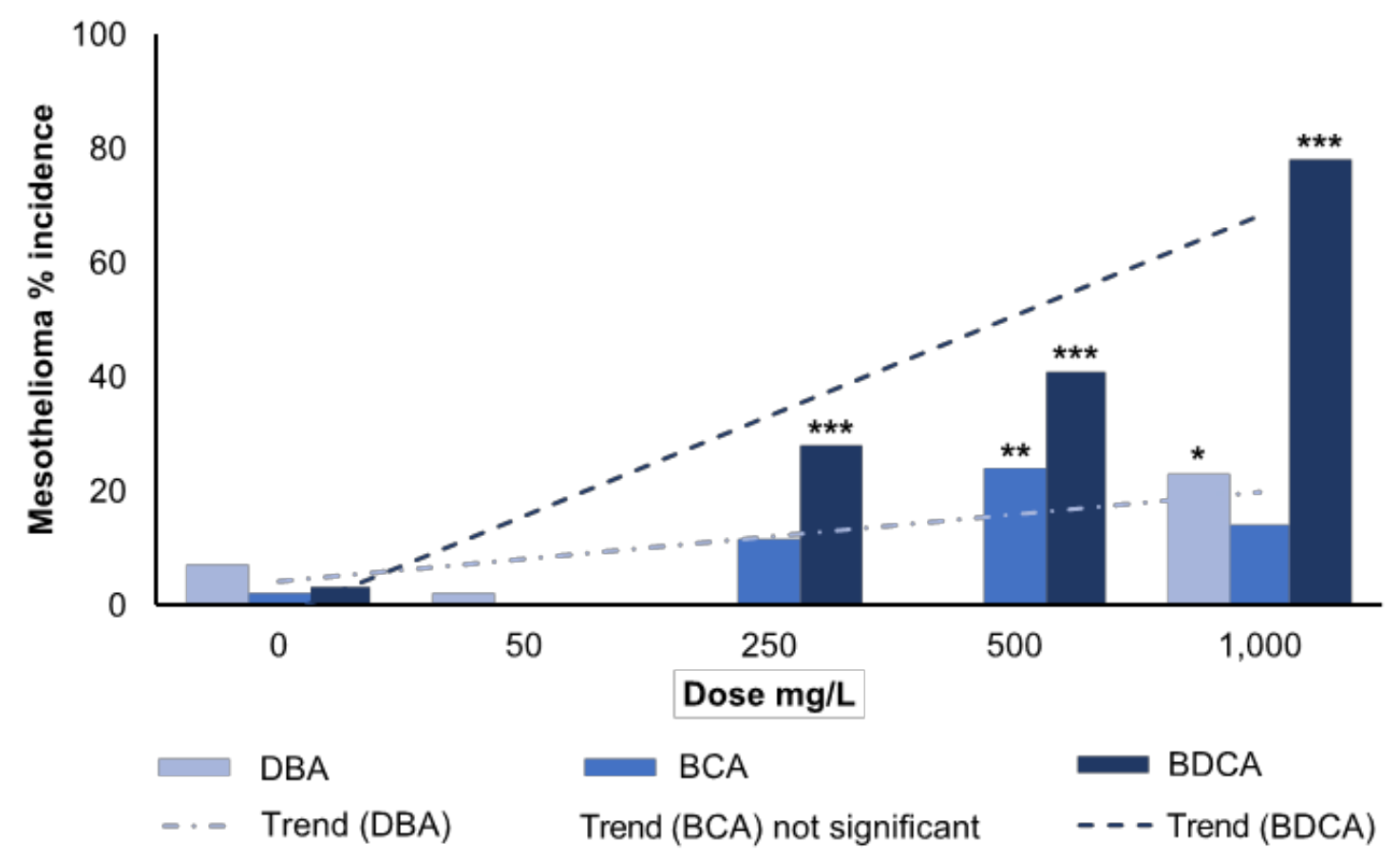

Figure 4-3. Malignant Mesothelioma Incidence in Male Rats Exposed to Bromochloroacetic Acid, Dibromoacetic Acid, or Bromodichloroacetic Acid in Drinking Water

Source: NTP (2007a; 2009; 2015).

${ }^{*} P<0.05 ; * * P<0.01 ; * * * P<0.001$, compared with corresponding control group.

$\mathrm{BDCA}=$ bromodichloroacetic acid, trend $=P<0.001 ; \mathrm{DBA}=$ dibromoacetic acid, trend $=P<0.001$.

Note: DBA was tested at 0, 50, $5001,000 \mathrm{mg} / \mathrm{L}$.

Trend refers to a positive trend and not the shape of the dose-response curve. $\mathrm{BCA}=$ bromochloroacetic acid, trend not significant.

\section{Dibromoacetic Acid}

Mononuclear-cell leukemia incidence was significantly increased by exposure to dibromoacetic acid (NTP 2007a) at the high dose in female rats with a positive dose-response trend. Historical control rates can help interpret these findings because the background rates of mononuclear-cell leukemia in F344/N rats are high and variable. The poly-3 adjusted rates for the mid (35\%) and high dose (47\%) exceeded the historical control ranges in drinking water studies (20\% to $30 \%)$ and thus increase the confidence that this is an exposure-related response. A significant increase in the incidence of mononuclear-cell leukemia was observed in male rats at the low but not the mid and high dose and no dose-response was observed; the incidence of tumors for the high dose was somewhat lower than the incidence in controls which exceeded the historical control range. The poly-3 adjusted rates for the controls (37\%), low (66\%), and mid (56\%) but not the high dose exceeded the historical control range of $26 \%$ to $34 \%$ for drinking water studies. Overall, the incidence of mononuclear-cell leukemia in male rats may be related to exposure to dibromoacetic acid but the findings are inconclusive. 
Lung adenoma and adenoma or carcinoma (combined) were also significantly increased by exposure to dibromoacetic acid (NTP 2007a) at the mid dose in male mice, and a significant dose response was observed for adenoma. The poly-3 adjusted incidence for lung adenoma or carcinoma at the mid (49\%) and high dose (37\%) and for adenoma at the mid (38\%) and high dose $(27 \%)$ exceeded the historical control range (12\% to $26 \%)$ for drinking water studies. For female mice, tumor incidence for lung adenoma or carcinoma at the high dose (15\%) exceeded the historical control range of $2 \%$ to $12 \%$. A significant dose response for adenoma was observed but none of the pairwise dose comparisons were statistically significant. Overall, the data provided indicate that the lung is a target organ site for dibromoacetic acid with the strongest evidence from male mice.

\section{Bromochloroacetic Acid}

In addition to causing malignant mesothelioma in male rats, bromochloroacetic acid also increased the neoplasms of the mammary gland in female rats and large intestine in female and male rats.

Bromochloroacetic acid (NTP 2009) administered in the drinking water significantly increased the incidence of multiple mammary gland fibroadenomas in the mid- and high-dose groups in female rat. This haloacetic acid also caused dose-related increases in the incidence of large intestinal adenoma in both male and female rats. Significant increases in incidence $(15.5 \%)$ were observed at the highest dose in female rats compared to controls. These are rare tumors with a historical control incidence in drinking water studies of $0 \%$ and can progress to malignant tumors of the large intestine.

A statistically significant increase in pancreatic islet adenoma in male rats exposed to bromochloroacetic acid was observed in the mid dose groups compared to controls, which exceeded the historical control rates for both drinking water studies ( $6 \%$ to $10 \%)$ and studies by all routes $(0 \%$ to $12 \%)$ for the poly-3 adjusted incidence for the $500 \mathrm{mg} / \mathrm{L}$ dose $(9 / 50,22 \%)$ (NTP 2009). However, the incidence was similar in the high-dose group (7\%) to the concurrent controls $(7 \%)$ and there were no significant increases in other types of pancreatic islet lesions (e.g., hyperplasia, carcinoma).

\section{Bromodichloroacetic Acid}

Compared to controls, exposure to bromodichloroacetic acid (NTP 2015) significantly increased the incidence of mammary gland fibroadenoma (in all exposed groups), carcinoma (high dose), adenoma or carcinoma combined (mid and high dose), and all types of neoplasms combined (in all exposed groups) in female rats. Significant dose-response trends were observed for mammary gland carcinoma, fibroadenoma, and adenoma, carcinoma, or fibroadenoma combined.

Bromodichloroacetic acid treatment resulted in an increase of $8 \%(4 / 50)$ over control values $(0 / 50)$ of large intestinal (cecum, colon, and rectum combined) adenoma in male rats with 2/50 each in the mid- and high-dose groups. No historical control data were available for the F344/NTac strain; however, large intestine tumors are very rare tumors in F344/N rats with a very low incidence of $0 / 699$ for 2013 historical control incidence and $0 \%$ to $2 \%$ for the 2009 historical control range) (NTP 2015). Overall, the evidence was considered equivocal because of the small numbers of neoplasms in the exposed animals. 
Skin tumors, keratoacanthoma, subcutaneous fibromas, and combined incidences of epithelial tumors (i.e., squamous-cell papilloma, keratoacanthoma, sebaceous gland adenoma, basal celladenoma, basal-cell carcinoma, or squamous-cell carcinoma [combined]) were significantly increased in male rats exposed to the highest dose of bromodichloroacetic acid (NTP 2015). Positive trends were observed for fibroma, keratoacanthoma, and basal-cell adenoma.

Harderian gland adenoma and adenoma or carcinoma (combined) incidences were significantly increased in the high- and mid-exposure groups in male mice exposed to bromodichloroacetic acid (NTP 2015). Significant positive dose-response trends were observed for adenoma and carcinoma as well as adenoma or carcinoma (combined). The poly-3-adjusted incidences of the combined neoplasms at all dose levels (low dose $=26 \%$, mid dose $=38 \%$, high dose $=51 \%$ ) exceeded the historical control range of $12 \%$ to $14 \%$ for drinking water controls and $6 \%$ to $24 \%$ for all routes.

Increases in the incidence of brain and oral cavity neoplasms were observed after administration of bromodichloroacetic acid in the drinking water. For each tumor type, the increase in the incidence of the neoplasm was small and non-significant but exceeded the historical control range. However, the low number of Fischer 344/NTac historical controls limited further interpretation of these findings. Overall, the evidence is unclear whether these effects are related to treatment.

\section{Synthesis across HAAs}

Overall, bromodichloroacetic acid appears to have the strongest association with neoplasms in experimental animals because it induced the largest number of different types of neoplasms (liver, malignant mesothelioma, mammary gland, skin, and Harderian gland, large intestine, and possibly neoplasms of the brain and oral cavity). In addition, it appears to have the strongest association with mesothelioma, which was the only neoplasm induced by all three brominecontaining haloacetic acids. Bromochloroacetic acid induced similar types of neoplasms as bromodichloroacetic acid - mesothelioma and mammary gland tumors - whereas the bromineonly haloacetic acid caused different types of tumors - mesothelioma, lung, and mononuclearcell leukemia.

\subsubsection{Transgenic Studies}

Two strains of male and female transgenic animals (Tg.AC hemizygous and p53 haploinsufficient mice) were exposed to dichloroacetic acid in drinking water and Tg.AC hemizygous transgenic mice were used to test dichloroacetic acid by dermal exposure. The purpose of these studies was to determine whether these animal models could serve as an adjunct to the 2-year rodent cancer assays for water disinfection by-products, given that dichloroacetic acid is positive in rodent cancer studies. The limitations of these transgenic models were discussed in Section 4.1. The expected neoplasms with exposure to carcinogens that affect the p53 gene are lymphoma or sarcoma in p53 haploinsufficient mice and squamous-cell papilloma or carcinoma of the skin or forestomach in Tg.AC hemizygous mice (Eastmond et al. 2013; Tennant et al. 2001).

One publication reported testing dichloroacetic acid administered in the drinking water in males and females of both strains of transgenic animals with two different study durations (NTP 2007b). After 41 weeks of exposure, dichloroacetic acid induced significant incidences of female 
Tg.AC hemizygous mice with multiple squamous-cell papilloma of the forestomach and lung alveolar/bronchiolar adenoma in males. No neoplasms or preneoplasms were significantly increased in p53 haploinsufficient mice.

Two dermal exposure studies of dichloroacetic acid were conducted in male and female Tg.AC hemizygous mice (NTP 2007b). Dermal exposure to dichloroacetic acid induced increased incidences of squamous-cell papilloma and epidermal hyperplasia of the skin at the site of application in both sexes. Although these increases were significant, this model is susceptible to false-positive findings of squamous-cell papilloma of the skin. It is not possible to distinguish dichloroacetic acid carcinogenic effects in this model system from a non-carcinogenic effect that leads to skin irritation and false-positive results.

Though these model systems are not ideal and cannot be used directly to interpret the carcinogenic potential in experimental animals, the presence of neoplasms at the site of application offers evidence not only of increased incidences but also of a specific location where the exposure occurred and further supports the relationship of the results to treatment with dichloroacetic acid.

\subsubsection{Initiation-promotion Studies}

Five initiation-promotion studies were identified that tested dichloroacetic acid, trichloroacetic acid, and monoiodoacetic acid. Dichloroacetic acid or trichloroacetic acid were administered in drinking water as a promoter in two sets of studies. In one set of studies, female mice were initiated by an intraperitoneal injection of $N$-methyl- $N$-nitrosourea (MNU) (Pereira et al. 1997). Dichloroacetic acid and trichloroacetic acid both significantly increased the multiplicity of hepatocellular adenomas and dichloroacetic acid significantly increased the multiplicity of foci of altered hepatocytes. In the second set of studies, male mice were injected intraperitoneally with ethylnitrosourea (ENU) (Herren-Freund et al. 1987). Dichloroacetic acid and trichloroacetic acid both significantly increased the incidence of hepatocellular adenoma and carcinoma at 2,000 and 5,000 $\mathrm{mg} / \mathrm{L}$ above that caused by ENU alone. Further, 5,000 mg/L of either haloacetic acid alone, without ENU, significantly increased hepatocellular adenoma and carcinoma.

Monoiodoacetic acid was administered by dermal application as a promoter to mice (sex not reported) that were initiated by dermal application of 7,12 dimethylbenz $[a]$ anthracene (DMBA) (Gwynn and Salaman 1953). Monoiodoacetic acid significantly increased skin papillomas (exact histological classification not reported) in the high-dose group when compared to either acetone or acetic acid controls.

Only the Herren-Freund et al. (1987) initiation-promotion study included groups without the initiator being administered. The remaining initiation-promotion studies only examined the added effect of haloacetic acids to an already established carcinogenic process and so are not directly interpretable as to animal carcinogenicity (Gwynn and Salaman 1953; Pereira et al. 1997).

\subsection{Synthesis}

The evidence for the carcinogenic potential of haloacetic acids in experimental animals is strong as numerous studies have shown significant increases in the incidences of neoplasia from exposure to several haloacetic acids. All haloacetic acids, except for the monochloroacetic acid, 
induced significantly increased incidences of liver neoplasms in mice or rats, which is consistent with a possible common carcinogenic mode of action (see Table 4-4).

Dichloroacetic acid and trichloroacetic acid induced hepatocellular adenoma and carcinoma in both sexes of $\mathrm{B}_{6} \mathrm{C}_{3} \mathrm{~F}_{1}$ mice, and in male Fischer 344 rats exposed to dichloroacetic acid.

Dibromoacetic acid induced hepatocellular adenoma and carcinoma in male and female mice, hepatoblastoma and lung tumors in male mice. In female rats, it induced mononuclear-cell leukemia and in male rats, malignant mesothelioma.

Bromochloroacetic acid caused tumors at several tissue sites in both rats and mice. It induced treatment-related malignant mesothelioma and adenoma of the large intestine in male rats, multiple fibroadenomas of the mammary gland in female rats, hepatoblastoma in male mice and hepatocellular adenoma and carcinoma in male and female mice.

Bromodichloroacetic acid had the most treatment-related cancer sites in both rats and mice. Male mice had treatment-related incidences of adenoma, adenoma or carcinoma (combined) of the Harderian gland, hepatoblastoma, and hepatocellular carcinoma. Female mice had increased incidences of hepatoblastoma, and hepatocellular adenoma and carcinoma. Male Fischer 344/NTac rats had increased incidences of malignant mesothelioma, epithelial tumors of the skin (combined) and subcutaneous fibroma, which typically does not progress to a malignancy.

Female rats had treatment-related increases in incidences of fibroadenoma (includes multiple) and carcinoma of the mammary gland.

The mechanisms by which haloacetic acids might induce cancer are discussed in Section 6 and overall conclusions for the carcinogenicity of haloacetic acids are reported in Section 8. 
Table 4-4. Results from Cancer Studies in Experimental Animals ${ }^{\mathrm{a}}$

\begin{tabular}{|c|c|c|c|}
\hline Chemical (Route) & Neoplasms in Mice (Sex) & Neoplasms in Rats (Sex) & Reference \\
\hline \multicolumn{4}{|l|}{ Monochloroacetic acid } \\
\hline Gavage & None & Not tested & NTP $(1992)^{b}$ \\
\hline \multicolumn{4}{|l|}{ Dichloroacetic acid } \\
\hline Drinking water & $\mathrm{NF}$ & $\begin{array}{l}\text { Liver - hepatocellular carcinoma }(\mathrm{M}) \\
\text { Liver - hepatocellular adenoma or } \\
\text { carcinoma }(\mathrm{M})\end{array}$ & DeAngelo et al. (1996) \\
\hline Drinking water & $\begin{array}{l}\text { Liver - hepatocellular adenoma and } \\
\text { carcinoma }(\mathrm{M} / \mathrm{F})\end{array}$ & NF & $\begin{array}{l}\text { DeAngelo et al. (1991; 1999), } \\
\text { Herren-Freund et al. (1987), } \\
\text { Daniel et al. (1992), } \\
\text { Wood et al. (2015), } \\
\text { Pereira (1996) }\end{array}$ \\
\hline \multicolumn{4}{|l|}{ Dibromoacetic acid } \\
\hline Drinking water & $\begin{array}{l}\text { Liver - hepatocellular adenoma and } \\
\text { carcinoma }(\mathrm{M} / \mathrm{F}) \\
\text { Liver - hepatoblastoma }(\mathrm{M}) \\
\text { Lung - alveolar/bronchiolar adenoma } \\
(\mathrm{M}) \\
\text { Lung - alveolar/bronchiolar adenoma } \\
\text { or carcinoma }(\mathrm{M})\end{array}$ & $\begin{array}{l}\text { Malignant mesothelioma (M) } \\
\text { Mononuclear-cell leukemia (F) }\end{array}$ & $\operatorname{NTP}(2007 a)^{b}$ \\
\hline \multicolumn{4}{|l|}{ Bromochloroacetic acid } \\
\hline Drinking water & $\begin{array}{l}\text { Liver - hepatocellular adenoma and } \\
\text { carcinoma }(\mathrm{M} / \mathrm{F}) \\
\text { Liver - hepatoblastoma }(\mathrm{M})\end{array}$ & $\begin{array}{l}\text { Malignant mesothelioma (M) } \\
\text { Mammary gland - fibroadenoma } \\
\text { (multiple only) (F) } \\
\text { Large intestine - adenoma (rare) } \\
(\mathrm{M} / \mathrm{F})\end{array}$ & NTP $(2009)^{b}$ \\
\hline
\end{tabular}


RoC Monograph on Haloacetic Acids

\begin{tabular}{|c|c|c|c|}
\hline Chemical (Route) & Neoplasms in Mice (Sex) & Neoplasms in Rats (Sex) & Reference \\
\hline \multicolumn{4}{|l|}{ Trichloroacetic acid } \\
\hline Drinking water & $\begin{array}{l}\text { Liver - hepatocellular adenoma and } \\
\text { carcinoma }(\mathrm{M} / \mathrm{F})\end{array}$ & NF & $\begin{array}{l}\text { DeAngelo et al. }(2008)^{\mathrm{b}} \\
\text { Herren-Freund et al. (1987) } \\
\text { Pereira (1996) }\end{array}$ \\
\hline \multicolumn{4}{|l|}{ Bromodichloroacetic acid } \\
\hline Drinking water & $\begin{array}{l}\text { Liver - hepatocellular adenoma }(\mathrm{F}) \\
\text { Liver - hepatocellular carcinoma } \\
(\mathrm{M} / \mathrm{F}) \\
\text { Liver - hepatoblastoma }(\mathrm{M} / \mathrm{F}) \\
\text { Harderian gland - adenoma }(\mathrm{M}) \\
\text { Harderian gland - adenoma or } \\
\text { carcinoma (combined) }(\mathrm{M})\end{array}$ & $\begin{array}{l}\text { Malignant mesothelioma (M) } \\
\text { Mammary gland - fibroadenoma and } \\
\text { carcinoma (F) } \\
\text { Skin - fibroma (M) } \\
\text { Skin - keratoacanthoma (M) } \\
\text { Skin - squamous-cell papilloma, } \\
\text { keratoacanthoma, sebaceous gland } \\
\text { adenoma, basal-cell adenoma, basal- } \\
\text { cell carcinoma, or squamous-cell } \\
\text { carcinoma (combined) (M) }\end{array}$ & NTP $(2015)^{b}$ \\
\hline
\end{tabular}

$\mathrm{F}=$ female; $\mathrm{M}=$ male $; \mathrm{NF}=$ none found.

a The percent tumor incidences for all neoplasms listed were significantly increased over control values except for adenoma of the large intestine in rats (M/F) which was considered treatment-related due to the rarity of these tumors and progression to malignancy.

${ }^{b}$ Full necropsy was performed. 


\section{Human Cancer Studies}

Water disinfection by-products include a complex mixture of chemicals created from reactions between water disinfection agents (such as chlorine) and organic matter in the water. These include a wide variety of compounds that lack reliable exposure measurement methods. Often, trihalomethanes as a class or a specific trihalomethane are used as a proxy measure for the complex mixture of chemicals in disinfected water (see Section 2.7.2 and Figure 2-5). To date, only one human epidemiological study has been identified that evaluated haloacetic acid exposures (i.e., any of the 13 individual chemicals or as a class or subclass) in humans and cancer risk. However, in addition to this cohort study, existing data in the primary literature of exposures to water disinfection mixtures or specific classes of water disinfection by-products (such as trihalomethanes) may serve as surrogates for chlorinated water. Findings from the cohort study are discussed below, along with a brief discussion of human cancer findings and any potential association with disinfection by-products. The discussion summarizes the review in the general remarks section of the International Agency for Research on Cancer (IARC) monograph on Some Chemicals Present in Industrial and Consumer Products, Food and Drinking-Water (IARC 2013c) and updates the literature since that monograph.

\subsection{Cohort Study}

Jones et al. (2017) investigated the risk of kidney cancers from ingested nitrate and other disinfection by-products in the Iowa Women's Health Study (IWHS), a cohort of 41,836 postmenopausal women followed for up to 24 years, from 1986 to 2010. This study categorized women's drinking water exposure by source: public water, private well, and other sources. Exposure then to water disinfection products was split into time at that source $(\leq 10$ years or $>10$ years), and the cancer analysis was done on women exposed to public water sources for greater than 10 years $(\mathrm{N}=15,577)$. Exposure to haloacetic acids, including a mixture of five regulated haloacetic acids (monochloroacetic acid, monobromoacetic acid, dichloroacetic acid, dibromoacetic acid, trichloroacetic acid) and individual haloacetic acids (dichloroacetic acid, trichloroacetic acid, and bromochloroacetic acid, which is unregulated) and trihalomethanes (total as well as individual) were estimated via an expert assessment that used available measures (data from plants, water source, quality, treatment, and disinfection type). A total of 266 incident kidney cancers were observed among all women in the study, with 125 occurring among women with greater than 10 years exposure to a public water source. No associations were seen between kidney cancer risk and either individual or combined haloacetic acid or trihalomethane measures. The data for this study are presented in Table 5-1.

\subsection{Other Human Cancer Studies of Disinfection By-products}

The IARC working groups reviewed several epidemiological studies (both cohort and casecontrol studies) of chlorinated water or specific disinfection by-products (i.e., trihalomethanes as a class or chloroform) primarily on urinary bladder cancer and some other types of cancer but did not make a formal evaluation of potential cancer hazards from chlorinated water because the monographs were on individual disinfection by-products. In general, IARC (2013c) reported positive associations in all nine case-control studies of DBP or chlorinated water, or both, and urinary bladder cancer, including a dose-response relationship in some studies. Among these studies, five found an association between the highest exposure levels of chlorinated water and 
bladder cancer (three among all participants, one among men only and one for women only). Six studies found an association between trihalomethanes and bladder cancer, with five finding a dose-response relationship (three of these for men only). One study (Cantor et al. 2010) found the association varied by genetic polymorphisms in GST and CYP genes. Results from three cohort studies were inconsistent, with only one study reporting a statistically significant risk to women for exposure to chloroform; however, no dose response was seen.

Increased risk for other types of cancer was seen in a limited number of studies, with two cohort studies reporting increased risks for lung, melanoma, breast, and esophageal cancers. Increased risks for kidney, brain, melanoma, and non-melanoma skin cancers were reported in four individual case-control studies. However, IARC (2004a; 2004b; 2013a; 2013b) has not made a formal evaluation of specific disinfection by-products, as the studies were not specific for the individual disinfection by-products under review. This complexity of exposure to a mixture and the correlation between different types of disinfection by-products make human epidemiological studies of individual chemicals difficult to conduct and interpret.

Since the IARC reviews, one case-control study in Spain was identified that found an elevated odds ratio $(\mathrm{OR}=1.43,95 \% \mathrm{CI}=0.83$ to 2.46$)$ for colorectal cancer and the highest level of brominated trihalomethanes (compared to lowest level), but did not find an association with total trihalomethanes (Villanueva et al. 2017). Another analysis within the Iowa Women's Health Study also found a non-significant increase in bladder cancer for those with the highest level of nitrate-nitrogen and trihalomethane exposure (Jones et al. 2016). Based on the evidence to date, there appears to be some association with disinfection by-products and cancer, particularly with urinary bladder cancer, but the extent of the involvement of the haloacetic acids individually or as a class is unclear.

\subsection{Preliminary Level of Evidence Conclusion}

Overall, the data from cancer studies in humans are inadequate to evaluate the relationship between human cancer and exposure specifically to the individual haloacetic acids, subclasses of haloacetic acid, or haloacetic acids as a class. 
Table 5-1. Haloacetic Acid Exposure and Kidney Cancer

\begin{tabular}{|c|c|c|c|c|c|c|}
\hline $\begin{array}{l}\text { Reference, Study } \\
\text { Design, Location, } \\
\text { and Year }\end{array}$ & $\begin{array}{c}\text { Population } \\
\text { Description \& } \\
\text { Exposure Assessment } \\
\text { Method }\end{array}$ & $\begin{array}{c}\text { Exposure Category } \\
\text { or Level }\end{array}$ & $\begin{array}{c}\text { Exposed } \\
\text { Cases/Deaths }\end{array}$ & $\begin{array}{l}\text { Hazard Ratio } \\
(95 \% \text { CI })\end{array}$ & Co-variates Controlled & $\begin{array}{c}\text { Comments, Strengths, and } \\
\text { Weaknesses }\end{array}$ \\
\hline $\begin{array}{l}\text { Jones et al. (2017) } \\
\text { Cohort Study - The } \\
\text { Iowa Women's Health } \\
\text { Study } \\
\text { USA } \\
19862010\end{array}$ & $\begin{array}{l}\text { Women age } 55-69 \text { at } \\
\text { baseline exposed to public } \\
\text { water source for greater } \\
\text { than } 10 \text { years. } \\
\text { Total population } \\
\mathrm{N}=41,836 \\
\text { Women exposed to public } \\
\text { water source }>10 \text { years: } \\
\mathrm{N}=15,577\end{array}$ & 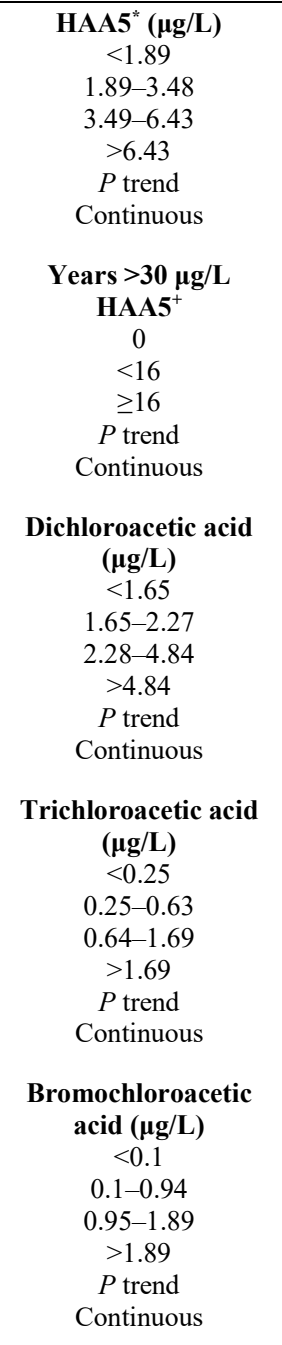 & $\begin{array}{r}38 \\
27 \\
35 \\
25 \\
125\end{array}$ & $\begin{array}{c}\text { Ref. 1.0 } \\
0.84(0.51-1.4) \\
0.78(0.49-1.2) \\
0.65(0.39-1.1) \\
0.18 \\
0.99(0.98-1.0) \\
\\
\\
\\
\text { Ref } 1.0 \\
0.76(0.37-1.6) \\
0.74(0.36-1.5) \\
0.32 \\
0.99(0.95-1.0) \\
\end{array}$ & $\begin{array}{l}\text { Age, smoking status, pack- } \\
\text { years of smoking, body mass } \\
\text { index, ln-transformed } \mathrm{NO}_{3}-\mathrm{N}\end{array}$ & $\begin{array}{l}\text { Exposure duration: Participants } \\
\text { included in this analysis were exposed } \\
\text { for at least } 10 \text { years at the same } \\
\text { location. } \\
\text { Confounding: While difficult to } \\
\text { separate the effects of the individual } \\
\text { disinfection by-products, this study } \\
\text { attempts to control for some of these } \\
\text { factors in the analysis, along with other } \\
\text { related factors. } \\
\text { Strengths: Long exposure duration for } \\
\text { participants and low loss to follow-up. } \\
\text { The study attempted to estimate } \\
\text { exposure levels in a systematic way for } \\
\text { participants. } \\
\text { Weaknesses: Lack of regular } \\
\text { measurement at all water facilities, and } \\
\text { lack of individual measurement for } \\
\text { exposure, and inability to fully separate } \\
\text { the effects of the individual disinfection } \\
\text { by-products. Study enrollment } \\
\text { restricted to premenopausal women. }\end{array}$ \\
\hline
\end{tabular}

${ }^{*}$ HAA5: regulated haloacetic acids (monochloroacetic, dichloroacetic, trichloroacetic, monobromoacetic, and dibromoacetic acids).

${ }^{+}$Number of years the annual average level was $>1 / 2$ the MCL (maximum containment level) value. 


\section{Mechanistic and Other Relevant Data}

Of the 13 haloacetic acids found in drinking water, six were tested for carcinogenicity in a longterm assay in experimental animals (see Section 4). Liver tumors were the most common; however, the brominated haloacetic acids induced tumors at several other sites. As stated in the Methods section, an objective of this monograph is to evaluate whether there are other relevant data that would allow the haloacetic acids to be evaluated as a class. The purpose of this section is to address the following key questions: (1) what are the biologically plausible modes of action through which these compounds may cause cancer in humans; (2) what are molecular initiating events and/or early and late key events associated with the potential modes of action; (3) and do the haloacetic acids, or subclasses, share a common mode(s) of carcinogenic action?

To facilitate the identification of potential mechanisms of cancer, the discussion of the body of literature was generally organized according to the 10 characteristics of carcinogens as defined by Smith et al. (2016) with a few modifications. The outline of this section provides a discussion of the data starting with early events and/or overall experimental support and is as follows: electrophilicity (Section 6.1); alteration of cellular metabolism (Section 6.2, somewhat related to altered nutrient supply, which is part of one of the characteristics of carcinogens); induction of oxidative stress (Section 6.3); genotoxicity and alteration of DNA repair (Section 6.4); induction of epigenetic alterations (Section 6.5); modulation of receptor-mediated effects (Section 6.6); inhibition of GST- $\zeta$ (Section 6.7, specific proposed mode of action related to electrophilicity), cell immortalization (Section 6.8); alteration of cell proliferation or cell death (Section 6.9); and induction of chronic inflammation or immunosuppression (Section 6.10). Studies that investigated global gene expression changes are relevant to multiple characteristics of carcinogens and are discussed in Section 6.11. Section 6.12 integrates the mechanistic data and provides a brief synthesis of the findings.

\subsection{Electrophilicity}

Haloacetic acids are recognized as electrophilic compounds due to electron withdrawal from the $\alpha$-carbon by the halogen substituents, and SN2 reactivity (Pals et al. 2011; Plewa et al. 2010). The available data from screening studies of HAAs for protein and DNA toxicity using complementary sets of $E$. coli strains (see Table 6-1) indicate that most haloacetic acids have a predominantly soft electrophilic nature and that the likely molecular initiating event is preferential reaction with protein sulfhydryl groups which may result in glutathione depletionrelated toxicity. However, three brominated species showed nonspecific reactivity (i.e., reaction with both proteins and DNA) in E. coli strains, and bromoiodoacetic acid was predicted to preferentially cause toxicity-based DNA damage in this screening assay. Reaction with thiol groups on proteins can cause indirect genotoxicity, or impair DNA repair through generation of reactive oxygen species (ROS) (Stalter et al. 2016a). Other modes of action discussed below, including inhibition of pyruvate dehydrogenase kinase (PDK), glyceraldehyde-3-phosphate dehydrogenase (GAPDH), and GST- $\zeta$, are consistent with the soft electrophilic nature of the haloacetic acids. Plewa et al. (2004b) showed that the rank order of cytotoxicity and genotoxicity of the monohaloacetic acids was correlated with their electrophilic reactivity (i.e., iodo- $>$ bromo- $\gg$ chloroacetic acid). Furthermore, the brominated acetic acids consistently show a greater capacity to induce oxidative stress and a greater mutagenic and genotoxic potency compared to the chlorinated forms (see Sections 6.3 and 6.4). Whether or not this is related to a 
greater capacity of the brominated di- and trihaloacetic acids to react directly with DNA has not been confirmed.

Table 6-1. Electrophilic Properties of Haloacetic Acids

\begin{tabular}{|c|c|c|c|c|c|c|}
\hline Haloacetic Acid & $\begin{array}{c}\text { ELUMo }_{\text {LUM }} \\
(\mathrm{eV})\end{array}$ & $\begin{array}{c}\text { ELUMo }_{\text {LUMod) }} \\
\text { (deprotonated }\end{array}$ & $\mathbf{T R}_{\mathrm{GSH}^{\mathrm{a}}}$ & $\mathrm{TR}_{\mathrm{GSH}}{ }^{\mathrm{a}}$ & TR & Classification $^{b}$ \\
\hline Chloroacetic & 4.54 & 9.43 & 0.72 & 0.69 & 0.92 & - \\
\hline Bromoacetic & 4.47 & 8.68 & 2.30 & 2.05 & 0.84 & GSH \\
\hline Iodoacetic & 2.88 & 7.18 & 2.68 & 1.61 & 0.81 & GSH \\
\hline Dichloroacetic & 3.07 & 8.44 & 1.55 & 1.81 & 0.5 & GSH \\
\hline Dibromoacetic & 2.76 & 7.51 & 1.70 & 1.25 & 1.9 & GSH/DNA \\
\hline Bromochloroacetic & 3.11 & 7.78 & 2.24 & 1.61 & 3.18 & GSH/DNA \\
\hline Chloroiodoacetic & 1.54 & 6.40 & 1.39 & 1.31 & 1.17 & GSH \\
\hline Bromoiodoacetic & 1.60 & 6.46 & 0.59 & 0.64 & 1.47 & DNA \\
\hline Trichloroacetic & 2.79 & 7.13 & 0.98 & 1.04 & 0.99 & - \\
\hline Tribromoacetic & 2.42 & 6.12 & 2.39 & 2.13 & 2.61 & GSH/DNA \\
\hline Bromodichloroacetic & 2.82 & 6.65 & 1.41 & 1.71 & 0.73 & GSH \\
\hline Chlorodibromoacetic & 2.47 & 6.42 & 1.10 & $\mathrm{c}$ & 0.95 & - \\
\hline
\end{tabular}

Source: Stalter et al. (2016a). The E. coli assays are used to measure differential cytotoxicity and indicate susceptibility to cytotoxic insults.

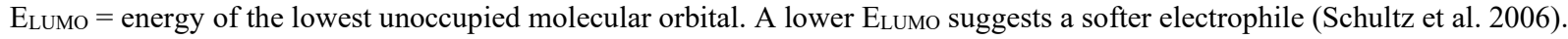

$\mathrm{TR}_{\mathrm{GSH}}=$ Toxic ratio of $\mathrm{EC}_{50}$ of $E$. coli $\mathrm{GSH}+/ \mathrm{GSH}-, \mathrm{TR}>1.2$ indicates reaction with soft nucleophiles.

$\mathrm{TR}_{\mathrm{DNA}}=$ Toxic ratio of $\mathrm{EC}_{50}$ of $E$. coli $\mathrm{DNA}$ repair +/DNA repair - , TR $>1.2$ indicates reaction with hard nucleophiles.

${ }^{a}$ Values presented for two independent experiments.

' Indicates if compounds react preferentially with proteins (GSH), DNA, nonspecifically with both (GSH/DNA), or neither (-).

${ }^{\mathrm{c}}$ Measured only in one experiment with two replicates.

\subsection{Alteration of Cellular Metabolism}

Modes of action that alter cellular energy metabolism include PDK and GAPDH inhibition (Dad et al. 2013; Pals et al. 2011; Pals et al. 2016; Wood et al. 2015). As mentioned above, inhibition of these enzymes is consistent with the soft electrophilic properties of haloacetic acids and results in disruption of cellular energy metabolism and oxidative stress. In the mitochondria, PDKs are a major gatekeeper of pyruvate entry into the tricarboxylic acid cycle while GAPDH is a cytosolic enzyme that catalyzes the sixth step of glycolysis (i.e., conversion of glucose to pyruvate) (Figure 6-1).

In one study, early life exposure to dichloroacetic acid for 10 weeks increased both the incidence and multiplicity of hepatocellular tumors in male and female mice at 98 weeks of age and was almost as carcinogenic as life-long exposures (see Section 4) (Wood et al. 2015). These authors noted that dichloroacetic acid has been characterized as a metabolic reprogramming agent because it is a structural analogue of pyruvate and inhibits PDK. PDK inhibition results in activation of the pyruvate dehydrogenase complex (PDH), thus, diverting pyruvate metabolism from the glycolytic pathway toward oxidative metabolism. Thus, a plausible mechanism of the latent carcinogenic effects of dichloroacetic acid could involve epigenetic effects leading to persistent changes in cell metabolism and PDH activation. Long-term induction of PDH and 
other oxidative pathways related to glucose metabolism are of unknown duration, but can promote mitochondrial stress, cell aging, cell injury, DNA damage, and potentially lead to cancer (Wood et al. 2015). Alterations in mitochondrial DNA are common events in hepatocellular carcinoma, and oxidative stress has been proposed to be involved in the progression of hepatocellular carcinoma, although this relationship has not been fully elucidated for haloacetic acids or other liver carcinogens (Hsu et al. 2013).

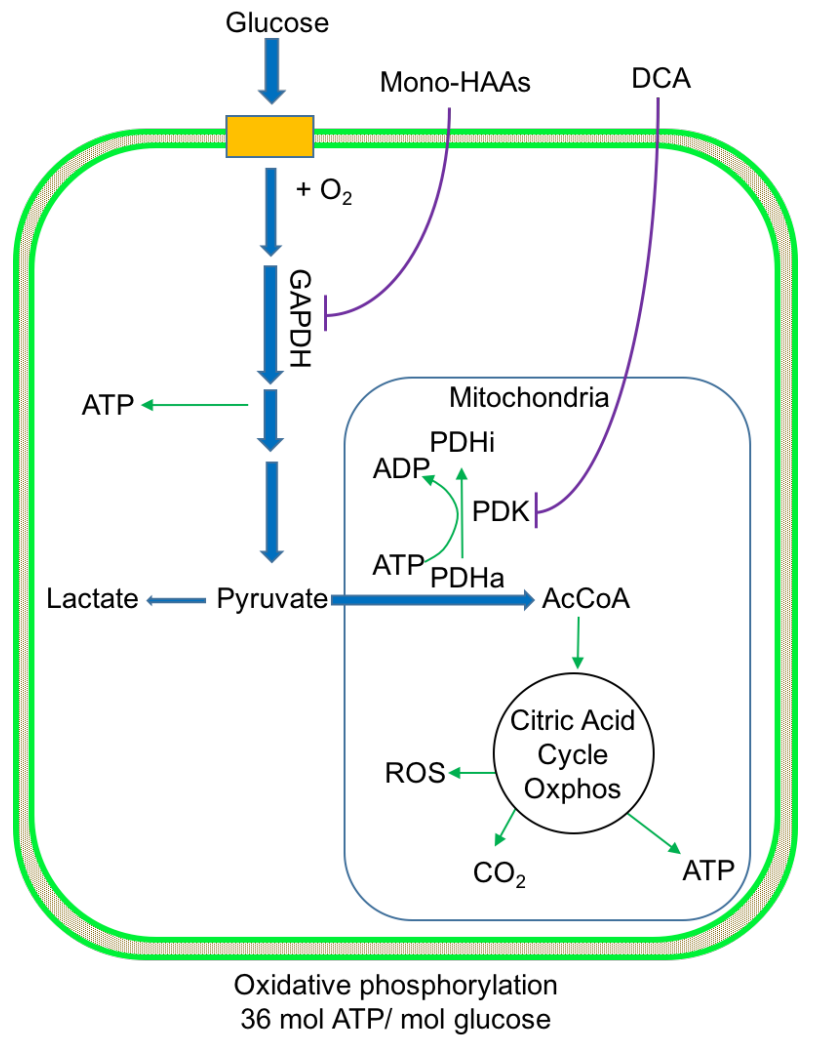

Figure 6-1. Inhibition of GAPDH and PDK by Haloacetic Acids and Effects on Glucose Metabolism

In normal differentiated (quiescent) cells, glucose is converted to pyruvate via glycolysis. Under aerobic conditions, most pyruvate enters the mitochondria where it is converted to acetyl-CoA by the pyruvate dehydrogenase (PDH) complex and is used to produce ATP via oxidative phosphorylation. Dichloroacetic acid (DCA) inhibits pyruvate dehydrogenase kinase (PDK), thus, enhancing oxidative metabolism and generation of reactive oxygen species (ROS). Monohaloacetic acids inhibit GAPDH, thus, blocking formation of pyruvate and inducing mitochondrial stress, decreased ATP, and generation of ROS.

Adapted from Bruchelt et al. (2014); Lu et al. (2015); Vander Heiden et al. (2009).

AcCoa = acetyl coenzyme A; ADP = adenosine monophosphate; $\mathrm{ATP}=$ adenosine triphosphate; $\mathrm{CO}_{2}=$ carbon dioxide;

$\mathrm{DCA}=$ dichloroacetic acid; GAPDH = glyceraldehyde-3-phosphate dehydrogenase; HAAs = haloacetic acids; $\mathrm{O}_{2}=$ oxygen; Oxphos = oxidative phosphorylation; $\mathrm{PDH}=$ pyruvate dehydrogenase; $\mathrm{PDK}=$ pyruvate dehydrogenase kinase; $\mathrm{ROS}=$ reactive oxygen species.

The monohaloacetic acids inhibit GAPDH in a concentration-dependent manner that is highly correlated with compound reactivity following the rank order of iodo- $>$ bromo- $\gg$ chloro- (Dad et al. 2013; Hernández-Fonseca et al. 2008; Pals et al. 2011; Pals et al. 2016). GAPDH inhibition blocks glucose metabolism to pyruvate and causes decreased ATP production, mitochondrial stress, increased intracellular $\mathrm{Ca}^{2+}$, generation of ROS, and genotoxicity. Dad et al. (2013) also showed that exogenous pyruvate supplementation enhanced ATP production in CHO cells and reduced genomic DNA damage. Treatment with calcium chelators also reduced DNA damage 
induced in CHO cells by bromoacetic acid (Pals et al. 2016). However, only chloroacetic acid (the weakest GAPDH inhibitor) has been tested for carcinogenicity in a long-term assay, and it was found to not be carcinogenic (NTP 1992).

In recent years, GAPDH has been implicated in other cell functions that are independent of its role in energy metabolism, including DNA repair, cell cycle progression, and cell death (Colell et al. 2009; Zhang et al. 2015a).

\subsection{Induction of Oxidative Stress}

In vitro studies using human or rodent cells and in vivo studies in rodents also show strong evidence that oxidative stress is a common feature of haloacetic acids-induced toxicity and that treatment with antioxidants reduces the genotoxic and cytotoxic effects of haloacetic acids (Celik et al. 2009; Cemeli et al. 2006; Dad et al. 2013; El Arem et al. 2014a; El Arem et al. 2014b; El Arem et al. 2014c; Ondricek et al. 2012; Pals et al. 2011; Stalter et al. 2016a). Numerous studies confirm that all haloacetic acids that have been tested induce oxidative stress either through activating the oxidative stress-responsive nuclear factor E2 related factor/antioxidant response elements (Nrf2/ARE) pathway, lipid peroxidation, and/or inducing oxidative DNA damage (i.e., 8-OHdG adducts) in mammalian cells (Attene-Ramos et al. 2010; Austin et al. 1995; Austin et al. 1996; Celik 2007; Cemeli et al. 2006; Hassoun and Cearfoss 2014; Hassoun et al. 2014; Hassoun and Mettling 2015; Hassoun and Cearfoss 2011; Hassoun et al. 2010a; Hassoun and Dey 2008; Hassoun and Ray 2003; Hassoun et al. 2010b; Larson and Bull 1992; Pals et al. 2013; Pals et al. 2011; Plewa et al. 2010; Procházka et al. 2015; Stalter et al. 2016a; Wang et al. 2014; Zhang et al. 2011).

EPA's toxicity forecaster (ToxCast) and the National Institutes of Health (NIH) Toxicology in the $21^{\text {st }}$ century (Tox21) databases show that dibromoacetic acid (both ToxCast and Tox21), and tribromoacetic acid and bromochloroacetic acid (Tox21) were positive under the conditions of the assays to screen for an increase in activity of human Nrf2 transcriptional factor (oxidative stress) (https://www.epa.gov/chemical-research/toxicity-forecaster-toxcasttm-data). Bromoacetic acid, chloroacetic acid, bromodichloroacetic acid, dichloroacetic acid, and trichloroacetic acid were negative under conditions of the Tox 21 assay. No other haloacetic acids were tested. The Nrf2-ARE signaling pathway is responsive to both electrophilic attack and oxidative stressors (Kensler et al. 2007).

In vitro studies (12 haloacetic acids) in human breast and liver cancer cell lines and in vivo (5 haloacetic acids) studies in rodents that compared biological markers of oxidative stress induced by three or more haloacetic acids reported the same general trends as follows:

mono- $>$ di- $>$ trihaloacetic acids and iodinated $>$ brominated $\gg$ chlorinated acetic acids

(Figure 6-2 and Figure 6-3) (Austin et al. 1996; Larson and Bull 1992; Pals et al. 2013; Stalter et al. 2016a). Oxidative stress was measured in vitro by activation of the Nrf2/ARE pathway and in vivo by $8-\mathrm{OHdG}$ and lipid peroxidation. Details on these studies, as well as data from a few other studies, are summarized in Appendix D (Table D-1). Thus, lipid peroxidation and oxidative damage to DNA potentially play a role in the carcinogenicity of haloacetic acids, and the significantly greater levels produced by brominated haloacetic acids suggest a greater potential to induce cancer than the chlorinated forms (Austin et al. 1996). Overall, dichloro- and trichloroacetic acid showed the weakest response. 


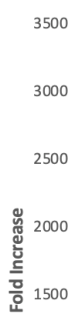$$
1000
$$$$
500
$$

$$
\text { 。 }
$$

A

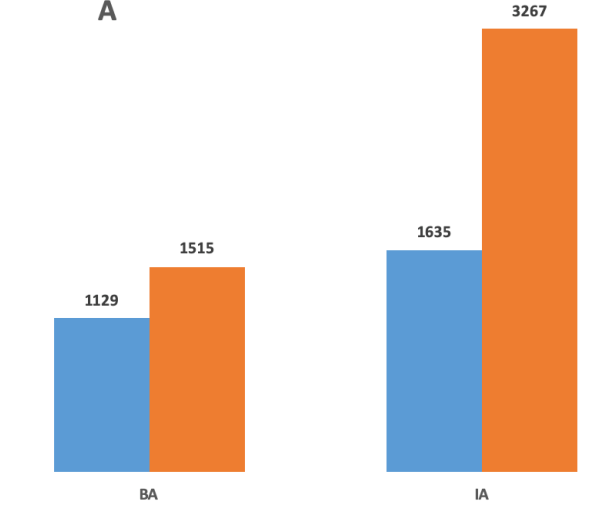

- AREc32 $\because$ ARE-bla
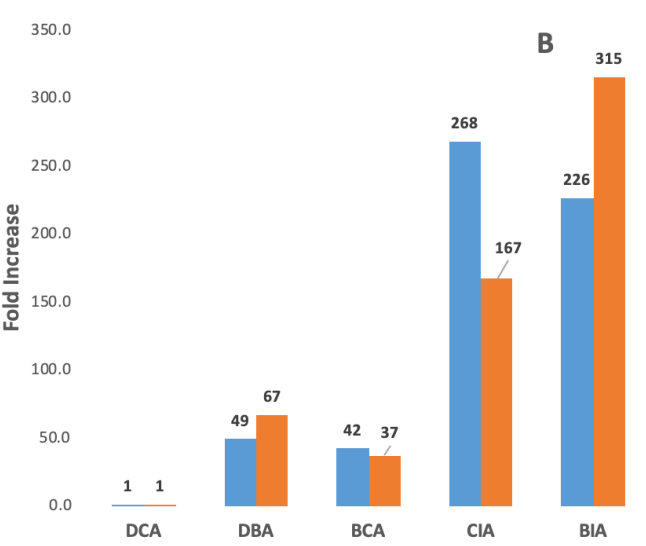

315

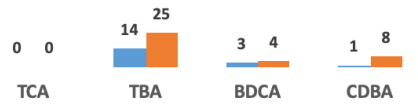

Figure 6-2. Relative Potency of Haloacetic Acids to Induce Oxidative Stress in Human Cancer Cell Lines; (A) Monohaloacetic Acids, (B) Di- and Trihaloacetic Acids

Source: Stalter et al. (2016a).

AREc32 assay = human breast cancer (MCF7 cell line); ARE-bla assay $=$ human hepatocellular carcinoma $($ HepG2) cell line; $\mathrm{CA}=$ monochloro-; $\mathrm{BA}=$ monobromo-;

IA = monoiodo-; DCA = dichloro-; DBA = dibromo-; BCA = bromochloro-; CIA = chloroiodo-; BIA = bromoiodo-; TCA = trichloro-; TBA = tribromo-;

BDCA = bromodichloro-; CDBA = chlorodibromoacetic acid; AREc32 = activation of Nrf2-ARE oxidative stress response pathway in a human breast cancer cell line MCF7;

ARE-bla = activation of oxidative stress response pathway in human hepatocellular carcinoma HepG2 cell line.

Relative potency estimates were derived by dividing all values by the lowest value reported in Table D-1 for the designated endpoint and represent a fold increase over the lowest estimate. 


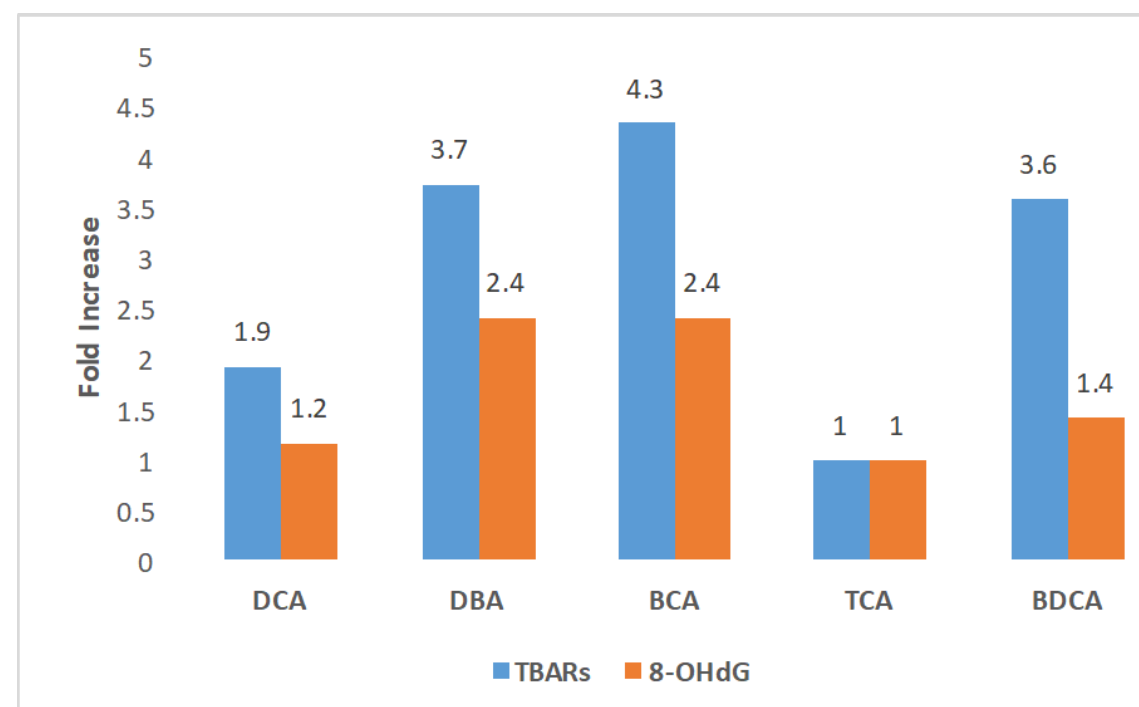

Figure 6-3. Relative Potency of Haloacetic Acids to Induce Oxidative Damage in Mouse Liver In Vivo

Sources: Austin et al. (1996); Larson and Bull (1992).

$\mathrm{DCA}=$ dichloro-; DBA = dibromo-; $\mathrm{BCA}=$ bromochloro-; $\mathrm{TCA}=$ trichloro-; BDCA = bromodichloroacetic acid;

TBARS $=$ thiobarbituric acid-reactive substances; $8-\mathrm{OHdG}=8$-hydroxydeoxyguanosine.

Relative potency estimates were derived by dividing all values by the lowest value reported in Table D-1 for the designated

endpoint and represent a fold increase over the lowest estimate.

\subsection{Genotoxicity and/or Alteration of DNA Repair}

Overall, haloacetic acids have been shown to have some mutagenic activity in bacterial and mammalian cells in vitro and mixed effects regarding DNA and chromosomal damage in vitro in mammalian cells and in vivo in rodents (see Table 6-2). All 13 haloacetic acids have some published genotoxicity data and the mutagenic and genotoxic effects of most of these compounds have been reviewed by U.S. and international agencies (IARC 2013a; 2013b; 2014a; 2014b; NTP 1992; 2007a; 2009; 2015; Richardson et al. 2007; USEPA 2003; 2011a). In addition, the Chemical Effects in Biological Systems (CEBs) database also contains genotoxicity data for 9 haloacetic acids that have been investigated by NTP (https://tools.niehs.nih.gov/cebs3/ui/). The genotoxicity data requested from CEBs is summarized in Appendix D, Table D-2. Dichloro- and trichloroacetic acid are the most extensively studied haloacetic acids, while genotoxicity data for the other compounds are more limited. Section 6.4.1 presents a brief summary of the findings. Studies that compared the mutagenicity/genotoxicity potency of three or more haloacetic acids are considered to be the most informative for evaluating patterns and are reviewed in more detail in Section 6.4.2. Many of these studies were included in the agency reviews.

\subsubsection{Mutagenic and Genotoxic Effects}

The mutagenic and genotoxic effects are summarized in Table 6-2 for 10 haloacetic acids (monochloro-, monobromo-, monoiodo-, dichloro-, dibromo-, bromochloro-, trichloro-, tribromo-, bromodichloro-, and chlorodibromoacetic acid). Chloroiodo-, bromoiodo-, and diiodoacetic acid are not included in this table because the only data available were limited to two studies that evaluated 12 haloacetic acids in the SOS umuC assay or the Comet assay in 
CHO cells. The results from these two studies are briefly mentioned in this section but are described in more detail in Section 6.4.2.

\section{Bacteria}

In general, mutagenicity and gentotoxicity (reverse mutations, SOS response, and prophage induction) results in various strains of Salmonella typhimurium and Escherichia coli were mostly negative for trichloroacetic acid; weakly positive or mixed for chloro-, dichloro-, and tribromoacetic acid; and generally positive for bromo-, iodo-, dibromo-, bromochloro-, bromodichloro-, and chlorodibromoacetic acid; metabolic activation was generally not required and did not usually enhance mutagenicity (Table 6-2). Positive results were more frequent when tested with tester strains designed to detect base-pair mutations (e.g., TA100) compared to tester strains detecting frameshift mutations (e.g., TA98). Cemeli et al. (2006) reported that the mutagenicity of iodoacetic acid (identified as the most potent mutagen among the haloacetic acids) was significantly reduced by treatment with antioxidants and supported the hypothesis that haloacetic acids induce genetic damage via an oxidative stress mechanism.

No studies were available for diiodoacetic acid. The only data for chloroiodo- and bromoiodoacetic acid are from a screening study for genetic damage in Salmonella using the SOS umuC assay and both were positive (Stalter et al. 2016a). This study is described in more detail in Section 6.4.2.

\section{Genetic Effects in Mammalian Cells In Vitro}

In vitro genotoxicity studies were available for all 13 haloacetic acids. The most commonly investigated effects included DNA damage/strand breaks, gene mutations, micronuclei, and chromosomal aberrations while results for sister chromatid exchange, aneuploidy, and unscheduled DNA synthesis were only available for one haloacetic acid. Test systems included CHO cells, mouse lymphoma cells, mouse and rat hepatocytes, human lymphoblastoid cells, and a mouse fibroblast cell line (NIH3T3).

The strongest evidence for genotoxicity is that chloro-, bromo-, iodo-, dibromo-, bromochloro-, tribromo-, and chlorodibromoacetic acids induced DNA strand breaks, with weaker evidence for micronucleus formation (e.g., inconsistent findings across studies depending on the cell type) (Table 6-2). Data also suggest that some of the haloacetic acids may cause chromosomal aberrations and gene mutations albeit fewer chemicals were tested in these assays. Findings for trichloroacetic acid are less clear; however, this chemical is considered not to be genotoxic based on negative in vitro tests and inconsistent results in vivo (IARC 2014b). Although two studies published after the IARC review reported that trichloroacetic acid induced micronuclei and chromosomal aberrations in human peripheral blood lymphocytes, there was no clear doseresponse relationship, cytotoxicity issues, and deficiencies in reporting and methodology that made it difficult to interpret the results (Varshney et al. 2013; 2014). Ali et al. (2014) reported that treatment with antioxidants reduced DNA damage induced by the three monohaloacetic acids in human sperm and peripheral blood lymphocytes and micronuclei in human lymphocytes.

Several in vitro studies reported differences in DNA repair kinetics or altered expression of genes involved in DNA repair following exposure to the monohaloacetic acids or trichloroacetic acid (Attene-Ramos et al. 2010; Komaki et al. 2009; Lan et al. 2016; Muellner et al. 2010). Lan et al. (2016) reported that trichloroacetic acid induced strong responses in nucleotide excision repair and mismatch repair and a moderate response in double-strand break repair in a high- 
throughput toxicogenomic assay. No other haloacetic acid was tested. These results are consistent with oxidative damage to DNA. Komaki et al. (2009) reported that CHO cells treated with bromoacetic acid had a statistically significant slower rate of repair compared to cells treated with chloroacetic acid or iodoacetic acid. The different rates of genomic repair suggest that these compounds induce different DNA lesions and/or a different distribution of DNA lesions. These data are consistent with studies of monohaloacetic acids in nontransformed human cells that reported altered transcription profiles for genes involved in DNA repair, particularly the repair of double-strand DNA breaks (Attene-Ramos et al. 2010; Muellner et al. 2010). Dmitriev and Grodzinsky (1975) reported that blue-green algae (Anacystis nidulans) exposed to iodoacetic acid prior to irradiation had an increased number of single-strand breaks and a lower rate of subsequent DNA repair.

\section{Genetic Effects In Vivo}

Although limited, the available data indicate that the haloacetic acids are not strong genotoxicants in vivo. The evidence for genotoxicity across haloacetic acids or across different types of endpoints for the same haloacetic acids was largely inconsistent, with some positive findings for DNA or chromosome damage.

In vivo genotoxicity studies were identified for eight haloacetic acids: chloro-, bromo-, dichloro-, dibromo-, bromochloro-, trichloro-, tribromo-, and bromodichloroacetic acid. Endpoints included DNA strand breaks, gene mutation, micronucleus formation, and chromosomal aberrations (Table 6-2). In general, only a few haloacetic acids were tested for each endpoint, and some haloacetic acids were tested for only a few endpoints, thus, limiting the ability to compare genotoxicity potential across haloacetic acids.

Dichloro- and trichloroacetic acid were the only haloacetic acids tested for DNA strand breaks in rodents. Results were mixed in liver but negative in other tissues (IARC 2014a; 2014b). Tribromoacetic acid did not induce DNA damage in zebrafish (Teixidó et al. 2015). Three haloacetic acids were tested for gene mutations with positive findings for dichloroacetic acid (lacI transgenic mouse liver assay), equivocal findings for chloroacetic acid (sex-linked recessive lethal germ cell mutations in Drosophila), and negative findings for iodoacetic acid (sex-linked recessive lethal germ cell mutations in Drosophila (CEBS 2017; IARC 2014a; NTP 1992).

Eight haloacetic acids were tested for micronuclei in rodent or newt larvae, peripheral lymphocytes, or rodent bone marrow. Findings were mixed for dichloroacetic acid (CEBS 2017; IARC 2014a; NTP 2007b), trichloroacetic acid (IARC 2014b), and dibromoacetic acid (IARC 2013a; NTP 2007a) and were negative for bromo-chloroacetic acid (NTP 2015); bromodichloroacetic acid (NTP 2015); and chloro-, bromo-, and tribromoacetic acid (Giller et al. 1997). Chloroacetic acid did not cause chromosomal aberrations in CHO cells but there was some evidence that trichloroacetic can cause chromosome aberrations in bone marrow of mice and chickens when administered by i.p. injection.

\section{Mutational Spectra in Liver Tumors}

Mouse liver tumors induced by three of the haloacetic acids (dichloro-, trichloro-, and bromodichloroacetic acid) showed different patterns in mutation frequency and/or spectra. A mutational analysis of liver tumors induced by dichloroacetic acid in male mice showed similar incidences of $H$-ras mutations ( $50 \%$ to $62 \%$ ) compared to spontaneous tumors in control animals ( $\sim 58 \%$ to $69 \%$ ) (Anna et al. 1994; Ferreira-Gonzalez et al. 1995). However, there was a 
shift in the spectrum of second exon $H$-ras mutations in dichloroacetic acid-treated animals, where dichloroacetic acid-induced tumors had a significantly lower incidence of CAA $\rightarrow$ AAA mutations and a significantly higher incidence of CAA $\rightarrow$ CTA mutations than spontaneous tumors. In contrast, only one $H$-ras codon 61 mutation was found out of 22 liver tumors (4.5\%) examined from female mice exposed to dichloroacetic acid (Schroeder et al. 1997). In trichloroacetic acid-induced mouse liver tumors, both the incidence and mutational spectrum of $H$-ras mutations $(45 \%)$ were not significantly different from spontaneous liver tumors, suggesting that trichloroacetic acid promotes the growth of spontaneously initiated hepatocytes (Ferreira-Gonzalez et al. 1995). Although these data suggest that liver tumor induction in male mice by both dichloro- and trichloroacetic acid involves activation of the $\mathrm{H}$-ras proto-oncogene, the specific mechanisms are likely different between the two compounds (Ferreira-Gonzalez et al. 1995; IARC 2014a).

NTP (2015) also conducted a comparative mutation analysis of 30 hepatoblastomas and adjacent hepatocellular carcinomas in mice exposed to bromodichloroacetic acid. The incidence of $\mathrm{H}$-ras mutations in bromodichloroacetic acid-induced hepatocellular carcinomas (13\%) was about the same as observed in adjacent hepatoblastomas (7\%) but was lower than in spontaneous hepatocellular carcinomas (55\%). On the other hand, the incidence of Ctnnb1 ( $\beta$-catenin) mutations in treatment-related hepatocellular carcinomas $(10 \%)$ was lower than in adjacent hepatoblastomas $(23 \%)$ but higher than in spontaneous tumors $(2 \%)$. There were no data for historical spontaneous hepatoblastomas in mice. H-ras codon 61 and Ctnnb1 exons 2 and 3 mutation spectra were different for the two tumor types, and although the sample size is small, the data suggest that these tumors are distinct entities. Only two hepatoblastomas had $\mathrm{H}$-ras mutations (both CAA $\rightarrow$ CTA) while three of four $H$-ras mutations in hepatocellular carcinomas contained CAA $\rightarrow$ CGA mutations and the other was a CAA $\rightarrow$ CTA mutation. There were no clear mutation spectrum patterns in the seven hepatoblastomas or the three hepatocellular carcinomas that contained Ctnnbl mutations. 
RoC Monograph on Haloacetic Acids

Table 6-2. Summary of the Mutagenic and Genotoxic Effects of Haloacetic Acids ${ }^{\mathrm{a}}$

\begin{tabular}{|c|c|c|c|c|c|c|c|c|c|c|}
\hline \multirow{2}{*}{ Test System } & \multicolumn{3}{|c|}{ Monohaloacetic Acids } & \multicolumn{3}{|c|}{ Dihaloacetic Acids } & \multicolumn{4}{|c|}{ Trihaloacetic Acids } \\
\hline & $\mathbf{C A}$ & $\mathbf{B A}$ & $\mathbf{I A}$ & DCA & DBA & BCA & TCA & TBA & BDCA & CDBA \\
\hline \multicolumn{11}{|l|}{ S. typhimurium } \\
\hline TA100 & $( \pm)$ & + & + & \pm & + & + & - & $\pm^{\mathrm{b}, \mathrm{c}}$ & + & $E^{d}$ \\
\hline TA98 & $( \pm)$ & $\mathrm{nr}$ & $\mathrm{nr}$ & \pm & \pm & - & - & - & + & - \\
\hline Other strains & - & $\mathrm{nr}$ & $\mathrm{nr}$ & - & \pm & - & - & $\mathrm{nr}$ & + & $\mathrm{nr}$ \\
\hline \multicolumn{11}{|l|}{ E. coli WP2 } \\
\hline Reverse mutation & $\mathrm{nr}$ & $\mathrm{nr}$ & $\mathrm{nr}$ & - & $\mathrm{nr}$ & - & $\mathrm{nr}$ & $\mathrm{nr}$ & + & + \\
\hline $\begin{array}{l}\lambda \text { Prophage } \\
\text { induction }\end{array}$ & $\mathrm{nr}$ & $\mathrm{nr}$ & $\mathrm{nr}$ & $-^{\mathrm{b}}$ & $\mathrm{nr}$ & $\mathrm{nr}$ & - & $\mathrm{nr}$ & $\mathrm{nr}$ & $\mathrm{nr}$ \\
\hline SOS chromotest & - & - & $\mathrm{nr}$ & $(+)$ & + & $\mathrm{nr}$ & - & + & $\mathrm{nr}$ & $\mathrm{nr}$ \\
\hline \multicolumn{11}{|l|}{ Mammalian cells } \\
\hline $\begin{array}{l}\text { DNA } \\
\text { damage/strand } \\
\text { breaks }\end{array}$ & + & + & + & - & + & + & - & + & - & $(+)$ \\
\hline Gene mutation & + & $\mathrm{nr}$ & $\mathrm{nr}$ & \pm & + & $\mathrm{nr}$ & $-^{\mathrm{d}}$ & $\mathrm{nr}$ & $\mathrm{nr}$ & $\mathrm{nr}$ \\
\hline $\begin{array}{l}\text { Micronucleus } \\
\text { formation }\end{array}$ & \pm & \pm & \pm & \pm & + & - & $?$ & $\mathrm{nr}$ & - & $\mathrm{nr}$ \\
\hline $\begin{array}{l}\text { Chromosomal } \\
\text { aberrations }\end{array}$ & - & $\mathrm{nr}$ & + & + & $\mathrm{nr}$ & $\mathrm{nr}$ & - & $\mathrm{nr}$ & $\mathrm{nr}$ & $\mathrm{nr}$ \\
\hline $\begin{array}{l}\text { Sister chromatid } \\
\text { exchanges }\end{array}$ & + & $\mathrm{nr}$ & $\mathrm{nr}$ & $\mathrm{nr}$ & $\mathrm{nr}$ & $\mathrm{nr}$ & $\mathrm{nr}$ & $\mathrm{nr}$ & $\mathrm{nr}$ & $\mathrm{nr}$ \\
\hline Aneuploidy & $\mathrm{nr}$ & $\mathrm{nr}$ & $\mathrm{nr}$ & - & $\mathrm{nr}$ & $\mathrm{nr}$ & $\mathrm{nr}$ & $\mathrm{nr}$ & $\mathrm{nr}$ & $\mathrm{nr}$ \\
\hline $\begin{array}{l}\text { Unscheduled } \\
\text { DNA synthesis }\end{array}$ & $\mathrm{nr}$ & $\mathrm{nr}$ & $\mathrm{nr}$ & $\mathrm{nr}$ & + & $\mathrm{nr}$ & $\mathrm{nr}$ & $\mathrm{nr}$ & $\mathrm{nr}$ & $\mathrm{nr}$ \\
\hline
\end{tabular}


RoC Monograph on Haloacetic Acids

\begin{tabular}{|c|c|c|c|c|c|c|c|c|c|c|}
\hline \multirow{2}{*}{ Test System } & \multicolumn{3}{|c|}{ Monohaloacetic Acids } & \multicolumn{3}{|c|}{ Dihaloacetic Acids } & \multicolumn{4}{|c|}{ Trihaloacetic Acids } \\
\hline & CA & BA & IA & DCA & DBA & BCA & TCA & TBA & BDCA & CDBA \\
\hline \multicolumn{11}{|l|}{ In vivo } \\
\hline $\begin{array}{l}\text { DNA } \\
\text { damage/strand } \\
\text { breaks }\end{array}$ & $\mathrm{nr}$ & $\mathrm{nr}$ & $\mathrm{nr}$ & \pm & $\mathrm{nr}$ & $\mathrm{nr}$ & \pm & $-^{\mathrm{e}}$ & $\mathrm{nr}$ & $\mathrm{nr}$ \\
\hline Gene mutation & $--^{\mathrm{e}}$ & $\mathrm{nr}$ & $-^{\mathrm{e}}$ & + & $\mathrm{nr}$ & $\mathrm{nr}$ & $\mathrm{nr}$ & $\mathrm{nr}$ & $\mathrm{nr}$ & $\mathrm{nr}$ \\
\hline $\begin{array}{l}\text { Micronucleus } \\
\text { formation }\end{array}$ & $-^{\mathrm{e}}$ & $-^{\mathrm{e}}$ & $\mathrm{nr}$ & \pm & \pm & - & \pm & $-^{\mathrm{e}}$ & - & $\mathrm{nr}$ \\
\hline $\begin{array}{l}\text { Chromosomal } \\
\text { aberrations }\end{array}$ & - & $\mathrm{nr}$ & $\mathrm{nr}$ & $\mathrm{nr}$ & $\mathrm{nr}$ & $\mathrm{nr}$ & $+^{\mathrm{f}}$ & $\mathrm{nr}$ & $\mathrm{nr}$ & $\mathrm{nr}$ \\
\hline
\end{tabular}

Sources: USEPA (2003; 2011a); IARC (2013a; 2013b; 2014a; 2014b); NTP (1992; 2007a; 2007b; 2009; 2015); Richardson et al. (2007); CEBS (2017); Ali et al. (2014);

Kargalioglu et al. (2002); Liviac et al. (2010); Plewa et al. (2004a); Plewa et al. (2010); Stalter et al. (2016a); Teixidó et al. (2015); Varshney et al. (2013; 2014); Zhang et al.

(2010).

$\mathrm{CA}=$ chloro-; $\mathrm{BA}=$ bromo-; IA = iodo-; DCA = dichloro-; DBA = dibromo-; $\mathrm{BCA}$ = bromochloro-; TCA = trichloro-; TBA = tribromo-; $\mathrm{BDCA}=$ bromodichloroacetic acid;

$\mathrm{CDBA}=$ chlorodibromoacetic acid; $\mathrm{nr}=$ not reported $/$ no data; $-=$ negative, $\mathrm{E}=$ equivocal; $\pm=$ mixed results; $(+)=$ weak positive; $( \pm)=$ weak positive or negative; $+=$ positive;

$?=$ reported as positive but results are questionable due to deficiencies in reporting and methods.

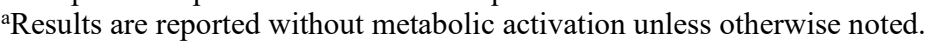

${ }^{\mathrm{b}}$ Positive with metabolic activation.

c Positive in the fluctuation test (liquid media) with or without metabolic activation.

${ }^{\mathrm{d}}$ Weak positive with metabolic activation in one study.

${ }^{e}$ Non-mammalian tests: newt larvae (micronucleus), zebrafish (DNA damage), Drosophila (sex-linked recessive lethal mutation).

fonly one oral study in mice, and two i.p. injection studies (mice and chickens). 


\subsubsection{Mutagenic and Genotoxic Potency}

Mutagenic or genotoxic potency and cytotoxicity of three or more haloacetic acids were directly compared in several studies in bacteria (S. typhimurium strain TA100, SOS umuC assay) and mammalian cells (HGPRT mutations, Comet and p53-bla assays) (Kargalioglu et al. 2002; Plewa et al. 2010; Plewa et al. 2004b; Richardson et al. 2008; Stalter et al. 2016a; Zhang et al. 2010; Zhang et al. 2016). These data are shown in Appendix D (Table D-3 and Table D-4) and are reported as the fold increase relative to the least potent haloacetic acid in each of five in vitro genetox assays in the figures below. Data for the umuC assay are plotted separately because the general trends present in the other assays are not as apparent in the umuC assay (discussed below). The SOS umuC assay is a screening test and does not provide a direct measurement of DNA damage or mutagenesis but rather measures the activation of SOS umuC-dependent error prone DNA repair. Data for a few other studies shown in Appendix D, Table D-3 and Table D-4 (Attene-Ramos et al. 2010; Escobar-Hoyos et al. 2013; Giller et al. 1997; Ono et al. 1991; Procházka et al. 2015) are not included in the figures below but show the same general patterns.

The data show that the mutagenic/genotoxic potency is highly influenced by both the number and type of halogen atoms with the general rank order of potency as: mono- $>$ di- $>$ trihaloacetic acids and iodinated $>$ brominated $\gg$ chlorinated acetic acids and is consistent with that reported for oxidative stress in the previous section. In fact, all haloacetic acids that were active toward DNA in bacteria or mammalian cells also induced oxidative stress (Stalter et al. 2016a).

Notable exceptions to the general trends reported above included the lack of mutagenic activity for the monohalogenated acetic acids and the high potency of brominated trihaloacetic acids, particularly tribromoacetic acid, in the SOS umuC assay (see Appendix D, Table D-3) (Stalter et al. 2016a). Stalter et al. (2016a) noted that induction ratios in the umuC assay were excluded from the data analysis when cytotoxicity exceeded $50 \%$, so the lack of mutagenic activity by monohaloacetic acids in the umuC assay may be a result of cytotoxicity masking induction of the reporter gene. However, Zhang et al. (2016) showed that the monohaloacetic acids were active in the SOS umuC assay. Therefore, Figure 6-4 integrates data for umuC for the di- and trihaloacetic acids from Stalter et al. (2016a) with data for the monohaloacetic acids from Zhang et al. (2016). Although no explanation was given for the high potency of the brominated trihaloacetic acids (especially tribromoacetic acid) in the umuC assay (Stalter et al. 2016a), the trihaloacetic acids were negative or weakly positive in other bacterial systems and in mammalian cells. Tribromoacetic acid is not included in Figure 6-4 because it exhibited a 2,500-fold increase relative to chloro- and trichloroacetic acid and appears to be an outlier.

Exceptions to the general trends observed in the in vitro genetox studies summarized in Figure 65 (Ames TA100 strain, HGPRT mutations, p53-bla, and Comet) include slightly more DNA damage in $\mathrm{CHO}$ cells exposed to dibromoacetic acid compared to bromoiodo- or diiodoacetic acid (Plewa et al. 2010), and dibromoacetic acid induced an 8-fold higher HGPRT mutant frequency in CHO cells than bromoacetic acid (Zhang et al. 2010). 


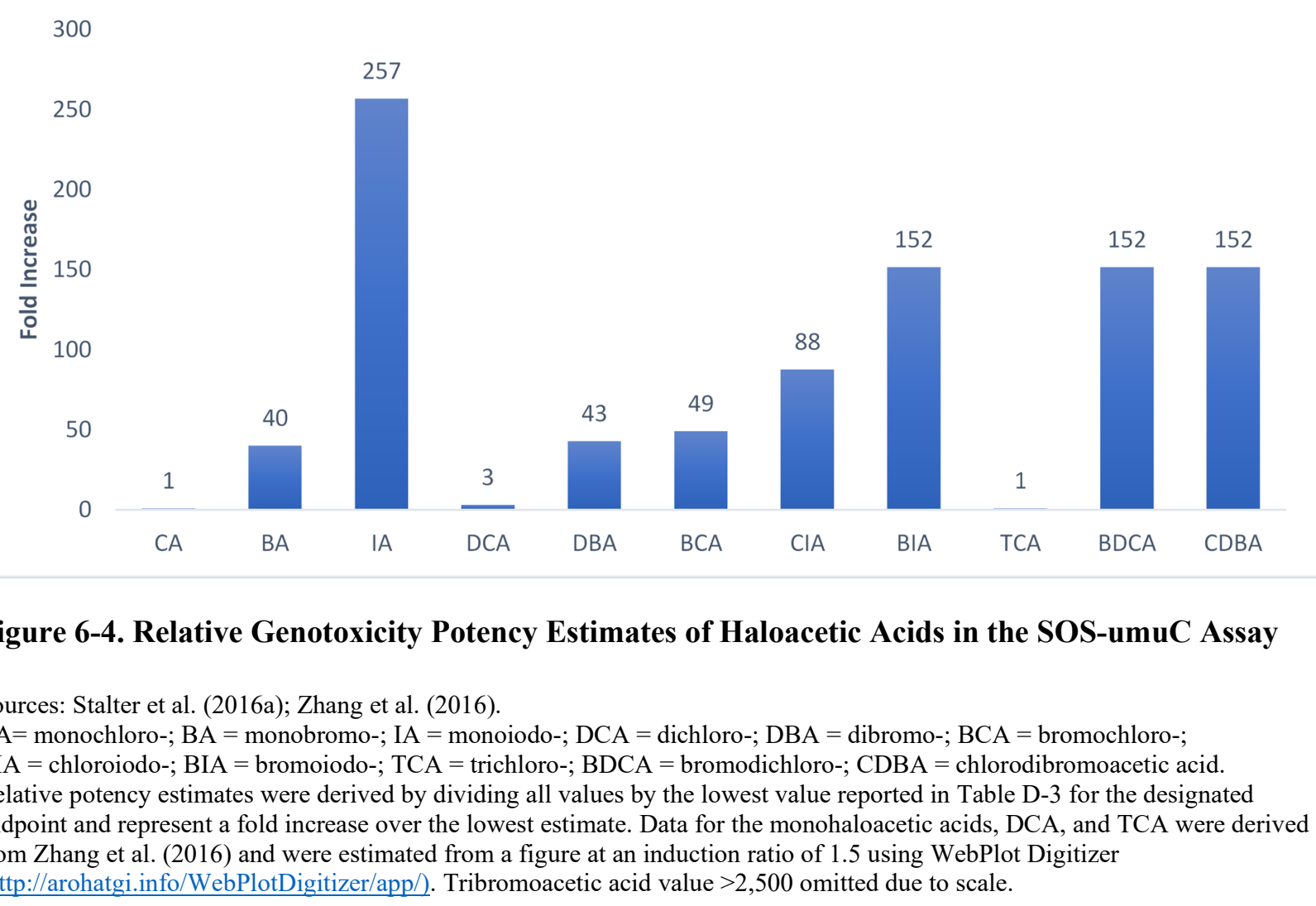



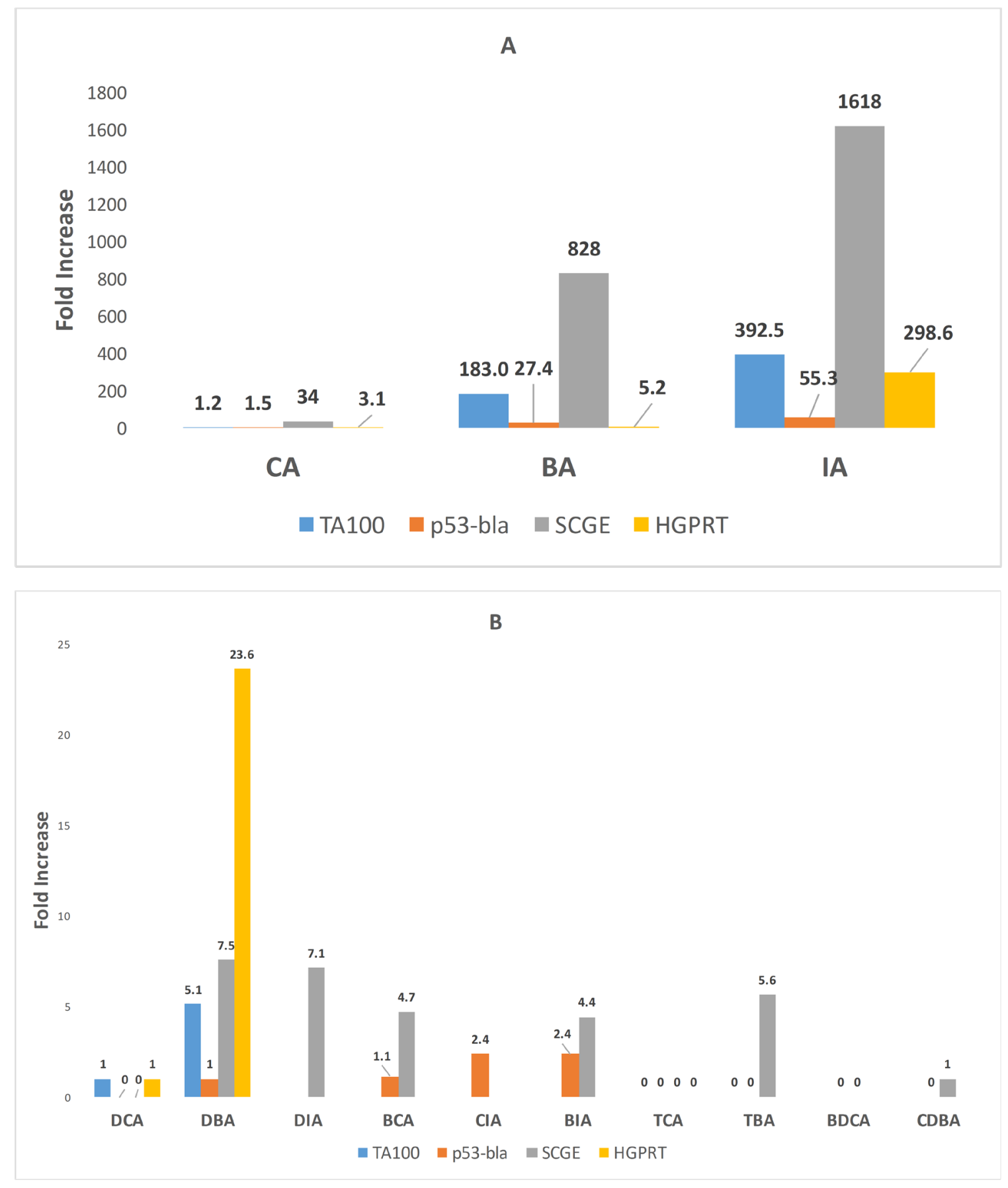

Figure 6-5. Relative Genotoxicity Potency Estimates of Haloacetic Acids in Bacteria and Mammalian Cells

Sources: Kargalioglu et al. (2002); Plewa et al. (2010); Plewa et al. (2004b); Stalter et al. (2016a); Zhang et al. (2010). $\mathrm{CA}=$ monochloro-; $\mathrm{BA}=$ monobromo-; IA = monoiodo-; DCA = dichloro-; DBA = dibromo-; DIA = diiodo-;

$\mathrm{BCA}=$ bromochloro-; CIA = chloroiodo-; $\mathrm{BIA}=$ bromoiodo-; TCA = trichloro-; TBA = tribromo-; $\mathrm{BDCA}=$ bromodichloro-; $\mathrm{CDBA}=$ chlorodibromoacetic acid.

Relative potency estimates were derived by dividing all values by the lowest value reported in Table D-3 and Table D-4 for the designated endpoint and represent a fold increase over the lowest estimate. Value of zero indicates that the compound was tested but inactive. (A) Monohaloacetic acid), (B) Di- and trihaloacetic acids. 


\subsection{Induction of Epigenetic Alterations}

Three haloacetic acids (dichloro-, dibromo-, and trichloroacetic acid) induced hypomethylation of DNA and the promoter regions of oncogenes (c-myc and insulin-like growth factor 2 [IGF-II]) genes in rodents. Hypomethylation of the promoter regions leads to increased expression of these

genes and may represent early events in the hepatocarcinogenicity of these haloacetic acids (IARC 2013a; 2014a; 2014b; Tao et al. 2005; Tao et al. 2004a). In contrast, the global methylation pattern in liver tumor and nontumor DNA harvested from mice after 98 weeks following early-life exposure to dichloroacetic acid was not altered (Wood et al. 2015). DNA methylation status has been suggested as a possible screening tool for predicting the potential carcinogenicity of the haloacetic acids (Kuppusamy et al. 2015; Pereira et al. 2001; Tao et al. 2004b). However, no clear potency trends were observed. Findings for the three compounds are summarized across studies below and the data from the individual studies are reported in Appendix D, Table D-5.

Dose-dependent hypomethylation of DNA from normal liver tissue, liver tumor, and normal kidney tissue; hypomethylation in the promoter regions of IGF-II, $c$-jun, and $c$-myc genes; and increased mRNA expression of these genes were reported in mice exposed to dichloro-, dibromo-, or trichloroacetic acid (Pereira et al. 2001; Pereira et al. 2004a; Tao et al. 2004b; Tao et al. 2005; Tao et al. 2004a; Tao et al. 2000a; 2000b; Tao et al. 1998). Dibromoacetic acid also induced liver and kidney DNA hypomethylation in male rats (Tao et al. 2005; Tao et al. 2004a). Hypomethylation patterns varied depending on the exposure conditions and type of tissue (tumor vs. nontumor).

Several studies show that hypomethylation was correlated with the carcinogenic and tumorpromoting activity of both dichloro- and trichloroacetic acid in the liver and kidney of rodents but that the mechanisms of their carcinogenic activity may be different (Pereira et al. 2001; Pereira et al. 2004a; Tao et al. 2004b; Tao et al. 2005; Tao et al. 2000b; Tao et al. 1998). Dichloro- and trichloroacetic acid-induced hypomethylation of the promoter region of the $c-m y c$ gene in mouse liver coincided with enhanced cell proliferation and suggests that these compounds induce hypomethylation by inducing DNA replication and inhibiting methylation of the newly synthesized DNA (Ge et al. 2001). When co-administered with chloroform, both trichloroacetic acid and dichloroacetic acid induced hypomethylation and promoted kidney tumors in male (but not female) mice (Pereira et al. 2001). Hypomethylation induced by haloacetic acids was also prevented by prior treatment with methionine, suggesting that haloacetic acids deplete S-adenosyl methionine levels (Pereira et al. 2004b; Pereira et al. 2004a; Tao et al. 2005; Tao et al. 2000a; 2000b).

\subsection{Modulation of Receptor-mediated Effects}

Overall, the data suggest that the carcinogenic activity of trichloroacetic acid in mouse liver is consistent with peroxisome proliferation (IARC 2004b; 2014b). The lack of a carcinogenic response in rats exposed to trichloroacetic acid may be explained by a much lower extent of peroxisome proliferation compared to mice (DeAngelo et al. 1989). In contrast, rats were more sensitive to the hepatocarcinogenicity of dichloroacetic acid than mice (DeAngelo et al. 1996).

Peroxisome proliferation, as measured by palmitoyl-CoA oxidation, appears to be a common effect of the seven haloacetic acids tested in vitro but with wide variation in potency and efficacy 
in cultured rat hepatocytes (Appendix D, Figure D-1) (Walgren et al. 2004). The lowest effective concentrations, based on palmitoyl-CoA oxidation, varied over about two orders of magnitude. Within the monohalo-substituted series, iodoacetic acid was more potent than bromo- or chloroacetic acid; however, no clear patterns were observed for the different halogen substitutions for the di- or trihaloacetic acid series. While monobromo- and monoiodoacetic acid induced significant increases in palmitoyl-CoA oxidation at the lowest concentrations (50 to 100 $\mu \mathrm{M})$, higher concentrations were cytotoxic. Thus, the cytotoxicity of the monohaloacetic acids would likely limit their effectiveness as PPAR $\alpha$ activators in vivo. Overall, dibromoacetic acid was the most effective inducer of palmitoyl-CoA reaching 6.2-fold at the maximum concentration tested $(3 \mathrm{mM})$. Dichloro-, trichloro-, and tribromoacetic acids were modest inducers of palmitoyl $\mathrm{CoA}$ with much flatter concentration/response curves. However, these data are not consistent with the available in vivo data discussed below.

In vitro studies using human cells also reported variable results. Peroxisome proliferation (as measured by palmitoyl-CoA oxidation) was not detected in one study using human cell lines exposed to dichloro- or trichloroacetic acid; however, palmitoyl-CoA oxidation was not detected in control human hepatocytes in these studies (Walgren et al. 2000a; 2000b). Other in vitro studies have shown that human PPAR $\alpha$ is activated by both dichloro- and trichloroacetic acid (IARC 2014b). Trichloroacetic acid at concentrations $>1 \mathrm{mM}$ induced comparable dose-related transactivation in human and mouse PPAR $\alpha$ in vitro (Maloney and Waxman 1999).

In vivo studies in rats and/or mice exposed to brominated or chlorinated haloacetic acids in drinking water showed a dose-related increase in acyl-CoA oxidase activity or hepatic peroxisome proliferation for dibromo- and trichloroacetic acid and the positive control (clofibric acid) but not for other haloacetic acids tested (chloro-, dichloro-, bromochloro-, or bromodichloroacetic acid) (DeAngelo et al. 1989; NTP 2015; Parrish et al. 1996; Tao et al. 2004a; Xu et al. 1995). Dichloroacetic acid produced a small, but significant increase only at the high dose while the response to dibromoacetic acid was dose related up to $1 \mathrm{~g} / \mathrm{L}$ but then declined at $3 \mathrm{~g} / \mathrm{L}$ (Parrish et al. 1996).

Trichloroacetic acid and dichloroacetic acid are relatively weak PPAR $\alpha$ agonists requiring $\mathrm{mM}$ concentrations (Corton 2008; DeAngelo et al. 1996; DeAngelo et al. 2008; DeAngelo et al. 1999; Laughter et al. 2004). However, dose-response characteristics for dichloroacetic acid show that PPAR $\alpha$ is not activated at concentrations that induce liver tumors in either rats or mice and indicates that the mode of action of dichloroacetic acid is PPAR $\alpha$-independent (DeAngelo et al. 1996; DeAngelo et al. 1999). In contrast, dose-response characteristics for trichloroacetic acid show that there is a relatively good correlation between trichloroacetic acid-induced liver tumors and induction of markers of PPAR $\alpha$ activation in the mouse (DeAngelo et al. 2008). In addition, markers of PPAR $\alpha$ activation are elevated at trichloroacetic acid doses that are below or coincident with doses that induce mouse liver tumors, and trichloroacetic acid-induced mouse liver tumors have properties similar to those induced by classic peroxisome proliferators (Corton 2008; DeAngelo et al. 2008).

\subsection{Inhibition of GST- $\zeta$}

GST- $\zeta$ inhibition has been suggested as a specific mode of action relevant to dihaloacetic acidinduced liver cancer in rodents; however, the available data are insufficient to fully define the key events or to assess their necessity or sufficiency for carcinogenicity. Several polymorphic 
variants of GST- $\zeta$ have been identified that differ in their susceptibility to inactivation (Blackburn et al. 2001; Blackburn et al. 2000; Board and Anders 2011; Cantor et al. 2010; Fang et al. 2006; Hayes and Strange 2000; Li et al. 2012; Shroads et al. 2010; Tzeng et al. 2000). Inhibition of GST- $\zeta$ by successive or continuous doses of dihaloacetic acids reduces metabolism and prolongs the plasma half-life (Gonzalez-Leon et al. 1999; Schultz et al. 2002).

GST- $\zeta$, also known as maleylacetoacetate isomerase (MAAI), catalyzes the penultimate step in the tyrosine catabolism pathway and metabolizes maleylacetoacetate to fumarylacetoacetate and maleylacetone to fumarylacetone (Anderson et al. 2004; Board and Anders 2011; Cornett et al. 1999; Schultz et al. 2002; Stacpoole 2011; Stacpoole et al. 2008; Theodoratos et al. 2009). These reactive metabolites may accumulate following inhibition of GST- $\zeta$, react with macromolecules, and induce oxidative stress (Blackburn et al. 2006). Hereditary tyrosinemia type 1 is a metabolic disease caused by a deficiency of the enzyme involved in the last step of tyrosine catabolism. Individuals with this disease develop hepatocellular carcinoma at a young age (Stacpoole 2011; Tanguay et al. 1996).

Schultz et al. (2002) reported that dichloroacetic acid reduced MAAI activity over $80 \%$ in young mice but not in old mice suggesting that reduced MAAI activity is unlikely to be the sole carcinogenic mode of action for dichloroacetic acid and may be important only during the early stages of exposure. This conclusion is further supported by observations that GST- $\zeta$-deficient mice do not spontaneously develop hepatocellular carcinoma (Fernández-Cañón et al. 2002; Schultz et al. 2002).

\subsection{Cell Immortalization}

Iodo- and dibromoacetic acid (the only haloacetic acids tested) caused cell transformation in an immortalized aneuploid mouse cell line (NIH3T3 or Balb/c 3T3 cells) (Fang and Zhu 2001; Wei et al. 2013). This assay is responsive to the later stages in carcinogenic transformation (i.e., induction of morphologically transformed foci (Tanaka et al. 2012). Moreover, Wei et al. (2013) reported that iodoacetic acid-transformed cells also exhibited anchorage-independent growth, agglutination with concanavalin $\mathrm{A}$, and they formed aggressive fibrosarcomas when injected into $\mathrm{Balb} / \mathrm{c}$ nude mice. Cell transformation assays are capable of detecting both genotoxic and nongenotoxic carcinogens and validation studies have shown generally good concordance with rodent bioassay results and reproducibility (Corvi et al. 2012; Creton et al. 2012; Tanaka et al. 2012).

\subsection{Alteration of Cell Proliferation and Cell Death}

Some data suggest that dichloro- and trichloroacetic acid alter cell proliferation and apoptosis; however, the data are inconsistent and the effects appear to be transitory [reviewed in (IARC 2014a; 2014b; USEPA 2003; 2011a)]. Several studies reported hepatocyte proliferation, increased thymidine incorporation in hepatic DNA, and increased cell division rates in trichloroacetic acid-induced hepatic foci and tumors (Channel et al. 1998; DeAngelo et al. 2008; Dees and Travis 1994; Ge et al. 2001; IARC 2014b; Pereira 1996; Stauber and Bull 1997; Styles et al. 1991). Increased labeling of hepatic DNA was observed at sub-necrotic doses suggesting that cell proliferation was not due to regenerative hyperplasia (Dees and Travis 1994). Studies with dichloroacetic acid reported increased cell proliferation of $c$-jun-positive hepatocytes, reparative hyperplasia in the liver, increased numbers of hepatic foci and hyperplastic nodules, 
increased cell replication rates in altered foci, promotion of growth and survival of initiated cells, and a dose-related decrease in apoptosis (IARC 2014a; Richmond et al. 1991; Sanchez and Bull 1990; Snyder et al. 1995; Stauber and Bull 1997; Stauber et al. 1998). Other studies have suggested that dichloro- and trichloroacetic acids are not direct-acting mitogens; however, dichloroacetic acid inhibited apoptosis and synergistically enhanced the mitogenic response to epidermal growth factor (EGF) in cultured rat hepatocytes (DeAngelo et al. 1991; Walgren et al. 2005).

Increased cell proliferation has been associated with increased expression of IGF-II as this gene has both mitogenic and anti-apoptotic activity in the liver (Tao et al. 2004b). As mentioned above (Section 6.5), both trichloro- and dichloroacetic acids increased $c-m y c$ and IGF-II expression and enhanced cell proliferation in rodent liver (Ge et al. 2001; Tao et al. 2004b; Tao et al. 2004a). Stauber et al. (1998) reported that both dichloro- and trichloroacetic acid promoted the formation of anchorage-independent mouse hepatocytes in vivo and in vitro in a dosedependent manner. The phenotypes of the anchorage-independent colonies promoted by dichloroacetic acid were primarily $c$-jun positive while those promoted by trichloroacetic acid were mainly $c$-jun negative, consistent with the phenotypes from liver tumors induced by these compounds. These data suggest that the mode of action of dichloro- and trichloroacetic acid may be to selectively stimulate the clonal expansion of phenotypically different populations of initiated cells.

Some in vitro data suggest that trichloroacetic acid and dichloroacetic acid, but not iodoacetic acid, inhibit gap-junctional intercellular communication (Benane et al. 1996; Klaunig et al. 1989; $\mathrm{Si}$ et al. 1987). Loss of gap junctional cellular communication may be an important step in carcinogenesis (Aasen et al. 2016). No data were available for other haloacetic acids regarding effects on gap-junctional intercellular communication. Benane et al. (1996) reported a dose- and treatment time-related inhibitory response for both haloacetic acids in a normal liver epithelial cell line from male Sprague Dawley rats. The lowest concentration and shortest time to reduce gap-junctional intracellular communication, as measured by dye transfer, was $1 \mathrm{mM}$ over 1 hour for trichloroacetic acid compared to $10 \mathrm{mM}$ over 6 hours for dichloroacetic acid. Thus, trichloroacetic acid appeared to be more potent than dichloroacetic acid. Trichloroacetic acid significantly reduced dye transfer in mouse hepatocytes at $0.1 \mathrm{mM}$ to $1 \mathrm{mM}$ after 4 hours treatment but not after 8 hours or 24 hours (Klaunig et al. 1989). In contrast, dye transfer was not affected in rat hepatocytes exposed to trichloroacetic acid concentrations up to $1 \mathrm{mM}$ for as long as 24 hours.

\subsection{Induction of Chronic Inflammation or Immunosuppression}

The evidence that haloacetic acids induce chronic inflammation or immunosuppression is generally weak and inconsistent and neither process has been identified as a potential mode of action for dichloro-, trichloro-, bromochloro-, or dibromoacetic acid (IARC 2013a; 2013b; 2014a; 2014b). Nevertheless, some data regarding these effects were available for the chloro-, bromo-, iodo-, dichloro-, dibromo-, bromochloro-, trichloro-, and bromodichloroacetic acids and are briefly reviewed here.

In the two-year cancer bioassay studies, mild chronic inflammation in the liver was reported in male mice chronically exposed to trichloroacetic acid (DeAngelo et al. 2008) or dichloroacetic acid (Daniel et al. 1992) but not in rats or mice exposed to dibromo-, bromochloro-, or 
chlorodibromoacetic acid (NTP 2007a; 2009; 2015). None of the 12 haloacetic acids evaluated activated the NF- $\mathrm{KB}$ stress-response pathway for inflammation in vitro using the human THP-1 leukemia cell line (Stalter et al. 2016a). However, Pals et al. (2013) reported that the three monohaloacetic acids, at non-cytotoxic concentrations, upregulated cyclooxygenase-2 (COX-2) in nontransformed human intestinal epithelial cells (line FHs 74 Int), suggesting a possible inflammatory response. Bromo- and iodoacetic acids also modulated the MAPK pathway in FHs 74 Int cells which suggests a response to cell stress and inflammation (Attene-Ramos et al. 2010).

Few studies have investigated the effects of haloacetic acids on the immune system. Neither dichloro- nor trichloroacetic acid were immunotoxic in rats exposed to concentrations of up to 5 $\mathrm{g} / \mathrm{L}$ in drinking water for 90 days (Mather et al. 1990). Ohashi et al. (2013) reported that dichloroacetic acid improved immune function and increased antitumor immunotherapeutic activity. Dibromoacetic acid did not significantly affect humoral immunity or innate immune function in mice at concentrations up to $1 \mathrm{~g} / \mathrm{L}$ in drinking water for 28 days (Smith et al. 2010a). Other studies have suggested that monoiodo-, dichloro-, dibromo-, or trichloroacetic acid induce some immune responses, including increased serum IgG and IgM in autoimmune-prone $\mathrm{MRL}^{+/+}$ mice, histological changes in the thymus and spleen, increased immune cell apoptosis, $\mathrm{T}$ cell activation and increased cytokine expression, and suppressed in vitro immune functions (Cai et al. 2007; Gao et al. 2008; Gao et al. 2016; Pan et al. 2015; Si et al. 1987).

\subsection{Effects on Gene Expression}

Toxicogenomics studies were available for chloro-, bromo-, iodo-, dichloro-, bromochloro-, trichloro-, and bromodichloroacetic acids and are discussed separately for the monohaloacetic acids and the di- and trihaloacetic acids. These data show that the haloacetic acids induce gene expression changes relevant to several of the characteristics of carcinogens and possible modes of action discussed in this monograph.

Comparative human cell toxicogenomic analysis indicated that the monohaloacetic acids altered the transcription levels of genes involved in stress response to DNA damage and regulation of different stages in cell cycle progression or apoptosis and provide support for several of the proposed modes of action (Attene-Ramos et al. 2010; Muellner et al. 2010; Pals et al. 2013). The major cell pathways affected are shown in Table 6-3. Most of these pathways show a strong association with carcinogenesis (Khanna and Jackson 2001; Plewa and Wagner 2015).

Table 6-3. Transcriptome Pathways in Human Cells Induced by Monohaloacetic Acids

\begin{tabular}{lccc}
\hline \multicolumn{1}{c}{ Pathway } & Chloro- & Bromo- & Iodo- \\
\hline ATM signaling & + & + & + \\
Cell cycle control & + & + & NA \\
Cyclins and cell cycle regulation & + & + & NA \\
MAPK signaling & NA & + & + \\
p53 signaling & NA & + & + \\
BRCA1, BRCA2, and ATR mediated & + & & + \\
cancer susceptibility and dsDNA repair & & + & + \\
Nrf2/ARE-dependent ROS & + & & + \\
\hline
\end{tabular}




\begin{tabular}{lccc}
\hline \multicolumn{1}{c}{ Pathway } & Chloro- & Bromo- & Iodo- \\
\hline PTGS2 (COX2)-mediated & + & + & + \\
MPO, LPO and NOX5 ROS & + & + & + \\
GSH/GSR & + & + & + \\
Peroxiredoxin oxidative stress & + & + & NA \\
\hline SOur
\end{tabular}

Source: Plewa and Wagner (2015).

$\mathrm{NA}=$ pathway not affected.

Several gene expression studies show that the di- and trihaloacetic acids induce expression changes in genes involved in oxidative stress-responsive pathways, DNA damage and repair, cell cycle progression, cell proliferation, metabolism, cancer progression, and apoptosis. However, the data are insufficient to determine any clear patterns in gene expression profiles that are related to physiochemical or toxicological properties of the haloacetic acids. These studies compared gene expression changes in normal liver tissue, preneoplastic liver nodules, and liver tumors from mice exposed to dichloro-, trichloro-, or bromodichloroacetic acid and control mice; mouse sperm or rat mesotheliomas exposed to bromochloroacetic acid; normal mammary gland tissue and tumors in rats exposed to bromodichloroacetic acid; and yeast treated with trichloroacetic acid and the data are summarized in Appendix D, Table D-6) (Choi and Park 1996; Kim et al. 2006; Lan et al. 2016; NTP 2015; Nelson et al. 1990; Thai et al. 2001; 2003; Tully et al. 2005).

Mice exposed to dichloroacetic acid for 4 weeks showed similar gene expression profiles in liver tissue as observed in dichloroacetic acid-induced liver tumors (Thai et al. 2001; 2003).

Trichloroacetic acid-activated pathways involved in oxidative DNA damage and tumor progression (Lan et al. 2016; Nelson et al. 1990) while bromochloroacetic acid altered expression of genes involved in cell communication and adhesion, cell cycle and cell proliferation, metabolism, signal transduction, apoptosis, invasion, and metastasis (Kim et al. 2006; Tully et al. 2005). Distinct gene expression profiles were observed across four different tissues following bromodichloroacetic acid exposure: hepatocellular carcinomas, hepatoblastomas, and adjacent normal liver tissue from exposed rats as well as normal liver tissue from controls (NTP 2015). Gene expression changes in treatment-related nontumor liver tissue were consistent with neoplastic signaling and may suggest that microenvironment changes preceded neoplastic transformation due to chemical treatment. However, these gene expression changes may also have been influenced by the microenvironment of the adjacent hepatocellular carcinomas. The gene expression profiles of mouse hepatoblastomas were similar to early embryonic mouse livers, suggesting that these tumors arose from the transformation of a hepatic stem or multipotent progenitor cell, while hepatocellular carcinomas arose from transformed hepatocytes. Significant upregulation of eight genes was found in mammary gland tumors from rats exposed to bromodichloroacetic acid but were not found in spontaneous tumors; five of these genes were associated with TGF-beta signaling and an aggressive tumor phenotype (Harvey et al. 2016; NTP 2015).

\subsection{Mode of Action Integration and Synthesis}

Overall, the data suggest that the haloacetic acids may induce cancer through electrophilic reactions with macromolecules leading to altered gene expression, inhibited protein function, oxidative stress, and mutagenic and genotoxic effects. The data suggest that the mechanisms are 
complex and likely involve multiple interactions of toxicokinetic factors and modes of action, as well as unknown factors and modes of action that may differ somewhat among the various subclasses of haloacetic acids based on halogen substitution patterns.

The potential modes of action and key events associated with the characteristics of carcinogens are listed in Table 6-4. Most compounds have been associated with most of the 10 characteristics of carcinogens and potential modes of action, with the possible exception of PPAR-alpha activation, are relevant to human cancer. Figure 6-6 identifies the specific haloacetic acids and subclasses that have been linked to a particular mode of action through in vitro and/or in vivo testing. The identification of the potential modes of action of the haloacetic acids is limited because not all 13 haloacetic acids have been tested for all of the key events. Biologically plausible modes of action with moderate to strong experimental support include oxidative damage, epigenetic alterations (i.e., DNA hypomethylation) leading to gene expression changes, GAPDH and PDK inhibition leading to metabolic reprogramming and oxidative stress, disruption of tyrosine catabolism by dihaloacetic acids via inhibition of GST- $\zeta$, and PPAR $\alpha$ activation. These effects are further supported by transcriptomic analyses showing that haloacetic acids affect expression of genes involved in oxidative stress response, DNA damage and repair, cell growth and proliferation, tissue remodeling, apoptosis, angiogenesis, cancer progression, fatty acid metabolism, and xenobiotic metabolism. Direct genotoxicity does not appear to be a primary mode of action for the haloacetic acids and, overall, the data suggest that oxidative stress is responsible for the mutagenic and genotoxic effects of these compounds.

Table 6-4. Possible Modes of Carcinogenic Action for Haloacetic Acids and the 10 Characteristics of Carcinogens

\begin{tabular}{|c|c|c|}
\hline $\begin{array}{l}\text { Characteristic(s) of } \\
\text { Carcinogens }\end{array}$ & Mode of Action & Key Events \\
\hline Electrophilicity & Irreversible binding to macromolecules & $\begin{array}{l}\text { 1. Haloacetic acids have an electrophilic } \\
\text { structure that can react with peptides, } \\
\text { proteins, or DNA to form adducts. } \\
\text { 2. Protein or DNA adducts result in altered } \\
\text { activity or DNA damage that advances } \\
\text { acquisition of multiple critical traits } \\
\text { contributing to carcinogenesis. }\end{array}$ \\
\hline $\begin{array}{l}\text { Altered nutrient } \\
\text { supply, } \\
\text { electrophilicity, } \\
\text { induction of } \\
\text { oxidative stress }\end{array}$ & $\begin{array}{l}\text { Reprogramming cellular energy metabolism } \\
\text { (inhibition of pyruvate dehydrogenase } \\
\text { kinase (PDK) }\end{array}$ & $\begin{array}{l}\text { 1. Haloacetic acids inhibition of PDK } \\
\text { increases pyruvate dehydrogenase } \\
\text { complex activity and oxidative } \\
\text { metabolism. } \\
\text { 2. Increase in oxidative metabolism leads to } \\
\text { an increase in reactive oxygen species } \\
\text { (ROS) and oxidative stress. } \\
\text { 3. Oxidative stress leads to acquisition of } \\
\text { multiple, critical traits contributing to } \\
\text { carcinogenesis. }\end{array}$ \\
\hline
\end{tabular}




\begin{tabular}{|c|c|c|}
\hline $\begin{array}{l}\text { Characteristic(s) of } \\
\text { Carcinogens }\end{array}$ & Mode of Action & Key Events \\
\hline $\begin{array}{l}\text { Altered nutrient } \\
\text { supply, } \\
\text { electrophilicity, } \\
\text { induction of } \\
\text { oxidative stress }\end{array}$ & $\begin{array}{l}\text { Inhibition of glyceraldehyde-3-phosphate } \\
\text { dehydrogenase (GAPDH) }\end{array}$ & $\begin{array}{l}\text { 1. Haloacetic acids inhibition of GAPDH } \\
\text { leads to inhibition of glycolysis. } \\
\text { 2. Inhibition of glycolysis leads to reduced } \\
\text { ATP levels and repressed pyruvate } \\
\text { generation. } \\
\text { 3. Reduced pyruvate leads to mitochondrial } \\
\text { stress, ROS generation, cytotoxicity, and } \\
\text { DNA damage. }\end{array}$ \\
\hline $\begin{array}{l}\text { Induction of } \\
\text { oxidative stress }\end{array}$ & Oxidative stress & $\begin{array}{l}\text { 1. Haloacetic acids induce oxidative stress } \\
\text { through multiple pathways. } \\
\text { 2. Oxidative stress can cause mutations and } \\
\text { damage to proteins, lipids, and DNA. } \\
\text { 3. Mutations and damage to macromolecules } \\
\text { activate cell-signaling pathways, induce } \\
\text { genomic instability, and cell } \\
\text { transformation and lead to cancer. }\end{array}$ \\
\hline $\begin{array}{l}\text { Genotoxicity and/or } \\
\text { alteration of DNA } \\
\text { repair }\end{array}$ & Mutagenicity and genotoxicity & $\begin{array}{l}\text { 1. Haloacetic acids induce genetic damage } \\
\text { in critical genes or form pro-mutagenic } \\
\text { adducts. } \\
\text { 2. Insufficient or mismatch repair of genetic } \\
\text { damage leads to fixed genetic damage. } \\
\text { 3. Unrepaired genetic damage leads to } \\
\text { clonal expansion of initiated cells. } \\
\text { 4. Clonal expansion leads to tumor } \\
\text { formation. }\end{array}$ \\
\hline $\begin{array}{l}\text { Induction of } \\
\text { epigenetic } \\
\text { alterations }\end{array}$ & DNA hypomethylation & $\begin{array}{l}\text { 1. Haloacetic acids induce epigenetic } \\
\text { changes (particularly DNA } \\
\text { hypomethylation) that alter gene } \\
\text { expression, DNA repair, and cell } \\
\text { phenotype. } \\
\text { 2. These changes advance acquisition of } \\
\text { multiple critical traits contributing to } \\
\text { carcinogenesis. }\end{array}$ \\
\hline $\begin{array}{l}\text { Electrophilicity, } \\
\text { induction of } \\
\text { oxidative stress }\end{array}$ & $\begin{array}{l}\text { Glutathione S-transferase zeta (GST- } \zeta \text { ) } \\
\text { inhibition }\end{array}$ & $\begin{array}{l}\text { 1. Haloacetic acids bind to GST- } \zeta \text { causing } \\
\text { irreversible inhibition. } \\
\text { 2. Deficiency in GST- } \zeta \text { results in reduced } \\
\text { metabolism and clearance of dihaloacetic } \\
\text { acids, higher levels of tyrosine } \\
\text { metabolites, oxidative stress, and } \\
\text { activation of stress-response pathways. } \\
\text { 3. Accumulation of tyrosine metabolites and } \\
\text { oxidative stress lead to tumor formation. }\end{array}$ \\
\hline
\end{tabular}




\section{Characteristic(s) of Carcinogens}

Modulation of receptor mediated effects

\section{Mode of Action}

Peroxisome proliferator-activated receptor $\alpha$ (PPAR $\alpha$ ) activation

\section{Key Events}

\section{Haloacetic acids activate PPAR $\alpha$ in the} liver.

2. PPAR $\alpha$ activation leads to altered cell proliferation and apoptosis.

3. Alterations in cell proliferation and apoptosis cause clonal expansion of initiated cells.

4. Clonal expansion of initiated cells leads to tumor formation.

Cell immortalization, induction of epigenetic alterations, genotoxicity
Cell transformation

Cell transformation

1

1. Haloacetic acids induce genetic and/or epigenetic alterations in the target cell.

2. These changes lead to altered gene expression and signal transduction and acquisition of a malignant phenotype including blocked cellular differentiation and morphological transformation, acquisition of an unlimited life span, genetic instability, anchorage-independent growth, foci formation, clonal expansion, and tumor formation.

\begin{tabular}{ll}
\hline Alteration of cell & Sustained cellular proliferation and \\
proliferation or cell & suppression of apoptosis \\
death &
\end{tabular}

1. Haloacetic acids induce sustained cell proliferation, cytotoxicity and reparative hyperplasia, and/or decreased programmed cell death (apoptosis) in target tissues.

2. Increased cell proliferation and reduced apoptosis.

3. Increases the probability that initiated cells will form and survive.

4. Survival of initiated cells leads to clonal expansion, foci formation, and tumor formation.

Sources: Dad et al. (2013); USEPA (2011b); IARC (2013a; 2013b; 2014a; 2014b); Pals et al. (2011); Smith et al. (2016); Wood et al. (2015). 


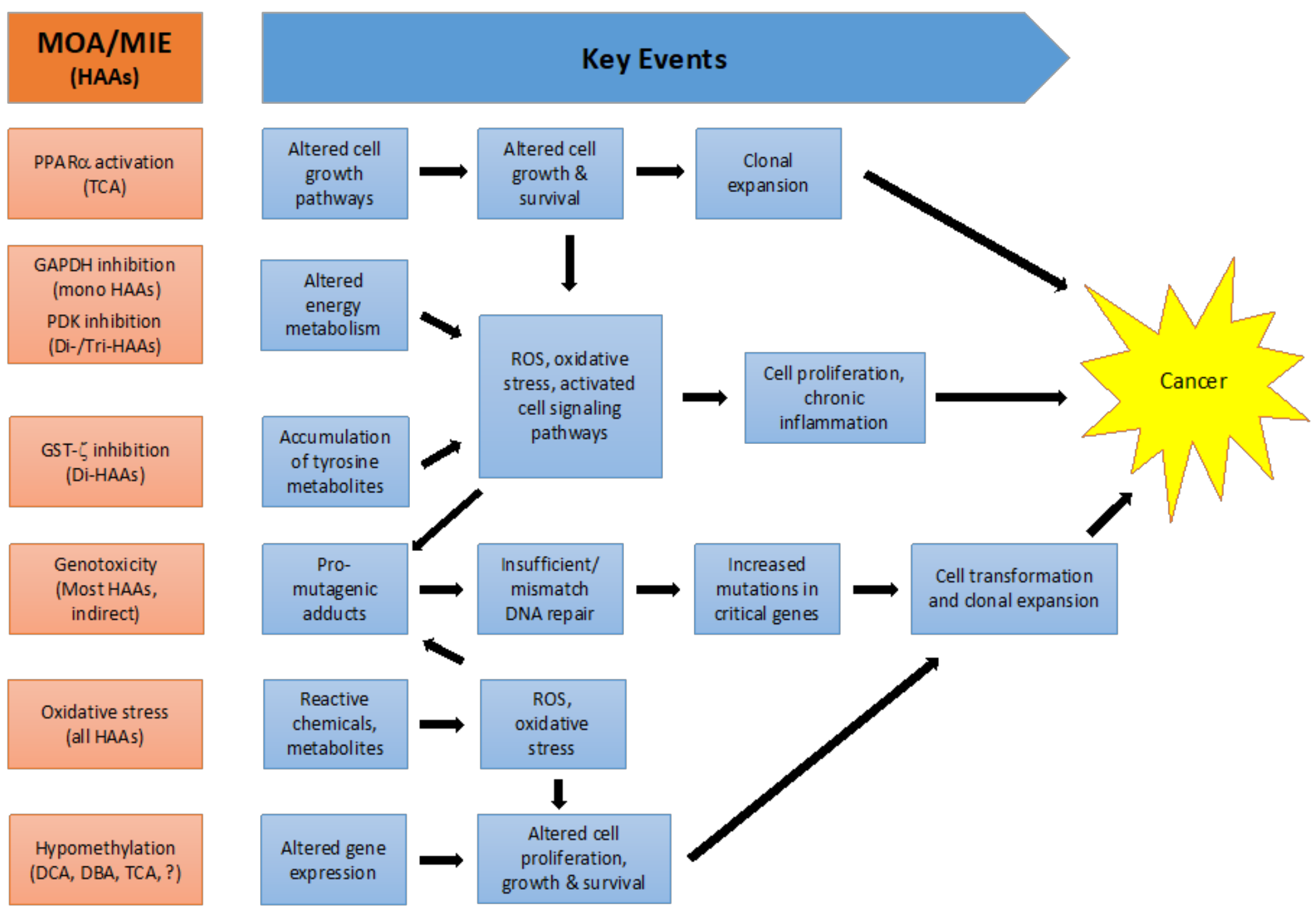

Figure 6-6. Interactions of Potential Modes of Action and Key Events Associated with Haloacetic Acid-induced Carcinogenicity

$\mathrm{MOA}=$ mode of action; MIE = molecular initiating event; HAA = haloacetic acid; PPAR $\alpha=$ peroxisome proliferator-activated receptor alpha; GAPDH $=$ glyceraldehyde-3phosphate dehydrogenase; PDK = pyruvate dehydrogenase kinase; GST- $\zeta=$ glutathione $S$-transferase zeta; ? = uncertain. 
RoC Monograph on Haloacetic Acids

\section{Evaluation of Haloacetic Acids as a Class or Subclass(es)}

Since only 6 of the 13 haloacetic acids considered in this monograph have been tested for carcinogenicity in experimental animals, the primary purpose of this section is to evaluate whether or not the carcinogenic potential of any or all of the haloacetic acids that have not been tested in long-term animal cancer bioassays could be reasonably predicted based on application of read-across-like principles and methods. The key questions addressed in this section are as follows:

1. Can haloacetic acids be evaluated as a class or subclass(es) for potential carcinogenicity based on a common mode(s) of carcinogenic action or key intermediate events that are relevant to carcinogenicity?

2. Can a read-across (e.g., QSAR) model and/or other models help inform the evaluation of the carcinogenicity of haloacetic acids that do not have animal carcinogenicity studies?

\subsection{Approach and Methods}

A read-across-like approach was used to determine whether haloacetic acids could be evaluated as a class or subclass(es) or if this approach could be applied to individual haloacetic acids that do not have cancer data. Read-across is a data gap-filling technique used with an analogue or category (group of chemicals whose physico-chemical, metabolic, and toxicological properties are likely to be similar or follow a regular pattern based on structural similarity) approach (ECHA 2008; Patlewicz et al. 2015). In the read-across approach, endpoint information for a tested chemical (source) is used to predict the same endpoint for another chemical (target) which is considered similar (Patlewicz et al. 2015; Schultz et al. 2015). Haloacetic acids as a class were judged to fit the general definition of a chemical category based on chemical structure, properties, and generally consistent patterns in toxicokinetics and toxicology. OECD (2017) defines a chemical category as, "a group of chemicals whose physicochemical and human health and/or ecotoxicological properties and/or environmental fate properties are likely to be similar or follow a regular pattern, usually as a result of structural similarity." In this context, the use of a read-across-like approach is intended to predict carcinogenicity for haloacetic acids that have not been tested in a cancer bioassay.

Two general approaches are described here: (1) a category approach in which a group of haloacetic acids, consisting of either all 13 molecules or a chemically defined subclass with fewer haloacetic acids can be evaluated together, and (2) evaluation of individual haloacetic acids using metabolism data and/or an analogue approach. The first approach would use basic read-across-like methods to determine if data gaps can be filled and would include an evaluation of all the relevant data presented in the previous sections of this monograph to determine if it is feasible to consider all haloacetic acids or a specific subclass of haloacetic acids as a category based on carcinogenicity (Section 7.2). The second approach will determine if individual haloacetic acids (without cancer data) could be evaluated as metabolites and/or with an analogue approach to read-across based on similar metabolic pathways and toxicokinetic data when compared to related chemicals (i.e., analogues) with cancer data (Section 7.3). The methods for 
the two variations of the category approach are described below in Sections 7.1.1 for all 13 haloacetic acids and 7.1.2 for potential subclasses, and the methods for the analogue approach are described in Section 7.1.3. The application of the category approach for all 13 haloacetic acids is discussed in Section 7.2, that for a subclass of haloacetic acids in Section 7.3, and the analogue approach in Section 7.4.

\subsubsection{Approach for Evaluating Haloacetic Acids as a Class}

The primary methods for the read-across-like approach for evaluating haloacetic acids as a class include (1) a comparison of the mechanistic data based on the characteristics of carcinogens across the different haloacetic acids, (2) an assessment of QSAR evaluations of haloacetic acids reported in the literature for biological effects, and (3) a comparison of cancer potency using QSAR modeling and reported animal cancer data for haloacetic acids.

The general trends in potency estimates for various mechanistic endpoints and chemical properties of the 13 haloacetic acids are shown in a heat map in Table 7-1, which summarizes data previously described in Section 1 (chemical properties), Section 3 (toxicokinetics), Section 4 (animal carcinogenicity), and Section 6 (mechanistic and other relevant data) that provide information potentially related to toxicity and carcinogenicity of HAAs. This table includes toxicokinetic data, physicochemical properties $\left(\mathrm{p} K_{\mathrm{a}}, \mathrm{E}_{\mathrm{LUMO}}\right.$, and binding affinity for proteins and DNA), in vitro and in vivo data for several key events potentially associated with carcinogenicity (see Section 6, Figure 6-6), and animal carcinogenicity (see Section 4). Each row in the table is independently scored and ranked on a color scale with darker to lighter shades indicating high to low value or potency, white representing negative $(\mathrm{N})$ results, and gray denoting no data. Most of the data in Table 7-2 were derived from the potency estimates discussed in Section 6 and tabulated in Appendix D.

Carcinogenic potency was assessed using two quantitative measures (both expressed as $\mathrm{mg} / \mathrm{kg}$ body weight per day) - a QSAR model for predicting TD $_{50}$ values (chronic dose rate that would induce tumors in half the animals tested) and benchmark doses (BMDs) as 95\% lower confidence corresponding to a $10 \%$ response level (BMDLs). The TD 50 values were predicted for all 13 haloacetic acids using a readily available open source QSAR model, the ADMET Predictor ${ }^{\mathrm{TM}}$ version 7.2 chronic carcinogenicity model (http://www.simulationsplus.com/software/admet-property-prediction-qsar/), for both rats and mice based on the parent compound structure and default settings. BMDL values for trichloro- and dichloroacetic acids were available from EPA's Integrated Risk Information System (IRIS) database (available at https://www.epa.gov/iris) and BMDL values for combined liver tumors in male mice (dibromo-, bromochloro-, and bromodichloroacetic acid were available from NTP studies (CEBS database available at https://cebs.niehs.nih.gov/multistage/). Predicted BMDLs and estimated TD $\mathrm{T}_{50} \mathrm{~S}$ (reported as reciprocals) are included in Table 7-1.

In addition, a subjective measure of carcinogenic potency was derived from the results of the animal cancer bioassays and results are included in Table 7-1. Values of 0 to 3 were assigned as follows: $\mathrm{N}=$ negative response, $1=$ liver tumors in mice only, $2=$ liver tumors in mice and rats, and $3=$ liver and other tumor sites in rats and mice. 
Table 7-1. Comparison of Relative Potency Estimates for Mechanistic Endpoints and Chemical Properties of Haloacetic Acids

\begin{tabular}{|c|c|c|c|c|c|c|c|c|c|c|c|c|c|}
\hline \multirow{2}{*}{ Endpoint } & \multicolumn{3}{|c|}{ Monohaloacetic Acids } & \multicolumn{6}{|c|}{ Dihaloacetic Acids } & \multicolumn{4}{|c|}{ Trihaloacetic Acids } \\
\hline & $\mathbf{C A}$ & $\mathbf{B A}$ & IA & DCA & DBA & DIA & BCA & CIA & BIA & TCA & TBA & BDCA & CDBA \\
\hline \multicolumn{14}{|l|}{ Toxicokinetics $^{\mathrm{a}}$} \\
\hline Unbound fraction (\%) & 27 & & & 94 & 89 & & 93 & & & 53 & 18 & 49 & 55 \\
\hline Total clearance $(\mathrm{mL} / \mathrm{kg} / \mathrm{h})$ & 262 & & & 267 & 491 & & 1037 & & & 92.5 & 754 & 286 & 486 \\
\hline \multicolumn{14}{|l|}{ Chemical properties $^{\mathrm{b}}$} \\
\hline $\mathrm{p} K_{\mathrm{a}}$ & 2.97 & 2.96 & 2.95 & 1.41 & 1.39 & & 1.4 & 1.47 & 1.67 & 0.66 & 0.03 & 0.05 & 0.04 \\
\hline ELUMO $_{\text {Leprotonated) }}$ & 9.43 & 8.68 & 7.18 & 8.44 & 7.51 & & 7.78 & 6.40 & 6.46 & 7.13 & 6.12 & 6.65 & 6.42 \\
\hline $\mathrm{TR}_{\mathrm{GSH}}$ & 0.71 & 2.18 & 2.15 & 1.68 & 1.48 & & 1.93 & 1.35 & 0.62 & 1.01 & 2.26 & 1.56 & 1.1 \\
\hline \multicolumn{14}{|l|}{ Oxidative stress in vivo $^{\mathrm{d}}$} \\
\hline 8-OHdG & & & & 1.4 & 2.9 & & 2.9 & & & 1.2 & & 1.7 & \\
\hline TBARS & & & & 129 & 250 & & 290 & & & 67 & & 240 & \\
\hline \multicolumn{14}{|l|}{ Genetox in vitro } \\
\hline SOS-umuC $\mathrm{C}^{\mathrm{c}, \mathrm{e}}$ & 60 & 2400 & 15400 & 180 & 2564 & & 2941 & 5263 & 9091 & 60 & 142860 & 9091 & 9091 \\
\hline Ames TA100 (-S9) & 44 & 6588 & 14129 & 36 & 183 & & & & & $\mathrm{~N}$ & $\mathrm{~N}$ & & \\
\hline Ames TA100 (-S9) & & & & 5.2 & 61.9 & & 60.6 & & & $\mathrm{~N}$ & 1.2 & 31.6 & 1.7 \\
\hline Comet $\mathrm{CHO}$ cells $\mathrm{s}^{\mathrm{h}}$ & 2439 & 58820 & 114900 & $\mathrm{~N}$ & 556 & 500 & 333 & & 313 & $\mathrm{~N}$ & 400 & $\mathrm{~N}$ & 71 \\
\hline HGPRT CHO cells ${ }^{\mathrm{i}}$ & 8.7 & 14.6 & 836 & 2.8 & 66.2 & & & & & $\mathrm{~N}$ & & & \\
\hline
\end{tabular}


RoC Monograph on Haloacetic Acids

\begin{tabular}{|c|c|c|c|c|c|c|c|c|c|c|c|c|c|}
\hline \multirow{2}{*}{ Endpoint } & \multicolumn{3}{|c|}{ Monohaloacetic Acids } & \multicolumn{6}{|c|}{ Dihaloacetic Acids } & \multicolumn{4}{|c|}{ Trihaloacetic Acids } \\
\hline & CA & BA & IA & DCA & DBA & DIA & BCA & CIA & BIA & TCA & TBA & BDCA & CDBA \\
\hline P53-bla ${ }^{\mathrm{c}}$ & 5882 & 105260 & 212770 & $\mathrm{~N}$ & 3846 & & 4348 & 9091 & 9091 & $\mathrm{~N}$ & $\mathrm{~N}$ & $\mathrm{~N}$ & $\mathrm{~N}$ \\
\hline PPAR $\alpha$ in vitro ${ }^{k}$ & 2 & 20 & 100 & 1 & 1 & & & & & 2 & 1 & & \\
\hline PPAR $\alpha$ in vivo ${ }^{1}$ & $\mathrm{~N}$ & & & 2 & 3.5 & & $\mathrm{~N}$ & & & 4.3 & & $\mathrm{~N}$ & \\
\hline Species/tumor site ${ }^{\mathrm{n}}$ & $\mathrm{N}$ & & & 2 & 3 & & 3 & & & 1 & & 3 & \\
\hline $\mathrm{TD}_{50} \mathrm{~s}$ rat $(\text { predicted })^{\circ}$ & 0.0041 & 0.0025 & 0.0015 & 0.0071 & 0.0029 & 0.0012 & 0.0044 & 0.0028 & 0.0019 & 0.0076 & 0.0027 & 0.0052 & 0.0037 \\
\hline $\mathrm{TD}_{50} \mathrm{~S}$ mouse (predicted) ${ }^{\circ}$ & 0.0021 & 0.0012 & 0.0007 & 0.0024 & 0.0011 & 0.0004 & 0.0016 & 0.0010 & 0.0007 & 0.0027 & 0.0011 & 0.0019 & 0.0014 \\
\hline BMDL $^{p}$ & & & & 0.49 & 0.04 & & 0.08 & & & 0.67 & & 0.06 & \\
\hline
\end{tabular}

Darker to lighter shade $=$ high to low value or potency, white $=$ negative $(\mathrm{N})$, gray $=$ no data.

a Schultz et al. (1999) (di- and trihaloacetic acids), Kaphalia et al. (1992); Saghir et al. (2001); Saghir and Rozman (2003) (chloroacetic acid, high doses).

${ }^{\mathrm{b}} \mathrm{p} K_{\mathrm{a}}=$ the negative log of the acid dissociation constant (lower $\mathrm{p} K_{\mathrm{a}}$ indicates stronger acid and greater dissociation at physiological $\left.\mathrm{pH}\right)$; ELumO $=$ energy of the lowest unoccupied molecular orbital (lower value indicates softer electrophile); TR = toxicity ratio (TR $\mathrm{GSH}_{\mathrm{G}}>1.2$ suggest the compound is a soft electrophile and preferentially reacts with protein,

$\mathrm{TR}_{\mathrm{DNA}}>1.2$ indicates hard electrophile and preferentially reacts with DNA, both values $>1.2$ indicates unspecific reactivity ) (Stalter et al. 2016a).

${ }^{\mathrm{c}} 1 / \mathrm{EC}$ IR1.5: Effective concentration that elicits an induction ratio of 1.5 (i.e., 1.5-fold or 50\% effect increase compared to the control) (Stalter et al. 2016a).

d8-OHdG/105 dG liver, TBARS: nmol malondialdehyde/g liver (Austin et al. 1996; Larson and Bull 1992).

${ }^{\mathrm{e}} 1 / \mathrm{EC}_{\mathrm{IR} 1.5}$ (Stalter et al. 2016a; Zhang et al. 2016).

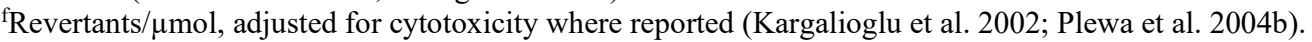

${ }^{g}$ Revertants/ $\mu \mathrm{mol}$ (CEBs database). Note: CEBS data are not directly comparable to Plewa et al. (2004b) and Kargalioglu et al. (2002) because of different methods.

${ }^{\mathrm{h}} 1 /$ genotoxic potency (i.e., HAA concentration calculated using regression analysis at the midpoint of the curve within a concentration range that expressed $>70 \%$ cell viability)

(Plewa et al. 2010).

iMutant frequency/mM (Zhang et al. 2010).

$\mathrm{j} 1$ = positive, 0.5 = weak positive, $0=$ negative (IARC 2013a; 2013b; 2014a; 2014b; NTP 2007b; NTP 2009; NTP 2015).

${ }^{\mathrm{k}} 1 / \mathrm{LEC}$ (lowest effective concentration) (Walgren et al. 2004).

${ }^{1}$ Fold increase compared to control (Acyl-CoA- oxidase activity (DeAngelo et al. 1989; NTP 2015; Parrish et al. 1996; Xu et al. 1995).

m\% reduction enzyme activity compared to controls (Anderson et al. 1999; Gonzalez-Leon et al. 1999).

${ }^{\mathrm{n}} \mathrm{N}=$ no evidence of carcinogenicity, $1=$ liver tumors in mice only, $2=$ liver tumors in rats and mice, $3=$ multiple tumor sites in rats and mice.

${ }^{\mathrm{O}}$ ADMET Predictor ${ }^{\mathrm{TM}}$ software.

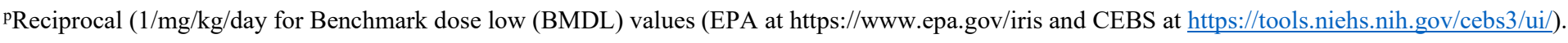




\subsubsection{Approach for Evaluating Subclasses of Haloacetic Acids}

The approach for evaluation of subclasses of haloacetic acids is essentially the same as for the set of 13 haloacetic acids, but by making subclasses based on similar chemical structures, e.g., number of halogens or type of halogen substitutions, it might be possible to apply the readacross-like methods described above to a set of molecules with more consistent chemical characteristics.

\subsubsection{Approach for Evaluating Haloacetic Acids for a Potential Analogue Approach}

The approach for identifying potential analogues among haloacetic acids uses one molecule with tumorigenicity data as a source chemical to inform the potential tumorigenicity of a second haloacetic acid that has not been tested in a cancer bioassay. Reasons for selecting a source chemical or chemicals for a target haloacetic acid include metabolism, which could provide direct evidence that the tumorigenic source chemical is metabolized to the target chemical and similarities of physicochemical properties that are related to potential key events in carcinogenicity (see Table 7-2).

\subsection{Evaluation of Haloacetic Acids as a Class}

Overall, studies of metabolism, clearance, cytotoxicity, genotoxicity, and other non-cancer adverse effects among the haloacetic acids provide some evidence that haloacetic acids could be considered as a class or subclass. As mentioned in Section 6, the haloacetic acids are generally considered soft electrophiles and the likely molecular initiating event is reaction with protein sulfhydryl groups. Reaction with proteins can cause indirect genotoxicity through generation of reactive oxygen species (ROS) (Stalter et al. 2016a). The available studies found a strong relationship for greater toxic potency with larger halogen size (i.e., iodo- $>$ bromo- $\gg$ chloro-) and decreasing toxicity with an increasing degree of halogenation (i.e., mono- $>$ di- $>$ tri-) (see Table 7-1). There are some exceptions to the general trends (e.g., trichloroacetic acid is the strongest PPAR $\alpha$ agonist while dichloroacetic acid shows low activity for many of the key events). In cases where data were available for only a few of the haloacetic acids (e.g., GST- $\zeta$ inhibition, in vivo genetic effects, or oxidative stress), the trends are not as evident because of incomplete data.

QSAR techniques have also successfully predicted several biological properties of the haloacetic acids as a category and have established similarity patterns among these chemicals. Two independent in vitro studies investigated different biological effects (oxidative stress and genotoxicity, and neural tube defects in mouse embryo cultures) of the haloacetic acids and reported that although the relative potency of the mono-, di-, and trihaloacetic acids was not highly correlated with any single property, there was a strong correlation when two chemical properties were considered together as independent variables: energy of the lowest unoccupied molecular orbital ( $\left.\mathrm{E}_{\mathrm{LUMO}}\right)$ and the acid dissociation constant $\left(\mathrm{p} K_{\mathrm{a}}\right)$ (Richard and Hunter 1996; Stalter et al. 2016a). A series of QSAR models further indicated that these two molecular parameters account for two opposing trends in the data: $E_{\text {LUMO }}$ was related to the intrinsic reactivity and correlated with increasing potency with halogen size, especially among the monohaloacetic acids. On the other hand, $\mathrm{p} K_{\mathrm{a}}$ was related to transport and bioavailability and correlated with decreasing potency with an increasing degree of halogenation within a series 
(i.e., bromo- $>$ dibromo- $>$ tribromoacetic acid) and increasing potency with halogen size among the di- and trihaloacetic acids (Richard and Hunter 1996). Related parameters that have shown moderate to strong correlations with cytotoxicity and/or genotoxicity of haloacetic acids include the log octanol/water partition coefficient $\left(\log K_{\text {ow }}\right)$, carbon-halogen bond length, and relative SN2 reactivity (Pals et al. 2011; Plewa et al. 2010; Plewa et al. 2004b).

Although the data show consistent trends in potency for many of the potential key events involved in the toxicity of these compounds, their relationship to carcinogenic potency is unknown. In addition, the available carcinogenicity data do not appear to support evaluating haloacetic acids as a class. Using a subjective measure of carcinogenicity (described above), the trend observed with the carcinogenicity data is somewhat consistent with the trends observed with other endpoints (i.e., brominated $>$ chlorinated forms and dichloroacetic acid $>$ trichloroacetic acid) but does not distinguish between di- or trihaloacetic acids containing at least one bromine atom. Moreover, chloroacetic acid also presents a challenge because the data do not explain the absence of rodent carcinogenicity when this compound shows a greater or similar genotoxic and oxidative stress potency than the di- or trihaloacetic acids. However, the maximum dose tested by oral exposure in mice was much lower $(100 \mathrm{mg} / \mathrm{L})$ than that used for the other tested haloacetic acids (at least $1,000 \mathrm{mg} / \mathrm{L}$ ) because of high toxicity of chloroacetic acid. The estimated $\mathrm{TD}_{50}$ and published BMDLs for carcinogenicity do not follow these general trends. The QSAR predicted TD 50 for carcinogenicity of all 13 haloacetic acids based on structural attributes and default settings that were within one order of magnitude of each other, did not predict that chloroacetic acid would be inactive as a rodent carcinogen, and predicted that trichloroacetic acid was the most potent. The published BMDL values (liver tumors in male mice) for dichloro-, dibromo-, bromochloro-, trichloro-, and bromodichloroacetic acid ranged from 1.5 to about $25 \mathrm{mg} / \mathrm{kg} /$ day, thus, they do not provide sufficient separation to determine a potency trend with any degree of confidence and also indicated that trichloroacetic acid was the most potent. In addition, the mechanisms by which haloacetic acids induce carcinogenic effects in experimental animals have not been conclusively determined and remain as a large source of uncertainty for read-across, especially for an apical endpoint as complex as carcinogenicity.

There is also evidence that, at least for dichloroacetic acid and trichloroacetic acid, the modes of action are likely different based on species affected and dose response of tumor formation, liver tumor mutation spectra, toxicokinetics, PPAR $\alpha$ activation, liver pathology, and tumor phenotypes (Anna et al. 1994; Bull 2000; Bull et al. 2002; Bull et al. 1990; Corton 2008; Ferreira-Gonzalez et al. 1995; Pereira and Phelps 1996; Stauber et al. 1998).

Based on the lack of a well-defined mechanism or mode(s) of action, combined with evidence that at least some of the haloacetic acids do not share a common mode(s) of action, the lack of a clear trend in carcinogenic potency, the absence of carcinogenic activity of chloroacetic acid in rodents, and the lack of a suitable QSAR model, the current data do not support considering all 13 haloacetic acids as a chemical class.

\subsection{Potential Haloacetic Acid Subclasses}

Although the current data were judged insufficient to support evaluating the set of 13 haloacetic acids as a category, the data were examined to determine if subclasses of haloacetic acids (see Table 7-2) could potentially be evaluated using a category approach. One consideration for this approach is the possibility that different mechanisms might exist for different subclasses of haloacetic acids. Potential analogues within each subclass were also considered to determine if 
haloacetic acids with cancer data could be matched with a target chemical (without cancer data) to predict the carcinogenicity of that target chemical.

Overall, available data did not identify any subclass (i.e., category based on number or type of halogen substitution) of haloacetic acids that could be evaluated for carcinogenicity because of the lack of a common mode of action, the lack of adequate cancer data, and/or inconsistencies in the cancer data among the members of that subclass. Of the subclasses of haloacetic acids, the confidence for a potential category for using read-across approaches was highest for subclasses that include brominated haloacetic acids, which are more similar with respect to tumor profiles, than those subclasses that included the chlorinated haloacetic acids (i.e., chloroacetic acid, dichloroacetic acid and trichloroacetic acid). The subclass with the highest potential was the diand trihaloacetic acids which includes three members with animal cancer data (dichloroacetic acid, bromochloroacetic acid, dibromoacetic acid) and three members without animal cancer data (chlorodibromoacetic acid, tribromoacetic acid, bromoiodoacetic acid). A strength of this approach is that chlorodibromoacetic acid and tribromoacetic acid are metabolized to the two dihaloacetic acids with animal cancer data. However, a read-across approach for the other members of a subclass without animal cancer data (bromoidooacetic acid) is more uncertain because of the lack of direct experimental evidence for effects of substitution of bromine or chlorine atoms with iodine on tumorigenicity. Additional toxicological data on key events may contribute to a better understanding of the mode(s) of action and could reduce uncertainty in the read-across of haloacetic acids in the future.

Even though no category could be identified for the 13 haloacetic acids as a class or for subclasses within the set, application of an analogue approach (see Section 7.1.3) is possible for chlorodibromoacetic acid and tribromoacetic acid, which is described in Section 7.4. Potential analogues within each subclass are identified in the Rationale column.

Table 7-2. Evaluation of Subclasses of Haloacetic Acids

\begin{tabular}{|c|c|c|c|}
\hline Subclass & Members $^{\mathrm{a}}$ & $\begin{array}{c}\text { Confidence for } \\
\text { Potential } \\
\text { Category }\end{array}$ & Rationale \\
\hline Monohaloacetic acids & $\mathrm{CA}, \mathrm{BA}, \mathrm{IA}$ & No & $\begin{array}{l}\text { CA tested negative in a long-term cancer } \\
\text { bioassay. IA was positive in the cell } \\
\text { transformation assay. Insufficient data to } \\
\text { read-across to BA or IA. }\end{array}$ \\
\hline Dihaloacetic acids & $\begin{array}{l}\text { DCA, DBA, DIA, } \\
\text { BCA, CIA, BIA }\end{array}$ & Low & $\begin{array}{l}\text { DCA, DBA, and BCA are rodent carcinogens } \\
\text { and are potential analogues for read-across to } \\
\text { the iodinated compounds; however, greater } \\
\text { uncertainty regarding impact of iodine } \\
\text { substitution on carcinogenicity. }\end{array}$ \\
\hline
\end{tabular}




\begin{tabular}{|c|c|c|c|}
\hline Subclass & Members $^{a}$ & $\begin{array}{c}\text { Confidence for } \\
\text { Potential } \\
\text { Category }\end{array}$ & Rationale \\
\hline Trihaloacetic acids & $\begin{array}{l}\text { TCA, TBA, BDCA, } \\
\text { CDBA }\end{array}$ & Low & $\begin{array}{l}\text { TCA and BDCA tested positive in cancer } \\
\text { bioassays. TCA may cause liver cancer via } \\
\text { different mechanisms than other haloacetic } \\
\text { acids. } \\
\text { Potential analogues: BDCA could be used as } \\
\text { an analogue for potential read-across to } \\
\text { CDBA, which is also metabolized to BCA. } \\
\text { There is more uncertainty with read-across to } \\
\text { TBA. }\end{array}$ \\
\hline $\begin{array}{l}\text { Chlorinated acetic } \\
\text { acids }\end{array}$ & $\begin{array}{l}\text { CA, DCA, BCA, CIA, } \\
\text { TCA }\end{array}$ & No & $\begin{array}{l}\text { All but CIA have been tested in long-term } \\
\text { cancer bioassays; however, the negative } \\
\text { findings of CA in cancer studies present a } \\
\text { challenge for read-across, and result in } \\
\text { increased uncertainty. } \\
\text { Potential analogues: BCA could be a } \\
\text { potential analogue for read-across to CIA. }\end{array}$ \\
\hline $\begin{array}{l}\text { Brominated acetic } \\
\text { acids }\end{array}$ & $\begin{array}{l}\text { BA, DBA, BCA, BIA, } \\
\text { TBA, BDCA, CDBA }\end{array}$ & $\begin{array}{l}\text { Maybe } \\
\text { Low/moderate }\end{array}$ & $\begin{array}{l}\text { DBA, BCA, and BDCA are rodent } \\
\text { carcinogens. TBA is metabolized to DBA and } \\
\text { CDBA is metabolized to BCA. The } \\
\text { uncertainty for this subclass is based on lack } \\
\text { of carcinogenicity with CA and a possible } \\
\text { unique mode of action for the monohaloacetic } \\
\text { acids. } \\
\text { Potential analogues: BCA is a potential } \\
\text { analogue for read-across to BIA, but more } \\
\text { uncertainty as noted above. BDCA is a } \\
\text { potential analogue for read-across to CDBA, } \\
\text { which is also metabolized to BCA. }\end{array}$ \\
\hline Iodinated acetic acids & IA, DIA, CIA, BIA & No & $\begin{array}{l}\text { None of the members have been tested in a } \\
\text { long-term cancer bioassay. The modes of } \\
\text { action may not be the same for the mono- and } \\
\text { dihaloacetic acids containing iodine. }\end{array}$ \\
\hline
\end{tabular}




\begin{tabular}{|c|c|c|c|}
\hline Subclass & Members $^{a}$ & $\begin{array}{c}\text { Confidence for } \\
\text { Potential } \\
\text { Category }\end{array}$ & Rationale \\
\hline $\begin{array}{l}\text { Brominated di- and } \\
\text { trihaloacetic acids }\end{array}$ & $\begin{array}{l}\text { DBA, BCA, BIA, } \\
\text { TBA, BDCA, CDBA }\end{array}$ & Moderate & $\begin{array}{l}\text { DBA, BCA, and BDCA are rodent } \\
\text { carcinogens. Based on similarity of tumor } \\
\text { profiles and trends in metabolism, } \\
\text { toxicokinetics, physicochemical properties, } \\
\text { and potential key events, the mode of action } \\
\text { for this subclass is possibly similar. However, } \\
\text { the similarities are greater within the dihalo- } \\
\text { and trihaloacetic acids than across these } \\
\text { molecules. }\end{array}$ \\
\hline & & & $\begin{array}{l}\text { Potential analogues: TBA is metabolized } \\
\text { directly to DBA and CDBA is metabolized to } \\
\text { BCA. In addition, BDCA is a potential } \\
\text { analogue for read-across to both CDBA and } \\
\text { TBA. Read-across to BIA is more uncertain } \\
\text { as noted above. }\end{array}$ \\
\hline
\end{tabular}

$\mathrm{CA}=$ chloroacetic acid; $\mathrm{BA}=$ bromoacetic acid; $\mathrm{IA}=$ iodoacetic acid; DCA $=$ dichloroacetic acid; DBA = dibromoacetic acid; $\mathrm{BCA}=$ bromochloroacetic acid; DIA = diiodoacetic acid; CIA = chloroiodoacetic acid; BIA = bromoiodoacetic acid; $\mathrm{TCA}=$ trichloroacetic acid; TBA = tribromoacetic acid; BDCA = bromodichloroacetic acid; CDBA = chlorodibromoacetic acid.

\subsection{Individual Di- and Tribromohaloacetic Acids}

Based on their metabolism to known rodent carcinogens, both bromochloroacetic acid and dibromoacetic acid are predicted to cause cancer in rodents. Chlorodibromo- and tribromoacetic acid are directly metabolized to bromochloro- and dibromoacetic acid, respectively (see Sections 3 and 7.4.1 below) and both dihaloacetic acids, as well as bromodichloroacetic acid (which could also be a potential analogue), have been shown to be rodent carcinogens (see Section 4). Thus, dibromoacetic acid was selected an analogue for read-across to tribromoacetic acid, and bromochloroacetic acid is as an analogue for read-across to chlorodibromoacetic acid based on their metabolism and similar physiochemical properties, toxicokinetics properties, and biological effects in vivo and in vitro (e.g., similar potencies for genetic and oxidative stress) (see Table 7-1). Supporting evidence for these conclusions is discussed below.

\subsubsection{Metabolism and Toxicokinetics}

Trihaloacetic acids are primarily metabolized by reductive dehalogenation that generates a dihaloacetic acid via a free radical intermediate (Anderson et al. 1999; Austin and Bull 1997; Saghir et al. 2011; Xu et al. 1995). Saghir et al. (2011) demonstrated that reductive dehalogenation of tribromoacetic acid in vitro by a rat liver enzyme preparation (microsomes) produced dibromoacetic acid in a 1:1 molar ratio with the bromide ion $\left(\mathrm{Br}^{-}\right)$liberated and there was no evidence of additional oxidative metabolism. This study also demonstrated that bromodichloro-, chlorodibromo-, and tribromoacetic acids were rapidly metabolized by rat liver microsomes to the di-haloacetic acid product corresponding to the loss of a single $\mathrm{Br}^{-}$. Further, substitution of bromines enhanced metabolism, thus, tribromo- and chlorodibromo- are metabolized to their corresponding dihaloacetic acid to a much greater degree than trichloroacetic acid (Saghir et al. 2011; Schultz et al. 1999). (See Section 3 for a more complete discussion of metabolism and toxicokinetics.) 


\subsubsection{Carcinogenicity Data}

Near lifetime exposure to bromodichloroacetic acid and dibromoacetic acid in the drinking water caused liver tumors in mice as well as tumors at other tissue sites (listed in Table 7-3) in rats and mice. Thus, chlorodibromoacetic acid and tribromoacetic acid are predicted to be animal carcinogens based on metabolism to bromochloroacetic acid and dibromoacetic acid, respectively. Moreover, all of the di- and trihaloacetic acids tested caused liver tumors in mice, which increases the confidence that chlorodibromoacetic acid and tribromoacetic acid would specifically cause liver tumors in mice. The three tested brominated di-and trihaloacetic acids, (dibromo-, bromochloro- and bromodichloroacetic acids), which are the postulated source chemicals, also caused malignant mesothelioma in male rats. Based on the greater metabolism of the brominated trihaloacetic acids compared to trichloroacetic acid, and the generally greater biological and carcinogenic activity with bromine substitution for chlorine, it is expected that the tumor profiles of chlorodibromoacetic and tribromoacetic acids will be more similar to their direct metabolites (bromochloroacetic acid and dibromoacetic acid, respectively) than the carcinogenicity of trichloroacetic acid and its metabolite dichloroacetic acid. Although no in vivo studies were identified for metabolism of trichloroacetic acid to dichloroacetic acid, oral exposure to trichloroethylene in mice resulted in dichloroacetic acid serum levels of only $0.048 \%$ of the trichloroacetic acid serum levels two hours after exposure (Kim et al. 2009) and unlike dichloroacetic acid, trichloroacetic acid administration in a 2-year cancer bioassay did not produce liver tumors in rats (DeAngelo et al. 1996; NTP 1992). The dihalogenated metabolites may not account for all of the carcinogenic potential of the trihaloacetic acids because bromodichloroacetic acid induced more tumor types in rodents than its primary metabolite, dichloroacetic acid. 
Table 7-3. Tumor Profiles in Source Chemicals and Predicted Tumor Profiles in Target Chemicals

\begin{tabular}{|c|c|c|c|c|c|}
\hline \multirow[t]{2}{*}{ Endpoint } & \multicolumn{3}{|c|}{ Source Chemicals } & \multicolumn{2}{|c|}{ Target Chemicals } \\
\hline & $\begin{array}{c}\text { BCA } \\
\text { (metabolite) }\end{array}$ & $\begin{array}{c}\text { DBA } \\
\text { (metabolite) }\end{array}$ & BDCA & CDBA & TBA \\
\hline Rats (sex) & Yes & Yes & Yes & Predicted & Predicted \\
\hline Liver $(\mathrm{M} / \mathrm{F})$ & No & No & No & - & - \\
\hline Mononuclear-cell leukemia (F) & No & Yes & No & - & - \\
\hline Malignant mesothelioma (M) & Yes & Yes & Yes & Likely site & Likely site \\
\hline Mammary (F) & Yes & No & Yes & - & - \\
\hline Skin & No & No & Yes & - & - \\
\hline Mice (sex) & Yes & Yes & Yes & Predicted & Predicted \\
\hline Liver (M/F) & Yes & Yes & Yes & $\begin{array}{l}\text { Very likely } \\
\text { site }\end{array}$ & $\begin{array}{l}\text { Very likely } \\
\text { site }\end{array}$ \\
\hline Lung (M) & No & Yes & No & - & - \\
\hline Harderian gland (M) & No & No & Yes & - & - \\
\hline
\end{tabular}

\subsubsection{Supporting Mechanistic Data}

In general, chlorodibromoacetic acid and tribromoacetic acid have similar toxicokinetic and biological effects compared with other brominated haloacetic acids that cause cancer in rodents (Table 7-1 and Table 7-3). Physicochemical properties also show that the electrophilicity increases with bromine content and that the trihaloacetic acids are stronger acids than the dihaloacetic acids. The available data for these two chemicals provide evidence that they also cause oxidative stress and genetic effects, e.g., mutations in bacteria and DNA strand breaks in cultured cells. These events are characteristic of other human carcinogens and support biological plausibility for the carcinogenicity of chlorodibromoacetic and tribromoacetic acids in humans.

\subsubsection{Conclusions}

The set of 13 haloacetic acids considered in this monograph did not form a category to evaluate all of them as a class because of (1) the lack of a well-defined mechanism or mode(s) of action, (2) data that suggest that at least some of the haloacetic acids do not share a common mode(s) of action, (3) the absence of carcinogenicity of chloroacetic acid, and (4) the lack of a clear trend in carcinogenic potency. QSAR model predictions of cancer potency were not consistent with the trends in the key events data. Therefore, the current data are inadequate to support considering all 13 haloacetic acids as a chemical class.

Subclasses of haloacetic acids based on number and types of halogen substitutions were also considered for making read-across predictions of carcinogenicity. The major limitations in the confidence for the read-across analyses are the lack of cancer data for any iodohaloacetic acids or monohaloacetic acids, the negative findings for chloroacetic acid (even though tested at a much lower dose in mice than other haloacetic acids), and data suggesting that trichloroacetic acid may cause cancer by different modes of action than dichloroacetic acid. None of the 
subclasses of haloacetic acids considered for read-across were considered to have sufficient evidence at this time to support their use as a category.

Consideration of one subclass with six di- and tribrominated haloacetic acids (dibromo-, bromochloro-, bromoiodo-, tribromo-, bromodichloro-, and chlorodibromoacetic acids) led to identification of two individual trihaloacetic acids as target chemicals for read-across based on metabolism and supporting mechanistic data. Cancer predictions were made for two members of this class that did not have cancer data: (1) tribromoacetic acid, which is metabolized to dibromoacetic acid (the source analogue), and (2) chlorodibromoacetic acid, which is metabolized to bromochloroacetic acid (which is the source analogue). Bromodichloroacetic acid is also a rodent carcinogen with similar physicochemical, toxicokinetic, and toxicological properties as the target chemicals, which provides additional support for the conclusion that both tribromoacetic acid and chlorodibromoacetic acid are reasonably anticipated to be rodent carcinogens. 


\section{Overall Cancer Evaluation and Preliminary Listing Recommendation}

The purpose of this monograph is to assess the carcinogenicity data for 13 haloacetic acids found as water disinfection by-products and to determine whether the scientific evidence meets the RoC criteria for listing as a class, subclasses, or as individual haloacetic acids. The overall evaluation integrates the assessments of the animal cancer studies (Section 4, Section 8.1), mechanistic and other relevant data (Section 6, Section 8.2), as well as the read-across analysis for evaluating haloacetic acids as a class or subclasses, to reach preliminary listing conclusions (see Figure 1 in Methods section).

Overall, the data from cancer studies in humans are inadequate to evaluate the relationship between human cancer and exposure specifically to the individual haloacetic acids, subclasses of haloacetic acids, or haloacetic acids as a class, as only one study was identified that provided risk estimates specific for a class of, or for individual haloacetic acids. However, studies on water disinfection by-products suggest the potential for cancer risk from chlorinated water and increase the confidence of the relevance of the animal cancer studies (conducted at higher doses) to humans.

\subsection{Evidence of Carcinogenicity from Studies in Experimental Animals}

There is sufficient evidence of carcinogenicity for dichloroacetic acid, dibromoacetic acid, bromochloroacetic acid, and bromodichloroacetic acid from studies in experimental animals.

The conclusion for each of these haloacetic acids is based on significantly increased incidences of malignant tumors or a combination of benign and malignant tumors at several organ sites in rodents or in several species by exposure in drinking water (see Section 4, Table 4-1 and Table 4-3, and Table 8-1 below). Exposure to dichloroacetic acid induced liver tumors (hepatocellular adenoma and carcinoma) in male Fischer 344 rats and in male and female B6 $3 \mathrm{~F}_{1}$ mice. Exposure to dibromoacetic acid, bromochloroacetic acid, and bromodichloroacetic acid induced liver tumors (hepatocellular adenoma, carcinoma) in both sexes and hepatoblastoma in male $\mathrm{B}_{6} \mathrm{C} 3 \mathrm{~F}_{1}$ mice and tumors at other sites in male and female Fischer 344 or Fischer $344 \mathrm{~N} / \mathrm{Tac}$ rats (for bromodichloroacetic acid). These three haloacetic acids all induced malignant mesothelioma in male rats and bromochloroacetic acid and bromodichloroacetic acid induced mammary gland tumors (fibroadenoma, carcinoma) in female rats. Bromodichloroacetic acid exposure also resulted in malignant skin tumors in male rats. Bromochloroacetic acid induced tumors in the large intestine in both sexes of rats. Although the large intestinal tumors were adenoma, they are considered to be supportive of a carcinogenic response because of their rarity and progression to malignant tumors. Dibromoacetic acid also induced lung tumors (alveolar/bronchiolar carcinoma) in male $\mathrm{B}_{6} \mathrm{C}_{3} \mathrm{~F}_{1}$ mice and bromodichloroacetic acid induced Harderian gland (benign or malignant) tumors in male rats.

The evidence of carcinogenicity from studies in experimental animals is not sufficient to meet the RoC criteria for listing monochloroacetic acid, monoiodoacetic acid, or trichloroacetic acid (TCA). Exposure to monochloroacetic acid by gavage did not induce tumors in male and female B6C $3 F_{1}$ mice or Fischer 344 rats. Monoiodoacetic acid applied dermally in a co-carcinogen 
study with 7,12 dimethylbenz[a]anthracene (DMBA) in mice (strain and sex not given) resulted in papillomas. In addition, monoiodoacetic acid transformed NIH3T3 cells in a cell transformation assay that resulted in aggressive fibrosarcomas after injection into Balb/c mice. Exposure to trichloroacetic acid in drinking water induced liver tumors in male and female $\mathrm{B}_{6} \mathrm{C} 3 \mathrm{~F}_{1}$ mice but not in male $\mathrm{F} 344$ rats (female rats not tested) and did not induce tumors in male mice with intraperitoneal injection. No cancer studies in experimental animals were available for monobromoacetic acid, diiodoacetic acid, chloroiodoacetic acid, bromoiodoacetic acid, tribromoacetic acid, and chlorodibromoacetic acid.

Table 8-1. Evidence of Cancer in Experimental Animals

\begin{tabular}{|c|c|c|c|c|c|c|c|c|c|c|c|c|c|c|c|c|c|c|c|c|}
\hline \multirow{3}{*}{ Neoplasm or Tissue } & \multicolumn{4}{|c|}{ DCA } & \multicolumn{4}{|c|}{ DBA } & \multicolumn{4}{|c|}{ BCA } & \multicolumn{4}{|c|}{ TCA } & \multicolumn{4}{|c|}{ BDCA } \\
\hline & \multicolumn{2}{|c|}{ Rats } & \multicolumn{2}{|c|}{ Mice } & \multicolumn{2}{|c|}{ Rats } & \multicolumn{2}{|c|}{ Mice } & \multicolumn{2}{|c|}{ Rats } & \multicolumn{2}{|c|}{ Mice } & \multicolumn{2}{|c|}{ Rats } & \multicolumn{2}{|c|}{ Mice } & \multicolumn{2}{|c|}{ Rats } & \multicolumn{2}{|c|}{ Mice } \\
\hline & M & $\mathbf{F}$ & $\mathbf{M}$ & $\mathbf{F}$ & $\mathbf{M}$ & $\mathbf{F}$ & $\mathbf{M}$ & $\mathbf{F}$ & $\mathbf{M}$ & $\mathbf{F}$ & $\mathbf{M}$ & $\mathbf{F}$ & M & $\mathbf{F}$ & $\mathbf{M}$ & $\mathbf{F}$ & $\mathbf{M}$ & $\mathbf{F}$ & $\mathbf{M}$ & $\mathbf{F}$ \\
\hline Liver & $\mathrm{X}$ & - & $X$ & $X$ & - & - & $X$ & $X$ & - & - & $\mathrm{X}$ & $X$ & - & - & $X$ & $\mathrm{X}$ & - & - & $\mathrm{X}$ & $\mathrm{X}$ \\
\hline $\begin{array}{l}\text { Mononuclear-cell } \\
\text { leukemia }\end{array}$ & - & - & - & - & - & $X$ & - & - & - & - & - & - & - & - & - & - & - & - & - & - \\
\hline $\begin{array}{l}\text { Malignant } \\
\text { mesothelioma }\end{array}$ & - & - & - & - & $X$ & - & - & - & $X$ & - & - & - & - & - & - & - & $\mathrm{X}$ & - & - & - \\
\hline Mammary gland & - & - & - & - & - & - & - & - & - & $X$ & - & - & - & - & - & - & - & $\mathrm{X}$ & - & - \\
\hline Lung & - & - & - & - & - & - & $X$ & - & - & - & - & - & - & - & - & - & - & - & - & - \\
\hline Skin & - & - & - & - & - & - & - & - & - & - & - & - & - & - & - & - & $\mathrm{X}$ & - & - & - \\
\hline Harderian gland & - & - & - & - & - & - & - & - & - & - & - & - & - & - & - & - & - & - & $\mathrm{X}$ & - \\
\hline Large intestine & - & - & - & - & - & - & - & - & $\mathrm{X}$ & $\mathrm{X}$ & - & - & - & - & - & - & - & - & - & - \\
\hline
\end{tabular}

$\mathrm{DCA}=$ dichloroacetic acid, $\mathrm{DBA}=$ dibromoacetic acid, $\mathrm{BCA}=$ bromochloroacetic acid, $\mathrm{TCA}=$ trichloroacetic acid, BDCA $=$ bromodichloroacetic acid.

\subsection{Summary of Mechanistic Data and Read-across Approach}

Key mechanistic cancer-initiating events are not known for the HAAs but most likely involve multiple biochemical pathways as several potential molecular initiating events have been identified. The selected haloacetic acids may induce cancer through binding to macromolecules, for example, causing oxidative stress through perturbation of energy metabolism within the cell or affecting regulation of genes involved in carcinogenicity.

Haloacetic acids did not form a category to evaluate as a class or a subclass because of lack of a well-defined mechanism or mode(s) of action and lack of a clear trend in carcinogenic potency. QSAR model predictions of cancer potency were not consistent with cancer data. Therefore, the current data are inadequate to support considering haloacetic acids as a chemical class or subclass.

\subsection{Preliminary Listing Recommendation}

These preliminary listing recommendations are based on applying the RoC listing criteria (https://ntp.niehs.nih.gov/go/rocprocess) to the body of scientific evidence provided in this monograph. 
Dichloroacetic acid, dibromoacetic acid, chlorobromoacetic acid, and bromodichloroacetic acid are reasonably anticipated to be human carcinogens based on sufficient evidence from studies in experimental animals and supporting mechanistic data that demonstrate biological plausibility of its carcinogenicity in humans.

- Dichloroacetic acid - liver tumors (male and female mice, male rats)

- Dibromoacetic acid - liver tumors (male and female mice), malignant mesothelioma (male rats), mononuclear-cell leukemia (female rats), lung tumors (male mice)

- Bromochloroacetic acid - liver tumors (male and female mice), malignant mesothelioma (male rats), mammary gland tumors (female rats), large intestinal tumors (male and female rats)

- Bromodichloroacetic acid - liver tumors (male and female mice), Harderian gland tumors (male mice), malignant mesothelioma and skin tumors (male rats), and mammary gland tumors (female rats)

Chlorodibromoacetic acid is reasonably anticipated to be human carcinogen based on (1) metabolism studies that provide convincing evidence that chlorodibromoacetic acid is metabolized to bromochloroacetic acid, (2) sufficient evidence for the carcinogenicity of bromochloroacetic acid from studies in experimental animals, and (3) supporting mechanistic data that demonstrate biological plausibility of its carcinogenicity in humans. These mechanisms are biologically plausible in humans.

Tribromoacetic acid is reasonably anticipated to be a human carcinogen based on (1) metabolism studies that provide convincing evidence that tribromoacetic acid is metabolized to dibromoacetic acid, (2) sufficient evidence for the carcinogenicity of dibromoacetic acid from studies in experimental animals, and (3) supporting mechanistic data that demonstrate biological plausibility of its carcinogenicity in humans. These mechanisms are biologically plausible in humans.

Distribution and mechanistic information relating to properties of carcinogens for almost all of the 13 HAAs is available (see Section 6); however, the data are inadequate to group all 13 haloacetic acids as a class or into subclasses based on the type and number of halogens. 


\section{References}

Aasen T, Mesnil M, Naus CC, Lampe PD, Laird DW. 2016. Gap junctions and cancer: communicating for 50 years. Nat Rev Cancer. 16(12):775-788.

http://dx.doi.org/10.1038/nrc.2016.105

Abbas R, Fisher JW. 1997. A physiologically based pharmacokinetic model for trichloroethylene and its metabolites, chloral hydrate, trichloroacetate, dichloroacetate, trichloroethanol, and trichloroethanol glucuronide in B6C3F1 mice. Toxicol Appl Pharmacol. 147(1):15-30. http://dx.doi.org/10.1006/taap.1997.8190

Ali A, Kurzawa-Zegota M, Najafzadeh M, Gopalan RC, Plewa MJ, Anderson D. 2014. Effect of drinking water disinfection by-products in human peripheral blood lymphocytes and sperm.

Mutat Res. 770:136-143. http://dx.doi.org/10.1016/j.mrfmmm.2014.08.003

Allen BC, Fisher JW. 1993. Pharmacokinetic modeling of trichloroethylene and trichloroacetic acid in humans. Risk Anal. 13(1):71-86. http://dx.doi.org/10.1111/j.1539-6924.1993.tb00730.x

American Chemistry Council. 2016. Chlorine and Drinking Water. http://chlorine.americanchemistry.com/DrinkingWaterFAQ/. [accessed: 2/1/16]

Anderson WB, Board PG, Anders MW. 2004. Glutathione transferase zeta-catalyzed bioactivation of dichloroacetic acid: reaction of glyoxylate with amino acid nucleophiles. Chem Res Toxicol. 17(5):650-662. http://dx.doi.org/10.1021/tx034099+

Anderson WB, Board PG, Gargano B, Anders MW. 1999. Inactivation of glutathione transferase zeta by dichloroacetic acid and other fluorine-lacking $\alpha$-haloalkanoic acids. Chem Res Toxicol. 12(12):1144-1149. http://dx.doi.org/10.1021/tx9900851

Anna CH, Maronpot RR, Pereira MA, Foley JF, Malarkey DE, Anderson MW. 1994. Ras protooncogene activation in dichloroacetic acid-induced, trichloroethylene-induced and tetrachloroethylene-induced liver-tumors in B6C3F1 mice. Carcinogenesis. 15(10):2255-2261. http://dx.doi.org/10.1093/carcin/15.10.2255

Ates N, Kaplan SS, Sahinkaya E, Kitis M, Dilek FB, Yetis U. 2007. Occurrence of disinfection by-products in low DOC surface waters in Turkey. J Hazard Mater. 142(1-2):526-534. http://dx.doi.org/10.1016/j.jhazmat.2006.08.076

Attene-Ramos MS, Wagner ED, Plewa MJ. 2010. Comparative human cell toxicogenomic analysis of monohaloacetic acid drinking water disinfection byproducts. Environ Sci Technol. 44(19):7206-7212. https://doi.org/10.1021/es1000193

Austin EW, Bull RJ. 1997. Effect of pretreatment with dichloroacetate or trichloroacetate on the metabolism of bromodichloroacetate. J Toxicol Environ Health. 52(4):367-383. http://dx.doi.org/10.1080/00984109708984071

Austin EW, Okita JR, Okita RT, Larson JL, Bull RJ. 1995. Modification of lipoperoxidative effects of dichloroacetate and trichloroacetate is associated with peroxisome proliferation. Toxicology. 97(1-3):59-69. http://dx.doi.org/10.1016/0300-483X(94)02926-L 
Austin EW, Parrish JM, Kinder DH, Bull RJ. 1996. Lipid peroxidation and formation of 8hydroxydeoxyguanosine from acute doses of halogenated acetic acids. Fundam Appl Toxicol. 31(1):77-82. http://dx.doi.org/10.1006/faat.1996.0078

Bader EL, Hrudey SE, Froese KL. 2004. Urinary excretion half life of trichloroacetic acid as a biomarker of exposure to chlorinated drinking water disinfection by-products. Occup Environ Med. 61(8):715-716. http://dx.doi.org/10.1136/oem.2003.008698

Barton HA, Bull R, Schultz I, Andersen ME. 1999. Dichloroacetate (DCA) dosimetry: Interpreting DCA-induced liver cancer dose response and the potential for DCA to contribute to trichloroethylene-induced liver cancer. Toxicol Lett. 106(1):9-21.

http://dx.doi.org/10.1016/S0378-4274(99)00016-8

Becalski A, Lau BP, Schrader TJ, Seaman SW, Sun WF. 2006. Formation of iodoacetic acids during cooking: Interaction of iodized table salt with chlorinated drinking water. Food Addit Contam. 23(10):957-962. http://dx.doi.org/10.1080/02652030600838407

Benane SG, Blackman CF, House DE. 1996. Effect of perchloroethylene and its metabolites on intercellular communication in clone 9 rat liver cells. J Toxicol Environ Health. 48(5):427-428. http://dx.doi.org/10.1080/009841096161168

Blackburn AC, Coggan M, Tzeng HF, Lantum H, Polekhina G, Parker MW, Anders MW, Board PG. 2001. GSTZ1d: A new allele of glutathione transferase zeta and maleylacetoacetate isomerase. Pharmacogenetics. 11(8):671-678. http://dx.doi.org/10.1097/00008571-200111000$\underline{00005}$

Blackburn AC, Matthaei KI, Lim C, Taylor MC, Cappello JY, Hayes JD, Anders MW, Board PG. 2006. Deficiency of glutathione transferase zeta causes oxidative stress and activation of antioxidant response pathways. Mol Pharmacol. 69(2):650-657.

http://dx.doi.org/10.1124/mol.105.018911

Blackburn AC, Tzeng HF, Anders MW, Board PG. 2000. Discovery of a functional polymorphism in human glutathione transferase zeta by expressed sequence tag database analysis. Pharmacogenetics. 10(1):49-57. http://dx.doi.org/10.1097/00008571-200002000-00007

Board PG, Anders MW. 2011. Glutathione transferase zeta: discovery, polymorphic variants, catalysis, inactivation, and properties of Gstz1-/- mice. Drug Metab Rev. 43(2):215-225. http://dx.doi.org/10.3109/03602532.2010.549132

Bond T, Goslan EH, Parsons S, Jefferson B. 2012. A critical review of trihalomethane and haloacetic acid formation from natural organic matter surrogates. Environ Tech Rev. 1(1):93113. http://dx.doi.org/10.1080/09593330.2012.705895

Bond T, Goslan EH, Parsons SA, Jefferson B. 2011. Treatment of disinfection by-product precursors. Environ Technol. 32(1):1-25. http://dx.doi.org/10.1080/09593330.2010.495138

Bruchelt G, Handgretinger R, Weckenmann M, Hahn T. 2014. Glucose metabolism and the antioxidative defense system in cancer cells: Options for the application of ROS-based anticancer drugs. In: Kanner S, editor. Tumor Metabolome Targeting and Drug Development. Totowa, NJ: Humana Press Inc. p. 109-130. 
Bull R. 1989. Importance of dichloroacetate and trichloroacetate to the hepatocarcinogenic response to trichloroeylene in B6C3F1 mice. Washington, DC: U.S. Air Force. AFOSR-TR-891325.

Bull RJ. 2000. Mode of action of liver tumor induction by trichloroethylene and its metabolites, trichloroacetate and dichloroacetate. Environ Health Perspect. 108:241-259.

http://dx.doi.org/10.1289/ehp.00108s2241

Bull RJ, Orner GA, Cheng RS, Stillwell L, Stauber AJ, Sasser LB, Lingohr MK, Thrall BD. 2002. Contribution of dichloroacetate and trichloroacetate to liver tumor induction in mice by trichloroethylene. Toxicol Appl Pharmacol. 182(1):55-65.

http://dx.doi.org/10.1006/taap.2002.9427

Bull RJ, Sanchez IM, Nelson MA, Larson JL, Lansing AJ. 1990. Liver tumor induction in B6C3F1 mice by dichloroacetate and trichloroacetate. Toxicology. 63(3):341-359.

http://dx.doi.org/10.1016/0300-483X(90)90195-M

Cai P, Boor PJ, Khan MF, Kaphalia BS, Ansari GA, Konig R. 2007. Immuno- and hepatotoxicity of dichloroacetic acid in MRL(+/+) and B6C3F1 mice. J Immunotoxicol. 4(2):107-115. http://dx.doi.org/10.1080/15476910701337225

Calderon RL. 2000. The epidemiology of chemical contaminants of drinking water. Food Chem Toxicol. 38(1 Suppl):S13-20. http://dx.doi.org/10.1016/S0278-6915(99)00133-7

Cantor KP, Villanueva CM, Silverman DT, Figueroa JD, Real FX, Garcia-Closas M, Malats N, Chanock S, Yeager M, Tardon A et al. 2010. Polymorphisms in GSTT1, GSTZ1, and CYP2E1, disinfection by-products, and risk of bladder cancer in Spain. Environ Health Perspect. 118(11):1545-1550. http://dx.doi.org/10.1289/ehp.1002206

Cardador MJ, Gallego M. 2011. Haloacetic acids in swimming pools: Swimmer and worker exposure. Environ Sci Technol. 45(13):5783-5790. http://dx.doi.org/10.1021/es103959d

Cardador MJ, Gallego M. 2015. Haloacetic acids content of fruit juices and soft drinks. Food Chem. 173:685-693. http://dx.doi.org/10.1016/j.foodchem.2014.10.105

Cardador MJ, Gallego M. 2017. Control of disinfection by-products in canned vegetables caused by water used in their processing. Food Addit Contam Part A Chem Anal Control Expo Risk Assess. 34(1):10-23. http://dx.doi.org/10.1080/19440049.2016.1241897

Carter JH, Carter HW, Deddens JA, Hurst BM, George MH, DeAngelo AB. 2003. A 2-year dose-response study of lesion sequences during hepatocellular carcinogenesis in the male $\mathrm{B} 6 \mathrm{C} 3 \mathrm{~F}(1)$ mouse given the drinking water chemical dichloroacetic acid. Environ Health Perspect. 111(1):53-64. http://dx.doi.org/10.1289/ehp.5442

Celik I. 2007. Determination of toxicity of trichloroacetic acid in rats: 50 days drinking water study. Pestic Biochem Physiol. 89(1):39-45. http://dx.doi.org/10.1016/j.pestbp.2007.02.006

Celik I, Temur A, Isik I. 2009. Hepatoprotective role and antioxidant capacity of pomegranate (Punica granatum) flowers infusion against trichloroacetic acid-exposed in rats. Food Chem Toxicol. 47(1):145-149. http://dx.doi.org/10.1016/j.fct.2008.10.020 
Cemeli E, Wagner ED, Anderson D, Richardson SD, Plewa MJ. 2006. Modulation of the cytotoxicity and genotoxicity of the drinking water disinfection byproduct iodoacetic acid by suppressors of oxidative stress. Environ Sci Technol. 40(6):1878-1883.

http://dx.doi.org/10.1021/es051602r

Centers for Disease Control and Prevention (CDC). 2015. Water Treatment. https://www.cdc.gov/healthywater/drinking/public/water treatment.html.

Centers for Disease Control and Prevention (CDC). 2016. Disinfection By-products. https://www.cdc.gov/safewater/chlorination-byproducts.html.

Chang EE, Guo HC, Li IS, Chiang PC, Huang CP. 2010a. Modeling the formation and assessing the risk of disinfection by-products in water distribution systems. J Environ Sci Health A Tox Hazard Subst Environ Eng. 45(10):1185-1194. http://dx.doi.org/10.1080/10934529.2010.493776

Chang HH, Tung HH, Chao CC, Wang GS. 2010b. Occurrence of haloacetic acids (HAAs) and trihalomethanes (THMs) in drinking water of Taiwan. Environ Monit Assess. 162(1-4):237-250. http://dx.doi.org/10.1007/s10661-009-0792-1

Channel SR, Latendresse JR, Kidney JK, Grabau JH, Lane JW, Steel-Goodwin L, Gothaus MC. 1998. A subchronic exposure to trichloroethylene causes lipid peroxidation and hepatocellular proliferation in male B6C3F1 mouse liver. Toxicol Sci. 43(2):145-154.

http://dx.doi.org/10.1093/toxsci/43.2.145

Chemical Effects in Biological Systems (CEBS). 2017. National Toxicology Program. https://manticore.niehs.nih.gov/cebssearch/.

ChemIDplus. 2017. ChemIDplus Advanced. National Library of Medicine. https://chem.nlm.nih.gov/chemidplus/chemidheavy.jsp and select Registry Number and search on CAS number. [Accessed: 5/5/17]

Choi SY, Park OJ. 1996. Differential display analysis of gene expression induced under DCA treatment in rat liver. J Biochem Mol Biol. 29(3):272-275.

Chowdhury S, Alhooshani K, Karanfil T. 2014. Disinfection byproducts in swimming pool: Occurrences, implications and future needs. Water Res. 53:68-109. http://dx.doi.org/10.1016/j.watres.2014.01.017

Colell A, Green DR, Ricci JE. 2009. Novel roles for GAPDH in cell death and carcinogenesis. Cell Death Differ. 16(12):1573-1581. http://dx.doi.org/10.1038/cdd.2009.137

Cornett R, James MO, Henderson GN, Cheung J, Shroads AL, Stacpoole PW. 1999. Inhibition of glutathione $S$-transferase zeta and tyrosine metabolism by dichloroacetate: A potential unifying mechanism for its altered biotransformation and toxicity. Biochem Biophys Res Commun. 262(3):752-756. http://dx.doi.org/10.1006/bbrc.1999.1287

Corton JC. 2008. Evaluation of the role of peroxisome proliferator-activated receptor alpha (PPARalpha) in mouse liver tumor induction by trichloroethylene and metabolites. Crit Rev Toxicol. 38(10):857-875. http://dx.doi.org/10.1080/10408440802209796 
Corvi R, Aardema MJ, Gribaldo L, Hayashi M, Hoffmann S, Schechtman L, Vanparys P. 2012. ECVAM prevalidation study on in vitro cell transformation assays: General outline and conclusions of the study. Mutat Res. 744(1):12-19. http://dx.doi.org/10.1016/j.mrgentox.2011.11.009

Creton S, Aardema MJ, Carmichael PL, Harvey JS, Martin FL, Newbold RF, O'Donovan MR, Pant K, Poth A, Sakai A et al. 2012. Cell transformation assays for prediction of carcinogenic potential: State of the science and future research needs. Mutagenesis. 27(1):93-101. http://dx.doi.org/10.1093/mutage/ger053

Curry SH, Chu PI, Baumgartner TG, Stacpoole PW. 1985. Plasma concentrations and metabolic effects of intravenous sodium dichloroacetate. Clin Pharmacol Ther. 37(1):89-93. http://dx.doi.org/10.1038/clpt.1985.17

Curry SH, Lorenz A, Chu PI, Limacher M, Stacpoole PW. 1991. Disposition and pharmacodynamics of dichloroacetate (DCA) and oxalate following oral DCA doses. Biopharm Drug Dispos. 12(5):375-390. http://dx.doi.org/10.1002/bdd.2510120507

Dad A, Jeong CH, Pals JA, Wagner ED, Plewa MJ. 2013. Pyruvate remediation of cell stress and genotoxicity induced by haloacetic acid drinking water disinfection by-products. Environ Mol Mutagen. 54(8):629-637. http://dx.doi.org/10.1002/em.21795

Daniel FB, DeAngelo AB, Stober JA, Olson GR, Page NP. 1992. Hepatocarcinogenicity of chloral hydrate, 2-chloroacetaldehyde, and dichloroacetic acid in the male B6C3F1 mouse. Fundam Appl Toxicol. 19(2):159-168. http://dx.doi.org/10.1016/0272-0590(92)90147-A

DeAngelo AB, Daniel FB, McMillan L, Wernsing P, Savage Jr RE. 1989. Species and strain sensitivity to the induction of peroxisome proliferation by chloroacetic acids. Toxicol Appl Pharmacol. 101(2):285-298. http://dx.doi.org/10.1016/0041-008X(89)90277-9

DeAngelo AB, Daniel FB, Most BM, Olson GR. 1996. The carcinogenicity of dichloroacetic acid in the male Fischer 344 rat. Toxicology. 114(3):207-221. http://dx.doi.org/10.1016/S0300$\underline{483 X(96) 03510-X}$

DeAngelo AB, Daniel FB, Most BM, Olson GR. 1997. Failure of monochloroacetic acid and trichloroacetic acid administered in the drinking water to produce liver cancer in male F344/N rats. J Toxicol Environ Health. 52(5):425-445. http://dx.doi.org/10.1080/00984109708984074

DeAngelo AB, Daniel FB, Stober JA, Olson GR. 1991. The carcinogenicity of dichloroacetic acid in the male B6C3F1 mouse. Fundam Appl Toxicol. 16(2):337-347.

http://dx.doi.org/10.1016/0272-0590(91)90118-N

DeAngelo AB, Daniel FB, Wong DM, George MH. 2008. The induction of hepatocellular neoplasia by trichloroacetic acid administered in the drinking water of the male B6C3F1 mouse. J Toxicol Environ Health A. 71(16):1056-1068. http://dx.doi.org/10.1080/15287390802111952

DeAngelo AB, George MH, House DE. 1999. Hepatocarcinogenicity in the male B6C3F1 mouse following a lifetime exposure to dichloroacetic acid in the drinking water: Dose-response determination and modes of action. J Toxicol Environ Health A. 58(8):485-507.

http://dx.doi.org/10.1080/009841099157115 
Deborde M, von Gunten U. 2008. Reactions of chlorine with inorganic and organic compounds during water treatment-Kinetics and mechanisms: A critical review. Water Res. 42(1-2):13-51. http://dx.doi.org/10.1016/j.watres.2007.07.025

Dees C, Travis C. 1994. Trichloroacetate stimulation of liver DNA synthesis in male and female mice. Toxicol Lett. 70(3):343-355. http://dx.doi.org/10.1016/0378-4274(94)90129-5

Dickenson ER, Summers RS, Croué JP, Gallard H. 2008. Haloacetic acid and trihalomethane formation from the chlorination and bromination of aliphatic beta-dicarbonyl acid model compounds. Environ Sci Technol. 42(9):3226-3233. http://dx.doi.org/10.1021/es0711866

Dmitriev AP, Grodzinsky DM. 1975. Effect of radiosensitizing agents on dna single-strand breaks and their repair in Anacystis nidulans. Plant Sci Lett. 4:77-83.

http://dx.doi.org/10.1016/0304-4211(75)90251-5

Duirk SE, Lindell C, Cornelison CC, Kormos J, Ternes TA, Attene-Ramos M, Osiol J, Wagner ED, Plewa MJ, Richardson SD. 2011. Formation of toxic iodinated disinfection by-products from compounds used in medical imaging. Environ Sci Technol. 45(16):6845-6854.

http://dx.doi.org/10.1021/es200983f

Eastmond DA, Vulimiri SV, French JE, Sonawane B. 2013. The use of genetically modified mice in cancer risk assessment: Challenges and limitations. Crit Rev Toxicol. 43(8):611-631. http://dx.doi.org/10.3109/10408444.2013.822844

El Arem A, Ghrairi F, Lahouar L, Thouri A, Saafi EB, Ayed A, Zekri M, Ferjani H, Haouas Z, Zakhama A et al. 2014a. Hepatoprotective activity of date fruit extracts against dichloroacetic acid-induced liver damage in rats. J Funct Foods. 9:119-130.

http://dx.doi.org/10.1016/j.jff.2014.04.018

El Arem A, Saafi EB, Ghrairi F, Thouri A, Zekri M, Ayed A, Zakhama A, Achour L. 2014 b. Aqueous date fruit extract protects against lipid peroxidation and improves antioxidant status in the liver of rats subchronically exposed to trichloroacetic acid. J Physiol Biochem. 70(2):451464. http://dx.doi.org/10.1007/s13105-014-0323-6

El Arem A, Zekri M, Thouri A, Saafi EB, Ghrairi F, Ayed A, Zakhama A, Achour L. 2014c. Oxidative damage and alterations in antioxidant enzyme activities in the kidneys of rat exposed to trichloroacetic acid: Protective role of date palm fruit. J Physiol Biochem. 70(2):297-309. http://dx.doi.org/10.1007/s13105-013-0302-3

Environmental Working Group (EWG). 2016. National Drinking Water Database: Haloacetic acids. Washington, D.C.: Environmental Working Group. https://www.ewg.org/tapwater/chemical-contaminants/Total-haloacetic-acids-HAAs/2456/.

Escobar-Hoyos LF, Hoyos-Giraldo LS, Londoño-Velasco E, Reyes-Carvajal I, Saavedra-Trujillo D, Carvajal-Varona S, Sánchez-Gómez A, Wagner ED, Plewa MJ. 2013. Genotoxic and clastogenic effects of monohaloacetic acid drinking water disinfection by-products in primary human lymphocytes. Water Res. 47(10):3282-3290.

http://dx.doi.org/10.1016/j.watres.2013.02.052 
European Chemicals Agency (ECHA). 2008. Guidance on information requirements and chemical safety assessment. Chapter R.6: QSARS and grouping of chemicals. European Chemicals Agency.

European Union (EU). 2007. European Union Risk Assessment Report: Sodium hypochlorite. Luxembourg: Office for Official Publications of the European Communities.

Fang C, Zhu H. 2001. [Malignant transformation experiment of NIH3T3 cells induced by dibromoacetic acid in drinking water]. Zhongguo Huanjing Kexue. 21(3):245-247.

Fang YY, Kashkarov U, Anders MW, Board PG. 2006. Polymorphisms in the human glutathione transferase zeta promoter. Pharmacogenet Genomics. 16(5):307-313.

http://dx.doi.org/10.1097/01.fpc.0000205000.07054.b3

Federal Register. 1998. National Primary Drinking Water Regulations: Disinfectants and Disinfection Byproducts. Fed Reg. 63(241):69390-69476.

Federal Register. 2016. Revisions to the Unregulated Contaminant Monitoring Rule (UCMR 4) for Public Water Systems and Announcement of Public Meeting. Fed Reg. 81(244):9266692692.

Fernández-Cañón JM, Baetscher MW, Finegold M, Burlingame T, Gibson KM, Grompe M. 2002. Maleylacetoacetate isomerase (MAAI/GSTZ)-deficient mice reveal a glutathione-dependent nonenzymatic bypass in tyrosine catabolism. Mol Cell Biol. 22(13):4943-4951.

http://dx.doi.org/10.1128/MCB.22.13.4943-4951.2002

Ferreira-Gonzalez A, DeAngelo AB, Nasim S, Garrett CT. 1995. Ras oncogene activation during hepatocarcinogenesis in $\mathrm{B} 6 \mathrm{C} 3 \mathrm{~F} 1$ male mice by dichloroacetic and trichloroacetic acids. Carcinogenesis. 16(3):495-500. http://dx.doi.org/10.1093/carcin/16.3.495

Froese KL, Sinclair MI, Hrudey SE. 2002. Trichloroacetic acid as a biomarker of exposure to disinfection by-products in drinking water: A human exposure trial in Adelaide, Australia. Environ Health Perspect. 110(7):679-687. http://dx.doi.org/10.1289/ehp.02110679

Fuhrman J, Shafer L, Repertinger S, Chan T, Hansen LA. 2005. Mechanisms of SEPA 0009induced tumorigenesis in v-rasHa transgenic Tg.AC mice. Toxicol Pathol. 33(6):623-630. http://dx.doi.org/10.1080/01926230500278975

Gao S, Wang Y, Zhang P, Dong Y, Li B. 2008. Subacute oral exposure to dibromoacetic acid induced immunotoxicity and apoptosis in the spleen and thymus of the mice. Toxicol Sci. 105(2):331-341. http://dx.doi.org/10.1093/toxsci/kfn139

Gao SY, Zhou XR, Gong TT, Jia LM, Li BX. 2016. Dibromoacetic acid induces thymocyte apoptosis by blocking cell cycle progression, increasing intracellular calcium, and the Fas/FasL pathway in vitro. Toxicol Pathol. 44(1):88-97. http://dx.doi.org/10.1177/0192623315612939

Ge R, Yang S, Kramer PM, Tao L, Pereira MA. 2001. The effect of dichloroacetic acid and trichloroacetic acid on DNA methylation and cell proliferation in B6C3F1 mice. J Biochem Mol Toxicol. 15(2):100-106. http://dx.doi.org/10.1002/jbt.5 
Ged EC, Boyer TH. 2014. Effect of seawater intrusion on formation of bromine-containing trihalomethanes and haloacetic acids during chlorination. Desalination. 345:85-93. http://dx.doi.org/10.1016/j.desal.2014.04.021

Giller S, Le Curieux F, Erb F, Marzin D. 1997. Comparative genotoxicity of halogenated acetic acids found in drinking water. Mutagenesis. 12(5):321-328.

http://dx.doi.org/10.1093/mutage/12.5.321

Gonzalez-Leon A, Merdink JL, Bull RJ, Schultz IR. 1999. Effect of pre-treatment with dichloroacetic or trichloroacetic acid in drinking water on the pharmacokinetics of a subsequent challenge dose in B6C3F1 mice. Chem-Biol Interact. 123(3):239-253.

http://dx.doi.org/10.1016/S0009-2797(99)00140-4

Gonzalez-Leon A, Schultz IR, Xu G, Bull RJ. 1997. Pharmacokinetics and metabolism of dichloroacetate in the F344 rat after prior administration in drinking water. Toxicol Appl Pharmacol. 146(2):189-195. http://dx.doi.org/10.1006/taap.1997.8232

Green T, Prout MS. 1985. Species differences in response to trichloroethylene. II. Biotransformation in rats and mice. Toxicol Appl Pharmacol. 79(3):401-411. http://dx.doi.org/10.1016/0041-008X(85)90138-3

Gulezian D, Jacobson-Kram D, McCullough CB, Olson H, Recio L, Robinson D, Storer R, Tennant R, Ward JM, Neumann DA. 2000. Use of transgenic animals for carcinogenicity testing: considerations and implications for risk assessment. Toxicol Pathol. 28(3):482-499.

http://dx.doi.org/10.1177/019262330002800320

Gwynn RH, Salaman MH. 1953. Studies on co-carcinogenesis. SH-reactors and other substances tested for co-carcinogenic action in mouse skin. Br J Cancer. 7(4):482-489.

http://dx.doi.org/10.1038/bjc.1953.50

Hammer R, VanBriesen J. 2012. In fracking's wake: New rules are needed to protect our health and environment from contaminated wastewater. Natural Resources Defense Council. NRDC Document May 2012 D:12-05-A.

Harvey JB, Hong HHL, Bhusari S, Ton TV, Wang Y, Foley JF, Peddada SD, Hooth M, DeVito M, Nyska A et al. 2016. F344/NTac rats chronically exposed to bromodichloroacetic acid develop mammary adenocarcinomas with mixed luminal/basal phenotype and Tgf $\beta$ dysregulation. Vet Pathol. 53(1):170-181. http://dx.doi.org/10.1177/0300985815571680

Hassoun E, Cearfoss J. 2014. Do antioxidant enzymes and glutathione play roles in the induction of hepatic oxidative stress in mice upon subchronic exposure to mixtures of dichloroacetate and trichloroacetate? Toxicol Environ Chem. 96(3):482-490.

http://dx.doi.org/10.1080/02772248.2014.947988

Hassoun E, Cearfoss J, Mamada S, Al-Hassan N, Brown M, Heimberger K, Liu MC. 2014. The effects of mixtures of dichloroacetate and trichloroacetate on induction of oxidative stress in livers of mice after subchronic exposure. J Toxicol Environ Health A. 77(6):313-323. http://dx.doi.org/10.1080/15287394.2013.864576 
Hassoun E, Mettling C. 2015. Dichloroacetate and trichloroacetate toxicity in AML12 cells: Role of oxidative stress. J Biochem Mol Toxicol. 29(11):508-512. http://dx.doi.org/10.1002/jbt.21720

Hassoun EA, Cearfoss J. 2011. Dichloroacetate- and trichloroacetate-induced modulation of superoxide dismutase, catalase, and glutathione peroxidase activities and glutathione level in the livers of mice after subacute and subchronic exposure. Toxicol Environ Chem. 93(2):332-344. http://dx.doi.org/10.1080/02772248.2010.509602

Hassoun EA, Cearfoss J, Spildener J. 2010a. Dichloroacetate- and trichloroacetate-induced oxidative stress in the hepatic tissues of mice after long-term exposure. J Appl Toxicol. 30(5):450-456. http://dx.doi.org/10.1002/jat.1516

Hassoun EA, Dey S. 2008. Dichloroacetate- and trichloroacetate-induced phagocytic activation and production of oxidative stress in the hepatic tissues of mice after acute exposure. J Biochem Mol Toxicol. 22(1):27-34. http://dx.doi.org/10.1002/jbt.20210

Hassoun EA, Ray S. 2003. The induction of oxidative stress and cellular death by the drinking water disinfection by-products, dichloroacetate and trichloroacetate in J774.A1 cells. Comp Biochem Physiol C Toxicol Pharmacol. 135(2):119-128. http://dx.doi.org/10.1016/S1532$\underline{0456(03) 00082-6}$

Hassoun EA, Spildener J, Cearfoss J. 2010b. The induction of tumor necrosis factor-alpha, superoxide anion, myeloperoxidase, and superoxide dismutase in the peritoneal lavage cells of mice after prolonged exposure to dichloroacetate and trichloroacetate. J Biochem Mol Toxicol. 24(2):136-144. http://dx.doi.org/10.1002/jbt.20322

Hayes FD, Short RD, Gibson JE. 1973. Differential toxicity of monochloroacetate, monofluoroacetate and monoiodoacetate in rats. Toxicol Appl Pharmacol. 26(1):93-102. http://dx.doi.org/10.1016/0041-008X(73)90089-6

Hayes JD, Strange RC. 2000. Glutathione S-transferase polymorphisms and their biological consequences. Pharmacology. 61(3):154-166. http://dx.doi.org/10.1159/000028396

Hazardous Substances Data Bank (HSDB). 2003. Iodoacetic acid. National Library of Medicine. http://toxnet.nlm.nih.gov/cgi-bin/sis/htmlgen?HSDB and search on CAS number or compound name. [accessed: 6/5/17]

Hazardous Substances Data Bank (HSDB). 2009. Bromoacetic acid. National Library of Medicine. http://toxnet.nlm.nih.gov/cgi-bin/sis/htmlgen?HSDB and search on CAS number or compound name. [accessed: 6/1/17]

Hazardous Substances Data Bank (HSDB). 2009a. Bromochloroacetic acid. National Library of Medicine. http://toxnet.nlm.nih.gov/cgi-bin/sis/htmlgen?HSDB and search on CAS number or compound name. [accessed: 12/21/15]

Hazardous Substances Data Bank (HSDB). 2009b. Bromodichloroacetic acid. National Library of Medicine. http://toxnet.nlm.nih.gov/cgi-bin/sis/htmlgen?HSDB and search on CAS number or compound name. [accessed: 12/21/15] 
Hazardous Substances Data Bank (HSDB). 2009c. Tribromoacetic acid. National Library of Medicine. http://toxnet.nlm.nih.gov/cgi-bin/sis/htmlgen?HSDB and search on CAS number or compound name. [accessed: 6/1/17]

Hazardous Substances Data Bank (HSDB). 2009d. Dibromochloroacetic acid. National Library of Medicine. http://toxnet.nlm.nih.gov/cgi-bin/sis/htmlgen?HSDB and search on CAS number or compound name. [accessed: 12/21/15]

Henderson GN, Curry SH, Derendorf H, Wright EC, Stacpoole PW. 1997. Pharmacokinetics of dichloroacetate in adult patients with lactic acidosis. J Clin Pharmacol. 37(5):416-425. http://dx.doi.org/10.1002/j.1552-4604.1997.tb04319.x

Hernández-Fonseca K, Cárdenas-Rodríguez N, Pedraza-Chaverri J, Massieu L. 2008. Calciumdependent production of reactive oxygen species is involved in neuronal damage induced during glycolysis inhibition in cultured hippocampal neurons. J Neurosci Res. 86(8):1768-1780.

http://dx.doi.org/10.1002/jnr.21634

Herren-Freund SL, Pereira MA, Khoury MD, Olson G. 1987. The carcinogenicity of trichloroethylene and its metabolites, trichloroacetic acid and dichloroacetic acid, in mouse liver. Toxicol Appl Pharmacol. 90(2):183-189. http://dx.doi.org/10.1016/0041-008X(87)90325-5

Hinckley AF, Bachand AM, Nuckols JR, Reif JS. 2005. Identifying public water facilities with low spatial variability of disinfection by-products for epidemiological investigations. Occup Environ Med. 62(7):494-499. http://dx.doi.org/10.1136/oem.2004.017798

Hladik ML, Focazio MJ, Engle M. 2014. Discharges of produced waters from oil and gas extraction via wastewater treatment plants are sources of disinfection by-products to receiving streams. Sci Total Environ. 466-467:1085-1093. http://dx.doi.org/10.1016/j.scitotenv.2013.08.008

Hsu CC, Lee HC, Wei YH. 2013. Mitochondrial DNA alterations and mitochondrial dysfunction in the progression of hepatocellular carcinoma. World J Gastroenterol. 19(47):8880-8886. http://dx.doi.org/10.3748/wjg.v19.i47.8880

Innes JR, Ulland BM. 1968. Evaluation of carcinogenic, teratogenic, and muragenic activities of selected pesticides and industrial chemicals. Vol. 1. Carcinogenic study. Bethesda, MD: National Cancer Institute. NCI-DCCP-CG-1973-1-1.

International Agency for Research on Cancer (IARC). 2004a. Dichloroacetic acid. In: Some Drinking-water Disinfectants and Contaminants, including Arsenic. Lyon, France: International Agency for Research on Cancer. p. 359-402.

International Agency for Research on Cancer (IARC). 2004b. Trichloroacetic acid. In: Some Drinking-water Disinfectants and Contaminants, including Arsenic. Lyon, France: International Agency for Research on Cancer. p. 403-440.

International Agency for Research on Cancer (IARC). 2013a. Dibromoacetic acid. In: Some Chemicals Present in Industrial and Consumer Products, Food and Drinking-water. Lyon, France: International Agency for Research on Cancer. p. 513-531. 
International Agency for Research on Cancer (IARC). 2013b. Bromochloroacetic acid. In: Some Chemicals Present in Industrial and Consumer Products, Food and Drinking-water. Lyon, France: International Agency for Research on Cancer. p. 495-511.

International Agency for Research on Cancer (IARC). 2013c. Some chemicals present in industrial and consumer products, food and drinking-water. Lyon, France: International Agency for Research on Cancer.

International Agency for Research on Cancer (IARC). 2014. Trichloroethylene, tetrachloroethylene, and some other chlorinated agents. Lyon, France: International Agency for Research on Cancer.

International Agency for Research on Cancer (IARC). 2014a. Dichloroacetic acid. In: Trichloroethylene, Tetrachloroethylene, and Some Other Chlorinated Agents. Lyon, France: International Agency for Research on Cancer. p. 353-391.

International Agency for Research on Cancer (IARC). 2014b. Trichloroacetic acid. In: Trichloroethylene, Tetrachloroethylene, and Some Other Chlorinated Agents. Lyon, France: International Agency for Research on Cancer. p. 393-437.

International Programme on Chemical Safety (IPCS). 2000. Disinfectants and disinfectant byproducts. Geneva, Switzerland: World Health Organization. Environmental Health Criteria 216.

Jacobs AC, Hatfield KP. 2013. History of chronic toxicity and animal carcinogenicity studies for pharmaceuticals. Vet Pathol. 50(2):324-333. http://dx.doi.org/10.1177/0300985812450727

James MO, Yan Z, Cornett R, Jayanti VM, Henderson GN, Davydova N, Katovich MJ, Pollock B, Stacpoole PW. 1998. Pharmacokinetics and metabolism of [14C]dichloroacetate in male Sprague-Dawley rats. Identification of glycine conjugates, including hippurate, as urinary metabolites of dichloroacetate. Drug Metab Dispos. 26(11):1134-1143.

Jones RR, Weyer PJ, DellaValle CT, Inoue-Choi M, Anderson KE, Cantor KP, Krasner S, Robien K, Freeman LE, Silverman DT et al. 2016. Nitrate from drinking water and diet and bladder cancer among postmenopausal women in Iowa. Environ Health Perspect. 124(11):17511758. http://dx.doi.org/10.1289/EHP191

Jones RR, Weyer PJ, Dellavalle CT, Robein K, Cantor KP, Krasner S, Beane Freeman LE, Ward MH. 2017. Ingested nitrate, disinfection by-products, and kidney cancer risk in older women. Epidemiology. 28(5):703-711. http://dx.doi.org/10.1097/EDE.0000000000000647

Kanan A. 2010. Occurrence and formation of disinfection by-products in indoor swimming pools water. A thesis presented to Clemson University.

Kaphalia BS, Bhat HK, Khan MF, Ansari GA. 1992. Tissue distribution of monochloroacetic acid and its binding to albumin in rats. Toxicol Ind Health. 8(1-2):53-61.

http://dx.doi.org/10.1177/074823379200800105

Kargalioglu Y, McMillan BJ, Minear RA, Plewa MJ. 2002. Analysis of the cytotoxicity and mutagenicity of drinking water disinfection by-products in Salmonella typhimurium. Teratog Carcinog Mutagen. 22(2):113-128. http://dx.doi.org/10.1002/tcm.10010 
Kensler TW, Wakabayashi N, Biswal S. 2007. Cell survival responses to environmental stresses via the Keap1-Nrf2-ARE pathway. Annu Rev Pharmacol Toxicol. 47:89-116. http://dx.doi.org/10.1146/annurev.pharmtox.46.120604.141046

Khanna KK, Jackson SP. 2001. DNA double-strand breaks: Signaling, repair and the cancer connection. Nat Genet. 27(3):247-254. http://dx.doi.org/10.1038/85798

Kim D, Amy GL, Karanfil T. 2015. Disinfection by-product formation during seawater desalination: A review. Water Res. 81:343-355. http://dx.doi.org/10.1016/j.watres.2015.05.040

Kim H, Haltmeier P, Klotz JB, Weisel CP. 1999. Evaluation of biomarkers of environmental exposures: Urinary haloacetic acids associated with ingestion of chlorinated drinking water. Environ Res. 80(2):187-195. http://dx.doi.org/10.1006/enrs.1998.3896

Kim H, Weisel CP. 1998. Dermal absorption of dichloro- and trichloroacetic acids from chlorinated water. J Exp Anal Environ Epidem. 8(4):555-575.

Kim J, Kang B. 2008. DBPs removal in GAC filter-adsorber. Water Res. 42(1-2):145-152. http://dx.doi.org/10.1016/j.watres.2007.07.040

Kim S, Collins LB, Boysen G, Swenberg JA, Gold A, Ball LM, Bradford BU, Rusyn I. 2009. Liquid chromatography electrospray ionization tandem mass spectrometry analysis method for simultaneous detection of trichloroacetic acid, dichloroacetic acid, $S$-(1,2dichlorovinyl)glutathione and $S$-(1,2-dichlorovinyl)-L-cysteine. Toxicology. 262(3):230-238. http://dx.doi.org/10.1016/j.tox.2009.06.013

Kim Y, Ton TV, DeAngelo AB, Morgan K, Devereux TR, Anna C, Collins JB, Paules RS, Crosby LM, Sills RC. 2006. Major carcinogenic pathways identified by gene expression analysis of peritoneal mesotheliomas following chemical treatment in F344 rats. Toxicol Appl Pharmacol. 214(2):144-151. http://dx.doi.org/10.1016/j.taap.2005.12.009

King WD, Dodds L, Armson BA, Allen AC, Fell DB, Nimrod C. 2004. Exposure assessment in epidemiologic studies of adverse pregnancy outcomes and disinfection byproducts. J Expo Anal Environ Epidemiol. 14(6):466-472. http://dx.doi.org/10.1038/sj.jea.7500345

Kissling GE, Malarkey DE, Vallant MK, Johnson JD, Hejtmancik MR, Herbert RA, Boorman GA. 2009. Evaluation of dichloroacetic acid for carcinogenicity in genetically modified Tg.AC hemizygous and p53 haploinsufficient mice. Toxicol Sci. 107(1):19-26. http://dx.doi.org/10.1093/toxsci/kfn228

Klaunig JE, Ruch RJ, Lin ELC. 1989. Effects of trichloroethylene and its metabolites on rodent hepatocyte intercellular communication. Toxicol Appl Pharmacol. 99(3):454-465. http://dx.doi.org/10.1016/0041-008X(89)90153-1

Komaki Y, Pals J, Wagner ED, Marinas BJ, Plewa MJ. 2009. Mammalian cell DNA damage and repair kinetics of monohaloacetic acid drinking water disinfection by-products. Environ Sci Technol. 43(21):8437-8442. http://dx.doi.org/10.1021/es901852z

Krasner SW, Kostopoulou M, Toledano MB, Wright J, Patelarou E, Kogevinas M, Villanueva CM, Carrasco-Turigas G, Santa Marina L, Fernández-Somoano A et al. 2016a. Occurrence of 
DBPs in drinking water of european regions for epidemiology studies. JAWWA. 108(10):E501E512. http://dx.doi.org/10.5942/jawwa.2016.108.0152

Krasner SW, Lee TC, Westerhoff P, Fischer N, Hanigan D, Karanfil T, Beita-Sandí W, TaylorEdmonds L, Andrews RC. 2016b. Granular activated carbon treatment may result in higher predicted genotoxicity in the presence of bromide. Environ Sci Technol. 50(17):9583-9591. http://dx.doi.org/10.1021/acs.est.6b02508

Krasner SW, Weinberg HS, Richardson SD, Pastor SJ, Chinn R, Sclimenti MJ, Onstad GD, Thruston AD, Jr. 2006. Occurrence of a new generation of disinfection byproducts. Environ Sci Technol. 40(23):7175-7185. http://dx.doi.org/10.1021/es060353j

Krishna S, Agbenyega T, Angus BJ, Bedu-Addo G, Ofori-Amanfo G, Henderson G, Szwandt IS, O'Brien R, Stacpoole PW. 1995. Pharmacokinetics and pharmacodynamics of dichloroacetate in children with lactic acidosis due to severe malaria. QJM. 88(5):341-349.

Krishna S, Supanaranond W, Pukrittayakamee S, Karter D, Supputamongkol Y, Davis TM, Holloway PA, White NJ. 1994. Dichloroacetate for lactic acidosis in severe malaria: A pharmacokinetic and pharmacodynamic assessment. Metabolism. 43(8):974-981. http://dx.doi.org/10.1016/0026-0495(94)90177-5

Krishna S, Supanaranond W, Pukrittayakamee S, Kuile FT, Ruprah M, White NJ. 1996. The disposition and effects of two doses of dichloroacetate in adults with severe falciparum malaria. Br J Clin Pharmacol. 41(1):29-34. http://dx.doi.org/10.1111/j.1365-2125.1996.tb00155.x

Kulling P, Andersson H, Boström K, Johansson LA, Lindström B, Nyström B. 1992. Fatal systemic poisoning after skin exposure to monochloroacetic acid. J Toxicol Clin Toxicol. 30(4):643-652. http://dx.doi.org/10.3109/15563659209017948

Kuppusamy SP, Kaiser JP, Wesselkamper SC. 2015. Epigenetic regulation in environmental chemical carcinogenesis and its applicability in human health risk assessment. Int J Toxicol. 34(5):384-392. http://dx.doi.org/10.1177/1091581815599350

Kusch GD, McCarty LP, Lanham JM. 1990. Monochloroacetic acid exposure: A case report. Pol J Occup Med. 3(4):409-414.

Lan J, Gou N, Rahman SM, Gao C, He M, Gu AZ. 2016. A quantitative toxicogenomics assay for high-throughput and mechanistic genotoxicity assessment and screening of environmental pollutants. Environ Sci Technol. 50(6):3202-3214. http://dx.doi.org/10.1021/acs.est.5b05097

Lantagne DS, Blount BC, Cardinali F, Quick R. 2008. Disinfection by-product formation and mitigation strategies in point-of-use chlorination of turbid and non-turbid waters in western Kenya. J Water Health. 6(1):67-82. http://dx.doi.org/10.2166/wh.2007.013

Lantagne DS, Cardinali F, Blount BC. 2010. Disinfection by-product formation and mitigation strategies in point-of-use chlorination with sodium dichloroisocyanurate in Tanzania. Am J Trop Med Hyg. 83(1):135-143. http://dx.doi.org/10.4269/ajtmh.2010.09-0431

Larson JL, Bull RJ. 1992. Metabolism and lipoperoxidative activity of trichloroacetate and dichloroacetate in rats and mice. Toxicol Appl Pharmacol. 115(2):268-277.

http://dx.doi.org/10.1016/0041-008X(92)90332-M 
Laughter AR, Dunn CS, Swanson CL, Howroyd P, Cattley RC, Corton JC. 2004. Role of the peroxisome proliferator-activated receptor alpha (PPARalpha) in responses to trichloroethylene and metabolites, trichloroacetate and dichloroacetate in mouse liver. Toxicology. 203(1-3):8398. http://dx.doi.org/10.1016/j.tox.2004.06.014

Lee KJ, Kim BH, Hong JE, Pyo HS, Park SJ, Lee DW. 2001. A study on the distribution of chlorination by-products (CBPs) in treated water in Korea. Water Res. 35(12):2861-2872. http://dx.doi.org/10.1016/S0043-1354(00)00583-2

Li W, Gu Y, James MO, Hines RN, Simpson P, Langaee T, Stacpoole PW. 2012. Prenatal and postnatal expression of glutathione transferase zeta 1 in human liver and the roles of haplotype and subject age in determining activity with dichloroacetate. Drug Metab Dispos. 40(2):232-239. http://dx.doi.org/10.1124/dmd.111.041533

Liang L, Singer PC. 2003. Factors influencing the formation and relative distribution of haloacetic acids and trihalomethanes in drinking water. Environ Sci Technol. 37(13):2920-2928. http://dx.doi.org/10.1021/es026230q

Lin ELC, Mattox JK, Bernard Daniel F. 1993. Tissue distribution, excretion, and urinary metabolites of dichloroacetic acid in the male Fischer 344 rat. J Toxicol Environ Health. 38(1):19-32. http://dx.doi.org/10.1080/15287399309531697

Liviac D, Creus A, Marcos R. 2010. Genotoxicity testing of three monohaloacetic acids in TK6 cells using the cytokinesis-block micronucleus assay. Mutagenesis. 25(5):505-509. http://dx.doi.org/10.1093/mutage/geq034

Lu J, Tan M, Cai Q. 2015. The Warburg effect in tumor progression: Mitochondrial oxidative metabolism as an anti-metastasis mechanism. Cancer Lett. 356(2 Pt A):156-164. http://dx.doi.org/10.1016/j.canlet.2014.04.001

Luijten M, Olthof ED, Hakkert BC, Rorije E, van der Laan JW, Woutersen RA, van Benthem J. 2016. An integrative test strategy for cancer hazard identification. Crit Rev Toxicol. 46(7):615639. http://dx.doi.org/10.3109/10408444.2016.1171294

Lukas G, Vyas KH, Brindle SD, Le Sher AR, Wagner WE, Jr. 1980. Biological disposition of sodium dichloroacetate in animals and humans after intravenous administration. J Pharm Sci. 69(4):419-421. http://dx.doi.org/10.1002/jps.2600690415

Lumpkin MH, Bruckner JV, Campbell JL, Dallas CE, White CA, Fisher JW. 2003. Plasma binding of trichloroacetic acid in mice, rats, and humans under cancer bioassay and environmental exposure conditions. Drug Metab Dispos. 31(10):1203-1207. http://dx.doi.org/10.1124/dmd.31.10.1203

Maisenbacher HW, Shroads AL, Zhong G, Daigle AD, Abdelmalak MM, Samper IS, Mincey BD, James MO, Stacpoole PW. 2013. Pharmacokinetics of oral dichloroacetate in dogs. J Biochem Mol Toxicol. 27(12):522-525. http://dx.doi.org/10.1002/jbt.21518

Malliarou E, Collins C, Graham N, Nieuwenhuijsen MJ. 2005. Haloacetic acids in drinking water in the United Kingdom. Water Res. 39(12):2722-2730.

http://dx.doi.org/10.1016/j.watres.2005.04.052 
Maloney EK, Waxman DJ. 1999. trans-Activation of PPARalpha and PPARgamma by structurally diverse environmental chemicals. Toxicol Appl Pharmacol. 161(2):209-218. http://dx.doi.org/10.1006/taap.1999.8809

Mather GG, Exon JH, Koller LD. 1990. Subchronic 90 day toxicity of dichloroacetic and trichloroacetic acid in rats. Toxicology. 64(1):71-80. http://dx.doi.org/10.1016/0300$\underline{483 X(90) 90100-U}$

McGuire MJ, McLain JL, Obolensky A. 2002. Information Collection Rule Data Analysis. AWWA Research Foundation and American Water Works Association.

McTigue NE, Cornwell DA, Graf K, Brown R. 2014. Occurrence and consequences of increased bromide in drinking water sources. JAWWA. 106:E492-E508.

http://dx.doi.org/10.5942/jawwa.2014.106.0141

Melnick RL, Nyska A, Foster PM, Roycroft JH, Kissling GE. 2007. Toxicity and carcinogenicity of the water disinfection byproduct, dibromoacetic acid, in rats and mice. Toxicology. 230(23):126-136. http://dx.doi.org/10.1016/j.tox.2006.11.006

Merdink JL, Bull RJ, Schultz IR. 2000. Trapping and identification of the dichloroacetate radical from the reductive dehalogenation of trichloroacetate by mouse and rat liver microsomes. Free Radic Biol Med. 29(2):125-130. http://dx.doi.org/10.1016/S0891-5849(00)00330-0

Merdink JL, Bull RJ, Schultz IR. 2001. Toxicokinetics of bromodichloroacetate in B6C3F1 mice. J Appl Toxicol. 21(1):53-57. http://dx.doi.org/10.1002/jat.732

Merdink JL, Gonzalez-Leon A, Bull RJ, Schultz IR. 1998. The extent of dichloroacetate formation from trichloroethylene, chloral hydrate, trichloroacetate, and trichloroethanol in B6C3F1 mice. Toxicol Sci. 45(1):33-41. http://dx.doi.org/10.1093/toxsci/45.1.33

Muellner MG, Attene-Ramos MS, Hudson ME, Wagner ED, Plewa MJ. 2010. Human cell toxicogenomic analysis of bromoacetic acid: A regulated drinking water disinfection by-product. Environ Mol Mutagen. 51(3):205-214. http://dx.doi/org/10.1002/em.20530

Müller G, Spassovski M, Henschler D. 1974. Metabolism of trichloroethylene in man. II. Pharmacokinetics of metabolites. Archives of toxicology. 32(4):283-295.

http://dx.doi.org/10.1007/BF00330110

National Toxicology Program (NTP). 1992. Toxicology and carcinogenesis studies of monochloroacetic acid (CAS No. 79-11-8) in F344/N rats and B6C3F1 mice (gavage studies). Research Triangle Park, NC: National Toxicology Program. NTP Technical Report No. 396. NIH Publication No. 92-2851.

National Toxicology Program (NTP). 2007a. Toxicology and carcinogenesis studies of dibromoacetic acid (CAS No. 631-64-1) in F344/N rats and B6C3F1 mice (drinking water studies). Research Triangle Park, NC: National Toxicology Program. NTP Technical Report No. 537. NIH Publication No. 07-4475.

National Toxicology Program (NTP). 2007b. Toxicology studies of dichloroacetic acid (CAS No. 79-43-6) in genetically modified (FVB Tg.Ac hemizygous) mice (dermal and drinking water studies) and carcinogenicity studies of dichloroacetic acid in genetically modified [B6.129- 
$\operatorname{Trp} 53^{\text {tmlbrd }}$ (N5) haploinsufficient] mice (drinking water studies). Research Triangle Park, NC: National Toxicology Program. NTP Genetically Modified Model Report No. 11. NIH Publication No. 07-4428.

National Toxicology Program (NTP). 2009. Toxicology and carcinogenesis studies of bromochloroacetic acid (CAS No. 5589-96-8) in F344/N rats and B6C3F1 mice (drinking water studies). Research Triangle Park, NC: National Toxicology Program. NTP Technical Report No. 549. NIH Publication No. 09-5890.

National Toxicology Program (NTP). 2015. Toxicology studies of bromodichloroacetic acid (CAS No. 71133-14-7) in F344/N rats and B6C3F1/N mice and toxicology and carcinogenesis studies of bromodichloroacetic acid in F344/Ntac rats and B6C3F1/N mice (drinking water studies). Research Triangle Park, NC: National Toxicology Program. NTP Technical Report No. 583.

National Toxicology Program (NTP). 2017. Report on Carcinogens protocol: Haloacetic acids found as water disinfection by-products. Research Triangle Park, NC: National Toxicology Program. https://ntp.niehs.nih.gov/ntp/roc/protocols/haloacetic acids.pdf.

Nelson KJ. 2015. Formation of haloacetic acids and Nitrosodimethylamine via the chlorination of carbon nanotubes. University of Iowa, Master of Science thesis. http://ir.uiowa.edu/etd/1708.

Nelson MA, Sanchez IM, Bull RJ, Sylvester SR. 1990. Increased expression of c-myc and c-Haras in dichloroacetate and trichloroacetate-induced liver tumors in $\mathrm{B} 6 \mathrm{C} 3 \mathrm{~F} 1$ mice. Toxicology. 64(1):47-57. http://dx.doi.org/10.1016/0300-483X(90)90098-2

Nieminski EC, Chaudhuri S, Lamoreaux T. 1993. The occurrence of DBPs in Utah drinking waters. JAWWA. 85(9):98-105. http://dx.doi.org/10.1002/j.1551-8833.1993.tb06067.x

Nissinen TK, Miettinen IT, Martikainen PJ, Vartiainen T. 2002. Disinfection by-products in Finnish drinking waters. Chemosphere. 48(1):9-20. http://dx.doi.org/10.1016/S0045$\underline{6535(02) 00034-6}$

Ohashi T, Akazawa T, Aoki M, Kuze B, Mizuta K, Ito Y, Inoue N. 2013. Dichloroacetate improves immune dysfunction caused by tumor-secreted lactic acid and increases antitumor immunoreactivity. Int J Cancer. 133(5):1107-1118. http://dx.doi.org/10.1002/ijc.28114

Ondricek AJ, Kashyap AK, Thamake SI, Vishwanatha JK. 2012. A comparative study of phytoestrogen action in mitigating apoptosis induced by oxidative stress. In Vivo. 26(5):765-775.

Ono Y, Somiya I, Kawamura M. 1991. The evaluation of genotoxicity using DNA repairing test for chemicals produced in chlorination and ozonation processes. Water Sci Technol. 23(13):329-338. http://dx.doi.org/10.2166/wst.1991.0431

Organization for Economic Co-operation and Development (OECD). 2017. Grouping of chemicals: Chemical categories and read-across. Organization for Economic Co-operation and Development. http://www.oecd.org/chemicalsafety/riskassessment/groupingofchemicalschemicalcategoriesandread-across.htm. [accessed: 10/22/17]

Pals J, Attene-Ramos MS, Xia M, Wagner ED, Plewa MJ. 2013. Human cell toxicogenomic analysis linking reactive oxygen species to the toxicity of monohaloacetic acid drinking water 
disinfection byproducts. Environ Sci Technol. 47(21):12514-12523.

http://dx.doi.org/10.1021/es403171b

Pals JA, Ang JK, Wagner ED, Plewa MJ. 2011. Biological mechanism for the toxicity of haloacetic acid drinking water disinfection byproducts. Environ Sci Technol. 45(13):5791-5797. http://dx.doi.org/10.1021/es2008159

Pals JA, Wagner ED, Plewa MJ. 2016. Energy of the lowest unoccupied molecular orbital, thiol reactivity, and toxicity of three monobrominated water disinfection byproducts. Environ Sci Technol. 50(6):3215-3221. http://dx.doi.org/10.1021/acs.est.5b05581

Pan Y, Wei X, Hao W. 2015. Trichloroethylene and its oxidative metabolites enhance the activated state and Th1 cytokine gene expression in jurkat cells. Int J Environ Res Public Health. 12(9):10575-10586. http://dx.doi.org/10.3390/ijerph120910575

Pan Y, Zhang X, Li Y. 2016. Identification, toxicity and control of iodinated disinfection byproducts in cooking with simulated chlor(am)inated tap water and iodized table salt. Water Res. 88:60-68. http://dx.doi.org/10.1016/j.watres.2015.10.002

Parinet J, Tabaries S, Coulomb B, Vassalo L, Boudenne JL. 2012. Exposure levels to brominated compounds in seawater swimming pools treated with chlorine. Water Res. 46(3):828-836. http://dx.doi.org/10.1016/j.watres.2011.11.060

Parrish JM, Austin EW, Stevens DK, Kinder DH, Bull RJ. 1996. Haloacetate-induced oxidative damage to DNA in the liver of male B6C3F1 mice. Toxicology. 110(1-3):103-111. http://dx.doi.org/10.1016/0300-483X(96)03342-2

Parvez S, Rivera-Núñez Z, Meyer A, Wright JM. 2011. Temporal variability in trihalomethane and haloacetic acid concentrations in Massachusetts public drinking water systems. Environ Res. 111(4):499-509. http://dx.doi.org/10.1016/j.envres.2010.12.008

Patlewicz G, Ball N, Boogaard PJ, Becker RA, Hubesch B. 2015. Building scientific confidence in the development and evaluation of read-across. Regul Toxicol Pharmacol. 72(1):117-133. http://dx.doi.org/10.1016/j.yrtph.2015.03.015

Paykoc ZV, Powell JF. 1945. The excretion of sodium trichloroacetate. J Pharm Exper Ther. $85: 289-293$.

Pereira MA. 1996. Carcinogenic activity of dichloroacetic acid and trichloroacetic acid in the liver of female B6C3F1 mice. Fundam Appl Toxicol. 31(2):192-199.

http://dx.doi.org/10.1006/faat.1996.0091

Pereira MA, Kramer PM, Conran PB, Tao L. 2001. Effect of chloroform on dichloroacetic acid and trichloroacetic acid-induced hypomethylation and expression of the c-myc gene and on their promotion of liver and kidney tumors in mice. Carcinogenesis. 22(9):1511-1519. http://dx.doi.org/10.1093/carcin/22.9.1511

Pereira MA, Li KW, Kramer PM. 1997. Promotion by mixtures of dichloroacetic acid and trichloroacetic acid of $N$-methyl- $N$-nitrosourea-initiated cancer in the liver of female B6C3F1 mice. Cancer Lett. 115(1):15-23. http://dx.doi.org/10.1016/S0304-3835(97)04699-5 
Pereira MA, Phelps JB. 1996. Promotion by dichloroacetic acid and trichloroacetic acid of $N$ methyl- $N$-nitrosourea-initiated cancer in the liver of female B6C3F1 mice. Cancer Lett. 102(12):133-141. http://dx.doi.org/10.1016/0304-3835(96)04156-0

Pereira MA, Wang W, Kramer PM, Tao L. 2004b. Prevention by methionine of dichloroacetic acid-induced liver cancer and DNA hypomethylation in mice. Toxicol Sci. 77(2):243-248. http://dx.doi.org/10.1093/toxsci/kfh031

Pereira MA, Wang W, Kramer PM, Tao LH. 2004a. DNA hypomethylation induced by nongenotoxic carcinogens in mouse and rat colon. Cancer Lett. 212(2):145-151.

http://dx.doi.org/10.1016/j.canlet.2004.03.024

Pérez-Garrido A, González MP, Escudero AG. 2008. Halogenated derivatives QSAR model using spectral moments to predict haloacetic acids (HAA) mutagenicity. Bioorg Med Chem. 16(10):5720-5732. http://dx.doi.org/10.1016/j.bmc.2008.03.070

Plewa M, Kargalioglu Y, Vankerk D, Minear R, Wagner E. 2000. Development of quantitative comparative cytotoxicity and genotoxicity assays for environmental hazardous chemicals. Water Sci Technol. 42(7-8):109. http://dx.doi.org/10.2166/wst.2000.0558

Plewa MJ, Cemeli E, Anderson D, Wagner E. 2004a. The genotoxicity of the drinking water disinfection by-product iodoacetic acid is reduced by modulators of oxidative stress. Environ Mol Mutagen. 44(3):220.

Plewa MJ, Kargalioglu Y, Vankerk D, Minear RA, Wagner ED. 2002. Mammalian cell cytotoxicity and genotoxicity analysis of drinking water disinfection by-products. Environ Mol Mutagen. 40(2):134-142. http://dx.doi.org/10.1002/em.10092

Plewa MJ, Simmons JE, Richardson SD, Wagner ED. 2010. Mammalian cell cytotoxicity and genotoxicity of the haloacetic acids, a major class of drinking water disinfection by-products. Environ Mol Mutagen. 51(8-9):871-878. http://dx.doi.org/10.1002/em.20585

Plewa MJ, Wagner ED. 2015. Chapter 1. Charting a new path to resolve the adverse health effects of DBPs. In: Karanfil T, Mitch B, Westerhoff P, Xie H, editors. Recent Advances in Disinfection By-Products. Washington, D.C.: American Chemical Society. p. 3-23.

Plewa MJ, Wagner ED, Richardson SD, Thruston AD, Jr., Woo YT, McKague AB. $2004 b$. Chemical and biological characterization of newly discovered iodoacid drinking water disinfection byproducts. Environ Sci Technol. 38(18):4713-4722.

http://dx.doi.org/10.1021/es049971v

Procházka E, Escher BI, Plewa MJ, Leusch FD. 2015. In vitro cytotoxicity and adaptive stress responses to selected haloacetic acid and halobenzoquinone water disinfection byproducts. Chem Res Toxicol. 28(10):2059-2068. http://dx.doi.org/10.1021/acs.chemrestox.5b00283

PubChem. 2005. PubChem Compound Database: Iodoacetic Acid. Bethesda, MD: National Library of Medicine. https://pubchem.ncbi.nlm.nih.gov/compound/iodoacetic acid\#section=Non-Human-ToxicityValues. [Accessed: 10/12/17] 
PubChem. 2016a. PubChem Compound Database: Diiodoacetic acid. Bethesda, MD: National Library of Medicine. http://pubchem.ncbi.nlm.nih.gov/ and search on diiodoacetic acid.

[Accessed: 5/16/16]

PubChem. 2016b. PubChem Compound Database: Chloroacetic acid. Bethesda, MD: National Library of Medicine. http://pubchem.ncbi.nlm.nih.gov/ and search on chloroacetic acid. [Accessed: 4/11/17]

PubChem. 2017. PubChem Compound Database: Chloroacetic acid. Bethesda, MD: National Library of Medicine. http://pubchem.ncbi.nlm.nih.gov/ and search on chloroacetic acid. [Accessed: 4/11/17]

Ratasuk C, Kositanont C, Ratanatamskul C. 2008. Removal of haloacetic acids by ozone and biologically active carbon. ScienceAsia. 34:293-298. http://dx.doi.org/10.2306/scienceasia1513$\underline{1874.2008 .34 .293}$

Raymer J, Michael LC. 2010. Uptake of water disinfection by-products into food. Research Triangle Park, NC: Research Triangle Institute. MR-0016-1008.

Reckhow DA, Platt TL, MacNeill AL, McClellan JN. 2001. Formation and degradation of dichloroacetonitrile in drinking waters. J Water Supply Res Technol. 50(1):1-13.

http://dx.doi.org/10.2166/aqua.2001.0001

Reckhow DA, Singer PC. 1985. Mechanisms of organic halide formation during fulvic acid chlorination and implications with respect to preozonation. In: Jolley RL, Bull RJ, Davis WP, Katz S, Roberts Jr. MH, Jacobs VA, editors. Water Chlorination: Chemistry, Environmental Impact and Health Effects. Chelsea, MI: Lewis Publishers, Inc. p. 1229-1257.

Regli S, Chen J, Messner M, Elovitz MS, Letkiewicz FJ, Pegram RA, Pepping TJ, Richardson SD, Wright JM. 2015. Estimating potential increased bladder cancer risk due to increased bromide concentrations in sources of disinfected drinking waters. Environ Sci Technol. 49(22):13094-13102. http://dx.doi.org/10.1021/acs.est.5b03547

Richard AM, Hunter ES, 3rd. 1996. Quantitative structure-activity relationships for the developmental toxicity of haloacetic acids in mammalian whole embryo culture. Teratology. 53(6):352-360. http://dx.doi.org/10.1002/(SICI)1096-9926(199606)53:6<352::AIDTERA6>3.0.CO;2-1

Richardson S. 2016. Reviewer form for ORoC information group on haloacetic acids to the National Toxicology Program.

Richardson SD, Fasano F, Ellington JJ, Crumley FG, Buettner KM, Evans JJ, Blount BC, Silva LK, Waite TJ, Luther GW et al. 2008. Occurrence and mammalian cell toxicity of iodinated disinfection byproducts in drinking water. Environ Sci Technol. 42(22):8330-8338. http://dx.doi.org/10.1021/es801169k

Richardson SD, Plewa MJ, Wagner ED, Schoeny R, Demarini DM. 2007. Occurrence, genotoxicity, and carcinogenicity of regulated and emerging disinfection by-products in drinking water: A review and roadmap for research. Mutat Res. 636(1-3):178-242.

http://dx.doi.org/10.1016/j.mrrev.2007.09.001 
Richardson SD, Postigo C. 2015. Formation of DBPs: State of the science. In: Karanfil T, Krasner SW, Westerhoff P, Xie Y, editors. Recent Advances in Disinfection By-Products. Washington, DC: American Chemical Society. p. 189-214.

Richmond RE, Carter JH, Carter HW, Daniel FB, DeAngelo AB. 1995. Immunohistochemical analysis of dichloroacetic acid (DCA)-induced hepatocarcinogenesis in male Fischer (F344) rats. Cancer Lett. 92(1):67-76. http://dx.doi.org/10.1016/0304-3835(94)03756-9

Richmond RE, De Angelo AB, Potter CL, Daniel FB. 1991. The role of hyperplastic nodules in dichloroacetic acid-induced hepatocarcinogenesis in $\mathrm{B} 6 \mathrm{C} 3 \mathrm{~F} 1$ male mice. Carcinogenesis. 12(8):1383-1387. http://dx.doi.org/10.1093/carcin/12.8.1383

Roberts MG, Singer PC, Obolensky A. 2002. Comparing total HAA and total THM concentrations using ICR data. JAWWA. 94(1):103-114. http://dx.doi.org/10.1002/j.1551$\underline{\text { 8833.2002.tb09386.x }}$

Roccaro P, Vagliasindi FGA, Korshin GV. 2014. Relationships between trihalomethanes, haloacetic acids, and haloacetonitriles formed by the chlorination of raw, treated, and fractionated surface waters. J Water Supply Res Technol. 63(1):21-30.

http://dx.doi.org/10.2166/aqua.2013.043

Rodriguez MJ, Sérodes J-B, Levallois P, Proulx F. 2007. Chlorinated disinfection by-products in drinking water according to source, treatment, season, and distribution location. J Environ Eng Sci. 6:355-365. http://dx.doi.org/10.1139/s06-055

Rogers DR. 1995. Accidental fatal monochloroacetic acid poisoning. Am J Forensic Med Pathol. 16(2):115-116. http://dx.doi.org/10.1097/00000433-199506000-00005

Rosinger A, Herrick K. 2016. Daily water intake among U.S. men and women, 2009-2012. NCHS Data Brief. (242):1-8.

Safe Drinking Water Foundation (SDWF). 2009. What is chlorination? Safe Drinking Water Foundation. https://www.safewater.org/PDFS/resourcesknowthefacts/WhatisChlorination.pdf.

Saghir SA, Fried K, Rozman KK. 2001. Kinetics of monochloroacetic acid in adult male rats after intravenous injection of a subtoxic and a toxic dose. J Pharmacol Exp Ther. 296(2):612622.

Saghir SA, Ghanayem BI, Schultz IR. 2011. Kinetics of trihalogenated acetic acid metabolism and isoform specificity in liver microsomes. Int J Toxicol. 30(5):551-561. http://dx.doi.org/10.1177/1091581811414213

Saghir SA, Rozman KK. 2003. Kinetics of monochloroacetic acid at subtoxic and toxic doses in rats after single oral and dermal administrations. Toxicol Sci. 76(1):51-64.

http://dx.doi.org/10.1093/toxsci/kfg214

Saghir SA, Schultz IR. 2002. Low-dose pharmacokinetics and oral bioavailability of

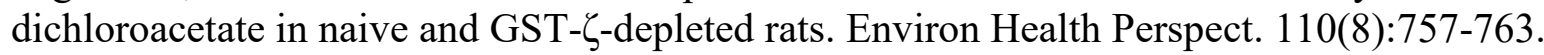
http://dx.doi.org/10.1289/ehp.02110757 
Saghir SA, Schultz IR. 2005. Toxicokinetics and oral bioavailability of halogenated acetic acids mixtures in naive and GSTzeta-depleted rats. Toxicol Sci. 84(2):214-224.

http://dx.doi.org/10.1093/toxsci/kfi070

Sanchez IM, Bull RJ. 1990. Early induction of reparative hyperplasia in the liver of B6C3F1 mice treated with dichloroacetate and trichloroacetate. Toxicology. 64(1):33-46.

http://dx.doi.org/10.1016/0300-483X(90)90097-Z

Schroeder M, DeAngelo AB, Mass MJ. 1997. Dichloroacetic acid reduces Ha-ras codon 61 mutations in liver tumors from female B6C3F1 mice. Carcinogenesis. 18(8):1675-1678. http://dx.doi.org/10.1093/carcin/18.8.1675

Schultz IR, Merdink JL, Gonzalez-Leon A, Bull RJ. 1999. Comparative toxicokinetics of chlorinated and brominated haloacetates in F344 rats. Toxicol Appl Pharmacol. 158(2):103-114. http://dx.doi.org/10.1006/taap.1999.8698

Schultz IR, Merdink JL, Gonzalez-Leon A, Bull RJ. 2002. Dichloroacetate toxicokinetics and disruption of tyrosine catabolism in B6C3F1 mice: Dose-response relationships and age as a modifying factor. Toxicology. 173(3):229-247. http://dx.doi.org/10.1016/S0300-

$\underline{483 X(02) 00034-3}$

Schultz IR, Shangraw RE. 2006. Effect of short-term drinking water exposure to dichloroacetate on its pharmacokinetics and oral bioavailability in human volunteers: A stable isotope study. Toxicol Sci. 92(1):42-50. http://dx.doi.org/10.1093/toxsci/kfj193

Schultz IR, Sylvester SR. 2001. Stereospecific toxicokinetics of bromochloro- and chlorofluoroacetate: Effect of GST- $\zeta$ depletion. Toxicol Appl Pharmacol. 175(2):104-113. http://dx.doi.org/10.1006/taap.2001.9250

Schultz TW, Amcoff P, Berggren E, Gautier F, Klaric M, Knight DJ, Mahony C, Schwarz M, White A, Cronin MT. 2015. A strategy for structuring and reporting a read-across prediction of toxicity. Regul Toxicol Pharmacol. 72(3):586-601. http://dx.doi.org/10.1016/j.yrtph.2015.05.016

Schultz TW, Carlson RE, Cronin MTD, Hermens JLM, Johnson R, O'Brien PJ, Roberts DW, Siraki A, Wallace KB, Veith GD. 2006. A conceptual framework for predicting the toxicity of reactive chemicals: Modeling soft electrophilicity. SAR QSAR Environ Res. 17(4):413-428. http://dx.doi.org/10.1080/10629360600884371

Seidel CJ, Samson CC, Bartrand T, Ergul A, Summers RS. 2017. Disinfection byproduct occurrence at large water systems after stage 2 DBPR. JAWWA. 109(7):17-30.

Shangraw RE, Fisher DM. 1996. Pharmacokinetics of dichloroacetate in patients undergoing liver transplantation. Anesthesiology. 84(4):851-858. http://dx.doi.org/10.1097/00000542$\underline{199604000-00012}$

Shangraw RE, Fisher DM. 1999. Pharmacokinetics and pharmacodynamics of dichloroacetate in patients with cirrhosis. Clinical pharmacology and therapeutics. 66(4):380-390.

https://doi.org/10.1053/cp.1999.v66.a101340 
Shroads AL, Coats BS, McDonough CW, Langaee T, Stacpoole PW. 2015. Haplotype variations in glutathione transferase zeta 1 influence the kinetics and dynamics of chronic dichloroacetate in children. J Clin Pharmacol. 55(1):50-55. http://dx.doi.org/10.1002/jcph.371

Shroads AL, Langaee T, Coats BS, Kurtz TL, Bullock J, Weithorn D, Gong Y, Wagner D, Ostrov DA, Johnson JA et al. 2010. Human polymorphisms in the glutathione transferase zeta 1 maleylacetoacetate isomerase gene predict the kinetics and toxicity of dichloroacetate. Drug Metab Rev. 42:204-204.

Si EC, Pfeifer RW, Yim GK. 1987. Iodoacetic acid and related sulfhydryl reagents fail to inhibit cell-cell communication: Mechanisms of immunotoxicity in vitro. Toxicology. 44(1):73-89. http://dx.doi.org/10.1016/0300-483X(87)90047-3

Singer PC, Weinberg HS, Brophy K, Liang L, Roberts M, Grisstede I, Krasner S, Baribeau H, Arora H, Najm I. 2002. Relative dominance of haloacetic acids and trihalomethanes in treated drinking water. AWWA Research Foundation and the American Water Works Association.

Smith EM, Plewa MJ, Lindell CL, Richardson SD, Mitch WA. 2010b. Comparison of byproduct formation in waters treated with chlorine and iodine: Relevance to point-of-use treatment. Environ Sci Technol. 44(22):8446-8452. http://dx.doi.org/10.1021/es102746u

Smith MJ, Germolec DR, Luebke RW, Sheth CM, Auttachoat W, Guo TL, White KL, Jr. 2010a. Immunotoxicity of dibromoacetic acid administered via drinking water to female $\mathrm{B}(6) \mathrm{C}(3) \mathrm{F}(1)$ mice. J Immunotoxicol. 7(4):333-343. http://dx.doi.org/10.3109/1547691X.2010.519744

Smith MT, Guyton KZ, Gibbons CF, Fritz JM, Portier CJ, Rusyn I, DeMarini DM, Caldwell JC, Kavlock RJ, Lambert P et al. 2016. Key characteristics of carcinogens as a basis for organizing data on mechanisms of carcinogenesis. Environ Health Perspect. 124(6):713-721.

http://dx.doi.org/10.1289/ehp.1509912

Snyder RD, Pullman J, Carter JH, Carter HW, DeAngelo AB. 1995. In vivo administration of dichloroacetic acid suppresses spontaneous apoptosis in murine hepatocytes. Cancer Res. 55(17):3702-3705.

Spalding JW, French JE, Stasiewicz S, Furedi-Machacek M, Conner F, Tice RR, Tennant RW. 2000. Responses of transgenic mouse lines p53(+/-) and Tg.AC to agents tested in conventional carcinogenicity bioassays. Toxicol Sci. 53(2):213-223. http://dx.doi.org/10.1093/toxsci/53.2.213

Stacpoole PW. 2011. The dichloroacetate dilemma: Environmental hazard versus therapeutic goldmine-both or neither? Environ Health Perspect. 119(2):155-158.

http://dx.doi.org/10.1289/ehp.1002554

Stacpoole PW, Henderson GN, Yan ZM, Cornett R, James MO. 1998. Pharmacokinetics, metabolism, and toxicology of dichloroacetate. Drug Metab Rev. 30(3):499-539.

http://dx.doi.org/10.3109/03602539808996323

Stacpoole PW, Kurtz TL, Han Z, Langaee T. 2008. Role of dichloroacetate in the treatment of genetic mitochondrial diseases. Adv Drug Deliv Rev. 60(13-14):1478-1487.

http://dx.doi.org/10.1016/j.addr.2008.02.014 
Stalter D, O'Malley E, von Gunten U, Escher BI. 2016a. Fingerprinting the reactive toxicity pathways of 50 drinking water disinfection by-products. Water Res. 91:19-30.

http://dx.doi.org/10.1016/j.watres.2015.12.047

Stalter D, O'Malley E, Von Gunten U, Escher BI. 2016b. Point-of-use water filters can effectively remove disinfection by-products and toxicity from chlorinated and chloraminated tap water. Environ Sci Water Res Tech. 2:875-883. http://dx.doi.org/10.1039/C6EW00068A

Stauber AJ, Bull RJ. 1997. Differences in phenotype and cell replicative behavior of hepatic tumors induced by dichloroacetate (DCA) and trichloroacetate (TCA). Toxicol Appl Pharmacol. 144(2):235-246. http://dx.doi.org/10.1006/taap.1997.8159

Stauber AJ, Bull RJ, Thrall BD. 1998. Dichloroacetate and trichloroacetate promote clonal expansion of anchorage-independent hepatocytes in vivo and in vitro. Toxicol Appl Pharmacol. 150(2):287-294. http://dx.doi.org/10.1006/taap.1998.8417

Stevens DK, Eyre RJ, Bull RJ. 1992. Adduction of hemoglobin and albumin invivo by metabolites of trichloroethylene, trichloroacetate, and dichloroacetate in rats and mice. Fundam Appl Toxicol. 19(3):336-342. http://dx.doi.org/10.1016/0272-0590(92)90171-D

Styles JA, Wyatt I, Coutts C. 1991. Trichloroacetic acid: Studies on uptake and effects on hepatic DNA and liver growth in mouse. Carcinogenesis. 12(9):1715-1719. http://dx.doi.org/10.1093/carcin/12.9.1715

Szczuka A, Parker KM, Harvey C, Hayes E, Vengosh A, Mitch WA. 2017. Regulated and unregulated halogenated disinfection byproduct formation from chlorination of saline groundwater. Water Res. 122:633-644. http://dx.doi.org/10.1016/j.watres.2017.06.028

Tanaka N, Bohnenberger S, Kunkelmann T, Munaro B, Ponti J, Poth A, Sabbioni E, Sakai A, Salovaara S, Sasaki K et al. 2012. Prevalidation study of the BALB/c 3T3 cell transformation assay for assessment of carcinogenic potential of chemicals. Mutat Res. 744(1):20-29. http://dx.doi.org/10.1016/j.mrgentox.2011.12.008

Tanguay RM, Jorquera R, Poudrier J, St-Louis M. 1996. Tyrosine and its catabolites: From disease to cancer. Acta Biochim Pol. 43(1):209-216.

Tao L, Li Y, Kramer PM, Wang W, Pereira MA. 2004b. Hypomethylation of DNA and the insulin-like growth factor-II gene in dichloroacetic and trichloroacetic acid-promoted mouse liver tumors. Toxicology. 196(1-2):127-136. http://dx.doi.org/10.1016/j.tox.2003.11.011

Tao L, Wang W, Li L, Kramer PK, Pereira MA. 2005. DNA hypomethylation induced by drinking water disinfection by-products in mouse and rat kidney. Toxicol Sci. 87(2):344-352. http://dx.doi.org/10.1093/toxsci/kfi257

Tao L, Wang W, Li L, Kramer PM, Pereira MA. 2004a. Effect of dibromoacetic acid on DNA methylation, glycogen accumulation, and peroxisome proliferation in mouse and rat liver.

Toxicol Sci. 82(1):62-69. http://dx.doi.org/10.1093/toxsci/kfh266

Tao L, Yang S, Xie M, Kramer PM, Pereira MA. 2000a. Hypomethylation and overexpression of c-jun and c-myc protooncogenes and increased DNA methyltransferase activity in dichloroacetic 
and trichloroacetic acid-promoted mouse liver tumors. Cancer Lett. 158(2):185-193. http://dx.doi.org/10.1016/S0304-3835(00)00518-8

Tao L, Yang S, Xie M, Kramer PM, Pereira MA. 2000b. Effect of trichloroethylene and its metabolites, dichloroacetic acid and trichloroacetic acid, on the methylation and expression of $c$ jun and $c-m y c$ protooncogenes in mouse liver: Prevention by methionine. Toxicol Sci. 54(2):399407. http://dx.doi.org/10.1093/toxsci/54.2.399

Tao LH, Kramer PM, Ge RG, Pereira MA. 1998. Effect of dichloroacetic acid and trichloroacetic acid on DNA methylation in liver and tumors of female B6C3F1 mice. Toxicol Sci. 43(2):139144. http://dx.doi.org/10.1093/toxsci/43.2.139

Teixidó E, Piqué E, Gonzalez-Linares J, Llobet JM, Gómez-Catalán J. 2015. Developmental effects and genotoxicity of 10 water disinfection by-products in zebrafish. J Water Health. 13(1):54-66. http://dx.doi.org/10.2166/wh.2014.006

Templin MV, Stevens DK, Stenner RD, Bonate PL, Turnan D, Bull RJ. 1995. Factors affecting species differences in the kinetics of metabolites of trichloroethylene. J Toxicol Environ Health. 44(4):435-447. http://dx.doi.org/10.1080/15287399509531972

Tennant R, Haseman J, Stoll RE. 2001. Transgenic assays and the identification of carcinogens. Environ Mol Mutagen. 37(1):86-88. http://dx.doi.org/10.1002/1098-2280(2001)37:1<86::AIDEM1010>3.0.CO;2-G

Tennant RW, Spalding J. 1996. Predictions for the outcome of rodent carcinogenicity bioassays: Identification of trans-species carcinogens and noncarcinogens. Environ Health Perspect. 104 Suppl 5:1095-1100.

Teo TL, Coleman HM, Khan SJ. 2015. Chemical contaminants in swimming pools: Occurrence, implications and control. Environ Int. 76:16-31. http://dx.doi.org/10.1016/j.envint.2014.11.012

Thai SF, Allen JW, DeAngelo AB, George MH, Fuscoe JC. 2001. Detection of early gene expression changes by differential display in the livers of mice exposed to dichloroacetic acid. Carcinogenesis. 22(8):1317-1322. http://dx.doi.org/10.1093/carcin/22.8.1317

Thai SF, Allen JW, DeAngelo AB, George MH, Fuscoe JC. 2003. Altered gene expression in mouse livers after dichloroacetic acid exposure. Mutat Res. 543(2):167-180.

http://dx.doi.org/10.1016/S1383-5742(03)00014-0

Theodoratos A, Tu WJ, Cappello J, Blackburn AC, Matthaei K, Board PG. 2009. Phenylalanineinduced leucopenia in genetic and dichloroacetic acid generated deficiency of glutathione transferase Zeta. Biochem Pharmacol. 77(8):1358-1363.

http://dx.doi.org/10.1016/j.bcp.2009.01.017

Tong Z, Board PG, Anders MW. 1998. Glutathione transferase zeta-catalyzed biotransformation of dichloroacetic acid and other $\alpha$-haloacids. Chem Res Toxicol. 11(11):1332-1338.

http://dx.doi.org/10.1021/tx980144f

Toxic Release Inventory (TRI). 2017. TRI Explorer Chemical Report. TRI on-site and off-site reported disposed of or otherwise released (in pounds), for all 19 facilities, for facilities in all 
industries, for chloroacetic acid chemical, U.S., 2015. U.S. Environmental Protection Agency. http://www.epa.gov/triexplorer. [accessed: 4/2017]

Tully DB, Luft JC, Rockett JC, Ren H, Schmid JE, Wood CR, Dix DJ. 2005. Reproductive and genomic effects in testes from mice exposed to the water disinfectant byproduct bromochloroacetic acid. Reprod Toxicol. 19(3 Spec Iss):353-366.

https://doi.org/10.1016/j.reprotox.2004.06.009

Tzeng HF, Blackburn AC, Board PG, Anders MW. 2000. Polymorphism- and species-dependent inactivation of glutathione transferase zeta by dichloroacetate. Chem Res Toxicol. 13(4):231236. http://dx.doi.org/10.1021/tx990175q

U.S. Environmental Protection Agency (USEPA). 2000. The history of drinking water treatment. U.S. Environmental Protection Agency. EPA 816/F-00/006.

U.S. Environmental Protection Agency (USEPA). 2003. Toxicological review of dichloroacetic acid. Washington, D.C.: U.S. Environmental Protection Agency. EPA 635/R-03/007.

U.S. Environmental Protection Agency (USEPA). 2005. Economic analysis for the final stage 2 disinfectants and disinfection byproducts rule. U.S. Environmental Protection Agency. EPA 815/R-05/010.

U.S. Environmental Protection Agency (USEPA). 2006. Economic analysis for the final ground water rule. U.S. Environmental Protection Agency. EPA 815/R-06/014.

U.S. Environmental Protection Agency (USEPA). 2010. Comprehensive disinfectants and disinfection byproducts rules (stage 1 and stage 2): Quick reference guide. U.S. Environmental Protection Agency. EPA 816/F-10/080.

U.S. Environmental Protection Agency (USEPA). 2011a. Toxicological review of trichloroacetic acid. Washington, D.C.: U.S. Environmental Protection Agency. EPA 635/R-09/003F.

U.S. Environmental Protection Agency (USEPA). 2011b. Toxicological review of trichloroethylene (CAS No. 79-01-6). In support of summary information on the Integrated Risk Information System (IRIS). Washington, D.C.: U.S. Environmental Protection Agency. EPA 635/R-09/011F.

U.S. Environmental Protection Agency (USEPA). 2015a. Basic information about your drinking water. U.S. Environmental Protection Agency. http://www.epa.gov/your-drinking-water/basicinformation-about-your-drinking-water.

U.S. Environmental Protection Agency (USEPA). 2015b. About private water wells. U.S. Environmental Protection Agency. http://www.epa.gov/privatewells/about-private-water-wells.

U.S. Environmental Protection Agency (USEPA). 2016a. Conventional treatment. U.S. Environmental Protection Agency. https://iaspub.epa.gov/tdb/pages/treatment/treatmentOverview.do?treatmentProcessId=19346819 21. [accessed: 10/17/16]

U.S. Environmental Protection Agency (USEPA). 2016b. Six-year review 3 compliance monitoring data (2006-2011). U.S. Environmental Protection Agency. 
https://www.epa.gov/dwsixyearreview/six-year-review-3-compliance-monitoring-data-20062011.

Vander Heiden MG, Cantley LC, Thompson CB. 2009. Understanding the Warburg effect: The metabolic requirements of cell proliferation. Science. 324(5930):1029-1033. http://dx.doi.org/10.1126/science.1160809

Varshney M, Chandra A, Chauhan LKS, Goel SK. 2013. Micronucleus induction by oxidative metabolites of trichloroethylene in cultured human peripheral blood lymphocytes: A comparative genotoxicity study. Environ Sci Pollut Res. 20(12):8709-8716. http://dx.doi.org/10.1007/s11356$\underline{013-1806-7}$

Varshney M, Chandra A, Chauhan LKS, Goel SK. 2014. In vitro cytogenetic assessment of trichloroacetic acid in human peripheral blood lymphocytes. Environ Sci Pollut Res. 21(2):843850. http://dx.doi.org/10.1007/s11356-013-1949-6

Villanueva CM, Fernández F, Malats N, Grimalt JO, Kogevinas M. 2003a. Meta-analysis of studies on individual consumption of chlorinated drinking water and bladder cancer. J Epidemiol Community Health. 57(3):166-173. http://dx.doi.org/10.1136/jech.57.3.166

Villanueva CM, Gracia-Lavedan E, Bosetti C, Righi E, Molina AJ, Martín V, Boldo E, Aragonés N, Perez-Gomez B, Pollan M et al. 2017. Colorectal cancer and long-term exposure to trihalomethanes in drinking water: A multicenter case-control study in Spain and Italy. Environ Health Perspect. 125(1):56-65. http://dx.doi.org/10.1289/EHP155

Villanueva CM, Kogevinas M, Grimalt JO. 2003b. Haloacetic acids and trihalomethanes in finished drinking waters from heterogeneous sources. Water Res. 37(4):953-958. http://dx.doi.org/10.1016/S0043-1354(02)00411-6

Von Tungeln LS, Yi P, Bucci TJ, Samokyszyn VM, Chou MW, Kadlubar FF, Fu PP. 2002. Tumorigenicity of chloral hydrate, trichloroacetic acid, trichloroethanol, malondialdehyde, 4hydroxy-2-nonenal, crotonaldehyde, and acrolein in the $\mathrm{B} 6 \mathrm{C} 3 \mathrm{~F}(1)$ neonatal mouse. Cancer Lett. 185(1):13-19. http://dx.doi.org/10.1016/S0304-3835(02)00231-8

Walgren JE, Kurtz DT, McMillan JM. 2000a. The effect of the trichloroethylene metabolites trichloroacetate and dichloroacetate on peroxisome proliferation and DNA synthesis in cultured human hepatocytes. Cell Biol Toxicol. 16(4):257-273.

http://dx.doi.org/10.1023/A:1007638227821

Walgren JE, Kurtz DT, McMillan JM. 2000b. Expression of PPARa in human hepatocytes and activation by trichloroacetate and dichloroacetate. Res Commun Mol Pathol Pharmacol. 108(12):116-132.

Walgren JL, Jollow DJ, McMillan JM. 2004. Induction of peroxisome proliferation in cultured hepatocytes by a series of halogenated acetates. Toxicology. 197(3):189-197.

http://dx.doi.org/10.1016/j.tox.2004.01.007

Walgren JL, Kurtz DT, McMillan JM. 2005. Lack of direct mitogenic activity of dichloroacetate and trichloroacetate in cultured rat hepatocytes. Toxicology. 211(3):220-230.

http://dx.doi.org/10.1016/j.tox.2005.03.009 
Wang S, Zheng W, Liu X, Xue P, Jiang S, Lu D, Zhang Q, He G, Pi J, Andersen ME et al. 2014. Iodoacetic acid activates Nrf2-mediated antioxidant response in vitro and in vivo. Environ Sci Technol. 48(22):13478-13488. http://dx.doi.org/10.1021/es502855x

Wei J, Ye B, Wang W, Yang L, Tao J, Hang Z. 2010. Spatial and temporal evaluations of disinfection by-products in drinking water distribution systems in Beijing, China. Sci Total Environ. 408(20):4600-4606. http://dx.doi.org/10.1016/j.scitotenv.2010.06.053

Wei X, Wang S, Zheng W, Wang X, Liu X, Jiang S, Pi J, Zheng Y, He G, Qu W. 2013. Drinking water disinfection byproduct iodoacetic acid induces tumorigenic transformation of NIH3T3 cells. Environ Sci Technol. 47(11):5913-5920. http://dx.doi.org/10.1021/es304786b

Weinberg HS, Krasner SW, Richardson SD, Thruston AD, Jr. 2002. The occurrence of disinfection by-products (DBPs) of health concern in drinking water: Results of a nationwide DBP occurrence study. Athens, GA: U.S. Environmental Protection Agency. EPA 600/R-02/068.

Werner D, Valdivia-Garcia M, Weir P, Haffey M. 2016. Trihalomethanes formation in point of use surface water disinfection with chlorine or chlorine dioxide tablets. Water Environ J. 30:271277. http://dx.doi.org/10.1111/wej.12209

Wood CE, Hester SD, Chorley BN, Carswell G, George MH, Ward W, Vallanat B, Ren HZ, Fisher A, Lake AD et al. 2015. Latent carcinogenicity of early-life exposure to dichloroacetic acid in mice. Carcinogenesis. 36(7):782-791. http://dx.doi.org/10.1093/carcin/bgv057

Wright JM, Murphy PA, Nieuwenhuijsen MJ, Savitz DA. 2006. The impact of water consumption, point-of-use filtration and exposure categorization on exposure misclassification of ingested drinking water contaminants. Sci Total Environ. 366(1):65-73.

http://dx.doi.org/10.1016/j.scitotenv.2005.08.010

Xu G, Stevens DK, Bull RJ. 1995. Metabolism of bromodichloroacetate in B6C3F1 mice. Drug Metab Dispos. 23(12):1412-1416.

Xu X, Mariano TM, Laskin JD, Weisel CP. 2002. Percutaneous absorption of trihalomethanes, haloacetic acids, and haloketones. Toxicol Appl Pharmacol. 184(1):19-26.

http://dx.doi.org/10.1006/taap.2002.9494

Yu KO, Barton HA, Mahle DA, Frazier JM. 2000. In vivo kinetics of trichloroacetate in male Fischer 344 rats. Toxicol Sci. 54(2):302-311. http://dx.doi.org/10.1093/toxsci/54.2.302

Zhai H, Zhang X. 2011. Formation and decomposition of new and unknown polar brominated disinfection byproducts during chlorination. Environ Sci Technol. 45(6):2194-2201.

http://dx.doi.org/10.1021/es1034427

Zhang JY, Zhang F, Hong CQ, Giuliano AE, Cui XJ, Zhou GJ, Zhang GJ, Cui YK. 2015a. Critical protein GAPDH and its regulatory mechanisms in cancer cells. Cancer Biol Med. 12(1):10-22. http://dx.doi.org/10.7497/j.issn.2095-3941.2014.0019

Zhang L, Xu L, Zeng Q, Zhang SH, Xie H, Liu AL, Lu WQ. 2012. Comparison of DNA damage in human-derived hepatoma line (HepG2) exposed to the fifteen drinking water disinfection byproducts using the single cell gel electrophoresis assay. Mutation research. 741(1-2):89-94. https://doi.org/10.1016/j.mrgentox.2011.11.004 
Zhang SH, Miao DY, Liu AL, Zhang L, Wei W, Xie H, Lu WQ. 2010. Assessment of the cytotoxicity and genotoxicity of haloacetic acids using microplate-based cytotoxicity test and CHO/HGPRT gene mutation assay. Mutat Res. 703(2):174-179.

http://dx.doi.org/10.1016/j.mrgentox.2010.08.014

Zhang SH, Miao DY, Tan L, Liu AL, Lu WQ. 2016. Comparative cytotoxic and genotoxic potential of 13 drinking water disinfection by-products using a microplate-based cytotoxicity assay and a developed SOS/umu assay. Mutagenesis. 31(1):35-41.

https://doi.org/10.1093/mutage/gev053

Zhang X, Bull RJ, Fisher J, Cotruvo JA, Cummings BS. 2011. The synergistic effect of sodium chlorite and bromochloroacetic acid on BrO3(-)-induced renal cell death. Toxicology. 289(23):151-159. http://dx.doi.org/10.1016/j.tox.2011.08.008

Zhang X, Echigo S, Minear RA, Plewa MJ. 2000. Characterization and comparison of disinfection by-products of four major disinfectants. In: Barrett SE, Krasner SW, Amy GL, editors. Natural Organic Matter and Disinfection By-Products. Washington, DC: American Chemical Society. p. 299-314.

Zhang YQ, Wu QP, Zhang JM, Yang XH. 2015b. Removal of bromide and bromate from drinking water using granular activated carbon. J Water Health. 13(1):73-78.

http://dx.doi.org/10.2166/wh.2014.084 


\section{Abbreviations}

${ }^{1} \mathrm{H}$ NMR proton nuclear magnetic resonance

8-OHdG 8-hydroxydeoxyguanosine

ACGIH American Conference of Governmental Industrial Hygienists

ADD average daily dose

ADME absorption, distribution, metabolism, and excretion

AEG Acute Exposure Guideline Level

AhR aryl hydrocarbon receptor

ALL acute lymphocytic leukemia

ALT serum alanine aminotransferase, alanine aminotransferase

ANOVA analysis of variance

AOP adverse outcome pathway

ARE antioxidant response element

ARNT aryl hydrocarbon nuclear translocator

AST

serum aspartate aminotransferase, aspartate aminotransferase

atm

atmosphere

ATSDR

Agency for Toxic Substances and Disease Registry

AWWA

American Water Works Association

BCA

bromochloroacetic acid

BDCA

bromodichloroacetic acid

BDL

below detection limit

BIA

bromoiodoacetic acid

BMD

benchmark dose

BMDL benchmark dose low

CA

chromosomal aberration

CASRN

Chemical Abstracts Service registry number

CDBA

chlorodibromoacetic acid

CDC

Centers for Disease Control and Prevention

CDR

Chemical Data Reporting Rule

CEBS Chemical Effects in Biological Systems database

CERHR Center for the Evaluation of Risks to Human Reproduction

$\mathrm{CHO}$ Chinese hamster ovary 


$\begin{array}{ll}\text { CIA } & \text { chloroiodoacetic acid } \\ \text { CIN } & \text { chromosomal instability } \\ \mathrm{cm}^{2} & \text { centimeters squared } \\ \mathrm{CO}_{2} & \text { carbon dioxide } \\ \mathrm{CT} & \text { chlorine concentration (C) times contact time (T) } \\ \mathrm{Cx} & \text { connexin } \\ \mathrm{Cx} 32 & \text { gap junction beta 1-protein; connexin32 } \\ \text { DBA } & \text { dibromoacetic acid } \\ \text { DBP } & \text { disinfection by-product } \\ \text { DBPR } & \text { Disinfectants and Disinfection By-products Rule } \\ \text { DCA } & \text { dichloroacetic acid } \\ \text { DIA } & \text { diiodoacetic acid } \\ \text { DLMI } & \text { dominant lethal mutation index } \\ \text { DLMR } & \text { dominant lethal mutation rate } \\ \text { DNA } & \text { deoxyribonucleic acid } \\ \text { dw } & \text { drinking water } \\ \text { EASE } & \text { Estimation and Assessment of Substance Exposure } \\ \text { EC } 50 & \text { concentration of a drug that gives a half-maximal response } \\ \text { EHOMO } & \text { energy of the highest occupied molecular orbital } \\ \text { ELUMO } & \text { energy of the lowest unoccupied molecular orbital } \\ \text { EPA, USEPA } & \text { Environmental Protection Agency, United States Environmental Protection } \\ \text { EQ } & \text { Agency } \\ \text { Erk MAPK } & \text { exposure quartiles model } \\ \text { EUSES } & \text { extracellular signal-regulated kinase mitogen activated pathway } \\ \text { EWG } & \text { European Union System for the Evaluation of Substances } \\ \text { Exp. } & \text { Environmental Working Group } \\ \text { F } & \text { exposed } \\ \text { FDA } & \text { female } \\ \text { FLARE } & \text { Food and Drug Administration } \\ \text { FR } & \text { fragment length analysis with repair enzyme } \\ \text { ft } & \text { federal Register } \\ \text { FTE } & \end{array}$




\begin{tabular}{|c|c|}
\hline $\mathrm{FU}$ & follow-up \\
\hline G & guanine \\
\hline GAC & Genetic Alterations in Cancer \\
\hline GC/MS & gas chromatography/mass spectroscopy \\
\hline GFR & glomerular filtration rate \\
\hline GI & gastrointestinal \\
\hline GIS & Geographic Information System \\
\hline GM & geometric mean \\
\hline GSH & glutathione \\
\hline GSSH & oxidized glutathione \\
\hline GST & glutathione $S$-transferase \\
\hline GST- $\zeta$ & glutathione $S$-transferase zeta \\
\hline HAA & haloacetic acid \\
\hline HAA5 & $\begin{array}{l}\text { sum of five haloacetic acids (bromoacetic acid, dibromoacetic acid, } \\
\text { chloroacetic acid, dichloroacetic acid, and trichloroacetic acid) }\end{array}$ \\
\hline HAA9 & $\begin{array}{l}\text { sum of nine haloacetic acids (bromoacetic acid, dibromoacetic acid, } \\
\text { chloroacetic acid, dichloroacetic acid, and trichloroacetic acid, } \\
\text { bromochloroacetic acid, bromodichloroacetic acid, dibromochloroacetic acid, } \\
\text { and tribromoacetic acid) }\end{array}$ \\
\hline $\mathrm{Hb}$ & hemoglobin \\
\hline HBV & Hepatitis B virus \\
\hline $\mathrm{HCB}$ & hexachlorobenzene \\
\hline HCL & hairy-cell leukemia \\
\hline $\mathrm{HCV}$ & Hepatitis $C$ virus \\
\hline HETA & Health Hazard Evaluation and Technical Assistance \\
\hline HGPRT & hypoxanthine-guanine phosphoribosyltransferase \\
\hline HHE & Health Hazard Evaluation \\
\hline HHS & Department of Health and Human Services \\
\hline HIC & highest ineffective concentration \\
\hline HID & highest ineffective dose \\
\hline HIV & Human immunodeficiency virus \\
\hline $\mathrm{HOBr}$ & hypobromous acid \\
\hline $\mathrm{HOCl}$ & hypochlorous acid \\
\hline HOI & hypoiodous acid \\
\hline
\end{tabular}




$\begin{array}{ll}\text { HPLC } & \text { high-performance liquid chromatography } \\ \text { hr } & \text { hour } \\ \text { HWE } & \text { healthy worker (hire or survival) effect } \\ \text { I } & \text { inconclusive } \\ \text { i.p. } & \text { intraperitoneal } \\ \text { i.v. } & \text { intravenous } \\ \text { IARC } & \text { International Agency for Research on Cancer } \\ \text { ICD-9 } & \text { International Classification of Diseases, Ninth Revision } \\ \text { ICD-O-2 } & \text { International Classification of Diseases for Oncology (revision 2) } \\ \text { IDLH } & \text { immediately dangerous to life and health } \\ \text { in } & \text { inch } \\ \text { IOM } & \text { Institute of Medicine } \\ \text { IRIS } & \text { Integrated Risk Information System } \\ \text { IUR } & \text { Inventory Update Rule } \\ \text { JEM } & \text { job-exposure matrix } \\ \text { kg } & \text { kilogram } \\ \text { L } & \text { liter } \\ \text { LEC } & \text { lowest effective concentration } \\ \text { LED } & \text { lowest effective dose } \\ \text { LHC } & \text { lymphohematopoietic cancer } \\ \text { LoD } & \text { limit of detection }\end{array}$

Log D logarithm of the n-octanol/buffer solution ( $\mathrm{pH} 7.4$ or 4.0 ) distribution coefficient

$\log \mathrm{K}_{\mathrm{ow}}, \log \mathrm{P} \log$ arithm of octanol/water partition coefficient

$\begin{array}{ll}\text { LOH } & \text { loss of heterozygosity } \\ \mathrm{M} & \text { male } \\ \mathrm{m}^{3} & \text { cubic meter } \\ \text { MAAI } & \text { maleylacetoacetate isomerase } \\ \text { MAPK } & \text { mitogen activated protein kinases } \\ \text { MBA } & \text { monobromoacetic acid } \\ \text { MCA } & \text { monochloroacetic acid } \\ \text { MCL } & \text { maximum contaminant level } \\ \text { MG } & \text { methylguanine }\end{array}$




\begin{tabular}{|c|c|}
\hline $\mathrm{mg}$ & milligram \\
\hline MIA & monoiodoacetic acid \\
\hline MIE & molecular initiating event \\
\hline $\mathrm{mL}$ & milliliter \\
\hline $\mathrm{mL} / \mathrm{kg}$ & milliliters per kilogram \\
\hline MM & multiple myeloma \\
\hline MN & micronuclei \\
\hline MOA & mode of action \\
\hline mol & mole \\
\hline MS & mass spectrometry \\
\hline $\mathrm{N}$ & number \\
\hline NA & not available; not applicable \\
\hline NCE & normochromatic erythrocyte \\
\hline NCTR & National Center for Toxicological Research \\
\hline ND & not detected; not determined; not done \\
\hline ng & nanogram \\
\hline NHANES & National Health and Nutrition Examination Survey \\
\hline NHL & non-Hodgkin lymphoma \\
\hline NIEHS & National Institute of Environmental Health Sciences \\
\hline NIH3T3 & mouse fibroblast cell line \\
\hline NIH & National Institutes of Health \\
\hline NIOSH & National Institute for Occupational Safety and Health \\
\hline NLM & National Library of Medicine \\
\hline NOES & National Occupational Exposure Survey \\
\hline NOM & natural organic matter \\
\hline NOS & not otherwise specified \\
\hline NPL & National Priorities List \\
\hline NR & not reported, none reported \\
\hline Nrf2 & nuclear factor (erythroid derived-2)-like 2, nuclear factor E2-related factor 2 \\
\hline ns & not specified \\
\hline NS & not significant \\
\hline nt & nucleotides \\
\hline NT & not tested \\
\hline
\end{tabular}




$\begin{array}{ll}\text { NTP } & \text { National Toxicology Program } \\ \text { OHAT } & \text { Office of Health Assessment and Translation } \\ \text { OR } & \text { odds ratio } \\ \text { OSHA } & \text { Occupational Safety and Health Administration } \\ \text { OTM } & \text { olive tail moment } \\ \text { pKa } & \text { acid dissociation constant } \\ \text { p.o. } & \text { per os (oral administration) } \\ \text { PBZ } & \text { personal breathing zone } \\ \text { PCE } & \text { polychromatic erythrocyte } \\ \text { PCNA } & \text { proliferating cell nuclear antigen } \\ \text { PDH } & \text { pyruvate dehydrogenase } \\ \text { PDK } & \text { pyruvate dehydrogenase (PDH) kinase } \\ \text { PEL } & \text { permissible exposure limit } \\ \text { PGE } 2 & \text { prostaglandin E } 2 \\ \text { PPAR } & \text { peroxisome proliferator-activated receptor alpha } \\ \text { ppm } & \text { parts per million } \\ \text { ppt } & \text { parts per trillion } \\ \text { QSAR } & \text { quantitative structure-activity relationship } \\ \text { R } & \text { estimated daily production of adducts } \\ \text { r } & \text { correlation coefficient } \\ \text { RAHC } & \text { Reasonably anticipated to be a human carcinogen } \\ \text { RBC } & \text { red blood cell } \\ \text { REL } & \text { recommended exposure limit } \\ \text { RLV } & \text { Rauscher-leukemia virus } \\ \text { RoC } & \text { Report on Carcinogens } \\ \text { ROS } & \text { reactive oxygen species } \\ \text { RQ } & \text { reportable quantity } \\ \text { RR } & \text { relative risk } \\ \text { RTG } & \text { relative total growth } \\ \text { s.c. } & \text { subcutaneous } \\ \text { SAFE } & \text { significance analysis of function and expression } \\ \text { SCE } & \text { single cell gel electrophoresis (Comet assay) } \\ \text { SCGE } & \end{array}$


SD standard deviation

SDWA Safe Drinking Water Act

SIC Standard Industrial Classification

sig statistically significant

SIR standardized incidence ratio

SMR standardized mortality ratio

$\mathrm{S}_{\mathrm{N}} 2$ substitution, nucleophilic, with 2 molecules in the rate-determining step

SOCMI synthetic organic chemical manufacturing industry

SRR standardized rate ratio, standardized relative risk

SSB single strand break

STS soft tissue sarcoma

TBA tribromoacetic acid

TBARS thiobarbituric acid-reactive substances

TCA trichloroacetic acid

$\mathrm{TD}_{50 \mathrm{~S}} \quad$ chronic dose rate that would induce tumors in half the animals tested

TDS Total Diet Study

THAAs total haloacetic acids

TL tail length

TLC thin-layer chromatography

TLV-TWA threshold limit value time-weighted average

TM tail moment

$t_{\max } \quad$ time to maximum concentration in plasma

TMD tail moment dispersion coefficient

TRI Toxics Release Inventory

TSCA Toxic Substances Control Act

TSFE time since first employment

TTHMs total trihalomethanes

UCMR4 Fourth Unregulated Contaminant Monitoring Rule

UDS unscheduled DNA synthesis

UK United Kingdom

$V_{D} \quad$ apparent volume of distribution

VOC volatile organic compound

WBC white blood cell 
RoC Monograph on Haloacetic Acids: Profile Proposed for the RoC

$\begin{array}{ll}\text { WHO } & \text { World Health Organization } \\ \mathrm{wt} \% & \text { weight percent } \\ \mathrm{yr} & \text { year or years } \\ \mu \mathrm{g} & \text { microgram }\end{array}$




\section{Glossary}

Abscission: A process by which flowers, fruit, or leaves naturally separate from the plant at a special separation layer.

Alkylating potential: The likelihood that a hydrogen will be replace by an alkyl group, especially in a biologically important molecule.

Ames assay: The Ames Salmonella/microsome mutagenicity assay is a short-term bacterial reverse mutation assay specifically designed to detect a wide range of chemical substances that can produce genetic damage that leads to gene mutations.

Amniotic fluid: The protective fluid surrounding the developing fetus within the amniotic sac of a pregnant female.

Aneuploidy: An abnormality involving a chromosome number that is not an exact multiple of the haploid number (one chromosome set is incomplete).

Apoptosis: Cell deletion by fragmentation into membrane-bound particles, which are phagocytosed by other cells.

Apurinic site: A location in DNA (also in RNA but much less likely) that has neither a purine nor a pyrimidine base, either spontaneously or due to DNA damage.

Arabinose resistance: The L-arabinose resistance test with Salmonella typhimurium (Ara test) is a forward mutation assay that selects a single phenotypic change (from L-arabinose sensitivity to L-arabinose resistance) in a unique tester strain (an araD mutant).

ARE-bla: Activation of oxidative stress response pathway in human hepatocellular carcinoma HepG2 cell line.

AREc32: Activation of Nrf2-ARE oxidative stress response pathway in a human breast cancer cell line MCF7.

Aroclor 1254-induced liver: Liver tissue treated with the polychlorinated biphenyl mixture Aroclor 1254 used as a source of S9 fraction for mutagenic and genotoxic effects testing.

Atomic size: The size of an atom measured as the atomic radius or the mean distance from the center of the nucleus to the outer boundary of the electron cloud.

Attrition bias: Systematic differences between comparison groups in withdrawals or exclusions of participants from the results of a study.

Basal-cell adenoma: A benign tumor of major or minor salivary glands or other organs composed of small cells showing peripheral palisading.

Basal-cell carcinoma: The most common type of skin cancer. It begins in the lowest layer of the epidermis (the outer layer of the skin), called the basal cell layer. It usually develops on sunexposed areas, especially the head and neck. Basal cell cancer grows slowly and is not likely to spread to distant parts of the body. 
Biexponential process: A process of drug (or xenobiotic) clearance with two phases with different rates. The first phase often involves rapid distribution of a drug to peripheral tissues, while the second phase represents clearance mechanisms that eliminate the drug from the body. (See "Two-compartment pharmacokinetic model.")

Bioavailability: The degree to which a drug or other substance becomes available to the target tissue after administration.

Biodegradation: Biotransformation; the conversion within an organism of molecules from one form to another. A change often associated with change in pharmacologic activity.

Biotransformation: The chemical conversion of substances by living organisms or enzyme preparations.

Boiling point: The boiling point of the anhydrous substance at atmospheric pressure $(101.3 \mathrm{kPa})$ unless a different pressure is stated. If the substance decomposes below or at the boiling point, this is noted $(\mathrm{dec})$. The temperature is rounded off to the nearest ${ }^{\circ} \mathrm{C}$.

Bond dissociation energy: The amount of energy needed to cause homolytic cleavage of a covalent bond. It is one of numerous measures of bond strength.

Carbon nanotubes: A tube-shaped material, made of carbon, having a diameter measuring on the nanometer scale. A nanometer is one-billionth of a meter.

Carcinoma: Cancer that begins in the skin or in tissues that line or cover internal organs.

Cell cycle arrest: A regulatory process that halts progression through the cell cycle during one of the normal phases $(\mathrm{G} 1, \mathrm{~S}, \mathrm{G} 2, \mathrm{M})$.

Chemical Data Reporting Rule: Chemical Data Reporting (CDR) is the new name for Inventory Update Reporting (IUR). The purpose of Chemical Data Reporting is to collect quality screening-level, exposure-related information on chemical substances and to make that information available for use by the U.S. Environmental Protection Agency (EPA) and, to the extent possible, to the public. The IUR/CDR data are used to support risk screening, assessment, priority setting and management activities and constitute the most comprehensive source of basic screening-level, exposure-related information on chemicals available to EPA. The required frequency of reporting currently is once every four years.

Coagulation and flocculation: Addition of chemicals to source water to allow particles to bind together and form larger particles called floc.

Cochran-Armitage trend test: A statistical test used in categorical data analysis when the aim is to assess for the presence of an association between a variable with two categories and a variable with $k$ categories. It modifies the chi-square test to incorporate a suspected ordering in the effects of the $k$ categories of the second variable.

Comet assay: Single cell gel electrophoresis for assessment of DNA damage in presumptive target tissues.

Congenital lactic acidosis: A rare disease caused by mutations in mitochondrial DNA (mtDNA) that affect the ability of cells to use energy and cause too much lactic acid to build up in the 
body, a condition called lactic acidosis. The word "congenital" means that the underlying condition that increases risk of developing lactic acidosis is present at birth.

Connexin proteins: A group of transmembrane proteins that form the intermembrane channels of gap junctions. They are used by inorganic ions and most small organic molecules to pass through cell interiors.

Conversion factor: A numerical factor used to multiply or divide a quantity when converting from one system of units to another.

CpG island: A short region of DNA in which the frequency of the CG sequence is higher than in other regions. "p" indicates that " $\mathrm{C}$ " and "G" are connected by a phosphodiester bond.

Critical temperature: The temperature at and above which a gas cannot be liquefied, no matter how much pressure is applied.

Delocalization of electron cloud: The spatial distribution of electrons shared among the atoms in a molecule.

Differential selection: Selective pressure for self renewal. Gene mutations that confer a growth or survival advantage on the cells that express them will be selectively enriched in the genome of tumors.

Dihaloacetic acids: Carboxylic acids in which two halogen atom takes the place of two hydrogen atoms in acetic acid.

Disinfection: Application of oxidants to water (chlorine, chloramine, chlorine dioxide, or ozone) or ultraviolet (UV) light to kill disease-causing microorganisms or to render them inactive.

Disposition: The description of absorption, distribution, metabolism, and excretion of a chemical in the body.

Dominant lethal mutation assay: The dominant lethal assay identifies germ cell mutagens by measuring the ability of a chemical to penetrate gonadal tissue and produce embryonic death due to chromosomal breakage in parent germ cells.

Double acid conjugate: A compound formed by the joining of two acids.

Ecological study: A study in which the units of analysis are populations or groups of people rather than individuals.

Electronegativity: A measure of the tendency of an atom to attract a bonding pair of electrons.

Electrophilic reactivity: The tendency of a charge or neutral molecule to be attracted to an electron rich center.

Electrophilic substitution reaction: A substitution reaction in which the new group introduced into the molecule was an electrophile.

Epigenetic mechanisms: Changes in gene function that do not involve a change in DNA sequence but are nevertheless mitotically and/or meiotically heritable. Examples include DNA 
methylation, alternative splicing of gene transcripts, and assembly of immunoglobulin genes in cells of the immune system.

FDA Good Laboratory Practice Regulations: A quality system codified by the U.S. Food and Drug Administration that prescribes operating procedures for conducting nonclinical laboratory studies that support or are intended to support applications for research or marketing permits for products regulated by the Food and Drug Administration.

Filtration: Passage of water through porous media to remove particles remaining from sedimentation.

Fisher's exact test: The test for association in a two-by-two table that is based on the exact hypergeometric distribution of the frequencies within the table.

Floc: A mass formed in a liquid through precipitation or aggregation of suspended particles.

Follow-up: Observation over a period of time of a person, group, or initially defined population whose appropriate characteristics have been assessed to observe changes in health status or health-related variables.

Fulvic acid: A family of organic acids, natural compounds, components of the humus, which is a fraction of soil organic matter.

Gap junctional cell communication: Intercellular communications through specialized connection between adjacent cells that directly connect the cytoplasm of the two cells, allowing molecules, ions, and electrical impulses to pass through.

Genomic instability: An increased propensity for genomic alterations that often occurs in cancer cells. During the process of cell division (mitosis) the inaccurate duplication of the genome in parent cells or the improper distribution of genomic material between daughter cells can result from genomic instability.

Glioma: A cancer of the brain that begins in glial cells (cells that surround and support nerve cells).

Haloacetic acids: Carboxylic acids in which one or more hydrogen atoms on the alpha carbon of acetic acid is replaced by halogen atoms. Haloacetic acids are commonly formed as disinfection by-products during water purification with chlorine-based disinfectants.

Halogen: One of a class of reactive nonmetallic chemical elements that form strongly acidic compounds with hydrogen and simple salts with cationic elements. Members of the class of halogens in order of increasing atomic weight are fluorine, chlorine, bromine, iodine, and astatine.

Harderian gland: An orbital gland of the majority of land vertebrates.

Hard nucleophile: A molecule that is highly polarized and tend to react with oxygen atoms in DNA or RNA.

Healthy worker hire effect: Initial selection of healthy individuals at time of hire so that their disease risks differ from the disease risks in the source (general) population. 
Healthy worker survival effect: A continuing selection process such that those who remain employed tend to be healthier than those who leave employment.

Hemangiosarcoma: A type of cancer that begins in the cells that line blood vessels.

Henry's Law constant: The ratio of the aqueous-phase concentration of a chemical to its equilibrium partial pressure in the gas phase. The larger the Henry's law constant the less soluble it is (i.e., greater tendency for vapor phase). The relationship is defined for a constant temperature, e.g., $25^{\circ} \mathrm{C}$.

Hepatoblastoma: An uncommon malignant liver cancer composed of tissue resembling fetal liver cells, mature liver cells, or bile duct cells.

Hepatocellular adenoma: A benign tumor that starts from hepatocytes, i.e., liver cells.

Hepatocellular carcinoma: A malignant tumor that starts from hepatocytes, i.e., liver cells.

Hepatoma: A liver tumor.

Hereditary tyrosinemia type 1: A metabolic disease caused by a deficiency of the enzyme involved in the last step of tyrosine catabolism.

Historical control range: Tumor rates found in control animals, usually those of the same species and strain as the test animals and exposed by the same route of administration.

Host-mediated assay: This assay evaluates the genotoxicity of a substance to microbial cells introduced (e.g., by intravenous injection) into a host animal. The host animal receives the test compound orally, and therefore acts as a source of chemical metabolism, distribution and excretion of the test compound.

Humic acid: A brown, melanin-tinted mixture of polymers, found in soils and water and resulting from breakdown of organic matter.

Immersion cleaning: A process in which a tank containing cleaning solvent at a temperature below its boiling point is used for metal parts cleaning. To use the vapor degreaser, the operator places the parts to be cleaned in a metal wire basket, removes the cover, and lowers the basket of parts by hand into the cleaning solvent. After a brief period of time, the operator raises the basket and allows the parts to drip-dry inside the degreaser.

Ionizability: The ability of an atom or molecule to lose or gain an electron, just becoming either positively or negatively charged.

Keratoacanthoma: A low-grade, or slow-growing, benign skin tumor that looks like a tiny dome or crater.

Keratosis: A localized horny overgrowth of the skin, such as a wart or callus.

Leaving group: A fragment that leaves a molecule as either an anion or neutral molecule.

Loss of heterozygosity: If there is one normal and one abnormal allele at a particular locus, as might be seen in an inherited autosomal dominant cancer susceptibility disorder, loss of the normal allele produces a locus with no normal function. When the loss of heterozygosity 
involves the normal allele, it creates a cell that is more likely to show malignant growth if the altered gene is a tumor suppressor gene.

Lung adenoma: A benign tumor of the lung.

Lymphoma: Cancer of the lymph nodes.

Lymphokine-activated killer cell: Killer cell lymphocytes activated in the presence of interleukin-2 (IL-2). Lymphokine-activated killer cells (LAKs) are cytotoxic effector cells with an exceptionally wide target cell spectrum including normal and malignant cells of different origins. LAKs exhibit a profound heterogeneity with regard to phenotype surface marker expression; it remains to be determined if they represent a unique cell lineage.

Malignant mesothelioma: A rare, aggressive form of cancer that develops in the lining of the lungs, abdomen, or heart.

Melting point: The melting point of the substance at atmospheric pressure $(101.3 \mathrm{kPa})$. When there is a significant difference between the melting point and the freezing point, a range is given. In case of hydrated substances (i.e., those with crystal water), the apparent melting point is given. If the substance decomposes at or below its melting point, this is noted (dec). The temperature is rounded off to the nearest ${ }^{\circ} \mathrm{C}$.

Metabolic activation: The chemical alteration of an exogenous substance by or in a biological system. The alteration may inactivate the compound or it may result in the production of an active metabolite of an inactive parent compound.

Metaplasia: A change of cells to a form that does not normally occur in the tissue in which it is found.

Methemoglobin: A form of hemoglobin found in the blood in small amounts. Unlike normal hemoglobin, methemoglobin cannot carry oxygen. Injury or certain drugs, chemicals, or foods may cause a higher-than-normal amount of methemoglobin to be made. This causes a condition called methemoglobinemia.

Micronuclei: Small nuclei separate from, and additional to, the main nucleus of a cell, produced during the telophase of mitosis or meiosis by lagging chromosomes or chromosome fragments derived from spontaneous or experimentally induced chromosomal structural changes.

Miscible: A physical characteristic of a liquid that forms one liquid phase with another liquid (e.g., water) when they are mixed in any proportion.

Molecular chaperone: Any of a diverse group of proteins that oversee the correct intracellular folding and assembly of polypeptides without being components of the final structure.

Molecular weight: The molecular weight of a substance is the weight in atomic mass units of all the atoms in a given formula. The value is rounded to the nearest tenth.

Monohaloacetic acids: Haloacetic acids containing only one halogen on the alpha carbon of acetic acid; one of fluoracetic acid, chloroacetic acid, bromoacetic acid, or iodoacetic acid. 
Mononuclear-cell leukemia: The most common type of leukemia in rats, also known as large cell granular lymphocyte leukemia (LGL) .

Morphologically transformed foci: Groups of cells transformed so they lose contact inhibition for their group and multiply to forms foci.

Multiple myeloma: A type of cancer that begins in plasma cells (white blood cells that produce antibodies). Also called Kahler disease, myelomatosis, and plasma cell myeloma.

Mutations: A change in the structure of a gene, resulting from the alteration of single base units in DNA, or the deletion, insertion, or rearrangement of larger sections of genes or chromosomes. The genetic variant can be transmitted to subsequent generations.

National Health and Nutrition Examination Survey: A program of studies designed to assess the health and nutritional status of adults and children in the United States. The survey is unique in that it combines interviews and physical examinations.

Natural killer cells: A type of white blood cell that contains granules with enzymes that can kill tumor cells or microbial cells. Also called large granular lymphocytes.

NF-KB activation: Activation of a protein complex (nuclear factor kappa-light-chain-enhancer of activated B cells) that controls transcription of DNA, cytokine production and cell survival.

Non-differential misclassification: The probability of erroneous classification of an individual, a value, or an attribute into a category other than that to which it should be assigned is the same in all study groups.

Non-Hodgkin lymphoma: A heterogeneous group of malignant lymphomas; the only common feature being an absence of the giant Reed-Sternberg cells characteristic of Hodgkin disease.

Normochromatic erythrocyte: A mature erythrocyte that lacks ribosomes and can be distinguished from immature, polychromatic erythrocytes by stains selective for RNA.

Nrf2: A protein that controls how certain genes are expressed. These genes help protect the cell from damage caused by free radicals (unstable molecules made during normal cell metabolism). Also called NFE2L2 and nuclear factor (erythroid-derived 2)-like 2.

Octanol/water partition coefficient $(\log K o w)$ : A measure of the equilibrium concentration of a compound between octanol and water.

One-compartment model: A pharmacokinetic modeling approach that models the entire body as a single compartment into which a drug is added by a rapid single dose, or bolus. It is assumed that the drug concentration is uniform in the body compartment at all times and is eliminated by a first order process that is described by a first order rate constant.

Ozone-depleting substance: A family of man-made compounds that includes, but are not, foot and eye protection, protective hearing devices (earplugs, muffs) hard hats, respirators and full body suits.

Phase I metabolism: Metabolism of drugs or other xenobiotic molecules, usually by oxidation or hydrolysis and involving a cytochrome P450 monooxygenase. 
Phase II metabolism: A conjugation reaction that forms a covalent linkage between a functional group on a xenobiotic molecule and glucuronic acid, sulfate, glutathione, amino acid, or acetate.

p53 haploinsufficient mice: Mice in which one copy of the p53 gene has been lost.

Papilloma: A small solid benign tumor with a clear-cut border that projects above the surrounding tissue.

Personal breathing zone: A sampling area as close as practical to an employee's nose and mouth, (i.e., in a hemisphere forward of the shoulders within a radius of approximately nine inches) so that it does not interfere with work performance or safety of the employee.

Peroxisome proliferation: The process by which multifunctional cellular organelles increase in number within the cell.

Personal protective equipment: Specialized clothing or equipment, worn by an employee to minimize exposure to a variety of hazards. Examples of PPE include such items as gloves

Physiological pH: The normal pH of blood; it is generally considered to be 7.4.

Placental barrier: The semipermeable layer of tissue in the placenta that serves as a selective membrane to substances passing from maternal to fetal blood.

Plaque assay: An assay for antibody production by single lymphocytes using cells isolated from the spleen or lymph nodes of animals injected with sheep red blood cells as an antigen. Incubation of the antibody-forming cells together with sheep red cells in an agar layer with exposure to guinea pig serum as complement results in formation of microscopic plaques (i.e., circular areas of hemolytic clearance around a lymphoid cell) due to release of hemolysin.

Plate incorporation: A commonly used procedure for performing a bacterial reverse mutation test. Suspensions of bacterial cells are exposed to the test substance in the presence and in the absence of an exogenous metabolic activation system. In the plate-incorporation method, these suspensions are mixed with an overlay agar and plated immediately onto minimal medium. After two or three days of incubation, revertant colonies are counted and compared with the number of spontaneous revertant colonies on solvent control plates.

Point emission: A release that can be identified with a single discharge source or attributed to a specific physical location.

Poly-3 trend test: A survival-adjusted statistical test that takes survival differences into account by modifying the denominator in the numerical (quantal) estimate of lesion incidence to reflect more closely the total number of animal years at risk.

Poly-3 trend test: A survival-adjusted statistical test that takes survival differences into account by modifying the denominator in the numerical (quantal) estimate of lesion incidence to reflect more closely the total number of animal years at risk.

Polychromatic erythrocyte: A newly formed erythrocyte (reticulocyte) containing RNA.

Polyethylene terephthalate: A synthetic resin made by copolymerizing ethylene glycol and terephthalic acid, widely used to make polyester fibers. 
Prophage lambda $(\lambda)$ : A virus in Escherichia coli $(E$. coli) bacteria that has integrated itself into the host E. coli DNA.

Proto-oncogene: A gene involved in normal cell growth. Mutations (changes) in a protooncogene may cause it to become an oncogene, which can cause the growth of cancer cells.

$\boldsymbol{P}_{\text {trend }}$ : Level of statistical significance of a change over time in a group selected to represent a larger population.

Renal clearance: A pharmacokinetic measurement of the volume of plasma from which a substance is completely removed per unit time.

Reverse osmosis: A process of water purification in which water passes through a porous membrane by application of hydrostatic pressure greater than the osmotic pressure removing ions, molecules, and larger particles from drinking water.

Sarcoma: A malignant tumor of connective or other nonepithelial tissue.

Saturable asymmetric transport: A process by which a molecule is carried across a cell membrane or cell barrier in one direction by a process that can be saturated at high concentrations.

Sebaceous gland adenoma: A benign epithelial neoplasm composed of sebaceous gland-like structures or tumors with well-recognized sebaceous differentiation by microscopic examination.

Sedimentation: Transfer of floc particles to basins where they either settle to the bottom or are removed by skimming.

Selection bias: An error in choosing the individuals or groups to take part in a study. Ideally, the subjects in a study should be very similar to one another and to the larger population from which they are drawn (for example, all individuals with the same disease or condition). If there are important differences, the results of the study may not be valid.

Sister-chromatid exchange: The exchange during mitosis of homologous genetic material between sister chromatids; increased as a result of inordinate chromosomal fragility due to genetic or environmental factors.

SKF-525A: An inhibitor of drug metabolism and cytochrome P-450 activity.

Soft nucleophile: A molecule with lower polarization that tends to bind with thiol or amino groups on proteins.

Soft tissue sarcoma: A cancer that begins in the muscle, fat, fibrous tissue, blood vessels, or other supporting tissue of the body.

Solubility: The ability of a substance to dissolve in another substance and form a solution. The Report on Carcinogens uses the following definitions (and concentration ranges) for degrees of solubility: (1) miscible (see definition), (2) freely soluble-capable of being dissolved in a specified solvent to a high degree $(>1,000 \mathrm{~g} / \mathrm{L})$, (3) soluble- capable of being dissolved in a specified solvent (10-1,000 g/L), (4) slightly soluble- capable of being dissolved in a specified 
solvent to a limited degree (1-10 g/L), and (5) practically insoluble- incapable of dissolving to any significant extent in a specified solvent $(<1 \mathrm{~g} / \mathrm{L})$.

SOS umuC assay: An assay using Salmonella typhimurium TA1535/pSK1002 that is used to evaluate the ability of testing substance or sample to induce DNA damage. The system is based on alterations in the induction of SOS response as a consequence of DNA damage.

Specific gravity: The ratio of the density of a material to the density of a standard material, such as water at a specific temperature; when two temperatures are specified, the first is the temperature of the material and the second is the temperature of water.

Spot test: Qualitative assay in which a small amount of test chemical is added directly to a selective agar medium plate seeded with the test organism, e.g., Salmonella. As the chemical diffuses into the agar, a concentration gradient is formed. A mutagenic chemical will give rise to a ring of revertant colonies surrounding the area where the chemical was applied; if the chemical is toxic, a zone of growth inhibition will also be observed.

Squamous-cell carcinoma: A type of malignant skin cancer that begins in the squamous cells. Squamous cells are the thin, flat cells that make up the epidermis, or the outermost layer of the skin.

Squamous-cell papilloma: A generally benign papilloma that arises from the stratified squamous epithelium of the skin, lip, oral cavity, tongue, pharynx, larynx, esophagus, cervix, vagina or anal canal. Squamous cell papillomas are a result of infection with human papillomavirus (HPV).

Steric bulk: An indicator of the stability of the spatial arrangement of atoms in a molecule.

T-helper cell: A type of immune cell that stimulates killer T cells, macrophages, and B cells to make immune responses. A helper T cell is a type of white blood cell and a type of lymphocyte. Also called CD4-positive T lymphocyte.

Tg.AC: A transgenic mouse model with the ability to mount a tumorigenic response within 6 months in skin paint assays when dosed topically with nonmutagenic carcinogens.

Time-weighted average: The average exposure concentration of a chemical measured over a period of time (not an instantaneous concentration).

Tissue:blood partition coefficient: The ratio of tissue chemical concentration to that of the venous outflow of the tissue when at equilibrium; it is an important parameter required for physiological based pharmacokinetic models.

Toxicokinetics: The mathematical description (toxicokinetic models) of the time course of disposition of a chemical in the body.

Transitions: DNA nucleotide substitution mutation in which a purine base is substituted for another purine base (adenine $\rightarrow$ guanine or guanine $\rightarrow$ adenine) or a pyrimidine base for another pyrimidine base (cytosine $\rightarrow$ thymine or thymine $\rightarrow$ cytosine).

Transversions: DNA nucleotide substitution mutation in which a purine base (adenine or guanine) is substituted for a pyrimidine base (cytosine or thymine) or vice versa. 
TRDNA: Toxic ratio of $\mathrm{EC}_{50}$ of $E$. coli $\mathrm{DNA}$ repair +/DNA repair -, TR $>1.2$ indicates reaction with hard nucleophiles.

TRGSH: Toxic ratio of $\mathrm{EC}_{50}$ of $E$. coli $\mathrm{GSH}+/ \mathrm{GSH}-, \mathrm{TR}>1.2$ indicates reaction with soft nucleophiles.

Trihaloacetic acids: Molecules in which all three hydrogens on the alpha carbon of acetic acid have been replaced by halogen atoms of either the same halogen or mixed halogens.

Trihalomethanes: Compounds in which three halogen atoms replace hydrogen atoms in a molecule of methane.

Tubular reabsorption: The process by which the nephron removes water and solutes from the tubular fluid (pre-urine) and returns them to the circulating blood.

Tubular secretion: The transfer of materials from peritubular capillaries to the renal tubular lumen; it is the opposite process of reabsorption. This secretion is caused mainly by active transport and passive diffusion.

Two-compartment pharmacokinetic model: A two-compartment pharmacokinetic model resolves the body into a central compartment and a peripheral compartment. The central compartment generally comprises tissues that are highly perfused such as heart, lungs, kidneys, liver and brain. The peripheral compartment comprises less well-perfused tissues such as muscle, fat and skin. A two-compartment model assumes that, following drug administration into the central compartment, the drug distributes between that compartment and the peripheral compartment. However, the drug does not achieve instantaneous distribution (i.e., equilibrium), between the two compartments. After a time interval ( $\mathrm{t}$ ), distribution equilibrium is achieved between the central and peripheral compartments, and elimination of the drug is assumed to occur from the central compartment.

Type-I error: The error of rejecting a true null hypothesis, i.e., declaring that a difference exists when it does not.

Type-II error: The error of failing to reject a false null hypothesis, i.e., declaring that a difference does not exist when in fact it does.

Vapor density, relative: A value that indicates how many times a gas (or vapor) is heavier than air at the same temperature. If the substance is a liquid or solid, the value applies only to the vapor formed from the boiling liquid.

Vapor pressure: The pressure of the vapor over a liquid (and some solids) at equilibrium, usually expressed as $\mathrm{mm} \mathrm{Hg}$ at a specific temperature $\left({ }^{\circ} \mathrm{C}\right)$.

Volume of distribution: The theoretical volume that would be necessary to contain the total amount of an administered drug at the same concentration that it is observed in the blood plasma.

Xenobiotic metabolism: A set of metabolic pathways that modify the chemical structure of compounds foreign to an organism's normal biochemistry, such any drug or poison. 


\section{Appendix A. Literature Search Strategy \\ Table of Contents}

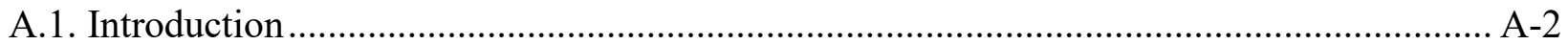

A.2. General Approach ............................................................................................ A-2

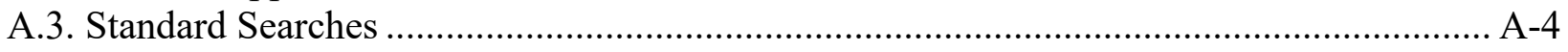

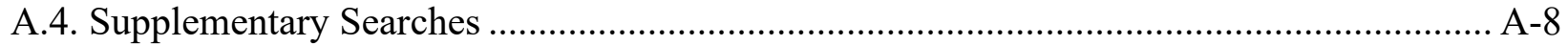

\section{Tables}

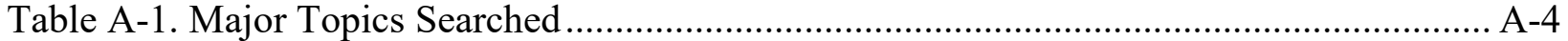

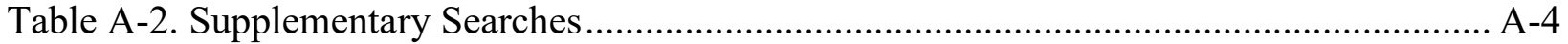

\section{Figures}

Figure A-1. Literature Search Strategy and Review ......................................................... A-3 


\section{A.1. Introduction}

The objective of the literature search approach is to identify published literature that is relevant for evaluating the potential carcinogenicity of the haloacetic acids of interest. As discussed in the Concept Document for haloacetic acids

(https://ntp.niehs.nih.gov/ntp/about ntp/bsc/2016/april/haa 508.pdf), the monograph relies on the IARC monograph and studies published since the monograph (new studies). The literature search strategy was used to identify new human cancer studies and recent reviews of mechanistic data.

\section{A.2. General Approach}

Database searching encompasses selecting databases and search terms and conducting the searches. Searches of several citation databases are generally conducted using search terms for the individual haloacetic acids, combined with search terms for cancer and/or specific topics, including epidemiological and mechanistic studies. A critical step in the process involves consultation with an information specialist to develop relevant search terms. These terms are used to search bibliographic databases. IARC volume 101 used literature found in PubMed before December 2012, so any searches limited by date sought new information published since 2011. The body of literature for haloacetic acids of interest was searched using narrowing terms for the relevant major topics within the bibliographic databases. The results were then processed in EndNote to remove duplicates before being transferred to Health Assessment Workplace Collaborative (HAWC) for screening. Figure A-1 illustrates the overall approach to the searches and screening and the numbers of citations identified. Table A-1 highlights the general concepts searched and databases consulted. To review all the terms used, please refer to the full search strings below. 


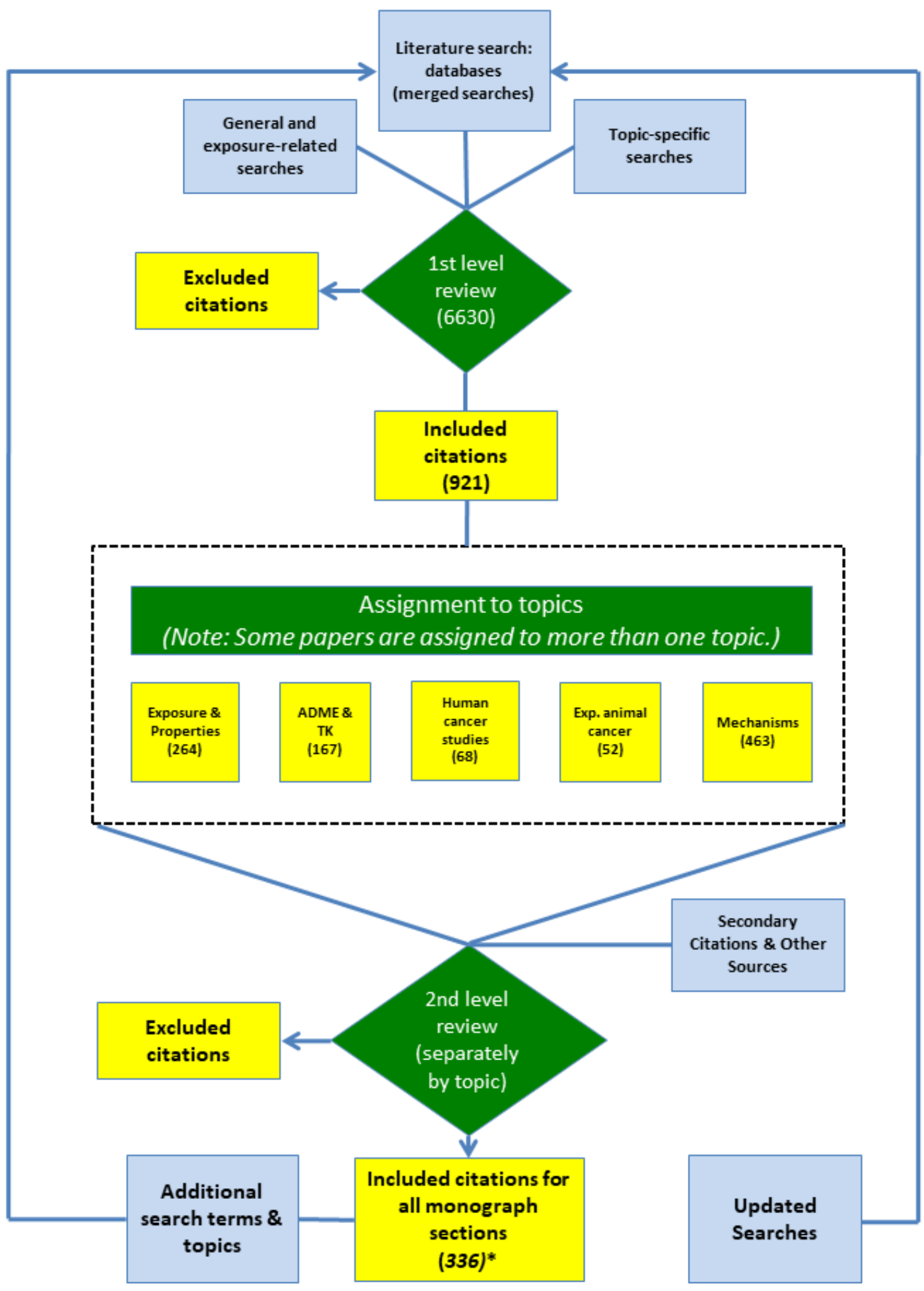

Figure A-1. Literature Search Strategy and Review

*ERRATUM: Errors were identified in the Report on Carcinogens Monograph on Haloacetic Acids Found as Water Disinfection By-products. The number of included citations for all monograph sections was incorrect in the original figure. These errors have been corrected; 327 was changed to 336 and italicized. 
Table A-1. Major Topics Searched

\begin{tabular}{lll}
\hline \multicolumn{1}{c}{ Topic } & \multicolumn{1}{c}{ Search Method } & \multicolumn{1}{c}{$\begin{array}{c}\text { Databases } \\
\text { Searched }\end{array}$} \\
\hline Exposure & 13 HAAs String AND occur*[tiab] & PubMed \\
Human Studies & 13 HAAs String AND ORoC Epidemiological (Human) & PubMed, Scopus, \\
& Studies Search AND ORoC Cancer Search & Web of Science \\
Animal Studies & 13 HAAs String AND Experimental Animals Studies & PubMed, Scopus, \\
& Search AND ORoC Cancer Search & Web of Science \\
Mechanism and Genetox & 13 HAAs String AND ORoC Characteristics of & PubMed, Scopus, \\
& Carcinogens Search & Web of Science \\
\hline
\end{tabular}

In addition to the standard search concepts described above, three special targeted searches were run to seek additional detail for the Human Cancer and Mechanistic sections of the monograph. To confirm full coverage on bladder cancer a targeted search was run for that endpoint alone. The primary use for Haloacetic Acids in the treatment and disinfection of water suggests that and research conducted on the subject of water treatment and disinfection methods in general may contain data of interest to the evaluation. A search was conducted to collect human studies referring to the general methods rather than the specific HAAs. Finally, in an effort to categorize the HAAs for possible read-across efforts and specific search was conducted on metabolic and mechanistic concepts thought to be common between some of the HAAs. Table A-2 highlights the general concepts searched and databases consulted for these special searches. To review all the terms used, please refer to the full search strings below in the section Supplementary Searches.

Table A-2. Supplementary Searches

\begin{tabular}{lll}
\hline \multicolumn{1}{c}{ Topic } & \multicolumn{1}{c}{ Search Method } & \multicolumn{1}{c}{$\begin{array}{c}\text { Databases } \\
\text { Searched }\end{array}$} \\
\hline Bladder Cancer & $\begin{array}{l}\text { Supplementary Bladder Cancer Search (see detailed } \\
\text { description below) }\end{array}$ & $\begin{array}{l}\text { PubMed, Scopus, } \\
\text { Web of Science }\end{array}$ \\
Human Studies on Water & DBPs OR disinfection OR water treatment OR treated water PubMed, Scopus, \\
Treatment or Disinfection & AND ORoC Cancer Search (see detailed description below) & Web of Science \\
Read Across & 13 HAAs String AND terms for select metabolic concepts & PubMed, Scopus, \\
& (see detailed description below for Mechanism Special & Web of Science \\
\hline
\end{tabular}

\section{A.3. Standard Searches}

\section{A.3.1. 13 HAAs}

A search of primary and universal terms for the 13 haloacetic acids chemicals and cancer. Limiting terms have been applied to reduce the number of irrelevant results returned that are associated with chemical peel treatments, wart removal methods, and trichloroacetic acid (TCA) precipitation. 
This search was used in most cases to characterize the haloacetic acids and was combined with narrowing terms for cancer, animal studies, human epidemiology studies, mechanistic literature (characteristics of carcinogens) and more.

\section{A.3.1.1. PubMed}

((Haloacetic-acid*[tiab]) OR Dihaloacetic-acid*[tiab]) OR Trihaloacetic-acid*[tiab] OR ("dichloroacetic acid"[nm] OR 79-43-6[rn] OR dichloroacetate[tiab] OR "dichloroacetic acid"[tiab] OR "Bichloracetic acid"[tiab] OR "Dichloracetic acid"[tiab] OR "Dichlorethanoic acid"[tiab] OR "Dichloroethanoic acid"[tiab]) OR ("Trichloroacetic Acid"[mh] OR 76-03-9[rn] OR "Trichloroacetic Acid"[tiab] OR Trichloroacetate[tiab] OR "Trichloracetic acid"[tiab]) OR ("Dibromoacetic acid"[nm] OR 631-64-1[rn] OR dibromoacetate[tiab] OR "Dibromoacetic acid"[tiab]) OR ("tribromoacetic acid"[nm] OR 75-96-7[rn] OR tribromoacetate[tiab] OR "tribromoacetic acid"[tiab]) OR ("Dichlorobromoacetic acid"[tiab] OR Bromodichloroacetate[tiab] OR "bromodichloroacetic acid"[nm] OR bromodichloroaceticacid[tiab] OR 71133-14-7[rn]) OR ("Dibromochloroacetic acid"[tiab] OR 5278-95-5[rn] OR bromochloroacetate[tiab]) OR ("bromochloroacetic acid"[nm] OR 5589-96-8[rn] OR "bromochloroacetic acid"[tiab] OR bromochloroacetate[tiab] OR "Chlorobromoacetic acid"[tiab]) OR (Diiodoacetic-acid[tiab] OR "598-89-0"[tiab] OR Diiodoacetate[tiab]) OR (71815-43-5[rn] OR Bromoiodoacetic-acid[tiab] OR Bromoiodoacetate[tiab]) OR (Chloroiodoacetic-acid[tiab] OR "Chloro(iodo)acetic acid"[tiab] OR 53715-09-6[rn] OR "2Chloro-2-iodoacetic acid"[tiab] OR "Acetic acid, 2-chloro-2-iodo-"[tiab] OR "chloro-iodoacetic acid"[tiab] OR Chloroiodoacetate[tiab]) OR ("Monochloroacetic acid"[tiab] OR "Monochloracetic acid"[tiab] OR "79-11-8"[rn] OR Chloroacetic-acid[tiab] OR "Chloroacetic acid"[nm] OR "Chloracetic acid"[tiab]) OR (Bromoacetic-acid[tiab] OR Bromoacetate[tiab] OR Monobromoacetic-acid[tiab] OR 79-08-3[rn]) OR ("Iodoacetic acid"[mh] OR 64-69-7[rn] OR Monoiodoacetic-acid[tiab] OR Monoiodoacetate[tiab] OR Monoiodine-acetate[tiab] OR Iodoacetate[tiab] OR Iodoacetic-acid[tiab]) NOT (trichloro-acetic-acid-peel*[tiab] OR trichloroacetic-acid-peel*[tiab] OR trichloracetic-acid-peel*[tiab] OR Trichloroacetic-Acidsolub* OR Trichloroacetic-Acid-insolub* OR Trichloroacetic-Acid-precipit* OR TCA-solub* OR TCA-insolub* OR TCA-precipit* OR anogenital-wart*[tiab] OR genital-wart*[tiab] OR "Condylomata Acuminata"[Mh] OR "Human papillomavirus"[tiab] OR "Human papillomavirus 31 "[mh] OR "Sexually transmitted diseas*"[tiab])

\section{A.3.1.2. Web of Science}

(TS=("Haloacetic acid*" OR "Dihaloacetic acid*" OR "Trihaloacetic acid*")) OR (TS=("dichloroacetic acid" OR "79-43-6" OR dichloroacetate OR "dichloroacetic acid" OR "Bichloracetic acid" OR "Dichloracetic acid" OR "Dichlorethanoic acid" OR "Dichloroethanoic acid" OR "76-03-9" OR "Trichloroacetic Acid" OR Trichloroacetate OR "Trichloracetic acid" OR "Dibromoacetic acid" OR "631-64-1" OR dibromoacetate OR "Dibromoacetic acid" OR "tribromoacetic acid" OR "75-96-7" OR tribromoacetate OR "tribromoacetic acid" OR "Dichlorobromoacetic acid" OR Bromodichloroacetate OR "bromodichloroacetic acid" OR "bromodichloroacetic-acid" OR "71133-14-7" OR "Dibromochloroacetic acid" OR "5278-95-5" OR bromochloroacetate OR "bromochloroacetic acid "OR "5589-96-8" OR "bromochloroacetic acid" OR bromochloroacetate OR "Chlorobromoacetic acid")) OR (TS=("Diiodoacetic acid" OR "598-89-0" OR Diiodoacetate OR "71815-43-5" OR "Bromoiodoacetic acid" OR

Bromoiodoacetate OR "Chloroiodoacetic acid" OR "Chloro(iodo)acetic acid" OR "53715-09-6" OR "2-Chloro-2-iodoacetic acid" OR "chloro-iodoacetic acid" OR Chloroiodoacetate)) OR 
(TS=("Monochloroacetic acid" OR "Monochloracetic acid" OR "79-11-8" OR "Chloroacetic acid" OR "Chloroacetic acid" OR "Chloracetic acid" OR "Iodoacetic acid" OR "64-69-7" OR "Monoiodoacetic acid" OR Monoiodoacetate OR "Monoiodine acetate" OR Iodoacetate OR "Bromoacetic acid" OR Bromoacetate OR "Monobromoacetic acid" OR "79-08-3")) NOT (TS=("trichloro-acetic acid peel*" OR "trichloroacetic acid peel*" OR "trichloracetic acid peel*" OR "Trichloroacetic-Acid solub*" OR "Trichloroacetic Acid insolub*" OR "Trichloroacetic Acid precipit*" OR "TCA solub*" OR "TCA insolub*" OR "TCA precipit*" OR "anogenital wart*" OR "genital wart*" OR "Condylomata Acuminata" OR "Human papillomavirus*" OR "Sexually transmitted diseas*"))

\section{A.3.1.3. Scopus}

((TITLE-ABS-KEY ("Haloacetic acid*" OR "Dihaloacetic acid*" OR "Trihaloacetic acid*")) OR (TITLE-ABS-KEY ("dichloroacetic acid" OR "79-43-6" OR dichloroacetate OR "dichloroacetic acid" OR "Bichloracetic acid" OR "Dichloracetic acid" OR "Dichlorethanoic acid" OR "Dichloroethanoic acid" OR "76-03-9" OR "Trichloroacetic Acid" OR trichloroacetate OR "Trichloracetic acid" OR "Dibromoacetic acid" OR "631-64-1" OR dibromoacetate OR "Dibromoacetic acid" OR "tribromoacetic acid" OR "75-96-7" OR tribromoacetate OR "tribromoacetic acid" OR "Dichlorobromoacetic acid" OR bromodichloroacetate OR "bromodichloroacetic acid" OR bromodichloroacetic-acid OR "71133-14-7" OR "Dibromochloroacetic acid" OR "5278-95-5" OR bromochloroacetate OR "bromochloroacetic acid" OR "5589-96-8" OR "bromochloroacetic acid" OR bromochloroacetate OR "Chlorobromoacetic acid")) OR (TITLE-ABS-KEY ("Diiodoacetic acid" OR "598-89-0" OR diiodoacetate OR "594-68-3" OR "71815-43-5" OR "Bromoiodoacetic acid" OR bromoiodoacetate OR "Chloroiodoacetic acid" OR "Chloro(iodo)acetic acid" OR "53715-09-6" OR "2-Chloro-2-iodoacetic acid" OR "chloro-iodoacetic acid" OR chloroiodoacetate)) OR (TITLE-ABS-KEY ("Monochloroacetic acid" OR "Monochloracetic acid" OR "79-11-8" OR "Chloroacetic acid" OR "Chloroacetic acid" OR "Chloracetic acid" OR "Iodoacetic acid" OR "64-69-7" OR "Monoiodoacetic acid" OR monoiodoacetate OR "Monoiodine acetate" OR iodoacetate OR "Bromoacetic acid" OR bromoacetate OR "Monobromoacetic acid" OR "79-083"))) AND NOT (TITLE-ABS-KEY("trichloro-acetic acid peel*" OR "trichloroacetic acid peel*" OR "trichloracetic acid peel*" OR "Trichloroacetic-Acid solub*" OR "Trichloroacetic Acid insolub*" OR "Trichloroacetic Acid precipit*" OR "TCA solub*" OR "TCA insolub*" OR "TCA precipit*" OR "anogenital wart*" OR "genital wart*" OR "Condylomata Acuminata" OR "Human papillomavirus*" OR "Sexually transmitted diseas*"))

\section{A.3.2. RoC Cancer String}

The PubMed String is the same as described in the Handbook Appendix (https://ntp.niehs.nih.gov/ntp/roc/handbook/rochandbookappendix_508.pdf), however additional options for wildcard use and truncation have allowed the same string to be shortened for WOS and Scopus. The altered strings are presented here.

\section{A.3.2.1. Web of Science}

$(\mathrm{TS}=(*$ broma OR $*$ bromas OR $*$ doma OR *domas OR *droma OR *dromas OR *eoma OR *eomas OR * goma OR * gomas OR *ioma OR *iomas OR *loma OR *lomas OR *moma OR

*momas OR *noma OR *nomas OR *omatosis OR *phoma OR *phomas OR *poma OR *pomas OR *phroma OR *phromas OR *sarcoma OR *sarcomas OR *scoma OR *scomas OR 
*thecoma OR *thecomas OR *thoma OR *thomas OR *toma OR *tomas OR *uroma OR *uromas OR *xoma OR *xomas OR *yoma OR *yomas OR *kaemia OR *kaemia OR *kemia OR *kemia OR *plakia OR *plakias )) OR (TS=("cancer" OR "cancerous" OR "cancers" OR "carcinogen" OR "carcinogenesis" OR "carcinogenic" OR "carcinogens" OR "carcinoid" OR "carcinomatosis" OR "cocarcinogenesis" OR "metaplasia” OR "anaplasia” OR "neoplasia” OR "neoplasia" OR "neoplasm" OR "neoplasms" OR "neoplastic" OR "tumor" OR "tumorgenesis" OR "tumorgenic" OR "tumorigenesis" OR "tumorigenic" OR "tumorogenesis" OR "tumorogenic" OR "tumors" OR "tumour" OR "tumours" OR "nonhodgkin" OR "nonhodgkins" OR "Hodgkin" OR "hodgkins”)) OR (TS=(“acrochordon” OR "acrochordons" OR "acrospiroma” OR “acrospiromas" OR "adenomatous” OR "adenosis" OR "BuschkeLowenstein" OR “chloroma” OR "chloromas” OR "CIN” OR “CLL” OR “dermoid” OR "dysmyelopoiesis" OR "epidermoid” OR "essential thrombocythemia" OR "exostosis” OR "fibroid” OR "fibroids" OR "lymphoproliferation" OR "lymphoproliferations" OR "lymphoproliferative" OR "macroglobulinemia" OR "macroglobulinemias" OR "malignancies" OR "malignancy" OR "malignant” OR "mastocytosis" OR "meigs syndrome" OR "micrometastases" OR "micrometastasis" OR "mycosis fungoides" OR "myelofibrosis" OR "myeloproliferation" OR "myeloproliferations" OR "myeloproliferative" OR "NSCLC" OR "papillomata” OR "papillomatosis" OR "pilomatricoma” OR "pilomatricomas" OR "polyposis" OR “poroma” OR “poromas” OR "premalignant” OR "preneoplastic” OR “seminomatous” OR "sezary syndrome" OR "struma ovarii" OR "waldenstrom” OR "waldenstroms” OR "oncogene fusion" OR "5q syndrome" OR "aberrant crypt foci" OR "Aberrant crypt focus" OR "carney complex" OR "denys drash" OR "leukostasis" OR "zollinger ellison")) OR ((TS=("sentinel lymph node" NOT “biopsy")) OR (TS=(“ASCO” NOT “fungi”)) OR (TS=("WAGR” AND "syndrome")))

\section{A.3.2.2. Scopus}

(TITLE-ABS $(*$ broma OR *bromas OR *doma OR *domas OR *droma OR *dromas OR *eoma OR *eomas OR * goma OR * gomas OR *ioma OR *iomas OR *loma OR *lomas OR *moma $\mathrm{OR} *$ momas $\mathrm{OR} *$ noma OR *nomas OR *omatosis OR *phoma OR *phomas OR *poma OR *pomas OR *phroma OR *phromas OR *sarcoma OR *sarcomas OR *scoma OR *scomas OR *thecoma OR *thecomas OR * thoma OR *thomas OR *toma OR *tomas OR *uroma OR *uromas OR *xoma OR *xomas OR *yoma OR *yomas OR *kaemia OR *kaemia OR *kemia OR *kemia OR *plakia OR *plakias )) OR (TITLE-ABS ("cancer" OR "cancerous" OR "cancers" OR "carcinogen" OR "carcinogenesis" OR "carcinogenic" OR "carcinogens" OR "carcinoid" OR "carcinomatosis" OR "cocarcinogenesis" OR "metaplasia" OR "anaplasia" OR "neoplasia" OR "neoplasia" OR "neoplasm" OR "neoplasms" OR "neoplastic" OR "tumor" OR "tumorgenesis" OR "tumorgenic" OR "tumorigenesis" OR "tumorigenic" OR "tumorogenesis" OR "tumorogenic" OR "tumors" OR "tumour" OR "tumours" OR "nonhodgkin" OR "nonhodgkins" OR "non-hodgkin" OR "non-hodgkins" OR "Hodgkin" OR "hodgkins")) OR (TITLE-ABS("acrochordon" OR "acrochordons" OR "acrospiroma" OR "acrospiromas" OR "adenomatous" OR "adenosis" OR "Buschke-Lowenstein" OR "chloroma" OR "chloromas" OR "CIN" OR "CLL" OR "dermoid" OR "dysmyelopoiesis" OR "epidermoid" OR "essential thrombocythemia" OR "exostosis" OR "fibroid" OR "fibroids" OR "lymphoproliferation" OR "lymphoproliferations" OR "lymphoproliferative" OR "macroglobulinemia" OR "macroglobulinemias" OR "malignancies" OR "malignancy" OR "malignant" OR "mastocytosis" OR "meigs syndrome" OR "micrometastases" OR "micrometastasis" OR "mycosis fungoides" OR "myelofibrosis" OR "myeloproliferation" OR "myeloproliferations" OR "myeloproliferative" 
OR "NSCLC" OR "papillomata" OR "papillomatosis" OR pilomatricoma OR pilomatricomas OR polyposis OR poroma OR poromas OR "premalignant" OR "preneoplastic" OR "seminomatous" OR "sezary syndrome" OR "struma ovarii" OR "waldenstrom" OR "waldenstroms" OR "oncogene fusion" OR "5q syndrome" OR "aberrant crypt foci" OR "Aberrant crypt focus" OR "carney complex" OR "denys drash" OR leukostasis OR "zollinger ellison")) OR ((TITLE-ABS ("ASCO" AND NOT "fungi")) OR (TITLE-ABS ("WAGR" AND "syndrome")))

\section{A.4. Supplementary Searches}

\section{A.4.1. Disinfection By-products, Water Disinfection, Water Treatment}

This search was used to run supplemental cancer searches to capture references for studies evaluating general categories of chemicals that could include the selected HAAs. The search was limited to the years 2011 and forward because the IARC evaluation was used as a source for earlier studies of this type.

\section{A.4.1.1. PubMed}

(Disinfection-ByProduct*[tiab] OR Disinfection-By-Product*[tiab]) OR water-disinfect*[tiab] OR disinfected-water[tiab]) OR ("treated water*"[tiab] OR "water treatment*"[tiab])

\section{A.4.1.2. Web of Science}

((TS=("Disinfection ByProduct*" OR "Disinfection By-Product*" )) OR (TS=(water n/2 disinfect*))) OR (TS= ("treated water" OR (water NEAR/2 treatment*)))

\section{A.4.1.3. Scopus}

(((TITLE-ABS-KEY ("Disinfection ByProduct*" OR "Disinfection By-Product*")) OR (TITLEABS-KEY (water W/2 disinfect*))) OR ((TITLE-ABS-KEY (water W/2 treatment* OR "treated water")))

\section{A.4.2. Supplementary Bladder Cancer Search}

While bladder cancer is represented in the RoC Cancer search string, a supplemental search was conducted to collect all bladder cancer literature, in case there were studies that discussed the relevant chemicals in the body of the paper but not in the title abstracts or keyword.

\section{A.4.2.1. PubMed}

As the most productive source of medical literature, a broader search was conducted in PubMed than the other two databases. Therefore the search was not limited by any haloacetic acid terms. However, the search was limited to the years 2011 and forward because the IARC evaluation was used as a source for earlier studies of this type. The other two databases included too many non-medical "bladder" concepts so the HAA terms were needed to focus the search.

(bladder[tiab] OR "Urinary Bladder"[Mh])

AND

RoC Cancer String 


\section{A.4.2.2. Web of Science}

$(\mathrm{TS}=($ bladder $))$

AND

13 HAAs Search (as described above)

\section{A.4.2.3. Scopus}

(TITLE-ABS-KEY (bladder*))

\section{AND}

AAs Search (as described above)

\section{A.4.3. Mechanism Special Search}

A search of select terms focused on mechanistic and metabolic concepts to help identify viable justifications for grouping chemicals for read-across. The specific concepts search were pyruvate dehydrogenase (excluding dichloroacetic acid terms), Glutathione Transferase Zeta, and cell transformation. These strings were combined with the 13 HAAs string.

\section{A.4.3.1. PubMed}

((GAPDH[tiab] OR Glyceraldehyde-3-Phosphate-Dehydrogenas*[tiab] OR "Glyceraldehyde-3Phosphate Dehydrogenases"[mh]) OR (tumorigenic-transformation*[tiab] OR Celltransformation*[tiab] OR "Cell Transformation, Neoplastic"[Mh]) OR ("Glutathione Transferase*"[tiab] OR "Glutathione Transferase"[mh] OR glutathione-S-transferase*[tiab] OR GST-zeta[tiab] OR GSTz[tiab]))

\section{A.4.3.2. Web of Science}

((TS=("Glyceraldehyde 3 Phosphate Dehydrogenas**" OR "GAPDH")) OR (TS=("tumorigenic transformation*" OR "Cell transformation*")) OR (TS=("Glutathione Transferase*" OR "glutathione-S-transferase*" OR "GST zeta" OR gstz)))

\section{A.4.3.3. Scopus}

((TITLE-ABS-KEY ("Glyceraldehyde 3 Phosphate Dehydrogenas**" OR "GAPDH")) OR (TITLE-ABS-KEY ("tumorigenic transformation*" OR "Cell transformation*")) OR (TITLEABS-KEY ("Glutathione Transferase*" OR "glutathione-S-transferase*" OR "GST zeta" OR gstz))) 


\section{Appendix B. Disposition and Toxicokinetics}

\section{Tables}

Table B-1. Pharmaco- or Toxicokinetic Parameters of Haloacetic Acids in Humans..................2

Table B-2. Toxicokinetic Parameters of Haloacetic Acids in Rats ...........................................

Table B-3. Toxicokinetic Parameters of Haloacetic Acids in Male B6C3F1 Mice..................... B-7 
Table B-1. Pharmaco- or Toxicokinetic Parameters of Haloacetic Acids in Humans

\begin{tabular}{|c|c|c|c|c|c|c|c|}
\hline HAA & $\begin{array}{l}\text { Dose, } \mathrm{mg} / \mathrm{kg} \\
\quad \text { (Route) }\end{array}$ & $\begin{array}{c}\mathrm{Vd} \\
(\mathrm{mL} / \mathrm{kg})\end{array}$ & $\begin{array}{c}\mathrm{AUC} \\
(\mathbf{m g} / \mathbf{L} \cdot \mathbf{h})\end{array}$ & $\begin{array}{l}\text { Plasma } \\
\text { T1/2 (h) }\end{array}$ & $\begin{array}{c}\text { Clearance } \\
(\mathrm{mL} / \mathrm{min} \bullet \mathrm{kg})\end{array}$ & Comments & Reference \\
\hline DCA & $\begin{array}{l}10 \text { (i.v.) } \\
20 \text { (i.v.) }\end{array}$ & $\begin{array}{l}337 \\
190 \\
\end{array}$ & $\begin{array}{l}14.9 \\
76.7\end{array}$ & $\begin{array}{l}0.34 \\
0.51\end{array}$ & $\begin{array}{l}11.31 \\
4.55\end{array}$ & $\begin{array}{l}\text { Two adults/dose (sex not specified). Data are } \\
\text { mean values for two subjects. }\end{array}$ & Lukas et al. (1980) \\
\hline DCA & $\begin{array}{l}10 \times 5 \text { (i.v.) } \\
25 \times 5 \text { (i.v.) } \\
50 \times 5 \text { (i.v.) }\end{array}$ & $\begin{array}{l}260 \\
270 \\
340 \\
290 \\
330\end{array}$ & $\begin{array}{l}\text { increased } \\
\text { with dose }\end{array}$ & $\begin{array}{l}1.06 \\
1.84 \\
3.14 \\
3.50 \\
6.23\end{array}$ & $\begin{array}{l}1393.8 \mathrm{mg} / \mathrm{kg} / \mathrm{h} \\
1089.1 \mathrm{mg} / \mathrm{kg} / \mathrm{h} \\
881.7 \mathrm{mg} / \mathrm{kg} / \mathrm{h} \\
950.2 \mathrm{mg} / \mathrm{kg} / \mathrm{h} \\
723.8 \mathrm{mg} / \mathrm{kg} / \mathrm{h}\end{array}$ & $\begin{array}{l}7 \text { men }+4 \text { women, } 5 \text { doses administered at } 2-\mathrm{h} \\
\text { intervals; } 3 \text { subjects at low dose, } 5 \text { subjects at mid } \\
\text { dose (including one from low dose group) and } 4 \\
\text { subjects at high dose. Vd, T1/2 and elimination rate } \\
\text { constants shown after each dose interval; however, } \\
\text { the dose was not specified. }\end{array}$ & Curry et al. (1985) \\
\hline DCA & $\begin{array}{l}50(\text { i.v. })+ \\
50 \times 2(\text { oral })\end{array}$ & $19.9 \mathrm{~L}$ & 609 & 2.65 & $102.1 \mathrm{~mL} / \mathrm{min}$ & $\begin{array}{l}8 \text { men }+4 \text { women; one i.v. and } 2 \text { oral doses given } \\
4 \text { days apart (randomized) }\end{array}$ & Curry et al. (1991) \\
\hline DCA & 46 (i.v.) & {$[750]$} & 261 & 2.3 & {$[5.33]$} & 13 adults (sex not specified) with severe malaria) & $\begin{array}{l}\text { Krishna et al. } \\
(1994)\end{array}$ \\
\hline DCA & 50 (i.v.) & 323 & 378 & 1.8 & 2.68 & 4 boys +4 girls with lactic acidosis from malaria & $\begin{array}{l}\text { Krishna et al. } \\
(1995)\end{array}$ \\
\hline DCA & $\begin{array}{l}46 \text { (i.v.) } \\
46 \times 2 \text { (i.v.) }\end{array}$ & 440 & NR & $\begin{array}{l}3.4 \\
4.4\end{array}$ & {$[2.17]$} & $\begin{array}{l}8 \text { men }+3 \text { women with severe malaria given one } \\
\text { dose and } 9 \text { subjects given a } 2 \text { nd dose } 12 \mathrm{~h} \text { after } 1^{\text {st }} . \\
\mathrm{Vd} \text { and } \mathrm{Cl} \text { data after } 2 \text { nd dose were reported as } \\
\text { similar to those after the } 1^{\text {st }} \text { dose. }\end{array}$ & $\begin{array}{l}\text { Krishna et al. } \\
\text { (1996) }\end{array}$ \\
\hline DCA & $40 \times 2$ (i.v.) & $\begin{array}{l}618 \\
618\end{array}$ & NR & $\begin{array}{l}{[7.58]} \\
{[4.65]}\end{array}$ & $\begin{array}{l}1.0 \text { (paleohepatic) } \\
1.7 \text { (neohepatic) }\end{array}$ & $\begin{array}{l}33 \text { adults (sex not specified) with end-stage liver } \\
\text { disease and liver transplant. } 2 \text { nd dose } 4 \text { h after } 1^{\text {st }} \\
\text { dose; } 2 \text {-compartment model. No clearance } \\
\text { occurred during the anhepatic phase. }\end{array}$ & $\begin{array}{l}\text { Shangraw and } \\
\text { Fisher (1996) }\end{array}$ \\
\hline DCA & $\begin{array}{l}35 \text { (i.v.) } \\
\text { controls } \\
\text { cirrhosis }\end{array}$ & $\begin{array}{l}413 \\
413 \\
\end{array}$ & NR & $\begin{array}{l}{[3.35]} \\
{[6.78]}\end{array}$ & $\begin{array}{l}2.14 \\
0.78 \\
\end{array}$ & $\begin{array}{l}5 \text { men }+1 \text { women (controls) } \\
5 \text { men }+2 \text { women (cirrhosis) } \\
2 \text {-compartment model }\end{array}$ & $\begin{array}{l}\text { Shangraw and } \\
\text { Fisher (1999) }\end{array}$ \\
\hline DCA & $50 \times 2$ (i.v.) & $\begin{array}{l}0.51 \mathrm{~L}^{\mathrm{a}} \\
0.27 \mathrm{~L}^{\mathrm{b}} \\
0.27 \mathrm{~L}^{\mathrm{c}}\end{array}$ & $\begin{array}{l}1233^{\mathrm{a}} \\
1863^{\mathrm{b}} \\
\mathrm{NR}\end{array}$ & $\begin{array}{l}5.94^{\mathrm{a}} \\
18.15^{\mathrm{b}} \\
49.37^{\mathrm{c}}\end{array}$ & $\begin{array}{l}{[1.02]^{\mathrm{a}}} \\
{[0.69]^{\mathrm{b}}} \\
{[0.33]^{\mathrm{c}}}\end{array}$ & $\begin{array}{l}66 \text { men }+45 \text { women with lactic acidosis. } 2 \text { nd dose } \\
2 \mathrm{~h} \text { after } 1 \mathrm{st} . \text { Pharmacokinetics in acidosis patients } \\
\text { were complex and differed from those in healthy } \\
\text { volunteers. Data for most patients fitted a 1- or } 2 \text { - } \\
\text { compartment model but a few fitted a 3- } \\
\text { compartment model or none of these. Plasma drug } \\
\text { clearance tended to decrease as the number of } \\
\text { compartments required to fit the data increased. }\end{array}$ & $\begin{array}{l}\text { Henderson et al. } \\
\text { (1997) }\end{array}$ \\
\hline
\end{tabular}




\begin{tabular}{|c|c|c|c|c|c|c|c|}
\hline HAA & $\begin{array}{c}\text { Dose, } \mathrm{mg} / \mathrm{kg} \\
\text { (Route) }\end{array}$ & $\begin{array}{c}\mathrm{Vd} \\
(\mathrm{mL} / \mathrm{kg}) \\
\end{array}$ & $\begin{array}{c}\mathrm{AUC} \\
(\mathrm{mg} / \mathrm{L} \cdot \mathbf{h})\end{array}$ & $\begin{array}{c}\text { Plasma } \\
T 1 / 2 \text { (h) }\end{array}$ & $\begin{array}{c}\text { Clearance } \\
(\mathrm{mL} / \mathrm{min} \bullet \mathrm{kg})\end{array}$ & Comments & Reference \\
\hline DCA & $\begin{array}{l}(50+50) \times 2 \\
\text { (i.v.) }\end{array}$ & $\begin{array}{l}0.29 \mathrm{~L}^{\mathrm{a}} \\
0.28 \mathrm{~L}^{\mathrm{b}}\end{array}$ & $\begin{array}{l}1954^{\mathrm{a}} \\
4306^{\mathrm{b}}\end{array}$ & $\begin{array}{l}8.77^{\mathrm{a}} \\
68.63^{\mathrm{b}}\end{array}$ & $\begin{array}{l}{[0.42]^{\mathrm{a}}} \\
{[0.28]^{\mathrm{b}}}\end{array}$ & $\begin{array}{l}15 \text { of the } 111 \text { patients mentioned above (sex not } \\
\text { specified) received a } 2 \text { nd treatment. No significant } \\
\text { differences compared to patients that received a } \\
\text { single treatment but drug clearance tended to } \\
\text { decrease with increase in number of drug } \\
\text { treatments. }\end{array}$ & $\begin{array}{l}\text { Henderson et al. } \\
\text { (1997) }\end{array}$ \\
\hline DCA & $\begin{array}{l}\frac{\text { Basal study }}{2(\text { oral })+0.3} \\
\text { (i.v.) } \\
\text { men } \\
\text { women } \\
\text { Chronic study } \\
(0.02 \times 14) \\
(\text { oral })+2 \\
(\text { oral })+0.3(\text { i.v }) \\
\text { men } \\
\text { women }\end{array}$ & $\begin{array}{l}374 \\
377\end{array}$ & $\begin{array}{l}212,755^{\mathrm{d}} \\
243,935^{\mathrm{d}}\end{array}$ & $\begin{array}{l}0.15 \\
0.16\end{array}$ & $\begin{array}{l}{[29.2]} \\
{[26.8]}\end{array}$ & $\begin{array}{l}8 \text { men }+8 \text { women: For basal study all subjects } \\
\text { consumed HAA-free bottled water for } 14 \text { days } \\
\text { then given unlabeled DCA in } 500 \mathrm{~mL} \text { bottled } \\
\text { water and } 5 \text { minutes later given i.v. }{ }^{13} \mathrm{C} \text {-labeled } \\
\text { DCA; chronic study used same subjects and began } \\
1 \text { day after the } 1^{\text {st }} \text { study. Subjects subsequently } \\
\text { ingested low concentrations of DCA in drinking } \\
\text { water for } 14 \text { days and on day } 15 \text { repeated protocol } \\
\text { of } 1^{\text {st }} \text { study. Only women were significantly } \\
\text { affected by chronic DCA exposure compared to } \\
\text { basal study with significantly increased AUC and } \\
\text { reduced clearance and Vd. }\end{array}$ & $\begin{array}{l}\text { Schultz and } \\
\text { Shangraw (2006) }\end{array}$ \\
\hline $\mathrm{TCA}$ & 3 (oral) & NR & NR & 50.6 & NR & 3 men administered a single oral dose of TCA & $\begin{array}{l}\text { Müller et al. } \\
(1974)\end{array}$ \\
\hline TCA & $\begin{array}{l}2.3-73 \mu \mathrm{g} / \text { day } \\
\text { (drinking water) }\end{array}$ & NR & NR & $\begin{array}{l}55.2-88.1 \\
(2.3-3.7 \\
\text { d) }\end{array}$ & NR & $\begin{array}{l}8 \text { men }+2 \text { women (elimination } \mathrm{T}^{1} / 2 \text { data based on } \\
3 \text { subjects). Monitored TCA levels in tap water } \\
\text { and urine during a } 12 \text {-day study period. Dose } \\
\text { range reflects mean intake over } 12 \text { days. }\end{array}$ & $\begin{array}{l}\text { Froese et al. } \\
(2002)\end{array}$ \\
\hline
\end{tabular}

Data in [brackets] indicate unit conversion of data reported in the study.

$\mathrm{HAA}=$ haloacetic acid, $\mathrm{Vd}=$ apparent volume of distribution, $\mathrm{AUC}=$ area under the concentration-time curve, $\mathrm{DCA}=$ dichloroacetic acid, $\mathrm{TCA}=$ trichloroacetic acid, $\mathrm{NR}=$ not reported.

ane-compartment model.

${ }^{\mathrm{b}}$ Two-compartment model.

'Three-compartment model.

${ }^{\mathrm{d}}$ AUC values provided for i.v. dose and oral dose, respectively. 
Table B-2. Toxicokinetic Parameters of Haloacetic Acids in Rats

\begin{tabular}{|c|c|c|c|c|c|c|c|c|}
\hline Haloacetic Acid & $\begin{array}{c}\text { Dose/Route } \\
\text { ( } \mu \mathrm{mol} / \mathbf{k g})\end{array}$ & $\mathbf{A U C}(\boldsymbol{\mu} \mathbf{M} \bullet \mathbf{h})$ & $\begin{array}{c}\text { Vdss } \\
(\mathrm{mL} / \mathbf{k g})\end{array}$ & $\begin{array}{c}\text { Total Body Cl } \\
(\mathrm{mL} / \mathrm{kg} / \mathrm{h})\end{array}$ & $\begin{array}{c}\text { Renal Cl } \\
(\mathrm{mL} / \mathrm{kg} / \mathrm{h})\end{array}$ & $\begin{array}{c}\text { Nonrenal Cl } \\
(\mathrm{mL} / \mathrm{kg} / \mathrm{h})\end{array}$ & $T^{1} / 2$ (h) & References \\
\hline Trichloro- & & & & & & & & \multirow{6}{*}{$\begin{array}{l}\text { Schultz et al. (1999) } \\
\text { Larson and Bull } \\
\text { (1992) } \\
\text { Saghir and Schultz } \\
(2005)\end{array}$} \\
\hline Single & 500 i.v. & $5406 \pm 144$ & $782 \pm 117$ & $93 \pm 3.0$ & $42.1 \pm 9.9$ & $50.4 \pm 11$ & $8.0 \pm 2.4$ & \\
\hline Single & [610] oral & $10,000 \pm 600$ & 485 & 58 & NR & NR & 5.8 & \\
\hline Single & [120] oral & $2530 \pm 70$ & 365 & 36 & NR & NR & 7.0 & \\
\hline Mixture $^{\mathrm{a}}$ & 25 i.v. & $1561 \pm 85$ & $287 \pm 23$ & $17.1 \pm 1.4$ & NR & NR & $12.03 \pm 0.36$ & \\
\hline GST- $\zeta$-depleted ${ }^{\mathrm{a}}$ & 25 i.v. & $1289 \pm 78$ & $200 \pm 10$ & $19.7 \pm 1.2$ & NR & NR & $7.49 \pm 0.15$ & \\
\hline Bromodichloro- & & & & & & & & \multirow{6}{*}{$\begin{array}{l}\text { Schultz et al. (1999) } \\
\text { Saghir and Schultz } \\
(2005)\end{array}$} \\
\hline Single & 500 i.v. & $1856 \pm 579$ & $730 \pm 138$ & $286 \pm 82$ & $89 \pm 2.7$ & $197 \pm 52$ & $1.85 \pm 0.30$ & \\
\hline Single & 100 i.v. & NR & $573 \pm 179$ & $138 \pm 41$ & NR & NR & $3.0 \pm 0.40$ & \\
\hline Single & 25 i.v. & NR & $328 \pm 62$ & $279 \pm 53.5$ & NR & NR & $1.3 \pm 0.25$ & \\
\hline Mixture $^{a}$ & 25 i.v. & $291 \pm 31$ & $368 \pm 6.0$ & $63.9 \pm 13.0$ & NR & NR & $3.49 \pm 0.14$ & \\
\hline GST- $\zeta$-depleted $^{\mathrm{a}}$ & 25 i.v. & $306 \pm 27$ & $308 \pm 21$ & $83.9 \pm 7.0$ & NR & NR & $2.33 \pm 0.10$ & \\
\hline Chlorodibromo- & & & & & & & & \multirow{5}{*}{$\begin{array}{l}\text { Schultz et al. (1999) } \\
\text { Saghir and Schultz } \\
(2005)\end{array}$} \\
\hline Single & 500 i.v. & $1107 \pm 331$ & $636 \pm 268$ & $486 \pm 153$ & $182 \pm 58$ & $304 \pm 137$ & $1.26 \pm 0.27$ & \\
\hline Single & 25 i.v. & NR & $264 \pm 45$ & $128 \pm 13$ & NR & NR & $1.40 \pm 0.25$ & \\
\hline Mixture $^{b}$ & 25 i.v. & $246 \pm 22$ & $247 \pm 25$ & $105 \pm 8$ & NR & NR & $1.55 \pm 0.21$ & \\
\hline 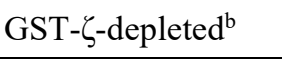 & 25 i.v. & $199 \pm 10$ & $281 \pm 12$ & $127 \pm 6$ & NR & NR & $1.62 \pm 0.13$ & \\
\hline Tribromo- & & & & & & & & \multirow{4}{*}{$\begin{array}{l}\text { Schultz et al. (1999) } \\
\text { Saghir and Schultz } \\
(2005)\end{array}$} \\
\hline Single & 500 i.v. & $676 \pm 110$ & $449 \pm 175$ & $754 \pm 116$ & $171 \pm 23$ & $582 \pm 126$ & $0.58 \pm 0.18$ & \\
\hline Mixture $^{b}$ & 25 i.v. & $121 \pm 36$ & $278 \pm 51$ & $291 \pm 77$ & NR & NR & $0.76 \pm 0.03$ & \\
\hline 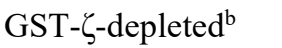 & 25 i.v. & $112 \pm 5$ & $237 \pm 21$ & $225 \pm 9$ & NR & NR & $0.85 \pm 0.11$ & \\
\hline
\end{tabular}




\begin{tabular}{|c|c|c|c|c|c|c|c|c|}
\hline Haloacetic Acid & $\begin{array}{l}\text { Dose/Route } \\
\text { ( } \mu \mathrm{mol} / \mathbf{k g})\end{array}$ & $\mathbf{A U C}(\boldsymbol{\mu M} \cdot \mathbf{h})$ & $\begin{array}{c}\mathbf{V d} \mathbf{d}_{\mathrm{ss}} \\
(\mathrm{mL} / \mathbf{k g})\end{array}$ & $\begin{array}{l}\text { Total Body Cl } \\
\text { (mL/kg/h) }\end{array}$ & $\begin{array}{c}\text { Renal Cl } \\
(\mathrm{mL} / \mathrm{kg} / \mathrm{h})\end{array}$ & $\begin{array}{c}\text { Nonrenal Cl } \\
(\mathrm{mL} / \mathrm{kg} / \mathrm{h})\end{array}$ & T1/2 (h) & References \\
\hline 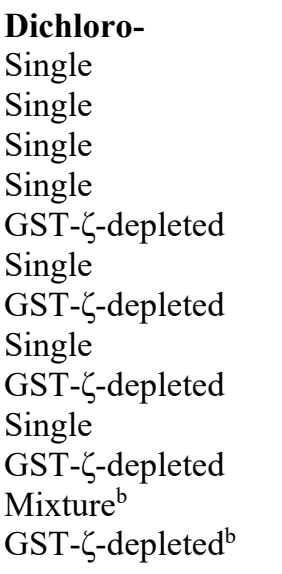 & $\begin{array}{l}500 \text { i.v. } \\
{[770] \text { oral }} \\
{[160] \text { oral }} \\
{[770] \text { i.v. }} \\
{[770] \text { i.v. }} \\
{[160] \text { i.v. }} \\
{[160] \text { i.v. }} \\
{[40] \text { i.v. }} \\
{[40] \text { i.v. }} \\
{[8] \text { i.v. }} \\
{[8] \text { i.v. }} \\
25 \text { i.v. } \\
25 \text { i.v. }\end{array}$ & $\begin{array}{l}2092 \pm 1821 \\
750 \pm 40 \\
13 \pm 4 \\
{[3360 \pm 1810]} \\
{[18,700 \pm 3100]} \\
{[110 \pm 6.6]} \\
{[1060 \pm 26]} \\
{[9.6 \pm 0.4]} \\
{[64 \pm 4]} \\
{[1.2 \pm 0.08]} \\
{[4.7 \pm 0.16]} \\
8.8 \pm 0.09 \\
145 \pm 33\end{array}$ & $\begin{array}{l}618 \pm 318 \\
1000 \\
2400 \\
618 \pm 319 \\
582 \pm 146 \\
223 \pm 111 \\
513 \pm 18.5 \\
415 \pm 47.2 \\
392 \pm 31.4 \\
508 \pm 68.6 \\
261 \pm 13.6 \\
405 \pm 82.0 \\
668 \pm 128\end{array}$ & $\begin{array}{l}267 \pm 104 \\
820 \\
2900 \\
267 \pm 105 \\
42.7 \pm 8.2 \\
1571 \pm 97 \\
168 \pm 22 \\
5265 \pm 636 \\
614 \pm 39 \\
6554 \pm 356 \\
1640 \pm 57 \\
2980 \pm 332 \\
199 \pm 42\end{array}$ & $\begin{array}{l}2.9 \pm 0.5 \\
\text { NR } \\
N R \\
2.9 \pm 0.5 \\
8.9 \pm 3.3 \\
N R \\
N R \\
N R \\
N R \\
N R \\
N R \\
N R \\
N R\end{array}$ & $\begin{array}{l}264 \pm 103 \\
\text { NR } \\
\text { NR } \\
265 \pm 103 \\
33.8 \pm 4.9 \\
\text { NR } \\
\text { NR } \\
\text { NR } \\
\text { NR } \\
\text { NR } \\
\text { NR } \\
\text { NR } \\
\text { NR }\end{array}$ & $\begin{array}{l}2.4 \pm 0.80 \\
0.9 \\
0.9 \\
2.4 \pm 0.15 \\
10.8 \pm 2.0 \\
0.15 \pm 0.01 \\
1.81 \pm 0.09 \\
0.08 \pm 0.003 \\
0.50 \pm 0.03 \\
0.07 \pm 0.001 \\
0.20 \pm 0.05 \\
0.15 \pm 0.04 \\
2.30 \pm 0.29\end{array}$ & $\begin{array}{l}\text { Schultz et al. (1999) } \\
\text { Larson and Bull } \\
\text { (1992) } \\
\text { Gonzalez-Leon et al. } \\
\text { (1997) } \\
\text { Saghir and Schultz } \\
\text { (2002) } \\
\text { Saghir and Schultz } \\
\text { (2005) }\end{array}$ \\
\hline $\begin{array}{l}\text { Dichloro- } \\
\text { Young (3-4 mo) } \\
\text { Young (3-4 mo) } \\
\text { Aged }(16 \mathrm{mo})\end{array}$ & $\begin{array}{l}{[400] \text { oral }} \\
{[400 \times 2] \text { oral }} \\
{[400 \times 2] \text { oral }}\end{array}$ & $\begin{array}{l}{[91 \pm 13]} \\
{[1,870 \pm 580]} \\
{[11,700 \pm 1920]}\end{array}$ & $\begin{array}{l}680 \pm 70 \\
390 \pm 140 \\
140 \pm 20 \\
\end{array}$ & NR & NR & NR & $\begin{array}{l}0.11 \pm 0.02 \\
5.4 \pm 0.76 \\
9.7 \pm 0.97 \\
\end{array}$ & James et al. (1998) \\
\hline 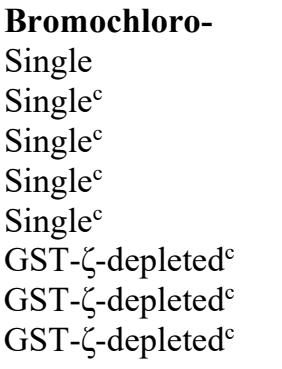 & $\begin{array}{l}500 \text { i.v. } \\
{[58] \text { i.v. }} \\
{[58] \text { (oral) }} \\
{[230] \text { (oral) }} \\
{[580] \text { (oral) }} \\
{[16] \text { (oral) }} \\
{[160] \text { (oral) }} \\
{[320] \text { (oral) }}\end{array}$ & $\begin{array}{l}576 \pm 286 \\
{[16.4 ; 19.8]} \\
{[2.7 ; 2.8]} \\
{[94 ; 137]} \\
{[450 ; 678]} \\
{[26 ; 2.8]} \\
{[117 ; 133]} \\
{[356 ; 375]}\end{array}$ & $\begin{array}{l}881 \pm 373 \\
\text { NR } \\
\text { NR } \\
\text { NR } \\
\text { NR } \\
\text { NR } \\
\text { NR } \\
\text { NR }\end{array}$ & $\begin{array}{l}1,037 \pm 453 \\
{[3510 ; 2920]} \\
{[21,240 ; 20,640]} \\
{[2460 ; 1670]} \\
{[1280 ; 852]} \\
{[6420 ; 5720]} \\
{[1420 ; 1190]} \\
{[940 ; 850]}\end{array}$ & $\begin{array}{l}36.9 \pm 20.8 \\
N R \\
N R \\
N R \\
N R \\
N R \\
N R \\
N R\end{array}$ & $\begin{array}{l}1014 \pm 443 \\
N R \\
N R \\
N R \\
N R \\
N R \\
N R \\
N R\end{array}$ & $\begin{array}{l}3.93 \pm 1.5 \\
0.10 ; 0.09 \\
0.25 ; 0.21 \\
0.62 ; 0.53 \\
0.71 ; 0.67 \\
0.05 ; 0.07 \\
0.16 ; 0.11 \\
0.08 ; 0.10\end{array}$ & $\begin{array}{l}\text { Schultz et al. (1999) } \\
\text { NTP (2009) }\end{array}$ \\
\hline 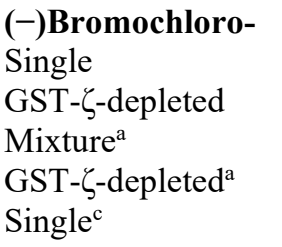 & $\begin{array}{l}520 \text { i.v. } \\
520 \text { i.v. } \\
25 \text { i.v. } \\
25 \text { i.v. } \\
\text { [58] i.v. }\end{array}$ & $\begin{array}{l}74.8 \pm 9.0 \\
584 \pm 135 \\
1.7 \pm 0.1 \\
7.3 \pm 1.1 \\
{[7.6 ; 4.7]}\end{array}$ & $\begin{array}{l}380 \pm 41 \\
417 \pm 139 \\
680 \pm 103 \\
361 \pm 53 \\
\text { NR }\end{array}$ & $\begin{array}{l}3712 \pm 140 \\
484 \pm 142 \\
7660 \pm 478 \\
1997 \pm 42 \\
{[7560 ; 12,400]}\end{array}$ & $\begin{array}{l}31.4 \pm 9.5 \\
17.4 \pm 10.8 \\
\mathrm{NR} \\
\mathrm{NR} \\
\mathrm{NR}\end{array}$ & $\begin{array}{l}3693 \pm 155 \\
468 \pm 143 \\
N R \\
N R \\
N R\end{array}$ & $\begin{array}{l}0.07 \pm 0.01 \\
0.40 \pm 0.02 \\
0.06 \pm 0.01 \\
0.19 \pm 0.03 \\
\mathrm{NR}\end{array}$ & $\begin{array}{l}\text { Schultz and } \\
\text { Sylvester (2001) } \\
\text { Saghir and Schultz } \\
(2005) \\
\text { NTP (2009) }\end{array}$ \\
\hline
\end{tabular}




\begin{tabular}{|c|c|c|c|c|c|c|c|c|}
\hline Haloacetic Acid & $\begin{array}{c}\text { Dose/Route } \\
(\mu \mathrm{mol} / \mathrm{kg})\end{array}$ & $\mathbf{A U C}(\boldsymbol{\mu M} \cdot \mathbf{h})$ & $\begin{array}{c}V d_{s s} \\
(\mathrm{~mL} / \mathrm{kg})\end{array}$ & $\begin{array}{c}\text { Total Body Cl } \\
(\mathrm{mL} / \mathrm{kg} / \mathrm{h})\end{array}$ & $\begin{array}{c}\text { Renal Cl } \\
(\mathrm{mL} / \mathrm{kg} / \mathrm{h})\end{array}$ & $\begin{array}{c}\text { Nonrenal Cl } \\
(\mathrm{mL} / \mathrm{kg} / \mathrm{h})\end{array}$ & T1/2 (h) & References \\
\hline $\begin{array}{l}\text { (+)Bromochloro- } \\
\text { Single } \\
\text { GST- } \zeta \text {-depleted } \\
\text { Mixture }^{\mathrm{a}} \\
\text { GST- } \zeta \text {-depleted }^{\mathrm{a}} \\
\text { Single }^{\mathrm{c}}\end{array}$ & $\begin{array}{l}520 \text { i.v. } \\
520 \text { i.v. } \\
25 \text { i.v. } \\
25 \text { i.v. } \\
{[58] \text { i.v. }}\end{array}$ & $\begin{array}{l}234 \pm 25 \\
487 \pm 119 \\
7.2 \pm 0.6 \\
28.9 \pm 3.5 \\
{[13.4 ; 10.4]}\end{array}$ & $\begin{array}{l}587 \pm 104 \\
467 \pm 168 \\
393 \pm 34 \\
246 \pm 25 \\
N R\end{array}$ & $\begin{array}{l}1,248 \pm 132 \\
591 \pm 136 \\
1,773 \pm 184 \\
466 \pm 56 \\
{[4310 ; 5570]}\end{array}$ & $\begin{array}{l}13.2 \pm 3.0 \\
13.4 \pm 7.4 \\
\mathrm{NR} \\
\mathrm{NR} \\
\mathrm{NR}\end{array}$ & $\begin{array}{l}1,236 \pm 127 \\
580 \pm 139 \\
\text { NR } \\
\text { NR } \\
\text { NR }\end{array}$ & $\begin{array}{l}0.40 \pm 0.09 \\
0.44 \pm 0.04 \\
0.19 \pm 0.01 \\
0.40 \pm 0.02 \\
\mathrm{NR}\end{array}$ & $\begin{array}{l}\text { Schultz and } \\
\text { Sylvester (2001) } \\
\text { Saghir and Schultz } \\
(2005) \\
\text { NTP (2009) }\end{array}$ \\
\hline $\begin{array}{l}\text { Dibromo- } \\
\text { Single } \\
\text { Mixture }^{\mathrm{a}} \\
\text { GST- } \zeta \text {-depleted }^{\mathrm{a}} \\
\text { Single }^{\mathrm{c}} \\
\text { Single }^{\mathrm{c}} \\
\text { Single }^{\mathrm{c}}\end{array}$ & $\begin{array}{l}500 \text { i.v. } \\
25 \text { i.v. } \\
25 \text { i.v. } \\
{[115] \text { oral }} \\
{[230] \text { oral }} \\
{[570] \text { oral }}\end{array}$ & $\begin{array}{l}1,120 \pm 362 \\
2.4 \pm 0.1 \\
13.2 \pm 2.5 \\
{[36 ; 50]} \\
{[95 ; 121]} \\
{[251 ; 353]}\end{array}$ & $\begin{array}{l}400 \pm 112 \\
987 \pm 142 \\
599 \pm 68 \\
N R \\
N R \\
N R\end{array}$ & $\begin{array}{l}491 \pm 116 \\
10,540 \pm 312 \\
2,390 \pm 71 \\
N R \\
N R \\
N R\end{array}$ & $\begin{array}{l}12.9 \pm 4.0 \\
\mathrm{NR} \\
\mathrm{NR} \\
\mathrm{NR} \\
\mathrm{NR} \\
\mathrm{NR}\end{array}$ & $\begin{array}{l}490 \pm 137 \\
N R \\
N R \\
N R \\
N R \\
N R\end{array}$ & $\begin{array}{l}0.72 \pm 0.12 \\
0.08 \pm 0.01 \\
0.22 \pm 0.02 \\
0.8 ; 0.87 \\
0.95 ; 0.77 \\
1.2 ; 0.98\end{array}$ & $\begin{array}{l}\text { Schultz et al. (1999) } \\
\text { Saghir and Schultz } \\
(2005) \\
\text { NTP (2007a) }\end{array}$ \\
\hline Monochloro- & $\begin{array}{l}{[2400] \text { oral }} \\
{[110] \text { oral }} \\
{[790] \text { i.v. }} \\
{[110] \text { i.v. }}\end{array}$ & $\begin{array}{l}{[3120 \pm 23]} \\
{[105 \pm 0.8]} \\
\text { NR } \\
\text { NR }\end{array}$ & $\begin{array}{l}\text { NR } \\
\text { NR } \\
1060 \\
3033\end{array}$ & $\begin{array}{l}558 \pm 2.4 \\
769 \pm 3.8 \\
262 \\
750\end{array}$ & $\begin{array}{l}\text { NR } \\
\text { NR } \\
154 \\
546\end{array}$ & $\begin{array}{l}\text { NR } \\
\text { NR } \\
\text { NR } \\
\text { NR }\end{array}$ & $\begin{array}{l}2.19 \pm 0.79 \\
1.89 \pm 0.11 \\
5.40 \\
3.25\end{array}$ & $\begin{array}{l}\text { Saghir and Rozman } \\
(2003) \\
\text { Saghir et al. (2001) }\end{array}$ \\
\hline
\end{tabular}

Data in brackets indicate unit conversions: (dose $\mathrm{mg} / \mathrm{kg} \bullet 1000 \mu \mathrm{g} / \mathrm{mg}) /(\mathrm{MW} \mu \mathrm{g} / \mu \mathrm{mol})=\operatorname{dose} \mu \mathrm{moles} / \mathrm{kg},(\mathrm{AUC} \mu \mathrm{g} / \mathrm{mL} \bullet \mathrm{hr} \bullet 1000 \mathrm{ng} / \mu \mathrm{g}) /(\mathrm{MW} \mathrm{ng} / \mathrm{nmol})=\mathrm{AUC} \mu \mathrm{M} \bullet \mathrm{hr}]$, or $(\mathrm{Cl}$ $\mathrm{mL} / \mathrm{min} / \mathrm{kg} \bullet 60 \mathrm{~min} / \mathrm{h})=\mathrm{Cl} \mathrm{mL} / \mathrm{kg} / \mathrm{h}$ ) where $\mathrm{MW}$ of trichloroacetic acid = 163.4, dichloroacetic acid = 128.9, bromochloroacetic acid $=173.4$, dibromoacetic acid $=217.86$, and monochloroacetic acid $=94.5$.

$\mathrm{Cl}=$ clearance, $\mathrm{Vd}_{\mathrm{ss}}=$ apparent steady state volume of distribution, $\mathrm{t} 1 / 2=$ half-life of elimination, $\mathrm{NR}=$ not reported.

${ }^{a}$ Administered as a mixture containing trichlor-, bromodichloro-, bromochloro-, and dibromoacetic acid.

${ }^{\mathrm{b}}$ Administered as a mixture containing chlorodibromo- tribromo- and dichloroacetic acid.

'Males; females. 
Table B-3. Toxicokinetic Parameters of Haloacetic Acids in Male B6C3F1 Mice

\begin{tabular}{|c|c|c|c|c|c|c|c|c|}
\hline Haloacetic Acid & $\begin{array}{c}\text { Dose/Route } \\
\text { (mg/kg) }\end{array}$ & $\mathbf{A U C}(\boldsymbol{\mu M} \bullet \mathbf{h})$ & $\begin{array}{c}\mathrm{Vd} \mathbf{d}_{\mathrm{ss}} \\
(\mathrm{mL} / \mathrm{kg})\end{array}$ & $\begin{array}{l}\text { Total Body Cl } \\
\text { (mL/kg/h) }\end{array}$ & $\begin{array}{c}\text { Renal Cl } \\
(\mathrm{mL} / \mathrm{kg} / \mathrm{h})\end{array}$ & $\begin{array}{c}\text { Nonrenal } \\
\text { Cl } \\
(\mathbf{m L} / \mathbf{k g} / \mathbf{h})\end{array}$ & T1/2 (h) & Reference \\
\hline $\begin{array}{l}\text { Trichloro- } \\
\text { Control } \\
\text { TCA-pretreat }^{\mathrm{a}} \\
\text { DCA-pretreat }^{\mathrm{a}}\end{array}$ & $\begin{array}{l}100 \text { i.v. } \\
100 \text { i.v. } \\
100 \text { i.v. }\end{array}$ & $\begin{array}{l}{[19,500 \pm 2240]} \\
{[23,000 \pm 3240]} \\
{[23,100 \pm 1,980]}\end{array}$ & $\begin{array}{l}571 \pm 91 \\
483 \pm 42 \\
521 \pm 15 \\
\end{array}$ & $\begin{array}{l}40.1 \pm 4.6 \\
37.2 \pm 5.2 \\
34.0 \pm 3.0 \\
\end{array}$ & $\begin{array}{l}28.1 \pm 9.1 \\
22.0 \pm 3.4 \\
20.2 \pm 1.9\end{array}$ & $\begin{array}{l}12 \\
15 \\
14\end{array}$ & $\begin{array}{l}10.0 \pm 2.0 \\
9.40 \pm 0.7 \\
10.7 \pm 1.0\end{array}$ & $\begin{array}{l}\text { Gonzalez-Leon } \\
\text { et al. (1999) }\end{array}$ \\
\hline Trichloro- & $\begin{array}{l}100 \text { oral } \\
20 \text { oral }\end{array}$ & $\begin{array}{l}7180 \pm 210 \\
2020 \pm 60\end{array}$ & $\begin{array}{l}555 \\
335\end{array}$ & $\begin{array}{l}66 \\
55\end{array}$ & NR & NR & $\begin{array}{l}5.8 \\
4.2\end{array}$ & $\begin{array}{l}\text { Larson and Bull } \\
\text { (1992) }\end{array}$ \\
\hline Bromodichloro- & $\begin{array}{l}100 \text { i.v. } \\
20 \text { i.v. } \\
5 \text { i.v. }\end{array}$ & $\begin{array}{l}3127 \pm 231 \\
709 \pm 255 \\
119 \pm 19 \\
\end{array}$ & $\begin{array}{l}518 \pm 21 \\
380 \pm 25 \\
383 \pm 26\end{array}$ & $\begin{array}{l}156 \pm 10 \\
217 \pm 76 \\
222 \pm 33\end{array}$ & $\begin{array}{l}3.7 \\
0 \\
0\end{array}$ & $\begin{array}{l}152.3 \\
217 \\
222 \\
\end{array}$ & $\begin{array}{l}2.05 \pm 0.10 \\
1.94 \pm 0.56 \\
1.33 \pm 0.15\end{array}$ & $\begin{array}{l}\text { Merdink et al. } \\
(2001)\end{array}$ \\
\hline Dichloro- & $\begin{array}{l}100 \text { oral } \\
20 \text { oral }\end{array}$ & $\begin{array}{l}30 \pm 0 \\
8 \pm 2\end{array}$ & $\begin{array}{l}32,500 \\
34,800\end{array}$ & $\begin{array}{l}14,300 \\
16,000\end{array}$ & NR & NR & $\begin{array}{l}1.6 \\
1.5\end{array}$ & $\begin{array}{l}\text { Larson and Bull } \\
\text { (1992) }\end{array}$ \\
\hline $\begin{array}{l}\text { Dichloro- } \\
\text { Control } \\
\text { TCA-pretreat }^{\mathrm{a}} \\
\text { DCA-pretreat }^{\mathrm{a}}\end{array}$ & $\begin{array}{l}100 \text { i.v. } \\
100 \text { i.v. } \\
100 \text { i.v. }\end{array}$ & $\begin{array}{l}{[690 \pm 93]} \\
{[2310 \pm 396]} \\
{[950 \pm 39]}\end{array}$ & $\begin{array}{l}548 \pm 96 \\
534 \pm 53 \\
475 \pm 26\end{array}$ & $\begin{array}{l}1188 \pm 147 \\
387 \pm 100 \\
813 \pm 37\end{array}$ & $\begin{array}{l}1.61 \pm 0.69 \\
3.13 \pm 1.8 \\
2.20 \pm 0.61\end{array}$ & $\begin{array}{l}1186 \\
384 \\
811\end{array}$ & $\begin{array}{l}0.35 \pm 0.1 \\
1.14 \pm 0.2 \\
0.40 \pm 0.3\end{array}$ & $\begin{array}{l}\text { Gonzalez-Leon } \\
\text { et al. (1999) }\end{array}$ \\
\hline $\begin{array}{l}\text { Dichloro- } \\
\text { Controls } \\
6 \mathrm{~h} \\
16 \mathrm{~h} \\
36 \mathrm{~h} \\
48 \mathrm{~h}\end{array}$ & $\begin{array}{l}20 \text { i.v. } \\
20 \text { i.v. } \\
20 \text { i.v. } \\
20 \text { i.v. } \\
20 \text { i.v. }\end{array}$ & $\begin{array}{l}{[22 \pm 4.7]} \\
{[143 \pm 10]} \\
{[123 \pm 36]} \\
{[60 \pm 12]} \\
{\left[32^{ \pm} 5.4\right]}\end{array}$ & $\begin{array}{l}497 \pm 160 \\
437 \pm 29 \\
691 \pm 27 \\
334 \pm 43 \\
467 \pm 62\end{array}$ & $\begin{array}{l}7420 \pm 1,460 \\
1085 \pm 179 \\
1051 \pm 204 \\
2408 \pm 392 \\
4887 \pm 740\end{array}$ & NR & NR & $\begin{array}{l}0.053 \pm 0.02 \\
0.30 \pm 0.04 \\
0.33 \pm 0.03 \\
0.11 \pm 0.01 \\
0.086 \pm 0.01\end{array}$ & $\begin{array}{l}\text { Schultz et al. } \\
(2002)\end{array}$ \\
\hline $\begin{array}{l}\text { aged controls } \\
\leq 16 \mathrm{~h}\end{array}$ & $\begin{array}{l}20 \text { i.v. } \\
20 \text { i.v. }\end{array}$ & $\begin{array}{l}{[98 \pm 46]} \\
{[75 \pm 2.6]}\end{array}$ & $\begin{array}{l}459 \pm 160 \\
597 \pm 68\end{array}$ & $\begin{array}{l}1903 \pm 850 \\
2296 \pm 852\end{array}$ & & & $\begin{array}{l}0.23 \pm 0.09 \\
0.24 \pm 0.05\end{array}$ & \\
\hline $\begin{array}{l}\text { Dibromo- } \\
\text { single }^{d} \\
\text { single }^{d} \\
\text { single }^{d}\end{array}$ & $\begin{array}{l}{[320] \text { oral }} \\
{[800] \text { oral }} \\
{[1600] \text { oral }}\end{array}$ & $\begin{array}{l}{[6.5 ; 5.6]} \\
{[36.9 ; 34.1]} \\
{[112 ; 113]}\end{array}$ & $\begin{array}{l}\text { NR } \\
\text { NR } \\
\text { NR }\end{array}$ & $\begin{array}{l}\text { NR } \\
\text { NR } \\
\text { NR }\end{array}$ & $\begin{array}{l}\text { NR } \\
\text { NR } \\
\text { NR }\end{array}$ & $\begin{array}{l}\text { NR } \\
\text { NR } \\
\text { NR }\end{array}$ & $\begin{array}{l}0.36 ; 0.33 \\
0.80 ; 0.67 \\
1.75 ; 1.99\end{array}$ & NTP (2007a) \\
\hline
\end{tabular}


RoC Monograph on Haloacetic Acids

\begin{tabular}{|c|c|c|c|c|c|c|c|c|}
\hline Haloacetic Acid & $\begin{array}{l}\text { Dose/Route } \\
\text { (mg/kg) }\end{array}$ & $\operatorname{AUC}(\boldsymbol{\mu M} \bullet \mathbf{h})$ & $\begin{array}{c}V d_{s s} \\
(\mathrm{~mL} / \mathbf{k g})\end{array}$ & $\begin{array}{c}\text { Total Body Cl } \\
\text { (mL/kg/h) }\end{array}$ & $\begin{array}{c}\text { Renal Cl } \\
(\mathrm{mL} / \mathrm{kg} / \mathrm{h})\end{array}$ & $\begin{array}{c}\text { Nonrenal } \\
\text { Cl } \\
(\mathrm{mL} / \mathrm{kg} / \mathbf{h})\end{array}$ & $T^{1} 1 / 2(h)$ & Reference \\
\hline Bromochloro- & & & & & & & & NTP (2009) \\
\hline Single $^{d}$ & [580] i.v. & {$[135 ; 128]$} & NR & {$[4280 ; 4520]$} & NR & NR & $0.089 ; 0.062$ & \\
\hline Single $^{d}$ & [580 ] (oral) & {$[25 ; 14.9]$} & NR & {$[23,100 ; 38,760]$} & NR & NR & $0.15 ; 0.18$ & \\
\hline Single $^{\mathrm{d}}$ & [1150 ] (oral) & {$[134 ; 74]$} & NR & {$[8640 ; 15 ; 600]$} & NR & NR & $0.25 ; 0.20$ & \\
\hline Single $^{d}$ & [2300] (oral) & {$[445 ; 331]$} & NR & {$[5180 ; 6960]$} & NR & NR & $0.32 ; 0.25$ & \\
\hline GST- $\zeta$-depleted ${ }^{\mathrm{d}}$ & [520 ] (oral) & {$[18.6 ; 134]$} & NR & {$[24,900 ; 4320]$} & NR & NR & $0.10 ; 0.22$ & \\
\hline GST-ל-depleted ${ }^{\mathrm{d}}$ & [1040 ] (oral) & {$[271 ; 327]$} & NR & {$[3400 ; 3530]$} & NR & NR & $0.22 ; 0.21$ & \\
\hline $\begin{array}{l}(-) \text { Bromochloro- } \\
\text { Single }^{\mathrm{d}}\end{array}$ & [580] i.v. & {$[50.8 ; 54.9]$} & NR & {$[11,340 ; 10 ; 500]$} & NR & NR & $0.03 ; 0.03$ & NTP (2009) \\
\hline $\begin{array}{l}(+) B r o m o c h l o r o- \\
\text { Single }^{d}\end{array}$ & [580] i.v. & {$[83.3 ; 97.1]$} & NR & {$[6900 ; 5930]$} & NR & NR & $0.08 ; 0.08$ & NTP (2009) \\
\hline
\end{tabular}

Data in brackets indicate unit conversion: $\mathrm{Cl} \mu \mathrm{g} / \mathrm{mL} \bullet \mathrm{hr} \bullet 1000 \mathrm{ng} / \mu \mathrm{g}) /(\mathrm{MW} \mathrm{ng} / \mathrm{nmol})=\mathrm{Cl} \mu \mathrm{M} \bullet \mathrm{hr}]$ or $(\mathrm{AUC} \mu \mathrm{g} / \mathrm{mL} \bullet \mathrm{hr} \bullet 1000 \mathrm{ng} / \mu \mathrm{g}) /(\mathrm{MW} \mathrm{ng} / \mathrm{nmol})=\mathrm{AUC} \mu \mathrm{M} \bullet \mathrm{hr})$.

$\mathrm{Cl}=$ clearance, $\mathrm{Vd}_{\mathrm{ss}}=$ apparent steady state volume of distribution, $\mathrm{t} 1 \frac{1}{2}=$ half-life of elimination, $\mathrm{NR}=$ not reported.

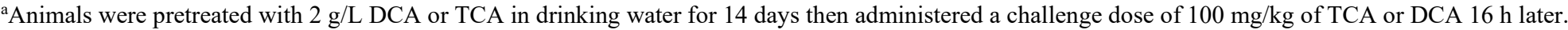

b8-week old mice exposed to $2 \mathrm{~g} / \mathrm{L}$ DCA in drinking water for 14 days and i.v. dose administered $6,16,36$, or $48 \mathrm{~h}$ after removal of DCA from drinking water.

c4-week old mice given $2 \mathrm{~g} / \mathrm{L}$ DCA in drinking water for 56 weeks and i.v. dose administered within $16 \mathrm{~h}$ after removal of DCA from the drinking water

${ }^{\mathrm{d}}$ Males; females. 


\section{Appendix C. Animal Studies}

\section{Table of Contents}

C.1. Monochloroacetic Acid: Study Quality for Animal Studies ...............................-4

C.2. Monoiodoacetic Acid: Study Quality for Animal Studies .................................

C.3. Dichloroacetic Acid: Study Quality for Animal Studies..................................-11

C.4. Dibromoacetic Acid: Study Quality for Animal Studies ...................................37

C.5. Bromochloroacetic Acid: Study Quality for Animal Studies..........................C-41

C.6. Trichloroacetic Acid: Study Quality for Animal Studies.................................45

C.7. Bromodichloroacetic Acid: Study Quality for Animal Studies ........................57

C.8. Animal Studies for Haloacetic Acids: Results by Tumor ..................................61

\section{Tables}

Table C-1. NTP 1992 (M Mouse): Monochloroacetic Acid: Gavage ........................-4

Table C-2. NTP 1992 (F Mouse): Monochloroacetic Acid: Gavage............................5

Table C-3. NTP 1992 (M Rat): Monochloroacetic Acid: Gavage..............................6

Table C-4. NTP 1992 (F Rat): Monochloroacetic Acid: Gavage ...............................7

Table C-5. DeAngelo et al. 1997 (M Rat): Monochloroacetic Acid: Drinking

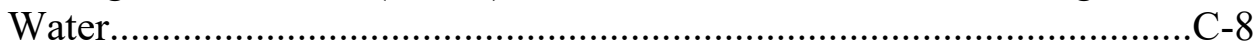

Table C-6. Gwynn and Salaman 1953 (NR Mouse): Iodoacetic Acid: Dermal ........C-9

Table C-7. DeAngelo et al. 1996 (M Rat [Study 1]): Dichloroacetic Acid: Drinking

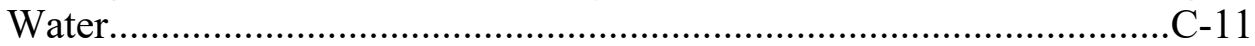

Table C-8. DeAngelo et al. 1996 (M Rat [Study 2]): Dichloroacetic Acid: Drinking

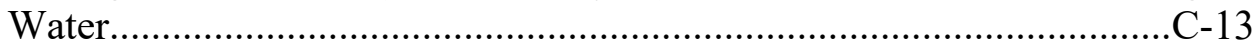

Table C-9. Richmond et al. 1995 (M Rat): Dichloroacetic Acid: Drinking Water .C-14

Table C-10. DeAngelo et al. 1991 (M Mouse [Study 1]): Dichloroacetic Acid: Drinking Water ...................................................................... 15

Table C-11. DeAngelo et al. 1991 (M Mouse [Study 2]): Dichloroacetic Acid: Drinking Water ........................................................................... -16

Table C-12. DeAngelo et al. 1999 (M Mouse): Dichloroacetic Acid: Drinking Water

Table C-13. Herren-Freund et al. 1987 (M Mouse): Dichloroacetic Acid: Drinking Water.

Table C-14. Herren-Freund et al. 1987 (M Mouse): Dichloroacetic Acid: Drinking Water (Initiation-promotion)

Table C-15. Wood et al. 2015 (M Mouse): Dichloroacetic Acid: Drinking Water.C-20

Table C-16. Wood et al. 2015 (F Mouse): Dichloroacetic Acid: Drinking Water ..C-21

Table C-17. Pereira 1996 (F Mouse [Study 1]): Dichloroacetic Acid (DCA): Drinking Water.... C-22

Table C-18. Pereira 1996 (F Mouse [Study 2]): Dichloroacetic Acid (DCA): Drinking Water. C-23

Table C-19. Pereira et al. 1997 (F Mouse): Dichloroacetic Acid (DCA): Drinking

Water $(\mathrm{I} / \mathrm{P})$............................................................................

Table C-20. Bull et al. 1990 (M Mouse): Dichloroacetic Acid: Drinking Water....C-25

Table C-21. Daniel et al. 1992 (M Mouse): Dichloroacetic Acid: Drinking Water C-26 
Table C-22. NTP 2007b (M \& F Mouse [Study 1]): Dichloroacetic Acid: DermalC-27 Table C-23. NTP 2007b (M Mouse [Study 2]): Dichloroacetic Acid: Dermal ........C-28 Table C-24. NTP 2007b (M Mouse [Study 1]): Dichloroacetic Acid: Drinking Water ..C-29

Table C-25. NTP 2007b (F Mouse [Study 1]): Dichloroacetic Acid: Drinking Water .C-30

Table C-26. NTP 2007b (M Mouse [Study 2]): Dichloroacetic Acid: Drinking Water ..C-31

Table C-27. NTP 2007b (F Mouse [Study 2]): Dichloroacetic Acid: Drinking Water .C-32

Table C-28. NTP 2007b (M Mouse [Study 3]): Dichloroacetic Acid: Drinking Water ..C-33

Table C-29. NTP 2007b (F Mouse [Study 3]): Dichloroacetic Acid: Drinking Water C-34

Table C-30. NTP 2007b (M Mouse [Study 4]): Dichloroacetic Acid: Drinking Water ..C-35

Table C-31. NTP 2007b (F Mouse [Study 4]): Dichloroacetic Acid: Drinking Water

(n)

Table C-32. NTP 2007a (M Mouse): Dibromoacetic Acid: Drinking Water ...........C-37

Table C-33. NTP 2007a (F Mouse): Dibromoacetic Acid: Drinking Water ............C-38

Table C-34. NTP 2007a (M Rat): Dibromoacetic Acid: Drinking Water ................. C-39

Table C-35. NTP 2007a (F Rat): Dibromoacetic Acid: Drinking Water....................-40

Table C-36. NTP 2009 (M Rat): Bromochloroacetic Acid: Drinking Water ...........C-41

Table C-37. NTP 2009 (F Rat): Bromochloroacetic Acid: Drinking Water.............C-42

Table C-38. NTP 2009 (M Mouse): Bromochloroacetic Acid: Drinking Water.....C-43

Table C-39. NTP 2009 (F Mouse): Bromochloroacetic Acid: Drinking Water ......C-44

Table C-40. DeAngelo et al. 1997 (M Rat): Trichloroacetic Acid: Drinking

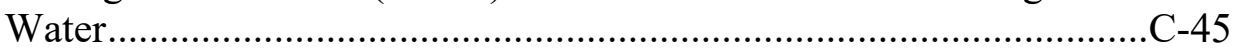

Table C-41. DeAngelo 2008 (M Mouse [Study 1]): Trichloroacetic Acid: Drinking

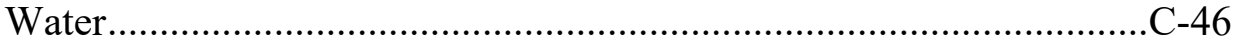

Table C-42. DeAngelo 2008 (M Mouse [Study 2]): Trichloroacetic Acid: Drinking

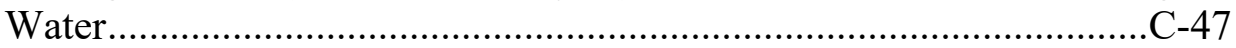

Table C-43. DeAngelo 2008 (M Mouse [Study 3]): Trichloroacetic Acid: Drinking

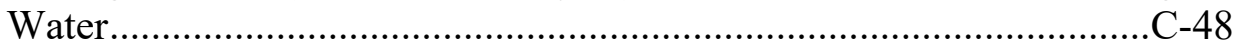

Table C-44. Herren-Freund et al. 1987 (M Mouse): Trichloroacetic Acid: Drinking

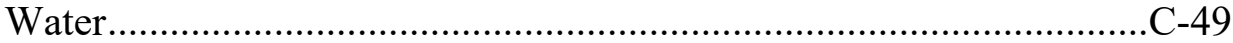

Table C-45. Herren-Freund et al. 1987 (M Mouse): Trichloroacetic Acid: Drinking

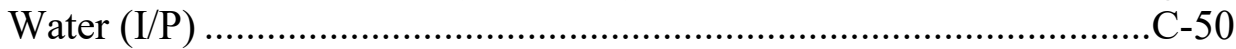

Table C-46. Pereira 1996 (F Mouse [Study 1]): Trichloroacetic Acid (TCA): Drinking Water. .C-51

Table C-47. Pereira 1996 (F Mouse [Study 2]): Trichloroacetic Acid (TCA): Drinking

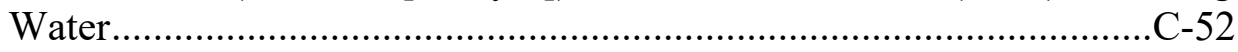

Table C-48. Pereira et al. 1997 (F Mouse): TCA: Drinking Water (I/P),................. -53 Table C-49. Bull et al. 1990 (M Mouse): Trichloroacetic Acid: Drinking Water ...C-54 Table C-50. Von Tungeln et al. 2002 (M+F Mouse [Study 1]): Trichloroacetic Acid: IP Injection. C-55 
Table C-51. Von Tungeln et al. 2002 (M+F Mouse [Study 2]): Trichloroacetic Acid: IP Injection. ..C-56

Table C-52. NTP 2015 (M Rat): Bromodichloroacetic Acid: Drinking Water .......C-57

Table C-53. NTP 2015 (F Rat): Bromodichloroacetic Acid: Drinking Water .........C-58

Table C-54. NTP 2015 (M Mouse): Bromodichloroacetic Acid: Drinking Water..C-59

Table C-55. NTP 2015 (F Mouse): Bromodichloroacetic Acid: Drinking Water ...C-60

Table C-56. Liver Tumors ..............................................................................6-

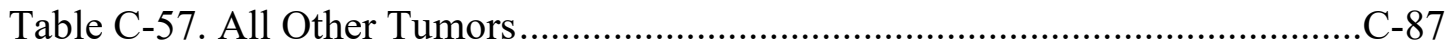

Table C-58. Transgenic Studies......................................................................... 100

Table C-59. Initiation-Promotion Studies........................................................... 106 


\section{C.1. Monochloroacetic Acid: Study Quality for Animal Studies}

\section{Table C-1. NTP 1992 (M Mouse): Monochloroacetic Acid: Gavage}

\begin{tabular}{|c|c|}
\hline Study Utility Domain and Question & Rating and Rationale \\
\hline \multicolumn{2}{|l|}{ Study design } \\
\hline Randomization & $\begin{array}{l}+++ \\
\text { Animals were randomly assigned to exposure groups. }\end{array}$ \\
\hline Controls & $\begin{array}{l}+++ \\
\text { Concurrent vehicle controls were used. }\end{array}$ \\
\hline Historical data & Yes \\
\hline Animal model (sensitivity) & $\begin{array}{l}+++ \\
\text { Both sexes of non-transgenic animals were used. }\end{array}$ \\
\hline Statistical power (sensitivity) & $\begin{array}{l}+++ \\
\text { Large numbers of animals }(50) \text { were used for each group. }\end{array}$ \\
\hline \multicolumn{2}{|l|}{ Exposure } \\
\hline Chemical characterization & $\begin{array}{l}+++ \\
\text { Chemical purity and stability were well characterized. }\end{array}$ \\
\hline Dosing regimen & $\begin{array}{l}++^{\mathrm{a}} \\
\text { There was no significant difference in survival and body weight was not significantly } \\
\text { decreased. There was a significant increase in neoplasm incidence. }\end{array}$ \\
\hline Exposure duration (sensitivity) & $\begin{array}{l}+++ \\
\text { A near life-span duration (106 weeks) was used. }\end{array}$ \\
\hline Dose-response (sensitivity) & $\begin{array}{l}++^{\mathrm{a}} \\
\text { Three exposure levels were used that spanned a range of } 20 \text {-fold. }\end{array}$ \\
\hline \multicolumn{2}{|l|}{ Outcome } \\
\hline Pathology & $\begin{array}{l}\text { All major organs and gross lesions were histologically evaluated and findings were } \\
\text { verified by an independent pathologist. }\end{array}$ \\
\hline Consistency between groups & $\begin{array}{l}+++ \\
\text { All groups were treated the same. }\end{array}$ \\
\hline Study duration (sensitivity) & $\begin{array}{l}+++ \\
\text { A near life-span duration (106 weeks) was used. }\end{array}$ \\
\hline \multicolumn{2}{|l|}{ Confounding } \\
\hline Confounding & $\begin{array}{l}++ \pm^{\mathrm{b}} \\
\text { Drinking water contained } 44.7 \mathrm{ug} / 1 \text { of dihaloacetic acids and } 3.8 \mathrm{ug} / \mathrm{l} \text { of dibromoacetic } \\
\text { acid. }\end{array}$ \\
\hline \multicolumn{2}{|l|}{ Reporting and analysis } \\
\hline Reporting data and statistics & $\begin{array}{l}+++ \\
\text { Appropriate statistical analyses were reported. }\end{array}$ \\
\hline Combining lesions & $\begin{array}{l}+++ \\
\text { Tumor combinations were appropriate. }\end{array}$ \\
\hline
\end{tabular}

Overall utility: +++. Large numbers of animals per group were used in both sexes and were continuously monitored for disease. Three dose levels spanning a range of 200 -fold were used. Lesions and all major organs were histologically evaluated and statistics were clearly reported.

aERRATUM: Errors were identified in the Report on Carcinogens Monograph on Haloacetic Acids Found as Water Disinfection By-products. The number of + signs was incorrect in the original table. These errors have been corrected; one + sign was removed.

'ERRATUM: Errors were identified in the Report on Carcinogens Monograph on Haloacetic Acids Found as Water Disinfection By-products. The number of + signs was incorrect in the original table. These errors have been corrected; one + sign was added and underlined. 
Table C-2. NTP 1992 (F Mouse): Monochloroacetic Acid: Gavage

\begin{tabular}{|c|c|}
\hline $\begin{array}{l}\text { Study Utility Domain and } \\
\text { Question }\end{array}$ & Rating and Rationale \\
\hline \multicolumn{2}{|l|}{ Study design } \\
\hline Randomization & $\begin{array}{l}+++ \\
\text { Animals were randomly assigned to exposure groups. }\end{array}$ \\
\hline Controls & $\begin{array}{l}+++ \\
\text { Concurrent vehicle controls were used. }\end{array}$ \\
\hline Historical data & Yes \\
\hline Animal model (sensitivity) & $\begin{array}{l}+++ \\
\text { Both sexes of non-transgenic animals were used. }\end{array}$ \\
\hline Statistical power (sensitivity) & $\begin{array}{l}+++ \\
\text { Large numbers of animals }(50) \text { were used for each group. }\end{array}$ \\
\hline \multicolumn{2}{|l|}{ Exposure } \\
\hline Chemical characterization & $\begin{array}{l}+++ \\
\text { Chemical purity and stability were well characterized. }\end{array}$ \\
\hline Dosing regimen & $\begin{array}{l}+++ \\
\text { There was no significant difference in survival or body weight. There was a } \\
\text { significant increase in neoplasm incidence. }\end{array}$ \\
\hline Exposure duration (sensitivity) & $\begin{array}{l}+++ \\
\text { A near life-span duration (106 weeks) was used. }\end{array}$ \\
\hline Dose-response (sensitivity) & $\begin{array}{l}+++ \\
\text { Three exposure levels were used that spanned a range of } 20 \text {-fold. }\end{array}$ \\
\hline \multicolumn{2}{|l|}{ Outcome } \\
\hline Pathology & $\begin{array}{l}\text { All major organs and gross lesions were histologically evaluated and findings } \\
\text { were verified by an independent pathologist. }\end{array}$ \\
\hline Consistency between groups & $\begin{array}{l}+++ \\
\text { All groups were treated the same. }\end{array}$ \\
\hline Study duration (sensitivity) & $\begin{array}{l}+++ \\
\text { A near life-span duration (106 weeks) was used. }\end{array}$ \\
\hline \multicolumn{2}{|l|}{ Confounding } \\
\hline Confounding & $\begin{array}{l}\text { Drinking water contained } 44.7 \mathrm{ug} / \mathrm{l} \text { of dihaloacetic acids and } 3.8 \mathrm{ug} / \mathrm{l} \text { of } \\
\text { dibromoacetic acid. }\end{array}$ \\
\hline \multicolumn{2}{|l|}{ Reporting and analysis } \\
\hline Reporting data and statistics & $\begin{array}{l}+++ \\
\text { Appropriate statistical analyses were reported. }\end{array}$ \\
\hline Combining lesions & $\begin{array}{l}+++ \\
\text { Tumor combinations were appropriate. }\end{array}$ \\
\hline
\end{tabular}

Overall utility: +++. Large numbers of animals per group were used in both sexes and were continuously monitored for disease. Three dose levels spanning a range of 200 -fold were used. Lesions and all major organs were histologically evaluated and statistics were clearly reported. 
Table C-3. NTP 1992 (M Rat): Monochloroacetic Acid: Gavage

\begin{tabular}{|c|c|}
\hline $\begin{array}{c}\text { Study Utility Domain and } \\
\text { Question }\end{array}$ & Rating and Rationale \\
\hline \multicolumn{2}{|l|}{ Study design } \\
\hline Randomization & $\begin{array}{l}+++ \\
\text { Animals were randomly assigned to exposure groups. }\end{array}$ \\
\hline Controls & $\begin{array}{l}+++ \\
\text { Concurrent vehicle controls were used. }\end{array}$ \\
\hline Historical data & Yes \\
\hline Animal model (sensitivity) & $\begin{array}{l}++ \\
\text { Both sexes of non-transgenic animals were used and the strain is in common } \\
\text { use. Rats were more sensitive to monochloroacetic acid non-neoplastic effects, } \\
\text { causing death and cardiomyopathy during the short term studies, compared to } \\
\text { mice and so their dose levels were much lower. }\end{array}$ \\
\hline Statistical power (sensitivity) & $\begin{array}{l}+++ \\
\text { The numbers of animals ( } 50 \text { at } 104 \text { weeks and } 10 \text { at } 6 \text { and } 15 \text { months) varied } \\
\text { considerably for each group depending on the time of sacrifice. }\end{array}$ \\
\hline \multicolumn{2}{|r|}{ 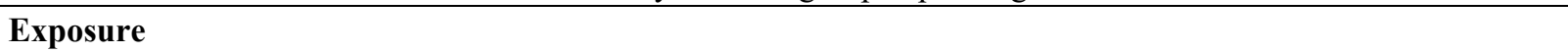 } \\
\hline Chemical characterization & $\begin{array}{l}+++ \\
\text { Chemical purity and stability were well characterized. }\end{array}$ \\
\hline Dosing regimen & $\begin{array}{l}++ \\
\text { There was a significant decrease in survival but not in body weight. There was } \\
\text { no significant increase in neoplasm incidence. Rats were more sensitive to } \\
\text { non-neoplastic effects, causing death and cardiomyopathy during the short } \\
\text { term studies, compared to mice and so their dose levels were much lower. }\end{array}$ \\
\hline Exposure duration (sensitivity) & $\begin{array}{l}+++ \\
\text { A near life-span duration (104 weeks) was used. }\end{array}$ \\
\hline Dose-response (sensitivity) & $\begin{array}{l}++ \\
\text { Two exposure levels were used that spanned a range of } 2 \text {-fold, making the } \\
\text { detection of a dose response limited. }\end{array}$ \\
\hline \multicolumn{2}{|r|}{ ( } \\
\hline Pathology & $\begin{array}{l}\text { All major organs and gross lesions were histologically evaluated and findings } \\
\text { were verified by an independent pathologist. }\end{array}$ \\
\hline Consistency between groups & $\begin{array}{l}+++ \\
\text { All groups were treated the same. }\end{array}$ \\
\hline Study duration (sensitivity) & $\begin{array}{l}+++ \\
\text { A near life-span duration (104 weeks) was used. }\end{array}$ \\
\hline \multicolumn{2}{|l|}{ Confounding } \\
\hline Confounding & $\begin{array}{l}+++ \\
\text { The test agent was well characterized, animals were treated the same between } \\
\text { groups, and were continually monitored for infectious diseases. }\end{array}$ \\
\hline \multicolumn{2}{|l|}{ Reporting and analysis } \\
\hline Reporting data and statistics & $\begin{array}{l}+++ \\
\text { Appropriate statistical analyses were reported. }\end{array}$ \\
\hline Combining lesions & $\begin{array}{l}+++ \\
\text { Tumor combinations were appropriate. }\end{array}$ \\
\hline
\end{tabular}

Overall utility: ++ . The study was well conducted to rule out confounding and with a strong power to detect tumor induction. However, only two exposed dose levels were tested, which limit the detection of dose response relationships. Rats were more sensitive to non-neoplastic effects, causing death and cardiomyopathy during the short term studies, compared to mice and so their dose levels were much lower. 
Table C-4. NTP 1992 (F Rat): Monochloroacetic Acid: Gavage

\begin{tabular}{|c|c|}
\hline $\begin{array}{l}\text { Study Utility Domain and } \\
\text { Question }\end{array}$ & Rating and Rationale \\
\hline \multicolumn{2}{|l|}{ Study design } \\
\hline Randomization & $\begin{array}{l}+++ \\
\text { Animals were randomly assigned to exposure groups. }\end{array}$ \\
\hline Controls & $\begin{array}{l}+++ \\
\text { Concurrent vehicle controls were used. }\end{array}$ \\
\hline Historical data & Yes \\
\hline Animal model (sensitivity) & $\begin{array}{l}\text { Both sexes of non-transgenic animals were used and the strain is in common } \\
\text { use. Rats were more sensitive to monochloroacetic acid non-neoplastic effects, } \\
\text { causing death and cardiomyopathy during the short term studies, compared to } \\
\text { mice and so their dose levels were much lower. }\end{array}$ \\
\hline Statistical power (sensitivity) & $\begin{array}{l}\text { The numbers of animals ( } 50 \text { at } 104 \text { weeks and } 10 \text { at } 6 \text { and } 15 \text { months) varied } \\
\text { considerably for each group depending on the time of sacrifice. }\end{array}$ \\
\hline \multicolumn{2}{|l|}{ Exposure } \\
\hline Chemical characterization & $\begin{array}{l}+++ \\
\text { Chemical purity and stability were well characterized. }\end{array}$ \\
\hline Dosing regimen & $\begin{array}{l}++ \\
\text { There was a significant decrease in survival but not in body weight. There was } \\
\text { no significant increase in neoplasm incidence, but there was a significant } \\
\text { increase in preneoplasm incidence. Rats were more sensitive to non-neoplastic } \\
\text { effects, causing death and cardiomyopathy during the short term studies, } \\
\text { compared to mice and so their dose levels were much lower. }\end{array}$ \\
\hline Exposure duration (sensitivity) & $\begin{array}{l}+++ \\
\text { A near life-span duration (104 weeks) was used. }\end{array}$ \\
\hline Dose-response (sensitivity) & $\begin{array}{l}\text { Two exposure levels were used that spanned a range of } 2 \text {-fold, making the } \\
\text { detection of a dose response limited. }\end{array}$ \\
\hline \multicolumn{2}{|l|}{ Outcome } \\
\hline Pathology & $\begin{array}{l}\text { All major organs and gross lesions were histologically evaluated and findings } \\
\text { were verified by an independent pathologist. }\end{array}$ \\
\hline Consistency between groups & $\begin{array}{l}+++ \\
\text { All groups were treated the same. }\end{array}$ \\
\hline Study duration (sensitivity) & $\begin{array}{l}+++ \\
\text { A near life-span duration (104 weeks) was used. }\end{array}$ \\
\hline \multicolumn{2}{|l|}{ Confounding } \\
\hline Confounding & $\begin{array}{l}\text { The test agent was well characterized, animals were treated the same between } \\
\text { groups, and were continually monitored for infectious diseases. }\end{array}$ \\
\hline \multicolumn{2}{|l|}{ Reporting and analysis } \\
\hline Reporting data and statistics & $\begin{array}{l}+++ \\
\text { Appropriate statistical analyses were reported. }\end{array}$ \\
\hline Combining lesions & $\begin{array}{l}+++ \\
\text { Tumor combinations were appropriate. }\end{array}$ \\
\hline
\end{tabular}

Overall utility: ++. The study was well conducted to rule out confounding and with a strong power to detect tumor induction. However, only two exposed dose levels were tested, which limit the detection of dose response relationships. Rats were more sensitive to non-neoplastic effects, causing death and cardiomyopathy during the short term studies, compared to mice and so their dose levels were much lower. 
Table C-5. DeAngelo et al. 1997 (M Rat): Monochloroacetic Acid: Drinking Water

\section{Study Utility Domain and Question \\ Rating and Rationale}

\section{Study design}

Randomization

Not reported.

Controls

$+++$

Concurrent vehicle controls of sodium chloride at equal molar concentrations as the trichloroacetic acid high dose group were used.

Historical data
Animal model (sensitivity)
Statistical power (sensitivity)
Exposure
Chemical characterization
Dosing regimen
Exposure duration (sensitivity)
Dose-response (sensitivity)

Yes

$++$

Only males of non-transgenic animals were used.

$+++$

Moderate numbers of animals (29-32) were used for each group.

$+++$

Chemical purity and stability were well characterized.

$+++$

There was no significant difference in survival, but there was a significant decrease in body weight that required dose reduction. There was no significant difference in neoplasm incidence.

$+++$

A near life-span duration (104 weeks) was used.

$+++$

Three exposure levels were used that spanned a range of 100 -fold.

\section{Outcome}

Pathology

$+++$

Full necropsies with histological evaluations were performed.

Consistency between groups $\quad+++$

Groups were not reported to have been treated differently.

Study duration (sensitivity) +++

A near life-span duration (104 weeks) was used.

\section{Confounding}

Confounding

$+++$

The rats were confirmed pathogen free and the chemical purity and stability were confirmed.

\section{Reporting and analysis}

Reporting data and statistics

$+++$

Appropriate statistical analyses were reported.

Combining lesions

$+++$

Lesions were reported, which included liver hyperplasia, adenomas, and carcinomas. The authors felt the hyperplasia were preneoplastic.

Overall utility: +++. A well conducted study on almost all aspects, but it only involved male rats. 


\section{C.2. Monoiodoacetic Acid: Study Quality for Animal Studies}

\section{Table C-6. Gwynn and Salaman 1953 (NR Mouse): Iodoacetic Acid: Dermal}

\begin{tabular}{ll}
\multicolumn{1}{c}{$\begin{array}{c}\text { Study Utility Domain and } \\
\text { Question }\end{array}$} & \multicolumn{1}{c}{ Rating and Rationale } \\
\hline Study design & Not reported. \\
Randomization & +++ \\
Controls & A concurrent negative control of acetic acid was used. \\
& No \\
Historical data & + \\
Animal model (sensitivity) & The sex of the mice were not reported. The strain of mouse is unfamiliar. \\
& + \\
Statistical power (sensitivity) & + \\
& Small and insufficient numbers of animals (12) were used for each group. \\
\hline
\end{tabular}

\section{Exposure}

Chemical characterization

Chemical purity and stability were not reported.

Dosing regimen

$+++$

There was no significant difference in survival and body weight was not reported. There was a significant increase in neoplasm incidence.

Exposure duration (sensitivity) +++

A short duration was used (27 weeks), but initiation/promotion studies are normally short.

Dose-response (sensitivity)

$+$

One exposure level was used. Preliminary tests showed this to be the maximumly tolerated dose without causing crusting or ulceration. dose was the MTD, not to cause crusting or ulceration. [1.4\% (average) was calculated by NTP from a reported $\mathrm{M} / 20-\mathrm{M} / 10$ solution, i.e., $1 / 20$ to $1 / 10$ of a molar solution. Based on a MW of 185.95 , it comes to $0.92975-1.8595 \%$, averaging to $1.4 \%$.]

Vehicle control (acetone):

21 days after $0.15 \%$ DMBA, acetone was administered $(2 / \mathrm{wk} \times 12 \mathrm{wk}$; $1 / \mathrm{wk} \times 15 \mathrm{wk})$.

Acetic acid negative control $(0.9 \%$ acetic acid $)$ :

39 days after $0.1 \%$ DMBA, $0.9 \%$ acetic acid was administered ( $1 / \mathrm{wk} \times 20 \mathrm{wk})$. Reported at $\mathrm{M} / 1-\mathrm{M} / 5$ solution, i.e., $1 / 10$ to $1 / 5$ of a molar solution. Based on a MW of 60.05 , it comes to $0.6-1.2 \%$, averaging to $0.9 \%$.

\section{Outcome}

Pathology

$+$

Not reported and necropsies were not likely to have occurred beyond histological examination of the skin tumors.

Consistency between groups

Not reported.

Study duration (sensitivity)

A short duration was used (30 weeks), but initiation/promotion studies are usually short. 
RoC Monograph on Haloacetic Acids

\begin{tabular}{ll}
\hline \multicolumn{1}{c}{$\begin{array}{c}\text { Study Utility Domain and } \\
\text { Question }\end{array}$} & \multicolumn{1}{c}{ Rating and Rationale } \\
\hline Confounding & + \\
Confounding & $\begin{array}{l}\text { Disease surveillance, animal husbandry, or chemical characterization were not } \\
\text { reported. }\end{array}$ \\
\hline
\end{tabular}

\section{Reporting and analysis}

Reporting data and statistics

Not reported.

Combining lesions

$+++$

Only benign papillomas were reported.

Overall utility: + . The chemicals were not characterized and purity was not reported. The sex of the animals were not reported and only a single dose level was tested on a very low number of animals per group. Histology of the neoplasms were carried out, but the skin tumors were classified as benign papillomas based on their appearance "macroscopically." Statistical significance was not calculated. 


\section{C.3. Dichloroacetic Acid: Study Quality for Animal Studies}

\section{Table C-7. DeAngelo et al. 1996 (M Rat [Study 1]): Dichloroacetic Acid: Drinking Water}

\begin{tabular}{ll}
\multicolumn{1}{c}{\begin{tabular}{c}
\multicolumn{1}{c}{ Study Utility Domain and } \\
Question
\end{tabular}} & \multicolumn{1}{c}{ Rating and Rationale } \\
\hline $\begin{array}{l}\text { Study design } \\
\text { Randomization }\end{array}$ & $\begin{array}{l}\text { Not reported. } \\
\text { Controls }\end{array}$ \\
& $\begin{array}{l}\text { Concurrent vehicle controls of sodium chloride at equal molar concentrations } \\
\text { as the high dose were used. }\end{array}$ \\
& Yes \\
Historical data & ++ \\
Animal model (sensitivity) & Only males of non-transgenic animals were used. \\
& ++ \\
Statistical power (sensitivity) & $\begin{array}{l}\text { The exact number of animals was not clearly reported. It appears to have been } \\
\text { between 21 to 33 for each group. }\end{array}$
\end{tabular}

\section{Exposure}

Chemical characterization

$+++$

Chemical purity and stability were well characterized.

Dosing regimen

$+++$

There were no significant differences in survival, but the high dose group was sacrificed early because of peripheral neuropathy and body weight was not significantly different. There was a significant increase in neoplasm incidence.

Exposure duration (sensitivity) $\quad+++$

A near life-span duration (100 weeks) was used. The high dose group was stopped at 60 weeks due to peripheral neuropathy and was not included in the study results.

Dose-response (sensitivity) $++$

Two exposure levels were effectively used that spanned a range of 10 -fold. The original high dose was 100-fold higher than the low exposure level, but caused toxicity, requiring dose reduction and were not reported.

\section{Outcome \\ Pathology \\ Consistency between groups}

Study duration (sensitivity)
$++$

Only the liver was histologically examined.

$++$

The high dose group had their dose reduced three times due to irreversible peripheral neuropathy and they were all scarified at 60 weeks, while other dose groups were scarified at 100 weeks. They also have 5 rats undergo full necropsies, with histological evaluations of all major organs. However, the high dose group results were not reported.

$+++$

A near life-span duration (100 weeks) was used. The high dose group was stopped at 60 weeks due to peripheral neuropathy and was not included in the study results. 
RoC Monograph on Haloacetic Acids

\begin{tabular}{ll}
\hline \multicolumn{1}{c}{$\begin{array}{c}\text { Study Utility Domain and } \\
\text { Question }\end{array}$} & \multicolumn{1}{c}{ Rating and Rationale } \\
\hline Confounding & ++ \\
Confounding & $\begin{array}{l}\text { Animals started out viral free, but continual disease surveillance was not } \\
\text { reported. The high dose group was treated differently but results from that } \\
\text { group were not reported. }\end{array}$ \\
\hline
\end{tabular}

\section{Reporting and analysis}

Reporting data and statistics

$+++$

Appropriate statistical analyses were reported.

Combining lesions

$+++$

Lesions were reported, which included liver hyperplasia, adenomas, and carcinomas. The authors felt the hyperplasia were preneoplastic.

Overall utility: ++. Animals were certified pathogen free, though were not reported to be continuously monitored for disease. Only two exposed dose levels were effectively reported and only males were tested. The duration was near life-span and historical controls were considered during data analysis. However, only liver lesion incidences were reported. 
Table C-8. DeAngelo et al. 1996 (M Rat [Study 2]): Dichloroacetic Acid: Drinking Water

\begin{tabular}{|c|c|}
\hline $\begin{array}{l}\text { Study Utility Domain and } \\
\text { Question }\end{array}$ & Rating and Rationale \\
\hline \multicolumn{2}{|l|}{ Study design } \\
\hline Randomization & Not reported. \\
\hline Controls & $\begin{array}{l}\text { Concurrent controls were exposed to deionized water (vehicle). } \mathrm{NaCl} \text { was } \\
\text { omitted from the water of control animals because no significant effects such } \\
\text { as differences in tumor incidence or altered water consumption was noted in } \\
\text { the previous bioassay at } 100 \text { weeks exposure. }\end{array}$ \\
\hline Historical data & Yes \\
\hline Animal model (sensitivity) & $\begin{array}{l}++ \\
\text { Only males of non-transgenic animals were used. }\end{array}$ \\
\hline Statistical power (sensitivity) & $\begin{array}{l}\text { The exact number of animals was not clearly reported. It appears to have been } \\
\text { between } 27 \text { to } 28 \text { for each group. }\end{array}$ \\
\hline \multicolumn{2}{|l|}{ Exposure } \\
\hline Chemical characterization & $\begin{array}{l}++ \\
\text { Chemical purity and stability were well characterized. }\end{array}$ \\
\hline Dosing regimen & $\begin{array}{l}\text { At sacrifice, the mean body weight of the animals }(1.6 \mathrm{~g} / \mathrm{l}) \text { was significantly } \\
\text { reduced to } 73 \% \text { of the control value. }\end{array}$ \\
\hline Exposure duration (sensitivity) & $\begin{array}{l}\text { A near life-span duration (103 weeks exposure period) was used. The high } \\
\text { dose group }(2.5 \mathrm{~g} / \mathrm{l}) \text { DCA was lowered to } 1.5 \mathrm{~g} / \mathrm{l} \text { at eight weeks exposure and } \\
\text { to } 1.0 \mathrm{~g} / \mathrm{l} \text { at } 26 \text { weeks exposure. A mean daily exposure concentration was } \\
\text { reported as } 1.6 \mathrm{~g} / 1 \text {. }\end{array}$ \\
\hline Dose-response (sensitivity) & $\begin{array}{l}+ \\
\text { One exposure level was used, which cause toxicity, requiring dose reduction. }\end{array}$ \\
\hline \multicolumn{2}{|r|}{ e } \\
\hline Pathology & No indication that a full necropsy was done. \\
\hline Consistency between groups & $\begin{array}{l}++ \\
103 \text { wk bioassay grossly evaluated liver, kidneys, spleen, testes, thyroid, } \\
\text { stomach, rectum, duodenum, ileum, jejunum, colon, and urinary bladder and } \\
\text { microscopically evaluated grossly detected lesions. }\end{array}$ \\
\hline Study duration (sensitivity) & $\begin{array}{l}+++ \\
\text { A near life-span duration (103 weeks exposure period) was used. }\end{array}$ \\
\hline \multicolumn{2}{|l|}{ Confounding } \\
\hline Confounding & $\begin{array}{l}\text { Animals started out viral free, but continual disease surveillance was not } \\
\text { reported. The } 100 \text { week and the } 103 \text { week DeAngelo } 1996 \text { studies were done } \\
\text { in two different laboratories but were reported in the same publication; it is } \\
\text { unclear if the same animal care procedures were performed at both locations. }\end{array}$ \\
\hline \multicolumn{2}{|l|}{ Reporting and analysis } \\
\hline Reporting data and statistics & $\begin{array}{l}+++ \\
\text { Appropriate statistical analyses were reported. }\end{array}$ \\
\hline Combining lesions & $\begin{array}{l}\text { Liver lesions were reported, which included liver hyperplasia, adenomas, and } \\
\text { carcinomas. }\end{array}$ \\
\hline
\end{tabular}

Overall utility: ++. Animals were certified pathogen free, though were not reported to be continuously monitored for disease. Only one exposed dose level was tested and only males were tested. The duration was near life-span and historical controls were considered during data analysis. However, only liver lesion incidences were reported. 
Table C-9. Richmond et al. 1995 (M Rat): Dichloroacetic Acid: Drinking Water

\begin{tabular}{ll}
\multicolumn{1}{c}{$\begin{array}{c}\text { Study Utility Domain and } \\
\text { Question }\end{array}$} & \multicolumn{1}{c}{ Rating and Rationale } \\
\hline $\begin{array}{ll}\text { Study design } \\
\text { Randomization }\end{array}$ & +++ \\
& Animals were randomly assigned to exposure groups. \\
Controls & +++ \\
& Concurrent vehicle controls of $2 \mathrm{~g} / 1$ of sodium chloride were used. \\
Historical data & No \\
Animal model (sensitivity) & ++ \\
& Only males of non-transgenic animals were used. \\
Statistical power (sensitivity) & ++ \\
& The number of animals was sufficient (23-29) for each group. \\
\hline
\end{tabular}

\section{Exposure}

Chemical characterization

Chemical purity and stability were not reported.

Dosing regimen

$$
+++
$$

There was no clear significant difference in survival and body weight was not reported. There was a non-significant increase in neoplasm incidence.

Exposure duration (sensitivity)

$+++$

Near life-span duration (104 weeks) were used.

Dose-response (sensitivity)

$+++$

Three exposure levels were used that spanned a range of 50 -fold.

\section{Outcome}

Pathology

$++$

Consistency between groups

Only the liver was histologically examined.

All groups were treated the same except for the last time point for sacrifice was 60 weeks for the $2.4 \mathrm{~g} / \mathrm{l}$ group and 104 weeks for all other groups. This was because of toxicity, causing tumors and hind limb paralysis.

Study duration (sensitivity) $\quad+++$

Near life-span and less than near life-span durations (104 weeks) were used.

\section{Confounding}

Confounding

$+$

Neither disease surveillance, nor chemical purity or characterization was reported. Neither survival nor body weight was clearly reported.

\section{Reporting and analysis}

Reporting data and statistics

$++$

Statistical significance was reported for neoplasm incidence, though no analysis of body weight changes or differences in survival were reported and body weights were not reported at all and survival was not clearly reported but was estimated by NTP to not have been greatly different.

Combining lesions $+++$

Total proliferative lesions were reported which included liver hyperplastic nodules, hepatocellular adenomas, and hepatocellular carcinomas.

Overall utility: ++. The chemical and animal husbandry conditions were not characterized and only a low to moderate number of males rats were tested. However, they were tested at three dose levels spanning a 50-fold range and the exposure duration was near life-span for all but the high dose group. Survival and body weights were not clearly reported and only the liver was histologically evaluated. 
Table C-10. DeAngelo et al. 1991 (M Mouse [Study 1]): Dichloroacetic Acid: Drinking Water

\begin{tabular}{ll}
\multicolumn{1}{c}{$\begin{array}{c}\text { Study Utility Domain and } \\
\text { Question }\end{array}$} & \multicolumn{1}{c}{ Rating and Rationale } \\
\hline Study design & \\
Randomization & +++ \\
& $\begin{array}{l}\text { Animals were randomly assigned to exposure groups. } \\
+++\end{array}$ \\
Controls & Concurrent vehicle controls of $2 \mathrm{~g} / 1$ of sodium chloride at equal molar \\
& concentrations as the high exposure dose level were used. \\
& No \\
Historical data & ++ \\
Animal model (sensitivity) & Only males of non-transgenic animals were used. \\
& ++ \\
Statistical power (sensitivity) & + Sufficient numbers of animals $(27-30)$ were used for each group. \\
&
\end{tabular}

\section{Exposure}

Chemical characterization

$+++$

Dosing regimen

Chemical purity and stability were well characterized.

There

There was no significant difference in survival and there was a significant decrease in body weight. There was a significant increase in neoplasm incidence.

Exposure duration (sensitivity) $+++$

A less than life-span durations (60 weeks for the high exposure group and 75 weeks for the other exposure group) were used.

Dose-response (sensitivity) $+++$

Three exposure levels were used that spanned a range of 100 -fold.

\section{Outcome}

Pathology

$++$

Consistency between groups

Only a select number of organs were examined and only lesions or tissues with lesions were histologically evaluated.

\section{$++$}

Different numbers of animals in each treatment group were tested at either 60 weeks or 75 weeks of exposure.

Study duration (sensitivity) $\quad+++$

A less than life-span durations ( 60 weeks for the high exposure group and 75 weeks for the other exposure group) were used.

\section{Confounding}

Confounding
$++$

The chemical was well characterized, but disease surveillance was not reported and different numbers of animals were sacrificed at different times. Further, only a select few organs were involved in the necropsy. The high dose group drank $60 \%$ less water than controls near the last third of the study and so the mean daily dose was decreased from $573 \mathrm{mg} / \mathrm{kg} /$ day to 387 . The medium and low dose had not difference in water intake compared to controls.

\section{Reporting and analysis}

Reporting data and statistics

Combining lesions
$+++$

Appropriate statistical analyses were reported.

$+++$

Only hepatocellular adenomas and carcinomas were combined.

Overall utility: +++. Three dose levels, which spanned a 100-fold range were tested in only males for up to 75 weeks. Only a few select organs were necropsied. 
Table C-11. DeAngelo et al. 1991 (M Mouse [Study 2]): Dichloroacetic Acid: Drinking Water

\begin{tabular}{|c|c|}
\hline $\begin{array}{l}\text { Study Utility Domain and } \\
\text { Question }\end{array}$ & Rating and Rationale \\
\hline \multicolumn{2}{|l|}{ Study design } \\
\hline Randomization & $\begin{array}{l}+++ \\
\text { Animals were randomly assigned to exposure groups. }\end{array}$ \\
\hline Controls & $\begin{array}{l}+++ \\
\text { Concurrent vehicle controls of } 1.5 \mathrm{~g} / \mathrm{l} \text { of acetic acid at equal molar } \\
\text { concentrations as the high exposure dose level were used. }\end{array}$ \\
\hline Historical data & No \\
\hline Animal model (sensitivity) & $\begin{array}{l}++ \\
\text { Only males of non-transgenic animals were used. }\end{array}$ \\
\hline Statistical power (sensitivity) & $\begin{array}{l}+ \\
\text { Small and insufficient numbers of animals }(10-12) \text { were used for each group. }\end{array}$ \\
\hline \multicolumn{2}{|l|}{ Exposure } \\
\hline Chemical characterization & $\begin{array}{l}+++ \\
\text { Chemical purity and stability were well characterized. }\end{array}$ \\
\hline Dosing regimen & $\begin{array}{l}++ \\
\text { There was no significant difference in survival and there was a significant } \\
\text { decrease in body weight. There was a significant increase in neoplasm } \\
\text { incidence. }\end{array}$ \\
\hline Exposure duration (sensitivity) & $\begin{array}{l}+++ \\
\text { A less than life-span durations ( } 60 \text { weeks for the high exposure group and } 75 \\
\text { weeks for the other exposure group) were used. }\end{array}$ \\
\hline Dose-response (sensitivity) & $\begin{array}{l}+ \\
\text { One exposure level was used. }\end{array}$ \\
\hline \multicolumn{2}{|l|}{ Outcome } \\
\hline Pathology & $\begin{array}{l}++ \\
\text { Only a select number of organs were examined and only lesions or tissues with } \\
\text { gross lesions were histologically evaluated. }\end{array}$ \\
\hline Consistency between groups & $\begin{array}{l}+++ \\
\text { Exposed and controls were treated the same. }\end{array}$ \\
\hline Study duration (sensitivity) & $\begin{array}{l}\text { A less than life-span durations ( } 60 \text { weeks for the high exposure group and } 75 \\
\text { weeks for the other exposure group) were used. }\end{array}$ \\
\hline \multicolumn{2}{|l|}{ Confounding } \\
\hline Confounding & $\begin{array}{l}++ \\
\text { The chemical was well characterized, but disease surveillance was not } \\
\text { reported. Further, only a select few organs were involved in the necropsy. The } \\
\text { water intake was significantly lower than controls ( } 69 \% \text { of that in controls), } \\
\text { though the DCA concentration was } 7 \% \text { higher than expected. }\end{array}$ \\
\hline \multicolumn{2}{|l|}{ Reporting and analysis } \\
\hline Reporting data and statistics & $\begin{array}{l}+++ \\
\text { Appropriate statistical analyses were reported. }\end{array}$ \\
\hline Combining lesions & $\begin{array}{l}+++ \\
\text { Only hepatocellular adenomas and carcinomas were combined. }\end{array}$ \\
\hline
\end{tabular}

Overall utility: ++. One dose level was tested in a small number of males for 60 weeks. Only a few select organs were necropsied. 
Table C-12. DeAngelo et al. 1999 (M Mouse): Dichloroacetic Acid: Drinking Water

\begin{tabular}{ll}
\multicolumn{1}{c}{$\begin{array}{c}\text { Study Utility Domain and } \\
\text { Question }\end{array}$} & \multicolumn{1}{c}{ Rating and Rationale } \\
\hline Study design & \\
Randomization & +++ \\
& Animals were randomly assigned to exposure groups. \\
Controls & +++ \\
& Two sets of concurrent vehicle controls were used, one for the $500,1,000$, \\
& 2,000, and 3,500 mg/L groups and one started a month later for the 50 mg/L \\
& group. \\
& No \\
Historical data & ++ \\
Animal model (sensitivity) & Only males of non-transgenic animals were used. \\
& ++ \\
Statistical power (sensitivity) & The numbers of animals (16-53) varied considerably for each group. \\
\end{tabular}

\section{Exposure}

Chemical characterization $\quad+++$

$\begin{array}{ll}\text { Chemical purity and stability were well characterized. } \\ \text { Dosing regimen } & +++ \\ & \text { There was a significant decrease in survival and body weight. There was a } \\ \text { significant increase in neoplasm incidence. }\end{array}$

Exposure duration (sensitivity) $\quad+++$

A near life-span duration (90-100 weeks) was used.

Dose-response (sensitivity) $\quad+++$

Four exposure levels were used that spanned a range of 7-fold.

Outcome
Pathology

Only gross lesions were histologically examined and normal tissue from all major organs was only histologically examined in 5 mice of the high dose group.

Consistency between groups $\quad++$

Only 5 mice from the high dose group had undergone histological examinations of all major organs, while the other groups only had histological examinations of gross lesions.

Study duration (sensitivity) $\quad+++$

A near life-span duration (90-100 weeks) was used.

\section{Confounding}

Confounding

$++$

The mice were initially viral, bacteria, and parasite free, but continual disease surveillance was not reported. All major organs from only 5 mice from the high dose group were histologically evaluated, only gross lesions were histologically evaluated in the other groups.

\section{Reporting and analysis}

Reporting data and statistics

$+++$

Appropriate statistical analyses were reported.

Combining lesions Tumor types were not combined.

Overall utility: ++. Only male mice, initially confirmed pathogen free, were used with differing numbers per group (as low was 16 in the high dose group). Continual disease surveillance was not reported. Multiple dose levels ranging 100-fold, were tested for a near life-span duration. However, only 5 high dose group mice received histological evaluations of all major organs, with histological evaluations of only gross lesions in the other groups. 
Table C-13. Herren-Freund et al. 1987 (M Mouse): Dichloroacetic Acid: Drinking Water

\begin{tabular}{|c|c|}
\hline $\begin{array}{l}\text { Study Utility Domain and } \\
\text { Question }\end{array}$ & Rating and Rationale \\
\hline \multicolumn{2}{|l|}{ Study design } \\
\hline Randomization & Not reported. \\
\hline Controls & $\begin{array}{l}\text { Concurrent vehicle controls of } 2 \mathrm{~g} / \mathrm{l} \text { of sodium chloride to match that found in } \\
\text { exposed groups and a positive control of phenobarbital at } 500 \mathrm{mg} / \mathrm{l} \text { (positive } \\
\text { controls are not reported here) were used. }\end{array}$ \\
\hline Historical data & No \\
\hline Animal model (sensitivity) & $\begin{array}{l}++ \\
\text { Only males of non-transgenic animals were used. }\end{array}$ \\
\hline Statistical power (sensitivity) & $\begin{array}{l}++ \\
\text { Moderate numbers of animals (22-26) were used for each group. }\end{array}$ \\
\hline \multicolumn{2}{|l|}{ Exposure } \\
\hline Chemical characterization & $\begin{array}{l}+++ \\
\text { Chemical purity and stability were well characterized. }\end{array}$ \\
\hline Dosing regimen & $\begin{array}{l}+++ \\
\text { Survival was not reported and body weight was significantly decreased. There } \\
\text { was a significant increase in neoplasm incidence. }\end{array}$ \\
\hline Exposure duration (sensitivity) & $\begin{array}{l}+++ \\
\text { A less than life-span duration (61 weeks) was used. }\end{array}$ \\
\hline Dose-response (sensitivity) & $\begin{array}{l}+ \\
\text { One exposure level was used, so dose response relationships could not be } \\
\text { measured. }\end{array}$ \\
\hline \multicolumn{2}{|l|}{ Outcome } \\
\hline Pathology & $\begin{array}{l}++ \\
\text { Only the liver was histologically examined. }\end{array}$ \\
\hline Consistency between groups & $\begin{array}{l}+++ \\
\text { All groups were treated the same. }\end{array}$ \\
\hline Study duration (sensitivity) & $\begin{array}{l}+++ \\
\text { A less than life-span duration (61 weeks) was used. }\end{array}$ \\
\hline \multicolumn{2}{|l|}{ Confounding } \\
\hline Confounding & $\begin{array}{l}+++ \\
\text { Disease surveillance was not reported, but chemical purity and stability were } \\
\text { tested. }\end{array}$ \\
\hline \multicolumn{2}{|l|}{ Reporting and analysis } \\
\hline Reporting data and statistics & $\begin{array}{l}+++ \\
\text { Appropriate statistical analyses were reported. }\end{array}$ \\
\hline Combining lesions & $\begin{array}{l}+++ \\
\text { Tumor types were not combined. }\end{array}$ \\
\hline
\end{tabular}

Overall utility: ++. The durations were less than near life-span. Only males were tested at a single dose level and only livers were histologically evaluated. 
Table C-14. Herren-Freund et al. 1987 (M Mouse): Dichloroacetic Acid: Drinking Water (Initiation-promotion)

\begin{tabular}{|c|c|}
\hline $\begin{array}{l}\text { Study Utility Domain and } \\
\text { Question }\end{array}$ & Rating and Rationale \\
\hline \multicolumn{2}{|l|}{ Study design } \\
\hline Randomization & Not reported. \\
\hline Controls & $\begin{array}{l}\text { Concurrent vehicle controls of } 2 \mathrm{~g} / \mathrm{l} \text { of sodium chloride to match that found in } \\
\text { exposed groups and a positive control of phenobarbital at } 500 \mathrm{mg} / 1 \text { (positive } \\
\text { controls are not reported here) were used. }\end{array}$ \\
\hline Historical data & No \\
\hline Animal model (sensitivity) & $\begin{array}{l}++ \\
\text { Only males of non-transgenic animals were used. }\end{array}$ \\
\hline Statistical power (sensitivity) & $\begin{array}{l}++ \\
\text { Moderate numbers of animals }(22-26) \text { were used for each group. }\end{array}$ \\
\hline \multicolumn{2}{|l|}{ Exposure } \\
\hline Chemical characterization & $\begin{array}{l}+++ \\
\text { Chemical purity and stability were well characterized. }\end{array}$ \\
\hline Dosing regimen & $\begin{array}{l}+++ \\
\text { Survival was not reported and body weight was significantly decreased. There } \\
\text { was a significant increase in neoplasm incidence. }\end{array}$ \\
\hline Exposure duration (sensitivity) & $\begin{array}{l}+++ \\
\text { A less than life-span duration (61 weeks) was used. }\end{array}$ \\
\hline Dose-response (sensitivity) & $\begin{array}{l}+ \\
\text { Two exposure levels were used which spanned a range of } 2.5 \text {-fold. }\end{array}$ \\
\hline \multicolumn{2}{|l|}{ Outcome } \\
\hline Pathology & $\begin{array}{l}++ \\
\text { Only the liver was histologically examined. }\end{array}$ \\
\hline Consistency between groups & $\begin{array}{l}+++ \\
\text { All groups were treated the same. }\end{array}$ \\
\hline Study duration (sensitivity) & $\begin{array}{l}+++ \\
\text { A less than life-span duration (61 weeks) was used. }\end{array}$ \\
\hline \multicolumn{2}{|l|}{ Confounding } \\
\hline Confounding & $\begin{array}{l}+++ \\
\text { Disease surveillance was not reported, but chemical purity and stability were } \\
\text { tested. }\end{array}$ \\
\hline \multicolumn{2}{|l|}{ Reporting and analysis } \\
\hline Reporting data and statistics & $\begin{array}{l}+++ \\
\text { Appropriate statistical analyses were reported. }\end{array}$ \\
\hline Combining lesions & $\begin{array}{l}+++ \\
\text { Tumor types were not combined. }\end{array}$ \\
\hline
\end{tabular}

Overall utility: ++. The duration was less than near life-span. Only males were tested at two narrow dose levels and only livers were histologically evaluated. 
Table C-15. Wood et al. 2015 (M Mouse): Dichloroacetic Acid: Drinking Water

\begin{tabular}{|c|c|}
\hline $\begin{array}{l}\text { Study Utility Domain and } \\
\text { Question }\end{array}$ & Rating and Rationale \\
\hline \multicolumn{2}{|l|}{ Study design } \\
\hline Randomization & Not reported. \\
\hline Controls & $\begin{array}{l}+++ \\
\text { Concurrent vehicle controls were used. }\end{array}$ \\
\hline Historical data & No \\
\hline Animal model (sensitivity) & $\begin{array}{l}+++ \\
\text { Both sexes of non-transgenic animals were used and the strain is in common } \\
\text { use. }\end{array}$ \\
\hline Statistical power (sensitivity) & $\begin{array}{l}++ \\
\text { Moderate numbers of animals (27) were used for each group, though the } \\
\text { original number of animals at the start of the study were not reported. }\end{array}$ \\
\hline \multicolumn{2}{|l|}{ Exposure } \\
\hline Chemical characterization & $\begin{array}{l}++ \\
\text { Purity was not reported. Stability had been shown previously in stock drinking } \\
\text { water over } 8-12 \text { days, while bottles were changed twice a week. }\end{array}$ \\
\hline Dosing regimen & $\begin{array}{l}\text { There was no significant difference in survival, but there was a significant } \\
\text { decrease in body weight. There was a significant increase in neoplasm } \\
\text { incidence. }\end{array}$ \\
\hline Exposure duration (sensitivity) & $\begin{array}{l}++ \\
\text { Exposure duration was short (10 weeks), though the observation duration was } \\
\text { near life-span ( } 94 \text { weeks). }\end{array}$ \\
\hline Dose-response (sensitivity) & $\begin{array}{l}+++ \\
\text { Three exposure levels were used that spanned a range of } 3.5 \text {-fold. These were } \\
\text { based on previous chronic studies in the same strain of male mice which were } \\
\text { estimated to be } 20,000-30,000 \text { times greater than those in normal tap water. }\end{array}$ \\
\hline \multicolumn{2}{|r|}{ e } \\
\hline Pathology & $\begin{array}{l}+ \\
\text { Only livers were examined. Even gross examination of other organs were not } \\
\text { reported. }\end{array}$ \\
\hline Consistency between groups & $\begin{array}{l}+++ \\
\text { Groups were not reported to have been treated differently. }\end{array}$ \\
\hline Study duration (sensitivity) & $\begin{array}{l}+++ \\
\text { A near life-span duration ( } 94 \text { weeks) was used. }\end{array}$ \\
\hline \multicolumn{2}{|l|}{ Confounding } \\
\hline Confounding & $\begin{array}{l}++ \\
\text { Continual disease surveillance was not reported. }\end{array}$ \\
\hline \multicolumn{2}{|l|}{ Reporting and analysis } \\
\hline Reporting data and statistics & $\begin{array}{l}+++ \\
\text { Appropriate statistical analyses were reported. }\end{array}$ \\
\hline Combining lesions & $\begin{array}{l}+++ \\
\text { Hepatocellular adenomas, hepatocellular carcinomas, and hepatocellular } \\
\text { blastomas were combined as neoplasms which is appropriate. }\end{array}$ \\
\hline
\end{tabular}

Overall utility: ++. Chemical stability was reported and target concentrations were verified, but purity was not reported. Disease surveillance was not reported. Three dose levels, previously shown to be carcinogenic were used. The exposure duration was short, but the observation duration was near life-span. Only livers were examined during necropsy. 
Table C-16. Wood et al. 2015 (F Mouse): Dichloroacetic Acid: Drinking Water

\begin{tabular}{|c|c|}
\hline $\begin{array}{l}\text { Study Utility Domain and } \\
\text { Question }\end{array}$ & Rating and Rationale \\
\hline \multicolumn{2}{|l|}{ Study design } \\
\hline Randomization & Not reported. \\
\hline Controls & $\begin{array}{l}+++ \\
\text { Concurrent vehicle controls were used. }\end{array}$ \\
\hline Historical data & No \\
\hline Animal model (sensitivity) & $\begin{array}{l}+++ \\
\text { Both sexes of non-transgenic animals were used and the strain is in common } \\
\text { use. }\end{array}$ \\
\hline Statistical power (sensitivity) & $\begin{array}{l}++ \\
\text { Moderate numbers of animals (27) were used for each group, though the } \\
\text { original number of animals at the start of the study were not reported. }\end{array}$ \\
\hline \multicolumn{2}{|l|}{ Exposure } \\
\hline Chemical characterization & $\begin{array}{l}++ \\
\text { Purity was not reported. Stability had been shown previously in stock drinking } \\
\text { water over } 8-12 \text { days, while bottles were changed twice a week. }\end{array}$ \\
\hline Dosing regimen & $\begin{array}{l}+++ \\
\text { There was no significant difference in survival, but there was a significant } \\
\text { decrease in body weight. There was a significant increase in neoplasm } \\
\text { incidence. }\end{array}$ \\
\hline Exposure duration (sensitivity) & $\begin{array}{l}++ \\
\text { Exposure duration was short (10 weeks), though the observation duration was } \\
\text { near life-span ( } 94 \text { weeks). }\end{array}$ \\
\hline Dose-response (sensitivity) & $\begin{array}{l}++ \\
\text { Two exposure levels were used that spanned a range of } 2 \text {-fold. These were } \\
\text { based on previous chronic studies in the same strain of male mice which were } \\
\text { estimated to be } 20,000-30,000 \text { times greater than those in normal tap water. }\end{array}$ \\
\hline \multicolumn{2}{|r|}{ e } \\
\hline Pathology & $\begin{array}{l}+ \\
\text { Only livers were examined. Even gross examination of other organs were not } \\
\text { reported. }\end{array}$ \\
\hline Consistency between groups & $\begin{array}{l}+++ \\
\text { Groups were not reported to have been treated differently. }\end{array}$ \\
\hline Study duration (sensitivity) & $\begin{array}{l}+++ \\
\text { A near life-span duration ( } 94 \text { weeks) was used. }\end{array}$ \\
\hline \multicolumn{2}{|l|}{ Confounding } \\
\hline Confounding & $\begin{array}{l}++ \\
\text { Continual disease surveillance was not reported. }\end{array}$ \\
\hline \multicolumn{2}{|l|}{ Reporting and analysis } \\
\hline Reporting data and statistics & $\begin{array}{l}+++ \\
\text { Appropriate statistical analyses were reported. }\end{array}$ \\
\hline Combining lesions & $\begin{array}{l}+++ \\
\text { Hepatocellular adenomas, hepatocellular carcinomas, and hepatocellular } \\
\text { blastomas were combined as neoplasms which is appropriate. }\end{array}$ \\
\hline
\end{tabular}

Overall utility: ++. Chemical stability was reported and target concentrations were verified, but purity was not reported. Disease surveillance was not reported. Two dose levels, previously shown to be carcinogenic were used. The exposure duration was short, but the observation duration was near life-span. Only livers were examined during necropsy. 
Table C-17. Pereira 1996 (F Mouse [Study 1]): Dichloroacetic Acid (DCA): Drinking Water

\section{Study Utility Domain and Question

\author{
Rating and Rationale
}

\begin{tabular}{ll}
\hline Study design & \\
Randomization & +++ \\
& $\begin{array}{l}\text { It was not reported if animals were randomly assigned to exposure groups, but } \\
\text { they were necropsied blinded and the mice were randomly assigned an ID }\end{array}$ \\
& number, which suggests they were randomly assigned to treatment groups, but \\
& it is not known for sure. \\
& +++ \\
& Concurrent vehicle controls of sodium chloride at equal molar concentrations \\
Controls & as in the high dose group were used. \\
& No \\
& ++ \\
Historical data & Only females of non-transgenic animals were used. \\
Animal model (sensitivity) & ++ \\
Statistical power (sensitivity) & The number of animals (15-90) varied considerably for each group.
\end{tabular}

\section{Exposure}

Chemical characterization

Chemical purity and stability were not reported.

Dosing regimen

$+++$

Survival was not reported, but there was a significant decreased in body weight and a significant increase in neoplasm incidence.

Exposure duration (sensitivity) +++

A near life-span duration (576 days) was used.

Dose-response (sensitivity) $\quad+++$

Three exposure levels were used that spanned a range of 10-fold.

\section{Outcome}

Pathology

$++$

Consistency between groups $\quad+++$

Only the liver was histologically examined.

Groups were not reported to have been treated differently.

Study duration (sensitivity) $\quad+++$

A near life-span duration (576 days) was used.

\section{Confounding}

Confounding

$++$

Continual disease surveillance and survival were not reported. The high exposure group had a significant decrease in water consumption.

\section{Reporting and analysis}

Reporting data and statistics

$+++$

Appropriate statistical analyses were reported.

Combining lesions

$+++$

Lesions were reported, which included liver foci, adenomas, and carcinomas.

The authors felt the foci were preneoplastic.

Overall utility: ++ . The chemicals were not characterized, not even purity was reported. Disease surveillance was not continually monitored. A variable number of only females was tested, with only their livers examined histologically. The study duration was near life-span. 
Table C-18. Pereira 1996 (F Mouse [Study 2]): Dichloroacetic Acid (DCA): Drinking Water

\author{
Study Utility Domain and \\ Question \\ Rating and Rationale
}

\begin{tabular}{ll}
\hline Study design & \\
Randomization & +++ \\
& $\begin{array}{l}\text { It was not reported if animals were randomly assigned to exposure groups, but } \\
\text { they were necropsied blinded and the mice were randomly assigned an ID }\end{array}$ \\
& number, which suggests they were randomly assigned to treatment groups, but \\
& it is not known for sure. \\
& +++ \\
& Concurrent vehicle controls of sodium chloride at equal molar concentrations \\
Controls & as in the high dose group were used. \\
& No \\
& ++ \\
Historical data & Only females of non-transgenic animals were used. \\
Animal model (sensitivity) & ++ \\
Statistical power (sensitivity) & The number of animals (15-90) varied considerably for each group.
\end{tabular}

\title{
Exposure
}

Chemical characterization

Chemical purity and stability were not reported.

Dosing regimen

$+++$

Survival was not reported, but there was a significant decreased in body weight and a significant increase in neoplasm incidence.

Exposure duration (sensitivity) ++

A less than life-span duration (360 days) was used.

Dose-response (sensitivity) $\quad+++$

Three exposure levels were used that spanned a range of 10 -fold.

\begin{tabular}{|c|c|}
\hline \multicolumn{2}{|l|}{ Outcome } \\
\hline Pathology & $\begin{array}{l}++ \\
\text { Only the liver was histologically examined. }\end{array}$ \\
\hline Consistency between groups & $\begin{array}{l}+++ \\
\text { Groups were not reported to have been treated differently. }\end{array}$ \\
\hline Study duration (sensitivity) & $\begin{array}{l}+++ \\
\text { A less than life-span duration (360 days) was used. }\end{array}$ \\
\hline \multicolumn{2}{|l|}{ Confounding } \\
\hline Confounding & $\begin{array}{l}\text { Continual disease surveillance and survival were not reported. The high } \\
\text { exposure group had a significant decrease in water consumption. }\end{array}$ \\
\hline \multicolumn{2}{|l|}{ Reporting and analysis } \\
\hline Reporting data and statistics & $\begin{array}{l}+++ \\
\text { Appropriate statistical analyses were reported. }\end{array}$ \\
\hline Combining lesions & $\begin{array}{l}\text { Lesions were reported, which included liver foci, adenomas, and carcinomas. } \\
\text { The authors felt the foci were preneoplastic. }\end{array}$ \\
\hline
\end{tabular}

Overall utility: ++ . The chemicals were not characterized, not even purity was reported. Disease surveillance was not continually monitored. A variable number of only females was tested, with only their livers examined histologically. Study duration was less than life-span. 
Table C-19. Pereira et al. 1997 (F Mouse): Dichloroacetic Acid (DCA): Drinking Water (I/P)

\begin{tabular}{|c|c|}
\hline $\begin{array}{c}\text { Study Utility Domain and } \\
\text { Question }\end{array}$ & Rating and Rationale \\
\hline \multicolumn{2}{|l|}{ Study design } \\
\hline Randomization & $\begin{array}{l}+++ \\
\text { Animals were randomly assigned to exposure groups with initial body weights } \\
\text { the same for each group. }\end{array}$ \\
\hline Controls & $\begin{array}{l}+++ \\
\text { Concurrent controls were appropriate for an initiation/promotion study in } \\
\text { which all groups received the initiator (NMU), and the negative control group } \\
\text { was given only the initiator and promotor vehicle. }\end{array}$ \\
\hline Historical data & No \\
\hline Animal model (sensitivity) & $\begin{array}{l}++ \\
\text { Only females of non-transgenic animals were used. }\end{array}$ \\
\hline Statistical power (sensitivity) & $\begin{array}{l}++ \\
\text { Small, but sufficient numbers of animals }(>20) \text { were used for each group. }\end{array}$ \\
\hline
\end{tabular}

\section{Exposure}

Chemical characterization

$+$

Dosing regimen

Chemical purity and stability were not reported.

Exposure duration (sensitivity)

$+++$

There was no significant difference in survival or body weight and there was a significant increase in neoplasm incidence.
Animals were exposed for 44 weeks, starting 4 weeks after a single injection of the initiator at $15 \mathrm{~d}$ of age. This is short for carcinogenicity studies, but initiation/promotion studies are normally shorter and tumors were significantly induced.
Dose-response (sensitivity) +++
Three exposure levels were used that spanned a range of 3-fold.

\section{Outcome}
Pathology
$++$
Only the liver was histologically examined.
Consistency between groups
$+++$
Groups were not reported to have been treated differently.
Study duration (sensitivity)
$+++$
A less than near life-span duration (48 weeks) was used, but initiation/promotion studies are normally short.
Confounding
Confounding$$
++
$$
Continual disease surveillance and survival were not reported.

\section{Reporting and analysis}
Reporting data and statistics
Combining lesions

\section{$++$}
Significance levels were reported, but the statistical test was not reported.$$
+++
$$
Lesions were reported, which included liver foci, adenomas, and carcinomas.
The authors felt the foci were preneoplastic.

$+++$

Overall utility: + . The chemicals were not characterized, not even purity was reported. Disease surveillance was not reported. A low number of only females were tested, with only their livers examined histologically. The statistical methods were not reported. 
Table C-20. Bull et al. 1990 (M Mouse): Dichloroacetic Acid: Drinking Water

\begin{tabular}{ll}
\multicolumn{1}{c}{$\begin{array}{c}\text { Study Utility Domain and } \\
\text { Question }\end{array}$} & \multicolumn{1}{c}{ Rating and Rationale } \\
\hline $\begin{array}{ll}\text { Study design } \\
\text { Randomization }\end{array}$ & +++ \\
& Animals were randomly assigned to exposure groups. \\
Controls & +++ \\
& Concurrent vehicle controls were used. \\
Historical data & No \\
Animal model (sensitivity) & ++ \\
& Only males of non-transgenic animals were used. \\
Statistical power (sensitivity) & + \\
& Small numbers of animals (11-24) were used for each group. \\
\hline
\end{tabular}

\section{Exposure}

Chemical characterization

Dosing regimen $\quad+++$

Chemical purity and stability were not verified.

There were no deaths and body weight was not reported. There was a significant increase in neoplasm incidence.

Exposure duration (sensitivity) $+++$

Dose-response (sensitivity) $\quad++$

A less than life-span duration (52 weeks) was used.

Two exposure levels were used that spanned a range of 2-fold.

\section{Outcome}

Pathology

Only livers from some animals were histologically evaluated. Results only reported overall lesions, which include hyperplasia. Liver lesions that were histologically evaluated were randomly selected and blindly evaluated.

Consistency between groups $+$

All untreated control lesions were histologically evaluated, but only some of the exposed groups were evaluated.

Study duration (sensitivity) $+++$

Confounding

Confounding

\section{Reporting and analysis}

Reporting data and statistics

Combining lesions

A less than life-span duration (52 weeks) was used.

$+$

Disease surveillance was not reported. Only samples of liver lesions were histologically evaluated and inappropriately reported.

Statistical evaluations were rarely reported and incidences that could be significant by Fisher's Exact test (calculated by NTP) were not reported as significant, so NTP calculations were included.

$++$

Only total lesions were adequately reported to allow for quantitation of the results. These included liver hyperplasia, hepatocellular adenoma, and hepatocellular carcinoma, which entail a continuum of the same disease process, however there were 4/73 lesion types that were also included but were neither hyperplastic nor neoplastic.

Overall utility: + . The chemical was not characterized, disease surveillance was not reported. A low number of mice per group were exposed for a less than near life-span duration and only males had results reported. Only livers were histologically examined. Not all lesions were histologically evaluated, but instead samples of lesions were evaluated. Results were reported so that incidences of specific neoplasms could not be determined but could be estimated. 
Table C-21. Daniel et al. 1992 (M Mouse): Dichloroacetic Acid: Drinking Water

\begin{tabular}{ll}
\hline \multicolumn{1}{c}{$\begin{array}{c}\text { Study Utility Domain and } \\
\text { Question }\end{array}$} & \multicolumn{1}{c}{ Rating and Rationale } \\
\hline Study design & \\
Randomization & Animals were randomly assigned to exposure groups. \\
& +++ \\
Controls & Concurrent vehicle controls were used. \\
& Yes \\
Historical data & ++ \\
Animal model (sensitivity) & Only males of non-transgenic animals were used. \\
& ++ \\
Statistical power (sensitivity) & ++ \\
& Moderate numbers of animals (20-24) were used for each group. \\
\hline
\end{tabular}

\section{Exposure}

Chemical characterization

$+++$

Chemical purity and stability were well characterized.

Dosing regimen

$+++$

There was no significant difference in survival or body weight. There was a significant increase in neoplasm incidence.

Exposure duration (sensitivity)

$+++$

A near life-span duration (104 weeks) was used.

Dose-response (sensitivity)

One exposure level was used, which was low compared to other similar studies from the same lab.

\section{Outcome}

Pathology

$+$

Histological evaluations were only done on liver, kidney, testes, spleen, and gross lesions.

Consistency between groups $\quad++$

Only 5 mice from the high dose group had undergone histological examinations of all major organs, while the other groups only had histological examinations of gross lesions.

Study duration (sensitivity) $\quad+++$

A near life-span duration (104 weeks) was used.

\section{Confounding}

Confounding

$++$

Continual disease surveillance was not reported. Only some mice received a full histological evaluation.

\section{Reporting and analysis}

Reporting data and statistics

$+++$

Appropriate statistical analyses were reported.

Combining lesions

$+++$

Lesions were reported, which included liver hyperplasia, adenomas, and carcinomas. The authors felt the hyperplasia were preneoplastic.

Overall utility: ++. Continual disease surveillance was not reported. Only males were tested and only at one dose level. Histological evaluations from all major organs only occurred in five mice per group, with histological evaluations in the other mice only occurring on tissues with gross lesions. 
Table C-22. NTP 2007b (M \& F Mouse [Study 1]): Dichloroacetic Acid: Dermal

\begin{tabular}{|c|c|}
\hline $\begin{array}{l}\text { Study Utility Domain and } \\
\text { Question }\end{array}$ & Rating and Rationale \\
\hline \multicolumn{2}{|l|}{ Study design } \\
\hline Randomization & $\begin{array}{l}+++ \\
\text { Animals were randomly assigned to exposure groups. }\end{array}$ \\
\hline Controls & $\begin{array}{l}+++ \\
\text { Concurrent vehicle controls of } 99.9 \% \text { acetone were used. }\end{array}$ \\
\hline Historical data & No \\
\hline Animal model (sensitivity) & $\begin{array}{l}+ \\
\text { Both sexes of transgenic animals, that are sensitive to carcinogens with a } \\
\text { propensity to develop squamous papillomas or carcinomas of the skin or } \\
\text { forestomach, were used. However, the transgenic strain is sensitive to skin } \\
\text { injury and will develop papillomas, suggesting it may overestimate a } \\
\text { chemical's carcinogenic potential. }\end{array}$ \\
\hline Statistical power (sensitivity) & $\begin{array}{l}+ \\
\text { Small and insufficient numbers of animals }(10) \text { were used for each group. }\end{array}$ \\
\hline \multicolumn{2}{|r|}{ ( } \\
\hline Chemical characterization & $\begin{array}{l}+++ \\
\text { Chemical purity and stability were well characterized. }\end{array}$ \\
\hline Dosing regimen & $\begin{array}{l}++ \\
\text { There was no significant difference in survival, but there was a significant } \\
\text { decrease in body weight. There was no significant increase in neoplasm } \\
\text { incidence, but there was in preneoplasm incidence. }\end{array}$ \\
\hline Exposure duration (sensitivity) & $\begin{array}{l}\text { While the duration was short }(39 \text { weeks) compared to carcinogenicity studies, } \\
\text { it was performed in transgenic mice prone to developing cancer. }\end{array}$ \\
\hline Dose-response (sensitivity) & $\begin{array}{l}+++ \\
\text { Three exposure levels were used that spanned a range of } 16 \text {-fold. }\end{array}$ \\
\hline \multicolumn{2}{|r|}{ ( 1} \\
\hline Pathology & $\begin{array}{l}\text { All major organs and gross lesions were histologically evaluated and findings } \\
\text { were verified by an independent pathologist. }\end{array}$ \\
\hline Consistency between groups & $\begin{array}{l}\text { All groups were treated the same except that positive controls underwent a } \\
\text { complete necropsy. However, positive controls will not be reported here. }\end{array}$ \\
\hline Study duration (sensitivity) & $\begin{array}{l}\text { While the duration was short }(39 \text { weeks) compared to carcinogenicity studies, } \\
\text { it was performed in transgenic mice prone to developing cancer. }\end{array}$ \\
\hline \multicolumn{2}{|l|}{ Confounding } \\
\hline Confounding & $\begin{array}{l}\text { The test agent was well characterized, animals were treated the same between } \\
\text { groups, and were continually monitored for infectious diseases. }\end{array}$ \\
\hline \multicolumn{2}{|l|}{ Reporting and analysis } \\
\hline Reporting data and statistics & $\begin{array}{l}+++ \\
\text { Appropriate statistical analyses were reported. }\end{array}$ \\
\hline Combining lesions & $\begin{array}{l}+++ \\
\text { Tumor types were not combined. }\end{array}$ \\
\hline
\end{tabular}

Overall utility: + . The study was well conducted except for a low number of transgenic animals per group, which may overestimate carcinogenic potential. The ability to translate hazards in this model to non-transgenic mice is limited. 
Table C-23. NTP 2007b (M Mouse [Study 2]): Dichloroacetic Acid: Dermal

\begin{tabular}{|c|c|}
\hline $\begin{array}{l}\text { Study Utility Domain and } \\
\text { Question }\end{array}$ & Rating and Rationale \\
\hline \multicolumn{2}{|l|}{ Study design } \\
\hline Randomization & $\begin{array}{l}+++ \\
\text { Animals were randomly assigned to exposure groups. }\end{array}$ \\
\hline Controls & $\begin{array}{l}+++ \\
\text { Concurrent vehicle controls of } 99.9 \% \text { acetone were used. }\end{array}$ \\
\hline Historical data & No \\
\hline Animal model (sensitivity) & $\begin{array}{l}+ \\
\text { Both sexes of transgenic animals, that are sensitive to carcinogens with a } \\
\text { propensity to develop squamous papillomas or carcinomas of the skin or } \\
\text { forestomach, were used. However, the transgenic strain is sensitive to skin } \\
\text { injury and will develop papillomas, suggesting it may overestimate a } \\
\text { chemical's carcinogenic potential. }\end{array}$ \\
\hline Statistical power (sensitivity) & $\begin{array}{l}++ \\
\text { Small and insufficient numbers of animals (15) were used for each group. }\end{array}$ \\
\hline \multicolumn{2}{|r|}{ e } \\
\hline Chemical characterization & $\begin{array}{l}+++ \\
\text { Chemical purity and stability were well characterized. }\end{array}$ \\
\hline Dosing regimen & $\begin{array}{l}++ \\
\text { There was no significant difference in survival or body weight. There was no } \\
\text { significant increase in neoplasm incidence, but there was a significant increase } \\
\text { in preneoplasm incidence. }\end{array}$ \\
\hline Exposure duration (sensitivity) & $\begin{array}{l}++ \\
\text { While the duration was short ( } 26 \text { weeks) compared to carcinogenicity studies, } \\
\text { it was performed in transgenic mice prone to developing cancer. }\end{array}$ \\
\hline Dose-response (sensitivity) & $\begin{array}{l}+++ \\
\text { Three exposure levels were used that spanned a range of } 16 \text {-fold. }\end{array}$ \\
\hline \multicolumn{2}{|r|}{$\mathrm{C}$} \\
\hline Pathology & $\begin{array}{l}+++ \\
\text { All major organs and gross lesions were histologically evaluated and findings } \\
\text { were verified by an independent pathologist. }\end{array}$ \\
\hline Consistency between groups & $\begin{array}{l}+++ \\
\text { All groups were treated the same except that positive controls underwent a } \\
\text { complete necropsy. However, positive controls will not be reported here. }\end{array}$ \\
\hline Study duration (sensitivity) & $\begin{array}{l}\text { While the duration was short ( } 26 \text { weeks) compared to carcinogenicity studies, } \\
\text { it was performed in transgenic mice prone to developing cancer. }\end{array}$ \\
\hline \multicolumn{2}{|l|}{ Confounding } \\
\hline Confounding & $\begin{array}{l}+++ \\
\text { The test agent was well characterized, animals were treated the same between } \\
\text { groups, and were continually monitored for infectious diseases. }\end{array}$ \\
\hline \multicolumn{2}{|l|}{ Reporting and analysis } \\
\hline Reporting data and statistics & $\begin{array}{l}+++ \\
\text { Appropriate statistical analyses were reported. }\end{array}$ \\
\hline Combining lesions & $\begin{array}{l}+++ \\
\text { Tumor types were not combined. }\end{array}$ \\
\hline
\end{tabular}

Overall utility: + . The study was well conducted except for a low number of transgenic animals per group, which may overestimate carcinogenic potential. The ability to translate hazards in this model to non-transgenic mice is limited. 
Table C-24. NTP 2007b (M Mouse [Study 1]): Dichloroacetic Acid: Drinking Water

\begin{tabular}{|c|c|}
\hline $\begin{array}{l}\text { Study Utility Domain and } \\
\text { Question }\end{array}$ & Rating and Rationale \\
\hline \multicolumn{2}{|l|}{ Study design } \\
\hline Randomization & $\begin{array}{l}+++ \\
\text { Animals were randomly assigned to exposure groups. }\end{array}$ \\
\hline Controls & $\begin{array}{l}+++ \\
\text { Concurrent vehicle controls of } 99.9 \% \text { acetone were used. }\end{array}$ \\
\hline Historical data & No \\
\hline Animal model (sensitivity) & $\begin{array}{l}+ \\
\text { Both sexes of transgenic animals, that are sensitive to carcinogens with a } \\
\text { propensity to develop squamous papillomas or carcinomas of the skin or } \\
\text { forestomach, were used. However, the transgenic strain is sensitive to skin } \\
\text { injury and will develop papillomas, suggesting it may overestimate a } \\
\text { chemical's carcinogenic potential. }\end{array}$ \\
\hline Statistical power (sensitivity) & $\begin{array}{l}+ \\
\text { Small and insufficient numbers of animals (10) were used for each group. }\end{array}$ \\
\hline \multicolumn{2}{|r|}{ e } \\
\hline Chemical characterization & $\begin{array}{l}+++ \\
\text { Chemical purity and stability were well characterized. }\end{array}$ \\
\hline Dosing regimen & $\begin{array}{l}+++ \\
\text { There was no significant difference in survival and no significant decrease in } \\
\text { body weight. There was a significant increase in neoplasm incidence. }\end{array}$ \\
\hline Exposure duration (sensitivity) & $\begin{array}{l}\text { While the duration was short ( } 26 \text { weeks) compared to carcinogenicity studies, } \\
\text { it was performed in transgenic mice prone to developing cancer. }\end{array}$ \\
\hline Dose-response (sensitivity) & $\begin{array}{l}+++ \\
\text { Three exposure levels were used that spanned a range of } 16 \text {-fold. }\end{array}$ \\
\hline \multicolumn{2}{|r|}{ ( } \\
\hline Pathology & $\begin{array}{l}+++ \\
\text { All major organs and gross lesions were histologically evaluated and findings } \\
\text { were verified by an independent pathologist. }\end{array}$ \\
\hline Consistency between groups & $\begin{array}{l}\text { All groups were treated the same except that positive controls underwent a } \\
\text { complete necropsy. However, positive controls will not be considered here. }\end{array}$ \\
\hline Study duration (sensitivity) & $\begin{array}{l}\text { While the duration was short ( } 26 \text { weeks) compared to carcinogenicity studies, } \\
\text { it was performed in transgenic mice prone to developing cancer. }\end{array}$ \\
\hline \multicolumn{2}{|l|}{ Confounding } \\
\hline Confounding & $\begin{array}{l}+++ \\
\text { The test agent was well characterized, animals were treated the same between } \\
\text { groups, and were continually monitored for infectious diseases. }\end{array}$ \\
\hline \multicolumn{2}{|l|}{ Reporting and analysis } \\
\hline Reporting data and statistics & $\begin{array}{l}+++ \\
\text { Appropriate statistical analyses were reported. }\end{array}$ \\
\hline Combining lesions & $\begin{array}{l}+++ \\
\text { Tumor types were not combined. }\end{array}$ \\
\hline
\end{tabular}

Overall utility: +. The study was well conducted except for a low number of transgenic animals per group, which may overestimate carcinogenic potential. The ability to translate hazards in this model to non-transgenic mice is limited. 
Table C-25. NTP 2007b (F Mouse [Study 1]): Dichloroacetic Acid: Drinking Water

\begin{tabular}{|c|c|}
\hline $\begin{array}{l}\text { Study Utility Domain and } \\
\text { Question }\end{array}$ & Rating and Rationale \\
\hline \multicolumn{2}{|l|}{ Study design } \\
\hline Randomization & $\begin{array}{l}+++ \\
\text { Animals were randomly assigned to exposure groups. }\end{array}$ \\
\hline Controls & $\begin{array}{l}+++ \\
\text { Concurrent vehicle controls of } 99.9 \% \text { acetone were used. }\end{array}$ \\
\hline Historical data & No \\
\hline Animal model (sensitivity) & $\begin{array}{l}+ \\
\text { Both sexes of transgenic animals, that are sensitive to carcinogens with a } \\
\text { propensity to develop squamous papillomas or carcinomas of the skin or } \\
\text { forestomach, were used. However, the transgenic strain is sensitive to skin } \\
\text { injury and will develop papillomas, suggesting it may overestimate a } \\
\text { chemical's carcinogenic potential. }\end{array}$ \\
\hline Statistical power (sensitivity) & $\begin{array}{l}+ \\
\text { Small and insufficient numbers of animals (10) were used for each group. }\end{array}$ \\
\hline \multicolumn{2}{|l|}{ Exposure } \\
\hline Chemical characterization & $\begin{array}{l}+++ \\
\text { Chemical purity and stability were well characterized. }\end{array}$ \\
\hline Dosing regimen & $\begin{array}{l}\text { There was no significant difference in survival, but there was a significant } \\
\text { decrease in body weight. There was no significant increase in neoplasm } \\
\text { incidence, but there was a significant increase in preneoplasm incidence. }\end{array}$ \\
\hline Exposure duration (sensitivity) & $\begin{array}{l}\text { While the duration was short ( } 26 \text { weeks) compared to carcinogenicity studies, } \\
\text { it was performed in transgenic mice prone to developing cancer. }\end{array}$ \\
\hline Dose-response (sensitivity) & $\begin{array}{l}+++ \\
\text { Three exposure levels were used that spanned a range of } 16 \text {-fold. }\end{array}$ \\
\hline \multicolumn{2}{|l|}{ Outcome } \\
\hline Pathology & $\begin{array}{l}\text { All major organs and gross lesions were histologically evaluated and findings } \\
\text { were verified by an independent pathologist. }\end{array}$ \\
\hline Consistency between groups & $\begin{array}{l}+++ \\
\text { All groups were treated the same except that positive controls underwent a } \\
\text { complete necropsy. However, positive controls will not be considered here. }\end{array}$ \\
\hline Study duration (sensitivity) & $\begin{array}{l}+++ \\
\text { While the duration was short ( } 26 \text { weeks) compared to carcinogenicity studies, } \\
\text { it was performed in transgenic mice prone to developing cancer. }\end{array}$ \\
\hline \multicolumn{2}{|l|}{ Confounding } \\
\hline Confounding & $\begin{array}{l}\text { The test agent was well characterized, animals were treated the same between } \\
\text { groups, and were continually monitored for infectious diseases. }\end{array}$ \\
\hline \multicolumn{2}{|l|}{ Reporting and analysis } \\
\hline Reporting data and statistics & $\begin{array}{l}+++ \\
\text { Appropriate statistical analyses were reported. }\end{array}$ \\
\hline Combining lesions & $\begin{array}{l}+++ \\
\text { Tumor types were not combined. }\end{array}$ \\
\hline
\end{tabular}

Overall utility: + . The study was well conducted except for a low number of transgenic animals per group, which may overestimate carcinogenic potential. The ability to translate hazards in this model to non-transgenic mice is limited. 
Table C-26. NTP 2007b (M Mouse [Study 2]): Dichloroacetic Acid: Drinking Water

\begin{tabular}{|c|c|}
\hline $\begin{array}{l}\text { Study Utility Domain and } \\
\text { Question }\end{array}$ & Rating and Rationale \\
\hline \multicolumn{2}{|l|}{ Study design } \\
\hline Randomization & $\begin{array}{l}+++ \\
\text { Animals were randomly assigned to exposure groups. }\end{array}$ \\
\hline Controls & $\begin{array}{l}+++ \\
\text { Concurrent vehicle controls of } 99.9 \% \text { acetone were used. }\end{array}$ \\
\hline Historical data & No \\
\hline Animal model (sensitivity) & $\begin{array}{l}+ \\
\text { Both sexes of transgenic animals, that are sensitive to carcinogens with a } \\
\text { propensity to develop squamous papillomas or carcinomas of the skin or } \\
\text { forestomach, were used. However, the transgenic strain is sensitive to skin } \\
\text { injury and will develop papillomas, suggesting it may overestimate a } \\
\text { chemical's carcinogenic potential. }\end{array}$ \\
\hline Statistical power (sensitivity) & $\begin{array}{l}++ \\
\text { Small and insufficient numbers of animals (15) were used for each group. }\end{array}$ \\
\hline \multicolumn{2}{|l|}{ Exposure } \\
\hline Chemical characterization & $\begin{array}{l}+++ \\
\text { Chemical purity and stability were well characterized. }\end{array}$ \\
\hline Dosing regimen & $\begin{array}{l}+ \\
\text { There was no significant difference in survival and no significant decrease in } \\
\text { body weight. There was no significant increase in neoplasm incidence. }\end{array}$ \\
\hline Exposure duration (sensitivity) & $\begin{array}{l}\text { While the duration was short ( } 26 \text { weeks) compared to carcinogenicity studies, } \\
\text { it was performed in transgenic mice prone to developing cancer. }\end{array}$ \\
\hline Dose-response (sensitivity) & $\begin{array}{l}+++ \\
\text { Three exposure levels were used that spanned a range of } 16 \text {-fold. }\end{array}$ \\
\hline \multicolumn{2}{|l|}{ Outcome } \\
\hline Pathology & $\begin{array}{l}+++ \\
\text { All major organs and gross lesions were histologically evaluated and findings } \\
\text { were verified by an independent pathologist. }\end{array}$ \\
\hline Consistency between groups & $\begin{array}{l}+++ \\
\text { All groups were treated the same except that positive controls underwent a } \\
\text { complete necropsy. However, positive controls will not be reported here. }\end{array}$ \\
\hline Study duration (sensitivity) & $\begin{array}{l}\text { While the duration was short ( } 26 \text { weeks) compared to carcinogenicity studies, } \\
\text { it was performed in transgenic mice prone to developing cancer. }\end{array}$ \\
\hline \multicolumn{2}{|l|}{ Confounding } \\
\hline Confounding & $\begin{array}{l}+++ \\
\text { The test agent was well characterized, animals were treated the same between } \\
\text { groups, and were continually monitored for infectious diseases. }\end{array}$ \\
\hline \multicolumn{2}{|l|}{ Reporting and analysis } \\
\hline Reporting data and statistics & $\begin{array}{l}+++ \\
\text { Appropriate statistical analyses were reported. }\end{array}$ \\
\hline Combining lesions & $\begin{array}{l}+++ \\
\text { Tumor types were not combined. }\end{array}$ \\
\hline
\end{tabular}

Overall utility: +. The study was well conducted except for a low number of transgenic animals per group, which may overestimate carcinogenic potential. The ability to translate hazards in this model to non-transgenic mice is limited. 
Table C-27. NTP 2007b (F Mouse [Study 2]): Dichloroacetic Acid: Drinking Water

\begin{tabular}{|c|c|}
\hline $\begin{array}{l}\text { Study Utility Domain and } \\
\text { Question }\end{array}$ & Rating and Rationale \\
\hline \multicolumn{2}{|l|}{ Study design } \\
\hline Randomization & $\begin{array}{l}+++ \\
\text { Animals were randomly assigned to exposure groups. }\end{array}$ \\
\hline Controls & $\begin{array}{l}+++ \\
\text { Concurrent vehicle controls of } 99.9 \% \text { acetone were used. }\end{array}$ \\
\hline Historical data & No \\
\hline Animal model (sensitivity) & $\begin{array}{l}+ \\
\text { Both sexes of transgenic animals, that are sensitive to carcinogens with a } \\
\text { propensity to develop squamous papillomas or carcinomas of the skin or } \\
\text { forestomach, were used. However, the transgenic strain is sensitive to skin } \\
\text { injury and will develop papillomas, suggesting it may overestimate a } \\
\text { chemical's carcinogenic potential. }\end{array}$ \\
\hline Statistical power (sensitivity) & $\begin{array}{l}++ \\
\text { Small and insufficient numbers of animals (15) were used for each group. }\end{array}$ \\
\hline \multicolumn{2}{|r|}{ e } \\
\hline Chemical characterization & $\begin{array}{l}+++ \\
\text { Chemical purity and stability were well characterized. }\end{array}$ \\
\hline Dosing regimen & $\begin{array}{l}++ \\
\text { There was a significant decrease in survival and body weight. There was no } \\
\text { significant increase in neoplasm incidence. }\end{array}$ \\
\hline Exposure duration (sensitivity) & $\begin{array}{l}++ \\
\text { While the duration was short ( } 26 \text { weeks) compared to carcinogenicity studies, } \\
\text { it was performed in transgenic mice prone to developing cancer. }\end{array}$ \\
\hline Dose-response (sensitivity) & $\begin{array}{l}+++ \\
\text { Three exposure levels were used that spanned a range of } 16 \text {-fold. }\end{array}$ \\
\hline \multicolumn{2}{|r|}{ ( } \\
\hline Pathology & $\begin{array}{l}+++ \\
\text { All major organs and gross lesions were histologically evaluated and findings } \\
\text { were verified by an independent pathologist. }\end{array}$ \\
\hline Consistency between groups & $\begin{array}{l}\text { All groups were treated the same except that positive controls underwent a } \\
\text { complete necropsy. However, positive controls will not be considered here. }\end{array}$ \\
\hline Study duration (sensitivity) & $\begin{array}{l}\text { While the duration was short ( } 26 \text { weeks) compared to carcinogenicity studies, } \\
\text { it was performed in transgenic mice prone to developing cancer. }\end{array}$ \\
\hline \multicolumn{2}{|l|}{ Confounding } \\
\hline Confounding & $\begin{array}{l}+++ \\
\text { The test agent was well characterized, animals were treated the same between } \\
\text { groups, and were continually monitored for infectious diseases. }\end{array}$ \\
\hline \multicolumn{2}{|l|}{ Reporting and analysis } \\
\hline Reporting data and statistics & $\begin{array}{l}+++ \\
\text { Appropriate statistical analyses were reported. }\end{array}$ \\
\hline Combining lesions & $\begin{array}{l}+++ \\
\text { Tumor types were not combined. }\end{array}$ \\
\hline
\end{tabular}

Overall utility: +. The study was well conducted except for a low number of transgenic animals per group, which may overestimate carcinogenic potential. The ability to translate hazards in this model to non-transgenic mice is limited. 
Table C-28. NTP 2007b (M Mouse [Study 3]): Dichloroacetic Acid: Drinking Water

\begin{tabular}{|c|c|}
\hline $\begin{array}{l}\text { Study Utility Domain and } \\
\text { Question }\end{array}$ & Rating and Rationale \\
\hline \multicolumn{2}{|l|}{ Study design } \\
\hline Randomization & $\begin{array}{l}+++ \\
\text { Animals were randomly assigned to exposure groups. }\end{array}$ \\
\hline Controls & $\begin{array}{l}+++ \\
\text { Concurrent vehicle controls of } 99.9 \% \text { acetone were used. }\end{array}$ \\
\hline Historical data & No \\
\hline Animal model (sensitivity) & $\begin{array}{l}+ \\
\text { Both sexes of transgenic animals, that are sensitive to carcinogens with a } \\
\text { propensity to develop lymphomas or sarcomas, were used. However, the } \\
\text { transgenic strain may overestimate a chemical's carcinogenic potential. }\end{array}$ \\
\hline Statistical power (sensitivity) & $\begin{array}{l}+ \\
\text { Small and insufficient numbers of animals (10) were used for each group. }\end{array}$ \\
\hline \multicolumn{2}{|l|}{ Exposure } \\
\hline Chemical characterization & $\begin{array}{l}+++ \\
\text { Chemical purity and stability were well characterized. }\end{array}$ \\
\hline Dosing regimen & $\begin{array}{l}++ \\
\text { There was no significant difference in survival, but there was a significant } \\
\text { decrease in body weight. There was no significant difference in neoplasm } \\
\text { incidence. }\end{array}$ \\
\hline Exposure duration (sensitivity) & $\begin{array}{l}\text { While the duration was short ( } 26 \text { weeks) compared to carcinogenicity studies, } \\
\text { it was performed in transgenic mice prone to developing cancer. }\end{array}$ \\
\hline Dose-response (sensitivity) & $\begin{array}{l}+++ \\
\text { Three exposure levels were used that spanned a range of } 16 \text {-fold. }\end{array}$ \\
\hline \multicolumn{2}{|l|}{ Outcome } \\
\hline Pathology & $\begin{array}{l}\text { All major organs and gross lesions were histologically evaluated and findings } \\
\text { were verified by an independent pathologist. }\end{array}$ \\
\hline Consistency between groups & $\begin{array}{l}+++ \\
\text { All groups were treated the same except that positive controls underwent a } \\
\text { complete necropsy. However, positive controls will not be considered here. }\end{array}$ \\
\hline Study duration (sensitivity) & $\begin{array}{l}\text { While the duration was short ( } 26 \text { weeks) compared to carcinogenicity studies, } \\
\text { it was performed in transgenic mice prone to developing cancer. }\end{array}$ \\
\hline \multicolumn{2}{|l|}{ Confounding } \\
\hline Confounding & $\begin{array}{l}\text { The test agent was well characterized, animals were treated the same between } \\
\text { groups, and were continually monitored for infectious diseases. }\end{array}$ \\
\hline \multicolumn{2}{|l|}{ Reporting and analysis } \\
\hline Reporting data and statistics & $\begin{array}{l}+++ \\
\text { Appropriate statistical analyses were reported. }\end{array}$ \\
\hline Combining lesions & $\begin{array}{l}+++ \\
\text { Tumor types were not combined. }\end{array}$ \\
\hline
\end{tabular}

Overall utility: +. The study was well conducted except for a low number of transgenic animals per group, which may overestimate carcinogenic potential. The ability to translate hazards in this model to non-transgenic mice is limited. 
Table C-29. NTP 2007b (F Mouse [Study 3]): Dichloroacetic Acid: Drinking Water

\begin{tabular}{|c|c|}
\hline $\begin{array}{l}\text { Study Utility Domain and } \\
\text { Question }\end{array}$ & Rating and Rationale \\
\hline \multicolumn{2}{|l|}{ Study design } \\
\hline Randomization & $\begin{array}{l}+++ \\
\text { Animals were randomly assigned to exposure groups. }\end{array}$ \\
\hline Controls & $\begin{array}{l}+++ \\
\text { Concurrent vehicle controls of } 99.9 \% \text { acetone were used. }\end{array}$ \\
\hline Historical data & No \\
\hline Animal model (sensitivity) & $\begin{array}{l}+ \\
\text { Both sexes of transgenic animals, that are sensitive to carcinogens with a } \\
\text { propensity to develop lymphomas or sarcomas, were used. However, the } \\
\text { transgenic strain may overestimate a chemical's carcinogenic potential. }\end{array}$ \\
\hline Statistical power (sensitivity) & $\begin{array}{l}+ \\
\text { Small and insufficient numbers of animals (10) were used for each group. }\end{array}$ \\
\hline \multicolumn{2}{|l|}{ Exposure } \\
\hline Chemical characterization & $\begin{array}{l}+++ \\
\text { Chemical purity and stability were well characterized. }\end{array}$ \\
\hline Dosing regimen & $\begin{array}{l}++ \\
\text { There was no significant difference in survival, but there was a significant } \\
\text { decrease in body weight. There was no significant difference in neoplasm } \\
\text { incidence. }\end{array}$ \\
\hline Exposure duration (sensitivity) & $\begin{array}{l}\text { While the duration was short ( } 26 \text { weeks) compared to carcinogenicity studies, } \\
\text { it was performed in transgenic mice prone to developing cancer. }\end{array}$ \\
\hline Dose-response (sensitivity) & $\begin{array}{l}+++ \\
\text { Three exposure levels were used that spanned a range of } 16 \text {-fold. }\end{array}$ \\
\hline \multicolumn{2}{|l|}{ Outcome } \\
\hline Pathology & $\begin{array}{l}\text { All major organs and gross lesions were histologically evaluated and findings } \\
\text { were verified by an independent pathologist. }\end{array}$ \\
\hline Consistency between groups & $\begin{array}{l}+++ \\
\text { All groups were treated the same except that positive controls underwent a } \\
\text { complete necropsy. However, positive controls will not be considered here. }\end{array}$ \\
\hline Study duration (sensitivity) & $\begin{array}{l}\text { While the duration was short ( } 26 \text { weeks) compared to carcinogenicity studies, } \\
\text { it was performed in transgenic mice prone to developing cancer. }\end{array}$ \\
\hline \multicolumn{2}{|l|}{ Confounding } \\
\hline Confounding & $\begin{array}{l}\text { The test agent was well characterized, animals were treated the same between } \\
\text { groups, and were continually monitored for infectious diseases. }\end{array}$ \\
\hline \multicolumn{2}{|l|}{ Reporting and analysis } \\
\hline Reporting data and statistics & $\begin{array}{l}+++ \\
\text { Appropriate statistical analyses were reported. }\end{array}$ \\
\hline Combining lesions & $\begin{array}{l}+++ \\
\text { Tumor types were not combined. }\end{array}$ \\
\hline
\end{tabular}

Overall utility: +. The study was well conducted except for a low number of transgenic animals per group, which may overestimate carcinogenic potential. The ability to translate hazards in this model to non-transgenic mice is limited. 
Table C-30. NTP 2007b (M Mouse [Study 4]): Dichloroacetic Acid: Drinking Water

\begin{tabular}{|c|c|}
\hline $\begin{array}{l}\text { Study Utility Domain and } \\
\text { Question }\end{array}$ & Rating and Rationale \\
\hline \multicolumn{2}{|l|}{ Study design } \\
\hline Randomization & $\begin{array}{l}+++ \\
\text { Animals were randomly assigned to exposure groups. }\end{array}$ \\
\hline Controls & $\begin{array}{l}+++ \\
\text { Concurrent vehicle controls of } 99.9 \% \text { acetone were used. }\end{array}$ \\
\hline Historical data & No \\
\hline Animal model (sensitivity) & $\begin{array}{l}+ \\
\text { Both sexes of transgenic animals, that are sensitive to carcinogens with a } \\
\text { propensity to develop lymphomas or sarcomas, were used. However, the } \\
\text { transgenic strain may overestimate a chemical's carcinogenic potential. }\end{array}$ \\
\hline Statistical power (sensitivity) & $\begin{array}{l}++ \\
\text { Small and insufficient numbers of animals (15) were used for each group. }\end{array}$ \\
\hline \multicolumn{2}{|l|}{ Exposure } \\
\hline Chemical characterization & $\begin{array}{l}+++ \\
\text { Chemical purity and stability were well characterized. }\end{array}$ \\
\hline Dosing regimen & $\begin{array}{l}++ \\
\text { There was no significant difference in survival, but there was a significant } \\
\text { decrease in body weight. There was no significant difference in neoplasm } \\
\text { incidence. }\end{array}$ \\
\hline Exposure duration (sensitivity) & $\begin{array}{l}++ \\
\text { While the duration was short ( } 26 \text { weeks) compared to carcinogenicity studies, } \\
\text { it was performed in transgenic mice prone to developing cancer. }\end{array}$ \\
\hline Dose-response (sensitivity) & $\begin{array}{l}+++ \\
\text { Three exposure levels were used that spanned a range of } 16 \text {-fold. }\end{array}$ \\
\hline \multicolumn{2}{|l|}{ Outcome } \\
\hline Pathology & $\begin{array}{l}\text { All major organs and gross lesions were histologically evaluated and findings } \\
\text { were verified by an independent pathologist. }\end{array}$ \\
\hline Consistency between groups & $\begin{array}{l}\text { All groups were treated the same except that positive controls underwent a } \\
\text { complete necropsy. However, positive controls will not be considered here. }\end{array}$ \\
\hline Study duration (sensitivity) & $\begin{array}{l}\text { While the duration was short ( } 26 \text { weeks) compared to carcinogenicity studies, } \\
\text { it was performed in transgenic mice prone to developing cancer. }\end{array}$ \\
\hline \multicolumn{2}{|l|}{ Confounding } \\
\hline Confounding & $\begin{array}{l}\text { The test agent was well characterized, animals were treated the same between } \\
\text { groups, and were continually monitored for infectious diseases. }\end{array}$ \\
\hline \multicolumn{2}{|l|}{ Reporting and analysis } \\
\hline Reporting data and statistics & $\begin{array}{l}+++ \\
\text { Appropriate statistical analyses were reported. }\end{array}$ \\
\hline Combining lesions & $\begin{array}{l}+++ \\
\text { Tumor types were not combined. }\end{array}$ \\
\hline
\end{tabular}

Overall utility: +. The study was well conducted except for a low number of transgenic animals per group, which may overestimate carcinogenic potential. The ability to translate hazards in this model to non-transgenic mice is limited. 
Table C-31. NTP 2007b (F Mouse [Study 4]): Dichloroacetic Acid: Drinking Water

\begin{tabular}{|c|c|}
\hline $\begin{array}{l}\text { Study Utility Domain and } \\
\text { Question }\end{array}$ & Rating and Rationale \\
\hline \multicolumn{2}{|l|}{ Study design } \\
\hline Randomization & $\begin{array}{l}+++ \\
\text { Animals were randomly assigned to exposure groups. }\end{array}$ \\
\hline Controls & $\begin{array}{l}+++ \\
\text { Concurrent vehicle controls of } 99.9 \% \text { acetone were used. }\end{array}$ \\
\hline Historical data & No \\
\hline Animal model (sensitivity) & $\begin{array}{l}+ \\
\text { Both sexes of transgenic animals, that are sensitive to carcinogens with a } \\
\text { propensity to develop lymphomas or sarcomas, were used. However, the } \\
\text { transgenic strain may overestimate a chemical's carcinogenic potential. }\end{array}$ \\
\hline Statistical power (sensitivity) & $\begin{array}{l}++ \\
\text { Small and insufficient numbers of animals (15) were used for each group. }\end{array}$ \\
\hline \multicolumn{2}{|l|}{ Exposure } \\
\hline Chemical characterization & $\begin{array}{l}+++ \\
\text { Chemical purity and stability were well characterized. }\end{array}$ \\
\hline Dosing regimen & $\begin{array}{l}++ \\
\text { There was no significant difference in survival, but there was a significant } \\
\text { decrease in body weight. There was no significant difference in neoplasm } \\
\text { incidence. }\end{array}$ \\
\hline Exposure duration (sensitivity) & $\begin{array}{l}++ \\
\text { While the duration was short ( } 26 \text { weeks) compared to carcinogenicity studies, } \\
\text { it was performed in transgenic mice prone to developing cancer. }\end{array}$ \\
\hline Dose-response (sensitivity) & $\begin{array}{l}+++ \\
\text { Three exposure levels were used that spanned a range of } 16 \text {-fold. }\end{array}$ \\
\hline \multicolumn{2}{|l|}{ Outcome } \\
\hline Pathology & $\begin{array}{l}\text { All major organs and gross lesions were histologically evaluated and findings } \\
\text { were verified by an independent pathologist. }\end{array}$ \\
\hline Consistency between groups & $\begin{array}{l}\text { All groups were treated the same except that positive controls underwent a } \\
\text { complete necropsy. However, positive controls will not be considered here. }\end{array}$ \\
\hline Study duration (sensitivity) & $\begin{array}{l}\text { While the duration was short ( } 26 \text { weeks) compared to carcinogenicity studies, } \\
\text { it was performed in transgenic mice prone to developing cancer. }\end{array}$ \\
\hline \multicolumn{2}{|l|}{ Confounding } \\
\hline Confounding & $\begin{array}{l}\text { The test agent was well characterized, animals were treated the same between } \\
\text { groups, and were continually monitored for infectious diseases. }\end{array}$ \\
\hline \multicolumn{2}{|l|}{ Reporting and analysis } \\
\hline Reporting data and statistics & $\begin{array}{l}+++ \\
\text { Appropriate statistical analyses were reported. }\end{array}$ \\
\hline Combining lesions & $\begin{array}{l}+++ \\
\text { Tumor types were not combined. }\end{array}$ \\
\hline
\end{tabular}

Overall utility: +. The study was well conducted except for a low number of transgenic animals per group, which may overestimate carcinogenic potential. The ability to translate hazards in this model to non-transgenic mice is limited. 


\section{C.4. Dibromoacetic Acid: Study Quality for Animal Studies}

\section{Table C-32. NTP 2007a (M Mouse): Dibromoacetic Acid: Drinking Water}

\begin{tabular}{|c|c|}
\hline $\begin{array}{l}\text { Study Utility Domain and } \\
\text { Question }\end{array}$ & Rating and Rationale \\
\hline \multicolumn{2}{|l|}{ Study design } \\
\hline Randomization & $\begin{array}{l}+++ \\
\text { Animals were randomly assigned to exposure groups. }\end{array}$ \\
\hline Controls & $\begin{array}{l}+++ \\
\text { Concurrent vehicle controls were used. }\end{array}$ \\
\hline Historical data & Yes \\
\hline Animal model (sensitivity) & $\begin{array}{l}+++ \\
\text { Both sexes of non-transgenic animals were used. }\end{array}$ \\
\hline Statistical power (sensitivity) & $\begin{array}{l}+++ \\
\text { Large numbers of animals }(50) \text { were used for each group. }\end{array}$ \\
\hline \multicolumn{2}{|l|}{ Exposure } \\
\hline Chemical characterization & $\begin{array}{l}+++ \\
\text { Chemical purity and stability were well characterized. }\end{array}$ \\
\hline Dosing regimen & $\begin{array}{l}+++ \\
\text { There was no significant difference in survival and body weight was not } \\
\text { significantly decreased. There was a significant increase in neoplasm } \\
\text { incidence. }\end{array}$ \\
\hline Exposure duration (sensitivity) & $\begin{array}{l}+++ \\
\text { A near life-span duration (106 weeks) was used. }\end{array}$ \\
\hline Dose-response (sensitivity) & $\begin{array}{l}+++ \\
\text { Three exposure levels were used that spanned a range of } 20 \text {-fold. }\end{array}$ \\
\hline \multicolumn{2}{|l|}{ Outcome } \\
\hline Pathology & $\begin{array}{l}+++ \\
\text { All major organs and gross lesions were histologically evaluated and findings } \\
\text { were verified by an independent pathologist. }\end{array}$ \\
\hline Consistency between groups & $\begin{array}{l}+++ \\
\text { All groups were treated the same. }\end{array}$ \\
\hline Study duration (sensitivity) & $\begin{array}{l}+++ \\
\text { A near life-span duration (106 weeks) was used. }\end{array}$ \\
\hline \multicolumn{2}{|l|}{ Confounding } \\
\hline Confounding & $\begin{array}{l}++ \\
\text { Drinking water contained } 44.7 \mathrm{ug} / \mathrm{l} \text { of dihaloacetic acids and } 3.8 \mathrm{ug} / \mathrm{l} \text { of } \\
\text { dibromoacetic acid. }\end{array}$ \\
\hline \multicolumn{2}{|l|}{ Reporting and analysis } \\
\hline Reporting data and statistics & $\begin{array}{l}+++ \\
\text { Appropriate statistical analyses were reported. }\end{array}$ \\
\hline Combining lesions & $\begin{array}{l}+++ \\
\text { Tumor combinations were appropriate. }\end{array}$ \\
\hline
\end{tabular}

Overall utility: +++. Large numbers of animals per group were used in both sexes and were continuously monitored for disease. Three dose levels spanning a range of 200-fold were used. Lesions and all major organs were histologically evaluated and statistics were clearly reported. 
Table C-33. NTP 2007a (F Mouse): Dibromoacetic Acid: Drinking Water

\begin{tabular}{|c|c|}
\hline $\begin{array}{c}\text { Study Utility Domain and } \\
\text { Question }\end{array}$ & Rating and Rationale \\
\hline \multicolumn{2}{|l|}{ Study design } \\
\hline Randomization & $\begin{array}{l}+++ \\
\text { Animals were randomly assigned to exposure groups. }\end{array}$ \\
\hline Controls & $\begin{array}{l}+++ \\
\text { Concurrent vehicle controls were used. }\end{array}$ \\
\hline Historical data & Yes \\
\hline Animal model (sensitivity) & $\begin{array}{l}+++ \\
\text { Both sexes of non-transgenic animals were used. }\end{array}$ \\
\hline Statistical power (sensitivity) & $\begin{array}{l}+++ \\
\text { Large numbers of animals }(50) \text { were used for each group. }\end{array}$ \\
\hline \multicolumn{2}{|l|}{ Exposure } \\
\hline Chemical characterization & $\begin{array}{l}+++ \\
\text { Chemical purity and stability were well characterized. }\end{array}$ \\
\hline Dosing regimen & $\begin{array}{l}+++ \\
\text { There was no significant difference in survival or body weight. There was a } \\
\text { significant increase in neoplasm incidence. }\end{array}$ \\
\hline Exposure duration (sensitivity) & $\begin{array}{l}+++ \\
\text { A near life-span duration (106 weeks) was used. }\end{array}$ \\
\hline Dose-response (sensitivity) & $\begin{array}{l}+++ \\
\text { Three exposure levels were used that spanned a range of } 20 \text {-fold. }\end{array}$ \\
\hline \multicolumn{2}{|l|}{ Outcome } \\
\hline Pathology & $\begin{array}{l}+++ \\
\text { All major organs and gross lesions were histologically evaluated and findings } \\
\text { were verified by an independent pathologist. }\end{array}$ \\
\hline Consistency between groups & $\begin{array}{l}+++ \\
\text { All groups were treated the same. }\end{array}$ \\
\hline Study duration (sensitivity) & $\begin{array}{l}+++ \\
\text { A near life-span duration (106 weeks) was used. }\end{array}$ \\
\hline \multicolumn{2}{|l|}{ Confounding } \\
\hline Confounding & $\begin{array}{l}++ \\
\text { Drinking water contained } 44.7 \mathrm{ug} / \mathrm{l} \text { of dihaloacetic acids and } 3.8 \mathrm{ug} / \mathrm{l} \text { of } \\
\text { dibromoacetic acid. }\end{array}$ \\
\hline \multicolumn{2}{|l|}{ Reporting and analysis } \\
\hline Reporting data and statistics & $\begin{array}{l}+++ \\
\text { Appropriate statistical analyses were reported. }\end{array}$ \\
\hline Combining lesions & $\begin{array}{l}+++ \\
\text { Tumor combinations were appropriate. }\end{array}$ \\
\hline
\end{tabular}

Overall utility: +++. Large numbers of animals per group were used in both sexes and were continuously monitored for disease. Three dose levels spanning a range of 200 -fold were used. Lesions and all major organs were histologically evaluated and statistics were clearly reported. 
Table C-34. NTP 2007a (M Rat): Dibromoacetic Acid: Drinking Water

\begin{tabular}{|c|c|}
\hline $\begin{array}{l}\text { Study Utility Domain and } \\
\text { Question }\end{array}$ & Rating and Rationale \\
\hline \multicolumn{2}{|l|}{ Study design } \\
\hline Randomization & $\begin{array}{l}+++ \\
\text { Animals were randomly assigned to exposure groups. }\end{array}$ \\
\hline Controls & $\begin{array}{l}+++ \\
\text { Concurrent vehicle controls were used. }\end{array}$ \\
\hline Historical data & Yes \\
\hline Animal model (sensitivity) & $\begin{array}{l}+++ \\
\text { Both sexes of non-transgenic animals were used. }\end{array}$ \\
\hline Statistical power (sensitivity) & $\begin{array}{l}+++ \\
\text { Large numbers of animals }(50) \text { were used for each group. }\end{array}$ \\
\hline \multicolumn{2}{|l|}{ Exposure } \\
\hline Chemical characterization & $\begin{array}{l}+++ \\
\text { Chemical purity and stability were well characterized. }\end{array}$ \\
\hline Dosing regimen & $\begin{array}{l}++ \\
\text { There was no significant difference in survival, but there was a significant } \\
\text { decrease in body weight. There was no significant increase in neoplasm } \\
\text { incidence but was a significant increase in preneoplasm incidence. }\end{array}$ \\
\hline Exposure duration (sensitivity) & $\begin{array}{l}+++ \\
\text { A near life-span duration (106 weeks) was used. }\end{array}$ \\
\hline Dose-response (sensitivity) & $\begin{array}{l}+++ \\
\text { Three exposure levels were used that spanned a range of } 20 \text {-fold. }\end{array}$ \\
\hline \multicolumn{2}{|l|}{ Outcome } \\
\hline Pathology & $\begin{array}{l}+++ \\
\text { All major organs and gross lesions were histologically evaluated and findings } \\
\text { were verified by an independent pathologist. }\end{array}$ \\
\hline Consistency between groups & $\begin{array}{l}+++ \\
\text { All groups were treated the same. }\end{array}$ \\
\hline Study duration (sensitivity) & $\begin{array}{l}+++ \\
\text { A near life-span duration (106 weeks) was used. }\end{array}$ \\
\hline \multicolumn{2}{|l|}{ Confounding } \\
\hline Confounding & $\begin{array}{l}++ \\
\text { Drinking water contained } 44.7 \mathrm{ug} / \mathrm{l} \text { of dihaloacetic acids and } 3.8 \mathrm{ug} / \mathrm{l} \text { of } \\
\text { dibromoacetic acid. }\end{array}$ \\
\hline \multicolumn{2}{|l|}{ Reporting and analysis } \\
\hline Reporting data and statistics & $\begin{array}{l}+++ \\
\text { Appropriate statistical analyses were reported. }\end{array}$ \\
\hline Combining lesions & $\begin{array}{l}+++ \\
\text { Tumor combinations were appropriate. }\end{array}$ \\
\hline
\end{tabular}

Overall utility: +++. Large numbers of animals per group were used in both sexes and were continuously monitored for disease. Three dose levels spanning a range of 200-fold were used. Lesions and all major organs were histologically evaluated and statistics were clearly reported. 
Table C-35. NTP 2007a (F Rat): Dibromoacetic Acid: Drinking Water

\begin{tabular}{ll}
\multicolumn{1}{c}{$\begin{array}{c}\text { Study Utility Domain and } \\
\text { Question }\end{array}$} & \multicolumn{1}{c}{ Rating and Rationale } \\
\hline Study design & \\
Randomization & +++ \\
& Animals were randomly assigned to exposure groups. \\
Controls & +++ \\
& Concurrent vehicle controls were used. \\
Historical data & Yes \\
Animal model (sensitivity) & +++ \\
& Both sexes of non-transgenic animals were used. \\
Statistical power (sensitivity) & +++ \\
& Large numbers of animals (50) were used for each group. \\
\hline
\end{tabular}

\section{Exposure}

Chemical characterization

$+++$

Chemical purity and stability were well characterized.

Dosing regimen

$+++$

There was no significant difference in survival, but there was a significant decrease in body weight. There was no significant increase in neoplasm incidence but was a significant increase in preneoplasm incidence.

Exposure duration (sensitivity) $\quad+++$

A near life-span duration (106 weeks) was used.

Dose-response (sensitivity) $\quad+++$

Three exposure levels were used that spanned a range of 20 -fold.

\section{Outcome}

Pathology

$+++$

All major organs and gross lesions were histologically evaluated and findings were verified by an independent pathologist.

Consistency between groups $\quad+++$

All groups were treated the same.

Study duration (sensitivity) $\quad+++$

A near life-span duration (106 weeks) was used.

\section{Confounding}

Confounding

$++$

Drinking water contained $44.7 \mathrm{ug} / \mathrm{l}$ of dihaloacetic acids and $3.8 \mathrm{ug} / \mathrm{l}$ of dibromoacetic acid.

\section{Reporting and analysis}

Reporting data and statistics

$+++$

Appropriate statistical analyses were reported.

Combining lesions

$+++$

Tumor combinations were appropriate.

Overall utility: +++. Large numbers of animals per group were used in both sexes and were continuously monitored for disease. Three dose levels spanning a range of 200-fold were used. Lesions and all major organs were histologically evaluated and statistics were clearly reported. 


\section{C.5. Bromochloroacetic Acid: Study Quality for Animal Studies}

\section{Table C-36. NTP 2009 (M Rat): Bromochloroacetic Acid: Drinking Water}

\begin{tabular}{|c|c|}
\hline $\begin{array}{l}\text { Study Utility Domain and } \\
\text { Question }\end{array}$ & Rating and Rationale \\
\hline \multicolumn{2}{|l|}{ Study design } \\
\hline Randomization & $\begin{array}{l}+++ \\
\text { Animals were randomly assigned to exposure groups with initial body weights } \\
\text { the same for each group. }\end{array}$ \\
\hline Controls & $\begin{array}{l}+++ \\
\text { Concurrent vehicle controls were used. }\end{array}$ \\
\hline Historical data & Yes \\
\hline Animal model (sensitivity) & $\begin{array}{l}+++ \\
\text { Both sexes of non-transgenic animals were used and the strain is in common } \\
\text { use. }\end{array}$ \\
\hline Statistical power (sensitivity) & $\begin{array}{l}+++ \\
\text { Large numbers of animals }(50) \text { were used for each group. }\end{array}$ \\
\hline
\end{tabular}

\section{Exposure}

Chemical characterization

$+++$

Chemical purity and stability were well characterized.

Dosing regimen

$+++$

There was no significant difference in survival, but there was a significant decrease in body weight and a significant increase in neoplasm incidence.

Exposure duration (sensitivity) +++

A near life-span duration (105 weeks) was used.

Dose-response (sensitivity) $\quad+++$

Three exposure levels were used that spanned a range of 4-fold.

\section{Outcome}

Pathology

$+++$

All major organs and gross lesions were histologically evaluated and findings were verified by an independent pathologist.

Consistency between groups

$+++$

All groups were treated the same.

Study duration (sensitivity)

$+++$

A near life-span duration (105 weeks) was used.

\section{Confounding}

Confounding

$+++$

The test agent was well characterized, animals were treated the same between groups, and were continually monitored for infectious diseases.

\section{Reporting and analysis}

Reporting data and statistics

$+++$

Appropriate statistical analyses were reported.

Combining lesions

$+++$

Tumor combinations were appropriate.

Overall utility: +++. A very high-quality study, with no major concerns. 
Table C-37. NTP 2009 (F Rat): Bromochloroacetic Acid: Drinking Water

\begin{tabular}{|c|c|}
\hline $\begin{array}{l}\text { Study Utility Domain and } \\
\text { Question }\end{array}$ & Rating and Rationale \\
\hline \multicolumn{2}{|l|}{ Study design } \\
\hline Randomization & $\begin{array}{l}+++ \\
\text { Animals were randomly assigned to exposure groups with initial body weights } \\
\text { the same for each group. }\end{array}$ \\
\hline Controls & $\begin{array}{l}+++ \\
\text { Concurrent vehicle controls were used. }\end{array}$ \\
\hline Historical data & Yes \\
\hline Animal model (sensitivity) & $\begin{array}{l}+++ \\
\text { Both sexes of non-transgenic animals were used and the strain is in common } \\
\text { use. }\end{array}$ \\
\hline Statistical power (sensitivity) & $\begin{array}{l}+++ \\
\text { Large numbers of animals (50) were used for each group. }\end{array}$ \\
\hline \multicolumn{2}{|l|}{ Exposure } \\
\hline Chemical characterization & $\begin{array}{l}+++ \\
\text { Chemical purity and stability were well characterized. }\end{array}$ \\
\hline Dosing regimen & $\begin{array}{l}++ \\
\text { There was no significant difference in survival, but there was a significant } \\
\text { decrease in body weight and a significant increase in neoplasm incidence. }\end{array}$ \\
\hline Exposure duration (sensitivity) & $\begin{array}{l}+++ \\
\text { A near life-span duration (105 weeks) was used. }\end{array}$ \\
\hline Dose-response (sensitivity) & $\begin{array}{l}+++ \\
\text { Three exposure levels were used that spanned a range of } 4 \text {-fold. }\end{array}$ \\
\hline \multicolumn{2}{|l|}{ Outcome } \\
\hline Pathology & $\begin{array}{l}+++ \\
\text { All major organs and gross lesions were histologically evaluated and findings } \\
\text { were verified by an independent pathologist. }\end{array}$ \\
\hline Consistency between groups & $\begin{array}{l}+++ \\
\text { All groups were treated the same. }\end{array}$ \\
\hline Study duration (sensitivity) & $\begin{array}{l}+++ \\
\text { A near life-span duration (105 weeks) was used. }\end{array}$ \\
\hline \multicolumn{2}{|l|}{ Confounding } \\
\hline Confounding & $\begin{array}{l}+++ \\
\text { The test agent was well characterized, animals were treated the same between } \\
\text { groups, and were continually monitored for infectious diseases. }\end{array}$ \\
\hline \multicolumn{2}{|l|}{ Reporting and analysis } \\
\hline Reporting data and statistics & $\begin{array}{l}+++ \\
\text { Appropriate statistical analyses were reported. }\end{array}$ \\
\hline Combining lesions & $\begin{array}{l}+++ \\
\text { Tumor combinations were appropriate. }\end{array}$ \\
\hline
\end{tabular}

Overall utility: +++. A very high-quality study, with no major concerns. 
Table C-38. NTP 2009 (M Mouse): Bromochloroacetic Acid: Drinking Water

Study Utility Domain and
Question $\quad$ Rating and Rationale

\begin{tabular}{|c|c|}
\hline \multicolumn{2}{|l|}{ Study design } \\
\hline Randomization & $\begin{array}{l}+++ \\
\text { Animals were randomly assigned to exposure groups with initial body weights } \\
\text { the same for each group. }\end{array}$ \\
\hline Controls & $\begin{array}{l}+++ \\
\text { Concurrent vehicle controls were used. }\end{array}$ \\
\hline Historical data & Yes \\
\hline Animal model (sensitivity) & $\begin{array}{l}+++ \\
\text { Both sexes of non-transgenic animals were used and the strain is in common } \\
\text { use. }\end{array}$ \\
\hline Statistical power (sensitivity) & $\begin{array}{l}+++ \\
\text { Large numbers of animals (50) were used for each group. }\end{array}$ \\
\hline \multicolumn{2}{|l|}{ Exposure } \\
\hline Chemical characterization & $\begin{array}{l}+++ \\
\text { Chemical purity and stability were well characterized. }\end{array}$ \\
\hline Dosing regimen & $\begin{array}{l}+++ \\
\text { There was no significant difference in survival, but there was a significant } \\
\text { decrease in body weight and a significant increase in neoplasm incidence. }\end{array}$ \\
\hline Exposure duration (sensitivity) & $\begin{array}{l}+++ \\
\text { A near life-span duration (105 weeks) was used. }\end{array}$ \\
\hline Dose-response (sensitivity) & $\begin{array}{l}+++ \\
\text { Three exposure levels were used that spanned a range of } 4 \text {-fold. }\end{array}$ \\
\hline \multicolumn{2}{|l|}{ Outcome } \\
\hline Pathology & $\begin{array}{l}+++ \\
\text { All major organs and gross lesions were histologically evaluated and findings } \\
\text { were verified by an independent pathologist. }\end{array}$ \\
\hline Consistency between groups & $\begin{array}{l}+++ \\
\text { All groups were treated the same. }\end{array}$ \\
\hline Study duration (sensitivity) & $\begin{array}{l}+++ \\
\text { A near life-span duration (105 weeks) was used. }\end{array}$ \\
\hline \multicolumn{2}{|l|}{ Confounding } \\
\hline Confounding & $\begin{array}{l}\text { The test agent was well characterized, animals were treated the same between } \\
\text { groups, and were continually monitored for infectious diseases. }\end{array}$ \\
\hline \multicolumn{2}{|l|}{ Reporting and analysis } \\
\hline Reporting data and statistics & $\begin{array}{l}+++ \\
\text { Appropriate statistical analyses were reported. }\end{array}$ \\
\hline Combining lesions & $\begin{array}{l}+++ \\
\text { Tumor combinations were appropriate. }\end{array}$ \\
\hline
\end{tabular}


Table C-39. NTP 2009 (F Mouse): Bromochloroacetic Acid: Drinking Water

\begin{tabular}{|c|c|}
\hline $\begin{array}{c}\text { Study Utility Domain and } \\
\text { Question }\end{array}$ & Rating and Rationale \\
\hline \multicolumn{2}{|l|}{ Study design } \\
\hline Randomization & $\begin{array}{l}+++ \\
\text { Animals were randomly assigned to exposure groups with initial body weights } \\
\text { the same for each group. }\end{array}$ \\
\hline Controls & $\begin{array}{l}+++ \\
\text { Concurrent vehicle controls were used. }\end{array}$ \\
\hline Historical data & Yes \\
\hline Animal model (sensitivity) & $\begin{array}{l}+++ \\
\text { Both sexes of non-transgenic animals were used and the strain is in common } \\
\text { use. }\end{array}$ \\
\hline Statistical power (sensitivity) & $\begin{array}{l}+++ \\
\text { Large numbers of animals }(50) \text { were used for each group. }\end{array}$ \\
\hline \multicolumn{2}{|l|}{ Exposure } \\
\hline Chemical characterization & $\begin{array}{l}+++ \\
\text { Chemical purity and stability were well characterized. }\end{array}$ \\
\hline Dosing regimen & $\begin{array}{l}+++ \\
\text { There was no significant difference in survival or body weight and there was a } \\
\text { significant increase in neoplasm incidence. }\end{array}$ \\
\hline Exposure duration (sensitivity) & $\begin{array}{l}+++ \\
\text { A near life-span duration (105 weeks) was used. }\end{array}$ \\
\hline Dose-response (sensitivity) & $\begin{array}{l}+++ \\
\text { Three exposure levels were used that spanned a range of } 4 \text {-fold. }\end{array}$ \\
\hline \multicolumn{2}{|l|}{ Outcome } \\
\hline Pathology & $\begin{array}{l}+++ \\
\text { All major organs and gross lesions were histologically evaluated and findings } \\
\text { were verified by an independent pathologist. }\end{array}$ \\
\hline Consistency between groups & $\begin{array}{l}+++ \\
\text { All groups were treated the same. }\end{array}$ \\
\hline Study duration (sensitivity) & $\begin{array}{l}+++ \\
\text { A near life-span duration (105 weeks) was used. }\end{array}$ \\
\hline \multicolumn{2}{|l|}{ Confounding } \\
\hline Confounding & $\begin{array}{l}+++ \\
\text { The test agent was well characterized, animals were treated the same between } \\
\text { groups, and were continually monitored for infectious diseases. }\end{array}$ \\
\hline \multicolumn{2}{|l|}{ Reporting and analysis } \\
\hline Reporting data and statistics & $\begin{array}{l}+++ \\
\text { Appropriate statistical analyses were reported. }\end{array}$ \\
\hline Combining lesions & $\begin{array}{l}+++ \\
\text { Tumor combinations were appropriate. }\end{array}$ \\
\hline
\end{tabular}

Overall utility: +++. A very high-quality study, with no major concerns. 


\title{
C.6. Trichloroacetic Acid: Study Quality for Animal Studies
}

\section{Table C-40. DeAngelo et al. 1997 (M Rat): Trichloroacetic Acid: Drinking Water}

\author{
Study Utility Domain and \\ Question \\ Rating and Rationale
}

\begin{tabular}{ll}
\hline Study design & \\
Randomization & Not reported. \\
Controls & +++ \\
& $\begin{array}{l}\text { Concurrent vehicle controls of sodium chloride at equal molar concentrations as } \\
\text { the trichloroacetic acid high dose group were used. }\end{array}$ \\
Historical data & No \\
Animal model (sensitivity) & ++ \\
& Only males of non-transgenic animals were used. \\
Statistical power (sensitivity) & ++
\end{tabular}

\section{Exposure}

Chemical characterization

$+++$

Chemical purity and stability were well characterized.

Dosing regimen

$++ \pm^{\mathrm{a}}$

There was no significant difference in survival, but there was a significant increase in body weight. There was no significant difference in neoplasm incidence.

Exposure duration (sensitivity) $\quad+++$

A near life-span duration (104 weeks) was used.

Dose-response (sensitivity) $\quad+++$

Three exposure levels were used that spanned a range of 100-fold.

\section{Outcome}

Pathology

$+++$

Full necropsies with histological evaluations were performed.

Consistency between groups $\quad+++$

Groups were not reported to have been treated differently.

Study duration (sensitivity)

$+++$

A near life-span duration (104 weeks) was used.

\section{Confounding}

Confounding

$+++$

The rats were confirmed pathogen free and the chemical purity and stability were confirmed.

\section{Reporting and analysis}

Reporting data and statistics

$+++$

Appropriate statistical analyses were reported.

Combining lesions

$+++$

Lesions were reported, which included liver hyperplasia, adenomas, and carcinomas. The authors felt the hyperplasia were preneoplastic.

Overall utility: +++. A well conducted study on almost all aspects, but it only involved male rats.

aERRATUM: Errors were identified in the Report on Carcinogens Monograph on Haloacetic Acids Found as Water Disinfection By-products. The number of + signs in this cell was incorrect in the original table. This error has been corrected; one + sign was added and underlined. 
Table C-41. DeAngelo 2008 (M Mouse [Study 1]): Trichloroacetic Acid: Drinking Water

\begin{tabular}{|c|c|}
\hline $\begin{array}{l}\text { Study Utility Domain and } \\
\text { Question }\end{array}$ & Rating and Rationale \\
\hline \multicolumn{2}{|l|}{ Study design } \\
\hline Randomization & $\begin{array}{l}+++ \\
\text { Animals were randomly assigned to exposure groups. }\end{array}$ \\
\hline Controls & $\begin{array}{l}+++ \\
\text { Concurrent vehicle controls of } 2 \mathrm{~g} / \mathrm{l} \text { of sodium chloride were used. }\end{array}$ \\
\hline Historical data & No \\
\hline Animal model (sensitivity) & $\begin{array}{l}\text { Only males of non-transgenic animals were used and the strain is in common } \\
\text { use. }\end{array}$ \\
\hline Statistical power (sensitivity) & $\begin{array}{l}+++ \\
\text { Moderate numbers of animals }(30) \text { were used for each group. }\end{array}$ \\
\hline
\end{tabular}

\section{Exposure}

Chemical characterization

$+++$

Chemical purity and stability were well characterized.

Dosing regimen

$+++$

There was no significant difference in survival or body weight and there was a significant increase in neoplasm incidence.

Exposure duration (sensitivity)

$++$

A less than life-span duration (60 weeks) was used.

Dose-response (sensitivity)

$+++$

Three exposed dose levels were used, which increased by 10 -fold each time, covering a wide dose range.

\section{Outcome}

Pathology

$+++$

A complete necropsy with histological examine was performed, including verification by an independent pathologist.

Consistency between groups $\quad++$

All tissues were evaluated from 5 mice of the high dose and negative control groups, while other mice had most organs and all organs with gross lesions histologically evaluated.

Study duration (sensitivity) + ++

A less than life-span duration (60 weeks) was used.

\section{Confounding}

Confounding

$+++$

Infectious disease detection was used and the vehicle control was appropriate.

\section{Reporting and analysis}

Reporting data and statistics

$+++$

Appropriate statistical analyses were reported.

Combining lesions

$+++$

Only hepatocellular adenomas and carcinomas were combined.

Overall utility: +++. Three dose levels were used that spanned a 100-fold range. Most organs were histologically evaluated and evaluations were confirmed by an independent pathologist. 
Table C-42. DeAngelo 2008 (M Mouse [Study 2]): Trichloroacetic Acid: Drinking Water

\section{Study Utility Domain and Question \\ Rating and Rationale}

\section{Study design}

Randomization

$+++$

Animals were randomly assigned to exposure groups.

Controls

$+++$

Concurrent vehicle controls of $1.5 \mathrm{~g} / \mathrm{l}$ of neutralized acetic acid in drinking water was used.

Historical data No

Animal model (sensitivity) $\quad+++$

Only males of non-transgenic animals were used and the strain is in common use.

Statistical power (sensitivity) +++

A large number of animals (42-51) were used for each group.

\section{Exposure}

Chemical characterization

$+++$

Chemical purity and stability were well characterized.

Dosing regimen

$+++$

There was no significant difference in survival or body weight and there was a significant increase in neoplasm incidence.

Exposure duration (sensitivity)

$+++$

A near life-span duration (104 weeks) was used.

Dose-response (sensitivity)

$+$

Only one exposure level was used.

\section{Outcome}

Pathology

$+++$

A complete necropsy with histological examine was performed, including verification by an independent pathologist.

Consistency between groups

$+++$

All treatment groups appear to have been treated similarly.

Study duration (sensitivity)

$+++$

A near life-span duration (104 weeks) was used.

\section{Confounding}

Confounding

$+++$

Infectious disease detection was used and husbandry was reported. Vehicle control was appropriate, though not ideal.

\section{Reporting and analysis}

Reporting data and statistics

$+++$

Appropriate statistical analyses were reported.

Combining lesions

$+++$

Only hepatocellular adenomas and carcinomas were combined.

Overall utility: ++. Only one dose level was tested but was given for a near life-span of a large number of animals. Most organs were histologically evaluated and evaluations were confirmed by an independent pathologist. 
Table C-43. DeAngelo 2008 (M Mouse [Study 3]): Trichloroacetic Acid: Drinking Water

\begin{tabular}{|c|c|}
\hline $\begin{array}{l}\text { Study Utility Domain and } \\
\text { Question }\end{array}$ & Rating and Rationale \\
\hline \multicolumn{2}{|l|}{ Study design } \\
\hline Randomization & $\begin{array}{l}+++ \\
\text { Mice were randomly assigned to exposure groups. }\end{array}$ \\
\hline Controls & $\begin{array}{l}+++ \\
\text { Concurrent vehicle controls of neutralized drinking water was used. }\end{array}$ \\
\hline Historical data & No \\
\hline Animal model (sensitivity) & $\begin{array}{l}+++ \\
\text { Only males of non-transgenic animals were used and the strain is in common } \\
\text { use. }\end{array}$ \\
\hline Statistical power (sensitivity) & $\begin{array}{l}+++ \\
\text { Large numbers of animals }(51-53) \text { were used for each group. }\end{array}$ \\
\hline
\end{tabular}

\section{Exposure}

Chemical characterization

$+++$

Chemical purity and stability were well characterized.

Dosing regimen

$++$

There was no significant difference in survival or body weight and there was a significant increase in neoplasm incidence, but the highest level was low compared to the other studies by this author.

Exposure duration (sensitivity)

$+++$

A near life-span duration (104 weeks) was used.

Dose-response (sensitivity) ++

Two expose levels were used that spanned a range of 10-fold.

\section{Outcome}

Pathology

$+++$

A complete necropsy with histological examine was performed, including verification by an independent pathologist.

Consistency between groups $\quad+++$

All exposure groups appear to have been treated similarly.

Study duration (sensitivity)

$+++$

A near life-span duration (104 weeks) was used.

\section{Confounding}

Confounding

$+++$

Infectious disease detection was used and the vehicle control was appropriate.

\section{Reporting and analysis}

Reporting data and statistics

$+++$

Appropriate statistical analyses were reported.

Combining lesions

+++

Only hepatocellular adenomas and carcinomas were combined.

Overall utility: ++. Only two dose levels were tested but they were low compared to other studies and were given for near a life-span of time to a large number of animals. Most organs were histologically evaluated and evaluations were confirmed by an independent pathologist. 
Table C-44. Herren-Freund et al. 1987 (M Mouse): Trichloroacetic Acid: Drinking Water

\section{Study Utility Domain and Question \\ Rating and Rationale}

\section{Study design}

Randomization

Not reported.

Controls

$+++$

Concurrent vehicle controls of $2 \mathrm{~g} / \mathrm{l}$ of sodium chloride to match that found in exposed groups and a positive control of phenobarbital at $500 \mathrm{mg} / \mathrm{l}$ (positive controls are not reported here) were used.

Historical data

Animal model (sensitivity)

Statistical power (sensitivity)

\section{No}

$++$

Only males of non-transgenic animals were used.

$++$

Moderate numbers of animals (22-26) were used for each group.

\section{Exposure}

Chemical characterization

$+++$

Chemical purity and stability were well characterized.

Dosing regimen

$+++$

Survival was not reported and body weight was significantly decreased. There was a significant increase in neoplasm incidence.

Exposure duration (sensitivity)

$+++$

A less than life-span duration (61 weeks) was used.

Dose-response (sensitivity)

One exposure level was used, so dose response relationships could not be measured.

\section{Outcome}

Pathology

$++$

Only the liver was histologically examined.

Consistency between groups $\quad+++$

All groups were treated the same.

Study duration (sensitivity) $\quad+++$

A less than life-span duration (61 weeks) was used.

\section{Confounding}

Confounding

$+++$

Disease surveillance was not reported, but chemical purity and stability were tested.

\section{Reporting and analysis}

Reporting data and statistics

$+++$

Appropriate statistical analyses were reported.

Combining lesions

$+++$

Tumor types were not combined.

Overall utility: ++. The durations were less than near life-span. Only males were tested at a single dose level and only livers were histologically evaluated. 
Table C-45. Herren-Freund et al. 1987 (M Mouse): Trichloroacetic Acid: Drinking Water (I/P)

\section{Study Utility Domain and Question \\ Rating and Rationale}

\section{Study design}

Randomization

Not reported.

Controls

$+++$

Concurrent vehicle controls of $2 \mathrm{~g} / \mathrm{l}$ of sodium chloride to match that found in exposed groups and a positive control of phenobarbital at $500 \mathrm{mg} / \mathrm{l}$ (positive controls are not reported here) were used.

Historical data

Animal model (sensitivity)

Statistical power (sensitivity)

\section{No}

$++$

Only males of non-transgenic animals were used.

$++$

Moderate numbers of animals (22-26) were used for each group.

\section{Exposure}

Chemical characterization

$+++$

Chemical purity and stability were well characterized.

Dosing regimen

$+++$

Survival was not reported and body weight was significantly decreased. There was a significant increase in neoplasm incidence.

Exposure duration (sensitivity)

$+++$

A less than life-span duration (61 weeks) was used.

Dose-response (sensitivity)

$+$

Two exposure levels were used which spanned a range of 2.5 -fold.

\section{Outcome}

Pathology

$++$

Only the liver was histologically examined.

Consistency between groups

$+++$

All groups were treated the same.

Study duration (sensitivity) $\quad+++$

A less than life-span duration (61 weeks) was used.

\section{Confounding}

Confounding

$+++$

Disease surveillance was not reported, but chemical purity and stability were tested.

\section{Reporting and analysis}

Reporting data and statistics

$+++$

Appropriate statistical analyses were reported.

Combining lesions

$+++$

Tumor types were not combined.

Overall utility: ++. The duration was less than near life-span. Only males were tested at two narrow dose levels and only livers were histologically evaluated. 
Table C-46. Pereira 1996 (F Mouse [Study 1]): Trichloroacetic Acid (TCA): Drinking Water

\section{Study Utility Domain and Question

\author{
Rating and Rationale
}

\section{Study design}

Randomization

$+++$

It was not reported if animals were randomly assigned to exposure groups, but they were necropsied blinded and the mice were randomly assigned an ID number, which suggests they were randomly assigned to treatment groups, but it is not known for sure.

Controls

$+++$

Concurrent vehicle controls of sodium chloride at equal molar concentrations as in the high dose group were used.

Historical data

No

Animal model (sensitivity)

$++$

Only females of non-transgenic animals were used.

Statistical power (sensitivity) $\quad++$

The number of animals (15-90) varied considerably for each group.

\section{Exposure}

Chemical characterization

Chemical purity and stability were not reported.

Dosing regimen

$$
+++
$$

Survival was not reported, but there was a significant decreased in body weight and a significant increase in neoplasm incidence.

Exposure duration (sensitivity) $\quad+++$

A near life-span duration (576 days) was used.

Dose-response (sensitivity) $\quad+++$

Three exposure levels were used that spanned a range of 10-fold.

\section{Outcome}

Pathology

$$
++
$$

Only the liver was histologically examined.

Consistency between groups $\quad+++$

Groups were not reported to have been treated differently.

Study duration (sensitivity)

$+++$

A near life-span duration (576 days) was used.

\section{Confounding}

Confounding

$++$

Continual disease surveillance and survival were not reported. The high exposure group had a significant decrease in water consumption.

\section{Reporting and analysis}

Reporting data and statistics

$+++$

Appropriate statistical analyses were reported.

Combining lesions

$$
+++
$$

Lesions were reported, which included liver foci, adenomas, and carcinomas.

The authors felt the foci were preneoplastic.

Overall utility: ++. The chemicals were not characterized, not even purity was reported. Disease surveillance was not continually monitored. A variable number of only females were tested, with only their livers examined histologically. 
Table C-47. Pereira 1996 (F Mouse [Study 2]): Trichloroacetic Acid (TCA): Drinking Water

\section{Study Utility Domain and Question

\author{
Rating and Rationale
}

\section{Study design}

Randomization

$+++$

It was not reported if animals were randomly assigned to exposure groups, but they were necropsied blinded and the mice were randomly assigned an ID number, which suggests they were randomly assigned to treatment groups, but it is not known for sure.

Controls

$+++$

Concurrent vehicle controls of sodium chloride at equal molar concentrations as in the high dose group were used.

Historical data

Animal model (sensitivity)

Statistical power (sensitivity)
No

$++$

Only females of non-transgenic animals were used.

$++$

The number of animals (15-90) varied considerably for each group.

\section{Exposure}

Chemical characterization

Chemical purity and stability were not reported.

Dosing regimen

$$
+++
$$

Survival was not reported, but there was a significant decreased in body weight and a significant increase in neoplasm incidence.

Exposure duration (sensitivity) ++

A less than life-span duration (360 days) was used.

Dose-response (sensitivity) $\quad+++$

Three exposure levels were used that spanned a range of 10-fold.

\section{Outcome}

Pathology

$++$

Only the liver was histologically examined.

Consistency between groups $\quad+++$

Groups were not reported to have been treated differently.

Study duration (sensitivity)

$+++$

A less than life-span duration (360 days) was used.

\section{Confounding}

Confounding

$++$

Continual disease surveillance and survival were not reported. The high exposure group had a significant decrease in water consumption.

\section{Reporting and analysis}

Reporting data and statistics

$+++$

Appropriate statistical analyses were reported.

Combining lesions

$$
+++
$$

Lesions were reported, which included liver foci, adenomas, and carcinomas.

The authors felt the foci were preneoplastic.

Overall utility: ++ . The chemicals were not characterized, not even purity was reported. Disease surveillance was not continually monitored. A variable number of only females were tested, with only their livers examined histologically. 
Table C-48. Pereira et al. 1997 (F Mouse): TCA: Drinking Water (I/P)

\section{Study Utility Domain and}

Question

\section{Rating and Rationale}

\begin{tabular}{|c|c|}
\hline \multicolumn{2}{|l|}{ Study design } \\
\hline Randomization & $\begin{array}{l}+++ \\
\text { Animals were randomly assigned to exposure groups with initial body weights } \\
\text { the same for each group. }\end{array}$ \\
\hline Controls & $\begin{array}{l}+++ \\
\text { Concurrent controls were appropriate for an initiation/promotion study in } \\
\text { which all groups received the initiator (NMU) and the negative control group } \\
\text { was given only the initiator and promotor vehicle. }\end{array}$ \\
\hline Historical data & No \\
\hline Animal model (sensitivity) & $\begin{array}{l}++ \\
\text { Only females of non-transgenic animals were used. }\end{array}$ \\
\hline Statistical power (sensitivity) & $\begin{array}{l}++ \\
\text { Small, but sufficient numbers of animals }(>20) \text { were used for each group. }\end{array}$ \\
\hline
\end{tabular}

\section{Exposure}

Chemical characterization

Chemical purity and stability were not reported.

Dosing regimen

$+++$

There was no significant decrease in survival or body weight and there was a significant increase in neoplasm incidence.

Exposure duration (sensitivity)

$+++$

Animals were exposed for 44 weeks, starting 4 weeks after a single injection of the initiator. This is short for carcinogenicity studies, but initiation/promotion studies are normally shorter and tumors were significantly induced.

Dose-response (sensitivity) +++

Three exposure levels were used that spanned a range of 3-fold.

\section{Outcome}

Pathology

$++$

Consistency between groups $\quad+++$

Only the liver was histologically examined.

Groups were not reported to have been treated differently.

Study duration (sensitivity)

$+++$

A less than near life-span duration (48 weeks) was used, but initiation/promotion studies are normally short.

\section{Confounding}

Confounding

$++$

Continual disease surveillance and survival were not reported.

\section{Reporting and analysis}

Reporting data and statistics

$++$

Significance levels were reported, but the statistical test was not reported.

Combining lesions

$+++$

Lesions were reported, which included liver foci, adenomas, and carcinomas.

The authors felt the foci were preneoplastic.

Overall utility: + . The chemicals were not characterized, not even purity was reported. Disease surveillance was not reported. A low number of only females were tested, with only their livers examined histologically. The statistical methods were not reported. 
Table C-49. Bull et al. 1990 (M Mouse): Trichloroacetic Acid: Drinking Water

\begin{tabular}{|c|c|}
\hline $\begin{array}{l}\text { Study Utility Domain and } \\
\text { Question }\end{array}$ & Rating and Rationale \\
\hline \multicolumn{2}{|l|}{ Study design } \\
\hline Randomization & +++ \\
\hline Controls & $\begin{array}{l}\text { Animals were randomly assigned to exposure groups. } \\
+++ \\
\text { Concurrent vehicle controls were used. }\end{array}$ \\
\hline Historical data & \\
\hline Animal model (sensitivity) & \\
\hline Statistical power (sensitivity) & $\begin{array}{l}\text { Only males of non-transgenic animals were used. } \\
+ \\
\text { Small numbers of animals }(11-24) \text { were used for each group. }\end{array}$ \\
\hline \multicolumn{2}{|r|}{ 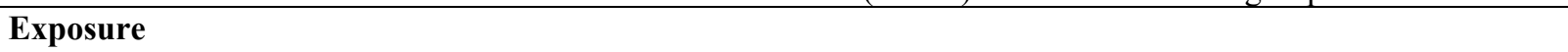 } \\
\hline Chemical characterization & ++ \\
\hline Dosing regimen & $\begin{array}{l}\text { Chemical purity and stability were not verified. } \\
+++ \\
\text { There were no deaths and body weight was not reported. There was a } \\
\text { significant increase in neoplasm incidence. }\end{array}$ \\
\hline Exposure duration (sensitivity) & \\
\hline Dose-response (sensitivity) & $\begin{array}{l}\text { A less than life-span duration ( } 52 \text { weeks) was used. } \\
++ \\
\text { Two exposure levels were used that spanned a range of 2-fold. }\end{array}$ \\
\hline \multicolumn{2}{|r|}{ 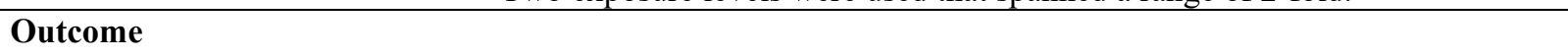 } \\
\hline Pathology & $\begin{array}{l}+ \\
\text { Only livers from some animals were histologically evaluated. Results only } \\
\text { reported overall lesions, which include hyperplasia. Liver lesions that were } \\
\text { histologically evaluated were randomly selected and blindly evaluated. }\end{array}$ \\
\hline Consistency between groups & $\begin{array}{l}\text { All untreated control lesions were histologically evaluated, but only some of } \\
\text { the exposed groups were. }\end{array}$ \\
\hline Study duration (sensitivity) & $\begin{array}{l}+++ \\
\text { A less than life-span duration ( } 52 \text { weeks) was used. }\end{array}$ \\
\hline \multicolumn{2}{|l|}{ Confounding } \\
\hline Confounding & $\begin{array}{l}+ \\
\text { Disease surveillance was not reported. Only samples of liver lesions were } \\
\text { histologically evaluated and inappropriately reported. }\end{array}$ \\
\hline \multicolumn{2}{|r|}{ 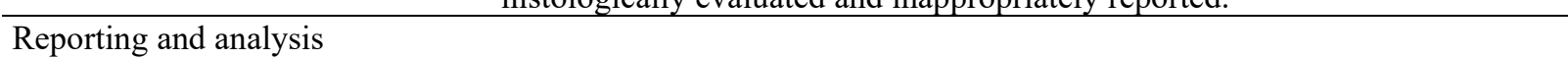 } \\
\hline Reporting data and statistics & $\begin{array}{l}+ \\
\text { Statistical evaluations were rarely reported and incidences that could be } \\
\text { significant by Fisher's Exact test (calculated by NTP) were not reported as } \\
\text { significant, so no NTP calculations were included. }\end{array}$ \\
\hline Combining lesions & $\begin{array}{l}\text { Only total lesions were adequately reported to allow for quantitation of the } \\
\text { results. These included liver hyperplasic nodules, hepatocellular adenoma, and } \\
\text { hepatocellular carcinoma, which entail and continuum of the same disease } \\
\text { process, however there were } 4 / 73 \text { lesions types that were also included but } \\
\text { were not hyperplastic or neoplastic. }\end{array}$ \\
\hline
\end{tabular}

Overall utility: + . The chemical was not characterized, disease surveillance was not reported. A low number of mice per group were exposed for a less than near life-span duration and only males had results reported. Only livers were histologically examined. Not all lesions were histologically evaluated, but instead samples of lesions were evaluated. Results were reported so that incidences of specific neoplasms could not be determined but could be estimated. 
Table C-50. Von Tungeln et al. 2002 (M+F Mouse [Study 1]): Trichloroacetic Acid: IP Injection

\section{Study Utility Domain and \\ Question

\author{
Rating and Rationale
}

\section{Study design \\ Randomization}

Controls

Historical data

Animal model (sensitivity)

Statistical power (sensitivity)

\section{Exposure}

Chemical characterization

Dosing regimen

Exposure duration (sensitivity)

Dose-response (sensitivity)

\section{Outcome}

Pathology

Consistency between groups

Study duration (sensitivity)

\section{Confounding}

Confounding

\section{Reporting and analysis}

Reporting data and statistics

Combining lesions

$+$

Randomization was not reported. However, survival during the first 28 days of age ranged from $100 \%$ to $71 \%$ (data not reported). After 28 days of age, surviving mice were allocated to each treatment group, after which survival was $92 \%$ or higher.

$$
+++
$$

Concurrent vehicle controls of DMSO and 4-aminobiphenyl positive controls were used.

\section{No}

$+++$

Both sexes of non-transgenic animals were used. Modifying factor is age of animals at study start.

$++$

Moderate numbers of animals (22-24) were used for each group.

Chemical purity and stability were not reported.

$+$

There was no significant difference in survival and body weight was not reported. There was no significant difference in neoplasm incidence.

\section{$+$}

Two doses were administered at the beginning of the study, no additional exposure occurred throughout the study.

$$
++
$$

Two exposure levels were used that spanned a range of 2-fold.

$++$

Necropsies and histological evaluations were stated to have occurred, but only incidences of liver tumors were reported.

$$
++
$$

Before the mice reached 28 days of age, mortality was as high as $29 \%$ and then a set number of the survivors were used for the remainder of the study. No information was reported about the early mortality.

$+++$

Duration was near life-span (20 months).

$$
++
$$

Mice were reported to be specific pathogen free, but mortality was high before the age of 28 days and this early mortality was not reported.

$$
+++
$$

Appropriate statistical analyses were reported.

$+++$

Only hepatocellular adenomas and carcinomas were combined.

Overall utility: ++ . The study used both positive and negative controls but did not characterize the chemicals and used a small, number of male mice per group. Only two doses were administered at two narrow dose levels, though the duration of observation was almost near life-span. Early mortality was not reported. 
Table C-51. Von Tungeln et al. 2002 (M+F Mouse [Study 2]): Trichloroacetic Acid: IP Injection

\section{Study Utility Domain and \\ Question

\author{
Rating and Rationale
}

\section{Study design \\ Randomization}

Controls

Historical data

Animal model (sensitivity)

Statistical power (sensitivity)

\section{Exposure}

Chemical characterization

Dosing regimen

Exposure duration (sensitivity)

Dose-response (sensitivity)

\section{Outcome}

Pathology

Consistency between groups

Study duration (sensitivity)

\section{Confounding}

Confounding

\section{Reporting and analysis}

Reporting data and statistics

Combining lesions

$+$

Randomization was not reported. However, survival during the first 28 days of age ranged from $100 \%$ to $71 \%$ (data not reported). After 28 days of age, surviving mice were allocated to each treatment group, after which survival was $92 \%$ or higher.

$$
+++
$$

Concurrent vehicle controls of DMSO and 4-aminobiphenyl positive controls were used.

\section{No}

$+++$

Both sexes of non-transgenic animals were used. Modifying factor is age of animals at study start.

$++$

Moderate numbers of animals (22-24) were used for each group.

Chemical purity and stability were not reported.

$+$

There was no significant difference in survival and body weight was not reported. There was no significant difference in neoplasm incidence after exposure of neonatal mouse to TCA.

\section{$+$}

Two doses were administered at the beginning of the study, no additional exposure occurred throughout the study.

\section{$++$}

Two exposure levels were used that spanned a range of 2-fold.

\section{$++$}

Necropsies and histological evaluations were stated to have occurred, but only incidences of liver tumors were reported.

$$
++
$$

Before the mice reached 28 days of age, mortality was as high as $29 \%$ and then a set number of the survivors were used for the remainder of the study. No information was reported about the early mortality.

$$
++
$$

Duration was less than life-span (12 months).

$++$

Mice were reported to be specific pathogen free, but mortality was high before the age of 28 days and this early mortality was not reported.

$+++$

Appropriate statistical analyses were reported.

$+++$

Only hepatocellular adenomas and carcinomas were combined.

Overall utility: ++ . The study used both positive and negative controls but did not characterize the chemicals and used a small, number of male mice per group. Only two doses were administered at two narrow dose levels, though the duration of observation was almost near life-span. Early mortality was not reported. 


\section{C.7. Bromodichloroacetic Acid: Study Quality for Animal Studies}

\section{Table C-52. NTP 2015 (M Rat): Bromodichloroacetic Acid: Drinking Water}

\begin{tabular}{|c|c|}
\hline $\begin{array}{l}\text { Study Utility Domain and } \\
\text { Question }\end{array}$ & Rating and Rationale \\
\hline \multicolumn{2}{|l|}{ Study design } \\
\hline Randomization & $\begin{array}{l}+++ \\
\text { Animals were randomly assigned to exposure groups but were not blinded. }\end{array}$ \\
\hline Controls & $\begin{array}{l}+++ \\
\text { Concurrent vehicle controls were used. }\end{array}$ \\
\hline Historical data & Yes \\
\hline Animal model (sensitivity) & $\begin{array}{l}+++ \\
\text { Both sexes of non-transgenic animals were used. }\end{array}$ \\
\hline Statistical power (sensitivity) & $\begin{array}{l}+++ \\
\text { Large numbers of animals }(50) \text { were used for each group. }\end{array}$ \\
\hline
\end{tabular}

\section{Exposure}

Chemical characterization

$+++$

Chemical purity and stability were well characterized.

Dosing regimen

$+++$

There was no significant decrease in survival, but there was a decrease in body weight and a significant increase in neoplasm incidence.

Exposure duration (sensitivity)

$+++$

A near life-span duration (105 weeks) was used.

Dose-response (sensitivity)

$+++$

Three exposure levels were used that spanned a range of 4-fold.

\section{Outcome}

Pathology

$+++$

All major organs and gross lesions were histologically evaluated and findings were verified by an independent pathologist.

Consistency between groups $\quad+++$

All groups were treated the same.

Study duration (sensitivity) $\quad+++$

A near life-span duration (105 weeks) was used.

\section{Confounding}

Confounding

$+++$

The test agent was well characterized, animals were treated the same between groups, and were continually monitored for infectious diseases.

\section{Reporting and analysis}

Reporting data and statistics

$+++$

Appropriate statistical analyses were reported.

Combining lesions

$+++$

Tumor combinations were appropriate.

Overall utility: +++. Well reported and designed study, with a large number of animals of both sexes exposed for near lifespan at three exposure levels. 
Table C-53. NTP 2015 (F Rat): Bromodichloroacetic Acid: Drinking Water

\begin{tabular}{|c|c|}
\hline $\begin{array}{l}\text { Study Utility Domain and } \\
\text { Question }\end{array}$ & Rating and Rationale \\
\hline \multicolumn{2}{|l|}{ Study design } \\
\hline Randomization & $\begin{array}{l}+++ \\
\text { Animals were randomly assigned to exposure groups but were not blinded. }\end{array}$ \\
\hline Controls & $\begin{array}{l}+++ \\
\text { controls adequate number }\end{array}$ \\
\hline Historical data & Yes \\
\hline Animal model (sensitivity) & $\begin{array}{l}+++ \\
\text { Both sexes of non-transgenic animals were used. }\end{array}$ \\
\hline Statistical power (sensitivity) & Large numbers of animals $(49-51)$ were used for each group. \\
\hline \multicolumn{2}{|l|}{ Exposure } \\
\hline Chemical characterization & $\begin{array}{l}+++ \\
\text { Chemical purity and stability were well characterized. }\end{array}$ \\
\hline Dosing regimen & $\begin{array}{l}\text { There was a significant decrease in survival and body weight and a significant } \\
\text { increase in neoplasm incidence. }\end{array}$ \\
\hline Exposure duration (sensitivity) & A near life-span duration (104 weeks) was used. \\
\hline Dose-response (sensitivity) & $\begin{array}{l}+++ \\
\text { Three exposure levels were used that spanned a range of } 4 \text {-fold. }\end{array}$ \\
\hline \multicolumn{2}{|r|}{ 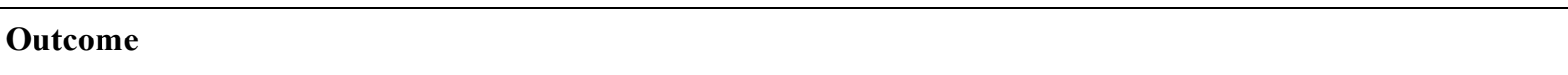 } \\
\hline Pathology & $\begin{array}{l}\text { All major organs and gross lesions were histologically evaluated and findings } \\
\text { were verified by an independent pathologist. }\end{array}$ \\
\hline Consistency between groups & $\begin{array}{l}+++ \\
\text { All groups were treated the same. }\end{array}$ \\
\hline Study duration (sensitivity) & $\begin{array}{l}+++ \\
\text { A near life-span duration (104 weeks) was used. }\end{array}$ \\
\hline \multicolumn{2}{|l|}{ Confounding } \\
\hline Confounding & $\begin{array}{l}\text { The test agent was well characterized, animals were treated the same between } \\
\text { groups, and were continually monitored for infectious diseases. }\end{array}$ \\
\hline \multicolumn{2}{|l|}{ Reporting and analysis } \\
\hline Reporting data and statistics & $\begin{array}{l}+++ \\
\text { Appropriate statistical analyses were reported. }\end{array}$ \\
\hline Combining lesions & $\begin{array}{l}+++ \\
\text { Tumor combinations were appropriate. }\end{array}$ \\
\hline
\end{tabular}

Overall utility: +++. Well reported and designed study, with a large number of animals of both sexes exposed for near lifespan at three exposure levels. 
Table C-54. NTP 2015 (M Mouse): Bromodichloroacetic Acid: Drinking Water

\begin{tabular}{|c|c|}
\hline $\begin{array}{l}\text { Study Utility Domain and } \\
\text { Question }\end{array}$ & Rating and Rationale \\
\hline \multicolumn{2}{|l|}{ Study design } \\
\hline Randomization & $\begin{array}{l}+++ \\
\text { Animals were randomly assigned to exposure groups but were not blinded. }\end{array}$ \\
\hline Controls & $\begin{array}{l}+++ \\
\text { Concurrent vehicle controls were used. }\end{array}$ \\
\hline Historical data & Yes \\
\hline Animal model (sensitivity) & $\begin{array}{l}+++ \\
\text { Both sexes of non-transgenic animals were used. }\end{array}$ \\
\hline Statistical power (sensitivity) & $\begin{array}{l}+++ \\
\text { Large numbers of animals }(50-51) \text { were used for each group. }\end{array}$ \\
\hline \multicolumn{2}{|l|}{ Exposure } \\
\hline Chemical characterization & $\begin{array}{l}+++ \\
\text { Chemical purity and stability were well characterized. }\end{array}$ \\
\hline Dosing regimen & $\begin{array}{l}+++ \\
\text { There was a significant decrease in survival and body weight, with a } \\
\text { significant increase in neoplasm incidence. }\end{array}$ \\
\hline Exposure duration (sensitivity) & $\begin{array}{l}+++ \\
\text { A near life-span duration (105 weeks) was used. }\end{array}$ \\
\hline Dose-response (sensitivity) & $\begin{array}{l}+++ \\
\text { Three exposure levels were used that spanned a range of } 4 \text {-fold. }\end{array}$ \\
\hline \multicolumn{2}{|l|}{ Outcome } \\
\hline Pathology & $\begin{array}{l}\text { All major organs and gross lesions were histologically evaluated and findings } \\
\text { were verified by an independent pathologist. }\end{array}$ \\
\hline Consistency between groups & $\begin{array}{l}+++ \\
\text { All groups were treated the same. }\end{array}$ \\
\hline Study duration (sensitivity) & $\begin{array}{l}+++ \\
\text { A near life-span duration (105 weeks) was used. }\end{array}$ \\
\hline \multicolumn{2}{|l|}{ Confounding } \\
\hline Confounding & $\begin{array}{l}\text { The test agent was well characterized, animals were treated the same between } \\
\text { groups, and were continually monitored for infectious diseases. }\end{array}$ \\
\hline \multicolumn{2}{|l|}{ Reporting and analysis } \\
\hline Reporting data and statistics & $\begin{array}{l}+++ \\
\text { Appropriate statistical analyses were reported. }\end{array}$ \\
\hline Combining lesions & $\begin{array}{l}+++ \\
\text { Tumor combinations were appropriate. }\end{array}$ \\
\hline
\end{tabular}

Overall utility: +++. Well reported and designed study, with a large number of animals of both sexes exposed for near lifespan at three exposure levels. 
Table C-55. NTP 2015 (F Mouse): Bromodichloroacetic Acid: Drinking Water

\begin{tabular}{|c|c|}
\hline $\begin{array}{l}\text { Study Utility Domain and } \\
\text { Question }\end{array}$ & Rating and Rationale \\
\hline \multicolumn{2}{|l|}{ Study design } \\
\hline Randomization & $\begin{array}{l}+++ \\
\text { Animals were randomly assigned to exposure groups but were not blinded. }\end{array}$ \\
\hline Controls & $\begin{array}{l}+++ \\
\text { Concurrent vehicle controls were used. }\end{array}$ \\
\hline Historical data & Yes \\
\hline Animal model (sensitivity) & Both sexes of non-transgenic animals were used. \\
\hline Statistical power (sensitivity) & $\begin{array}{l}\text { There was no significant decrease in survival, but there was a decrease in body } \\
\text { weight and a significant increase in neoplasm incidence. }\end{array}$ \\
\hline \multicolumn{2}{|l|}{ Exposure } \\
\hline Chemical characterization & $\begin{array}{l}+++ \\
\text { Chemical purity and stability were well characterized. }\end{array}$ \\
\hline Dosing regimen & $\begin{array}{l}+++ \\
\text { Three exposure levels were used that spanned a range of } 4 \text {-fold. }\end{array}$ \\
\hline Exposure duration (sensitivity) & $\begin{array}{l}+++ \\
\text { A near life-span duration (105 weeks) was used. }\end{array}$ \\
\hline Dose-response (sensitivity) & $\begin{array}{l}+++ \\
\text { Three exposure levels were used that spanned a range of } 4 \text {-fold. }\end{array}$ \\
\hline \multicolumn{2}{|l|}{ Outcome } \\
\hline Pathology & $\begin{array}{l}\text { All major organs and gross lesions were histologically evaluated and findings } \\
\text { were verified by an independent pathologist. }\end{array}$ \\
\hline Consistency between groups & $\begin{array}{l}+++ \\
\text { All groups were treated the same. }\end{array}$ \\
\hline Study duration (sensitivity) & $\begin{array}{l}+++ \\
\text { A near life-span duration (105 weeks) was used. }\end{array}$ \\
\hline \multicolumn{2}{|l|}{ Confounding } \\
\hline Confounding & $\begin{array}{l}\text { The test agent was well characterized, animals were treated the same between } \\
\text { groups, and were continually monitored for infectious diseases. }\end{array}$ \\
\hline \multicolumn{2}{|l|}{ Reporting and analysis } \\
\hline Reporting data and statistics & $\begin{array}{l}+++ \\
\text { Appropriate statistical analyses were reported. }\end{array}$ \\
\hline Combining lesions & $\begin{array}{l}+++ \\
\text { Tumor combinations were appropriate. }\end{array}$ \\
\hline
\end{tabular}

Overall utility: +++. Well reported and designed study, with a large number of animals of both sexes exposed for near lifespan at three exposure levels. 


\section{C.8. Animal Studies for Haloacetic Acids: Results by Tumor}

Studies in this section are grouped by number of halogen substitutions on the alpha carbon of acetic acid (mono- to di- to trihaloacetic acids) followed by increasing electrophilicity of the HAA (i.e., chloro- to bromo- to iodoacetic acid; dichloro- to dibromoacetic acid; trichloro- to tribromo- to bromodichloroacetic acid). This format follows the text in the monograph. Animals for a given study are grouped by male then female rats first, followed by male then female mice; monochloroacetic acid is the only gavage study and is listed first, followed by drinking water studies.

Table C-56. Liver Tumors

\begin{tabular}{|c|c|c|c|c|}
\hline $\begin{array}{l}\text { Reference and Study } \\
\text { Design }\end{array}$ & Exposure & Dose Levels & $\begin{array}{l}\text { Tumor Incidence }(\mathbf{n} / \mathbf{N}) \\
(\%)\end{array}$ & Comments \\
\hline $\begin{array}{l}\text { NTP (1992) } \\
\text { Animal: } \\
\text { Rat F344/N } \\
\text { M 6-7 weeks } \\
\text { Study duration: } \\
104 \text { weeks }\end{array}$ & $\begin{array}{l}\text { Agent: } \\
\text { Monochloroacetic acid } \\
99 \% \\
\text { Treatment: } \\
\text { Gavage } \\
0 \\
15 \\
30 \mathrm{mg} / \mathrm{kg} \mathrm{bw} \\
5 \text { doses } / \text { week } \times 104 \\
\text { weeks }\end{array}$ & $\begin{array}{l}0 \\
15 \\
30 \\
\text { Liver - Carcin } \\
0 \\
15 \\
30\end{array}$ & $\begin{array}{l}\text { ma } \\
0 / 53 \\
1 / 53(2 \%) \\
0 / 53\end{array}$ & $\begin{array}{l}\text { Survival: After } 104 \text { weeks, the survival of the } 30 \mathrm{mg} / \mathrm{kg} \\
\text { group was lower than controls and there was a significant } \\
\text { trend: } 27 / 53 * \text { (trend }=0.011)-21 / 53,16 / 53 *(=0.015) \text {. } \\
\text { Body weight: Body weights were similar to controls during } \\
\text { the } 6 \text { and } 15 \text { month interim evaluations as well as the } 2 \text { year } \\
\text { study. } \\
\text { Other comments: No neoplasms were found at the } 6 \text { month } \\
\text { evaluation and no treatment related neoplasms were found at } \\
\text { the } 15 \text { month interim evaluation or at the end of the study. } \\
\text { Strengths and limitations: The study was well conducted to } \\
\text { rule out confounding and with a strong power to detect tumor } \\
\text { induction. However, only two exposed dose levels were } \\
\text { tested, which limit the detection of dose response } \\
\text { relationships. Rats were more sensitive to non-neoplastic } \\
\text { effects, causing death and cardiomyopathy during the short } \\
\text { term studies, compared to mice and so their dose levels were } \\
\text { much lower. }\end{array}$ \\
\hline $\begin{array}{l}\text { NTP (1992) } \\
\text { Animal: } \\
\text { Rat F344/N }\end{array}$ & $\begin{array}{l}\text { Agent: } \\
\text { Monochloroacetic acid } \\
99 \%\end{array}$ & $\begin{array}{l}\text { Liver - Adenor } \\
0 \\
15\end{array}$ & $\begin{array}{l}1 / 53(2 \%) \\
0 / 53\end{array}$ & $\begin{array}{l}\text { Survival: After } 104 \text { weeks, the survival of the } 30 \mathrm{mg} / \mathrm{kg} \\
\text { group was lower than controls and there was a significant }\end{array}$ \\
\hline
\end{tabular}




\begin{tabular}{|c|c|c|c|c|}
\hline $\begin{array}{c}\text { Reference and Study } \\
\text { Design }\end{array}$ & Exposure & Dose Levels & $\begin{array}{c}\text { Tumor Incidence (n/N) } \\
(\%)\end{array}$ & Comments \\
\hline $\begin{array}{l}\text { F 6-7 weeks } \\
\text { Study duration: } \\
104 \text { weeks }\end{array}$ & $\begin{array}{l}\text { Treatment: } \\
\text { Gavage } \\
0 \\
15 \\
30 \mathrm{mg} / \mathrm{kg} \mathrm{bw} \\
5 \mathrm{doses} / \text { week } \times 104 \\
\text { weeks }\end{array}$ & 30 & $0 / 53$ & $\begin{array}{l}\text { trend: } 37 / 53 *(\text { Trend }=0.043)-19 / 53^{* * *}(=0.001) \text {, } \\
26 / 53^{*}(=0.046) \text {. } \\
\text { Body weight: Body weights were similar to controls during } \\
\text { the } 6 \text { and } 15 \text { month interim evaluations as well as the } 2 \text { year } \\
\text { study. } \\
\text { Other comments: No neoplasms were found at the } 6 \text { month } \\
\text { evaluation and no treatment related neoplasms were found at } \\
\text { the } 15 \text { month interim evaluation or at the end of the study. } \\
\text { Strengths and limitations: The study was well conducted to } \\
\text { rule out confounding and with a strong power to detect tumor } \\
\text { induction. However, only two exposed dose levels were } \\
\text { tested, which limit the detection of dose response } \\
\text { relationships. Rats were more sensitive to non-neoplastic } \\
\text { effects, causing death and cardiomyopathy during the short } \\
\text { term studies, compared to mice and so their dose levels were } \\
\text { much lower. }\end{array}$ \\
\hline \multirow{13}{*}{$\begin{array}{l}\text { NTP (1992) } \\
\text { Animal: } \\
\text { Mouse B6C3F1 } \\
\text { M 7-8 weeks } \\
\text { Study duration: } \\
104 \text { weeks }\end{array}$} & \multirow{13}{*}{$\begin{array}{l}\text { Agent: } \\
\text { Monochloroacetic acid } \\
99 \% \\
\text { Treatment: } \\
\text { Gavage } \\
0 \\
50 \\
100 \mathrm{mg} / \mathrm{kg} \text { in deionized } \\
\text { water } \\
5 \text { doses } / \text { week } \times 104 \\
\text { weeks }\end{array}$} & \multicolumn{2}{|c|}{ Liver - Adenoma ${ }^{a}$} & \multirow{13}{*}{$\begin{array}{l}\text { Survival: The } 100 \mathrm{mg} / \mathrm{kg} \text { group was lower than controls and } \\
\left.\text { there was a significant trend: } 46 / 60^{* * *} \text { (trend }<0.001\right)- \\
39 / 60,21 / 60^{* * *}(<0.001) \text {. } \\
\text { Body weight: Body weights were similar to controls. } \\
\text { Strengths and limitations: The study was well conducted to } \\
\text { rule out confounding and with a strong power to detect tumor } \\
\text { induction. However, only two exposed dose levels were } \\
\text { tested, which limit the detection of dose response } \\
\text { relationships. }\end{array}$} \\
\hline & & 0 & $6 / 60(12.7 \%)$ & \\
\hline & & 50 & $6 / 59(14.8 \%)$ & \\
\hline & & 100 & $1 / 59(4.2 \%)$ & \\
\hline & & \multirow{2}{*}{\multicolumn{2}{|c|}{ Trend $\mathrm{p}$ value: $=0.0 .059 \mathrm{~N}$}} & \\
\hline & & & Liver - Carcinoma ${ }^{\mathrm{a}}$ & \\
\hline & & 0 & $6 / 60(11.7 \%)$ & \\
\hline & & 50 & $2 / 59(4.7 \%)$ & \\
\hline & & 100 & $5 / 59(19.9 \%)$ & \\
\hline & & \multicolumn{2}{|c|}{ Trend $\mathrm{p}$ value: $=0.440 \mathrm{~N}$} & \\
\hline & & \multicolumn{2}{|c|}{ Liver - Adenoma or carcinoma ${ }^{a}$} & \\
\hline & & 0 & $12 / 60(23.6 \%)$ & \\
\hline & & 50 & $8 / 59(19.1 \%)$ & \\
\hline
\end{tabular}




\begin{tabular}{|c|c|c|c|c|}
\hline $\begin{array}{c}\text { Reference and Study } \\
\text { Design }\end{array}$ & Exposure & Dose Levels & $\begin{array}{c}\text { Tumor Incidence (n/N) } \\
(\%)\end{array}$ & Comments \\
\hline & & 100 & $6 / 59(23.3 \%)$ & \\
\hline & & \multicolumn{3}{|c|}{ Trend $\mathrm{p}$ value: $=0.082 \mathrm{~N}$} \\
\hline \multirow{8}{*}{$\begin{array}{l}\text { NTP (1992) } \\
\text { Animal: } \\
\text { Mouse B6C3F1 } \\
\text { F 7-8 weeks } \\
\text { Study duration: } \\
104 \text { weeks }\end{array}$} & \multirow{8}{*}{$\begin{array}{l}\text { Agent: } \\
\text { Monochloroacetic acid } \\
99 \% \\
\text { Treatment: } \\
\text { Gavage } \\
0 \\
50 \\
100 \mathrm{mg} / \mathrm{kg} \text { in deionized } \\
\text { water } \\
5 \text { doses } / \text { week } \times 104 \\
\text { weeks }\end{array}$} & \multicolumn{2}{|c|}{ Liver - Adenoma } & \multirow{8}{*}{$\begin{array}{l}\text { Survival: Survival of the exposed groups were similar to } \\
\text { controls: } 42 / 60-40 / 60,44 / 60 \text {. } \\
\text { Body weight: Body weights of the low dose group were } \\
\text { similar to controls, but after a year the high dose group had } \\
\text { significantly lower body weight. } \\
\text { Strengths and limitations: The study was well conducted to } \\
\text { rule out confounding and with a strong power to detect tumor } \\
\text { induction. However, only two exposed dose levels were } \\
\text { tested, which limit the detection of dose response } \\
\text { relationships. }\end{array}$} \\
\hline & & 0 & $1 / 60(2 \%)$ & \\
\hline & & 50 & $1 / 60(2 \%)$ & \\
\hline & & 100 & $2 / 60(3 \%)$ & \\
\hline & & \multicolumn{2}{|c|}{ Liver - Carcinoma } & \\
\hline & & 0 & $0 / 60$ & \\
\hline & & 50 & $1 / 59(2 \%)$ & \\
\hline & & 100 & $0 / 60$ & \\
\hline \multirow{17}{*}{$\begin{array}{l}\text { DeAngelo et al. (1997) } \\
\text { Animal: } \\
\text { Rat F344/N } \\
\text { M 28-30 days } \\
\text { Study duration: } \\
104 \text { weeks }\end{array}$} & \multirow{11}{*}{$\begin{array}{l}\text { Agent: } \\
\text { Monochloroacetic acid } \\
>99 \% \\
\text { Treatment: } \\
\text { Drinking water } \\
0+ \\
50 \\
500 \\
2,000++\mathrm{mg} / \mathrm{L} \text { in } \\
\text { drinking water ad } \\
\text { libitum } \times 104 \text { weeks }\end{array}$} & \multicolumn{2}{|c|}{ Liver - Adenoma } & \multirow{17}{*}{$\begin{array}{l}\text { Survival: No significant difference in survival: } \\
23 / 29-24 / 32,23 / 32,25 / 29 \text {. } \\
\text { Body weight: The } 2.0 \mathrm{~g} / 1 \mathrm{MCA} \text { was decreased to } 1.5 \mathrm{~g} / 1 \\
\text { after } 8 \text { weeks and to } 1 \mathrm{~g} / \mathrm{l} \text { after } 24 \text { weeks because of } \\
\text { significant differences in body weight gain. The } 0.5 \mathrm{~g} / \mathrm{l} \text { group } \\
\text { had } 13 \% \text { lower body weight than untreated controls. } \\
\text { Significantly increased preneoplastic lesions: Hyperplastic } \\
\text { nodules were reported but were not significantly increased. } \\
\text { They are likely considered part of the continuum toward } \\
\text { neoplasia as it was reported combined with adenomas and } \\
\text { carcinomas as proliferative lesions and other publications by } \\
\text { this author under similar studies reported that a similar lesion } \\
\text { (large foci of cellular alteration) was only distinguishable } \\
\text { from adenomas because the nodules caused compression at } \\
\text { less than } 80 \% \text { of its surface (DeAngelo et al. } 2008 \text { ). } \\
\text { Other comments: Amount of water consumed was similar } \\
\text { among groups ( } 76.9 \mathrm{ml} / \mathrm{kg} / \mathrm{d}-70.5, \mathrm{ml} / \mathrm{kg} / \mathrm{d}, 55.6 \mathrm{ml} / \mathrm{kg} / \mathrm{d} \text {, } \\
55.5 \mathrm{ml} / \mathrm{kg} / \mathrm{d} \text { ). } \\
\text { Strengths and limitations: A well conducted study on } \\
\text { almost all aspects, but only involved male rats. }\end{array}$} \\
\hline & & 0 & & \\
\hline & & 0 & & \\
\hline & & 50 & $2 / 25(8 \%)$ & \\
\hline & & 500 & $0 / 23$ & \\
\hline & & 2,000 & $1 / 25(4 \%)$ & \\
\hline & & \multirow{2}{*}{\multicolumn{2}{|c|}{ Liver - Carcinoma }} & \\
\hline & & & & \\
\hline & & 0 & $0 / 23$ & \\
\hline & & 50 & $0 / 25$ & \\
\hline & & 500 & $0 / 23$ & \\
\hline & \multirow{6}{*}{$\begin{array}{l}+31-32 \mathrm{mM} \mathrm{NaCl} \\
\text { ( isomolar to } 5,000 \\
\mathrm{mg} / \mathrm{L} \text { TCA) } \\
++2,000 \mathrm{mg} / \mathrm{L} \times 8 \mathrm{wk}, \\
\text { then } 1,500 \mathrm{mg} / \mathrm{L} \text { to } 24 \\
\text { weeks, then } 1,000 \mathrm{mg} / \mathrm{L} \text {; } \\
\text { averaging } 1,100 \mathrm{mg} / \mathrm{L} \\
\text { throughout the study }\end{array}$} & 2,000 & $0 / 25$ & \\
\hline & & \multicolumn{2}{|c|}{ Liver - Adenoma or carcinoma } & \\
\hline & & 0 & $1 / 23(4 \%)$ & \\
\hline & & 50 & $2 / 25(8 \%)$ & \\
\hline & & 500 & $0 / 23$ & \\
\hline & & 2,000 & $1 / 25(4 \%)$ & \\
\hline
\end{tabular}




\begin{tabular}{|c|c|c|c|c|}
\hline $\begin{array}{c}\text { Reference and Study } \\
\text { Design }\end{array}$ & Exposure & Dose Levels & $\begin{array}{c}\text { Tumor Incidence (n/N) } \\
(\%)\end{array}$ & \multirow[b]{2}{*}{$\begin{array}{l}\text { Comments } \\
\text { Survival: There were no significant differences in survival in } \\
\text { the } 0.05 \text { or } 0.5 \mathrm{~g} / 1 \text { groups. The } 5 \mathrm{~g} / \mathrm{l} \text { group rats had } \\
\text { irreversible peripheral neuropathy and were sacrificed at } 60 \\
\text { weeks and were excluded from the study analysis. } \\
\text { Body weight: Body weights did not differ after } 100 \text { weeks of } \\
\text { treatment. } \\
\text { Significantly increased preneoplastic lesions: Hyperplastic } \\
\text { nodules were not significantly increased. They are likely } \\
\text { considered part of the continuum toward neoplasia as it was } \\
\text { reported combined with adenomas and carcinomas as } \\
\text { proliferative lesions and other publications by this author } \\
\text { under similar studies reported that a similar lesion (large foci } \\
\text { of cellular alteration) was only distinguishable from } \\
\text { adenomas because the nodules caused compression at less } \\
\text { than } 80 \% \text { of its surface (DeAngelo et al. } 2008 \text { ). } \\
\text { Other comments: The exact value for N at the beginning of } \\
\text { the study is not confirmed as the paper did not clearly report } \\
\text { them. Water consumption did not differ among groups. The } \\
\text { percent incidence was reported and fractional incidence was } \\
\text { extrapolated from that and the original number of animals } \\
\text { per group, however these calculations did not exactly match } \\
\text { the percent incidence. All non-hepatic neoplasms were } \\
\text { considered spontaneous and not treatment related and } \\
\text { included, testicular cancer ( } 97 \%-100 \%, 100 \% \text { ) and leukemia } \\
\text { (24\%-20\%, } 43 \% \text { ). } \\
\text { Strengths and limitations: Animals were certified pathogen } \\
\text { free, though were not reported to be continuously monitored } \\
\text { for disease. Only two exposed dose levels were effectively } \\
\text { reported and only males were tested. The duration was near } \\
\text { life-span and historical controls were considered during data } \\
\text { analysis. However, only liver lesion incidences were } \\
\text { reported. }\end{array}$} \\
\hline $\begin{array}{l}\text { DeAngelo et al. (1996) } \\
\text { Animal: } \\
\text { Rat (Study 1) F344 } \\
\text { M 28-30 days (59-79g } \\
\text { bw) } \\
\text { Study duration: } \\
100 \text { weeks }\end{array}$ & $\begin{array}{l}\text { Agent: } \\
\text { Dichloroacetic acid } \\
>99 \% \\
\text { Treatment: } \\
\text { Drinking water } \\
0+ \\
50 \\
500 \\
5,000++\mathrm{mg} / \mathrm{L} \text { in } \\
\text { drinking water ad } \\
\text { libitum } \times 100 \text { weeks }\end{array}$ & $\begin{array}{l}\text { Liver - Adeno } \\
0 \\
50 \\
500 \\
\text { Trend } p \text { value: } \\
\text { Liver - Carcin } \\
0\end{array}$ & $\begin{array}{l}\text { a } \\
1 / 23(4.4 \%) \\
0 / 26 \\
5 / 29(17.2 \%) \\
0.05 \\
\mathbf{m a} \\
0 / 23 \\
0 / 26 \\
3 / 29(10.3 \%) \\
0.05\end{array}$ & \\
\hline $\begin{array}{l}\text { DeAngelo et al. (1996) } \\
\text { Animal: } \\
\text { Rat (Study 2) F344 }\end{array}$ & $\begin{array}{l}\text { Agent: } \\
\text { Dichloroacetic acid } \\
>99 \%\end{array}$ & $\begin{array}{l}\text { Liver - Adeno } \\
0 \\
2,500\end{array}$ & $\begin{array}{l}0 / 33 \\
3 / 28(10.7 \%)\end{array}$ & $\begin{array}{l}\text { Survival: There were no significant differences in survival in } \\
\text { the } 0.05 \text { or } 0.5 \mathrm{~g} / 1 \text { groups. The } 5 \mathrm{~g} / 1 \text { group rats had }\end{array}$ \\
\hline
\end{tabular}




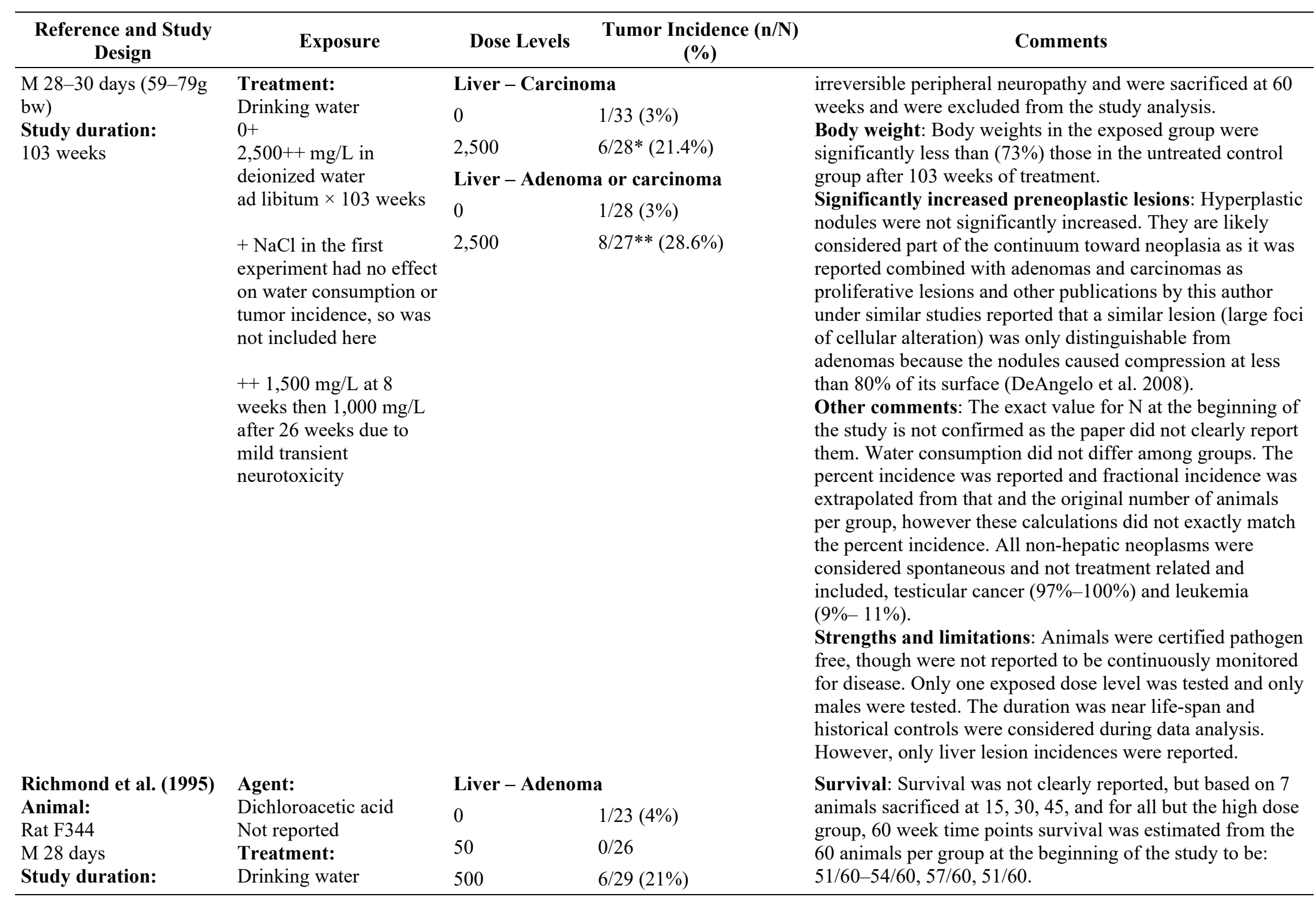




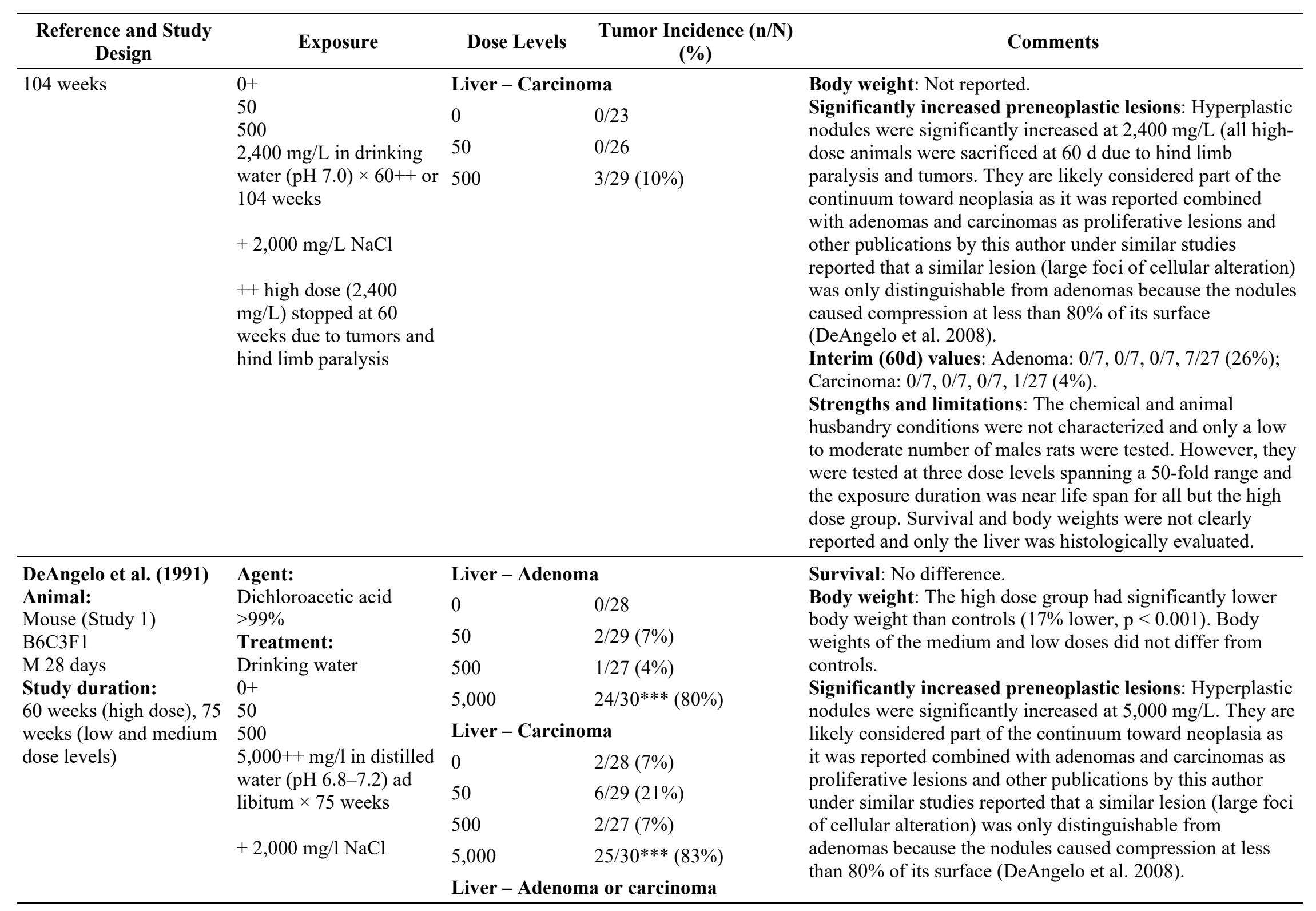




\begin{tabular}{|c|c|c|c|c|}
\hline $\begin{array}{c}\text { Reference and Study } \\
\text { Design }\end{array}$ & Exposure & Dose Levels & $\begin{array}{c}\text { Tumor Incidence (n/N) } \\
(\%)\end{array}$ & Comments \\
\hline & \multirow{4}{*}{$\begin{array}{l}++ \text { Exposure duration } \\
\text { was reduced to } 60 \text { weeks }\end{array}$} & 0 & $2 / 28(7 \%)$ & \multirow{4}{*}{$\begin{array}{l}\text { Other comments: Only the high dose group was } \\
\text { quantitatively reported (as a percentage-fractional incidence } \\
\text { was back calculated from percent), the other groups were } \\
\text { extrapolated from a graph. Nine animals from each group } \\
\text { were scarified at } 60 \text { weeks, with the remainder sacrificed at } \\
75 \text { weeks. All high dose animals were sacrificed at } 60 \text { weeks. } \\
\text { Strengths and limitations: Three dose levels, which } \\
\text { spanned a } 100 \text {-fold range were tested in only males for up to } \\
75 \text { weeks. Only a few select organs were necropsied. }\end{array}$} \\
\hline & & 50 & $7 / 29(24 \%)$ & \\
\hline & & 500 & $3 / 27(11 \%)$ & \\
\hline & & 5,000 & $27 / 30 * * *(90 \%)$ & \\
\hline \multirow{9}{*}{$\begin{array}{l}\text { DeAngelo et al. (1991) } \\
\text { Animal: } \\
\text { Mouse (Study 2) } \\
\text { B6C3F1 } \\
\text { M } 28 \text { days } \\
\text { Study duration: } \\
60 \text { weeks }\end{array}$} & \multirow{7}{*}{$\begin{array}{l}\text { Agent: } \\
\text { Dichloroacetic acid } \\
>99 \% \\
\text { Treatment: } \\
\text { Drinking water } \\
0+ \\
3,500 \mathrm{mg} / 1 \text { in distilled } \\
\text { water }(\mathrm{pH} 6.8-7.2) \text { ad } \\
\text { libitum } \times 60 \text { weeks }\end{array}$} & \multicolumn{2}{|c|}{ Liver - Adenoma } & \multirow{9}{*}{$\begin{array}{l}\text { Survival: No difference. } \\
\text { Body weight: The high dose group had significantly lower } \\
\text { body weight than controls }(13 \% \text { lower, } \mathrm{p}<0.001) \text {. Body } \\
\text { weights of the medium and low doses did not differ from } \\
\text { controls. } \\
\text { Significantly increased preneoplastic lesions: Hyperplastic } \\
\text { nodules were significantly increased at } 3,500 \mathrm{mg} / \mathrm{L} \text {. They are } \\
\text { likely considered part of the continuum toward neoplasia as } \\
\text { it was reported combined with adenomas and carcinomas as } \\
\text { proliferative lesions and other publications by this author } \\
\text { under similar studies reported that a similar lesion (large foci } \\
\text { of cellular alteration) was only distinguishable from } \\
\text { adenomas because the nodules caused compression at less } \\
\text { than } 80 \% \text { of its surface (DeAngelo et al. } 2008 \text { ). } \\
\text { Other comments: Incidences were only reported as a } \\
\text { percentage-fractional incidence was back calculated from } \\
\text { percent. All animals were sacrificed at } 60 \text { weeks. } \\
\text { Strengths and limitations: One dose level was tested in a } \\
\text { small number of males for } 60 \text { weeks. Only a few select } \\
\text { organs were necropsied. }\end{array}$} \\
\hline & & 0 & $0 / 10$ & \\
\hline & & 3,500 & $12 / 12 * * *(100 \%)$ & \\
\hline & & \multicolumn{2}{|c|}{ Liver - Carcinoma } & \\
\hline & & 0 & $0 / 10$ & \\
\hline & & 3,500 & $8 / 12 * * *(67 \%)$ & \\
\hline & & \multicolumn{2}{|c|}{ Liver - Adenoma or carcinoma } & \\
\hline & $+1,500 \mathrm{mg} / \mathrm{l}$ acetic acid & 0 & $0 / 10$ & \\
\hline & & 3,500 & $12 / 12 * * *(100 \%)$ & \\
\hline \multirow{4}{*}{$\begin{array}{l}\text { DeAngelo et al. (1999) } \\
\text { Animal: } \\
\text { Mouse B6C3F1 } \\
\text { M 28-30 days }(18-21 \mathrm{~g} \\
\text { bw) }\end{array}$} & Agent: & \multicolumn{2}{|c|}{ Liver - Adenoma } & \multirow{4}{*}{$\begin{array}{l}\text { Survival: Significant decrease in survival at the two highest } \\
\text { doses and a significant trend }(<0.05): 50 / 53-33 / 35,24 / 25 \text {, } \\
32 / 41,14 / 25^{*}, 8 / 16^{*} \text {. } \\
\text { Body weight: The high dose group }(3.5 \mathrm{~g} / 1) \text { had significantly } \\
\text { lower body weight after } 52 \text { weeks and continued throughout }\end{array}$} \\
\hline & $\begin{array}{l}\text { Dichloroacetic acid } \\
>99 \%\end{array}$ & 0 & $5 / 53(10 \%)$ & \\
\hline & Treatment: & 500 & $5 / 25(20 \%)$ & \\
\hline & Drinking water & 1,000 & $21 / 41 *(51.4 \%)$ & \\
\hline
\end{tabular}




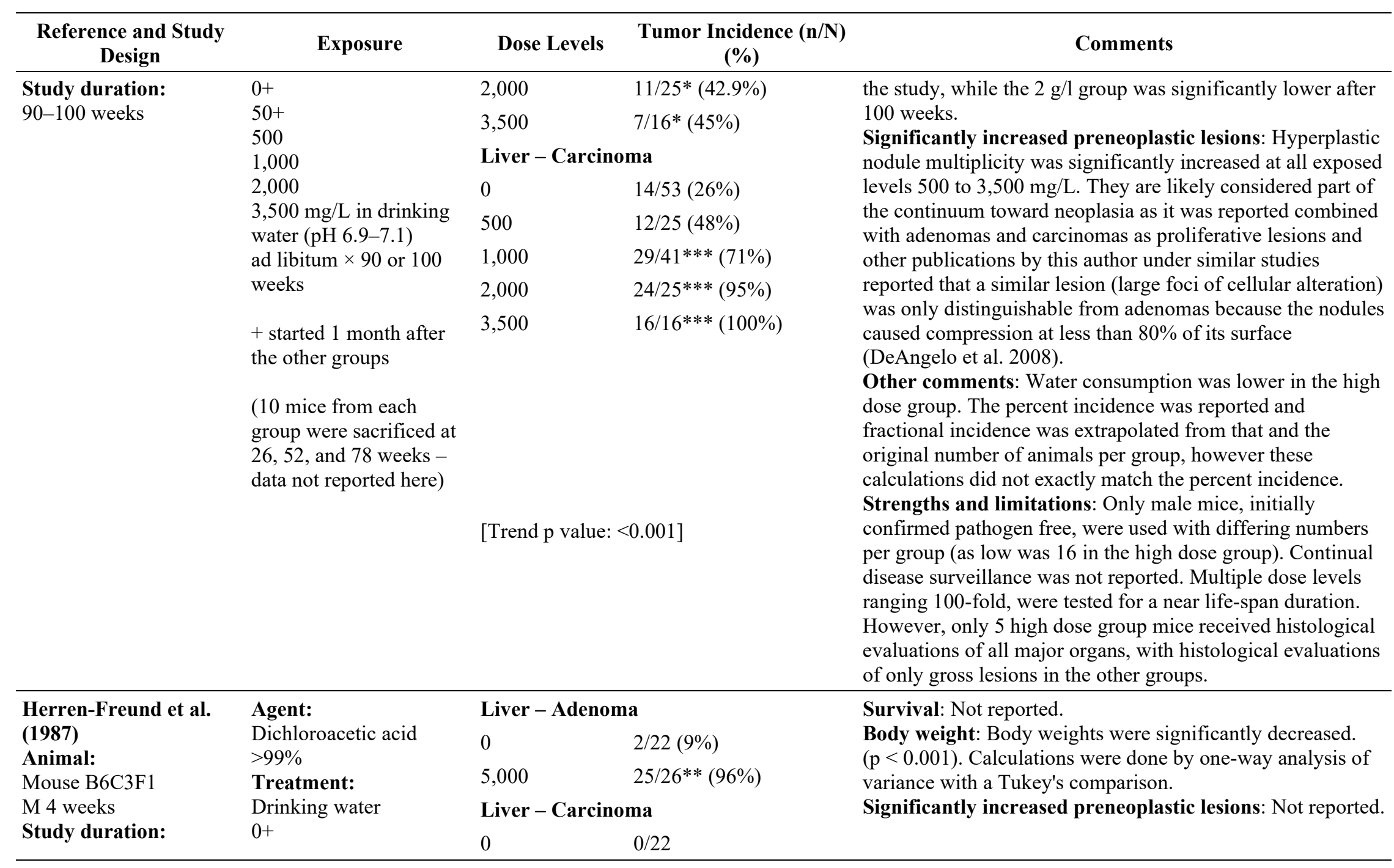




\begin{tabular}{|c|c|c|c|c|}
\hline $\begin{array}{c}\text { Reference and Study } \\
\text { Design }\end{array}$ & Exposure & Dose Levels & $\begin{array}{l}\text { Tumor Incidence (n/N) } \\
(\%)\end{array}$ & Comments \\
\hline 61 weeks & $\begin{array}{l}5,000 \mathrm{mg} / 1 \text { in drinking } \\
\text { water }(\mathrm{pH} 6.5-7.5) \mathrm{ad} \\
\text { libitum } \times 61 \text { weeks } \\
+2,000 \mathrm{mg} / \mathrm{l} \text { of } \mathrm{NaCl} \\
\end{array}$ & 5,000 & $21 / 26^{* *}(81 \%)$ & $\begin{array}{l}\text { Strengths and limitations: The durations were less than } \\
\text { near life-span. Only males were tested at a single dose level } \\
\text { and only livers were histologically evaluated. }\end{array}$ \\
\hline \multirow{21}{*}{$\begin{array}{l}\text { Wood et al. (2015) } \\
\text { Annimal: } \\
\text { Mouse B6C3F1 } \\
\text { M } 28 \text { days } \\
\text { Study duration: } \\
94 \text { weeks }\end{array}$} & \multirow{21}{*}{$\begin{array}{l}\text { Agent: } \\
\text { Dichloroacetic acid } \\
\text { Not reported } \\
\text { Treatment: } \\
\text { Drinking water } \\
0 \\
1,000 \\
2,000 \\
3,500 \mathrm{mg} / \mathrm{L} \text { deionized } \\
\text { water }(\mathrm{pH} 6.8-7.1) \\
\text { ad libitum } \times 10 \text { weeks }\end{array}$} & \multicolumn{2}{|c|}{ Liver - Adenoma } & \multirow{21}{*}{$\begin{array}{l}\text { Survival: Survival was similar in all groups. } \\
\text { Body weight: Body weight of the high dose group, after } \\
\text { DCA exposure had stopped, was decreased by } 12 \% \\
\text { compared to controls. } \\
\text { Other comments: The original number of mice used were } \\
\text { reported as those given a specific dose of DCA and were not } \\
\text { differentiated by those given phenobarbital and those that } \\
\text { were not. The incidence denominator was differentiated by } \\
\text { co-administration of phenobarbital and only represents those } \\
\text { animals given only dichloroacetic acid. Water consumption } \\
\text { was decreased at the medium and high dose groups, which } \\
\text { limited the daily intake to (target dose mg/kg/d: } 0-168,315 \text {, } \\
429 \text {; Measured dose mg/kg/d: } 0-136,232,297 \text { ), so the high } \\
\text { dose was not nearly as high as expected. } \\
\text { Strengths and limitations: Chemical stability was reported } \\
\text { and target concentrations were verified, but purity was not } \\
\text { reported. Disease surveillance was not reported. Three dose } \\
\text { levels, previously shown to be carcinogenic were used. The } \\
\text { exposure duration was short, but the observation duration } \\
\text { was near life-span. Only livers were examined during } \\
\text { necropsy. }\end{array}$} \\
\hline & & 0 & $5 / 27(19 \%)$ & \\
\hline & & 1,000 & $13 / 27(48 \%)$ & \\
\hline & & 2,000 & $11 / 27(41 \%)$ & \\
\hline & & 3,500 & $15 / 26 *(58 \%)$ & \\
\hline & & \multirow{2}{*}{\multicolumn{2}{|c|}{$\begin{array}{l}\text { Trend } \mathrm{p} \text { value: }<0.05 \\
\text { Liver }- \text { Carcinoma }\end{array}$}} & \\
\hline & & & & \\
\hline & & \multicolumn{2}{|c|}{$0 \quad 8 / 27(30 \%)$} & \\
\hline & & 1,000 & $8 / 27(30 \%)$ & \\
\hline & & 2,000 & $6 / 27(22 \%)$ & \\
\hline & & 3,500 & $19 / 26^{*}(73 \%)$ & \\
\hline & & \multicolumn{2}{|c|}{ Trend $\mathrm{p}$ value: $<0.01$} & \\
\hline & & \multicolumn{2}{|c|}{ Liver - Hepatoblastoma } & \\
\hline & & 0 & $0 / 27$ & \\
\hline & & 1,000 & $1 / 27(4 \%)$ & \\
\hline & & 2,000 & $0 / 27$ & \\
\hline & & 3,500 & $0 / 26$ & \\
\hline & & \multicolumn{2}{|c|}{$\begin{array}{l}\text { Liver - Adenoma, carcinoma, and } \\
\text { hepatoblastoma }\end{array}$} & \\
\hline & & 0 & $12 / 27(44 \%)$ & \\
\hline & & 1,000 & $15 / 27(56 \%)$ & \\
\hline & & 2,000 & $14 / 27(52 \%)$ & \\
\hline
\end{tabular}




\begin{tabular}{|c|c|c|c|c|}
\hline $\begin{array}{c}\text { Reference and Study } \\
\text { Design }\end{array}$ & Exposure & Dose Levels & $\begin{array}{l}\text { Tumor Incidence (n/N) } \\
(\%)\end{array}$ & Comments \\
\hline & & 3,500 & $24 / 26 * *(92 \%)$ & \\
\hline & & Irend $\mathrm{p}$ value: $<0.01$ & 0.01 & \\
\hline \multirow{17}{*}{$\begin{array}{l}\text { Wood et al. (2015) } \\
\text { Animal: } \\
\text { Mouse B6C3F1 } \\
\text { F } 28 \text { days } \\
\text { Study duration: } \\
94 \text { weeks }\end{array}$} & \multirow{17}{*}{$\begin{array}{l}\text { Agent: } \\
\text { Dichloroacetic acid } \\
\text { Not reported } \\
\text { Treatment: } \\
\text { Drinking water } \\
0 \\
1,000 \\
2,000 \mathrm{mg} / \mathrm{L} \text { in deionized } \\
\text { water }(\mathrm{pH} 6.8-7.1) \\
\text { ad libitum } \times 10 \text { weeks }\end{array}$} & \multicolumn{2}{|c|}{ Liver-Adenoma } & \multirow{16}{*}{$\begin{array}{l}\text { Survival: Survival was similar in all groups. } \\
\text { Body weight: Body weight of the high dose group, after } \\
\text { DCA exposure had stopped, was decreased by } 12 \% \\
\text { compared to controls. } \\
\text { Other comments: The original number of mice used were } \\
\text { reported as those given a specific dose of DCA and were not } \\
\text { differentiated by those given phenobarbital and those that } \\
\text { were not. The incidence denominator was differentiated by } \\
\text { co-administration of phenobarbital and only represents those } \\
\text { animals given only dichloroacetic acid. Water consumption } \\
\text { was decreased at the medium and high dose groups, which } \\
\text { limited the daily intake to (target dose mg/kg/d: } 0-168,315 \text {, } \\
429 \text {; Measured dose mg/kg/d: } 0-136,232,297) \text {, so the high } \\
\text { dose was not nearly as high as expected. } \\
\text { Strengths and limitations: Chemical stability was reported } \\
\text { and target concentrations were verified, but purity was not } \\
\text { reported. Disease surveillance was not reported. Two dose } \\
\text { levels, previously shown to be carcinogenic, were used. The } \\
\text { exposure duration was short, but the observation duration } \\
\text { was near life-span. Only livers were examined during } \\
\text { necropsy. }\end{array}$} \\
\hline & & 0 & $0 / 27$ & \\
\hline & & 1,000 & $9 / 26 * *(35 \%)$ & \\
\hline & & 2,000 & $6 / 28(21 \%)$ & \\
\hline & & \multicolumn{2}{|c|}{ Liver - Carcinoma } & \\
\hline & & 0 & $0 / 27$ & \\
\hline & & 1,000 & $2 / 26(8 \%)$ & \\
\hline & & 2,000 & $3 / 28(11 \%)$ & \\
\hline & & \multicolumn{2}{|c|}{ Liver - Hepatoblastoma } & \\
\hline & & 0 & $0 / 27$ & \\
\hline & & 1,000 & $0 / 26$ & \\
\hline & & 2,000 & $0 / 28$ & \\
\hline & & \multicolumn{2}{|c|}{$\begin{array}{l}\text { Liver - Adenoma, carcinoma, and } \\
\text { hepatoblastoma }\end{array}$} & \\
\hline & & 0 & $0 / 27$ & \\
\hline & & 1,000 & $10 / 26^{* *}(38 \%)$ & \\
\hline & & 2,000 & $9 / 28 * *(32 \%)$ & \\
\hline & & \multicolumn{2}{|c|}{$[$ Trend $\mathrm{p}$ value: $<0.01]$} & \\
\hline \multirow{6}{*}{$\begin{array}{l}\text { Pereira (1996) } \\
\text { Animal: } \\
\text { Mouse (Study 1) } \\
\text { B6C3F1 } \\
\text { F 7-8 weeks } \\
\text { Study duration: } \\
576 \text { days }\end{array}$} & Agent: & \multicolumn{2}{|c|}{ Liver - Adenoma } & \multirow{6}{*}{$\begin{array}{l}\text { Survival: Not reported } \\
\text { Body weight: The high dose level of DCA was caused } \\
\text { significant weight loss after } 35 \text { weeks and beyond, while the } \\
\text { high dose of TCA caused it at } 51 \text { weeks, with near } \\
\text { significant decreases beyond. } \\
\text { Significantly increased preneoplastic lesions: The foci of } \\
\text { altered hepatocytes were reported combined with neoplasms } \\
\text { but not separately. They are likely considered part of the }\end{array}$} \\
\hline & Dichloroacetic acid & 0 & $2 / 90(2.2 \%)$ & \\
\hline & $\begin{array}{l}\text { (DCA) } \\
\text { Not reported }\end{array}$ & 260 & $3 / 50(6 \%)$ & \\
\hline & Treatment: & 860 & $7 / 28 *(25 \%)$ & \\
\hline & Drinking water & $\begin{array}{l}2,600 \\
\text { intermittent }\end{array}$ & $3 / 34(8.8 \%)$ & \\
\hline & & 2,600 & $16 / 19 *(84.2 \%)$ & \\
\hline
\end{tabular}




\begin{tabular}{|c|c|c|c|c|}
\hline $\begin{array}{c}\text { Reference and Study } \\
\text { Design }\end{array}$ & Exposure & Dose Levels & $\begin{array}{c}\text { Tumor Incidence (n/N) } \\
(\%)\end{array}$ & Comments \\
\hline & $860++$ & \multicolumn{2}{|c|}{ Liver - Carcinoma } & \multirow{7}{*}{$\begin{array}{l}\text { continuum toward neoplasia as it was reported combined } \\
\text { with adenomas and carcinomas as proliferative lesions and } \\
\text { other publications by this author under similar studies } \\
\text { reported that a similar lesion (large foci of cellular alteration) } \\
\text { was only distinguishable from adenomas because the nodules } \\
\text { caused compression at less than } 80 \% \text { of its surface } \\
\text { (DeAngelo et al. 2008). } \\
\text { Strengths and limitations: The chemicals were not } \\
\text { characterized, not even purity was reported. Disease } \\
\text { surveillance was not continually monitored. A variable } \\
\text { number of only females was tested, with only their livers } \\
\text { examined histologically. The study duration was near life- } \\
\text { span. }\end{array}$} \\
\hline & $2,600+++$ & 0 & $2 / 90(2.2 \%)$ & \\
\hline & $\begin{array}{l}2,600++\mathrm{mg} / \mathrm{L} \text { in } \\
\text { drinking water ad }\end{array}$ & 260 & $0 / 50$ & \\
\hline & libitum $\times 360$ days & 860 & $1 / 28(3.6 \%)$ & \\
\hline & $+20 \mathrm{mmol} / \mathrm{L} \mathrm{NaCl}$ & $\begin{array}{l}2,600 \\
\text { intermittent }\end{array}$ & $1 / 34(2.9 \%)$ & \\
\hline & $\begin{array}{l}++ \text { Concentrations were } \\
\text { reported at } \mathrm{mmol} / \mathrm{L} \text { and } \\
\mathrm{NTP} \text { converted them to } \\
\mathrm{mg} / \mathrm{L} \text { based on a mw of } \\
28.942 \mathrm{~g} / \mathrm{mol}\end{array}$ & [Trend $\mathrm{p}$ value: & $5 / 19[* *](26.3 \%)$ & \\
\hline & $\begin{array}{l}+++ \text { intermittent cycles } \\
\text { of } 24 \text { days on, } 48 \text { days } \\
\text { off }\end{array}$ & & & \\
\hline Pereira (1996) & Agent: & \multicolumn{2}{|c|}{ Liver - Adenoma } & \multirow{12}{*}{$\begin{array}{l}\text { Survival: Not reported } \\
\text { Body weight: The high dose level of DCA was caused } \\
\text { significant weight loss after } 35 \text { weeks and beyond, while the } \\
\text { high dose of TCA caused it at } 51 \text { weeks, with near } \\
\text { significant decreases beyond. } \\
\text { Significantly increased preneoplastic lesions: The foci of } \\
\text { altered hepatocytes were reported combined with neoplasms, } \\
\text { but not separately. They are likely considered part of the } \\
\text { continuum toward neoplasia as it was reported combined } \\
\text { with adenomas and carcinomas as proliferative lesions and } \\
\text { other publications by this author under similar studies } \\
\text { reported that a similar lesion (large foci of cellular alteration) } \\
\text { was only distinguishable from adenomas because the nodules } \\
\text { caused compression at less than } 80 \% \text { of its surface } \\
\text { (DeAngelo et al. 2008). }\end{array}$} \\
\hline Animal: & Dichloroacetic acid & 0 & $1 / 40(2.5 \%)$ & \\
\hline $\begin{array}{l}\text { Mouse (Study 2) } \\
\text { B6C3F1 }\end{array}$ & $\begin{array}{l}(\mathrm{DCA}) \\
\text { Not reported }\end{array}$ & 260 & $0 / 40$ & \\
\hline F 7-8 weeks & Treatment: & 860 & $3 / 20(15 \%)$ & \\
\hline Study duration: & Drinking water & 2,600 & $0 / 15$ & \\
\hline & $\begin{array}{l}0+ \\
260++\end{array}$ & intermittent & & \\
\hline & $860++$ & 2,600 & $7 / 20 *(35 \%)$ & \\
\hline & $2,600+++$ & \multicolumn{2}{|c|}{ Liver - Carcinoma } & \\
\hline & $\begin{array}{l}2,600++\mathrm{mg} / \mathrm{L} \text { in } \\
\text { drinking water ad }\end{array}$ & 0 & $0 / 40$ & \\
\hline & libitum $\times 360$ days & 260 & $0 / 40$ & \\
\hline & & 860 & $0 / 20$ & \\
\hline & $+20 \mathrm{mmol} / \mathrm{L} \mathrm{NaCl}$ & $\begin{array}{l}2,600 \\
\text { intermittent }\end{array}$ & $0 / 15$ & \\
\hline
\end{tabular}




\begin{tabular}{|c|c|c|c|c|}
\hline $\begin{array}{c}\text { Reference and Study } \\
\text { Design }\end{array}$ & Exposure & Dose Levels & $\begin{array}{c}\text { Tumor Incidence (n/N) } \\
(\%)\end{array}$ & Comments \\
\hline & $\begin{array}{l}++ \text { Concentrations were } \\
\text { reported at mmol/L and } \\
\mathrm{NTP} \text { converted them to } \\
\mathrm{mg} / \mathrm{L} \text { based on a mw of } \\
28.942 \mathrm{~g} / \mathrm{mol} \\
+++ \text { intermittent cycles } \\
\text { of } 24 \text { days on, } 48 \text { days } \\
\text { off }\end{array}$ & 2,600 & $1 / 20(5 \%)$ & $\begin{array}{l}\text { Strengths and limitations: The chemicals were not } \\
\text { characterized, not even purity was reported. Disease } \\
\text { surveillance was not continually monitored. A variable } \\
\text { number of only females was tested, with only their livers } \\
\text { examined histologically. Study duration was less than life- } \\
\text { span. }\end{array}$ \\
\hline \multirow{8}{*}{$\begin{array}{l}\text { Bull et al. (1990) } \\
\text { Animal: } \\
\text { Mouse B6C3F1 } \\
\text { M } 5 \text { weeks } \\
\text { Study duration: } \\
52 \text { weeks }\end{array}$} & \multirow{8}{*}{$\begin{array}{l}\text { Agent: } \\
\text { Dichloroacetic acid } \\
\text { Analytical grade } \\
\text { Treatment: } \\
\text { Drinking water } \\
0 \\
1,000 \\
2,000 \mathrm{mg} / \mathrm{L} \text { in drinking } \\
\text { water }(\mathrm{pH} 6.8-7.2) \text { ad } \\
\text { libitum } \times 52 \text { weeks }\end{array}$} & \multicolumn{2}{|c|}{ Liver - Adenoma } & \multirow{8}{*}{$\begin{array}{l}\text { Survival: All mice survived. } \\
\text { Significantly increased preneoplastic lesions: A non- } \\
\text { significant increase in hyperplasia was reported. } \\
\text { Strengths and limitations: The chemical was not } \\
\text { characterized, disease surveillance was not reported. A low } \\
\text { number of mice per group were exposed for a less than near } \\
\text { life-span duration and only males had results reported. Only } \\
\text { livers were histologically examined. Not all lesions were } \\
\text { histologically evaluated, but instead samples of lesions were } \\
\text { evaluated. Results were reported so that incidences of } \\
\text { specific neoplasms could not be determined but could be } \\
\text { estimated. }\end{array}$} \\
\hline & & 0 & $0 / 2$ & \\
\hline & & 1,000 & $0 / 1$ & \\
\hline & & 2,000 & $2 / 10(20 \%)$ & \\
\hline & & \multicolumn{2}{|c|}{ Liver - Carcinoma } & \\
\hline & & 0 & $0 / 2$ & \\
\hline & & 1,000 & $0 / 1$ & \\
\hline & & 2,000 & $5 / 10(50 \%)$ & \\
\hline \multirow{10}{*}{$\begin{array}{l}\text { Daniel et al. (1992) } \\
\text { Animal: } \\
\text { Mouse B6C3F1 } \\
\text { M } 28 \text { days } \\
\text { Study duration: } \\
104 \text { weeks }\end{array}$} & \multirow{10}{*}{$\begin{array}{l}\text { Agent: } \\
\text { Dichloroacetic acid } \\
>95 \% \\
\text { Treatment: } \\
\text { Drinking water } \\
0 \\
0 \\
500 \\
500 \mathrm{mg} / \mathrm{l} \text { in distilled } \\
\text { water }(\mathrm{pH} 6.8-7.2) \mathrm{ad} \\
\text { libitum } \times 104 \text { weeks }\end{array}$} & Liver - Adenor & & \multirow{10}{*}{$\begin{array}{l}\text { Survival: Survival was not significantly different: } 13 / 10 \text {, } \\
10 / 10-16 / 18,8 / 10 \\
\text { Body weight: No significant differences in body weight. } \\
\text { Significantly increased preneoplastic lesions: Hyperplastic } \\
\text { nodules were not significantly increased. They are likely } \\
\text { considered part of the continuum toward neoplasia as it was } \\
\text { reported combined with adenomas and carcinomas as } \\
\text { proliferative lesions and other publications by this author } \\
\text { under similar studies reported that a similar lesion (large foci } \\
\text { of cellular alteration) was only distinguishable from }\end{array}$} \\
\hline & & 0 & $1 / 20(5 \%)$ & \\
\hline & & 500 & & \\
\hline & & & $10 / 24 * *(42 \%)$ & \\
\hline & & \multirow{2}{*}{\multicolumn{2}{|c|}{ Liver - Carcinoma }} & \\
\hline & & & & \\
\hline & & 0 & $2 / 20(10 \%)$ & \\
\hline & & 500 & $15 / 24 * *(63 \%)$ & \\
\hline & & \multicolumn{2}{|c|}{ Liver - Adenoma or carcinoma } & \\
\hline & & 0 & $3 / 20(15 \%)$ & \\
\hline
\end{tabular}




\begin{tabular}{|c|c|c|c|c|}
\hline $\begin{array}{c}\text { Reference and Study } \\
\text { Design }\end{array}$ & Exposure & Dose Levels & $\begin{array}{c}\text { Tumor Incidence (n/N) } \\
(\%)\end{array}$ & Comments \\
\hline & $\begin{array}{l}\text { Two sets of animals were } \\
\text { used as they were born, } \\
\text { both groups are the } \\
\text { same, just started at } \\
\text { different times. Except } \\
\text { for the body weights, the } \\
\text { two groups were } \\
\text { statistically analyzed as } \\
\text { one combined group. }\end{array}$ & 500 & $18 / 24 * *(75 \%)$ & $\begin{array}{l}\text { adenomas because the nodules caused compression at less } \\
\text { than } 80 \% \text { of its surface (DeAngelo et al. 2008). } \\
\text { Other comments: All tumors occurred at necropsy and did } \\
\text { not cause premature mortality. Both groups of controls and } \\
\text { exposed mice were combined into one group each. Fractional } \\
\text { incidence was based on surviving animals as the } \\
\text { denominator and percent incidence was also reported. } \\
\text { Strengths and limitations: Continual disease surveillance } \\
\text { was not reported. Only males were tested and only at one } \\
\text { dose level. Histological evaluations from all major organs } \\
\text { only occurred in five mice per group, with histological } \\
\text { evaluations in the other mice only occurring on tissues with } \\
\text { gross lesions. }\end{array}$ \\
\hline \multirow{16}{*}{$\begin{array}{l}\text { NTP (2007a) } \\
\text { Animal: } \\
\text { Mouse B6C3F1 } \\
\text { M } 6 \text { weeks } \\
\text { Study duration: } \\
106 \text { weeks }\end{array}$} & Agent: & \multicolumn{2}{|c|}{ Liver - Adenoma ${ }^{a}$} & \multirow{16}{*}{$\begin{array}{l}\text { Survival: Survival was similar in all groups. } \\
31 / 50-38 / 50,34 / 50,31 / 50 \\
\text { Body weight: Body weights were greater in the } 50 \text { and } 500 \\
\mathrm{mg} / 1 \text { groups compared to the untreated controls after } 85 \\
\text { weeks. } \\
\text { Significantly increased preneoplastic lesions: Spleen } \\
\text { hematopoiesis } 18 / 49-20 / 50,28 / 50,38 / 50 \\
\text { Other comments: Water consumption was similar to } \\
\text { controls. Onset was reported in days. } \\
\text { Strengths and limitations: Large numbers of animals per } \\
\text { group were used in both sexes and were continuously } \\
\text { monitored for disease. Three dose levels spanning a range of } \\
200 \text {-fold were used. Lesions and all major organs were } \\
\text { histologically evaluated and statistics were clearly reported. }\end{array}$} \\
\hline & Dibromoacetic acid & 0 & $18 / 49(42 \%)$ & \\
\hline & $\begin{array}{l}>99 \% \\
\text { Treatment: }\end{array}$ & 50 & $37 / 50 * * * \mathrm{~b}(78 \%)$ & \\
\hline & Drinking water & 500 & $37 / 50 * * * \mathrm{~b}(80 \%)$ & \\
\hline & & 1,000 & $42 / 50 * * * \mathrm{~b}(89 \%)$ & \\
\hline & & \multicolumn{2}{|c|}{ Trend $\mathrm{p}$ value: $<0.001$} & \\
\hline & $1,000 \mathrm{mg} / \mathrm{L}$ of drinking & \multicolumn{2}{|c|}{ Liver - Carcinoma ${ }^{a}$} & \\
\hline & $\begin{array}{l}\text { water ad libitum } \times 106 \\
\text { weeks }\end{array}$ & 0 & $14 / 49(31 \%)$ & \\
\hline & \multirow{8}{*}{$\begin{array}{l}\text { Average daily dose: } 0-4 \text {, } \\
45,87 \mathrm{mg} / \mathrm{kg}\end{array}$} & 50 & $9 / 50(19 \%)$ & \\
\hline & & 500 & $19 / 50(41 \%)$ & \\
\hline & & 1,000 & $26 / 50 * c(55 \%)$ & \\
\hline & & \multicolumn{2}{|c|}{ Trend $\mathrm{p}$ value: $<0.001$} & \\
\hline & & \multicolumn{2}{|c|}{ Liver - Adenoma or carcinoma ${ }^{a}$} & \\
\hline & & 0 & $28 / 49(61 \%)$ & \\
\hline & & 50 & $41 / 50 * * \mathrm{~d}(86 \%)$ & \\
\hline & & 500 & $42 / 50 * * * \mathrm{~d}(88 \%)$ & \\
\hline
\end{tabular}




\begin{tabular}{|c|c|c|c|c|}
\hline $\begin{array}{c}\text { Reference and Study } \\
\text { Design }\end{array}$ & Exposure & Dose Levels & $\begin{array}{c}\text { Tumor Incidence }(\mathbf{n} / \mathbf{N}) \\
(\%)\end{array}$ & Comments \\
\hline & & 1,000 & $47 / 50 * * * \mathrm{~d}(96 \%)$ & \\
\hline & & \multicolumn{3}{|c|}{ Trend $\mathrm{p}$ value: $<0.001$} \\
\hline & & \multicolumn{3}{|c|}{ Liver - Hepatoblastoma ${ }^{a}$} \\
\hline & & 0 & \multicolumn{2}{|l|}{$0 / 49$} \\
\hline & & 50 & \multicolumn{2}{|l|}{$4 / 50(9 \%)$} \\
\hline & & 500 & \multicolumn{2}{|l|}{$6 / 50 *(13 \%)$} \\
\hline & & 1,000 & \multicolumn{2}{|l|}{$18 / 50 * * * \mathrm{e}(39 \%)$} \\
\hline & & \multicolumn{3}{|c|}{ Trend $\mathrm{p}$ value: $<0.001$} \\
\hline & & \multicolumn{3}{|c|}{$\begin{array}{l}\text { Liver - Adenoma, carcinoma or } \\
\text { hepatoblastoma }^{a}\end{array}$} \\
\hline & & 0 & \multicolumn{2}{|l|}{$28 / 49(61 \%)$} \\
\hline & & 50 & \multicolumn{2}{|l|}{$41 / 50 * *(86 \%)$} \\
\hline & & 500 & \multicolumn{2}{|l|}{$43 / 50 * * *(90 \%)$} \\
\hline & & 1,000 & \multicolumn{2}{|l|}{$48 / 50 * * *(97 \%)$} \\
\hline & & \multicolumn{3}{|c|}{ Trend $\mathrm{p}$ value: $<0.001$} \\
\hline \multirow{11}{*}{$\begin{array}{l}\text { NTP (2007a) } \\
\text { Animal: } \\
\text { Mouse B6C3F1 } \\
\text { F } 6 \text { weeks } \\
\text { Study duration: } \\
106 \text { weeks }\end{array}$} & Agent: & \multicolumn{2}{|c|}{ Liver - Adenoma ${ }^{a}$} & \multirow{11}{*}{$\begin{array}{l}\text { Survival: Survival was similar in all groups. } \\
38 / 50-35 / 50,32 / 50,32 / 50 \\
\text { Body weight: Body weights were similar to the untreated } \\
\text { controls. } \\
\text { Other comments: Water consumption was similar to } \\
\text { controls. Onset was reported in days. } \\
\text { Strengths and limitations: Large numbers of animals per } \\
\text { group were used in both sexes and were continuously } \\
\text { monitored for disease. Three dose levels spanning a range of } \\
\text { 200-fold were used. Lesions and all major organs were } \\
\text { histologically evaluated and statistics were clearly reported. }\end{array}$} \\
\hline & Dibromoacetic acid & 0 & $19 / 49(41 \%)$ & \\
\hline & $\begin{array}{l}>99 \% \\
\text { Treatment: }\end{array}$ & 50 & $26 / 50(57 \%)$ & \\
\hline & Drinking water & 500 & $32 / 50 * * \mathrm{f}(70 \%)$ & \\
\hline & & 1,000 & $35 / 49 * * * \mathrm{f}(76 \%)$ & \\
\hline & 500 & \multicolumn{2}{|c|}{ Trend $\mathrm{p}$ value: $<0.001$} & \\
\hline & $1,000 \mathrm{mg} / \mathrm{L}$ of drinking & \multicolumn{2}{|c|}{ Liver - Carcinoma $^{\mathrm{a}}$} & \\
\hline & $\begin{array}{l}\text { water ad libitum × } 106 \\
\text { weeks }\end{array}$ & 0 & $3 / 49(7 \%)$ & \\
\hline & & 50 & $3 / 50(7 \%)$ & \\
\hline & Average daily dose: $0-$ & 500 & $12 / 50^{* * \mathrm{~g}}(27 \%)$ & \\
\hline & & 1,000 & $8 / 49(18 \%)$ & \\
\hline
\end{tabular}




\begin{tabular}{|c|c|c|c|c|}
\hline $\begin{array}{c}\text { Reference and Study } \\
\text { Design }\end{array}$ & Exposure & Dose Levels & $\begin{array}{c}\text { Tumor Incidence (n/N) } \\
(\%)\end{array}$ & Comments \\
\hline & & \multicolumn{3}{|c|}{ Trend $\mathrm{p}$ value: $=0.019$} \\
\hline & & \multicolumn{3}{|c|}{ Liver - Adenoma or carcinoma ${ }^{a}$} \\
\hline & & 0 & \multicolumn{2}{|l|}{$22 / 49(48 \%)$} \\
\hline & & 50 & \multicolumn{2}{|l|}{$28 / 50(61 \%)$} \\
\hline & & 500 & \multicolumn{2}{|l|}{$37 / 50 * * * \mathrm{~h}(80 \%)$} \\
\hline & & 1,000 & \multicolumn{2}{|l|}{$37 / 49 * * * \mathrm{~h}(80 \%)$} \\
\hline & & \multicolumn{3}{|c|}{ Trend $\mathrm{p}$ value: $<0.001$} \\
\hline & & \multicolumn{3}{|c|}{ Liver - Hepatoblastoma } \\
\hline & & 0 & \multicolumn{2}{|l|}{$1 / 49(2 \%)$} \\
\hline & & 50 & \multicolumn{2}{|l|}{$0 / 50$} \\
\hline & & 500 & \multicolumn{2}{|l|}{$1 / 50(2 \%)$} \\
\hline & & 1,000 & \multicolumn{2}{|l|}{$0 / 49$} \\
\hline \multirow{8}{*}{$\begin{array}{l}\text { NTP (2009) } \\
\text { Animal: } \\
\text { Rat F344/N } \\
\text { M 6-7 weeks } \\
\text { Study duration: } \\
105 \text { weeks }\end{array}$} & Agent: & \multicolumn{2}{|c|}{ Liver - Adenoma ${ }^{a}$} & \multirow{8}{*}{$\begin{array}{l}\text { Survival: No significant difference: } \\
31 / 50-26 / 50,25 / 50,29 / 50 \\
\text { Body weight: } 1,000 \mathrm{mg} / 1 \text { group was } 10 \% \text { less than controls } \\
\text { after } 69 \text { weeks. } \\
\text { Strengths and limitations: A very high-quality study, with } \\
\text { no major concerns. }\end{array}$} \\
\hline & Bromochloroacetic acid & \multicolumn{2}{|c|}{$0 \quad 2 / 50^{\mathrm{i}}(4.6 \%)$} & \\
\hline & $96 \%$ & & \multirow{2}{*}{$\begin{array}{l}2 / 50^{1}(4.6 \%) \\
0 / 50\end{array}$} & \\
\hline & Treatment: & 250 & & \\
\hline & Drinking water & 500 & $3 / 50^{\mathrm{i}}(7.5 \%)$ & \\
\hline & & 1,000 & \multirow[t]{3}{*}{$4 / 50^{\mathrm{i}}(9.5 \%)$} & \\
\hline & & & & \\
\hline & $\begin{array}{l}1,000 \mathrm{mg} / \mathrm{L} \text { of drinking } \\
\text { water ad libitum } \times 105 \\
\text { weeks }\end{array}$ & & & \\
\hline \multirow{6}{*}{$\begin{array}{l}\text { NTP (2009) } \\
\text { Animal: } \\
\text { Rat F344/N } \\
\text { F 6-7 weeks } \\
\text { Study duration: } \\
105 \text { weeks }\end{array}$} & Agent: & \multicolumn{2}{|c|}{ Liver - Adenoma ${ }^{a}$} & \multirow{6}{*}{$\begin{array}{l}\text { Survival: No significant difference: } \\
34 / 50-31 / 50,37 / 50,35 / 50 \\
\text { Body weight: } 1,000 \mathrm{mg} / 1 \text { group was }<10 \% \text { of controls. after } \\
85 \text { weeks. }\end{array}$} \\
\hline & Bromochloroacetic acid & 0 & $0 / 50$ & \\
\hline & $96 \%$ & & 00 & \\
\hline & Treatment: & 250 & $0 / 50$ & \\
\hline & Drinking water & 500 & $0 / 50$ & \\
\hline & 0 & 1,000 & $3 / 50^{\mathrm{j}}(6.6 \%)$ & \\
\hline
\end{tabular}




\begin{tabular}{|c|c|c|c|c|}
\hline $\begin{array}{c}\text { Reference and Study } \\
\text { Design }\end{array}$ & Exposure & Dose Levels & $\begin{array}{c}\text { Tumor Incidence }(\mathbf{n} / \mathbf{N}) \\
(\%)\end{array}$ & Comments \\
\hline & $\begin{array}{l}250 \\
500 \\
1,000 \mathrm{mg} / \mathrm{L} \text { of drinking } \\
\text { water ad libitum } \times 105 \\
\text { weeks }\end{array}$ & \multicolumn{2}{|c|}{ Trend $\mathrm{p}$ value: $=0.012$} & $\begin{array}{l}\text { Significantly increased preneoplastic lesions: Lung } \\
\text { alveolar epithelium hyperplasia occurred at increased } \\
\text { incidences. } \\
\text { Strengths and limitations: A very high-quality study, with } \\
\text { no major concerns. }\end{array}$ \\
\hline \multirow{21}{*}{$\begin{array}{l}\text { NTP (2009) } \\
\text { Animal: } \\
\text { Mouse B6C3F1 } \\
\text { M 6-7 weeks } \\
\text { Study duration: } \\
105 \text { weeks }\end{array}$} & \multirow{21}{*}{$\begin{array}{l}\text { Agent: } \\
\text { Bromochloroacetic acid } \\
96 \% \\
\text { Treatment: } \\
\text { Drinking water } \\
0 \\
250 \\
500 \\
1,000 \mathrm{mg} / \mathrm{L} \text { of drinking } \\
\text { water ad libitum } \times 105 \\
\text { weeks }\end{array}$} & \multicolumn{2}{|c|}{ Liver - Adenoma ${ }^{a}$} & \multirow{21}{*}{$\begin{array}{l}\text { Survival: } 38 / 50-35 / 50,30 / 50,21 / 50 \\
\text { Body weight: } 1,000 \mathrm{mg} / 1 \text { group was } 12 \% \text { lower than controls } \\
\text { after } 97 \text { weeks. } \\
\text { Strengths and limitations: A very high-quality study, with } \\
\text { no major concerns. }\end{array}$} \\
\hline & & 0 & $27 / 50(58.7 \%)$ & \\
\hline & & 250 & $40 / 50^{* * \mathrm{k}}(83.6 \%)$ & \\
\hline & & 500 & $40 / 50^{* * \mathrm{k}}(83.7 \%)$ & \\
\hline & & 1,000 & $31 / 50(67.4 \%)$ & \\
\hline & & \multicolumn{2}{|c|}{ Liver - Carcinoma ${ }^{\mathrm{a}}$} & \\
\hline & & 0 & $19 / 50(39.6 \%)$ & \\
\hline & & 250 & $25 / 50^{1}(52.5 \%)$ & \\
\hline & & 500 & $36 / 50 * * * 1(76.9 \%)$ & \\
\hline & & 1,000 & $45 / 50 * * * 1(92.7 \%)$ & \\
\hline & & \multicolumn{2}{|c|}{ Trend $\mathrm{p}$ value: $<0.001$} & \\
\hline & & \multicolumn{2}{|c|}{ Liver - Adenoma or carcinoma ${ }^{a}$} & \\
\hline & & 0 & $34 / 50(70.6 \%)$ & \\
\hline & & 250 & $44 / 50^{* \mathrm{~m}}(89.7 \%)$ & \\
\hline & & 500 & $49 / 50 * * * \mathrm{~m}(99.9 \%)$ & \\
\hline & & 1,000 & $49 / 50 * * * \mathrm{~m}(98.6 \%)$ & \\
\hline & & \multicolumn{2}{|c|}{ Trend $\mathrm{p}$ value: $<0.001$} & \\
\hline & & \multicolumn{2}{|c|}{ Liver - Hepatoblastoma ${ }^{a}$} & \\
\hline & & 0 & $4 / 50(8.8 \%)$ & \\
\hline & & 250 & $11 / 50 *(23.8 \%)$ & \\
\hline & & 500 & $28 / 50^{* * * \mathrm{n}}(61.3 \%)$ & \\
\hline
\end{tabular}


RoC Monograph on Haloacetic Acids

\begin{tabular}{|c|c|c|c|c|}
\hline $\begin{array}{c}\text { Reference and Study } \\
\text { Design }\end{array}$ & Exposure & Dose Levels & $\begin{array}{c}\text { Tumor Incidence }(\mathbf{n} / \mathbf{N}) \\
(\%)\end{array}$ & Comments \\
\hline \multirow{26}{*}{$\begin{array}{l}\text { NTP (2009) } \\
\text { Animal: } \\
\text { Mouse B6C3F1 } \\
\text { F 6-7 weeks } \\
\text { Study duration: } \\
105 \text { weeks }\end{array}$} & \multirow{26}{*}{$\begin{array}{l}\text { Agent: } \\
\text { Bromochloroacetic acid } \\
96 \% \\
\text { Treatment: } \\
\text { Drinking water } \\
0 \\
250 \\
500 \\
1,000 \mathrm{mg} / \mathrm{L} \text { of drinking } \\
\text { water ad libitum } \times 105 \\
\text { weeks }\end{array}$} & 1,000 & $34 / 50 * * * \mathrm{n}(73.7 \%)$ & \multirow{25}{*}{$\begin{array}{l}\text { Survival: } 36 / 50-42 / 50,32 / 50,40 / 50 \\
\text { Body weight: No significant difference. } \\
\text { Strengths and limitations: A very high-quality study, with } \\
\text { no major concerns. }\end{array}$} \\
\hline & & \multicolumn{2}{|c|}{ Trend $\mathrm{p}$ value: $<0.001$} & \\
\hline & & \multicolumn{2}{|c|}{$\begin{array}{l}\text { Liver - Adenoma, carcinoma, or } \\
\text { hepatoblastoma }^{\text {a }}\end{array}$} & \\
\hline & & 0 & $21 / 50(43.8 \%)$ & \\
\hline & & 250 & $32 / 50 *(66.3 \%)$ & \\
\hline & & 500 & $43 / 50 * * *(90.7 \%)$ & \\
\hline & & 1,000 & $49 / 50 * * *(98 \%)$ & \\
\hline & & \multicolumn{2}{|c|}{ Trend $p$ value: $<0.001$} & \\
\hline & & \multicolumn{2}{|c|}{ Liver - Adenoma ${ }^{\mathrm{a}}$} & \\
\hline & & 0 & $27 / 50(59.4 \%)$ & \\
\hline & & 250 & $48 / 50 * * * 0 \quad(96 \%)$ & \\
\hline & & & $44 / 50 * * * 0$ & \\
\hline & & & $44 / 200(90.970)$ & \\
\hline & & 1,000 & $46 / 50 * * * 0(95.2 \%)$ & \\
\hline & & \multicolumn{2}{|c|}{ Trend $\mathrm{p}$ value: $<0.001$} & \\
\hline & & \multicolumn{2}{|c|}{ Liver - Carcinoma ${ }^{a}$} & \\
\hline & & 0 & $14 / 50^{\mathrm{p}}(31.1 \%)$ & \\
\hline & & 250 & $23 / 50^{\mathrm{p}}(48.3 \%)$ & \\
\hline & & 500 & $26 / 50^{* \mathrm{p}}(56.1 \%)$ & \\
\hline & & 1,000 & $20 / 50^{\mathrm{p}}(42.3 \%)$ & \\
\hline & & \multicolumn{2}{|c|}{ Liver - Adenoma or carcinoma ${ }^{a}$} & \\
\hline & & 0 & $31 / 50^{\mathrm{q}}(67.6 \%)$ & \\
\hline & & 250 & $49 / 50 * * * \mathrm{q}(98 \%)$ & \\
\hline & & 500 & $46 / 50 * * * \mathrm{q}(94.6 \%)$ & \\
\hline & & 1,000 & $46 / 50 * * * \mathrm{q}(95.2 \%)$ & \\
\hline & & \multicolumn{2}{|c|}{ Trend $\mathrm{p}$ value: $<0.001$} & \\
\hline
\end{tabular}




\begin{tabular}{|c|c|c|c|c|}
\hline $\begin{array}{c}\text { Reference and Study } \\
\text { Design }\end{array}$ & Exposure & Dose Levels & $\begin{array}{c}\text { Tumor Incidence (n/N) } \\
(\%)\end{array}$ & Comments \\
\hline $\begin{array}{l}\text { DeAngelo et al. (1997) } \\
\text { Animal: } \\
\text { Rat F344/N } \\
\text { M 28-30 days } \\
\text { Study duration: } \\
104 \text { weeks }\end{array}$ & $\begin{array}{l}\text { Agent: } \\
\text { Trichloroacetic acid } \\
>99 \% \\
\text { Treatment: } \\
\text { Drinking water } \\
0+ \\
2,500++\mathrm{mg} / \mathrm{L} \text { in } \\
\text { drinking water }(\mathrm{pH} 6.9- \\
7.1) \text { ad libitum } \times 104 \\
\text { weeks }\end{array}$ & $\begin{array}{l}\text { Liver - Adeno } \\
0 \\
50 \\
500 \\
5,000 \\
\text { Liver - Carcin } \\
0\end{array}$ & $\begin{array}{l}\text { a or carcinoma } \\
1 / 23(4 \%) \\
1 / 24(4 \%) \\
3 / 20(15 \%) \\
1 / 22(5 \%)\end{array}$ & $\begin{array}{l}\text { Survival: No significant difference in survival: } \\
23 / 29-24 / 32,19 / 32,22 / 29 \\
\text { Body weight: Body weights were similar among the } 0.05 \\
\text { and } 0.5 \mathrm{~g} / \mathrm{l} \text { groups but decreased more than } 10 \% \text { compared to } \\
\text { controls in the } 5 \mathrm{~g} / 1 \text { group. } \\
\text { Significantly increased preneoplastic lesions: Hyperplastic } \\
\text { nodules were reported but were not significantly increased. } \\
\text { They are likely considered part of the continuum toward } \\
\text { neoplasia as it was reported combined with adenomas and } \\
\text { carcinomas as proliferative lesions and other publications by } \\
\text { this author under similar studies reported that a similar lesion } \\
\text { (large foci of cellular alteration) was only distinguishable } \\
\text { from adenomas because the nodules caused compression at } \\
\text { less than } 80 \% \text { of its surface (DeAngelo et al. } 2008 \text { ). } \\
\text { Other comments: Amount of water consumed was similar } \\
\text { among groups ( } 76.9 \mathrm{ml} / \mathrm{kg} / \mathrm{d}-71.2 \text {, ml } / \mathrm{kg} / \mathrm{d}, 70.6 \mathrm{ml} / \mathrm{kg} / \mathrm{d} \text {, } \\
74,2 \mathrm{~m} / \mathrm{kg} / \mathrm{d} \text { ). } \\
\text { Strengths and limitations: A well conducted study on } \\
\text { almost all aspects but only involved male rats. }\end{array}$ \\
\hline $\begin{array}{l}\text { DeAngelo et al. (2008) } \\
\text { Animal: } \\
\text { Mouse (Study 1) } \\
\text { B6C3F1 } \\
\text { M 28-30 days } \\
\text { Study duration: } \\
60 \text { weeks }\end{array}$ & $\begin{array}{l}\text { Agent: } \\
\text { Trichloroacetic acid } \\
99 \% \\
\text { Treatment: } \\
\text { Drinking water } \\
0+ \\
50 \\
500 \\
5,000 \mathrm{mg} / \mathrm{L} \text { in drinking } \\
\text { water ad libitum } \times 60 \\
\text { weeks }\end{array}$ & $\begin{array}{l}\text { Liver - Adeno } \\
0 \\
50 \\
500 \\
5,000 \\
\text { Liver - Carcin } \\
0 \\
50 \\
500\end{array}$ & $\begin{array}{l}\text { 2/30 (7\%) } \\
4 / 27(15 \%) \\
6 / 29(21 \%) \\
11 / 29^{\mathrm{r}}(38 \%) \\
\mathbf{m a} \\
2 / 30(7 \%) \\
1 / 27(4 \%) \\
6 / 29(21 \%)\end{array}$ & $\begin{array}{l}\text { Survival: No difference in survival: } 30 / 30-27 / 30,29 / 30 \text {, } \\
29 / 30 \\
\text { Body weight: Not reported. } \\
\text { Significantly increased preneoplastic lesions: Large foci of } \\
\text { cellular alteration were significantly increased at } 5,000 \mathrm{mg} / \mathrm{L} \\
(\mathrm{p}<0.05) \text {. Large foci of cellular alteration were considered } \\
\text { preneoplastic. } \\
\text { Other comments: Denominators of incidences are based on } \\
\text { surviving mice. Water consumption decreased in } 0.5 \text { and } 5.0 \\
\text { g/l groups. }\end{array}$ \\
\hline
\end{tabular}




\begin{tabular}{|c|c|c|c|c|}
\hline $\begin{array}{c}\text { Reference and Study } \\
\text { Design }\end{array}$ & Exposure & Dose Levels & $\begin{array}{c}\text { Tumor Incidence (n/N) } \\
(\%)\end{array}$ & Comments \\
\hline \multirow[b]{2}{*}{$\begin{array}{l}\text { DeAngelo et al. (2008) } \\
\text { Animal: } \\
\text { Mouse (Study 2) } \\
\text { B6C3F1 } \\
\text { M 28-30 days } \\
\text { Study duration: } \\
\text { 104 weeks }\end{array}$} & $+2,000 \mathrm{mg} / \mathrm{L} \mathrm{NaCl}$ & $\begin{array}{l}5,000 \\
\text { Liver - Adeno } \\
0 \\
50 \\
500 \\
5,000\end{array}$ & $\begin{array}{l}11 / 29^{\mathrm{r}}(38 \%) \\
\text { la or carcinoma } \\
4 / 30(13 \%) \\
4 / 27(15 \%) \\
11 / 29^{\mathrm{r}}(38 \%) \\
16 / 29^{\mathrm{r}}(55 \%)\end{array}$ & $\begin{array}{l}\text { Strengths and limitations: Three dose levels were used that } \\
\text { spanned a } 100 \text {-fold range. Most organs were histologically } \\
\text { evaluated and evaluations were confirmed by an independent } \\
\text { pathologist. }\end{array}$ \\
\hline & $\begin{array}{l}\text { Agent: } \\
\text { Trichloroacetic acid } \\
99 \% \\
\text { Treatment: } \\
\text { Drinking water } \\
0+ \\
4,500 \mathrm{mg} / \mathrm{L} \text { in drinking } \\
\text { water ad libitum } \times 104 \\
\text { weeks } \\
+1.5 \mathrm{~g} / \mathrm{L} \text { of neutralized } \\
\text { acetic acid }\end{array}$ & $\begin{array}{l}\text { Liver - Carcin } \\
0 \\
4,500 \\
\text { Liver - Adeno } \\
0 \\
4,500\end{array}$ & $\begin{array}{l}\text { ma } \\
3 / 25(12 \%) \\
28 / 36^{\mathrm{r}}(78 \%) \\
\text { a or carcinoma } \\
3 / 25(12 \%) \\
32 / 36^{\mathrm{r}}(89 \%)\end{array}$ & $\begin{array}{l}\text { Survival: No difference in survival: } 34 / 51-30 / 42 \\
\text { Body weight: No reported. } \\
\text { Significantly increased preneoplastic lesions: Large foci of } \\
\text { cellular alteration were not significantly increased. Large } \\
\text { foci of cellular alteration were considered preneoplastic. } \\
\text { Other comments: Denominators of incidences are based on } \\
\text { surviving mice. Water consumption decreased in } 0.5 \text { and } 5.0 \\
\text { g/l groups. } \\
\text { Strengths and limitations: Only one dose level was tested } \\
\text { but was given for a near life-span of a large number of } \\
\text { animals. Most organs were histologically evaluated and } \\
\text { evaluations were confirmed by an independent pathologist. }\end{array}$ \\
\hline $\begin{array}{l}\text { DeAngelo et al. (2008) } \\
\text { Animal: } \\
\text { Mouse (Study 3) } \\
\text { B6C3F1 } \\
\text { M 28-30 days } \\
\text { Study duration: } \\
\text { 104 weeks }\end{array}$ & $\begin{array}{l}\text { Agent: } \\
\text { Trichloroacetic acid } \\
99 \% \\
\text { Treatment: } \\
\text { Drinking water } \\
0 \\
50 \\
500 \mathrm{mg} / \mathrm{L} \text { in neutralized } \\
\text { drinking water ad } \\
\text { libitum } \times 104 \text { weeks }\end{array}$ & $\begin{array}{l}\text { Liver - Adeno } \\
0 \\
50 \\
500 \\
\text { Liver - Carcin } \\
0 \\
50 \\
500 \\
\text { [Trend p value: }\end{array}$ & $\begin{array}{l}9 / 42(21 \%) \\
8 / 35(23 \%) \\
19 / 37^{\mathrm{r}}(51 \%) \\
\mathbf{m a} \\
23 / 42(55 \%) \\
14 / 35(40 \%) \\
29 / 37^{\mathrm{r}}(78 \%)\end{array}$ & $\begin{array}{l}\text { Survival: No difference in survival: } 34 / 51-29 / 53,27 / 51 \\
\text { Body weight: No reported. } \\
\text { Significantly increased preneoplastic lesions: Large foci of } \\
\text { cellular alteration were significantly increased at } 500 \mathrm{mg} / \mathrm{L} \\
(\mathrm{p}<0.05 \text {. Large foci of cellular alteration were considered } \\
\text { preneoplastic. } \\
\text { Other comments: Denominators of incidences are based on } \\
\text { surviving mice. No difference in water consumption } \\
\text { occurred. } \\
\text { Strengths and limitations: Only two dose levels were } \\
\text { tested, but they were low compared to other studies and were } \\
\text { given for near a life-span of time to a large number of }\end{array}$ \\
\hline
\end{tabular}




\begin{tabular}{|c|c|c|c|c|}
\hline $\begin{array}{l}\text { Reference and Study } \\
\text { Design }\end{array}$ & Exposure & Dose Levels & $\begin{array}{l}\text { Tumor Incidence }(\mathbf{n} / \mathbf{N}) \\
(\%)\end{array}$ & Comments \\
\hline \multirow{12}{*}{$\begin{array}{l}\text { Herren-Freund et al. } \\
\text { (1987) } \\
\text { Animal: } \\
\text { Mouse B6C3F1 } \\
\text { M } 4 \text { weeks } \\
\text { Study duration: } \\
61 \text { weeks }\end{array}$} & & \multicolumn{2}{|c|}{ Liver - Adenoma or carcinoma } & \multirow{4}{*}{$\begin{array}{l}\text { animals. Most organs were histologically evaluated and } \\
\text { evaluations were confirmed by an independent pathologist. }\end{array}$} \\
\hline & & 0 & $27 / 42(64 \%)$ & \\
\hline & & 50 & $20 / 35(57 \%)$ & \\
\hline & & 500 & $32 / 37^{r}(87 \%)$ & \\
\hline & Agent: & \multicolumn{2}{|c|}{ Liver - Adenoma } & \multirow{8}{*}{$\begin{array}{l}\text { Survival: Not reported. } \\
\text { Body weight: Body weights were significantly decreased } \\
(\mathrm{p}<0.001) \text {. Calculations were done by one-way analysis of } \\
\text { variance with a Tukey's comparison. } \\
\text { Significantly increased preneoplastic lesions: Not reported. } \\
\text { Strengths and limitations: The durations were less than } \\
\text { near life-span. Only males were tested at a single dose level } \\
\text { and only livers were histologically evaluated. }\end{array}$} \\
\hline & Trichloroacetic acid & 0 & $2 / 22(9 \%)$ & \\
\hline & $\begin{array}{l}>99 \% \\
\text { Treatment: }\end{array}$ & 5,000 & $8 / 22 * *(36 \%)$ & \\
\hline & Drinking water & & & \\
\hline & $0+$ & \multicolumn{2}{|c|}{ Liver - Carcinoma } & \\
\hline & $\begin{array}{l}5,000 \mathrm{mg} / \mathrm{L} \text { in drinking } \\
\text { water }(\mathrm{pH} 6.5-7.5) \text { ad }\end{array}$ & 0 & $0 / 22$ & \\
\hline & libitum $\times 61$ weeks & 5,000 & $7 / 22 * *(32 \%)$ & \\
\hline & $+2,000 \mathrm{mg} / \mathrm{L} \mathrm{NaCl}$ & & & \\
\hline \multirow{12}{*}{$\begin{array}{l}\text { Pereira (1996) } \\
\text { Animal: } \\
\text { Mouse (Study 1) } \\
\text { B6C3F1 } \\
\text { F 7-8 weeks } \\
\text { Study duration: } \\
\text { 576 days }\end{array}$} & Agent: & \multicolumn{2}{|c|}{ Liver - Adenoma } & \multirow{12}{*}{$\begin{array}{l}\text { Survival: Not reported } \\
\text { Body weight: The high dose level of DCA was caused } \\
\text { significant weight loss after } 35 \text { weeks and beyond, while the } \\
\text { high dose of TCA caused it at } 51 \text { weeks, with near } \\
\text { significant decreases beyond. } \\
\text { Significantly increased preneoplastic lesions: The foci of } \\
\text { altered hepatocytes were reported combined with neoplasms } \\
\text { but not separately. They are likely considered part of the } \\
\text { continuum toward neoplasia as it was reported combined } \\
\text { with adenomas and carcinomas as proliferative lesions and } \\
\text { other publications by this author under similar studies } \\
\text { reported that a similar lesion (large foci of cellular alteration) } \\
\text { was only distinguishable from adenomas because the nodules } \\
\text { caused compression at less than } 80 \% \text { of its surface } \\
\text { (DeAngelo et al. 2008). } \\
\text { Strengths and limitations: The chemicals were not } \\
\text { characterized, not even purity was reported. Disease }\end{array}$} \\
\hline & Trichloroacetic acid & 0 & $2 / 90(2.2 \%)$ & \\
\hline & Not reported & 330 & $4 / 53(7.6 \%)$ & \\
\hline & Treatment: & 1,100 & $3 / 27(11.1 \%)$ & \\
\hline & Drinking water & 3,300 & $7 / 18 *(38.9 \%)$ & \\
\hline & & \multicolumn{2}{|c|}{ Liver - Carcinoma } & \\
\hline & $1,100++$ & 0 & $2 / 90(2.2 \%)$ & \\
\hline & $\begin{array}{l}3,300++\mathrm{mg} / \mathrm{L} \text { in filtered } \\
\text { and deionized water } \mathrm{pH}\end{array}$ & 330 & $0 / 53$ & \\
\hline & $6.5-7.5$ ad libitum $\times 576$ & 1,100 & $5 / 27 * *(18.5 \%)$ & \\
\hline & days & 3,300 & $5 / 18 * *(27.8 \%)$ & \\
\hline & $+20.0 \mathrm{mmol} / \mathrm{L} \mathrm{NaCl}$ & & & \\
\hline & & & & \\
\hline
\end{tabular}




\begin{tabular}{|c|c|c|c|c|}
\hline $\begin{array}{c}\text { Reference and Study } \\
\text { Design }\end{array}$ & Exposure & Dose Levels & $\begin{array}{c}\text { Tumor Incidence (n/N) } \\
(\%)\end{array}$ & Comments \\
\hline & $\begin{array}{l}++ \text { Concentrations were } \\
\text { reported as } \mathrm{mmol} / \mathrm{L} \text { and } \\
\text { calculated to } \mathrm{mg} / \mathrm{L} \text { based } \\
\text { on a mw of } 163.3869 \\
\mathrm{~g} / \mathrm{mol}\end{array}$ & \multicolumn{2}{|c|}{ [Trend $\mathrm{p}$ value: $<0.001]$} & $\begin{array}{l}\text { surveillance was not continually monitored. A variable } \\
\text { number of only females were tested, with only their livers } \\
\text { examined histologically. }\end{array}$ \\
\hline \multirow{12}{*}{$\begin{array}{l}\text { Pereira (1996) } \\
\text { Animal: } \\
\text { Mouse (Study 2) } \\
\text { B6C3F1 } \\
\text { F 7-8 weeks } \\
\text { Study duration: } \\
\text { 360 days }\end{array}$} & \multirow{12}{*}{$\begin{array}{l}\text { Agent: } \\
\text { Trichloroacetic acid } \\
\text { (TCA) } \\
\text { Not reported } \\
\text { Treatment: } \\
\text { Drinking water } \\
0+ \\
330++ \\
1,100++ \\
3,300++\mathrm{mg} / \mathrm{L} \text { in filtered } \\
\text { and deionized water, } \mathrm{pH} \\
6.5-7.5 \text { ad libitum } \times 360 \\
\text { days } \\
+20 \mathrm{mmol} / \mathrm{L} \mathrm{NaCl} \\
++ \text { Concentrations were } \\
\text { reported as } \mathrm{mmol} / \mathrm{L} \text { and } \\
\text { were calculated to } \mathrm{mg} / \mathrm{L} \\
\text { based on a mw of } \\
163.3869 \mathrm{~g} / \mathrm{mol}\end{array}$} & \multicolumn{2}{|c|}{ Liver - Adenoma } & \multirow{12}{*}{$\begin{array}{l}\text { Survival: Not reported } \\
\text { Body weight: The high dose level of DCA was caused } \\
\text { significant weight loss after } 35 \text { weeks and beyond, while the } \\
\text { high dose of TCA caused it at } 51 \text { weeks, with near } \\
\text { significant decreases beyond. } \\
\text { Significantly increased preneoplastic lesions: The foci of } \\
\text { altered hepatocytes were reported combined with neoplasms } \\
\text { but not separately. They are likely considered part of the } \\
\text { continuum toward neoplasia as it was reported combined } \\
\text { with adenomas and carcinomas as proliferative lesions and } \\
\text { other publications by this author under similar studies } \\
\text { reported that a similar lesion (large foci of cellular alteration) } \\
\text { was only distinguishable from adenomas because the nodules } \\
\text { caused compression at less than } 80 \% \text { of its surface } \\
\text { (DeAngelo et al. 2008). } \\
\text { Strengths and limitations: The chemicals were not } \\
\text { characterized, not even purity was reported. Disease } \\
\text { surveillance was not continually monitored. A variable } \\
\text { number of only females were tested, with only their livers } \\
\text { examined histologically. }\end{array}$} \\
\hline & & 0 & $1 / 40(2.5 \%)$ & \\
\hline & & 330 & $3 / 40(7.5 \%)$ & \\
\hline & & 1,100 & 3/19 (15.8\%) & \\
\hline & & 3,300 & $2 / 20(10 \%)$ & \\
\hline & & \multicolumn{2}{|c|}{ Liver - Carcinoma } & \\
\hline & & 0 & $0 / 40$ & \\
\hline & & 330 & $0 / 40$ & \\
\hline & & 1,100 & $0 / 19$ & \\
\hline & & \multirow[t]{3}{*}{3,300} & $5 / 20 *(25 \%)$ & \\
\hline & & & & \\
\hline & & & & \\
\hline \multirow{7}{*}{$\begin{array}{l}\text { Bull et al. (1990) } \\
\text { Animal: } \\
\text { Mouse B6C3F1 } \\
\text { M } 5 \text { weeks } \\
\text { Study duration: } \\
52 \text { weeks }\end{array}$} & \multirow{7}{*}{$\begin{array}{l}\text { Agent: } \\
\text { Trichloroacetic acid } \\
\text { Analytical grade } \\
\text { Treatment: } \\
\text { Drinking water } \\
0 \\
1,000\end{array}$} & \multicolumn{2}{|c|}{ Liver - Adenoma } & \multirow{7}{*}{$\begin{array}{l}\text { Survival: All mice survived. } \\
\text { Significantly increased preneoplastic lesions: A non- } \\
\text { significant increase in hyperplasia was reported. } \\
\text { Strengths and limitations: The chemical was not } \\
\text { characterized; disease surveillance was not reported. A low } \\
\text { number of mice per group were exposed for a less than near } \\
\text { life-span duration and only males had results reported. Only } \\
\text { livers were histologically examined. Not all lesions were } \\
\text { histologically evaluated but, instead, samples of lesions were }\end{array}$} \\
\hline & & 0 & $0 / 2$ & \\
\hline & & 1,000 & $2 / 5(40 \%)$ & \\
\hline & & 2,000 & $1 / 11(9 \%)$ & \\
\hline & & \multicolumn{2}{|c|}{ Liver - Carcinoma } & \\
\hline & & 0 & $0 / 2$ & \\
\hline & & 1,000 & & \\
\hline
\end{tabular}




\begin{tabular}{|c|c|c|c|c|}
\hline $\begin{array}{c}\text { Reference and Study } \\
\text { Design }\end{array}$ & Exposure & Dose Levels & $\begin{array}{c}\text { Tumor Incidence }(\mathbf{n} / \mathbf{N}) \\
(\%)\end{array}$ & Comments \\
\hline & $\begin{array}{l}2,000 \mathrm{mg} / \mathrm{L} \text { in drinking } \\
\text { water }(\mathrm{pH} 6.8-7.2) \text { ad } \\
\text { libitum } \times 52 \mathrm{wk}\end{array}$ & 2,000 & $4 / 11(36.4 \%)$ & $\begin{array}{l}\text { evaluated. Results were reported so that incidences of } \\
\text { specific neoplasms could not be determined but could be } \\
\text { estimated. }\end{array}$ \\
\hline \multirow{11}{*}{$\begin{array}{l}\text { Von Tungeln et al. } \\
\text { (2002) } \\
\text { Animal: } \\
\text { Mouse (Study 1) } \\
\text { B6C3F1 } \\
\text { M } 8 \text { days (neonatal) } \\
\text { Study duration: } \\
20 \text { months }\end{array}$} & \multirow{8}{*}{$\begin{array}{l}\text { Agent: } \\
\text { Trichloroacetic acid } \\
\text { Purity not reported } \\
\text { Treatment: } \\
\text { ip injection } \\
0+ \\
1,000 \mathrm{nmol}\end{array}$} & \multicolumn{2}{|c|}{ Liver - Adenoma } & \multirow{11}{*}{$\begin{array}{l}\text { Survival: One mouse died after the age of } 28 \text { days in the } 20 \\
\text { month vehicle control group. All other groups had no } \\
\text { mortality after } 28 \text { days of age. } \\
\text { Body weight: Not reported. } \\
\text { Other comments: Early mortality, before } 28 \text { days of age } \\
\text { was not reported, but was as high as } 29 \% \text { in some groups } \\
\text { (which may have included testing of other chemicals). } \\
\text { Strengths and limitations: The study used both positive and } \\
\text { negative controls but did not characterize the chemicals and } \\
\text { used a small, number of male mice per group. Only two } \\
\text { doses were administered at two narrow dose levels, though } \\
\text { the duration of observation was almost near life-span. Early } \\
\text { mortality was not reported. }\end{array}$} \\
\hline & & 0 & $0 / 23$ & \\
\hline & & & & \\
\hline & & 1,000 & $4 / 23(17 \%)$ & \\
\hline & & \multicolumn{2}{|c|}{ Liver - Carcinoma } & \\
\hline & & 0 & $0 / 23$ & \\
\hline & & & $0 / 23$ & \\
\hline & & 1,000 & $1 / 23(4 \%)$ & \\
\hline & \multirow{3}{*}{$\begin{array}{l}1 / 3 \text { of the dose was } \\
\text { injected at age } 8 \text { days } \\
\text { and } 2 / 3 \text { at age } 15 \text { days }\end{array}$} & \multicolumn{2}{|c|}{ Liver - Adenoma or carcinoma } & \\
\hline & & 0 & $0 / 23$ & \\
\hline & & 1,000 & $5 / 23[*](22 \%)$ & \\
\hline \multirow{10}{*}{$\begin{array}{l}\text { Von Tungeln et al. } \\
\text { (2002) } \\
\text { Animal: } \\
\text { Mouse (Study 1) } \\
\text { B6C3F1 } \\
\text { F } 8 \text { days (neonatal) } \\
\text { Study duration: } \\
20 \text { months }\end{array}$} & \multirow{9}{*}{$\begin{array}{l}\text { Agent: } \\
\text { Trichloroacetic acid } \\
\text { Purity not reported } \\
\text { Treatment: } \\
\text { ip injection } \\
0+ \\
1,000 \text { nmol } \\
1 / 3 \text { of the dose was } \\
\text { injected at age } 8 \text { days } \\
\text { and } 2 / 3 \text { at age } 15 \text { days }\end{array}$} & \multicolumn{2}{|c|}{ Liver - Adenoma } & \multirow{10}{*}{$\begin{array}{l}\text { Survival: One mouse died after the age of } 28 \text { days in the } 20 \\
\text { month vehicle control group. All other groups had no } \\
\text { mortality after } 28 \text { days of age. } \\
\text { Body weight: Not reported. } \\
\text { Other comments: Early mortality, before } 28 \text { days of age } \\
\text { was not reported, but was as high as } 29 \% \text { in some groups } \\
\text { (which may have included testing of other chemicals). } \\
\text { Strengths and limitations: The study used both positive and } \\
\text { negative controls but did not characterize the chemicals and } \\
\text { used a small, number of male mice per group. Only two } \\
\text { doses were administered at two narrow dose levels, though } \\
\text { the duration of observation was almost near life-span. Early } \\
\text { mortality was not reported. }\end{array}$} \\
\hline & & 0 & $0 / 23$ & \\
\hline & & 1,000 & $0 / 23$ & \\
\hline & & \multicolumn{2}{|c|}{ Liver - Carcinoma } & \\
\hline & & 0 & $0 / 23$ & \\
\hline & & & & \\
\hline & & 1,000 & $0 / 23$ & \\
\hline & & \multicolumn{2}{|c|}{ Liver - Adenoma or carcinoma } & \\
\hline & & 0 & $0 / 23$ & \\
\hline & + DMSO & 1,000 & $0 / 23$ & \\
\hline \multirow{5}{*}{$\begin{array}{l}\text { Von Tungeln et al. } \\
\text { (2002) } \\
\text { Animal: } \\
\text { Mouse (Study 2) } \\
\text { B6C3F1 }\end{array}$} & \multirow{5}{*}{$\begin{array}{l}\text { Agent: } \\
\text { Trichloroacetic acid } \\
\text { Purity not reported } \\
\text { Treatment: } \\
\text { ip injection }\end{array}$} & \multicolumn{2}{|c|}{ Liver - Adenoma } & Survival: One mouse died after the age of 28 days in the 20 \\
\hline & & 0 & $0 / 24$ & month vehicle control group. All other groups had no \\
\hline & & & & mortality after 28 days of age. \\
\hline & & 2,000 & $4 / 24(17 \%)$ & Body weight: Not reported. \\
\hline & & \multicolumn{2}{|c|}{ Liver - Carcinoma } & \\
\hline
\end{tabular}




\begin{tabular}{|c|c|c|c|c|}
\hline $\begin{array}{c}\text { Reference and Study } \\
\text { Design }\end{array}$ & Exposure & Dose Levels & $\begin{array}{c}\text { Tumor Incidence (n/N) } \\
(\%)\end{array}$ & Comments \\
\hline \multirow{6}{*}{$\begin{array}{l}\text { M } 8 \text { days (neonatal) } \\
\text { Study duration: } \\
12 \text { months }\end{array}$} & $0+$ & 0 & $0 / 24$ & \multirow{6}{*}{$\begin{array}{l}\text { Other comments: Early mortality, before } 28 \text { days of age was } \\
\text { not reported, but was as high as } 29 \% \text { in some groups (which } \\
\text { may have included testing of other chemicals). } \\
\text { Strengths and limitations: The study used both positive and } \\
\text { negative controls but did not characterize the chemicals and } \\
\text { used a small, number of male mice per group. Only two } \\
\text { doses were administered at two narrow dose levels, though } \\
\text { the duration of observation was almost near life-span. Early } \\
\text { mortality was not reported. }\end{array}$} \\
\hline & $2,000 \mathrm{nmol}$ & 2,000 & $0 / 24$ & \\
\hline & $3 / 7$ of the dose was & Liver - Adeno & la or carcinoma & \\
\hline & injected at age 8 days & 0 & $0 / 24$ & \\
\hline & and $4 / 7$ at age 15 days. & 2,000 & $4 / 24(17 \%)$ & \\
\hline & + DMSO & & & \\
\hline \multirow{10}{*}{$\begin{array}{l}\text { Von Tungeln et al. } \\
\text { (2002) } \\
\text { Animal: } \\
\text { Mouse (Study 2) } \\
\text { B6C3F1 } \\
\text { F } 8 \text { days (neonatal) } \\
\text { Study duration: } \\
12 \text { months }\end{array}$} & Agent: & \multicolumn{2}{|c|}{ Liver - Adenoma } & \multirow{10}{*}{$\begin{array}{l}\text { Survival: One mouse died after the age of } 28 \text { days in the } 20 \\
\text { month vehicle control group. All other groups had no } \\
\text { mortality after } 28 \text { days of age. } \\
\text { Body weight: Not reported. } \\
\text { Other comments: Early mortality, before } 28 \text { days of age was } \\
\text { not reported, but was as high as } 29 \% \text { in some groups (which } \\
\text { may have included testing of other chemicals). } \\
\text { Strengths and limitations: The study used both positive anc } \\
\text { negative controls but did not characterize the chemicals and } \\
\text { used a small, number of male mice per group. Only two } \\
\text { doses were administered at two narrow dose levels, though } \\
\text { the duration of observation was almost near life-span. Early } \\
\text { mortality was not reported. }\end{array}$} \\
\hline & $\begin{array}{l}\text { Trichloroacetic acid } \\
\text { Purity not reported }\end{array}$ & 0 & $0 / 24$ & \\
\hline & Treatment: & & & \\
\hline & ip injection & 2,000 & $0 / 24$ & \\
\hline & $\begin{array}{l}0+ \\
2,000 \mathrm{nmol}\end{array}$ & \multicolumn{2}{|c|}{ Liver - Carcinoma } & \\
\hline & \multirow{5}{*}{$\begin{array}{l}3 / 7 \text { of the dose was } \\
\text { injected at age } 8 \text { days } \\
\text { and } 4 / 7 \text { at age } 15 \text { days. }\end{array}$} & 0 & $0 / 24$ & \\
\hline & & 2,000 & $0 / 24$ & \\
\hline & & \multicolumn{2}{|c|}{ Liver - Adenoma or carcinoma } & \\
\hline & & 0 & $0 / 24$ & \\
\hline & & 2,000 & $0 / 24$ & \\
\hline \multirow{9}{*}{$\begin{array}{l}\text { NTP (2015) } \\
\text { Animal: } \\
\text { Mouse B6C3F1/N } \\
\text { M 5-6 weeks } \\
\text { Study duration: } \\
105 \text { weeks }\end{array}$} & Agent: & \multicolumn{2}{|c|}{ Liver - Adenoma $^{\mathrm{a}}$} & \multirow{9}{*}{$\begin{array}{l}\text { Survival: Significant decrease in survival. } \\
\text { Body weight: Significant decreased in body weight after } 57 \\
\text { weeks at } 1,000 \mathrm{mg} / \mathrm{l} \text { and after } 73 \text { weeks at } 500 \mathrm{mg} / \mathrm{l} \text {. } \\
\text { Strengths and limitations: Well reported and designed } \\
\text { study, with a large number of animals of both sexes exposed } \\
\text { for near life-span at three exposure levels. }\end{array}$} \\
\hline & Bromodichloroacetic & 0 & $39 / 50(87 \%)$ & \\
\hline & $\begin{array}{l}\text { accd } \\
97 \%\end{array}$ & 250 & $41 / 50(90 \%)$ & \\
\hline & Treatment: & 500 & $42 / 49(91 \%)$ & \\
\hline & $\begin{array}{l}\text { Drinking water } \\
0\end{array}$ & 1,000 & $40 / 51(91 \%)$ & \\
\hline & 250 & \multicolumn{2}{|c|}{ Liver - Carcinoma ${ }^{a}$} & \\
\hline & $\begin{array}{l}500 \\
1000 \mathrm{mg} / \mathrm{L} \text { of drinking }\end{array}$ & 0 & $12 / 50(29 \%)$ & \\
\hline & water ad libitum $\times 105$ & 250 & $22 / 50 *(50 \%)$ & \\
\hline & weeks & 500 & $27 / 49 * * * \mathrm{t}(66 \%)$ & \\
\hline
\end{tabular}


RoC Monograph on Haloacetic Acids

\begin{tabular}{|c|c|c|c|c|}
\hline $\begin{array}{c}\text { Reference and Study } \\
\text { Design }\end{array}$ & Exposure & Dose Levels & $\begin{array}{c}\text { Tumor Incidence }(\mathbf{n} / \mathbf{N}) \\
(\%)\end{array}$ & Comments \\
\hline & & 1,000 & $39 / 51 * * * \mathrm{t}(87 \%)$ & \\
\hline & & \multicolumn{3}{|c|}{ Trend $\mathrm{p}$ value: $<0.001$} \\
\hline & & \multicolumn{3}{|c|}{ Liver - Adenoma or carcinoma ${ }^{a}$} \\
\hline & & 0 & $42 / 50(91 \%)$ & \\
\hline & & 250 & $47 / 50(98 \%)$ & \\
\hline & & 500 & $46 / 49(97 \%)$ & \\
\hline & & 1,000 & $48 / 51(98 \%)$ & \\
\hline & & \multicolumn{3}{|c|}{ Liver - Hepatoblastoma ${ }^{a}$} \\
\hline & & 0 & $4 / 50(10 \%)$ & \\
\hline & & 250 & $24 / 50^{* * * u}(54 \%)$ & \\
\hline & & 500 & $40 / 49^{* * * u}(87 \%)$ & \\
\hline & & 1,000 & $34 / 51 * * * u(78 \%)$ & \\
\hline & & \multicolumn{3}{|c|}{ Trend $\mathrm{p}$ value: $<0.001$} \\
\hline & & \multicolumn{3}{|c|}{$\begin{array}{l}\text { Liver - Adenoma, carcinoma, or } \\
\text { hepatoblastoma }\end{array}$} \\
\hline & & 0 & $42 / 50(91 \%)$ & \\
\hline & & 250 & $50 / 50 *(100 \%)$ & \\
\hline & & 500 & $48 / 49(98 \%)$ & \\
\hline & & 1,000 & $49 / 51 *(99 \%)$ & \\
\hline & & \multicolumn{3}{|c|}{ Trend $\mathrm{p}$ value: $=0.036$} \\
\hline & & \multicolumn{3}{|c|}{ Liver - Hemangiosarcoma ${ }^{a}$} \\
\hline & & 0 & $1 / 50(3 \%)$ & \\
\hline & & 250 & $4 / 50(10 \%)$ & \\
\hline & & 500 & $2 / 49(6 \%)$ & \\
\hline & & 1,000 & $4 / 51(12 \%)$ & \\
\hline
\end{tabular}


RoC Monograph on Haloacetic Acids

\begin{tabular}{|c|c|c|c|c|}
\hline $\begin{array}{c}\text { Reference and Study } \\
\text { Design }\end{array}$ & Exposure & Dose Levels & $\begin{array}{c}\text { Tumor Incidence (n/N) } \\
(\%)\end{array}$ & Comments \\
\hline \multirow{26}{*}{$\begin{array}{l}\text { NTP (2015) } \\
\text { Animal: } \\
\text { Mouse B6C3F1/N } \\
\text { F 5-6 wk } \\
\text { Study duration: } \\
105 \text { wk }\end{array}$} & \multirow{26}{*}{$\begin{array}{l}\text { Agent: } \\
\text { Bromodichloroacetic } \\
\text { acid } \\
97 \% \\
\text { Treatment: } \\
\text { Drinking water } \\
0 \\
250 \\
500 \\
1,000 \mathrm{mg} / \mathrm{L} \text { of drinking } \\
\text { water ad libitum } \times 105 \\
\text { weeks }\end{array}$} & \multicolumn{2}{|c|}{ Liver - Adenoma ${ }^{a}$} & \multirow{26}{*}{$\begin{array}{l}\text { Survival: No effect on survival. } \\
30 / 50-33 / 50,29 / 50,27 / 50 \\
\text { Body weight: Significant decrease in body weight after } 73 \\
\text { weeks at } 1,000 \mathrm{mg} / 1 \text { and after } 89 \text { weeks at } 250 \mathrm{mg} / \mathrm{L} \text {. } \\
\text { Strengths and limitations: Well reported and designed } \\
\text { study, with a large number of animals of both sexes exposed } \\
\text { for near life-span at three exposure levels. }\end{array}$} \\
\hline & & 0 & $33 / 49^{v}(75 \%)$ & \\
\hline & & 250 & $42 / 50^{* v}(91 \%)$ & \\
\hline & & 500 & $42 / 49^{* v}(93 \%)$ & \\
\hline & & 1,000 & $44 / 50^{* * v}(93 \%)$ & \\
\hline & & \multicolumn{2}{|c|}{ Trend $\mathrm{p}$ value: $=0.009$} & \\
\hline & & \multicolumn{2}{|c|}{ Liver - Carcinoma $a^{a}$} & \\
\hline & & 0 & $9 / 49(21 \%)$ & \\
\hline & & 250 & $17 / 50^{\mathrm{w}}(38 \%)$ & \\
\hline & & 500 & $22 / 49^{* * x}(50 \%)$ & \\
\hline & & 1,000 & $26 / 50^{* * * x}(59 \%)$ & \\
\hline & & \multicolumn{2}{|c|}{ Trend $\mathrm{p}$ value: $<0.001$} & \\
\hline & & \multicolumn{2}{|c|}{ Liver - Adenoma or carcinoma ${ }^{a}$} & \\
\hline & & 0 & $36 / 49(81.1 \%)$ & \\
\hline & & 250 & $44 / 50 *(93.7 \%)$ & \\
\hline & & 500 & $43 / 49 *(94.7 \%)$ & \\
\hline & & 1,000 & $46 / 50 *(95.5 \%)$ & \\
\hline & & \multicolumn{2}{|c|}{ Trend $\mathrm{p}$ value: $=0.013$} & \\
\hline & & \multicolumn{2}{|c|}{ Liver - Hepatoblastoma ${ }^{a}$} & \\
\hline & & 0 & $0 / 49$ & \\
\hline & & 250 & $1 / 50(2 \%)$ & \\
\hline & & 500 & $4 / 49(9 \%)$ & \\
\hline & & 1,000 & $6 / 50^{* \mathrm{y}}(14 \%)$ & \\
\hline & & \multicolumn{2}{|c|}{ Trend $p$ value: $=0.003$} & \\
\hline & & \multicolumn{2}{|c|}{ Liver - Hemangiosarcoma ${ }^{a}$} & \\
\hline & & 0 & $2 / 49(5 \%)$ & \\
\hline
\end{tabular}




\begin{tabular}{|c|c|c|c|c|}
\hline $\begin{array}{c}\text { Reference and Study } \\
\text { Design }\end{array}$ & Exposure & Dose Levels & $\begin{array}{c}\text { Tumor Incidence (n/N) } \\
(\%)\end{array}$ & Comments \\
\hline & & 250 & $4 / 50(9 \%)$ & \\
\hline & & 500 & 4/49 (9\%) & \\
\hline & & 1,000 & $8 / 50 *(19 \%)$ & \\
\hline & & \multicolumn{2}{|c|}{ Trend $\mathrm{p}$ value: $=0.026$} & \\
\hline
\end{tabular}

$*<0.05 ; * *<0.01 ; * * *<0.00 \mathrm{p}$ value.

[ ] = p value calculated by NTP using Fisher's Exact Test for pairwise comparisons or Cochran-Armitage Trend Test.

${ }^{a}$ Adjusted percent incidence based on Poly-3 estimated neoplasm incidence after adjustment for intercurrent mortality.

${ }^{b}$ Exceeds historical controls from drinking water studies: 84/197 (range 34\%-63\%); exceeds historical controls from studies of all routes: 490/1,506 (range 12\%-63\%).

'Exceeds historical controls from drinking water studies: 57/197 (range 18\%-42\%); exceeds historical controls from studies of all routes: 344/1,506 (range 8\%-46\%).

${ }^{\mathrm{d}}$ Exceeds historical controls from drinking water studies: 122/197 (range 48\%-85\%); exceeds historical controls from studies of all routes: 745/1,506 (range 20\%-85\%).

${ }^{e}$ Exceeds historical controls from drinking water studies: $11 / 197$ (range $0 \%-13 \%$ ); exceeds historical controls from studies of all routes: $22 / 1,506$ (range $0 \%-13 \%$ ).

fExceeds historical controls from drinking water studies: 93/248 (range 18\%-61\%): exceeds historical controls from studies of all routes: 312/1,549 (range 6\%-61\%).

${ }^{9}$ Exceeds historical controls from drinking water studies: 28/248 (range 4\%-26\%); exceeds historical controls from studies of all routes: $128 / 1,549$ (range 0\%-26\%).

hExceeds historical controls from drinking water studies: 110/248 (range 20\%-63\%); exceeds historical controls from studies of all routes: 408/1,549 (range 8\%-63\%).

${ }^{i}$ Exceeds historical controls from drinking water studies: 4/300 (range 0\%-4\%); exceeds historical controls from studies of all routes: 10/1,199 (range 0\%-4\%).

${ }^{j}$ Exceeds historical controls from drinking water studies: 3/250 (range 0\%-4\%).

${ }^{\mathrm{k} E x c e e d s ~ h i s t o r i c a l ~ c o n t r o l s ~ f r o m ~ d r i n k i n g ~ w a t e r ~ s t u d i e s: ~ 140 / 247 ~(r a n g e ~ 37 \%-72 \%) ; ~ e x c e e d s ~ h i s t o r i c a l ~ c o n t r o l s ~ f r o m ~ s t u d i e s ~ o f ~ a l l ~ r o u t e s: ~ 544 / 1,146 ~(r a n g e ~ 14 \%-72 \%) . ~}$

${ }^{1}$ Exceeds historical controls from drinking water studies: 91/247 (range 28\%-48\%); exceeds historical controls from studies of all routes: $317 / 1,146$ (range $8 \%-48 \%$ ).

${ }^{m}$ Exceeds historical controls from drinking water studies: 182/247 (range 57\%-85\%); exceeds historical controls from studies of all routes: 729/1,146 (range 20\%-85\%).

${ }^{n}$ Exceeds historical controls from drinking water studies: 28/247 (range 0\%-34\%); exceeds historical controls from studies of all routes: 43/1,146 (range 0\%-34\%).

${ }^{\circ}$ Exceeds historical controls from drinking water studies: 133/297 (range 29\%-61\%); exceeds historical controls from studies of all routes: 345/1,245 (range 6\%-62\%).

pExceeds historical controls from drinking water studies: 51/297 (range 6\%-28\%); exceeds historical controls from studies of all routes: $131 / 1,245$ (range $0 \%-28 \%$ ).

${ }^{q}$ Exceeds historical controls from drinking water studies: 158/297 (range 35\%-63\%); exceeds historical controls from studies of all routes: 419/1,245 (range 8\%-64\%). ${ }^{\mathrm{r}} \mathrm{p}<0.03$.

$\mathrm{s} \mathrm{p}=0.054$.

tExceeds historical controls from drinking water studies: 38/100 (range 24\%-52\%); exceeds historical controls from studies of all routes: 348/949 (range 22\%-56\%).

"Exceeds historical controls from drinking water studies: 10/100 (range 8\%-12\%); exceeds historical controls from studies of all routes: $40 / 949$ (range $0 \%-12 \%$ ).

${ }^{\vee}$ Exceeds historical controls from drinking water studies: 71/98 (range 67\%-78\%); exceeds historical controls from studies of all routes: $378 / 948$ (range 14\%-78\%).

${ }^{w}$ Exceeds historical controls from drinking water studies: 20/98 (range 18\%-22\%).

${ }^{x}$ Exceeds historical controls from drinking water studies: 20/98 (range 18\%-22\%); exceeds historical controls from studies of all routes: 152/948 (range 4\%-46\%).

${ }^{y}$ Exceeds historical controls from drinking water studies: $10 / 98$ (range 8\%-12\%); exceeds historical controls from studies of all routes: $40 / 948$ (range $0 \%-12 \%$ ). 
Table C-57. All Other Tumors

\begin{tabular}{|c|c|c|c|c|}
\hline $\begin{array}{c}\text { Reference and Study } \\
\text { Design }\end{array}$ & Exposure & Dose Levels & $\begin{array}{c}\text { Tumor Incidence (n/N) } \\
(\%)\end{array}$ & Comments \\
\hline $\begin{array}{l}\text { (1992) } \\
\text { Animal: } \\
\text { Mouse B6C3F1 } \\
\text { M 7-8 weeks } \\
\text { Study duration: } \\
104 \text { weeks }\end{array}$ & $\begin{array}{l}\text { Agent: } \\
\text { Monochloroacetic acid } \\
99 \% \\
\text { Treatment: } \\
\text { Gavage } \\
0 \\
50 \\
100 \mathrm{mg} / \mathrm{kg} \text { bw in } \\
\text { deionized water } \\
5 \text { doses } / \text { week } \times 104 \\
\text { weeks }\end{array}$ & $\begin{array}{l}0 \\
50 \\
100\end{array}$ & nor NOS & $\begin{array}{l}\text { Survival: The } 100 \mathrm{mg} / \mathrm{kg} \text { group was lower than controls } \\
\left.\text { and there was a significant trend: } 46 / 60^{* * *} \text { (trend }<0.001\right) \\
-39 / 60,21 / 60^{* * *}(<0.001) \\
\text { Body weight: Body weights were similar to controls. } \\
\text { Significantly increased preneoplastic lesions: The } \\
\text { incidence of forestomach pre-neoplasia (squamous cell } \\
\text { hyperplasia) was significantly increased at } 100 \mathrm{mg} / \mathrm{kg} \text {. The } \\
\text { incidence of nasal cavity pre-neoplasia (olfactory } \\
\text { epithelium metaplasia) was not significantly increased. } \\
\text { Metaplasia was from olfactory epithelium to ciliated } \\
\text { columnar respiratory epithelium. } \\
\text { Strengths and limitations: The study was well conducted } \\
\text { to rule out confounding and with a strong power to detect } \\
\text { tumor induction. However, only two exposed dose levels } \\
\text { were tested, which limit the detection of dose response } \\
\text { relationships. }\end{array}$ \\
\hline $\begin{array}{l}\text { NTP (1992) } \\
\text { Animal: } \\
\text { Mouse B6C3F1 } \\
\text { F 7-8 weeks } \\
\text { Study duration: } \\
104 \text { weeks }\end{array}$ & $\begin{array}{l}\text { Agent: } \\
\text { Monochloroacetic acid } \\
99 \% \\
\text { Treatment: } \\
\text { Gavage } \\
0 \\
50 \\
100 \mathrm{mg} / \mathrm{kg} \mathrm{bw} \text { in } \\
\text { deionized water } \\
5 \text { doses } / \text { week } \times 104 \\
\text { weeks }\end{array}$ & $\begin{array}{l}\text { All organs }-\mathbf{T} \\
0 \\
50\end{array}$ & $\begin{array}{l}\text { nor NOS } \\
\text { None } \\
\text { None }\end{array}$ & $\begin{array}{l}\text { Survival: Survival of the exposed groups were similar to } \\
\text { controls: } 42 / 60-40 / 60,44 / 60 \\
\text { Body weight: Body weights of the low dose group were } \\
\text { similar to controls, but after a year the high dose group had } \\
\text { significantly lower body weight. } \\
\text { Significantly increased preneoplastic lesions: The } \\
\text { incidences of pre-neoplasia in the forestomach (squamous } \\
\text { cell hyperplasia) and nasal cavity were significantly } \\
\text { increased at } 100 \mathrm{mg} / \mathrm{kg} \text {. Hyperplasia included diffuse, } \\
\text { focal, and multifocal lesions. Metaplasia was from } \\
\text { olfactory epithelium to ciliated columnar respiratory } \\
\text { epithelium. } \\
\text { Strengths and limitations: The study was well conducted } \\
\text { to rule out confounding and with a strong power to detect } \\
\text { tumor induction. However, only two exposed dose levels } \\
\text { were tested, which limit the detection of dose response } \\
\text { relationships. }\end{array}$ \\
\hline
\end{tabular}




\begin{tabular}{|c|c|c|c|c|}
\hline $\begin{array}{c}\text { Reference and Study } \\
\text { Design }\end{array}$ & Exposure & Dose Levels & $\begin{array}{c}\text { Tumor Incidence (n/N) } \\
(\%)\end{array}$ & Comments \\
\hline $\begin{array}{l}\text { NTP (2007a) } \\
\text { Animal: } \\
\text { Rat F344/N } \\
\text { M } 6 \text { weeks } \\
\text { Study duration: } \\
106 \text { weeks }\end{array}$ & $\begin{array}{l}\text { Agent: } \\
\text { Dibromoacetic acid } \\
\text { >99\% } \\
\text { Treatment: } \\
\text { Drinking water } \\
0 \\
50 \\
500 \\
1,000 \mathrm{mg} / \mathrm{L} \text { of drinking } \\
\text { water }(\mathrm{pH} 5) \text { ad } \\
\text { libitum } \times 106 \text { weeks }\end{array}$ & $\begin{array}{l}\text { Whole body - } \\
0 \\
50 \\
500 \\
1,000 \\
\text { Trend p value: } \\
\text { Whole body - } \\
0 \\
50 \\
500 \\
1,000 \\
\text { Lung - Adeno } \\
0 \\
50 \\
500 \\
1,000 \\
\text { Lung - Adeno } \\
0 \\
50 \\
500 \\
1,000\end{array}$ & $\begin{array}{l}\text { Ialignant mesothelioma } \\
3 / 50(7 \%) \\
1 / 50(2 \%) \\
0 / 50 \\
10 / 50^{* \mathrm{~b}}(23 \%) \\
.001 \\
\text { lononuclear cell leukemiaa } \\
17 / 50^{\mathrm{c}}(37 \%) \\
31 / 50^{* * \mathrm{c}}(66 \%) \\
24 / 50^{\mathrm{c}}(56 \%) \\
13 / 50(30 \%) \\
\mathrm{a}^{\mathrm{a}} \\
2 / 50(4.6 \%) \\
0 / 50 \\
4 / 50(10.1 \%) \\
2 / 50(4.9 \%) \\
\text { a or carcinoma } \\
2 / 50(4.6 \%) \\
1 / 50(2.4 \%) \\
5 / 50(12.6 \%) \\
2 / 50(4.9 \%)\end{array}$ & $\begin{array}{l}\text { Survival: Survival was similar in all groups. } \\
34 / 50-24 / 50,30 / 50,28 / 50 \\
\text { Body weight: Body weights were lower in the } 500 \text { (after } \\
57 \text { weeks) and } 1,000 \text { (after } 29 \text { weeks) } \mathrm{mg} / 1 \text { groups } \\
\text { compared to the untreated controls. } \\
\text { Significantly increased preneoplastic lesions: Liver } \\
\text { cystic degeneration }\left(3 / 50-9 / 50^{*}, 11 / 50^{*}, 15 / 50^{* *} \text { ) }\right. \\
\text { Other comments: Water consumption was reduced in the } \\
1,000 \mathrm{mg} / 1 \text { group after } 2 \text { years. } \\
\text { Strengths and limitations: Large numbers of animals per } \\
\text { group were used in both sexes and were continuously } \\
\text { monitored for disease. Three dose levels spanning a range } \\
\text { of } 200 \text {-fold were used. Lesions and all major organs were } \\
\text { histologically evaluated and statistics were clearly } \\
\text { reported. }\end{array}$ \\
\hline $\begin{array}{l}\text { NTP (2007a) } \\
\text { Animal: } \\
\text { Rat F344/N } \\
\text { F } 6 \text { weeks } \\
\text { Study duration: }\end{array}$ & $\begin{array}{l}\text { Agent: } \\
\text { Dibromoacetic acid } \\
>99 \% \\
\text { Treatment: } \\
\text { Drinking water }\end{array}$ & $\begin{array}{l}\text { Whole body - } \\
0 \\
50 \\
500\end{array}$ & $\begin{array}{l}\text { Ialignant mesothelioma } \\
0 / 50 \\
0 / 50 \\
1 / 50(2 \%)\end{array}$ & $\begin{array}{l}\text { Survival: Survival was similar in all groups. } \\
34 / 50-39 / 50,35 / 50,32 / 50 \\
\text { Body weight: Body weights were lower in the } 1,000 \text { (after } \\
49 \text { weeks) } \mathrm{mg} / \mathrm{l} \text { groups compared to the untreated controls. }\end{array}$ \\
\hline
\end{tabular}




\begin{tabular}{|c|c|c|c|c|}
\hline $\begin{array}{c}\text { Reference and Study } \\
\text { Design }\end{array}$ & Exposure & Dose Levels & $\begin{array}{c}\text { Tumor Incidence (n/N) } \\
(\%)\end{array}$ & Comments \\
\hline \multirow[t]{12}{*}{106 weeks } & \multirow{5}{*}{$\begin{array}{l}0 \\
50 \\
500 \\
1,000 \mathrm{mg} / \mathrm{L} \text { of drinking } \\
\text { water }(\mathrm{pH} 5) \text { ad } \\
\text { libitum } \times 106 \text { weeks }\end{array}$} & 1,000 & $0 / 50$ & \multirow{12}{*}{$\begin{array}{l}\text { Significantly increased preneoplastic lesions: Significan } \\
\text { increases in the incidence of lung per-neoplasia (alveolar } \\
\text { epithelium hyperplasia) occurred at } 500 \text { and } 1,000 \mathrm{mg} / \mathrm{L} \text {. } \\
\text { Kidney nephropathy }\left(18 / 50-32 / 50^{* *}, 37 / 50^{* *}, 40 / 50^{* *}\right) \\
\text { Other comments: Water consumption was reduced in the } \\
1,000 \mathrm{mg} / 1 \text { group after } 2 \text { years. } \\
\text { Strengths and limitations: Large numbers of animals per } \\
\text { group were used in both sexes and were continuously } \\
\text { monitored for disease. Three dose levels spanning a range } \\
\text { of } 200 \text {-fold were used. Lesions and all major organs were } \\
\text { histologically evaluated and statistics were clearly } \\
\text { reported. }\end{array}$} \\
\hline & & Whole body -1 & Iononuclear cell leukemia ${ }^{a}$ & \\
\hline & & 0 & $11 / 50(24 \%)$ & \\
\hline & & 50 & $13 / 50(27 \%)$ & \\
\hline & & 500 & $16 / 50^{\mathrm{d}}(35 \%)$ & \\
\hline & \multirow{7}{*}{$\begin{array}{l}\text { Mean daily doses }(0-2 \text {, } \\
25,45 \mathrm{mg} / \mathrm{kg} \text { bw) }\end{array}$} & 1,000 & $22 / 50^{* \mathrm{~d}}(47 \%)$ & \\
\hline & & Trend $\mathrm{p}$ value: $=$ & 0.006 & \\
\hline & & Lung - Adenor & a or carcinoma & \\
\hline & & 0 & $2 / 50(4 \%)$ & \\
\hline & & 50 & $3 / 50(8 \%)$ & \\
\hline & & 500 & $2 / 50(4 \%)$ & \\
\hline & & 1,000 & $5 / 50^{\mathrm{e}}(10 \%)$ & \\
\hline \multirow{13}{*}{$\begin{array}{l}\text { NTP (2007a) } \\
\text { Animal: } \\
\text { Mouse B6C3F1 } \\
\text { M } 6 \text { weeks } \\
\text { Study duration: } \\
106 \text { weeks }\end{array}$} & \multirow{8}{*}{$\begin{array}{l}\text { Agent: } \\
\text { Dibromoacetic acid } \\
>99 \% \\
\text { Treatment: } \\
\text { Drinking water } \\
0 \\
50 \\
500 \\
1,000 \mathrm{mg} / \mathrm{L} \text { of drinking } \\
\text { water }(\mathrm{pH} 5) \text { ad } \\
\text { libitum } \times 106 \text { weeks }\end{array}$} & Lung - Adenor & & \multirow{13}{*}{$\begin{array}{l}\text { Survival: Survival was similar in all groups. } \\
31 / 50-38 / 50,34 / 50,31 / 50 \\
\text { Body weight: Body weights were greater in the } 50 \text { and } \\
500 \mathrm{mg} / \mathrm{l} \text { groups compared to the untreated controls after } \\
85 \text { weeks. } \\
\text { Significantly increased preneoplastic lesions: The } \\
\text { incidence of lung pre-neoplasia (Alveolar epithelium } \\
\text { hyperplasia) was not significantly increased compared to } \\
\text { controls. Spleen hematopoiesis occurred at an significant } \\
\text { increased incidences at } 500 \text { and } 1,000 \mathrm{mg} / \mathrm{L} \text {. } \\
\text { Other comments: Water consumption was similar to } \\
\text { controls. } \\
\text { Strengths and limitations: Large numbers of animals per } \\
\text { group were used in both sexes and were continuously } \\
\text { monitored for disease. Three dose levels spanning a range } \\
\text { of } 200 \text {-fold were used. Lesions and all major organs were } \\
\text { histologically evaluated and statistics were clearly } \\
\text { reported. }\end{array}$} \\
\hline & & 0 & $7 / 49(16 \%)$ & \\
\hline & & 50 & $5 / 50(11 \%)$ & \\
\hline & & 500 & $17 / 50 * \mathrm{f}(38 \%)$ & \\
\hline & & 1,000 & $12 / 50^{\mathrm{g}}(27 \%)$ & \\
\hline & & Trend $p$ value: $=$ & 0.019 & \\
\hline & & Lung - Carcin & & \\
\hline & & 0 & $5 / 49(10 \%)$ & \\
\hline & \multirow{5}{*}{$\begin{array}{l}\text { Average daily dose: } 0-4 \text {, } \\
45,87 \mathrm{mg} / \mathrm{kg}\end{array}$} & 50 & $8 / 50^{\mathrm{h}}(16 \%)$ & \\
\hline & & 500 & $8 / 50^{\mathrm{h}}(16 \%)$ & \\
\hline & & 1,000 & $7 / 50^{\mathrm{h}}(14 \%)$ & \\
\hline & & Lung - Adenor & a or carcinoma ${ }^{a}$ & \\
\hline & & 0 & $12 / 49^{\mathrm{i}}(28 \%)$ & \\
\hline
\end{tabular}




\begin{tabular}{|c|c|c|c|c|}
\hline $\begin{array}{c}\text { Reference and Study } \\
\text { Design }\end{array}$ & Exposure & Dose Levels & $\begin{array}{c}\text { Tumor Incidence (n/N) } \\
(\%)\end{array}$ & Comments \\
\hline & & 50 & $12 / 50(26 \%)$ & \\
\hline & & 500 & $22 / 50 * j(49 \%)$ & \\
\hline & & 1,000 & $17 / 50^{i}(37 \%)$ & \\
\hline \multirow{17}{*}{$\begin{array}{l}\text { NTP (2007a) } \\
\text { Animal: } \\
\text { Mouse B6C3F1 } \\
\text { F } 6 \text { weeks } \\
\text { Study duration: } \\
106 \text { weeks }\end{array}$} & \multirow{9}{*}{$\begin{array}{l}\text { Agent: } \\
\text { Dibromoacetic acid } \\
>99 \% \\
\text { Treatment: } \\
\text { Drinking water } \\
0 \\
50 \\
500 \\
1,000 \mathrm{mg} / \mathrm{L} \text { of drinking } \\
\text { water }(\mathrm{pH} 5) \text { ad } \\
\text { libitum } \times 106 \text { weeks }\end{array}$} & \multicolumn{2}{|c|}{ Lung - Adenoma ${ }^{\mathrm{a}}$} & \multirow{17}{*}{$\begin{array}{l}\text { Survival: Survival was similar in all groups. } \\
38 / 50-35 / 50,32 / 50,32 / 50 \\
\text { Body weight: Body weights were similar to the untreated } \\
\text { controls. } \\
\text { Other comments: Water consumption was similar to } \\
\text { controls. } \\
\text { Strengths and limitations: Large numbers of animals per } \\
\text { group were used in both sexes and were continuously } \\
\text { monitored for disease. Three dose levels spanning a range } \\
\text { of } 200 \text {-fold were used. Lesions and all major organs were } \\
\text { histologically evaluated and statistics were clearly } \\
\text { reported. }\end{array}$} \\
\hline & & 0 & $1 / 50(2 \%)$ & \\
\hline & & 50 & $3 / 50(7 \%)$ & \\
\hline & & 500 & $3 / 50(7 \%)$ & \\
\hline & & & T/20 (1/0) & \\
\hline & & 1,000 & $6 / 50^{\mathrm{k}}(13 \%)$ & \\
\hline & & \multicolumn{2}{|c|}{ Trend $\mathrm{p}$ value: $=0.044$} & \\
\hline & & \multicolumn{2}{|c|}{ Lung - Carcinoma } & \\
\hline & & 0 & $1 / 50(2 \%)$ & \\
\hline & \multirow{8}{*}{$\begin{array}{l}\text { Average daily dose: } 0-4 \text {, } \\
35,65 \mathrm{mg} / \mathrm{kg}\end{array}$} & 50 & $2 / 50(4 \%)$ & \\
\hline & & 500 & $2 / 50(4 \%)$ & \\
\hline & & 1,000 & $2 / 50(4 \%)$ & \\
\hline & & \multicolumn{2}{|c|}{ Lung - Adenoma or carcinoma ${ }^{a}$} & \\
\hline & & 0 & $2 / 50(4 \%)$ & \\
\hline & & 50 & $5 / 50(11 \%)$ & \\
\hline & & 500 & $5 / 50(11 \%)$ & \\
\hline & & 1,000 & $7 / 50^{1}(15 \%)$ & \\
\hline \multirow{7}{*}{$\begin{array}{l}\text { NTP (2009) } \\
\text { Animal: } \\
\text { Rat F344/N } \\
\text { M 6-7 weeks } \\
\text { Study duration: } \\
105 \text { weeks }\end{array}$} & Agent: & \multicolumn{2}{|c|}{ Mammary gland - Fibroadenoma } & \multirow{7}{*}{$\begin{array}{l}\text { Survival: No significant difference: } \\
31 / 50-26 / 50,25 / 50,29 / 50 \\
\text { Body weight: } 1,000 \mathrm{mg} / 1 \text { group was } 10 \% \text { less than } \\
\text { controls after } 69 \text { weeks. } \\
\text { Significantly increased preneoplastic lesions: The } \\
\text { incidence of lung pre-neoplasia (alveolar epithelium } \\
\text { hyperplasia) was not significantly increased. }\end{array}$} \\
\hline & Bromochloroacetic acid & 0 & $3 / 50(6 \%)$ & \\
\hline & $96 \%$ & 0 & $3 / 30(0 \%)$ & \\
\hline & Treatment: & 250 & $4 / 50(8 \%)$ & \\
\hline & Drinking water & 500 & $3 / 50(6 \%)$ & \\
\hline & $\begin{array}{l}0 \\
250\end{array}$ & 1,000 & $4 / 50(8 \%)$ & \\
\hline & 500 & \multicolumn{2}{|c|}{ Lung - Adenoma or carcinoma ${ }^{a}$} & \\
\hline
\end{tabular}


RoC Monograph on Haloacetic Acids

\begin{tabular}{|c|c|c|c|c|}
\hline $\begin{array}{c}\text { Reference and Study } \\
\text { Design }\end{array}$ & Exposure & Dose Levels & $\begin{array}{c}\text { Tumor Incidence (n/N) } \\
(\%)\end{array}$ & Comments \\
\hline & \multirow{20}{*}{$\begin{array}{l}1,000 \mathrm{mg} / \mathrm{L} \text { of drinking } \\
\text { water } \times 105 \text { weeks }\end{array}$} & 0 & $3 / 50(7 \%)$ & \multirow{20}{*}{$\begin{array}{l}\text { Strengths and limitations: A very high-quality study, } \\
\text { with no major concerns. }\end{array}$} \\
\hline & & 250 & $1 / 50(2.5 \%)$ & \\
\hline & & 500 & $0 / 50$ & \\
\hline & & 1,000 & $3 / 50(7.1 \%)$ & \\
\hline & & \multicolumn{2}{|c|}{ Pancreatic islets - Adenoma ${ }^{a}$} & \\
\hline & & 0 & $3 / 50(7 \%)$ & \\
\hline & & 250 & $4 / 50(9.4 \%)$ & \\
\hline & & 500 & $9 / 50 *(21.6 \%)$ & \\
\hline & & 1,000 & $3 / 50(7.1 \%)$ & \\
\hline & & \multicolumn{2}{|c|}{ All organs - Malignant mesothelioma ${ }^{a}$} & \\
\hline & & 0 & $1 / 50(2.3 \%)$ & \\
\hline & & 250 & $5 / 50(11.7 \%)$ & \\
\hline & & 500 & $10 / 50 * *(23.7 \%)$ & \\
\hline & & 1,000 & $6 / 50(14 \%)$ & \\
\hline & & \multicolumn{2}{|c|}{ Large intestine - Adenoma $^{\mathrm{a}}$} & \\
\hline & & 0 & $0 / 50$ & \\
\hline & & 250 & $2 / 50(4.8 \%)$ & \\
\hline & & 500 & $0 / 50$ & \\
\hline & & 1,000 & $4 / 50(9.5 \%)$ & \\
\hline & & \multicolumn{2}{|c|}{ Trend $p$ value: $=0.031$} & \\
\hline \multirow{5}{*}{$\begin{array}{l}\text { NTP (2009) } \\
\text { Animal: } \\
\text { Rat F344/N } \\
\text { F 6-7 weeks } \\
\text { Study duration: }\end{array}$} & \multirow{5}{*}{$\begin{array}{l}\text { Agent: } \\
\text { Bromochloroacetic acid } \\
96 \% \\
\text { Treatment: } \\
\text { Drinking water }\end{array}$} & \multicolumn{2}{|c|}{ Mammary gland - Fibroadenoma ${ }^{a}$} & \multirow{5}{*}{$\begin{array}{l}\text { Survival: No significant difference: } \\
34 / 50-31 / 50,37 / 50,35 / 50 \\
\text { Body weight: } 1,000 \mathrm{mg} / 1 \text { group was }<10 \% \text { of controls. } \\
\text { after } 85 \text { weeks. }\end{array}$} \\
\hline & & 0 & $43 / 50(92 \%)$ & \\
\hline & & 0 & & \\
\hline & & 250 & $43 / 50(90 \%)$ & \\
\hline & & 500 & $47 / 50(96.9 \%)$ & \\
\hline
\end{tabular}




\begin{tabular}{|c|c|c|c|c|}
\hline $\begin{array}{c}\text { Reference and Study } \\
\text { Design }\end{array}$ & Exposure & Dose Levels & $\begin{array}{c}\text { Tumor Incidence (n/N) } \\
(\%)\end{array}$ & Comments \\
\hline \multirow[t]{23}{*}{105 weeks } & \multirow{23}{*}{$\begin{array}{l}0 \\
250 \\
500 \\
1,000 \mathrm{mg} / \mathrm{L} \text { of drinking } \\
\text { water ad libitum } \times 105 \\
\text { weeks }\end{array}$} & 1,000 & $46 / 50(96.9 \%)$ & \multirow{23}{*}{$\begin{array}{l}\text { Significantly increased preneoplastic lesions: The } \\
\text { incidence of lung pre-neoplasia (alveolar epithelium } \\
\text { hyperplasia) was significantly increased at } 1,000 \mathrm{mg} / \mathrm{L} \text {. } \\
\text { Strengths and limitations: A very high-quality study, } \\
\text { with no major concerns. }\end{array}$} \\
\hline & & \multirow{2}{*}{\multicolumn{2}{|c|}{ 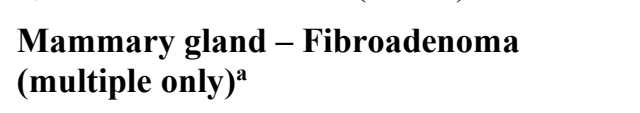 }} & \\
\hline & & & & \\
\hline & & 0 & $22 / 50(44 \%)$ & \\
\hline & & 250 & $24 / 50(48 \%)$ & \\
\hline & & 500 & $43 / 50 * *(86 \%)$ & \\
\hline & & 1,000 & $38 / 50 * *(76 \%)$ & \\
\hline & & \multicolumn{2}{|c|}{ Lung - Adenoma or carcinoma } & \\
\hline & & 0 & $1 / 50(2 \%)$ & \\
\hline & & 250 & $1 / 50(2 \%)$ & \\
\hline & & 500 & $2 / 50(4 \%)$ & \\
\hline & & 1,000 & $2 / 50(4 \%)$ & \\
\hline & & \multicolumn{2}{|c|}{ Pancreatic islets - Adenoma ${ }^{a}$} & \\
\hline & & 0 & $3 / 49(7 \%)$ & \\
\hline & & 250 & $1 / 50(2.3 \%)$ & \\
\hline & & 500 & $1 / 50(2.2 \%)$ & \\
\hline & & 1,000 & $2 / 50(4.4 \%)$ & \\
\hline & & \multicolumn{2}{|c|}{ Large intestine - Adenoma ${ }^{a}$} & \\
\hline & & 0 & $0 / 50$ & \\
\hline & & 250 & $0 / 50$ & \\
\hline & & 500 & $3 / 50(6.6 \%)$ & \\
\hline & & 1,000 & $7 / 50 * *(15.5 \%)$ & \\
\hline & & \multicolumn{2}{|c|}{ Trend $\mathrm{p}$ value: $<0.001$} & \\
\hline \multirow{2}{*}{$\begin{array}{l}\text { NTP (2009) } \\
\text { Animal: }\end{array}$} & \multirow{2}{*}{$\begin{array}{l}\text { Agent: } \\
\text { Bromochloroacetic acid }\end{array}$} & \multicolumn{2}{|c|}{ Harderian gland - Adenoma ${ }^{a}$} & Survival: $38 / 50-35 / 50,30 / 50,21 / 50$ \\
\hline & & 0 & $5 / 50(11.1 \%)$ & \\
\hline
\end{tabular}




\begin{tabular}{|c|c|c|c|c|}
\hline $\begin{array}{c}\text { Reference and Study } \\
\text { Design }\end{array}$ & Exposure & Dose Levels & $\begin{array}{c}\text { Tumor Incidence }(\mathbf{n} / \mathbf{N}) \\
(\%)\end{array}$ & Comments \\
\hline $\begin{array}{l}\text { Mouse B6C3F1 } \\
\text { M 6-7 weeks } \\
\text { Study duration: } \\
105 \text { weeks }\end{array}$ & $\begin{array}{l}96 \% \\
\text { Treatment: } \\
\text { Drinking water } \\
0 \\
250 \\
500 \\
1,000 \mathrm{mg} / \mathrm{L} \text { of drinking } \\
\text { water ad libitum } \times 105 \\
\text { weeks }\end{array}$ & $\begin{array}{l}250 \\
500 \\
1,000\end{array}$ & $\begin{array}{l}9 / 50(20 \%) \\
9 / 50(20.7 \%) \\
8 / 50(18.5 \%)\end{array}$ & $\begin{array}{l}\text { Body weight: } 1,000 \mathrm{mg} / \mathrm{l} \text { group was } 12 \% \text { lower than } \\
\text { controls after } 97 \text { weeks. } \\
\text { Strengths and limitations: A very high-quality study, } \\
\text { with no major concerns. }\end{array}$ \\
\hline $\begin{array}{l}\text { NTP (2009) } \\
\text { Animal: } \\
\text { Mouse B6C3F1 } \\
\text { F 6-7 weeks } \\
\text { Study duration: } \\
105 \text { weeks }\end{array}$ & $\begin{array}{l}\text { Agent: } \\
\text { Bromochloroacetic acid } \\
96 \% \\
\text { Treatment: } \\
\text { Drinking water } \\
0 \\
250 \\
500 \\
1,000 \mathrm{mg} / \mathrm{L} \text { of drinking } \\
\text { water ad libitum } \times 105 \\
\text { weeks }\end{array}$ & $\begin{array}{l}\text { Harderian gla } \\
0 \\
250 \\
500 \\
1,000\end{array}$ & $\begin{array}{l}d-\text { Adenoma }^{\mathrm{a}} \\
1 / 50(2.2 \%) \\
7 / 50 *(14.5 \%) \\
1 / 50(2.2 \%) \\
7 / 50 *(14.7 \%)\end{array}$ & $\begin{array}{l}\text { Survival: } 36 / 50-42 / 50,32 / 50,40 / 50 \\
\text { Body weight: No significant difference. } \\
\text { Significantly increased preneoplastic lesions: Harderian } \\
\text { gland focal hyperplasia was also significantly increased in } \\
\text { the } 250 \mathrm{mg} / 1 \text { group. } \\
\text { Other comments: The significance was possibly found } \\
\text { because of the low incidence of the untreated controls, } \\
\text { which were at the bottom end of the historical control } \\
\text { range. } \\
\text { Strengths and limitations: A very high-quality study, } \\
\text { with no major concerns. }\end{array}$ \\
\hline $\begin{array}{l}\text { NTP (2015) } \\
\text { Animal: } \\
\text { Rat F344/NTac } \\
\text { M 5-6 wk } \\
\text { Study duration: } \\
105 \text { wk }\end{array}$ & $\begin{array}{l}\text { Agent: } \\
\text { Bromodichloroacetic } \\
\text { acid } \\
97 \% \\
\text { Treatment: } \\
\text { Drinking water } \\
0 \\
250 \\
500 \\
1,000 \mathrm{mg} / \mathrm{L} \text { of drinking } \\
\text { water ad libitum } \times 105 \\
\text { weeks }\end{array}$ & $\begin{array}{l}\text { Whole body }- \\
0 \\
250 \\
500 \\
1,000 \\
\text { Trend p value: } \\
\text { Mammary gla } \\
0 \\
250 \\
500\end{array}$ & $\begin{array}{l}\text { Ialignant mesothelioma } \\
1 / 50(3 \%) \\
12 / 50^{* * *}(28 \%) \\
18 / 50^{* * *}(41 \%) \\
37 / 50^{* * *}(78 \%) \\
0.001 \\
\text { d - Fibroadenoma }{ }^{a} \\
0 / 50 \\
2 / 50(5 \%) \\
3 / 50(7 \%)\end{array}$ & $\begin{array}{l}\text { Survival: No effect on survival. } \\
19 / 50-21 / 50,25 / 50,19 / 50 \\
\text { Body weight: Significant decrease of body weight after } 89 \\
\text { weeks with } 1,000 \mathrm{mg} / 1 \text {, associated with a } 10 \% \text { in water } \\
\text { consumption. } \\
\text { Other comments: Large intestine includes cecum, colon, } \\
\text { and rectum. } \\
\text { Strengths and limitations: Well reported and designed } \\
\text { study, with a large number of animals of both sexes } \\
\text { exposed for near life-span at three exposure levels. }\end{array}$ \\
\hline
\end{tabular}


RoC Monograph on Haloacetic Acids

\begin{tabular}{|c|c|c|c|c|}
\hline $\begin{array}{c}\text { Reference and Study } \\
\text { Design }\end{array}$ & Exposure & Dose Levels & $\begin{array}{c}\text { Tumor Incidence (n/N) } \\
(\%)\end{array}$ & Comments \\
\hline & & 1,000 & $1 / 50(3 \%)$ & \\
\hline & & \multicolumn{2}{|c|}{$\begin{array}{l}\text { Brain-Glioma or oligodendroglioma } \\
\text { (original evaluation and extended }_{\text {evaluations) }^{\mathrm{a}}}\end{array}$} & \\
\hline & & 0 & $1 / 50(3 \%)$ & \\
\hline & & 250 & $1 / 50(3 \%)$ & \\
\hline & & 500 & $4 / 50(10 \%)$ & \\
\hline & & 1,000 & $3 / 50(8 \%)$ & \\
\hline & & \multicolumn{2}{|c|}{ Skin - Fibroma ${ }^{a}$} & \\
\hline & & 0 & $4 / 50(10 \%)$ & \\
\hline & & 250 & $6 / 50(15 \%)$ & \\
\hline & & 500 & $10 / 50(23 \%)$ & \\
\hline & & 1,000 & $15 / 50 * *(36 \%)$ & \\
\hline & & \multicolumn{2}{|c|}{ Trend $\mathrm{p}$ value: $<0.001$} & \\
\hline & & \multicolumn{2}{|c|}{ Skin - Keratoacanthoma ${ }^{a}$} & \\
\hline & & 0 & $7 / 50(17 \%)$ & \\
\hline & & 250 & $3 / 50(8 \%)$ & \\
\hline & & 500 & $10 / 50(23 \%)$ & \\
\hline & & 1,000 & $15 / 50 *(37 \%)$ & \\
\hline & & \multicolumn{2}{|c|}{ Trend $\mathrm{p}$ value: $=0.003$} & \\
\hline & & \multicolumn{2}{|c|}{ Skin - Squamous cell papilloma ${ }^{a}$} & \\
\hline & & 0 & $3 / 50(8 \%)$ & \\
\hline & & 250 & $1 / 50(3 \%)$ & \\
\hline & & 500 & $0 / 50$ & \\
\hline & & 1,000 & $1 / 50(3 \%)$ & \\
\hline & & \multicolumn{2}{|c|}{ Skin - Basal cell adenoma ${ }^{a}$} & \\
\hline
\end{tabular}


RoC Monograph on Haloacetic Acids

\begin{tabular}{|c|c|c|c|c|}
\hline $\begin{array}{l}\text { Reference and Study } \\
\text { Design }\end{array}$ & Exposure & Dose Levels & $\begin{array}{c}\text { Tumor Incidence (n/N) } \\
(\%)\end{array}$ & Comments \\
\hline & & 0 & $0 / 50$ & \\
\hline & & 250 & $0 / 50$ & \\
\hline & & 500 & $4 / 50(9 \%)$ & \\
\hline & & 1,000 & $4 / 50(10 \%)$ & \\
\hline & & \multicolumn{3}{|c|}{ Trend $p$ value: $=0.012$} \\
\hline & & \multicolumn{3}{|c|}{$\begin{array}{l}\text { Skin - Squamous cell papilloma, } \\
\text { keratoacanthoma, sebaceous gland } \\
\text { adenoma, basal cell adenoma, basal cell } \\
\text { carcinoma, or squamous cell carcinoma }^{a}\end{array}$} \\
\hline & & 0 & $9 / 50(22 \%)$ & \\
\hline & & 250 & $7 / 50(17 \%)$ & \\
\hline & & 500 & $15 / 50(34 \%)$ & \\
\hline & & 1,000 & $21 / 50 * *(50 \%)$ & \\
\hline & & \multicolumn{3}{|c|}{ Trend $\mathrm{p}$ value: $<0.001$} \\
\hline & & \multicolumn{3}{|c|}{ Large intestine - Adenoma } \\
\hline & & 0 & $0 / 50$ & \\
\hline & & 250 & $0 / 50$ & \\
\hline & & 500 & $2 / 50(4 \%)$ & \\
\hline & & 1,000 & $2 / 50(4 \%)$ & \\
\hline & & \multicolumn{3}{|c|}{$\begin{array}{l}\text { Oral cavity - Squamous cell papilloma or } \\
\text { squamous cell carcinoma }^{\mathrm{a}}\end{array}$} \\
\hline & & 0 & $1 / 50(3 \%)$ & \\
\hline & & 250 & $0 / 50$ & \\
\hline & & 500 & $3 / 50(7 \%)$ & \\
\hline & & 1,000 & $3 / 50(8 \%)$ & \\
\hline
\end{tabular}




\begin{tabular}{|c|c|c|c|c|}
\hline $\begin{array}{c}\text { Reference and Study } \\
\text { Design }\end{array}$ & Exposure & Dose Levels & $\begin{array}{c}\text { Tumor Incidence (n/N) } \\
(\%)\end{array}$ & Comments \\
\hline \multirow{28}{*}{$\begin{array}{l}\text { NTP (2015) } \\
\text { Animal: } \\
\text { Rat F344/NTac } \\
\text { F 5-6 wk } \\
\text { Study duration: } \\
\text { up to } 104 \text { wk }\end{array}$} & \multirow{28}{*}{$\begin{array}{l}\text { Agent: } \\
\text { Bromodichloroacetic } \\
\text { acid } \\
>97 \% \\
\text { Treatment: } \\
\text { Drinking water } \\
0 \\
250 \\
500 \\
1000 \mathrm{mg} / \mathrm{L} \text { of drinking } \\
\text { water ad libitum } \times 104 \\
\text { weeks }\end{array}$} & \multirow{3}{*}{\multicolumn{2}{|c|}{$\begin{array}{l}\text { Brain - Glioma or oligodendroglioma } \\
\text { (original evaluation and extended } \\
\text { evaluations) }^{\mathrm{a}}\end{array}$}} & \multirow{27}{*}{$\begin{array}{l}\text { Survival: Survival significantly decrease for the } 500 \text { and } \\
1,000 \mathrm{mg} / 1 \text { groups and there was a significant negative } \\
\text { trend of survival with exposure level. } \\
34 / 50-26 / 50,7 / 50^{* * *}, 2 / 50^{* * *} \\
\text { Body weight: Significant body weight loss compared to } \\
\text { controls ( } 10 \% \text { lower than control) from } 1,000 \mathrm{mg} / \mathrm{l} \text { after } 13 \\
\text { weeks and ( } 20 \% \text { lower than control) after } 52 \text { weeks. Water } \\
\text { consumption was decreased during the first year but was } \\
\text { similar to controls during the second year. Body weight } \\
\text { loss was not related to decreased water consumption. } \\
\text { Other comments: Large intestine includes the colon and } \\
\text { rectum. The cecum was not reported, suggesting an } \\
\text { incidence of zero. } \\
\text { Strengths and limitations: Well reported and designed } \\
\text { study, with a large number of animals of both sexes } \\
\text { exposed for near life-span at three exposure levels. }\end{array}$} \\
\hline & & & & \\
\hline & & & & \\
\hline & & 0 & $1 / 50(2.2 \%)$ & \\
\hline & & 0 & $1 / 50(2.2 \%)$ & \\
\hline & & 250 & $0 / 50$ & \\
\hline & & 500 & $3 / 50(9 \%)$ & \\
\hline & & 1000 & $1 / 50(35 \%)$ & \\
\hline & & 1000 & $1 / 20(3.570)$ & \\
\hline & & \multicolumn{2}{|c|}{ Mammary gland - Fibroadenoma ${ }^{a}$} & \\
\hline & & 0 & $28 / 50(60.1 \%)$ & \\
\hline & & 250 & $47 / 50 * * *(96.6 \%)$ & \\
\hline & & 500 & $47 / 50 * * *(99.1 \%)$ & \\
\hline & & 1000 & $39 / 50 * * *(89.6 \%)$ & \\
\hline & & \multicolumn{2}{|c|}{ Trend $\mathrm{p}$ value: $<0.001$} & \\
\hline & & \multicolumn{2}{|c|}{ Mammary gland - Adenoma } & \\
\hline & & 0 & $1 / 50(2 \%)$ & \\
\hline & & 250 & $2 / 50(4 \%)$ & \\
\hline & & 500 & $3 / 50(6 \%)$ & \\
\hline & & 1000 & $1 / 50(2 \%)$ & \\
\hline & & \multicolumn{2}{|c|}{ Mammary gland - Carcinoma ${ }^{a}$} & \\
\hline & & 0 & $0 / 50$ & \\
\hline & & 250 & $1 / 50(2.3 \%)$ & \\
\hline & & 500 & $3 / 50(9.1 \%)$ & \\
\hline & & 1000 & $8 / 50 * * *(25.8 \%)$ & \\
\hline & & \multicolumn{2}{|c|}{ Trend p value: $<0.001$} & \\
\hline & & \multicolumn{2}{|c|}{ Mammary gland - Adenoma or carcinoma } & \\
\hline & & 0 & $1 / 50(2 \%)$ & \\
\hline
\end{tabular}


RoC Monograph on Haloacetic Acids

\begin{tabular}{|c|c|c|c|c|}
\hline $\begin{array}{c}\text { Reference and Study } \\
\text { Design }\end{array}$ & Exposure & Dose Levels & $\begin{array}{c}\text { Tumor Incidence (n/N) } \\
(\%)\end{array}$ & Comments \\
\hline & & 250 & $3 / 50(6 \%)$ & \\
\hline & & 500 & $6 / 50 *(12 \%)$ & \\
\hline & & 1000 & $9 / 50 * *(18 \%)$ & \\
\hline & & \multicolumn{2}{|c|}{$\begin{array}{l}\text { Mammary gland - Adenoma, carcinoma, } \\
\text { or fibroadenoma }\end{array}$} & \\
\hline & & 0 & $28 / 50(60.1 \%)$ & \\
\hline & & 250 & $47 / 50 * * *(96.6 \%)$ & \\
\hline & & 500 & $48 / 50 * * *(99.4 \%)$ & \\
\hline & & 1000 & $42 / 50 * * *(92.5 \%)$ & \\
\hline & & \multicolumn{2}{|c|}{ Trend $\mathrm{p}$ value: $<0.001$} & \\
\hline & & \multicolumn{2}{|c|}{ Skin - Fibroma ${ }^{\mathrm{a}}$} & \\
\hline & & 0 & $2 / 50(4.4 \%)$ & \\
\hline & & 250 & $0 / 50$ & \\
\hline & & 500 & $3 / 50(8.9 \%)$ & \\
\hline & & 1000 & $2 / 50(6.9 \%)$ & \\
\hline & & \multicolumn{2}{|c|}{ Skin - Basal cell adenoma } & \\
\hline & & 0 & $0 / 50$ & \\
\hline & & 250 & $0 / 50$ & \\
\hline & & 500 & $0 / 50$ & \\
\hline & & 1000 & $1 / 50(2 \%)$ & \\
\hline & & \multicolumn{2}{|c|}{ Large intestine - Adenoma ${ }^{a}$} & \\
\hline & & 0 & $1 / 50(2.2 \%)$ & \\
\hline & & 250 & $0 / 50$ & \\
\hline & & 500 & $1 / 50(3.1 \%)$ & \\
\hline & & 1000 & $2 / 50(7 \%)$ & \\
\hline
\end{tabular}




\begin{tabular}{|c|c|c|c|c|}
\hline $\begin{array}{l}\text { Reference and Study } \\
\text { Design }\end{array}$ & Exposure & Dose Levels & $\begin{array}{c}\text { Tumor Incidence }(\mathbf{n} / \mathbf{N}) \\
(\%)\end{array}$ & Comments \\
\hline & & \multicolumn{2}{|c|}{$\begin{array}{l}\text { Oral cavity - Squamous cell papilloma or } \\
\text { squamous cell carcinoma }^{\text {a }}\end{array}$} & \\
\hline & & 0 & $0 / 50$ & \\
\hline & & 250 & $2 / 50(4.6 \%)$ & \\
\hline & & 500 & $1 / 50(3.1 \%)$ & \\
\hline & & 1000 & $2 / 50(6.9 \%)$ & \\
\hline \multirow{19}{*}{$\begin{array}{l}\text { NTP (2015) } \\
\text { Animal: } \\
\text { Mouse B6C3F1/N } \\
\text { M 5-6 wk } \\
\text { Study duration: } \\
105 \text { wk }\end{array}$} & \multirow{19}{*}{$\begin{array}{l}\text { Agent: } \\
\text { Bromodichloroacetic } \\
\text { acid } \\
97 \% \\
\text { Treatment: } \\
\text { Drinking water } \\
0 \\
250 \\
500 \\
1,000 \mathrm{mg} / \mathrm{L} \text { of drinking } \\
\text { water ad libitum } \times 105 \\
\text { weeks }\end{array}$} & \multicolumn{2}{|c|}{ Harderian gland - Adenoma ${ }^{a}$} & \multirow{19}{*}{$\begin{array}{l}\text { Survival: Significant decrease in survival. } \\
\text { Body weight: Significant decreased in body weight after } \\
57 \text { weeks at } 1,000 \mathrm{mg} / 1 \text { and after } 73 \text { weeks at } 500 \mathrm{mg} / \mathrm{lL} \\
\text { Strengths and limitations: Well reported and designed } \\
\text { study, with a large number of animals of both sexes } \\
\text { exposed for near life-span at three exposure levels. }\end{array}$} \\
\hline & & 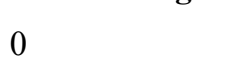 & $6 / 50(15 \%)$ & \\
\hline & & & & \\
\hline & & 250 & $11 / 50(26 \%)$ & \\
\hline & & 500 & $14 / 49 *(38 \%)$ & \\
\hline & & & $19 / 51 * * *(49 \%)$ & \\
\hline & & \multirow{2}{*}{\multicolumn{2}{|c|}{ 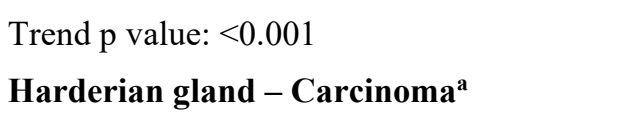 }} & \\
\hline & & & & \\
\hline & & 0 & $0 / 50$ & \\
\hline & & 250 & $0 / 50$ & \\
\hline & & 500 & $0 / 49$ & \\
\hline & & 1,000 & $3 / 51(9 \%)$ & \\
\hline & & \multicolumn{2}{|c|}{ Trend $\mathrm{p}$ value: $=0.008$} & \\
\hline & & \multicolumn{2}{|c|}{$\begin{array}{l}\text { Harderian gland - Adenoma or } \\
\text { carcinoma }^{\mathrm{a}}\end{array}$} & \\
\hline & & 0 & $6 / 50(15 \%)$ & \\
\hline & & 250 & $11 / 50(26 \%)$ & \\
\hline & & 500 & $14 / 49 *(38 \%)$ & \\
\hline & & 1,000 & $20 / 51 * * *(51 \%)$ & \\
\hline & & \multicolumn{2}{|c|}{ Trend p value: $<0.001$} & \\
\hline
\end{tabular}


RoC Monograph on Haloacetic Acids

\begin{tabular}{|c|c|c|c|c|}
\hline $\begin{array}{c}\text { Reference and Study } \\
\text { Design }\end{array}$ & Exposure & Dose Levels & $\begin{array}{c}\text { Tumor Incidence (n/N) } \\
(\%)\end{array}$ & Comments \\
\hline $\begin{array}{l}\text { NTP (2015) } \\
\text { Animal: } \\
\text { Mouse B6C3F1/N } \\
\text { F 5-6 wk } \\
\text { Study duration: } \\
105 \text { wk }\end{array}$ & $\begin{array}{l}\text { Agent: } \\
\text { Bromodichloroacetic } \\
\text { acid } \\
97 \% \\
\text { Treatment: } \\
\text { Drinking water } \\
0 \\
250 \\
500 \\
1,000 \mathrm{mg} / \mathrm{L} \text { of drinking } \\
\text { water ad libitum } \times 105 \\
\text { weeks }\end{array}$ & $\begin{array}{l}\text { Harderian glan } \\
\text { carcinoma }^{\mathrm{a}} \\
0 \\
250 \\
500 \\
1,000\end{array}$ & $\begin{array}{l}5 / 50(12 \%) \\
4 / 50(9 \%) \\
7 / 50(16 \%) \\
6 / 50(14 \%)\end{array}$ & $\begin{array}{l}\text { Survival: No significant change in survival. } \\
\text { Body weight: Significant decrease in body weight after } 73 \\
\text { weeks at } 1,000 \mathrm{mg} / 1 \text { and after } 89 \text { weeks at } 250 \mathrm{mg} / \mathrm{L} \text {. } \\
\text { Strengths and limitations: Well reported and designed } \\
\text { study, with a large number of animals of both sexes } \\
\text { exposed for near life-span at three exposure levels. }\end{array}$ \\
\hline
\end{tabular}

$*<0.05, * *<0.01, * * *<0.001 \mathrm{p}$ value.

${ }^{a}$ Adjusted percent incidence based on Poly- 3 estimated neoplasm incidence after adjustment for intercurrent mortality.

bexceeds historical controls from drinking water studies: 15/250 (range 0\%-12\%); exceeds historical controls from studies of all routes: $57 / 1,459$ (range $0 \%-12 \%$ ).

${ }^{c}$ Exceeds historical controls from drinking water studies: 79/250 (range 26\%-34\%); exceeds historical controls from studies of all routes: 622/1,459 (range 22-68\%).

${ }^{\mathrm{d}}$ Exceeds historical controls from drinking water studies: 47/200 (range 20\%-30\%); exceeds historical controls from studies of all routes: 383/1,459 (range 12-52\%).

${ }^{e}$ Exceeds historical controls from drinking water studies: 8/200 (range 2\%-6\%).

${ }^{\mathrm{f} E x c e e d s}$ historical controls from drinking water studies: 26/199 (range 6\%-20\%); exceeds historical controls from studies of all routes: 258/1,507 (range 4-28\%).

${ }^{\mathrm{g}}$ Exceeds historical controls from drinking water studies: 26/199 (range 6\%-20\%).

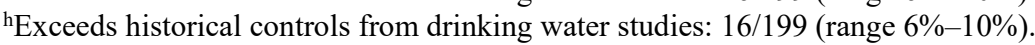

${ }^{i}$ Exceeds historical controls from drinking water studies: 41/199 (range 12\%-26\%).

${ }^{\mathrm{j} E x c e e d s ~ h i s t o r i c a l ~ c o n t r o l s ~ f r o m ~ d r i n k i n g ~ w a t e r ~ s t u d i e s: ~ 41 / 199 ~(r a n g e ~ 12 \%-26 \%) ; ~ e x c e e d s ~ h i s t o r i c a l ~ c o n t r o l s ~ f r o m ~ s t u d i e s ~ o f ~ a l l ~ r o u t e s: ~ 385 / 1,507 ~(r a n g e ~ 12-44 \%) . ~}$

${ }^{k}$ Exceeds historical controls from drinking water studies: 13/250 (range 2\%-12\%); exceeds historical controls from studies of all routes: 80/1,552 (range 0\%-12\%).

${ }^{1}$ Exceeds historical controls from drinking water studies: 16/250 (range 2\%-12\%); exceeds historical controls from studies of all routes: 117/1,552 (range 0\%-14\%). 
Table C-58. Transgenic Studies

\begin{tabular}{|c|c|c|c|c|}
\hline $\begin{array}{c}\text { Reference and Study } \\
\text { Design }\end{array}$ & Exposure & Dose Levels & $\begin{array}{c}\text { Tumor Incidence }(\mathbf{n} / \mathbf{N}) \\
(\%)\end{array}$ & Comments \\
\hline $\begin{array}{l}\text { NTP (2007b) } \\
\text { Animal: } \\
\text { Mouse (Study 1) FVB } \\
\text { Tg.AC hemizygous } \\
\text { (FVB/N-TgN(v-Ha- } \\
\text { ras)Led) } \\
\text { M } 6 \text { weeks } \\
\text { Study duration: } \\
39 \text { weeks }\end{array}$ & $\begin{array}{l}\text { Agent: } \\
\text { Dichloroacetic acid } \\
98.5 \%-99 \% \\
\text { Treatment: } \\
\text { Dermal } \\
0 \\
31.25 \\
125 \\
500 \mathrm{mg} / \mathrm{kg} \text { bw in } \\
\text { Water:Acetone }(1: 2)(\mathrm{pH} \\
6-8) \\
5 \text { doses/week } \times 39 \text { weeks }\end{array}$ & $\begin{array}{l}\text { Skin - Squamo } \\
0 \\
31.25 \\
125 \\
500\end{array}$ & $\begin{array}{l}0 / 10 \\
0 / 10 \\
2 / 10(20 \%) \\
8 / 10 * *(80 \%)\end{array}$ & $\begin{array}{l}\text { Survival: Survival was similar to untreated controls: } 9 / 10- \\
6 / 10,8 / 10,7 / 10 \\
\text { Body weight: Body weights were significantly lower in } \\
31.25 \mathrm{mg} / \mathrm{kg} \text { group after } 22 \text { weeks, } 500 \mathrm{mg} / \mathrm{kg} \text { after } 21 \\
\text { weeks, and } 125 \mathrm{mg} / \mathrm{kg} \text { temporarily was lower from weeks } 28 \\
\text { to } 38 \text { but were the same as controls by the end of the study. } \\
\text { Significantly increased preneoplastic lesions: The } \\
\text { incidence of pre-neoplasia of the skin (epidermis } \\
\text { hyperplasia) was significantly increased at } 125 \text { and } 500 \\
\text { mg/kg. } \\
\text { Other comments: Only reporting neoplasms at the site of } \\
\text { application. } \\
\text { Strengths and limitations: The study was well conducted } \\
\text { except for a low number of transgenic animals per group, } \\
\text { which may overestimate carcinogenic potential. The ability } \\
\text { to translate hazards in this model to non-transgenic mice is } \\
\text { limited. }\end{array}$ \\
\hline $\begin{array}{l}\text { NTP (2007b) } \\
\text { Animal: } \\
\text { Mouse (Study 1) FVB } \\
\text { Tg.AC hemizygous } \\
\text { (FVB/N-TgN(v-Ha- } \\
\text { ras)Led) } \\
\text { F } 6 \text { weeks } \\
\text { Study duration: } \\
39 \text { weeks }\end{array}$ & $\begin{array}{l}\text { Agent: } \\
\text { Dichloroacetic acid } \\
98.5 \%-99 \% \\
\text { Treatment: } \\
\text { Dermal } \\
0 \\
31.25 \\
125 \\
500 \mathrm{mg} / \mathrm{kg} \text { bw in } \\
\text { Water:Acetone }(1: 2)(\mathrm{pH} \\
6-8) \\
5 \text { doses/week } \times 39 \text { weeks }\end{array}$ & $\begin{array}{l}\text { Skin - Squamo } \\
0 \\
31.25 \\
125 \\
500\end{array}$ & $\begin{array}{l}\text { Is cell papilloma } \\
0 / 10 \\
0 / 10 \\
0 / 10 \\
6 / 10 * *(60 \%)\end{array}$ & $\begin{array}{l}\text { Survival: Survival was similar to untreated controls: } 8 / 10- \\
5 / 10,6 / 10,8 / 10 \\
\text { Body weight: Body weights of } 31.25 \text { and } 125 \mathrm{mg} / \mathrm{kg} \text { groups } \\
\text { were greater than controls at the end of the study, and } 500 \\
\mathrm{mg} / \mathrm{kg} \text { were greater after } 17 \text { weeks. } \\
\text { Significantly increased preneoplastic lesions: The } \\
\text { incidence of pre-neoplasia of the skin (epidermis } \\
\text { hyperplasia) was significantly increased at } 500 \mathrm{mg} / \mathrm{kg} \text {. } \\
\text { Other comments: Only reporting neoplasms at the site of } \\
\text { application. } \\
\text { Strengths and limitations: The study was well conducted } \\
\text { except for a low number of transgenic animals per group, } \\
\text { which may overestimate carcinogenic potential. The ability } \\
\text { to translate hazards in this model to non-transgenic mice is } \\
\text { limited. }\end{array}$ \\
\hline
\end{tabular}




\begin{tabular}{|c|c|c|c|c|}
\hline $\begin{array}{l}\text { Reference and Study } \\
\text { Design }\end{array}$ & Exposure & Dose Levels & $\begin{array}{l}\text { Tumor Incidence }(\mathbf{n} / \mathbf{N}) \\
(\%)\end{array}$ & Comments \\
\hline $\begin{array}{l}\text { NTP (2007b) } \\
\text { Animal: } \\
\text { Mouse (Study 2) FVB } \\
\text { Tg.AC hemizygous } \\
\text { (FVB/N-TgN(v-Ha- } \\
\text { ras)Led) } \\
\text { M } 6 \text { weeks } \\
\text { Study duration: } \\
26 \text { weeks }\end{array}$ & $\begin{array}{l}\text { Agent: } \\
\text { Dichloroacetic acid } \\
98.5 \%-99 \% \\
\text { Treatment: } \\
\text { Dermal } \\
0 \\
31.25 \\
125 \\
500 \mathrm{mg} / \mathrm{kg} \text { bw in } \\
\text { Water:Acetone }(1: 2)(\mathrm{pH} \\
6-8) \\
5 \text { doses/week } \times 26 \text { weeks }\end{array}$ & $\begin{array}{l}\text { Skin - Squamo } \\
0 \\
31.25 \\
125\end{array}$ & $\begin{array}{l}\text { Is cell papilloma } \\
0 / 15 \\
0 / 15 \\
1 / 15(7 \%) \\
2 / 15(13 \%)\end{array}$ & $\begin{array}{l}\text { Survival: Survival was similar to untreated controls: } 13 / 15- \\
\text { 14/15, } 14 / 15,12 / 15 \\
\text { Body weight: Body weights were similar to untreated } \\
\text { controls. } \\
\text { Significantly increased preneoplastic lesions: The } \\
\text { incidence of pre-neoplasia of the skin (epidermis } \\
\text { hyperplasia) was significantly increased at } 125 \text { and } 500 \\
\text { mg/kg. The severity grades of the hyperplasia in all cases } \\
\text { were minimal. } \\
\text { Other comments: Only reporting neoplasms at the site of } \\
\text { application. } \\
\text { Strengths and limitations: The study was well conducted } \\
\text { except for a low number of transgenic animals per group, } \\
\text { which may overestimate carcinogenic potential. The ability } \\
\text { to translate hazards in this model to non-transgenic mice is } \\
\text { limited. }\end{array}$ \\
\hline $\begin{array}{l}\text { NTP (2007b) } \\
\text { Animal: } \\
\text { Mouse (Study 2) FVB } \\
\text { Tg.AC hemizygous } \\
\text { (FVB/N-TgN(v-Ha- } \\
\text { ras)Led) } \\
\text { F } 6 \text { weeks } \\
\text { Study duration: } \\
26 \text { weeks }\end{array}$ & $\begin{array}{l}\text { Agent: } \\
\text { Dichloroacetic acid } \\
98.5 \%-99 \% \\
\text { Treatment: } \\
\text { Dermal } \\
0 \\
31.25 \\
125 \\
500 \mathrm{mg} / \mathrm{kg} \text { bw in } \\
\text { Water:Acetone }(1: 2)(\mathrm{pH} \\
6-8) \\
5 \text { doses/week } \times 26 \text { weeks }\end{array}$ & $\begin{array}{l}\text { Skin - Squamo } \\
0 \\
31.25 \\
125 \\
500\end{array}$ & $\begin{array}{l}\text { Is cell papilloma } \\
0 / 15 \\
0 / 15 \\
0 / 15 \\
2 / 15(13 \%)\end{array}$ & $\begin{array}{l}\text { Survival: Survival was similar to untreated controls: } 11 / 15- \\
12 / 15,14 / 15,15 / 15 \\
\text { Body weight: Body weights were similar to untreated } \\
\text { controls. } \\
\text { Significantly increased preneoplastic lesions: The } \\
\text { incidence of pre-neoplasia of the skin (epidermis } \\
\text { hyperplasia) was significantly increased at } 125 \text { and } 500 \\
\text { mg/kg. The severity grades of the hyperplasia in all cases } \\
\text { were minimal. } \\
\text { Other comments: Only reporting neoplasms at the site of } \\
\text { application. } \\
\text { Strengths and limitations: The study was well conducted } \\
\text { except for a low number of transgenic animals per group, } \\
\text { which may overestimate carcinogenic potential. The ability } \\
\text { to translate hazards in this model to non-transgenic mice is } \\
\text { limited. }\end{array}$ \\
\hline $\begin{array}{l}\text { NTP (2007b) } \\
\text { Animal: }\end{array}$ & $\begin{array}{l}\text { Agent: } \\
\text { Dichloroacetic acid }\end{array}$ & $\begin{array}{l}\text { Lung - Adenon } \\
0\end{array}$ & $1 / 10(10 \%)$ & $\begin{array}{l}\text { Survival: Survival was similar to untreated controls: } 9 / 1 \\
9 / 10,10 / 10,10 / 10\end{array}$ \\
\hline
\end{tabular}




\begin{tabular}{|c|c|c|c|c|}
\hline $\begin{array}{c}\text { Reference and Study } \\
\text { Design }\end{array}$ & Exposure & Dose Levels & $\begin{array}{c}\text { Tumor Incidence }(\mathbf{n} / \mathbf{N}) \\
(\%)\end{array}$ & Comments \\
\hline $\begin{array}{l}\text { Mouse (Study 1) FVB } \\
\text { Tg.AC hemizygous } \\
\text { (FVB/N-TgN(v-Ha- } \\
\text { ras)Led) } \\
\text { M } 6 \text { weeks } \\
\text { Study duration: } \\
41 \text { weeks }\end{array}$ & $\begin{array}{l}98.5 \%-99 \% \\
\text { Treatment: } \\
\text { Drinking water } \\
0 \\
500 \\
1,000 \\
2,000 \mathrm{mg} / \mathrm{L} \text { in drinking } \\
\text { water } \\
\text { ad libitum } \times 26 \text { weeks }\end{array}$ & $\begin{array}{l}500 \\
1,000 \\
2,000\end{array}$ & $\begin{array}{l}3 / 10(30 \%) \\
\text { Squamous cell papilloma }\end{array}$ & $\begin{array}{l}\text { Body weight: Body weights were significantly greater than } \\
\text { untreated controls at } 500 \mathrm{mg} / \mathrm{l} \text { after } 17 \text { weeks and } 1,000 \mathrm{mg} / 1 \\
\text { after } 21 \text { weeks. } \\
\text { Other comments: Water consumption at } 2,000 \mathrm{mg} / \mathrm{l} \text { was less } \\
\text { than controls. } \\
\text { Strengths and limitations: The study was well conducted } \\
\text { except for a low number of transgenic animals per group, } \\
\text { which may overestimate carcinogenic potential. The ability } \\
\text { to translate hazards in this model to non-transgenic mice is } \\
\text { limited. }\end{array}$ \\
\hline $\begin{array}{l}\text { NTP (2007b) } \\
\text { Animal: } \\
\text { Mouse (Study 1) FVB } \\
\text { Tg.AC hemizygous } \\
\text { (FVB/N-TgN(v-Ha- } \\
\text { ras)Led) } \\
\text { F } 6 \text { weeks } \\
\text { Study duration: } \\
41 \text { weeks }\end{array}$ & $\begin{array}{l}\text { Agent: } \\
\text { Dichloroacetic acid } \\
98.5 \%-99 \% \\
\text { Treatment: } \\
\text { Drinking water } \\
0 \\
500 \\
1,000 \\
2,000 \mathrm{mg} / \mathrm{L} \text { in drinking } \\
\text { water } \\
\text { ad libitum } \times 26 \text { weeks }\end{array}$ & $\begin{array}{l}\text { Forestomach - } \\
\text { (multiple only) } \\
0 \\
500 \\
1,000 \\
2,000\end{array}$ & $\begin{array}{l}7 / 10(70 \%) \\
7 / 10(70 \%) \\
6 / 10(60 \%) \\
\text { Squamous cell papilloma } \\
1 / 10(10 \%) \\
6 / 10 *(60 \%) \\
4 / 10(40 \%) \\
4 / 10(40 \%)\end{array}$ & $\begin{array}{l}\text { Survival: Survival was similar to untreated controls: } 7 / 10- \\
9 / 10,7 / 10,8 / 10 \\
\text { Body weight: Body weights of } 1,000 \text { and } 2,000 \mathrm{mg} / 1 \text { were } \\
\text { significantly lower than untreated controls after } 15 \text { and } 15 \\
\text { weeks, respectively. } \\
\text { Other comments: Water consumption at } 2,000 \mathrm{mg} / 1 \text { was less } \\
\text { than controls. } \\
\text { Strengths and limitations: The study was well conducted } \\
\text { except for a low number of transgenic animals per group, } \\
\text { which may overestimate carcinogenic potential. The ability } \\
\text { to translate hazards in this model to non-transgenic mice is } \\
\text { limited. }\end{array}$ \\
\hline
\end{tabular}




\begin{tabular}{|c|c|c|c|c|}
\hline $\begin{array}{c}\text { Reference and Study } \\
\text { Design }\end{array}$ & Exposure & Dose Levels & $\begin{array}{c}\text { Tumor Incidence }(\mathbf{n} / \mathbf{N}) \\
(\%)\end{array}$ & Comments \\
\hline $\begin{array}{l}\text { NTP (2007b) } \\
\text { Animal: } \\
\text { Mouse (Study 2) FVB } \\
\text { Tg.AC hemizygous } \\
\text { (FVB/N-TgN(v-Ha- } \\
\text { ras)Led) } \\
\text { M } 6 \text { weeks } \\
\text { Study duration: } \\
26 \text { weeks }\end{array}$ & $\begin{array}{l}\text { Agent: } \\
\text { Dichloroacetic acid } \\
98.5 \%-99 \% \\
\text { Treatment: } \\
\text { Drinking water } \\
0 \\
500 \\
1,000 \\
2,000 \mathrm{mg} / \mathrm{L} \text { in drinking } \\
\text { water } \\
\text { ad libitum } \times 26 \text { weeks }\end{array}$ & $\begin{array}{l}\text { Lung - Carcin } \\
0 \\
500 \\
1,000 \\
2,000\end{array}$ & $\begin{array}{l}0 / 15 \\
0 / 15 \\
1 / 15(7 \%) \\
0 / 15\end{array}$ & $\begin{array}{l}\text { Survival: Survival was similar to untreated controls: } 14 / 15- \\
13 / 15,11 / 15,14 / 15 \\
\text { Body weight: Body weights were significantly greater than } \\
\text { untreated controls at } 500 \mathrm{mg} / 1 \text { after } 17 \text { weeks and } 1,000 \mathrm{mg} / 1 \\
\text { after } 21 \text { weeks. } \\
\text { Other comments: Water consumption at } 2,000 \mathrm{mg} / 1 \text { was less } \\
\text { than controls. } \\
\text { Strengths and limitations: The study was well conducted } \\
\text { except for a low number of transgenic animals per group, } \\
\text { which may overestimate carcinogenic potential. The ability } \\
\text { to translate hazards in this model to non-transgenic mice is } \\
\text { limited. }\end{array}$ \\
\hline $\begin{array}{l}\text { NTP (2007b) } \\
\text { Animal: } \\
\text { Mouse (Study 2) FVB } \\
\text { Tg.AC hemizygous } \\
\text { (FVB/N-TgN(v-Ha- } \\
\text { ras)Led) } \\
\text { F } 6 \text { weeks } \\
\text { Study duration: } \\
26 \text { weeks }\end{array}$ & $\begin{array}{l}\text { Agent: } \\
\text { Dichloroacetic acid } \\
98.5 \%-99 \% \\
\text { Treatment: } \\
\text { Drinking water } \\
0 \\
500 \\
1,000 \\
2,000 \mathrm{mg} / \mathrm{L} \text { in drinking } \\
\text { water } \\
\text { ad libitum } \times 26 \text { weeks }\end{array}$ & $\begin{array}{l}\text { Lung - Carcin } \\
0 \\
500 \\
1,000 \\
2,000\end{array}$ & $\begin{array}{l}\mathbf{m a} \\
0 / 15 \\
1 / 15(7 \%) \\
0 / 15 \\
1 / 15(7 \%)\end{array}$ & $\begin{array}{l}\text { Survival: Survival was significantly lower than untreated } \\
\text { controls at } 500 \text { and } 2,000 \mathrm{mg} / \mathrm{l}: 15 / 15-8 / 15^{*}(=0.009), 13 / 15 \text {, } \\
10 / 15^{*}(=0.05) \\
\text { Body weight: Body weights of } 1,000 \text { and } 2,000 \mathrm{mg} / 1 \text { were } \\
\text { significantly lower than untreated controls after } 15 \text { and } 15 \\
\text { weeks, respectively. } \\
\text { Other comments: Water consumption at } 2,000 \mathrm{mg} / 1 \text { was less } \\
\text { than controls. } \\
\text { Strengths and limitations: The study was well conducted } \\
\text { except for a low number of transgenic animals per group, } \\
\text { which may overestimate carcinogenic potential. The ability } \\
\text { to translate hazards in this model to non-transgenic mice is } \\
\text { limited. }\end{array}$ \\
\hline $\begin{array}{l}\text { NTP (2007b) } \\
\text { Animal: } \\
\text { Mouse (Study 3) p53 } \\
\text { Haploinsufficient } \\
\text { M } 6 \text { weeks }\end{array}$ & $\begin{array}{l}\text { Agent: } \\
\text { Dichloroacetic acid } \\
98.5 \%-99 \% \\
\text { Treatment: } \\
\text { Drinking water }\end{array}$ & $\begin{array}{l}\text { Lung - Adenon } \\
0 \\
500 \\
1,000\end{array}$ & $\begin{array}{l}\text { a or carcinoma } \\
0 / 10 \\
0 / 10 \\
0 / 10\end{array}$ & $\begin{array}{l}\text { Survival: Survival was similar to untreated controls: } 9 / 10- \\
10 / 10,9 / 10,10 / 10 \\
\text { Body weight: Body weights of } 500,1,000 \text {, and } 2,000 \mathrm{mg} / 1 \\
\text { were significantly lower than untreated controls after } 4,3 \text {, } \\
\text { and } 1 \text { weeks, respectively. }\end{array}$ \\
\hline
\end{tabular}




\begin{tabular}{|c|c|c|c|c|}
\hline $\begin{array}{c}\text { Reference and Study } \\
\text { Design }\end{array}$ & Exposure & Dose Levels & $\begin{array}{l}\text { Tumor Incidence (n/N) } \\
(\%)\end{array}$ & Comments \\
\hline $\begin{array}{l}\text { Study duration: } \\
41 \text { weeks }\end{array}$ & $\begin{array}{l}0 \\
500 \\
1,000 \\
2,000 \mathrm{mg} / \mathrm{L} \text { in drinking } \\
\text { water } \\
\text { ad libitum } \times 26 \text { weeks }\end{array}$ & 2,000 & $0 / 10$ & $\begin{array}{l}\text { Other comments: Water consumption at } 1,000 \text { and } 2,000 \\
\text { mg/l were less than controls. } \\
\text { Strengths and limitations: The study was well conducted } \\
\text { except for a low number of transgenic animals per group, } \\
\text { which may overestimate carcinogenic potential. The ability } \\
\text { to translate hazards in this model to non-transgenic mice is } \\
\text { limited. }\end{array}$ \\
\hline $\begin{array}{l}\text { NTP (2007b) } \\
\text { Animal: } \\
\text { Mouse (Study 3) p53 } \\
\text { Haploinsufficient } \\
\text { F } 6 \text { weeks } \\
\text { Study duration: } \\
\text { 41 weeks }\end{array}$ & $\begin{array}{l}\text { Agent: } \\
\text { Dichloroacetic acid } \\
98.5 \%-99 \% \\
\text { Treatment: } \\
\text { Drinking water } \\
0 \\
500 \\
1,000 \\
2,000 \mathrm{mg} / \mathrm{L} \text { in drinking } \\
\text { water } \\
\text { ad libitum } \times 26 \text { weeks }\end{array}$ & $\begin{array}{l}\text { Lung - Adenor } \\
0 \\
500 \\
1,000 \\
2,000\end{array}$ & $\begin{array}{l}0 / 10 \\
0 / 10 \\
0 / 10 \\
0 / 10\end{array}$ & $\begin{array}{l}\text { Survival: Survival was similar to untreated controls: } 10 / 10- \\
9 / 10,10 / 10,9 / 10 \\
\text { Body weight: Body weights of } 500,1,000 \text { and } 2,000 \mathrm{mg} / 1 \\
\text { were significantly lower than untreated controls after } 27,9 \text {, } \\
\text { and } 9 \text { weeks, respectively. } \\
\text { Other comments: Water consumption at } 1,000 \text { and } 2,000 \\
\mathrm{mg} / 1 \text { were less than controls. } \\
\text { Strengths and limitations: The study was well conducted } \\
\text { except for a low number of transgenic animals per group, } \\
\text { which may overestimate carcinogenic potential. The ability } \\
\text { to translate hazards in this model to non-transgenic mice is } \\
\text { limited. }\end{array}$ \\
\hline $\begin{array}{l}\text { NTP (2007b) } \\
\text { Animal: } \\
\text { Mouse (Study 4) p53 } \\
\text { Haploinsufficient } \\
\text { M } 6 \text { weeks } \\
\text { Study duration: } \\
26 \text { weeks }\end{array}$ & $\begin{array}{l}\text { Agent: } \\
\text { Dichloroacetic acid } \\
98.5 \%-99 \% \\
\text { Treatment: } \\
\text { Drinking water } \\
0 \\
500 \\
1,000 \\
2,000 \mathrm{mg} / \mathrm{L} \text { in drinking } \\
\text { water } \\
\text { ad libitum } \times 26 \text { weeks }\end{array}$ & $\begin{array}{l}\text { Lung - Adenor } \\
0 \\
500 \\
1,000 \\
2,000\end{array}$ & $\begin{array}{l}\text { a or carcinoma } \\
0 / 15 \\
0 / 15 \\
0 / 15 \\
0 / 15\end{array}$ & $\begin{array}{l}\text { Survival: Survival was similar to untreated controls: } 15 / 15- \\
15 / 15,15 / 15,15 / 15 \\
\text { Body weight: Body weights of } 1,000 \text { and } 2,000 \mathrm{mg} / 1 \text { were } \\
\text { significantly lower than untreated controls after } 4 \text { and } 2 \\
\text { weeks, respectively. } \\
\text { Other comments: Water consumption at } 1,000 \text { and } 2,000 \\
\text { mg/l were less than controls. } \\
\text { Strengths and limitations: The study was well conducted } \\
\text { except for a low number of transgenic animals per group, } \\
\text { which may overestimate carcinogenic potential. The ability } \\
\text { to translate hazards in this model to non-transgenic mice is } \\
\text { limited. }\end{array}$ \\
\hline $\begin{array}{l}\text { NTP (2007b) } \\
\text { Animal: }\end{array}$ & $\begin{array}{l}\text { Agent: } \\
\text { Dichloroacetic acid }\end{array}$ & $\begin{array}{l}\text { Lung - Adenor } \\
0\end{array}$ & $\begin{array}{l}\text { a or carcinoma } \\
0 / 15\end{array}$ & $\begin{array}{l}\text { Survival: Survival was similar to untreated controls: } 15 / 15- \\
15 / 15,14 / 15,14 / 15\end{array}$ \\
\hline
\end{tabular}


RoC Monograph on Haloacetic Acids

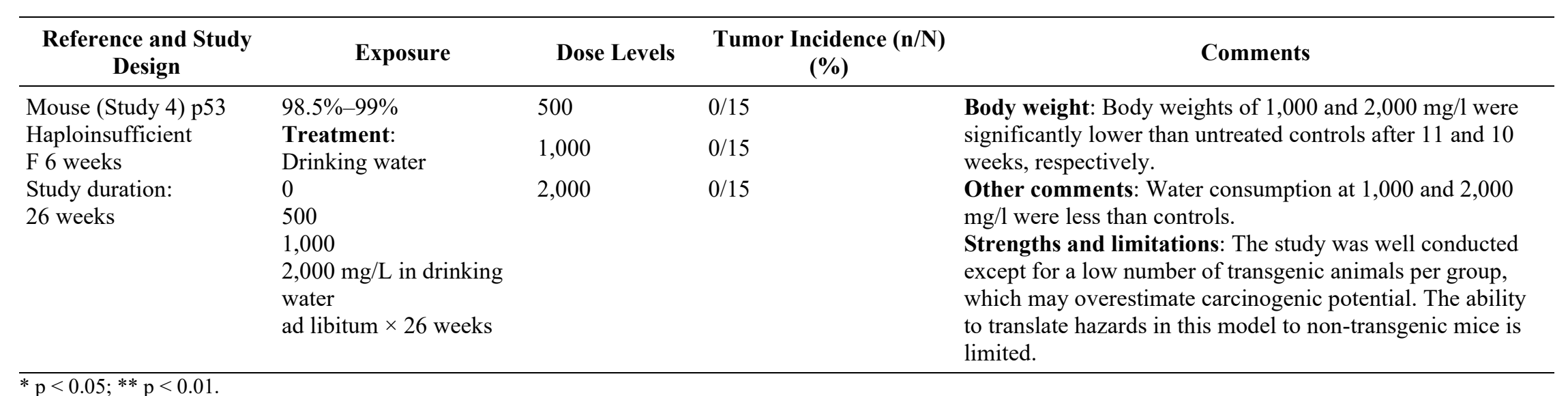


Table C-59. Initiation-Promotion Studies

\begin{tabular}{|c|c|c|c|c|}
\hline $\begin{array}{c}\text { Reference and Study } \\
\text { Design }\end{array}$ & Exposure & Dose Levels & $\begin{array}{c}\text { Tumor Incidence }(\mathbf{n} / \mathbf{N}) \\
(\%)\end{array}$ & Comments \\
\hline $\begin{array}{l}\text { Gwynn and Salaman } \\
\text { (1953) } \\
\text { Animal: } \\
\text { Mouse Stock albino "S" } \\
\text { strain } \\
\text { NR NR } \\
\text { Study duration: } \\
30 \text { weeks }\end{array}$ & $\begin{array}{l}\text { Agent: } \\
\text { Monoiodoacetic acid } \\
\text { Not reported } \\
\text { Treatment: } \\
\text { Dermal } \\
\text { Initiator: } \\
\text { 9,10-dimethyl-1,2- } \\
\text { benzanthracene (DMBA) } \\
\text { in acetone: single dose } \\
0.15 \% \text { in } 3 \mathrm{ml} \\
\text { Promotor: } \\
\text { Iodoacetic acid in } \\
\text { acetone: } \\
\text { start } 21 \text { days after } \\
\text { DMBA } \\
1.4 \%(2 / \mathrm{wk} \times 12 \mathrm{wk}, \text { then } \\
1 / \mathrm{wk} \times 15 \mathrm{wk})\end{array}$ & Skin - Papillon & $\begin{array}{l}1 / 16(6.25 \%) \\
8 / 10[@ @]\left[\left[^{\# \#}\right](80 \%)\right.\end{array}$ & $\begin{array}{l}\text { Survival: Only two of the exposed mice died. } \\
\text { Body weight: Not reported. } \\
\text { Strengths and limitations: The chemicals were not } \\
\text { characterized and purity was not reported. The sex of the } \\
\text { animals were not reported and only a single dose level was } \\
\text { tested on a very low number of animals per group. Histology } \\
\text { of the neoplasms were carried out, but the skin tumors were } \\
\text { classified as benign papillomas based on their appearance } \\
\text { "macroscopically." Statistical significance was not } \\
\text { calculated. }\end{array}$ \\
\hline $\begin{array}{l}\text { Herren-Freund et al. } \\
\text { (1987) } \\
\text { Animal: } \\
\text { Mouse B6C3F1 } \\
\text { M } 4 \text { weeks } \\
\text { Study duration: } \\
61 \text { weeks }\end{array}$ & $\begin{array}{l}\text { Agent: } \\
\text { Dichloroacetic acid } \\
>99 \% \\
\text { Treatment: } \\
\text { Drinking water } \\
\text { Initiator: } \\
\text { Ethylnitrosourea (ENU): } \\
\text { ip injection at } 15 \text { days } \\
\text { old } \\
0+ \\
2.5 \mu \mathrm{g} / \mathrm{g} \text { bw }\end{array}$ & $\begin{array}{l}0 / 0 \\
0 / 5,000\end{array}$ & $\begin{array}{l}0 / 22 \\
21 / 26 * *(81 \%)\end{array}$ & $\begin{array}{l}\text { Survival: Not reported. } \\
\text { Body weight: Body weights were significantly decreased } \\
(p<0.001) \text {. Calculations were done by one-way analysis of } \\
\text { variance with a Tukey's comparison. } \\
\text { Strengths and limitations: The duration was less than near } \\
\text { life-span. Only males were tested at two narrow dose levels } \\
\text { and only livers were histologically evaluated. }\end{array}$ \\
\hline
\end{tabular}




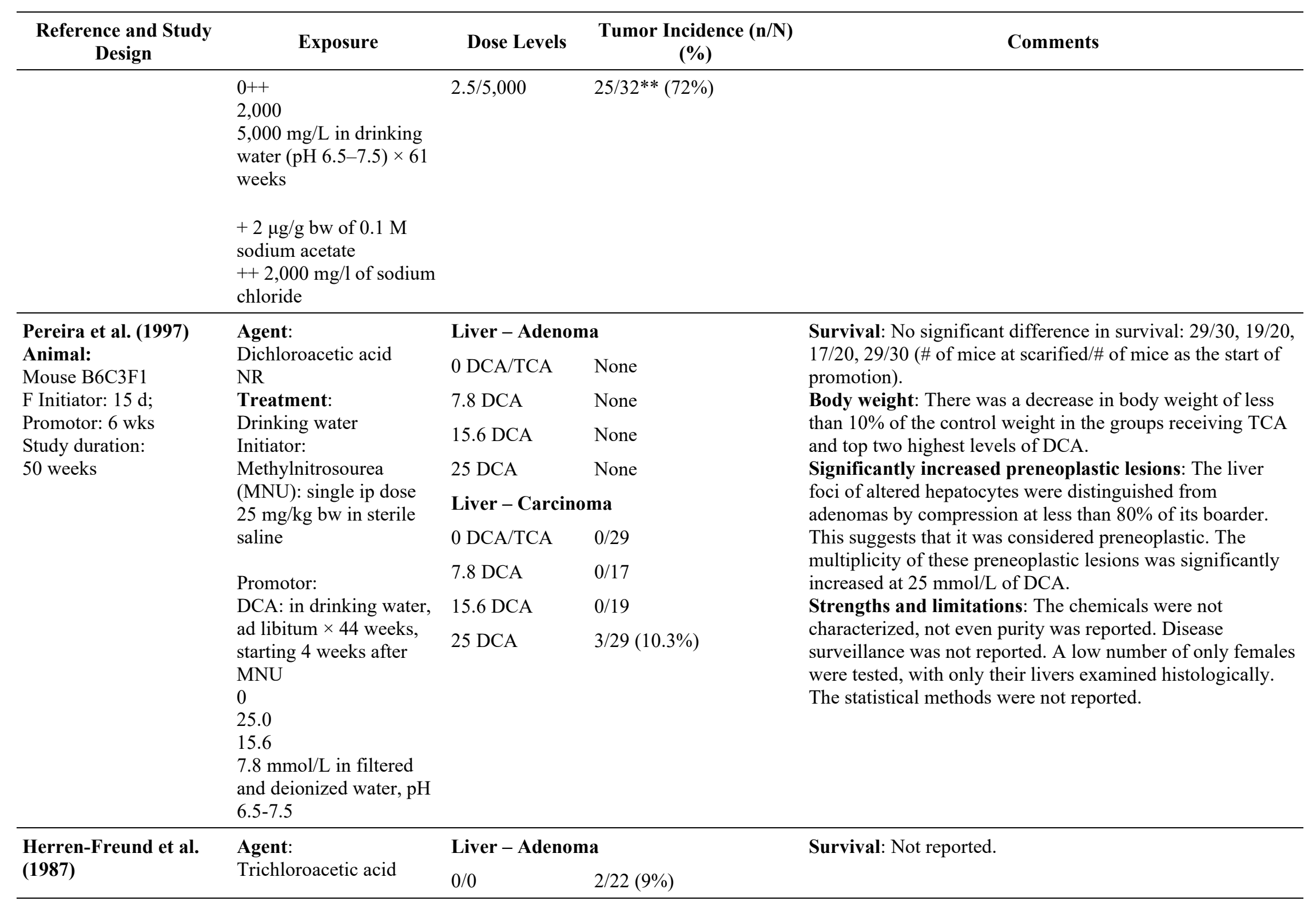




\begin{tabular}{|c|c|c|c|c|}
\hline $\begin{array}{c}\text { Reference and Study } \\
\text { Design }\end{array}$ & Exposure & Dose Levels & $\begin{array}{c}\text { Tumor Incidence }(\mathbf{n} / \mathbf{N}) \\
(\%)\end{array}$ & Comments \\
\hline \multirow{15}{*}{$\begin{array}{l}\text { Animal: } \\
\text { Mouse B6C3F1 } \\
\text { M } 15 \text { days } \\
\text { Study duration: } \\
61 \text { weeks }\end{array}$} & \multirow{7}{*}{$\begin{array}{l}>99 \% \\
\text { Treatment: } \\
\text { Drinking water } \\
\text { Initiator: } \\
\text { Ethylnitrosourea (ENU): } \\
\text { ip injection at } 15 \text { days } \\
\text { old } \\
0+ \\
2.5 \\
10 \mu \mathrm{g} / \mathrm{g} \mathrm{bw}\end{array}$} & $0 / 5,000$ & $8 / 22 * *(36 \%)$ & \multirow{15}{*}{$\begin{array}{l}\text { Body weight: Body weights were significantly decreased } \\
(\mathrm{p}<0.001) \text {. Calculations were done by one-way analysis of } \\
\text { variance with a Tukey's comparison. } \\
\text { Strengths and limitations: The duration was less than near } \\
\text { life-span. Only males were tested at two narrow dose levels } \\
\text { and only livers were histologically evaluated. }\end{array}$} \\
\hline & & $2.5 / 0$ & $1 / 22(5 \%)$ & \\
\hline & & $2.5 / 2,000$ & $11 / 33 * *(33 \%)$ & \\
\hline & & $2.5 / 5,000$ & $6 / 23 * *(26 \%)$ & \\
\hline & & $10 / 0$ & $9 / 23(39 \%)$ & \\
\hline & & $10 / 5,000$ & $11 / 28(39 \%)$ & \\
\hline & & \multicolumn{2}{|c|}{ Liver - Carcinoma } & \\
\hline & \multirow{7}{*}{$\begin{array}{l}\text { Promotor: } \\
\text { TCA: in drinking water } \\
(\mathrm{pH} 6.5-7.5) \text { at } 4 \text { weeks } \\
\text { old } \\
0++ \\
2,000 \\
5,000 \mathrm{mg} / \mathrm{L} \text { in drinking } \\
\text { water }(\mathrm{pH} 6.5-7.5) \times 61 \\
\text { weeks }\end{array}$} & $0 / 0$ & $0 / 22$ & \\
\hline & & $0 / 5,000$ & $7 / 22 * *(32 \%)$ & \\
\hline & & $2.5 / 0$ & $1 / 22(5 \%)$ & \\
\hline & & $2.5 / 2,000$ & $16 / 33 * *(48 \%)$ & \\
\hline & & $2.5 / 5,000$ & $11 / 23 * *(48 \%)$ & \\
\hline & & $10 / 0$ & $9 / 23(39 \%)$ & \\
\hline & & $10 / 5,000$ & $15 / 28(54 \%)$ & \\
\hline & $\begin{array}{l}+2 \mu \mathrm{g} / \mathrm{g} \text { bw of } 0.1 \mathrm{M} \\
\text { sodium acetate } \\
++2,000 \mathrm{mg} / \mathrm{L} \mathrm{NaCl}\end{array}$ & & & \\
\hline \multirow{7}{*}{$\begin{array}{l}\text { Pereira et al. (1997) } \\
\text { Animal: } \\
\text { Mouse B6C3F1 } \\
\text { F Initiator: } 15 \mathrm{~d} \text {; } \\
\text { Promotor: } 6 \text { wks } \\
\text { Study duration: } \\
50 \text { weeks }\end{array}$} & \multirow{7}{*}{$\begin{array}{l}\text { Agent: } \\
\text { Trichloroacetic acid } \\
\text { Vendor, but not purity } \\
\text { given } \\
\text { Treatment: } \\
\text { Drinking water } \\
\text { Initiator: } \\
\text { Methylnitrosourea } \\
\text { (MNU): single ip dose in } \\
\text { sterile saline }\end{array}$} & \multicolumn{2}{|c|}{ Liver - Adenoma } & \multirow{7}{*}{$\begin{array}{l}\text { Survival: No significant difference in survival: } 29 / 30,20 / 20 \text {, } \\
29 / 30 \text { (\# of mice at scarified/\# of mice as the start of } \\
\text { promotion). } \\
\text { Body weight: There was a decrease in body weight of less } \\
\text { than } 10 \% \text { of the control weight in the groups receiving TCA } \\
\text { and top two highest levels of DCA. } \\
\text { Significantly increased preneoplastic lesions: The liver } \\
\text { foci of altered hepatocytes were distinguished from } \\
\text { adenomas by compression at less than } 80 \% \text { of its boarder. } \\
\text { This suggests that it was considered preneoplastic. The }\end{array}$} \\
\hline & & 0 DCA/TCA & None & \\
\hline & & $6 \mathrm{TCA}$ & None & \\
\hline & & 25 TCA & None & \\
\hline & & \multicolumn{2}{|c|}{ Liver - Carcinoma } & \\
\hline & & 0 DCA/TCA & $0 / 29$ & \\
\hline & & 6 TCA & $0 / 20$ & \\
\hline
\end{tabular}


RoC Monograph on Haloacetic Acids

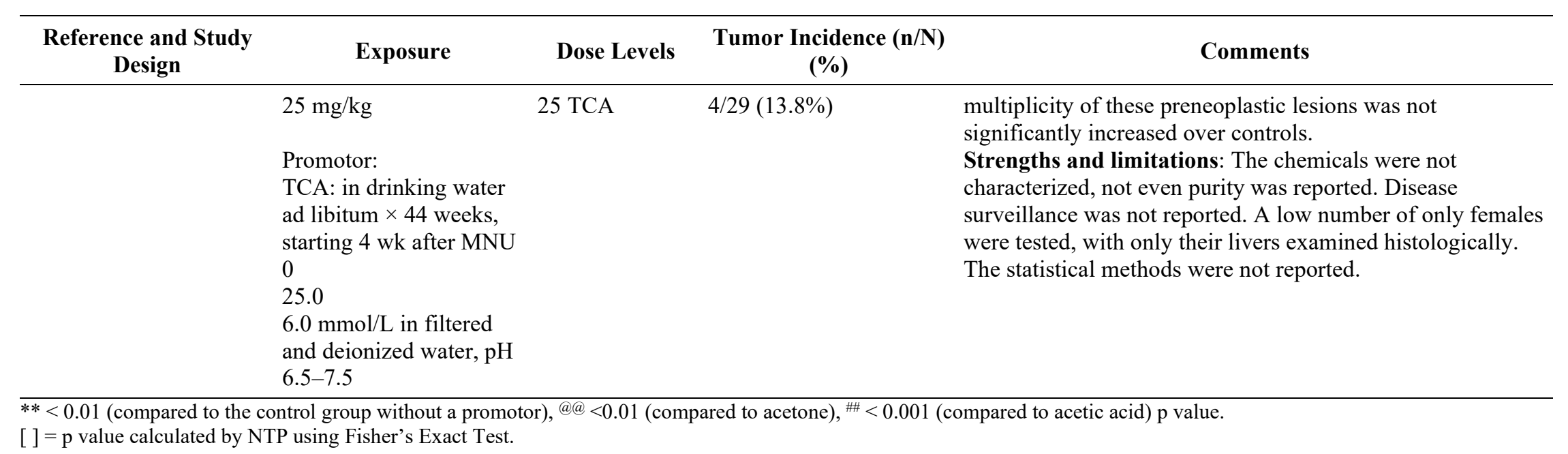




\section{Appendix D. Oxidative Stress and Genotoxic Potency Data for Haloacetic Acids}

\section{Tables}

Table D-1. In Vitro and In Vivo Haloacetic Acid-induced Oxidative Stress ........................... D-2

Table D-2. Summary of Genetic Toxicology Results of Haloacetic Acids in CEBs ............... D-3

Table D-3. Mutagenic/Genotoxic Potency Estimates of Haloacetic Acids in Bacteria............. D-5

Table D-4. Mutagenic/Genotoxic Potency Estimates of Haloacetic Acids in Mammalian

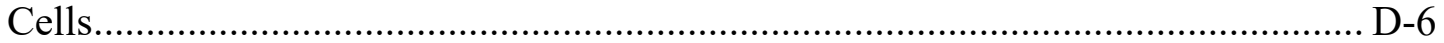

Table D-5. Epigenetic Effects of Haloacetic Acids in Mouse and Rat Tissues........................ D-7

Table D-6. Gene Expression Studies of Di- and Trihaloacetic Acids in Yeast and Rodent

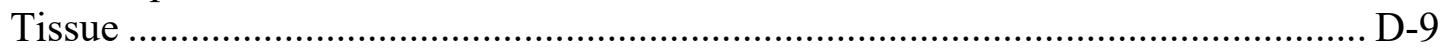

\section{Figures}

Figure D-1. Palmitoyl-CoA Oxidation in Cultured Rat Hepatocytes Exposed to Haloacetic Acids. 
Table D-1. In Vitro and In Vivo Haloacetic Acid-induced Oxidative Stress

\begin{tabular}{|c|c|c|c|c|c|c|c|c|c|c|c|c|c|}
\hline \multirow{2}{*}{$\begin{array}{l}\text { Test System (Potency } \\
\text { Measurement, Units) }\end{array}$} & \multicolumn{3}{|c|}{ Monohaloacetic Acids } & \multicolumn{5}{|c|}{ Dihaloacetic Acids } & \multicolumn{4}{|c|}{ Trihaloacetic Acids } & \multirow[b]{2}{*}{ Reference } \\
\hline & $\mathbf{C A}$ & $\mathbf{B A}$ & IA & DCA & DBA & BCA & CIA & BIA & TCA & TBA & BDCA & CDBA & \\
\hline $\begin{array}{l}\text { AREc32: human breast cancer } \\
\text { cell line }(\mathrm{MCF} 7)(1 / \mathrm{mM} \text {, } \\
\mathrm{IR}=1.5)\end{array}$ & 3.7 & 192 & 278 & 0.17 & 8.3 & 7.1 & 45.5 & 38.5 & - & 2.3 & 0.5 & 0.2 & $\begin{array}{l}\text { Stalter et al. } \\
(2016 a)\end{array}$ \\
\hline $\begin{array}{l}\text { ARE-bla: human hepatocellular } \\
\text { carcinoma cell line }(\text { HepG } 2) \\
(1 / \mathrm{mM}, \mathrm{IR}=1.5)\end{array}$ & 4.0 & 90.9 & 196 & 0.06 & 4.0 & 2.2 & 10 & 18.9 & - & 1.5 & 0.25 & 0.46 & $\begin{array}{l}\text { Stalter et al. } \\
(2016 a)\end{array}$ \\
\hline $\begin{array}{l}\text { ARE-bla: human hepatocellular } \\
\text { carcinoma cell line (HepG2) } \\
(1 / \mathrm{mM}, \mathrm{IR}=1.5)\end{array}$ & 14 & 141 & 256 & - & - & - & - & - & - & - & - & - & $\begin{array}{l}\text { Procházka et al. } \\
\text { (2015) }\end{array}$ \\
\hline $\begin{array}{l}\text { ARE-bla: human hepatocellular } \\
\text { carcinoma cell line (HepG2) } \\
(1 / \mathrm{mM}, \mathrm{IR}=1.5)\end{array}$ & 116 & 510 & 1,010 & - & - & - & - & - & - & - & - & - & Pals et al. (2013) \\
\hline $\begin{array}{l}\text { Lipid peroxidation; male mice, } \\
\text { single } 300 \mathrm{mg} / \mathrm{kg} \text { oral dose } \\
\text { TBARS (nmol/g liver, wet } \mathrm{wt} \text { ) }\end{array}$ & - & - & - & 129 & $250^{\mathrm{a}}$ & $290^{\mathrm{a}}$ & - & - & 67 & - & $240^{\mathrm{a}}$ & - & $\begin{array}{l}\text { Austin et al. } \\
\text { (1996); Larson } \\
\text { and Bull (1992) }\end{array}$ \\
\hline $\begin{array}{l}\text { Oxidative DNA damage; male } \\
\text { mice, single } 300 \mathrm{mg} / \mathrm{kg} \text { oral dose } \\
\left(8-\mathrm{OHdG} / 10^{5} \mathrm{dG} \text { liver }\right)\end{array}$ & - & - & - & $1.4^{\mathrm{a}}$ & $2.9^{\mathrm{a}}$ & $2.9^{\mathrm{a}}$ & - & - & $1.2^{\mathrm{a}}$ & - & $1.7^{\mathrm{a}}$ & - & $\begin{array}{l}\text { Austin et al. } \\
\text { (1996) }\end{array}$ \\
\hline $\begin{array}{l}\text { Oxidative DNA damage; male } \\
\text { mice, } 21 \text { day water- } 0.5 \text { and } 2 \\
\mathrm{~g} / \mathrm{L}\left(8-\mathrm{OHdG} / 10^{5} \mathrm{dG} \text { liver }\right)\end{array}$ & $\begin{array}{l}- \\
-\end{array}$ & $\begin{array}{l}- \\
-\end{array}$ & $\begin{array}{l}- \\
-\end{array}$ & $\begin{array}{l}- \\
-\end{array}$ & $\begin{array}{l}1.4^{\mathrm{a}} \\
1.8^{\mathrm{a}}\end{array}$ & $\begin{array}{l}1.2^{\mathrm{a}} \\
1.6^{\mathrm{a}}\end{array}$ & $\begin{array}{l}- \\
-\end{array}$ & $\begin{array}{l}- \\
-\end{array}$ & $\begin{array}{l}- \\
-\end{array}$ & $\begin{array}{l}- \\
-\end{array}$ & $\begin{array}{l}- \\
-\end{array}$ & $\begin{array}{l}- \\
-\end{array}$ & $\begin{array}{l}\text { Parrish et al. } \\
\text { (1996) }\end{array}$ \\
\hline
\end{tabular}


RoC Monograph on Haloacetic Acids

Table D-2. Summary of Genetic Toxicology Results of Haloacetic Acids in CEBs

\begin{tabular}{|c|c|c|c|}
\hline Haloacetic Acid & Study Type & Results & URL \\
\hline Chloro- & Ames & - & https://tools.niehs.nih.gov/cebs3/ntpViews/?studyNumber=002-02485-0003-0000-4 \\
\hline Chloro- & Ames & - & $\underline{\text { https://tools.niehs.nih.gov/cebs3/ntpViews/?studyNumber=002-02485-0004-0000-5 }}$ \\
\hline Chloro- & Mammalian cell cytogenetics $(\mathrm{CA})$ & - & $\underline{\text { https://tools.niehs.nih.gov/cebs3/ntpViews/?studyNumber=002-02485-0002-0000-3 }}$ \\
\hline Chloro- & Mammalian cell cytogenetics (SCE) & + & https://tools.niehs.nih.gov/cebs3/ntpViews/?studyNumber=002-02485-0001-0000-2 \\
\hline Chloro- & Mammalian cell mutagenicity & + & $\underline{\text { https://tools.niehs.nih.gov/cebs3/ntpViews/?studyNumber=002-02485-0010-0000-2 }}$ \\
\hline Chloro- & Drosophila germ cell mutagenicity & $\mathrm{E}$ & $\underline{\text { https://tools.niehs.nih.gov/cebs3/ntpViews/?studyNumber=002-02485-0009-0000-0 }}$ \\
\hline Bromo- & Ames & + & https://tools.niehs.nih.gov/cebs3/ntpViews/?studyNumber=002-01737-0001-0000-1 \\
\hline Bromo- & Ames & + & https://tools.niehs.nih.gov/cebs3/ntpViews/?studyNumber=002-01737-0002-0000-2 \\
\hline Iodo- & Ames & $\mathrm{E}$ & https://tools.niehs.nih.gov/cebs3/ntpViews/?studyNumber=002-02289-0001-0000-4 \\
\hline Iodo- & Ames & $(+)$ & https://tools.niehs.nih.gov/cebs3/ntpViews/?studyNumber=002-02289-0002-0000-5 \\
\hline Iodo- & Drosophila germ cell mutagenicity & - & $\underline{\text { https://tools.niehs.nih.gov/cebs3/ntpViews/?studyNumber }=002-02289-0003-0000-6}$ \\
\hline Dichloro- & Ames & + & $\underline{\text { https://tools.niehs.nih.gov/cebs3/ntpViews/?studyNumber }=002-02007-0008-0000-9}$ \\
\hline Dichloro- & Ames & + & $\underline{\text { https://tools.niehs.nih.gov/cebs3/ntpViews/?studyNumber }=002-02007-0009-0000-0}$ \\
\hline Dichloro- & $\begin{array}{l}\text { Male mice (micronucleus) } \\
\text { Female mice (micronucleus) }\end{array}$ & $\begin{array}{l}- \\
-\end{array}$ & $\underline{\text { https://tools.niehs.nih.gov/cebs3/ntpViews/?studyNumber }=002-02007-0004-0000-5}$ \\
\hline Dichloro- & $\begin{array}{l}\text { Male mice (micronucleus) } \\
\text { Female mice (micronucleus) }\end{array}$ & $\begin{array}{l}- \\
-\end{array}$ & $\underline{\text { https://tools.niehs.nih.gov/cebs3/ntpViews/?studyNumber }=002-02007-0006-0000-7}$ \\
\hline Dichloro- & $\begin{array}{l}\text { Male mice (micronucleus) } \\
\text { Female mice (micronucleus) }\end{array}$ & - & https://tools.niehs.nih.gov/cebs3/ntpViews/?studyNumber=002-02007-0007-0000-8 \\
\hline Dichloro- & $\begin{array}{l}\text { Male mice (micronucleus) } \\
\text { Female mice (micronucleus) }\end{array}$ & $\begin{array}{l}- \\
+\end{array}$ & $\underline{\text { https://tools.niehs.nih.gov/cebs3/ntpViews/?studyNumber }=002-02007-0005-0000-6}$ \\
\hline Dibromo- & Ames & + & $\underline{\text { https://tools.niehs.nih.gov/cebs3/ntpViews/?studyNumber }=002-01996-0006-0000-3}$ \\
\hline Dibromo- & $\begin{array}{l}\text { Male mice (micronucleus) } \\
\text { Female mice (micronucleus) }\end{array}$ & $\begin{array}{l}+ \\
-\end{array}$ & https://tools.niehs.nih.gov/cebs3/ntpViews/?studyNumber=002-01996-0005-0000-2 \\
\hline Bromochloro- & Ames & + & $\underline{\text { https://tools.niehs.nih.gov/cebs3/ntpViews/?studyNumber=002-01740-0005-0000-9 }}$ \\
\hline
\end{tabular}


RoC Monograph on Haloacetic Acids

\begin{tabular}{|c|c|c|c|}
\hline Haloacetic Acid & Study Type & Results & URL \\
\hline Bromochloro- & Ames & + & https://tools.niehs.nih.gov/cebs3/ntpViews/?studyNumber=002-01740-0006-0000-0 \\
\hline Bromochloro- & $\begin{array}{l}\text { Male mice (micronucleus) } \\
\text { Female mice (micronucleus) }\end{array}$ & - & https://tools.niehs.nih.gov/cebs3/ntpViews/?studyNumber=002-01740-0004-0000-8 \\
\hline Trichloro- & Ames & - & $\underline{\text { https://tools.niehs.nih.gov/cebs3/ntpViews/?studyNumber }=002-02942-0001-0000-0}$ \\
\hline Tribromo- & Ames & + & $\underline{\text { https://tools.niehs.nih.gov/cebs3/ntpViews/?studyNumber }=002-02933-0002-0000-1}$ \\
\hline Bromodichloro- & Ames & + & $\underline{\text { https://tools.niehs.nih.gov/cebs3/ntpViews/?studyNumber }=002-01742-0018-0000-5}$ \\
\hline Bromodichloro- & Ames & $(+)$ & $\underline{\text { https://tools.niehs.nih.gov/cebs3/ntpViews/?studyNumber }=002-01742-0004-0000-0}$ \\
\hline Bromodichloro- & $\begin{array}{l}\text { Male mice (micronucleus) } \\
\text { Female mice (micronucleus) }\end{array}$ & $\begin{array}{l}- \\
-\end{array}$ & $\underline{\text { https://tools.niehs.nih.gov/cebs3/ntpViews/?studyNumber }=002-01742-0003-0000-9}$ \\
\hline
\end{tabular}

$-=$ negative,$(+)=$ weak positive,$+=$ positive, $\mathrm{E}=$ equivocal . 
Table D-3. Mutagenic/Genotoxic Potency Estimates of Haloacetic Acids in Bacteria

\begin{tabular}{|c|c|c|c|c|c|c|c|c|c|c|c|c|c|}
\hline \multirow{2}{*}{$\begin{array}{l}\text { Test System (Potency } \\
\text { Measurement, Units) }\end{array}$} & \multicolumn{3}{|c|}{ Monohaloacetic Acids } & \multicolumn{5}{|c|}{ Dihaloacetic Acids } & \multicolumn{4}{|c|}{ Trihaloacetic Acids } & \multirow[t]{2}{*}{ Reference } \\
\hline & $\mathbf{C A}$ & $\mathbf{B A}$ & $\mathbf{I A}$ & DCA & DBA & BCA & CIA & BIA & TCA & TBA & BDCA & CDBA & \\
\hline $\begin{array}{l}\text { SOS-umuC: TA1535/pSK1002 } \\
\text { - S9 }(1 / \mathrm{M}, \mathrm{IR}=1.5) \\
+\mathrm{S} 9(1 / \mathrm{M}, \mathrm{IR}=1.5)\end{array}$ & $\begin{array}{l}-^{\mathrm{a}} \\
-{ }^{\mathrm{a}}\end{array}$ & $-^{\mathrm{a}}$ & $\begin{array}{l}-^{\mathrm{a}} \\
-{ }^{\mathrm{a}}\end{array}$ & $\begin{array}{l}- \\
-\end{array}$ & $\begin{array}{l}2,564 \\
1,493\end{array}$ & $\begin{array}{l}2,941 \\
1,064\end{array}$ & $\begin{array}{l}5,263 \\
2,083\end{array}$ & $\begin{array}{c}9,091 \\
11,490\end{array}$ & $\begin{array}{l}- \\
-\end{array}$ & $\begin{array}{c}142,860 \\
13,890\end{array}$ & $\begin{array}{c}9,091 \\
455\end{array}$ & $\begin{array}{c}9,091 \\
625\end{array}$ & $\begin{array}{l}\text { Stalter et al. } \\
(2016 a)\end{array}$ \\
\hline $\begin{array}{l}\text { SOS-umuC: TA } 1535 / \mathrm{pSK} 1002 \\
\text { - S9 }(1 / \mathrm{M}, \mathrm{IR}=2) \\
\text { - S9 }(1 / \mathrm{M}, \mathrm{IR}=1.5)\end{array}$ & $\begin{array}{l}(+) \\
60^{\mathrm{b}} \\
\end{array}$ & $\begin{array}{l}1,107 \\
2,400^{\mathrm{b}}\end{array}$ & $\begin{array}{c}8,696 \\
15,400^{\mathrm{b}}\end{array}$ & $\begin{array}{c}83 \\
180^{\mathrm{b}}\end{array}$ & $\begin{array}{c}89 \\
760^{\mathrm{b}}\end{array}$ & $\begin{array}{l}- \\
- \\
\end{array}$ & - & $\begin{array}{l}- \\
-\end{array}$ & $\begin{array}{l}(+) \\
60^{\mathrm{b}}\end{array}$ & $\begin{array}{l}- \\
-\end{array}$ & $\begin{array}{l}- \\
-\end{array}$ & $\begin{array}{l}- \\
-\end{array}$ & $\begin{array}{l}\text { Zhang et al. } \\
(2016)\end{array}$ \\
\hline $\begin{array}{l}\text { SOS-umuC: TA1535/pSK1002 } \\
- \text { S9 }(\beta \text {-galactosidase activity) } \\
+ \text { S9 }(\beta \text {-galactosidase activity) }\end{array}$ & $\begin{array}{l}- \\
- \\
\end{array}$ & $\begin{array}{l}- \\
- \\
\end{array}$ & $\begin{array}{l}- \\
- \\
\end{array}$ & $\begin{array}{l}\text { neg } \\
1.5 \\
\end{array}$ & $\begin{array}{l}- \\
- \\
\end{array}$ & $\begin{array}{l}- \\
- \\
\end{array}$ & $\begin{array}{l}- \\
- \\
\end{array}$ & $\begin{array}{l}- \\
- \\
\end{array}$ & $\begin{array}{l}0.72 \\
1.18 \\
\end{array}$ & $\begin{array}{l}- \\
- \\
\end{array}$ & $\begin{array}{l}- \\
- \\
\end{array}$ & $\begin{array}{l}- \\
- \\
\end{array}$ & $\begin{array}{l}\text { Ono et al. } \\
(1991)\end{array}$ \\
\hline $\begin{array}{l}\text { Ames preincubation: TA100 } \\
-\mathrm{S} 9 \text { (revertants/ } \mu \mathrm{mol})\end{array}$ & 27 & 5,465 & 14,129 & - & 148 & - & - & - & - & - & - & - & $\begin{array}{l}\text { Plewa et al. } \\
(2000) \text {; Plewa } \\
\text { et al. }(2004 b)\end{array}$ \\
\hline $\begin{array}{l}\text { Ames preincubation: TA100 } \\
\text { - S9 }\left(_{\text {revertants } / \mu \mathrm{mol})^{\mathrm{d}}}\right. \\
+\mathrm{S} 9\left(_{\text {revertants } / \mu \mathrm{mol})^{\mathrm{d}}}\right.\end{array}$ & $\begin{array}{l}44 \\
63 \\
\end{array}$ & $\begin{array}{l}6,588 \\
2,642 \\
\end{array}$ & $\begin{array}{l}- \\
- \\
\end{array}$ & $\begin{array}{l}36 \\
13 \\
\end{array}$ & $\begin{array}{l}183 \\
165 \\
\end{array}$ & $\begin{array}{l}- \\
- \\
\end{array}$ & $\begin{array}{l}- \\
- \\
\end{array}$ & $\begin{array}{l}- \\
- \\
\end{array}$ & $\begin{array}{l}- \\
- \\
\end{array}$ & $\begin{array}{l}- \\
- \\
\end{array}$ & $\begin{array}{l}- \\
- \\
\end{array}$ & $\begin{array}{l}- \\
- \\
\end{array}$ & $\begin{array}{l}\text { Kargalioglu et } \\
\text { al. (2002) }\end{array}$ \\
\hline $\begin{array}{l}\text { Ames preincubation: TA98 } \\
-\mathrm{S} 9{\text { (revertants } / \mu \mathrm{mol})^{\mathrm{d}}}^{\mathrm{d}} \\
+\mathrm{S} 9 \text { (revertants } / \mu \mathrm{mol})^{\mathrm{d}}\end{array}$ & $\begin{array}{r}6 \\
- \\
\end{array}$ & $\begin{array}{l}351 \\
179 \\
\end{array}$ & $\begin{array}{l}- \\
- \\
\end{array}$ & $\begin{array}{l}2 \\
- \\
\end{array}$ & $\begin{array}{l}16 \\
12 \\
\end{array}$ & $\begin{array}{l}- \\
- \\
\end{array}$ & $\begin{array}{l}- \\
- \\
\end{array}$ & $\begin{array}{l}- \\
- \\
\end{array}$ & $\begin{array}{l}- \\
- \\
\end{array}$ & $\begin{array}{l}- \\
- \\
\end{array}$ & $\begin{array}{l}- \\
- \\
\end{array}$ & $\begin{array}{l}- \\
- \\
\end{array}$ & $\begin{array}{l}\text { Kargalioglu et } \\
\text { al. (2002) }\end{array}$ \\
\hline $\begin{array}{l}\text { Ames preincubation: RSJ100 } \\
\text { - S9 }(\text { revertants } / \mu \mathrm{mol})^{\mathrm{d}} \\
+\mathrm{S} 9(\text { revertants } / \mu \mathrm{mol})^{\mathrm{d}}\end{array}$ & $\begin{array}{l}- \\
-\end{array}$ & $\begin{array}{l}- \\
-\end{array}$ & $\begin{array}{l}- \\
-\end{array}$ & $\begin{array}{l}17 \\
-\end{array}$ & $\begin{array}{l}- \\
-\end{array}$ & $\begin{array}{l}- \\
-\end{array}$ & $\begin{array}{l}- \\
-\end{array}$ & $\begin{array}{l}- \\
-\end{array}$ & $\begin{array}{l}- \\
-\end{array}$ & $\begin{array}{l}- \\
-\end{array}$ & $\begin{array}{l}- \\
-\end{array}$ & $\begin{array}{l}- \\
-\end{array}$ & $\begin{array}{l}\text { Kargalioglu et } \\
\text { al. (2002) }\end{array}$ \\
\hline $\begin{array}{l}\text { SOS chromotest: } E . \text { coli } \mathrm{PQ} 37 \\
-\mathrm{S} 9(1 /(\mathrm{mg} / \mathrm{mL}), \mathrm{IR}=1.5) \\
+\mathrm{S} 9(1 /(\mathrm{mg} / \mathrm{mL}), \mathrm{IR}=1.5)\end{array}$ & $\begin{array}{l}- \\
- \\
\end{array}$ & $\begin{array}{l}- \\
- \\
\end{array}$ & $\begin{array}{l}- \\
- \\
\end{array}$ & $\begin{array}{l}2 \\
- \\
\end{array}$ & $\begin{array}{c}5 \\
10 \\
\end{array}$ & $\begin{array}{l}- \\
- \\
\end{array}$ & $\begin{array}{l}- \\
- \\
\end{array}$ & $\begin{array}{l}- \\
- \\
\end{array}$ & $\begin{array}{l}- \\
- \\
\end{array}$ & $\begin{array}{l}1.3 \\
10 \\
\end{array}$ & $\begin{array}{l}- \\
- \\
\end{array}$ & $\begin{array}{l}- \\
- \\
\end{array}$ & $\begin{array}{l}\text { Giller et al. } \\
\text { (1997) }\end{array}$ \\
\hline $\begin{array}{l}\text { Ames fluctuation: TA100 } \\
\text { - S9 }(1 /[\mathrm{mg} / \mathrm{mL}]) \\
+\mathrm{S} 9(1 /[\mathrm{mg} / \mathrm{mL}])\end{array}$ & $\begin{array}{l}- \\
- \\
\end{array}$ & $\begin{array}{l}- \\
50\end{array}$ & $\begin{array}{l}- \\
- \\
\end{array}$ & $\begin{array}{c}10 \\
0.67\end{array}$ & $\begin{array}{c}100 \\
33\end{array}$ & $\begin{array}{l}- \\
- \\
\end{array}$ & $\begin{array}{l}- \\
- \\
\end{array}$ & $\begin{array}{l}- \\
- \\
\end{array}$ & $\begin{array}{l}0.57 \\
0.33 \\
\end{array}$ & $\begin{array}{l}0.5 \\
0.2 \\
\end{array}$ & $\begin{array}{l}- \\
- \\
\end{array}$ & $\begin{array}{l}- \\
- \\
\end{array}$ & $\begin{array}{l}\text { Giller et al. } \\
\text { (1997) }\end{array}$ \\
\hline
\end{tabular}

$\mathrm{CA}=$ chloro-, BA = bromo-, IA = iodo-, DCA = dichloro-, DBA = dibromo-, BCA = bromochloro-, CIA = chloroiodo-, BIA = bromoiodo-, TCA = trichloro-, TBA = tribromo-,

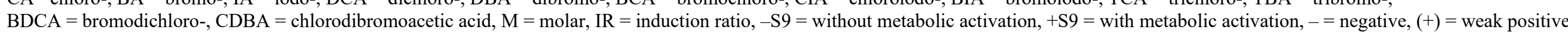
but no potency value reported, blank cell $=$ not tested.

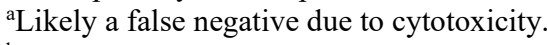

bPotency values at an induction ratio of 1.5 were estimated from figures using WebPlot Digitizer @ http://arohatgi.info/WebPlotDigitizer/app/.

${ }^{\mathrm{c}}$ Calculated as $[(\mathrm{A}-\mathrm{B}) / \mathrm{B}]$ where $\mathrm{A}=$ the $\beta$-galactosidase activity of the test agent and $\mathrm{B}$ is the baseline activity $(<0.5$, negative; $>0.5-1.0$, weak positive; $>1.0-2.0$, positive).

${ }^{\mathrm{d}}$ Values adjusted for cytotoxicity. 
RoC Monograph on Haloacetic Acids

Table D-4. Mutagenic/Genotoxic Potency Estimates of Haloacetic Acids in Mammalian Cells

\begin{tabular}{|c|c|c|c|c|c|c|c|c|c|c|c|c|c|}
\hline \multirow{2}{*}{$\begin{array}{l}\text { Test System (Potency } \\
\text { Measurement, Units) }\end{array}$} & \multicolumn{3}{|c|}{ Monohaloacetic Acids } & \multicolumn{5}{|c|}{ Dihaloacetic Acids } & \multicolumn{4}{|c|}{ Trihaloacetic Acids } & \multirow[b]{2}{*}{ Reference } \\
\hline & $\mathbf{C A}$ & BA & IA & DCA & DBA & BCA & $\begin{array}{l}\text { CIA or } \\
\text { (DIA) }\end{array}$ & BIA & TCA & TBA & BDCA & CDBA & \\
\hline $\begin{array}{l}\text { p53-bla: human colon } \\
\text { carcinoma cell line HCT-116 } \\
(1 / \mathrm{M}, \mathrm{IR}=1.5)\end{array}$ & 5,882 & 105,260 & 212,770 & - & 3,846 & 4,348 & 9,091 & 9,091 & - & - & - & - & $\begin{array}{l}\text { Stalter et al. } \\
(2016 a)\end{array}$ \\
\hline
\end{tabular}

SCGE: CHO AS52 cells

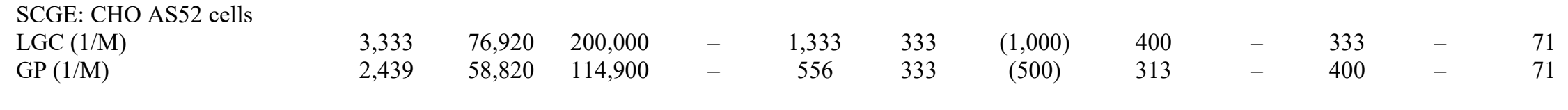

Plewa et al.

al. (2010); Plewa et al. (2004b);

Richardson et al. (2008)

\begin{tabular}{|c|c|c|c|c|c|c|c|c|c|c|c|c|c|}
\hline $\begin{array}{l}\text { SCGE: CHO AS52 cells } \\
\text { (tail moment units/ } \mu \mathrm{mol} \text { ) }\end{array}$ & - & 68,900 & - & - & 887 & - & - & - & - & 254 & - & - & $\begin{array}{l}\text { Plewa et al. } \\
(2000)\end{array}$ \\
\hline $\begin{array}{l}\text { HGPRT mutations: CHO-K1 } \\
\text { cells (mutant frequency/mM) }\end{array}$ & 8.7 & 14.6 & 835.9 & 2.8 & 66.2 & - & - & - & - & - & - & - & $\begin{array}{l}\text { Zhang et al. } \\
(2010)\end{array}$ \\
\hline $\begin{array}{l}\text { SCGE assay: HepG2 cells } \\
\operatorname{MEC~}(1 / \mu \mathrm{M})\end{array}$ & - & 10 & 100 & 0.1 & 1 & - & - & - & 0.01 & - & - & - & $\begin{array}{l}\text { Zhang et al. } \\
(2012)\end{array}$ \\
\hline $\begin{array}{l}\text { p53-bla: human colon } \\
\text { carcinoma cell line HCT-116 } \\
(1 / \mathrm{M}, \mathrm{IR}=1.5)\end{array}$ & 10,000 & 98,039 & 156,250 & - & - & - & - & - & - & - & - & - & $\begin{array}{l}\text { Procházka et al. } \\
(2015)\end{array}$ \\
\hline $\begin{array}{l}\text { SCGE: human lymphocytes } \\
\text { GP }(1 / \mathrm{mM})\end{array}$ & 1.2 & 83 & 96 & - & - & - & - & - & - & - & - & - & $\begin{array}{l}\text { Escobar-Hoyos } \\
\text { et al. }(2013)\end{array}$ \\
\hline $\begin{array}{l}\text { Mitotic index: human } \\
\text { lymphocytes } \mathrm{EC}_{50}(1 / \mathrm{mM})\end{array}$ & 1.4 & 12.7 & 20.3 & - & - & - & - & - & - & - & - & - & $\begin{array}{l}\text { Escobar-Hoyos } \\
\text { et al. }(2013)\end{array}$ \\
\hline $\begin{array}{l}\text { SCGE: human small intestine } \\
\text { epithelial cells } \mathrm{EC}_{50}(1 / \mathrm{mM})\end{array}$ & 0.29 & 17.7 & 45.7 & - & - & - & - & - & - & - & - & - & $\begin{array}{l}\text { Attene-Ramos et } \\
\text { al. }(2010)\end{array}$ \\
\hline
\end{tabular}

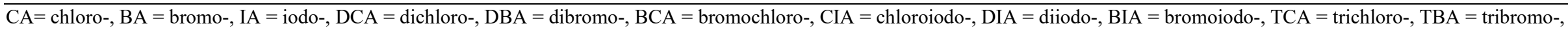

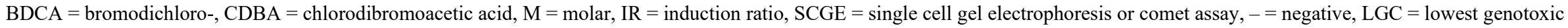

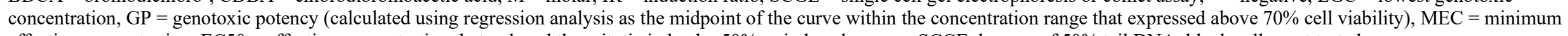
effective concentration, EC50 = effective concentration that reduced the mitotic index by $50 \%$ or induced average SCGE damage of $50 \%$ tail DNA, blank cell $=$ not tested. 
Table D-5. Epigenetic Effects of Haloacetic Acids in Mouse and Rat Tissues

\begin{tabular}{|c|c|c|c|c|c|c|c|}
\hline \multirow[b]{2}{*}{ Species (sex) } & \multirow[b]{2}{*}{ Tissue } & \multirow[b]{2}{*}{ HAA } & \multirow[b]{2}{*}{ Conc $(g / L)$} & \multicolumn{2}{|c|}{ Hypomethylation } & \multirow[b]{2}{*}{ Comments } & \multirow[b]{2}{*}{ Reference } \\
\hline & & & & 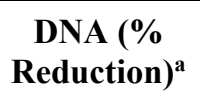 & Genes & & \\
\hline Mice $(\mathrm{M}, \mathrm{F})$ & Kidney & $\begin{array}{l}\text { DCA } \\
\text { TCA }\end{array}$ & $\begin{array}{l}3.2 \\
4.0\end{array}$ & $\begin{array}{l}40 \\
65\end{array}$ & $c-m y c$ & $\begin{array}{l}\text { Mice treated for } 7 \text { days. Unlike the liver, effects in kidney only in males. } \\
c-m y c \text { hypomethylation prevented by treatment with methionine. }\end{array}$ & Tao et al. (2005) \\
\hline $\begin{array}{l}\text { Mice }(\mathrm{M}) \\
\text { Rats }(\mathrm{M})\end{array}$ & Kidney & DBA & $1-2$ & $\begin{array}{l}40-60 \\
45-56\end{array}$ & $c-m y c$ & $\begin{array}{l}\text { High dose caused reduction at } 7 \text { days and } 28 \text { days; at low dose, } \\
\text { significant reduction only after } 28 \text { days. }\end{array}$ & Tao et al. (2005) \\
\hline $\begin{array}{l}\text { Mice }(F) \\
\text { Rats }(\mathrm{M})\end{array}$ & Liver & DBA & $1-2$ & $\begin{array}{l}45-70 \\
33-52\end{array}$ & $\begin{array}{l}c-m y c \\
I G F-I I\end{array}$ & $\begin{array}{l}\text { Both doses caused significant reduction after } 7 \text { and } 28 \text { days. mRNA } \\
\text { expression of } c-m y c \text { and IGF-II genes significantly increased in mice and } \\
\text { c-myc expression increased in rats. }\end{array}$ & Tao et al. (2004a) \\
\hline Mice $(F)$ & $\begin{array}{l}\text { Liver } \\
\text { Liver tumors }\end{array}$ & $\begin{array}{l}\text { DCA } \\
\text { TCA }\end{array}$ & $\begin{array}{l}2.6^{\mathrm{b}} \\
3.3^{\mathrm{b}}\end{array}$ & $\begin{array}{l}27-85 \\
27-85\end{array}$ & $I G F-I I$ & $\begin{array}{l}\text { Hypomethylation status in DCA- and TCA-promoted liver tumors that } \\
\text { were initiated by MNU and in normal liver. Both compounds caused the } \\
\text { same reduction in liver and liver tumor DNA (estimated from a figure) } \\
\text { but there was significantly greater reduction in liver tumors compared to } \\
\text { normal liver tissue. } 79.3 \% \text { of } 28 \mathrm{CpG} \text { sites in the promoter region of the } \\
\text { IGF-II gene were methylated in control mouse liver compared to } 46.4 \% \\
\text { and } 58 \% \text { in normal liver and } 8.7 \% \text { and } 10.7 \% \text { in liver tumors of DCA- } \\
\text { and TCA-treated mice, respectively. IGF-II expression was increased } \\
4.5 \text { - to } 5.1 \text {-fold in tumors compared to normal liver. }\end{array}$ & Tao et al. (2004b) \\
\hline Mice (F) & Liver & $\begin{array}{l}\text { DCA } \\
\text { TCA }\end{array}$ & $\begin{array}{l}500 \mathrm{mg} / \mathrm{kg} \\
500 \mathrm{mg} / \mathrm{kg}\end{array}$ & NR & $\begin{array}{l}c-j u n \\
c-m y c\end{array}$ & $\begin{array}{l}\text { Single gavage dose administered daily for } 5 \text { days. Treatment with } \\
\text { methionine prevented hypomethylation. }\end{array}$ & Tao et al. (2000a) \\
\hline Mice (F) & $\begin{array}{l}\text { Liver } \\
\text { Liver tumors }\end{array}$ & $\begin{array}{l}\text { DCA } \\
\text { TCA }\end{array}$ & $\begin{array}{l}2.6^{\mathrm{b}} \\
3.3^{\mathrm{b}}\end{array}$ & NR & $\begin{array}{l}c-j u n \\
c-m y c\end{array}$ & $\begin{array}{l}\text { mRNA expression and protein levels of } c-m y c \text { and } c-j u n \text { were increased } \\
\text { in DCA- and TCA-promoted liver tumors but not normal tissue. DNA } \\
\text { methyltransferase (MTase) activity increased in liver tumors promoted } \\
\text { by DCA and TCA (greater effect for DCA) but decreased in normal } \\
\text { liver. Increased MTase activity is associated with silencing tumor } \\
\text { suppressor genes. }\end{array}$ & Tao et al. (2000b) \\
\hline Mice (F) & $\begin{array}{l}\text { Liver } \\
\text { Liver tumors }\end{array}$ & $\begin{array}{l}\text { DCA } \\
\text { TCA }\end{array}$ & $\begin{array}{l}3.2^{\mathrm{b}} \\
4.0^{\mathrm{b}}\end{array}$ & $\begin{array}{c}36^{\mathrm{c}} \\
40-51^{\mathrm{c}}\end{array}$ & NR & $\begin{array}{l}\text { Hypomethylation status was measured in DCA- and TCA-promoted liver } \\
\text { tumors that were initiated by MNU and in normal liver. } \\
\text { Hypomethylation in normal liver was observed after } 11 \text { days but not after } \\
44 \text { weeks. Methylation status in adenomas also returned to normal with } \\
\text { termination of DCA exposure } 1 \text { week prior to sacrifice but not with } \\
\text { TCA. }\end{array}$ & Tao et al. (1998) \\
\hline
\end{tabular}




\begin{tabular}{|c|c|c|c|c|c|c|c|}
\hline \multirow[b]{2}{*}{ Species (sex) } & \multirow[b]{2}{*}{ Tissue } & \multirow[b]{2}{*}{ HAA } & \multirow[b]{2}{*}{ Conc $(g / L)$} & \multicolumn{2}{|c|}{ Hypomethylation } & \multirow[b]{2}{*}{ Comments } & \multirow[b]{2}{*}{ Reference } \\
\hline & & & & $\begin{array}{c}\text { DNA (\% } \\
\text { Reduction) }^{\text {a }}\end{array}$ & Genes & & \\
\hline Mice $(F)$ & $\begin{array}{c}\text { Liver } \\
\text { Liver tumors }\end{array}$ & DCA & 3.2 & 55 & NR & $\begin{array}{l}\text { Mice sacrificed after } 8 \text { or } 44 \text { weeks of exposure. Methionine treatment } \\
\text { prevented hypomethylation, reduced DCA-induced tumor multiplicity, } \\
\text { and slowed the progression of foci to tumors. (Hypomethylation } \\
\text { estimated from a figure in the paper with results after } 8 \text {-weeks exposure.) }\end{array}$ & $\begin{array}{l}\text { Pereira et al. } \\
(2004 a)\end{array}$ \\
\hline Mice (F) & $\begin{array}{l}\text { Liver } \\
\text { Kidney }\end{array}$ & $\begin{array}{l}\text { DCA } \\
\text { TCA }\end{array}$ & $\begin{array}{l}500 \mathrm{mg} / \mathrm{kg} \\
500 \mathrm{mg} / \mathrm{kg}\end{array}$ & NR & $c-m y c$ & $\begin{array}{l}\text { Single gavage dose administered daily for } 5 \text { days. Both DCA and TCA } \\
\text { induced hypomethylation and expression of } c-m y c \text { in liver. Co- } \\
\text { administration of chloroform prevented DCA- but not TCA-induced } \\
\text { hypomethylation. In a second experiment, chronic administration of TCA } \\
\text { in the drinking water promoted kidney tumors. DCA also promoted } \\
\text { kidney tumors when co-administered with chloroform. }\end{array}$ & $\begin{array}{l}\text { Pereira et al. } \\
\text { (2001) }\end{array}$ \\
\hline Mice (F) & $\begin{array}{c}\text { Liver } \\
\text { Kidney } \\
\text { Bladder }\end{array}$ & $\begin{array}{l}\text { DCA } \\
\text { TCA }\end{array}$ & $\begin{array}{l}500 \mathrm{mg} / \mathrm{kg} \\
500 \mathrm{mg} / \mathrm{kg}\end{array}$ & NR & $c-m y c$ & $\begin{array}{l}\text { Hypomethylation of the promoter region of } c \text {-myc in liver, kidney, and } \\
\text { urinary bladder occurred after } 72 \text { and } 96 \text { hours (but not at earlier time } \\
\text { points) after a single gavage dose of either DCA or TCA. Enhanced cell } \\
\text { proliferation in the liver also reported after } 72 \text { and } 96 \text { hours. }\end{array}$ & Ge et al. (2001) \\
\hline
\end{tabular}

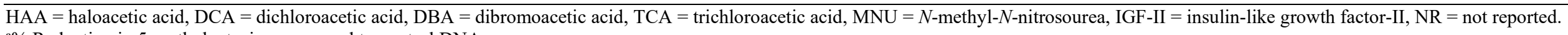
a\% Reduction in 5-methylcytosine compared to control DNA.

${ }^{\mathrm{b}}$ Converted from $20 \mathrm{mmol} / \mathrm{L}$ or $25 \mathrm{mmol} / \mathrm{L}, \mathrm{MW} \mathrm{DCA}=128.9, \mathrm{TCA}=163.4$, administered in drinking water for 44 to 46 weeks beginning at 6 weeks of age.

'Reduction in liver tumors compared to normal liver tissue from the same animal. TCA promoted both adenomas and carcinomas, DCA only adenomas. 
Table D-6. Gene Expression Studies of Di- and Trihaloacetic Acids in Yeast and Rodent Tissue

\begin{tabular}{|c|c|c|c|}
\hline Haloacetic Acid & Test System & Results & Reference \\
\hline Dichloro- & $\begin{array}{l}\text { Mouse normal liver ( } 4 \text { wk treatment) and } \\
\text { liver tumors induced by dichloroacetic acid } \\
\text { after } 93 \text { weeks }\end{array}$ & $\begin{array}{l}\text { Normal liver: } 15 \text { genes differentially expressed ( } 14 \text { were suppressed) in the } \\
\text { functional categories of cell growth, tissue remodeling, apoptosis, cancer progression, } \\
\text { fatty acid metabolism, and xenobiotic metabolism. } \\
\text { Hepatocellular carcinomas: } 11 \text { of the same } 15 \text { genes showed a similar expression } \\
\text { pattern as in normal liver from exposed mice. }\end{array}$ & Thai et al. (2003) \\
\hline Dichloro- & $\begin{array}{l}\text { Mouse normal liver ( } 4 \text { wk treatment) and } \\
\text { liver tumors induced by dichloroacetic acid } \\
\text { after } 93 \text { weeks }\end{array}$ & $\begin{array}{l}\text { Normal liver: Six differentially expressed genes ( } 5 \text { were suppressed; one gene was } \\
\text { induced) involved in fatty acid metabolism, tissue remodeling and tumor invasion. No } \\
\text { altered genes identified that are involved in genotoxicity pathways. } \\
\text { Hepatocellular carcinomas: Four genes showed similar expression pattern as in } \\
\text { normal liver from exposed mice. }\end{array}$ & Thai et al. (2001) \\
\hline Dichloro- & Rat normal liver (i.p. injection) & $\begin{array}{l}\text { One gene with } 50 \% \text { homology to a mouse fibroblast growth factor mRNA identified } \\
\text { and might be involved in hepatocellular proliferation and DNA synthesis. }\end{array}$ & Choi and Park (1996) \\
\hline $\begin{array}{l}\text { Dichloro- } \\
\text { Trichloro- }\end{array}$ & Mouse liver tumors (chronic exposure) & $\begin{array}{l}\text { Hyperplastic nodules and hepatocellular carcinomas: Increased expression of } c \text { - } \\
m y c \text { and } c \text { - } H \text {-ras compared to surrounding tissue or controls in both preneoplastic } \\
\text { nodules and carcinomas. } M y c \text { expression was similar in DCA-induced nodules and } \\
\text { carcinomas. However, myc expression in TCA-induced tumors was significantly } \\
\text { higher than in DCA-induced nodules and tumors and appeared to be related to the } \\
\text { early progression of TCA-induced tumors to a malignant state. } c-H \text {-ras expression } \\
\text { was higher in carcinomas from both treatments than in hyperplastic nodules or normal } \\
\text { liver, thus, was closely associated with malignancy. }\end{array}$ & Nelson et al. (1990) \\
\hline Trichloro- & $\begin{array}{l}\text { Green-fluorescent protein (GFP)-tagged } \\
\text { yeast reporter strains }\end{array}$ & $\begin{array}{l}\text { Activated DNA repair pathways suggested strong base damage, mismatches and } \\
\text { double-strand breaks. Damage was consistent with oxidative DNA damage. }\end{array}$ & Lan et al. (2016) \\
\hline
\end{tabular}


RoC Monograph on Haloacetic Acids

\begin{tabular}{|c|c|c|c|}
\hline Haloacetic Acid & Test System & Results & Reference \\
\hline Bromodichloro- & $\begin{array}{l}\text { Mouse: normal liver tissue and tumors } \\
\text { (chronic exposure) }\end{array}$ & 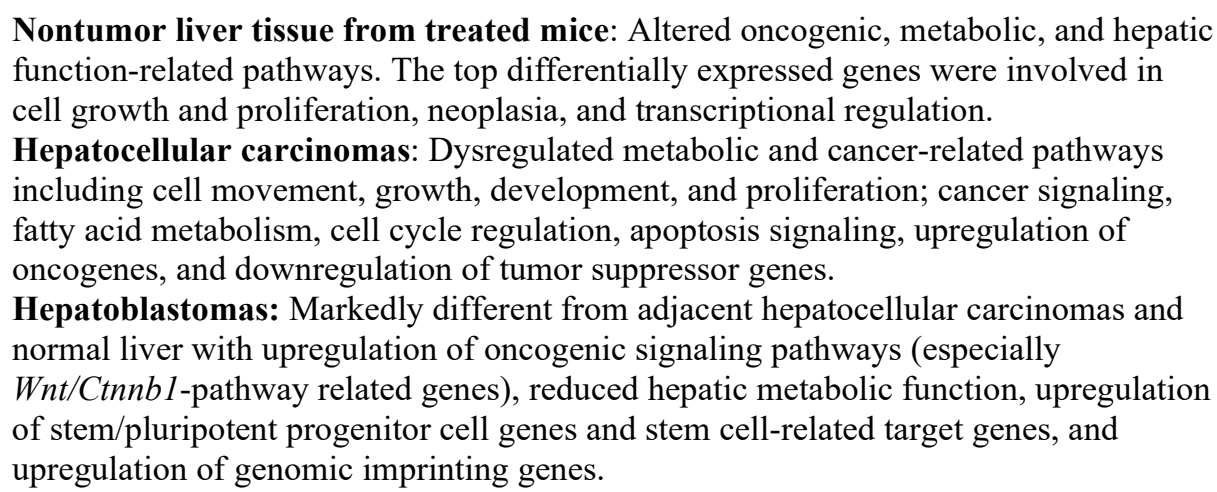 & NTP (2015) \\
\hline Bromodichloro- & $\begin{array}{l}\text { Rat: normal mammary tissue and tumors } \\
\text { (chronic exposure) }\end{array}$ & $\begin{array}{l}\text { Mammary adenocarcinomas: Eight genes significantly upregulated. Five associated } \\
\text { with } T g f \beta \text { pathway signaling, including its effects on matrix remodeling, mammary } \\
\text { gland cancer progression, angiogenesis, tumor invasion, and metastasis. }\end{array}$ & NTP (2015) \\
\hline Bromochloro- & $\begin{array}{l}\text { Rat: peritoneal mesothelioma (chronic } \\
\text { exposure) }\end{array}$ & $\begin{array}{l}\text { Mesotheliomas: } 169 \text { cancer-related genes differentially expressed and were } \\
\text { categorized into binding activity, cell growth and proliferation, cell cycle progression, } \\
\text { apoptosis, invasion, and metastasis. Important carcinogenic pathways involved in rat } \\
\text { peritoneal mesothelioma development included insulin-like growth factor-1 (IGF-1), } \\
\text { p38 MAPK, Wnt/ß-catenin, and integrin signaling and are similar to mesotheliomas in } \\
\text { humans. }\end{array}$ & Kim et al. (2006) \\
\hline Bromochloro- & Mouse sperm (daily treatment for 14 days) & $\begin{array}{l}\text { Testes-expressed genes: } 40 \text { genes with altered expression involved in cell } \\
\text { communication and adhesion, cell cycle and cell proliferation, metabolism, signal } \\
\text { transduction, stress response, spermatogenesis, and male fertility. }\end{array}$ & Tully et al. (2005) \\
\hline
\end{tabular}



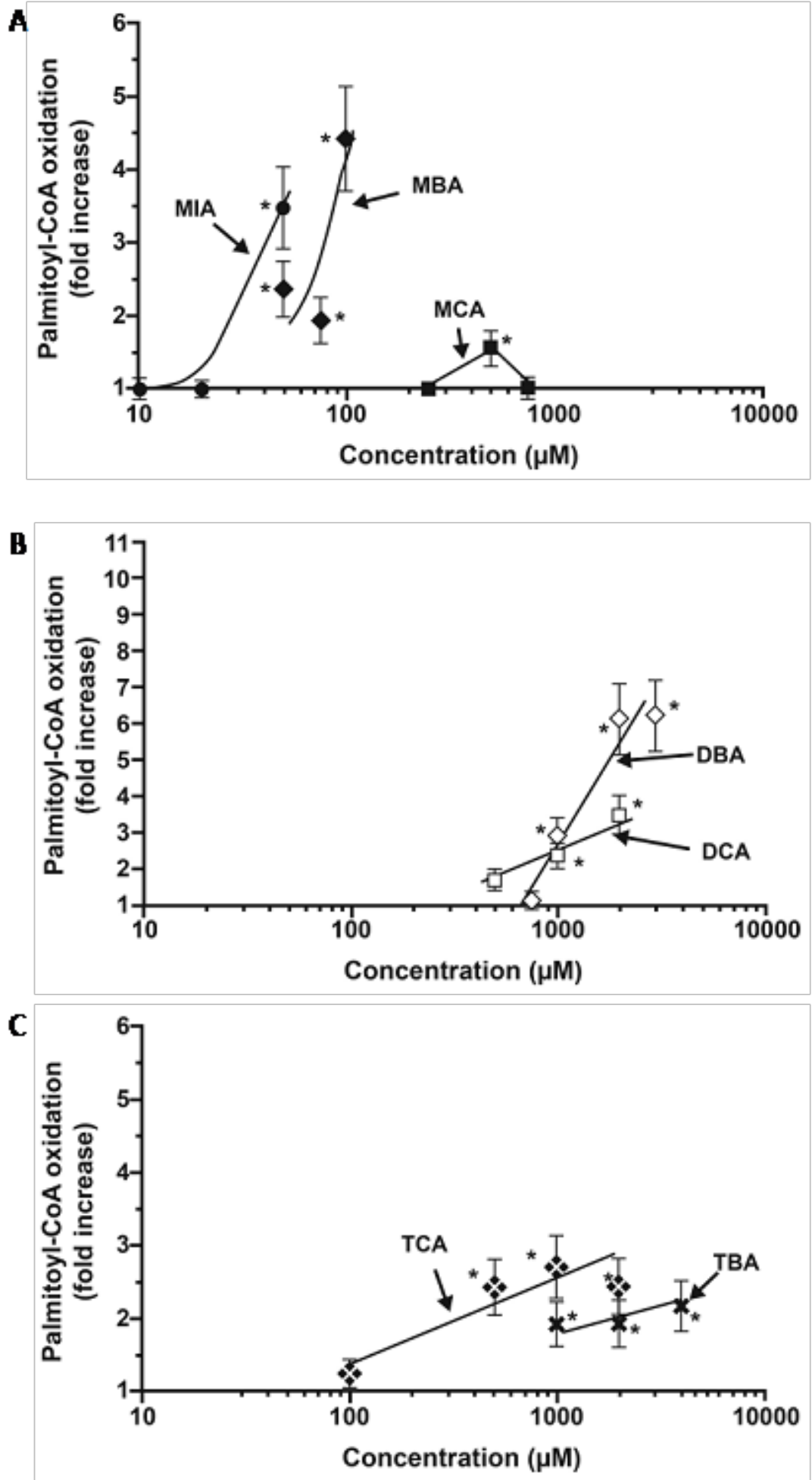

Figure D-1. Palmitoyl-CoA Oxidation in Cultured Rat Hepatocytes Exposed to Haloacetic Acids

Source: Walgren et al. (2004) (used by permission from Elsevier Ireland Ltd., License No. 4061470820696).

$\mathrm{A}=$ monohaloacetic acids: monoiodo- (MIA), monobromo- (MBA), and monochloroacetic acid (MCA); $\mathrm{B}=$ dihaloacetic acids: dibromo- (DBA) and dichloroacetic acid (DCA); $\mathrm{C}=$ trihaloacetic acids: trichloro- $(\mathrm{TCA})$ and tribromoacetic acid (TBA). 


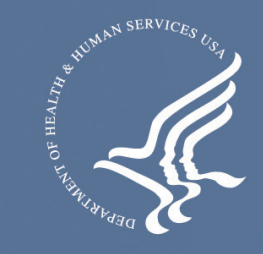

\section{National Toxicology Program}

National Institute of Environmental Health Sciences

National Institutes of Health

P.O. Box 12233, MD K2-05

Durham, NC 27709

Tel: 984-287-3211

ntpwebrequest@niehs.nih.gov

https://ntp.niehs.nih.gov 